\author{
Social Inequalities and \\ the Politicization of Ethnic Cleavages \\ in Botswana, Ghana, Nigeria, and Senegal, 1999-2019 \\ Jules Baleyte, Amory Gethin, \\ Yajna Govind, Thomas Piketty
}

September 2020

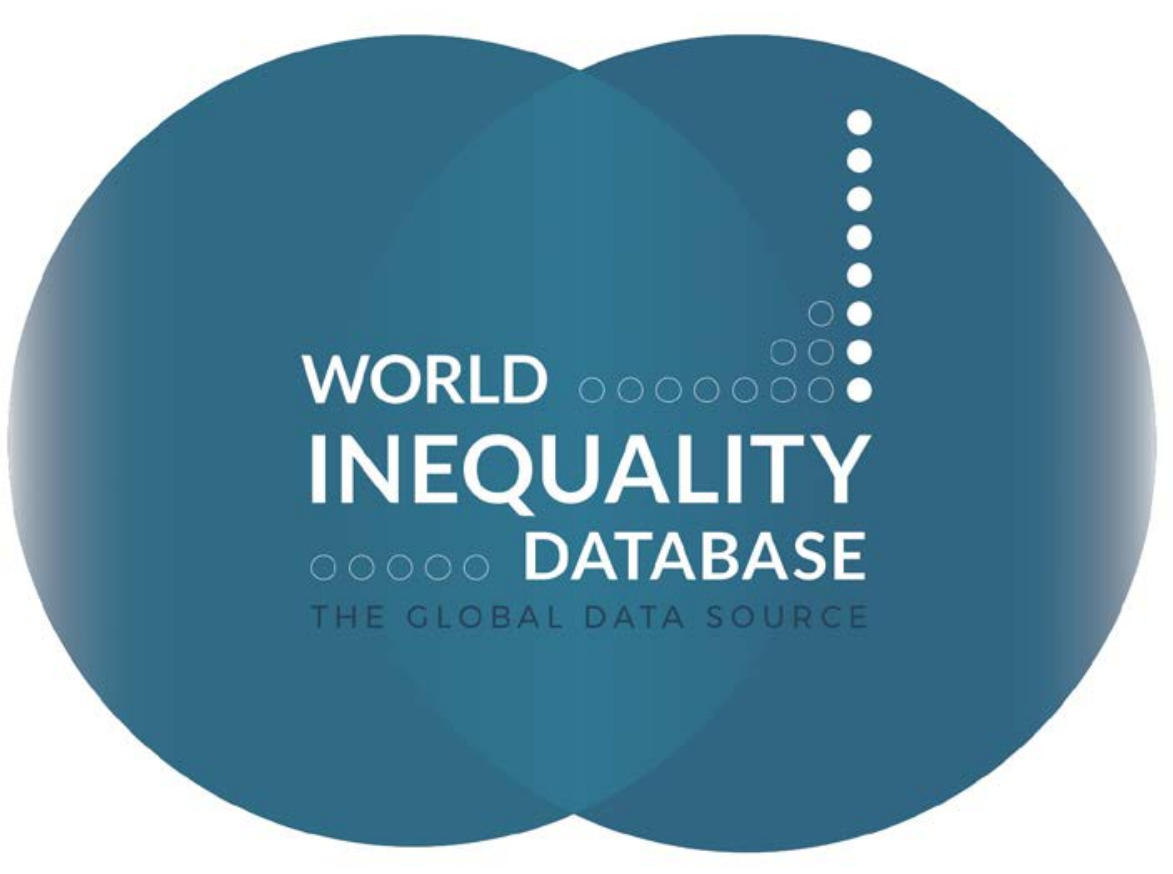

World Inequality Lab 


\title{
Social Inequalities and the Politicization of Ethnic Cleavages in Botswana, Ghana, Nigeria, and Senegal, 1999-2019 1
}

\author{
Jules Baleyte \\ Amory Gethin \\ Yajna Govind \\ Thomas Piketty
}

\begin{abstract}
This paper draws on political attitudes surveys to document the evolution of political cleavages in Botswana, Ghana, Nigeria, and Senegal, four African countries that have held regular multi-party elections in the past two decades. We discuss how colonialism, the politicization of ethnic identities, and the structure of social inequalities have differentially shaped party politics in these countries. Ethnic cleavages are tightly linked to ethnic inequalities, and are highest in Nigeria, at intermediate levels in Ghana, and lowest in Botswana and Senegal. We find evidence of strong educational and rural-urban divides, which cannot be explained by ethnic or regional affiliations. Our results suggest that in these four countries, electoral politics are not only explained by patronage, valence, or leader effects, but also clearly have a socioeconomic dimension. At a time when class cleavages have partly collapsed in old Western democracies, these African democracies could well be moving towards class-based party systems.
\end{abstract}

\footnotetext{
${ }^{1}$ Jules Baleyte: Institut national de la statistique et des études économiques; Amory Gethin, Yajna Govind, Thomas Piketty: Paris School of Economics - World Inequality Lab. We are very grateful to Catherine Lena Kelly, Dominika Koter, Clara Martínez-Toledano, Paul Nugent, Anja Osei, Amy Poteete, and Nicolas van de Walle for their useful advices.
} 


\section{Introduction}

International observers often perceive electoral politics in Sub-Saharan Africa as plagued by ethnic factionalism, patronage, and nepotism. A common, related view holds that African political parties do not have distinct ideological visions, but are instead convenient vehicles for mobilizing resources and group identities. Unlike Western democracies, where electoral behaviors continue to manifest deep-seated cleavages and clearly identifiable social conflicts, African democracies would primarily oppose charismatic leaders whose success would depend on their ability to be perceived as competent by both their electorate and political elites; valence issues would be at least as important as position issues (Bleck and van de Walle 2018). The need of experience in power explains in part why incumbent African presidents rarely lose elections, together with the role of political finance, patronage networks, electoral manipulation or use of violence. It also explains why opponents need access to state resources, sometimes renouncing their ideological principles, to join the ruling party, and implement policies that can depend more on international aid than on ideological choices or programmatic platforms. These factors cannot be ignored, but they sometimes tend to obliterate other important dimensions of democratic conflicts. To what extent do political parties represent longer-lasting social divides beyond vote-seeking strategies and valence issues? How strong are ethnic cleavages in Africa when it comes to the electoral arena, and how do these cleavages interact with the structure of inequalities, the history of political party formation, and the legacies of colonialism? Do socioeconomic issues play any role in distinguishing political actors and determining electoral behaviors, and could "class cleavages" be emerging?

This paper aims to provide some insights into these questions by documenting the determinants of the vote in four of the countries that held multi-party elections between 1999 and 2019: Botswana, Ghana, Nigeria, and Senegal. These countries are, among Sub-Saharan African countries, some of the highest ranked in terms of quality of democracy, fairness of elections, and competitiveness, which allows us to capture variations in the structure of the 
vote with a reasonable degree of confidence. ${ }^{2}$ To do so, we use the Afrobarometer surveys, which have collected information on identification with political parties or coalitions, electoral behaviors, and the main sociodemographic characteristics of voters since the late 1990s. While our results should be interpreted with care given important issues of misreporting and mismeasurement of political attitudes, we believe that they can still be useful to identify key distinguishing factors and broad patterns of change. By definition, our focus on four countries with some of the most competitive elections in Africa precludes any conclusion with respect to why democracies prevail in some countries and not in others. ${ }^{3}$ Instead, our objective is to understand how democratization, when it succeeds, leads political parties to mobilize voters on issues that are rooted in deeper ethnic, regional, and socioeconomic transformations. Our analysis, organized in four case studies, leads us to two main findings.

First, we document large variations, both across countries and across time, in the strength of ethnic cleavages: ethnolinguistic affiliations have a strong impact on the vote in Nigeria, a moderate impact in Ghana, and a weak impact in Botswana and Senegal. We argue that these variations mirror major differences in the strength of ethnic inequalities and spatial segregation. In Nigeria, extreme disparities between the primarily Muslim north and the Christian south, reinforced by the British during the colonial period, have been associated with rising ethnoreligious polarization. Ethnolinguistic affiliations also play a role in Ghana, opposing the poorer North to the wealthier Ashanti region, but all parties have had to rely on cross-ethnic coalitions to win elections, limiting political polarization along ethnic or regional lines. In Botswana and Senegal, finally, we find both low levels of ethnic inequalities and only weak associations between ethnic identities and voting behaviors.

\footnotetext{
${ }^{2}$ See for instance The Economic Intelligence Unit (2019). On the role of authoritarian incumbents' strategies in shaping multi-party systems in Africa, see Riedl (2014).

${ }^{3}$ To be sure, the four countries considered here are not the only ones holding competitive multi-party elections in Sub-Saharan Africa, and this study could easily be extended to countries such as Benin, Mauritius, or Mali.
} 
Secondly, turning to other determinants of electoral behaviors, we identify two other strong electoral cleavages, common to all four countries: a rural-urban cleavage, and what we interpret as an emerging "class divide", as education - among the only comparable, though imperfect, measures of socioeconomic status at our disposal - has had an exceptionally strong and growing effect on vote choice. Crucially, we find that parties supported by underprivileged ethnic groups also receive greater support from the lower educated beyond ethnic affiliations. Even in Nigeria, where party politics seem to be drifting towards a unidimensional Christian-Muslim cleavage, a significant share of lower-educated Christians still vote for the "center-left" All Progressives Congress. Educational and rural-urban cleavages have also been on the rise in Botswana and Senegal, as highest-educated voters have massively turned towards opposition to the incumbent, while rural areas have favored the continuity of patronage and have been more supportive of the development policies implemented by the ruling coalitions. ${ }^{4}$

Together, these findings point to relatively clear relationships between social inequalities and political representation, with poorer ethnic groups, underdeveloped regions, rural areas, and lower-educated individuals often voting for the same parties or coalitions. We interpret this as evidence that inequalities do matter in structuring partisan affiliations in these four countries, though with interesting variations in the respective roles of patronage, issue-based evaluations, and ethnic identities in shaping these divides. While it may be too early to talk about "class cleavages" or "class consciousness", our results clearly suggest that socioeconomic status is playing a growing role in electoral politics, partly, but not only, through its congruence with ethnic, regional or rural-urban cleavages, and that political competition could well be moving closer towards "left-right" divides in the future. ${ }^{5}$

\footnotetext{
${ }^{4}$ On the importance of the link between rural areas and incumbent parties, see for instance Wachman and Boone (2018).

${ }^{5}$ These findings resonate well with studies showing variations on reasons for supporting democracy or on trust in the government across social classes, for instance Moehler (2005) and Letsa and Wilfahrt (2018).
} 
The picture that emerges from this analysis thus departs quite significantly from the idea that elections in Sub-Saharan Africa are mainly contests between opportunistic actors. While resources, incumbency, and competency are important, they often crucially interact with social inequalities and economic perceptions. Studying democratization through the lens of the political representation of these inequalities can, we believe, be useful to identify potential trajectories of political cleavages and party systems on the African continent. It also paves the way for paying renewed attention to parties' platforms, and how programmatic linkages contribute to organizing and transforming these political conflicts.

\section{Botswana}

Botswana stands out in the economic and political context in Africa. Since its independence in 1966, it has progressed into a sound economic position in parallel with democratic stability. Botswana is today the longest standing multi-party democratic system in Africa and unlike other countries in the region, it has fair and recurrent elections, relatively good political records and high voter turnouts. Yet, its political scene is not devoid of challenges - with a single-party dominance since independence, a weak and fragmented opposition and an unlevelled playing field for the different parties. On the economic side, its growth "miracle" (in part due to the discovery of diamonds in the 1970s) did not benefit all sections of society. Botswana remains marked by a high level of poverty and is among the most unequal countries in the world (Chancel, Cogneau, Gethin and Myczkowski 2019). ${ }^{6}$

Despite maintaining a democratic setting with political plurality and fair elections, Botswana has largely remained a dominant party system with the opposition starting to pose a real threat only in the recent decades. This section provides an insight into the political evolution in Botswana by analyzing the dominance of the Botswana Democratic Party (BDP) since independence and its gradual loss of the upper hand in recent elections. We find that the transition from the single-party dominance to an effective multi-party system is both party-

\footnotetext{
${ }^{6}$ See “Top 10 percent national income share,” World Inequality Database, https://wid.world/world.
} 
and electorate-driven. While party fragmentations and within-party factionalism are often cited as the leading explanation for the political outcomes in Botswana, we show that political cleavages in terms of urban-rural divides, education and occupation are also crucial, and increasingly so.

\section{The Emergence and Political Dominance of the BDP}

Unlike South Africa, Botswana was indirectly ruled by the British in the form of the Bechuanaland Protectorate through the close collaboration of the colonial and native elites and the chiefdom system. The early 1960s saw growing political movements and demand for independence propelled by growing nationalist sentiments in view of the incoming wave of South African refugees into the Protectorate. This led to the creation of various parties, namely the Bechuanaland People's Party (BPP) in 1960, the Bechuanaland Independence Party (BIP), a split from the former, the Bechuanaland Democratic Party (BDP) by Seretse Khama in 1962 and eventually the Botswana National Front (BNF) in 1965. Many scholars note that there were no marked ideological differences between the different existing parties, as they had all been created with the aim of achieving an independent state by gathering nation-wide support (Nengwekhulu 1979; Polhemus 1983). However, while policy proposals might not provide a clear-cut idea of their respective positions, they clearly differed from one another.

Initially formed as a nationalist movement with a radical anti-colonial position (Acemoglu, Johnson and Robinson 2002), the BPP strongly advocated for the abolition of chieftainship and the end of colonial rule and white domination (Somolekae 2005). This garnered wide support from the urban areas and working class, even if they consisted a minority in the country's population. On the other hand, the BPP's position was not shared by Whites, peasants, and moderates. In response, the elites, who consisted of the colonial cattle-owning class, the rich peasantry as well as the newly-formed intellectual class, created an alliance in the form of the BDP. In view of the socialist and perceived radical nature of the BPP, the 
colonial government tacitly supported the moderate BDP, giving them a decisive edge in their establishment as a dominant party in the post-colonial period (Comaroff and Comaroff 1997).

Seretse Khama, as the leader of the BDP, managed to secure enormous support from both the traditional elites (Bamangwato group) due to his legitimacy linked to his lineage, as well as the intellectuals due to his educational background (Acemoglu, Johnson and Robinson 2002), bridging the gap between the supporters and opponents of the BPP. By valuing the traditional rural structures, The BDP thus secured both the common and elite rural population. As a result, the BDP won 80 percent of the popular votes and 90 percent of the seats in the first post-colonial election, compared to only 14 percent of votes going to the BPP. This contributed to a relatively smooth transition and transfer of power to the native elites during the decolonization period.

The BNF, a split from the BPP, later emerged as the leading opposition party with an initial stated aim to fight against the "neo-colonialist regime of the BDP" (Polhemus 1983), based on a coalition between a radical, Kenneth Koma and a former chief of the Bangwaketse tribe, Batheon. Despite the clear traditional advantage of Khama, the BDP advocated for a united democratic government serving all nationals irrespective of color, race or tribe and Khama was re-elected with ease in the three following elections, confronting the left-leaning BPP and the BNF. The opposition parties held a stronghold at the regional level, without posing a real threat to the BDP as the main national party.

The development program of the BDP consisted of significant investment on education, health and infrastructure. In the early stages of development, these investments largely served the interest of the ruling political elites (Acemoglu, Johnson and Robinson 2002). Despite the absence of very strong ideological demarcations, the parties' positions did differ: the BDP has been characterized as moderate and embracing liberalism while the BPP and the BNF were closer to socialism (Polhemus 1983). 
Upon his death in 1980, Khama was replaced by Masire whose stance was in line with the prevailing liberal economic policies. The 1984 election and onwards saw a rising support for the opposition party, the BNF, even if it did not translate into a proportionate increase in its share of seats in parliament owing to the electoral system. The following decades were characterized by high growth, yet high poverty in the rural areas and high inequality (Acemoglu, Johnson and Robinson 2002). The 1994 elections marked a major turning point in Botswana's party system. Rapid urbanization and redrawing of electoral boundaries led to an increased importance of the urban votes, putting the BDP in a difficult position (see Figure 1) given its traditional reliance on the rural areas. As a result, since the 1994 elections, the BNF has represented a serious contender in the political arena in Botswana, hinting at the end of the one-party dominant system.

[Figure 1 here]

In the BDP, Fetus Mogae replaced Masire and ran for election in 1999. The formation of the Botswana Congress Party (BCP), a split from the BNF, fragmented the opposition and helped the BDP to secure a large majority in the parliament despite its meagre improvement in terms of popular votes.

\section{An Uneven Playing Field between the BDP and Opposition Parties}

Despite the decline in support for the BDP, it has managed to remain in power for more than fifty years since independence. The inability of the opposition parties to obtain a majority in the elections has been attributed to the vast number of challenges and issues that they have faced. Above all, the opposition is plagued with internal struggles, which has resulted in various important splits since 1994, for instance with the creation of the BCP and the National Democratic Front (NDF) in 2003. This tendency portrays a lack of cohesion and damages the reputation of the opposition as a strong contender. 
The specificity of the electoral system in Botswana has also given an advantage to the BDP. The first-past-the-post (FPTP) system is a simple majority system in which the winner takes it all, which can result in a different scenario than the distribution of popular votes. This system has put the opposition parties at a major disadvantage in the electoral race in Botswana, and they have demanded a reform towards a more representative system such as proportional representation. For instance, in the 2000s general elections, the BDP secured around 78 percent of the seats in parliament despite obtaining only half of the votes. ${ }^{7}$

The fact that the FPTP does not reflect voters' preferences is exacerbated by the fragmentation of the opposition parties. Despite various attempts to come together ${ }^{8}$, either through unity or cooperation, they have failed to garner enough stability and support. They have often relied on charismatic and powerful leaders to hold parties together. Disagreements about the leaders and the style of leadership within the party often led to party splits and lack of survival in the absence of the main political figure.

In addition, party funding plays a significant role in allowing the BDP to keep the upper-hand over the opposition parties. The electoral system in Botswana does not require transparency of electoral financing and no public financial support is provided to the parties, despite the relative easiness to set up and register a new party. Being financially stronger thanks to higher membership but also generous private donors, the BDP is able to have a permanent structure in different parts of the country and field candidates in all constituencies, unlike the opposition parties.

Exploiting its position, the BDP has politicized public services (Doorenspleet and Nijzink 2014) through rewarding or punishing private actors based on their loyalty or lack thereof. Contracts for the state-owned diamond mining industry are also controlled by the BDP and

\footnotetext{
${ }^{7}$ In addition, Botswana has a system of special nominations, initially put in place to ensure seats for experts but mostly used by the BDP to obtain additional seats. (Somolekae 2005, p. 25).

${ }^{8}$ BNF, BAM and BCP signed a memorandum of understanding on 15 August 2005 (Somolekae 2005).
} 
used as a quid pro quo to retain support. Demand for political funding from the state by the opposition has been met with deaf ears and the BDP strategically associated such a reform with wasting of public funds. This would have helped to maintain competition in the elections, bring more equality between parties, and realign parties' incentives away from fund-raising (Sebudubudu and Osei-Hwedie 2010). In addition to the above advantages, the BDP also enjoys benefits from its incumbency such as unequal media coverage.

Divisions among the opposition, the ensuing vote-splitting, the FPTP electoral system, and incumbency advantages explain to some extent the success of the BDP in retaining power in the recent decades. However, while most studies have focused on the internal organization of parties, the existing political cleavages among the electorate explaining divisions between the BDP and the opposition parties have been sidelined.

\section{The Lack of Ethnic Cleavage in Botswana}

Strikingly, unlike in Nigeria and Ghana (see below), both ethnic inequalities (Figure 2) and ethnic cleavages (Figure 3) appear to be remarkably low in Botswana, with the share of votes received by the BDP varying little across major ethnolinguistic groups. This lack of ethnic cleavage has often been interpreted as resulting from the country's relative ethnic and religious homogeneity (Acemoglu, Johnson, and Robinson 2002): in the post-colonial era, the main religion has been Christianity and the main ethnic group the Tswana (about 80 percent of the population). However, the depoliticization of group identities in Botswana must also be located in the context of broader historical processes and political choices. The BDP indeed always represented traditional elites cross-cutting ethnic and religious lines, adopted a nonracial and nonethnic policy (excluding for instance questions related to ethnicity in the census), and developed policies deliberately downplaying social divisions (Poteete 2013). This arguably contributed to both limiting the political salience of ethnic identities and moderating interethnic inequalities.

[Figures 2 and 3 here] 
On the other hand, the different parties draw support from different regions, even if regional gaps in voting behaviors in Botswana are also relatively low in comparative perspective (see appendix Figure AB4). Botswana is divided into 17 administrative districts, of which 10 rural districts and 7 urban districts, which can be further categorized into northern and southern regions. ${ }^{9}$ The BDP traditionally derives greater support from the northern areas, in contrast to the opposition parties whose support base are relatively more scattered, with the BNF being stronger in southern regions, the BIP in north-western regions, and the BPP in north-eastern areas (Sebudubudu and Osei-Hwedie 2010).

\section{Towards Class Cleavages?}

While no marked ethnic or regional cleavages can be discerned, there are strong differences in voting between the rural and urban areas. ${ }^{10}$ The BDP has historically gathered strong support from the rural areas. At the time of independence, Khama managed to secure the support of both the common and elite rural population and maintained this electoral base through patronage. In the wake of elections, the BDP has also largely invested funds in the rural areas (such as the setting up of the Accelerated Rural Development Program in 1974) to ensure continued support. State resources have been disproportionately spent on public services to the sections of the population that support the BDP (Acemoglu, Johnson, and Robinson 2002). ${ }^{11}$

However, rapid urbanization since the 1980s and the emerging construction and service sectors (Poteete 2009) meant the continued gradual erosion of the BDP's electoral base over the years. While it still gathers more support from the rural electorate and increasingly so in recent years (Figure 4), the latter's share in the total population has significantly declined

\footnotetext{
${ }^{9}$ Northern regions consist of Ghanzi, Ngamiland, Chobe, North-East and Central while Southern regions comprise of Kgatleng, South-East, Kweneng, Southern and Kgalagadi as per historical division.

${ }^{10}$ See Appendix Figure AB4.

${ }^{11}$ Acemoglu, Johnson, and Robinson, “An African Success Story”.
} 
from 82.3 percent in the 1980s (Doorenspleet and Nijzink 2014) to around 30 percent in recent years, largely due to urbanization and poor economic conditions in those areas, hence threatening support for the BDP (see appendix Figure AA4).

[Figure 4 here]

In contrast, due to the acute dissatisfaction regarding the employment conditions, wages, unemployment, and housing access in the urban areas, urban workers have predominantly supported the opposition parties. The BNF has adapted its position from a more radical to a social democratic stance over time, thereby increasing its political appeal and gaining in popularity in the recent decade. The egalitarian stance of the BNF appeals to the working class and explains its popularity in the urban areas. While not performing well in parliamentary elections, the BNF has better scores in (urban) local governments (OseiHwedie 2001).

With reduced economic growth since the 1980s and persistently high levels of inequality, the increasingly educated (see appendix Figure AA4) and urbanized population tend to support the BDP less. These socio-economic structural changes tend to decrease the importance of traditional structures and rural areas and as a result, their influence on political choices (Poteete 2012). The diverging views have been exacerbated by the authoritarian-style of Ian Khama, Seretse Khama's son, since he took office in 2009. Figure 5 shows that there was not much of a difference in voting behaviors across education levels in 1999, but this rapidly changed between 2009 and 2019 as a growing cleavage along educational lines emerged (see also appendix Figure AB1). Higher-educated voters have gradually reduced their support for the BDP, with the most diverging point being the 2019 elections, when barely 30 percent of tertiary-educated voters supported the BDP compared to more than 70 percent of illiterates, a gap that is robust to controlling for other observable characteristics (see appendix Figure $\mathrm{AB} 1)$.

[Figure 5 here] 
In the absence of precise estimates of voting patterns by income, we can also focus on the vote for the BDP based on occupational groups. The BDP still draws massive support from farmers as was historically the case, with the difference between the share of farmers and nonfarmers voting for the BDP being persistently around 10 to 15 percentage points over the recent decades (See appendix Figure $\mathrm{AB} 10$ and $\mathrm{AC7}$ ). The gap between farmers and professionals has however been widening over time.

Together, these results suggest that Botswana could well be moving towards class cleavages, as the BDP's decline has increasingly forced the party to rely on poorer rural areas and lowereducated citizens for continued support. This trajectory bears similarities with the transformation of other dominant-party systems, such as South Africa (Gethin 2020) or India (Banerjee, Gethin and Piketty 2018), where the weakening of ruling parties' dominance came with a restriction of their voting base to disadvantaged social groups. Interestingly, however, this dynamic has had no ethnic component in Botswana, and seems rather to have been driven by growing rural-urban and educational divides.

\section{Other Determinants of Electoral Behaviors: The Roles of Age and Gender}

In addition, voting behaviors in Botswana can also be traced along age and gender lines. The youth and women are generally very active in Botswana politics but continue to be marginalized in the party structure due to cultural barriers, despite some progress on this front (Somolekae 2005). In elections, the BDP enjoys significant support from women (NzongolaNtalaja and Lee 1998), helped by its women's wing, its influence in many female-led organizations, and the increased number of women assigned to top public positions (OseiHwedie 2001) associated with the will of the BDP. Around 60 to 65 percent of women have voted for the BDP compared to less than 50 percent of men, and this difference is significant even after controlling for education and occupation (see appendix Figures AB7 and AC4). Generation-wise, the BDP generally obtains a higher share of its votes from the older sections of the population (see appendix Figure AB6). Close to 70 percent of the latter group have 
voted for the BDP in most elections, compared to around 50 percent or lower of younger voters. The BDP has however attempted to retain young votes by bringing new young candidates to the political scene (Osei-Hwedie 2001).

\section{Conclusion}

Declining support for the BDP has been associated with different factors, namely urbanization despite continued support from the rural areas, and the reduced influence of the traditional chieftainship system among the increasingly educated and urbanized populations. While helped by the electoral system and the fragmented opposition groups, the BDP's electoral victories have become increasingly challenged. The BDP has also experienced internal factions, especially after the arrival of Ian Khama in 2008. Strong dissent within the BDP led to the first major split from the BDP since its creation, with the creation of the Botswana Movement for Democracy (BMD) in 2010. The opposition, including the BMD, joined forces under the "Umbrella for Democratic Change" political alliance in the 2014 election. This election represented the culmination of the BDP's loss of support, scoring less than 50 percent of popular votes, an all-time low performance since independence. The BDP nevertheless secured 59 percent of the seats in parliament.

Botswana has largely remained a one-party dominant system since its independence in 1966. The recent decades have seen the weakening of the BDP, which is attributed to structural, institutional and concentration of power in the leader, giving the opposition the opportunity to attract more support and become a serious contender. While party fragmentation and factionalism within opposition parties play a significant role in the understanding of political outcomes in Botswana, underlying cleavages such as the urban-rural, educational and occupational divides are becoming increasingly important. 


\section{Ghana}

Since 1992 and the establishment of the Fourth Republic, the Ghanaian party system has mainly opposed two political parties, the National Democratic Congress (NDC) and the New Patriotic Party (NPP). This section documents a strong and stable ethnoregional cleavage between wealthier, higher-educated Akan populations, who overwhelmingly support the NPP, to supporters of the NDC overrepresented in the Ewe ethnic group of the Volta region as well as in the marginalized northern areas of the country. We also find evidence of rural-urban and educational divides, with poorer rural areas and less-educated voters being more favorable to the NDC beyond ethnoregional affiliations. These results are consistent with the idea that while economic ideologies of the NDC and the NPP may appear quite similar in view of the continuity of their policies pursued since the 1980s, the more social outlook of the NDC, compared to the more economically liberal ideology of the NPP, could pave the way to the stabilization of independent class cleavages in the future.

\section{The Making of a Two-Party System}

Ghanaian political life truly developed in the 1950s. The first movement pushing for selfgovernance, the United Gold Coast Convention (UGCC), originated two essential traditions in Ghanaian political history: the Danquah-Busia tradition, that the NPP now claims to follow (Fordwor 2010), and the Nkrumaist tradition. The Danquah-Busia tradition historically pushed for a liberal and democratic vision of the nation, advocating a multi-party parliamentary democracy with limited state intervention and privileged cooperation with the powers and institutions of the Western world. In contrast, the Nkrumah ideology appeared to be more indeterminate, sometimes referred to in the literature as "populist". It called for increased state intervention in social and economic domains as well as geopolitical nonalignment in the Cold War (Skinner 2015). These two movements split in 1949, when Kwame Nkrumah's decided to leave the UGCC to found the Convention People's Party (CPP). This separation was not based on ethnic grounds, since the UGCC's Banquah-Dusia tradition did keep Ashanti and Ewe members in the party until 1979: it was primarily aimed to achieve 
more radical independence. As the head of the CPP, Nkrumah won various elections organized by the British until the independence of the country in 1957. Under his leadership, economic development was accompanied by an authoritarian drift, characterized by the deportation and imprisonment of political opponents and the gradual ban of other parties. In 1960, in an election establishing a presidential system, he was elected with nearly 90 percent of votes against the United Party ${ }^{12}$ gathering the opposition under the leadership of Joseph Danquah - even though abstention was substantial and the election results were rigged in rural constituencies (Gocking 2005).

Despite Nkrumah's international reputation and his asserted pan-Africanism, the corruption of the CPP and the growing authoritarianism of the regime - that notably transformed Ghana into a one-party country - led to a military coup in February 1966. The National Liberation Council called opposition leader Kofi Busia, just back from exile, to establish the Second Republic. He was appointed Prime Minister, and president Edward Akufo-Addo was voted in by the electoral council. Amidst increasing economic difficulties, linked to the volatility in the cocoa market and to austerity policies aiming to reduce the debts left by the Nkrumah regime, a new coup d'état put an end to the Busia government after twenty-seven months. What followed was period of turmoil characterized by a succession of coups, until Flight Lieutenant Jerry Rawlings seized power in September 1979 and handed it over to a president elected in elections as free and fair as allowed by the country's situation. ${ }^{13}$ The victory of the People's National Party (PNP) revealed the persistence of the Nkrumah tradition. It also included a younger generation, such as future president Hilla Limann, who could not be blamed for past corruption. Opposition to the PNP, based on the Danquah-Busia tradition, was divided into two. The Popular Front Party (PFP) was a direct continuation of the ruling party of the Second Republic, the Progress Party (PP). The United National Convention (UNC) was also made up of former members of the PP, and was based on a coalition of Ga and Ewe populations that

\footnotetext{
${ }^{12}$ Figure 6 groups the United Party and the New Patriotic Party, consistently with their ideological proximity and the Danquah-Busia heritage claimed by the NPP.

${ }^{13}$ In these elections, Rawlings prohibited the use of names or symbols of previous parties, which explains the name changes of the parties shown in Figure 6: the CPP became PNP, and Busia's PP became PFP.
} 
rejected the perceived domination of cadres from the Ashanti and Brong-Ahafo regions within the PFP (Jeffries 1980). Despite ideological similarities, dissensions appeared too strong to unite the Danquah-Busia tradition in the second round, while minor parties chose Limann, whose modest origin from the northern regions inspired part of the country. ${ }^{14}$

On December 31 1981, a new coup put an end to the Third Republic. Rawlings regained power, carrying out a "revolution" and waging a "holy war against corruption", and took over the leadership of the new government, the Provisional National Defense Council (PNDC) (Gocking 2005). In a context of serious economic difficulties, he undertook to develop the country by applying a liberal economic policy in cooperation with the International Monetary Fund (IMF) and the World Bank, including austerity and currency devaluation policies. Politically, the PNDC exercised a tight control over the media, religion, justice, and political opponents for several years, and banned political parties.

As the Cold War came to an end and the urban and educated population increased, both the international context and growing contestation within the country led the PNDC to initiate a process of gradual democratization. The introduction of local elections in 1988 was a first step in this process. It was soon followed by a new constitution, the return of a multi-party system, and the restoration of press freedom in 1992. By anticipating popular protests and diplomatic pressures instead of facing them directly, some African governments, such as the PNDC, used democratization as a temporary palliative to retain power (Bleck and van de Walle 2018).

As a result, at the beginning of the Fourth Republic and the 1992 presidential election campaign, Jerry Rawlings had already been campaigning for several months as the head of the PNDC, which became the National Democratic Congress (NDC), mobilizing the benefits of incumbency to his advantage. Against him stood a single significant party, the New Patriotic Party (NPP). The NPP was led by Adu Boahen, who had been very critical of the PNDC

\footnotetext{
${ }^{14}$ Figure 6 presents the results of the second round of this election, opposing PNP candidate Limann to PFP candidate Owusu.
} 
government for several years, and represented the Danquah-Busia tradition. As shown in Figure 6, parties claiming to follow the Nkrumah tradition have never been able to play an active role in politics since then. This can be explained by the recuperation of Nkrumah's legacy - in particular by Rawlings' NDC, which did not hesitate to revive its past hymns and slogans (Gocking 2005) -, but also by the emergence of a new generation of voters who have not experienced Nkrumah's achievements.

Starting in 1992, a cycle of political alternations began and lasted until today. This is shown in Figure 6, which plots the results of the first round of presidential elections. ${ }^{15}$ Since the end of the $20^{\text {th }}$ century, both parties have succeeded in winning elections and holding power. Rawlings was elected in 1992 and left in 2000 at the end of the two-term limit stipulated by the constitution. John Kufuor (NPP) took over the presidency until 2008, after which the NDC returned to power under the mandates of John Atta Mills and John Dramani Mahama in 2012. The latter lost the 2016 election against Nana Akuffo-Addo (NPP), son of the former President of the Second Republic.

[Figure 6 here]

Ghana's political alternations and two-party system stand out as an exception among African democracies, where incumbency offers such a substantial electoral advantage - in terms of resource mobilization, political experience that can be advertised to voters, and sometimes election manipulation - that it can become difficult for opposition parties to triumph or even exist (Bleck and van de Walle 2018). These two parties have thus demonstrated their ability to survive outside of government, which can be explained by their incorporation into ancient political traditions embodying key figures of national history such as Nkrumah, Danquah, Busia or Rawlings, which have helped to strengthen voter loyalty. Both parties have managed

\footnotetext{
15 With the exception of 2008, when John Atta Mills (NDC) won against Nana Akuffo-Addo (NPP) in the second round, the winner of the first round has always been elected president.
} 
to survive the departure of their key political figures at the end of their two presidential mandates - Rawlings for the NDC and Kufuor for the NPP - and to later come back to power.

\section{The Role of Ethnic Cleavages}

Ghanaian democratization has therefore led to the emergence of a clear divide between two camps, in large part inherited from the two traditions that emerged from the Ghanaian independence movement: the NDC representing a more social-democratic "center-left" tradition, and the NPP adopting a more liberal "center-right" perspective. What have been the key factors distinguishing these two parties in the past three decades? Unlike in Botswana, ethnic cleavages have been relatively strong in Ghana. For some voters, the two traditional parties, the NDC and the NPP, are perceived as defending the interests of the Ewe and Ashanti populations respectively. The Ashantis are a sub-group of the Akan, the ethnic group comprising more than half of the Ghanaian population. The NPP is understood as representing the interests of the rich and educated Akan community, concentrated in the Ashanti region, despite its efforts to establish itself in other regions. A number of votes directed to the NDC would thus amount to anti-Akan votes (Nugent 1999). Two-thirds of NPP voters identify themselves as Akans, compared to only one-fifth of NDC voters, corresponding to the Fanti and Sefwi sub-groups in particular (Bleck and van de Walle 2018). This distinction is visible in the ethnolinguistic cleavages represented in Figure 8: Ewe speakers tend to be more supportive of the NDC, and so do speakers of the Gur languages widespread in the North of the country, ${ }^{16}$ as opposed to Akan speakers who tend to vote for the NPP.

[Figures 7, 8, and 9 here]

As ethnic groups are concentrated in specific regions, moreover, ethnic divides have naturally been reflected by equally strong regional cleavages: the Volta region, home to the majority of Ewe, and the northern regions have overwhelmingly voted for the NDC, while the Ashanti

\footnotetext{
${ }^{16}$ On the linguistic composition of Ghanaian regions, see appendix Figure BA16.
} 
and Brong-Ahafo regions have systematically supported the NPP (Figure 9). ${ }^{17}$ These divides mirror important spatial inequalities, with the northern regions concentrating over 45 percent of illiterates but only 10 percent of university graduates (Figure 7), as well as a larger share of the very poor (Ghana Statistical Service 2015). The NPP therefore seems to have represented the wealthier Akan, while the NDC has been more popular among marginalized ethnic groups since democratization.

However, the ethnic perspective remains limited when it comes to fully describing voting behaviors: these regions are not exclusively composed of these two ethnic groups, and the sizes of the Ashanti and Ewe groups themselves (only 15\% and 13\% of the total population) do not constitute a sufficient political majority that could be used by a single party (Jockers, Kohnert and Nugent 2009). Furthermore, the NDC, which had many Ewe members during the Rawlings era, would be more akin to a Fante confederation, also an Akan sub-group, under the rule of John Atta Mills.

Ethnic issues therefore appear to be of limited importance in political debates, in part because the sizes of the different groups are too small for ethnic mobilization to be an effective strategy without risking to alienate other coalitions. This political need to overcome ethnic cleavages has probably played a role in allowing Ghana's more peaceful and less violent form of democracy to function, especially when compared to countries with major ethnic tensions such as Nigeria. Ethnic considerations do however play an implicit role, which is visible in candidates' considerations when it comes to choosing their running mate. In 2000, for instance, the NDC could not associate the Ashanti wife of the former president, Nana Konadu Rawlings, to the Fante candidate John Atta Mills: this would have created an entirely Akan duo risking to destabilize part of the NDC's Ewe electorate. Martin Amidu, both an Ewe and a Northerner, then appeared more appropriate in view of the elections. Similarly, the NPP

\footnotetext{
${ }^{17}$ Due to low sample sizes, we include the Upper East and Upper West with the Northern region. Notice that a number of regions have been further divided, but not Ashanti, following a 2018 referendum held under the NPP government, which could be interpreted as an attempt to further splinter the NDC vote.
} 
promotes an alliance between the Ashanti, the Akyem and the Akwapim, all Akan subgroups, but the Akyem candidate Nana Akufo-Addo had to surround himself with numerous Ashanti personalities to reassure voters in 2008 (Jockers, Kohnert and Nugent 2009).

Without clearly claiming ethnic favoritism, parties often stir up local rivalries and are quick to criticize the actions of their opponents, accusing them of endangering national unity (Tonah 2009). Other regional cleavages exist and need to be analyzed in relation to the ethnic dimension. Indeed, the north of the country is socio-economically underdeveloped and composed of a multitude of peoples, sometimes with their own system of governance and leadership, and local conflicts are sometimes instrumentalized against a political party. In 1994, the ethnoreligious conflict opposing Konkomba Christians to Dagomba Muslims, which resulted in more than a thousand casualties, contributed to discrediting the image of the NDC government. The government was in particular accused by the opposition of entertaining the conflict and of lacking impartiality, after failing to meet electoral commitments to the Konkombas (Gocking 2005). Similarly, the NPP was accused of negligence following the assassination of the King of Dagbon in 2002, amidst a crisis opposing the Abudu clan to the Andani clan, due to a strong presence of Abudu members in the government, including the vice-president and the minister of the interior (Nugent 2005). In 2008, the NPP enjoyed the support of the Dagombas Abudu, while the rest of the Dagombas were more favorable to the NDC.

\section{The Mitigation of the Rural-urban Cleavage}

The ethnic factor can only partially account for the regional cleavages that we have documented. Indeed, other socio-economic differences overlap regional disparities, in particular a rural-urban divide. In the 1990s, rural-urban differences in election outcomes were a direct result of the economic policies pursued by the NDC government: economic development enabled electrification in the countryside, improved access to drinking water, and the creation of roads. The government also carried out an economic program to support cocoa farmers. At the same time, liberalization and privatization policies affected the mainly 
urban public sector, and were accompanied in the Ghanaian case by increasing efficiency in the taxation of urban residents (Nugent 1999).

As a result, rural areas have historically been much more supportive of the NDC, a fact that Rawlings was aware of in his election campaigns. The north of the country has is in particular remained much less urbanized than the south, and the opposition had difficulties getting its message given the weakness of print media and the high cost of election campaigns.

This advantage of the NDC in rural areas has, however, declined since the late 1990s, as shown in Figure 10, especially after controls. This can be explained by the arrival of the NPP to power, which was then able to benefit from the electoral advantages of development policies too, but also by the development of the country. Once vital infrastructures were built, it became difficult for the NDC to claim improvements in living conditions that were achieved twenty years earlier. This cleavage is also visible when studying the structure of the vote by occupation: historically, farmers were more likely to vote for the NDC (see appendix Figure BC8). Therefore, the NDC has been supported by majorities of both the lower classes and the rural areas. This phenomenon differs significantly from what is generally observed in Europe or Japan, where left-wing parties tend to be supported by both the poor and urban areas. The Ghanaian NDC is in this respect more comparable to the Pakistan People's Party, who has always been supported by rural areas in Pakistan.

[Figure 10 here]

Cities have historically backed the NPP, but this support has also been waning, especially in the Accra region where the NDC vote has been growing. This can be explained by the process of migration from rural areas to the cities: the rural population has declined from nearly 70 percent of the population in the 1980s to 43 percent in 2018 (World Bank 2020). Rapid urbanization and city growth have led to a deterioration in living conditions, with more than a third of Ghanaians urbanites living in shantytowns in 2015 (Garba and Benna 2016), and to an increase in urban unemployment. The growing precariousness of cities was thus accompanied 
by the rise of the NDC vote, consistently with the fact that this party is more popular among disadvantaged voters. The management of cities has been complex under these conditions. Urban unemployment was a problem that the NPP tried to face without real success in the early 2000s, notably by increasing the availability of training courses, as creating jobs directly proved to be particularly difficult. Moreover, newcomers in cities often come from the north of the country, and keep their habit of voting for the NDC. This explains voting behaviors observed in Asawase, for example, which cannot be explained by dissent within the Ashanti population, but rather to the presence of northern populations (Nugent 2005). This phenomenon is linked to the existence of zongos in southern cities, Muslim neighborhoods which are generally marginalized and underdeveloped, and where the NDC gets a majority of votes (see appendix Figure BB8).

\section{Socio-economic Inequalities and Political Platforms}

The NDC, finally, has not only represented poorer ethnic groups, marginalized regions and rural areas: an educational cleavage also seems to have emerged, with university graduates consistently being less likely to vote NDC by 5 to 10 percentage points, even after controlling for region, language, and other sociodemographic variables (Figure 11). This effect is less strong than in the other countries studied in this paper, but it clearly suggests that socioeconomic status, beyond ethnoregional affiliations, is playing an additional role in framing political cleavages in Ghana. If ethnic inequalities are to decrease in the future, this could well open a potential for the emergence of stronger independent class cleavages as seems to have been the case in Botswana.

[Figure 11 here]

These socio-economic cleavages partly explain the divergent interests of these groups. Democratic priorities only start to become important once a certain level of affluence is reached, for example: as the Ghanaian population has become more urbanized, more educated and richer since independence, it has had greater access to information and has become 
increasingly politicized, while rural areas in the North have remained isolated (Bleck and van de Walle 2018). Therefore, wealthy and educated urban Ghanaian elites were more sensitive to the NPP's rhetoric denouncing the authoritarianism of Rawlings' NDC in the 1990s, pointing to the lack of democratic foundation for its violent rise to power, and demanding that policies against corruption be implemented in the early 2000s (Gocking 2005).

The NPP has often tried to focus the debate on economic and democratic issues, claiming that Rawlings had stolen their own agenda of economic development in the 1980s and 1990s. Yet, differences in economic ideologies seem to have been relatively limited. The international economic policy of the NPP in the 2000s, which included the subscription to the IMF and World Bank's Heavily Indebted Poor Countries program, was a continuation of the NDC's practices. The good results obtained by the government, furthermore, partly stemmed from exogenous variations in the price of gold and cocoa, and the economic failures of the NDC leading to its defeat in 2016 also had their roots in the international economic environment.

Other criteria, including valence criteria, play a role in electoral behaviors: Rawlings established himself in the 1990s thanks to his qualities as a speaker as well as his experience in power, emphasizing for instance his role in obtaining international aid contributions to promote the economic development of the country. Issues of valence were also taken up by the NPP in its 2000 campaign, which insisted on the defaults of the NDC and promised opposite policies without clearly outlining how the expected changes would be carried out in practice. Similarly, the NDC's criticisms of the NPP tend to focus on stereotyping the NPP as a "democracy of private property" as opposed to the "social democracy" advocated by the NDC (Nugent 2005). The analysis of political differences between the two parties should however not be limited to such valence criteria. While it is true that economic development was made possible thanks to a continuity in the policies pursued by the two parties, the platforms they presented during the 2020 elections did reveal markedly different economic ideologies, more economically liberal in the case of the NPP, and more social in the case of the NDC. The NPP insisted for instance on fiscal discipline, considered as necessary for the 
economy to function properly. They also voted for a "fiscal responsibility" law in 2018, as well as for the creation of a fiscal discipline council and a financial stability council.

Other criteria playing a more modest role can be mentioned. The NPP has generally targeted the youth, who have been less influenced by the PNDC and NDC propaganda on Rawlings' role in the development of Ghana. This factor has however lost in importance as the legacy of Rawlings disappeared from the NDC's primary concerns (see appendix Figure BB6). Similarly, women have historically been more likely to vote for the NDC, in part because of the popularity of Jerry Rawlings' wife Nana Konadu Rawlings as leader of the 31 December Women's Movement, which promotes women's rights and calls for the political mobilization of women (Gocking 2005). As she founded her own party in 2012, splitting from the NDC, support for the NDC among women has eroded, which may explain the decline observed in 2016 with just under 40 percent of women choosing the NDC against 48 percent of men (see appendix Figure BB7).

\section{Nigeria}

Nigeria's Fourth Republic was inaugurated in 1999 after three decades of turbulent political events, including short democratic experiences interrupted by military interventions, frequent communal violence, and a major civil war. Since then, Africa's most populated and most diverse country, comprising more than 250 ethnic groups in 36 semi-autonomous states, has witnessed six elections and a peaceful handover from the People's Democratic Party (PDP) to the opposition All Progressive Congress (APC) in 2015.

In this section, we analyze how democratization and the consolidation of a two-party system in Nigeria has crystallized pre-existing ethnic, regional, and religious divides, and how these emerging political cleavages have mirrored long-lasting social inequalities. Three main findings emerge from our analysis. First, we document the persistence of extreme ethnoregional inequalities, which take the form of a divide between the poorer North and the wealthier South. These regional inequalities are tightly, though imperfectly, linked to 
ethnolinguistic and religious affiliations. Secondly, we show that the development of a twoparty system has been associated with the emergence of a sharp religious cleavage, with Muslims supporting the APC and Christians supporting the PDP. Thirdly, we provide evidence that these ethnoreligious divides have a clear class component, which is the manifestation of the regional concentration of economic resources. However, class cleavages are not entirely explained by religion, ethnicity or region, which is visible in the high support for the APC among lower-educated Christians. This points to the possibility of new class coalitions across religious groups, which could potentially play a role in moderating ethnoreligious tensions and moving Nigerian politics away from communal conflicts.

\section{From Independence to the Fourth Republic: A Turbulent Political History}

In 1914, the British created 'Nigeria' by amalgamating a number of West African territories. The objective, according to Governor-General Frederick Lugard, was to provide a unified railway policy. The integration of this large and diverse territory under a single polity was the result of an arbitrary process imposed from outside by the colonizer. It had no foundations in previous political regimes or even shared historical narratives. If anything, the British had reinforced pre-existing ethnoregional differences between the southern and the northern regions, maintaining indigenous systems of government and law, limiting the penetration of southern Christian missionaries in the Muslim north, and insulating the north from the effects of modern economic development. This was an integral part of their strategy of "indirect rule". ${ }^{18}$

The result was an almost complete absence of pan-Nigerian national movement. The Nigerian Youth Movement (NYM), founded in 1934 in Lagos, aimed to bring together the different ethnicities under a unified territory independent from the British Empire. But the protection of the Muslim emirates by the British, increasingly perceived as a tactic of divide-and-rule by the nascent nationalist forces, prevented the organization from building membership in the

\footnotetext{
${ }^{18}$ On the following historical overview, see for instance Sklar (1963), Bourne (2015) and Agbu (2016).
} 
north. The north eventually came to view the NYM as representing southern interests. As the British split the southern protectorate into West and East in 1938, divisions grew between Yoruba and Igbo factions until the NYM broke apart in 1941 (Bourne 2015).

The political parties that emerged in independent Nigeria, most of which with roots in the colonial period, were all regionally and ethnically based. The Northern People's Congress (NPC), formed in 1949, was supported by traditional Hausa and Fulani rulers of the northern states, and received 38 percent of nationwide votes in the 1964 parliamentary elections. The National Council of Nigeria and the Cameroons (NCNC) was stronger among the Igbo people of the eastern region. The Action Group (AG), formed in 1951 from a Yoruba cultural organization, had its roots in the west. In the 1959 general elections conducted just before independence, the NCNC, the NPC, and the AG received 34 percent, 26 percent, and 25 percent of votes respectively. Most other small parties and independents were anchored on sectional local interests (Agbu 2016).

The 1964 election produced a major realignment, as the NPC built a conservative alliance with the new Yoruba Nigerian National Democratic Party (NNDP), created by Samuel Akintola in opposition to the Action Group. The Igbo NCNC was marginalized and had to build a minority opposition coalition with the remaining AG representatives. On 15 January 1966, a group of mostly Igbo army officers overthrew the NPC-NNDP coalition, but they were ousted from power by a counter-coup carried out by general Johnson Aguiyi-Ironsi. As the new government attempted to unify the nation through a decree promoting government centralization, however, northern officers launched another coup in July 1966. Meanwhile, the massacre of thousands of Igbo people in the North fueled secessionist sentiments in the Southeast of the country, until the military governor of the eastern region, Emeka Ojukwu, declared the independence of the Republic of Biafra in May 1967. This triggered the Nigerian Civil War (1967-1970), which left several hundreds of thousands civilian and military casualties, until the surrender of secessionist forces. Demands for a Biafran Republic have continued until the present day, assuming a renewed violent dimension since the return of democracy (Johnson and Olaniyan 2017). 
What followed was a long period of political instability. A constituent assembly was elected in 1977 to draft a new constitution and elections were held in 1979, but military officials overthrew the Second Republic following violence and widespread electoral fraud in the elections of 1983. Presidential elections were held in 1993, but were annulled by president Ibrahim Babangida. Democracy was finally restored at the turn of the twenty-first century, when General Abdulsalami Abubakar appointed the Independent National Electoral Commission (INEC), and parliamentary elections were held in 1999.

The first elections of the Fourth Republic suggested that Nigeria was to move towards a dominant party system, as the center-right People's Democratic Party (PDP) succeeded in building a unique multi-ethnic and multi-regional coalition. Alliances with local elites, distribution of patronage, appointment of INEC officials, ballot rigging, and vote buying gave the PDP a substantial incumbent advantage (Herskovits 2007; Dauda, Adamu and AhmoduTijani 2019). Crucially, the party was able to accommodate regional interests through an informal arrangement: key positions would alternate between the six geopolitical regions and across north and south. Olusegun Obasanjo, a Yoruba Christian, was chosen by PDP leaders in 1999 to represent a shift from the historical domination of the north in national politics (Lewis 2011). All these factors contributed to the victories of the PDP by large margins in the first four elections of 1999, 2003, 2007, and 2011 (see Figure 12).

[Figure 12 here]

Several events contributed to the decline of the PDP and its defeat in the 2015 and 2019 elections. In 2010, president Umaru Yar'Adua, a Muslim from the northern Katsina State, died of heart disease. Vice-President Goodluck Jonathan, a Christian from the Niger Delta, took his place, and ran as PDP candidate in the presidential election of 2011. This led to growing dissatisfaction and defection of northern elites to opposition parties, as they had expected the PDP to field a northern candidate given that Yar'Adua's mandate had lasted less than three years, after eight years of southern domination of the executive. Corruption, 
economic mismanagement, and rising insecurity due to the escalation of violence by the neoSalafist sect Boko Haram in the northeast, further reduced support for the PDP (Lewis and Kew 2015). The All Progressive Congress (APC), formed in 2013 as the result of a merger between the three biggest opposition parties, received 54 percent of votes in the 2015 general election. Key to its success was the leadership of General Muhammadu Buhari, who had already headed the country between 1983 and 1985 and was perceived as more competent to address corruption and the Boko Haram crisis (Bleck and van de Walle 2018). ${ }^{19}$ As Goodluck Jonathan conceded defeat, Nigeria witnessed for the first time in its history a peaceful transfer of power from one political party to another.

\section{The Structure of Social Inequalities in Nigeria}

Before turning to our analysis of the structure of political cleavages, it is worth providing a brief overview of ethnic, religious, and regional affiliations in Nigeria. Geographically, Nigeria is a federation of 36 states and a Federal Capital Territory (Abuja), which can be grouped into six large geopolitical zones: North-Central (or Middle-Belt), North East, North West, South East, South South, and South West. Northern regions are home to about half of the Nigerian electorate and to the majority of Muslims speaking Hausa and Fulani languages. Southern regions are home to the majority of Christians, in particular the Igbo people mostly living in the South East and the Yoruba people concentrated in the South West. These three ethnolinguistic groups together amount to about three quarters of the Nigerian adult population; the remaining groups include a large variety of people mainly speaking other languages of the Benue-Congo, Atlantic-Congo, and Volta-Niger families. It is also important to stress that regions, ethnicities, and religions do not perfectly overlap: for instance, there are sizable Christian minorities in the northern regions, and a significant share of Yoruba people are Muslims (see appendix Figures CA1 to CA18).

\footnotetext{
${ }^{19}$ Valence issues therefore played a particularly important role in Nigeria in recent elections compared to other countries in sub-Saharan Africa: see Bleck and van de Walle (2018), p. 212.
} 
Ethnoregional affiliations in Nigeria are tightly linked to economic resources. This is the outcome of a long-run process of uneven development which has its roots in colonial expansion. The British not only chose to limit the socio-cultural integration of the poorer Muslim states by keeping in place local elites and systems of government. They also deliberately prevented economic development and educational expansion in the North, as the emergence of new educated elites in the South had been a powerful catalyzer for the birth of a national movement (Onapajo and Usman 2015). The result was a long-lasting legacy of regional inequality. The democratization of 1999 and the growth of the Nigerian economy failed to reduce existing income disparities. Instead, the last twenty years have been characterized by growing income polarization, driven by the South-South and South-West regions concentrating a greater share of output, and the North East and North West lagging behind (Awoyemi, Oluwatayo and Obayelu 2010; Clementi, Dabalen, Molini and Schettino 2017). Income inequality has increased, with the share of income accruing to the top 10 percent rising from 44 percent in 1985 to 49 percent in 2009 (Chancel, Cogneau, Gethin and Myczkowski 2019). Economic deprivation has steadily declined in most regions of Nigeria, but this is not the case in the North East and the North West, where poverty headcount ratios and malnutrition have remained stable at very high levels (World Bank 2016). This has fueled the rise of Boko Haram, which has become increasingly attractive to the destitute youths and children (David, Asuelime and Adekoye 2015). The majority of Nigerians cite poverty, unemployment, and lack of opportunities as the main reason for joining extremist groups (Okenyodo, Gondyi and Lewis 2014).

This persistently skewed regional distribution of resources is directly visible in the strong link between educational achievements and religious affiliations. In 2019, Muslims represented about 40 percent of the adult population, but more than 80 percent of illiterates (see Figure 13). Meanwhile, nearly seven out of ten tertiary-educated citizens were Christians. Religion, ethnolinguistic affiliations, and inequality therefore have remained strongly if not increasingly associated in contemporary Nigeria.

[Figure 13 here] 
How has the rise of the opposition to the People's Democratic Party and the end of the dominant-party system of the first elections of the Fourth Republic affected political cleavages in Nigeria? Figures 14 and 15 show that there has been a surge in religious divides since 2003. In the elections of 2003, 2007, and 2011, support for the PDP varied little among religious groups, even if Muslims were slightly more likely to vote for the opposition. The two most recent elections marked a clear rupture: the share of Muslims voting for the PDP dropped from 53 percent in 2011 to 25 percent in 2015 and only 12 percent in 2019 . Meanwhile, Christians have remained as likely, if not more likely, to vote for the PDP.

[Figures 14 and 15 here]

Controlling for other sociodemographic variables, in particular region and language, reduces the upward trend in religious voting: in 2019, Muslims were more likely to support the APC by 50 percentage points before controls and by 28 percentage points after controls. This mirrors the spatial separation of religious groups in Nigeria, with the majority of Muslims living in the northern regions, and the majority of Christians living in the South. However, the fact that Muslim-Christian cleavage remains very high even after controlling for region and language suggests that growing religious polarization has gone beyond the North-South divide. This reflects the fact that Christian minorities of the North have continued to vote for the PDP, while Yoruba Muslims of the South West have shifted their support to the APC. In the appendix, we indeed provide evidence that religion is now a stronger predictor of voting behaviors than region or ethnicity: for instance, the North-West region was more likely to vote for the APC by 18 percentage points in 2019, but only by 4 percentage points after controlling for religion and language. Religion also clearly differentiates voting behaviors among multi-religious regions (see appendix Figures CB13, CB14, and CC6). 
Therefore, it seems that Nigeria has been dangerously moving towards a "bipolar, MuslimChristian political identity that overlays a two-party system" (Cox, Orsborn and Sisk 2014). This political polarization was triggered by the defection of Muslim leaders from the PDP following the candidacy of Goodluck Jonathan in 2011. It was arguably strengthened by widening regional inequalities and extreme poverty in the North, which have reinforced discontent towards the PDP among Muslims. The rise of Boko Haram has also fueled ethnic tensions. Many Christians view Boko Haram as a creation of Nigerian Muslims to wipe out Christians, while conspiracy theories depicting Boko Haram as a deliberate attempt to discredit their religion are widespread among Muslims (Olaniyan and Asuelime 2014). In 2014, as much as 38 percent of Nigerians believed that most or all Nigerian Muslims were involved in supporting and assisting groups that have launched attacks and kidnappings in Nigeria (Okenyodo, Gondyi and Lewis 2014). Resort to hate speech and ethno-regional appeals by candidates, pre-election violence, vote-buying, and the escalation of communal conflicts in the Middle-Belt have also played a role in inflaming religious tensions (Hamalai, Egwu and Omotola 2017; Ayeni 2019; Bagga 2019).

\section{Beyond Ethnoreligious Identities: Towards Class Cleavages?}

Given the particular significance of regional inequalities in Nigeria, to what extent have ethnoreligious cleavages represented class cleavages since democratization, and to what extent have class cleavages developed beyond religion and ethnicity? Figure 16 documents a dramatic shift of highest-educated voters towards the PDP. Between 1999 and 2011, education did not appear to clearly influence voting behaviors; in 2019, secondary- and tertiary-educated voters have become more likely to vote for the PDP by 34 percentage points. This directly reflects the fact that less-educated Muslims have shifted to the APC: growing religious tensions have mechanically created differential voting behaviors among education groups through pre-existing ethnoregional inequalities. However, this divide cannot be solely explained by these inequalities: even after controlling for region, language, religion, age, gender, occupation, and rural-urban location, highest-educated voters were still more likely to support the APC by 17 percentage points in 2019. This can be explained by the fact that in 
spite of the emergence of extreme religious polarizations, education still clearly distinguishes voting behaviors within religious groups. In 2019, support for the PDP among Christians varied from 63 percent among tertiary-educated individuals to only 35 percent among illiterates (see appendix Figures CB11 and CB12). ${ }^{20}$

[Figure 16 here]

How can we interpret the emergence of what seems to be a new class cleavage in Nigeria? We cannot exclude the possibility that it might represent a form of mismeasured ethnic divide. Nigeria is an extremely diverse country, with over 250 languages and an even higher number of sub-ethnic groups. Very localized ethnic tensions, which we cannot perfectly capture in this analysis, might be politicized by the parties, with the PDP generally representing "wealthier" or "dominant" groups. Another possibility is that an independent class cleavage could be genuinely emerging, overarching existing ethnic, religious, or regional identities. Educational expansion has been associated with higher political mobilization and electoral turnout among those who most benefited from it, especially among ethnic minorities, which suggests that development has indeed become a political object (Larreguy and Marshall 2017). As noted by Ayo Obe, although "it is common to hear the lament that the two parties are 'just the same,' there is in fact a discernible ideological difference between them [...]. "On the one side are broadly conservative, promarket forces, today represented by the PDP; on the other is a progressive tendency that stresses social welfarism and policies directly aimed at the poor, which today's APC seeks to embody." (Obe 2019). If educational divides do partly represent these differences in policy orientations, this would pave the way for the emergence of a crosscutting cleavage, with the APC representing not only Muslims, but also poorer Christians. Future elections will tell us whether Nigeria is moving towards an all-encompassing bi-polar religious divide, or whether new cleavages will on the contrary allow the political space to move towards non-sectarian socioeconomic issues.

\footnotetext{
${ }^{20}$ Higher support for the PDP among higher-educated voters within each religious group already existed in 2003, but to a lesser extent.
} 


\section{Senegal}

Having never experienced any coup d'état or ethnic conflict in its history, ${ }^{21}$ Senegal, with its early democratic opening, is often regarded as an example for African democracies. Since 1978, political pluralism has indeed enabled the setup of multi-party elections, marked by peaceful government changes. However, the Senegal of the 1990s and 2000s is sometimes referred to as a "competitive authoritarian" regime because of the limitation of civil liberties and the uneven playing field constraining the opposition (Kelly 2020). Furthermore, the past decades have been characterized by a proliferation of political parties, sometimes more likely to be vehicles for their leaders than election-oriented. These political specificities, together with the low salience of ideology-based differentiations between political parties, make the analysis of political cleavages in Senegal difficult. It is nevertheless possible to distinguish trends between the incumbent party and the opposition which, as we will show, is a particularly noteworthy dynamic in the Senegalese context of continuity, with political leaders often coming from previous governments. Our results show that ethnic and religious differences play only a moderate role in comparison to a significant cleavage opposing the Dakar region, young and better educated, to the rest of the country, poor and less urbanized, which prefers the continuity of patronage from the incumbent.

\section{A Political History Marked by the Power of Incumbents}

Integrated as a French colony within French West Africa from the end of the 19th century, Senegal gradually gained autonomy after World War II and merged with present-day Mali to form an independent federation, which quickly broke up in 1960 to give birth to today's two countries. In Senegal, the President of the Republic, Leopold Sedar Senghor, and the President of the Council, Mamadou Dia, shared a common vision of a Senegalese national

\footnotetext{
${ }^{21}$ With the notable exception of the armed conflict that opposed the separatist Movement of Democratic Forces of Casamance to the Senegalese government between 1982 and the mid-2010s.
} 
identity beyond regional, ethnic, or religious cleavages. However, tensions due to relations with France, and its commercial interests, led to a political crisis in 1962: Dia was arrested and imprisoned, an act denounced by Western personalities.

The country was then led by a party, the Senegalese Progressive Union (Union progressiste sénégalaise, UPS), which became the single party after 1966 under the presidency of Senghor and then Abdou Diouf, designated as his successor in 1980. The transition to a multi-party system was gradual. The 1976 constitutional revision enabled the creation of three political parties assigned to defined ideologies: democratic socialism, liberalism and communism. The UPS, now rebranded as Socialist Party (Parti socialiste, PS), occupied the socialist position. The liberal option was granted to the Senegalese Democratic Party (Parti démocratique sénégalais, PDS), despite it having originally claimed to be a socialist workers' party based on the work ethic of the Mouride brotherhood and on the economic development of agricultural production (Desouches 1983; Osei 2013). This doctrinal discrepancy, between the categorization imposed by the constitution and the socialist references retained in the party's statutes, may have contributed to explain the PDS's ideological ambiguities observed to date, and indirectly that of the entire Senegalese political class.

In 1981, a multiparty system was completely authorized and the proliferation of political parties began. There were 174 Senegalese parties in 2010, two thirds of which having never run on their own individual party labels in presidential or legislative elections as of 2010 (Kelly 2020). The Senegalese case thus appears to fall outside the scope of classical theories of political party formation, which posit that the number of parties should depend on the structure of the electoral system and on the importance of various societal divides. Instead, some political parties in Senegal have no electoral objectives, nor promote particular ideologies or interests, but rather aim to access state resources and patronage networks. These parties are generally personal vehicles enabling their leader to gain reputation and legitimacy in order to negotiate a place in the power structure. These strategies of alliance, union, and cooptation was for example illustrated by the participation of the opposition leader of the PDS, Abdoulaye Wade, to several PS governments in the 1990s. Another specificity of 
Senegalese party politics is "political transhumance", with politicians switching party affiliation, for example after an electoral defeat, mainly in order to access state resources (Kelly 2020).

Having gained experience in political governance and recognition that comes with it, along with foreign funding that the government could not limit (unlike local funding), Wade left governments to run for office in several instances. Struggles over succession within the PS also led to a legitimacy crisis, resulting in the departure of Moustapha Niasse and Djibo Kâ to found their own parties: the Alliance of the Forces of Progress (Alliance des forces de progrès, AFP) and the Union for Democratic Renewal (Union pour le renouveau démocratique, URD). The resulting break-up of PS socialist forces enabled Wade to win the second round of the presidential election in 2000, in particular thanks to the formation of a common front with dissidents of the government against the incumbent.

As another illustration of the party proliferation and clientelism characterizing the political system, Wade created the Coalition Around the President in the 21st Century (Cap 21), a club that any political party could join in exchange for monthly salaries, bags of rice and access to a presidential intermediary. During his first mandate, Wade appointed Niasse and then Seck as Prime Ministers. They would be his main opponents in the 2007 election, along with Diouf's successor at the head of the PS, Ousmane Tanor Dieng, but Wade, relying on the advantages of incumbency, was nevertheless re-elected in the first round. Similarly, Wade's main opponent in 2012 was a former Prime Minister, Macky Sall, who founded his own party, the Alliance for the Republic (Alliance pour la République, APR), following a succession dispute with Wade who wanted his own son to become his successor. Thanks to an all-party alliance against the PDS, including former members of past PDS coalitions, Sall was elected president in the second round and was easily re-elected in 2019. During this latest election, historical parties, the PS and the PDS, were unable to participate as their leaders were imprisoned following controversial court decisions, while surprising alliances were formed, in the context of "the disappearance of ideology in a political space that has been slowly crumbling since the 1980s" (Ba 2019). 
Figure 17 shows the evolution of the vote shares received by the main parties in the first round of presidential elections since 2000. The similarities between PDS voters up to 2012 and APR voters after 2012 led us to consider them jointly in our analysis. It is quite clear that a number of voters followed Macky Sall in his choice to differentiate himself from Wade in 2008, as the president faced public discontent and major demonstrations for several reasons (Koter 2013). First, Wade's 2012 campaign appeared illegitimate given the constitutional twoterm limit, although the Constitutional Court decided not to count his first term prior to the constitutional reform. Secondly, he had also tried to change electoral rules to allow easier victories in the first round, which gave rise to the opposition movement M23. Finally, he was accused of nepotism by organizing, in disregard of the members of his party, the succession for his own son Karim Wade, who was himself accused of corruption and finally imprisoned in the following years. The lack of political organization independent of Wade and of career progression opportunities within the PDS can explain why members like Sall and Seck left the party, and why the party decayed once Wade's unpopularity became too strong (Osei 2013). Another reason of our choice is our objective to analyze the structure of political cleavages with respect to the power of incumbency, particularly salient in Senegal, focusing on the commonalities of the incumbents and the common characteristics of their voters.

[Figure 17 here]

\section{The Limited Political Role of Ethnic and Religious Cleavages}

Ethnic and religious inequalities appear to be much less pronounced in Senegal than in the countries studied above. The country is composed of several ethnic groups. The Wolofs are the majority group, amounting to 44 percent of the population, and are mainly located in the West, North, and Centre of the country. The Haalpulaar, Fulani speakers representing 28 percent of the population, are concentrated in the North, Casamance, and South-East. Other more localized groups also exist, such as the Sereres in the Centre, the Mandés in the SouthEast and the Diolas in Casamance. 
Figure 18 presents data on educational inequalities between these different groups. Compared to the Ghanaian and Nigerian cases presented in this paper, they appear to be limited: Wolofs represent between 35 and 50 percent of all education categories, without any clear gradient, even though the proportion of Halpulaars decreases with the level of education, from 30 percent of illiterates to 17 percent of the tertiary-educated.

[Figure 18 here]

Figure 19 shows that as in Botswana, ethnolinguistic cleavages are not the main discriminating factor when it comes to voting in Senegal. Ethnic groups have indeed relatively similar voting behaviors, with the exception of a slight preference towards candidates of one's own ethnicity, which explains the success of Macky Sall among Fulani voters in 2012 and 2019.

[Figure 19 here]

The absence of ethnic divide in Senegal is a well-known fact (Diouf 2000; Koter 2016). It partly stemmed from the desire of the founders of the Senegalese nation, Léopold Sédar Senghor and Mamadou Dia, to build a state above ethnic differences, assimilating all groups into a national consensus (Diédhiou 2020). This objective was reinforced by interethnic marriages, significant migration between regions and the development of multilingualism. Many Senegalese from different ethnic backgrounds speak wolof as a second or third language, and wolof could even be seen as "the irreducible core of the state" (O'Brien 1998). The low levels of interethnic inequalities in Senegal, finally, arguably both resulted from and contributed to enhance this process of peaceful coexistence and incorporation. That being said, tensions may arise when the "Wolof-Islamic model" tries to establish itself too strongly on reluctant groups (Diouf 2001), or when the candidates use these differences to denounce alleged calls for an ethnic vote by their opponents. This is what Abdoulaye Wade did when he used the threat of a Fulani vote in favor of Macky Sall, which could have, in his words, 
jeopardized the unity of the nation, as an electoral argument among the Wolof population (Ba 2020).

The second identity factor that we now have to consider is the religious factor. The vast majority of Senegalese people are Muslim (95 percent), divided into different brotherhoods, the main ones being the Tijaniyyah (the Tijānīs) and the Mouridiya (the Mourides), amounting to 32 percent and 23 percent of the population in 2019 respectively, according to Afrobarometer surveys (see appendix Figures DA3). The role of religion in politics is generally weak in Senegal, a country known for its religious tolerance (Diouf 2013). Relatedly, we do not find evidence of strong inequalities between religious groups, even if the Mouridiya are slightly less educated while Christians are overrepresented among highereducated voters. The small Christian minority, about 5 percent of the electorate, has been more supportive of the opposition, but this is mainly because it is integrated into the educated and urbanized elite of the western cities, a determining factor of the vote. Therefore, while religion could be a strong determinant of socioeconomic and sociopolitical differentiation in Nigeria and to some extent Ghana, this has not been the case in Senegal.

Muslim brotherhoods do however play a role in Senegalese political life through their leaders, khalifs and marabouts. Almost one out of two Mourides takes into account the opinion of his religious guide in a decisive way, while the Tijaniya give greater importance to the opinion of the head of the family (Monjib 1998). Initially, despite being Christian, Senghor relied on the support of Muslim leaders to build a coalition across these religious divides, while at the same time forging strong links between citizens and the state through religious brotherhoods (Foucher and Dahou 2009). Religious recommendations, in particular the "ndigel" of the Great Khalif of the Mourides, can have an impact, which explains why Abdoulaye Wade emphasized his Mouride membership in order to get his approval (Marfaing and Kohnert 2019). This explains the voting behaviors of individuals belonging to this brotherhood, especially in 2007 (see appendix Figure DB8). Thus, the holy city of the Mourides, Touba, represents a necessary visit during election campaigns, and can historically be considered as the stronghold of the PDS, even if it does not have a local branch there. 
In 2019, however, due to uncertainties surrounding the Wade clan and to a certain fear of losing some of their legitimacy by dividing their community, religious leaders and the Khalif did not make any general recommendation. This allowed local marabouts, who often have different concerns, to hold greater influence. This differentiation of votes between Sufi brotherhoods, which are no longer linked to a single party, further diminishes the impact of the religious cleavage, in a context where 77 percent of Senegalese people already claim that they are not influenced by religious authorities when it comes to electoral matters (Osei $2013) .^{22}$

\section{The Advantage of Incumbency and the Rural-Urban Cleavage}

Our previous historical account has shown that Senegalese politics are based on the strong persistence of political power over time: incumbents are generally re-elected, and the main opponents have all had a chance to rule with the government. The alternation of 2012 was only possible thanks to the combination of several factors. As Catherine Kelly showed, parties need to have both experience in high-level state administration and international sources of private financing to be able to play the role of opposition party without being dependent on incumbents to survive. The advantage of the outgoing president thus appears to be considerable in Senegal (Kelly 2020).

Incumbent advantage is strongest in rural areas, where information is less readily available: the dominant parties, the PDS and then the APR, obtain their best scores in these areas, as shown in Figure 20. Even more revealing, in rural counties such as Linguère or Matam in northern Senegal, exceptional evolutions took place that can be linked to the difference in the status of the candidate: in these constituencies, opposition candidate Wade obtained 10 percent of the vote in 2000, while President Wade obtained 60 percent in 2007 (Koter 2013). It seems that Wade relied on an urban electoral base when he was in the opposition in the

\footnotetext{
${ }^{22}$ This proportion falls to 61 percent in the region of the holy city of Touba.
} 
1990s, and then on a rural base once he was in power, although it gradually decreased after 2007 due to the dissatisfaction mentioned above. Conversely, incumbents do not perform well in Dakar, where they score on average less than in the rest of the country by 14 percentage points since 1978 (Koter 2013).

[Figure 20 here]

In the absence of policies truly benefitting farmers, ${ }^{23}$ Dominika Koter explains this cleavage by the greater efficiency of clientelism in rural areas. Indeed, in the cities, citizens have greater independence from local leaders, while the social cohesion of small communities increases the role of intermediaries and facilitates the monitoring of small polling stations. Differences in development yet also have to be factored in: for example, 79 percent of urbanites have access to drinking water compared to 38 percent of residents of rural areas. Such wealth gaps contribute to greater efficiency in patronage, since it is easier to fulfill these needs with limited funding, especially given that results are known in each polling station, which makes it possible to provide rewards conditionally on election results in the village polling station. Campaign strategies are therefore highly dependent on candidate financing, with only the wealthiest candidates being able to afford expensive nationwide mobilization campaigns. During these campaigns, contributions made or promised to the village appear to be more interesting to villagers than national political agendas: in 2007 and 2012, Wade did not even campaign in Dakar, while Niasse or Deng hardly ever left the major cities.

In that sense, patronage plays an important role in structuring cleavages, as in the cases of Thailand and the Philippines described by Mark Thompson (Thompson 2016). The upper classes tend to denounce patronage and denigrate the behaviors of the poor, perceived as ignoring the common good of the nation as they focus on their immediate personal interests. However, a different view is possible: patronage has a very real economic and distributive

\footnotetext{
${ }^{23}$ Even on the contrary, the rural areas, where 60 percent of the Senegalese population is localized, would receive only 10 percent of public investment (Koter 2013).
} 
dimension, as transfers received by low-income voters do effectively contribute to poverty reduction among beneficiaries. Poorer voters in rural areas may thus fear a government change that would jeopardize clientelistic networks and the regular flow of transfers, established by the ruling party, which contributes to explaining their electoral support for incumbents.

\section{The Educational Cleavage, Symptomatic of Senegal's Political Divisions}

This rural-urban cleavage is profoundly linked to an educational cleavage between rural and urban areas, given the higher education levels of young people studying at universities, which are necessarily located in cities, as well as observed migrations from the countryside to the attractive cities. Higher education, however, constitutes in itself an even greater divide in electoral choices, as shown in Figure 21. Even after controls, highest-educated citizens are much less likely to vote for the ruling party, with a difference of 15 percentage points.

[Figure 21 here]

The lack of education can indeed make it difficult to understand political events and issues, implying that lower-educated citizens are more likely to be bought, influenced by intermediaries or manipulated in their choices by a candidate knowing the workings of power or having exceptional charismatic skills, as seems to be the case of Wade (Osei 2013). Thus, the likelihood of victory of a candidate is an important factor motivating voters and intermediaries hoping to receive a later reward. The marabout and politician Mouhamadou Mamoune Niass, for example, chose to publicly support Wade in 2007 when he had a good chance of re-election but pulled away in 2012 when the risk of defeat increased, claiming that he would never associate himself with a loser (Koter 2013).

The educational cleavage lies at the heart of a more general cleavage: young people are generally better educated and more urbanized (see appendix Figures DA20 and DA22), since cities are places of study and work and since they benefit more from the improved education 
due to the country's development. Young people play an important role, since they vote in majority against the incumbents; Wade, for example, managed to mobilize them under the Sopi ("change" in wolof) coalition in 2000 (see appendix Figure DC10). Social networks controlled by young people from privileged backgrounds are also places where debates take place and where political choices made by governments are questioned and denounced.

Support for opposition forces among higher-educated and younger voters corresponds to a rejection of undemocratic government methods and corruption among the political class, as shown for example in 2019 by the emergence of Ousmane Sonko at the head of the Senegalese Patriots for Work, Ethics and Fraternity (Patriotes du Sénégal pour le travail, l'éthique et la fraternité, PASTEF). Faced with a shaky democracy and a certain authoritarian drift of the regime, which charged for example its main political opponents before the 2019 elections, Sonko proposed solutions to corruption and advocated a radical change in the system, claiming his integrity and liberation from the colonial legacy (Marfaing and Kohnert 2019). Originally from Casamance, he also mobilized part of the local electorate, sometimes considered marginalized because of its geographical remoteness.

This electoral cleavage also naturally appears between regions, since the western region, including the capital Dakar, concentrates the most educated and urban population (see appendix Figure DA14), and therefore votes less for the incumbent party (see appendix Figure DB4). Trends towards regionalization are also discernible in the sense that candidates obtain a larger share of votes in their region of origin: Sall in Fatick, Wade in Kébémer or Seck in Thiès, for example (Osei 2013).

Unlike Ghana and Nigeria, therefore, and closer to the Botswanan case, Senegal does not have particularly marked ethnic or religious cleavages that would systematically determine the outcome of elections. This absence was partially the legacy of the non-ethnic dimension of the independence movement, and was arguably reinforced by the weakness of interethnic and interreligious inequalities in the contemporary era. The growing authoritarianism of the Wade and then Sall governments has been associated with democratic demands from the urban and 
educated youth, while another part of the population, benefiting from the patronage of political elites, prefers the continuity of well-known incumbents with experience in power. This cleavage could well be the discriminating factor in the next elections if democratic competition appears to not be too distorted.

\section{References}

D. Acemoglu, S. Johnson, and J. A. Robinson, "An African Success Story: Botswana," (2002).

O. Agbu, "An Overview of Party Formation in Nigeria, 1960-1999," in Elections and Governance in Nigeria's Fourth Republic, ed. O. Agbu (Codesria, 2016), 27-36.

T. T. Awoyemi, I. Oluwatayo, and O. Obayelu, "Inequality, Polarization and Poverty in Nigeria" (Working Papers PMMA 2010-04, 2010).

O. O. Ayeni, "Commodification of Politics: Party Funding and Electoral Contest in Nigeria", SAGE Open 9, no. 2 (2019): 1-8.

B. Ba, "Faut-il craindre une menace peule au Sénégal?," Slate Afrique, http://www.slateafrique.com/84081/senegal-peril-pulaar-theses-et-foutaises (accessed July 10, 2020).

S. Ba, "Présidentielle au Sénégal : une Nouvelle Configuration Politique se Dessine," Le Monde Afrique (2 février 2019).

F. Bagga, Central Nigeria: Overcoming Dangerous Speech and Endemic Religious Divides (United States Commission on International Religious Freedom, 2019)

A. Banerjee, A. Gethin, and T. Piketty, "Growing Cleavages in India? Evidence from the Changing Structure of Electorates, 1962-2014” (WID.world Working Paper, 2018). 
J. Bleck and N. van de Walle, Electoral Politics in Africa since 1990: Continuity and Change (Cambridge University Press, 2018).

R. Bourne, Nigeria: A New History of a Turbulent Century (Zed Books, 2015).

L. Chancel, D. Cogneau, A. Gethin, and A. Myczkowski, "How Large Are African Inequalities? Towards Distributional National Accounts in Africa, 1990-2017” (WID.world Working Paper 2019/13, 2019).

F. Clementi, A. L. Dabalen, V. Molini, and F. Schettino, "When the Centre Cannot Hold: Patterns of Polarization in Nigeria," The Review of Income and Wealth 63, no. 4 (2017): 608632.

J. L. Comaroff, and J. Comaroff, "Postcolonial Politics and Discourses of Democracy in Southern Africa: An Anthropological Reflection on African Political Modernities," Journal of Anthropological Research 53, no. 2 (1997): 123-146.

F. D. Cox, C. R. Orsborn, and T. D. Sisk, "Religion and Social Cohesion in Nigeria: Frustration, Polarization, and Violence," (Sié Chéou Kang Center for International Security and Diplomacy, 2014).

M. Dauda, A. Adamu, and L. Ahmodu-Tijani, "Vote Trading in Nigeria Politics," Asian People Journal 2, no. 2 (2019): 42-51.

O. J. David, L. E. Asuelime, and R. A. Adekoye, “Is Boko Haram Poverty Driven?” African Renaissance 12, no. 1 (2015): 129-150.

C. Desouches, Le Parti démocratique sénégalais, une opposition légale en Afrique (BergerLevrault, 1983).

P. Diédhiou, "Les Intellectuels Sénégalais et la Question des Identités Ethniques au Sénégal," REFSICOM, http://www.refsicom.org/295 (accessed July 10, 2020). 
M. Diouf, Histoire du Sénégal. Le modèle islamo-wolof et ses périphéries (Maisonneuve \& Larose, 2001).

M. Diouf, Sénégal : Les Ethnies et la Nation (L’harmattan, 2000).

M. Diouf, Tolerance, Democracy, and Sufis in Senegal (Columbia University, 2013).

R. Doorenspleet and L. Nijzink, eds. Party Systems and Democracy in Africa (Springer, 2014).

K. Fordwor, The Danquah-Busia Tradition in the Politics of Ghana (Unimax Macmillan, 2010).

V. Foucher and T. Dahou. "Senegal since 2000. Rebuilding Hegemony in a Global Age," Turning Points in African Democracy (2009): 13-30.

S. Garba and U. Benna, Population Growth and Rapid Urbanization in the Developing World (IGI Global, 2016), 95.

A. Gethin, "Extreme Inequality and the Structure of Political Cleavages in South Africa, 1994-2019” (WID.world Working Paper 2020/13, 2020)

Ghana Statistical Service, Ghana Poverty Mapping Report (Ghana Statistical Service Report, 2015)

R. Gocking, The History of Ghana (Greenwood Press, 2005), Chapitre 7.

L. Hamalai, S. Egwu, and J. S. Omotola, Nigeria's 2015 Election: Continuity and Change in Electoral Democracy (Palgrave Macmillan, 2017), Chapter 2

R. Jeffries, "The Ghanaian Elections of 1979," African Affairs 79, no. 316 (1980): 397-414. 
H. Jockers, D. Kohnert, and P. Nugent, "The Successful Ghana Election of 2008: A Convenient Myth?” The Journal of Modern African Studies 48, no. 1 (2009): 95-115.

I. Johnson and A. Olaniyan, "The Politics of Renewed Quest for a Biafra Republic in Nigeria," Defense and Security Analysis 33, no. 4 (2017): 320-332.

J. Herskovits, “Nigeria’s Rigged Democracy,” Foreign Affairs 86, no. 4 (2007): 115-130

C. Kelly, Party Proliferation and Political Contestation in Africa, Senegal in Comparative Perspective (Palgrave Macmillan, 2020).

D. Koter, "Urban and Rural Voting Patterns in Senegal: The Spatial Aspects of Incumbency 1978-2012,” The Journal of Modern African Studies 51, no.4 (2013): 653-679.

D. Koter, Beyond Ethnic Politics in Africa (Cambridge University Press, 2016).

H. Larreguy and J. Marshall, "The Effect of Education on Civic and Political Engagement in Non-Consolidated Democracies: Evidence from Nigeria," Review of Economics and Statistics 99, no. 3 (2017): 387-401.

N. W. Letsa and M. Wilfahrt, "Popular Support for Democracy in Autocratic Regimes: A Micro-Level Analysis of Preferences," Comparative Politics 50, no. 2 (2018): 231-273.

P. Lewis, "Nigeria Votes: More Openness, More Conflict," Journal of Democracy 22, no. 4 (2011): 60-74.

P. Lewis and D. Kew, "Nigeria's Hopeful Election," Journal of Democracy 26, no. 3 (2015): 94-109.

L. Marfaing and D. Kohnert, "Les élections présidentielles de 2019 au Sénégal ou la lente ascension des nouvelles générations," Canadian Journal of African Studies / Revue canadienne des études africaines 53, no. 2 (2019): 355-366. 
D. C. Moehler, "Free and Fair or Fraudulent and Forged: Elections And Legitimacy In Africa" (Afrobarometer Working Paper, 2005)

M. Monjib, "Comportement électoral, politique et socialisation confrérique au Sénégal," Politique Africaine 68 (1998): 53-61.

R. Nengwekhulu, "Some Findings on the Origins of Political Parties in Botswana," Pula: Botswana Journal of African Studies 1, no. 2 (1979): 47-76.

P. Nugent, "Living in the Past: Urban, Rural and Ethnic Themes in the 1992 and 1996 Elections in Ghana," The Journal of Modern African Studies 37, no. 2 (1999): 287-319.

P. Nugent, "The 2004 Elections in Ghana: Anatomy of a Two-party System," Politique Africaine 97, no. 1 (2005): 133-150.

G. Nzongola-Ntalaja and M. C. Lee, eds. The State and Democracy in Africa (Africa World Press, 1998).

D. O'Brien, “The shadow-politics of Wolofisation," The Journal of Modern African Studies 36, no. 1 (1998):25-46.

A. Obe, "Aspirations and Realities in Africa: Nigeria's Emerging Two-Party System?" Journal of Democracy 30, no. 3 (2019): 109-123.

K. Okenyodo, N. D. Gondyi, and P. Lewis, "Security and Armed Extremism in Nigeria: Setting a New Agenda" (Afrobarometer Dispatch No. 29, 2014).

A. Olaniyan and L. Asuelime, "Boko Haram Insurgency and the Widening of Cleavages in Nigeria," African Security 7, no. 2 (2014): 91-109; Onapajo and Usman, "Fuelling the Flames". 
H. Onapajo and A. A. Usman, "Fuelling the Flames: Boko Haram and Deteriorating Christian-Muslim Relations in Nigeria," Journal of Muslim Affairs 35, no. 1 (2015): 106122.

A. Osei, "Party-Voter Linkage in Senegal: The Rise and Fall of Abdoulaye Wade and the Parti Démocratique Sénégalais.”, Journal of African elections 12 (2013): 84-108

B. Z. Osei-Hwedie, "The Political Opposition in Botswana: The Politics of Factionalism and Fragmentation," Transformation 45 (2001): 57-77.

J. H. Polhemus, "Botswana Votes: Parties and Elections in an African Democracy," The Journal of Modern African Studies 21, no. 3 (1983): 397-430.

A. R. Poteete, "Electoral Competition, Factionalism, and Persistent Party Dominance in Botswana," The Journal of Modern African Studies (2012): 75-102.

A. R. Poteete, "Is Development Path Dependent or Political? A Reinterpretation of MineralDependent Development in Botswana," The Journal of Development Studies 45, no. 4 (2009): 544-571.

A. R. Poteete, "The Absence of Intergroup Violence in Botswana: An Assessment of the Role of Development Strategies," in W. Ascher and N. Mirovitskaya, The Economic Roots of Conflict and Cooperation in Africa (Palgrave Macmillan, 2013).

R. B. Riedl, Authoritarian Origins of Democratic Party Systems in Africa (Cambridge University Press, 2014).

D. Sebudubudu and B. Z. Osei-Hwedie. "In Permanent Opposition: Botswana's Other Political Parties," South African Journal of International Affairs 17, no. 1 (2010): 85-102.

K. Skinner, The Fruits of Freedom in British Togoland: Literacy, Politics and Nationalism, 1914-2014 (Cambridge University Press, 2015). 
R. L. Sklar, Nigerian Political Parties: Power in an Emergent African Nation (Princeton University Press, 1963)

G. Somolekae, "Political Parties in Botswana" (EISA Research Report, 2005).

The Economic Intelligence Unit, Democracy Index 2018: Me too? Political participation, protest and democracy (Technical Report, 2019).

M. Thompson, "The Moral Economy of Electoralism and the Rise of Populism in the Philippines and Thailand," Journal of Developing Societies 32, no. 3 (2016): 246-269.

S. Tonah, "Democratisation and the Resurgence of Ethnic Politics in Ghana, 1992-2006," in G. Rosenthal and A. Bogner, Ethnicity, Belonging and Biography: Ethnographical and Biographical Perspectives (Lit Verlag, 2009).

M. Wachman and C. Boone, "Captured Countryside? Stability and Change in Sub-National Support for African Incumbent Parties," Comparative Politics 50, no. 2 (2018): 189-208.

World Bank, Poverty Reduction in Nigeria in the Last Decade (Technical Report 2016).

World Bank, "Rural Population (\% of Total Population)," The World Bank, https://data.worldbank.org/indicator/SP.RUR.TOTL.ZS?locations=GH (accessed June 24, 2020). 
Figure 1 - Election results in Botswana, 1965-2019

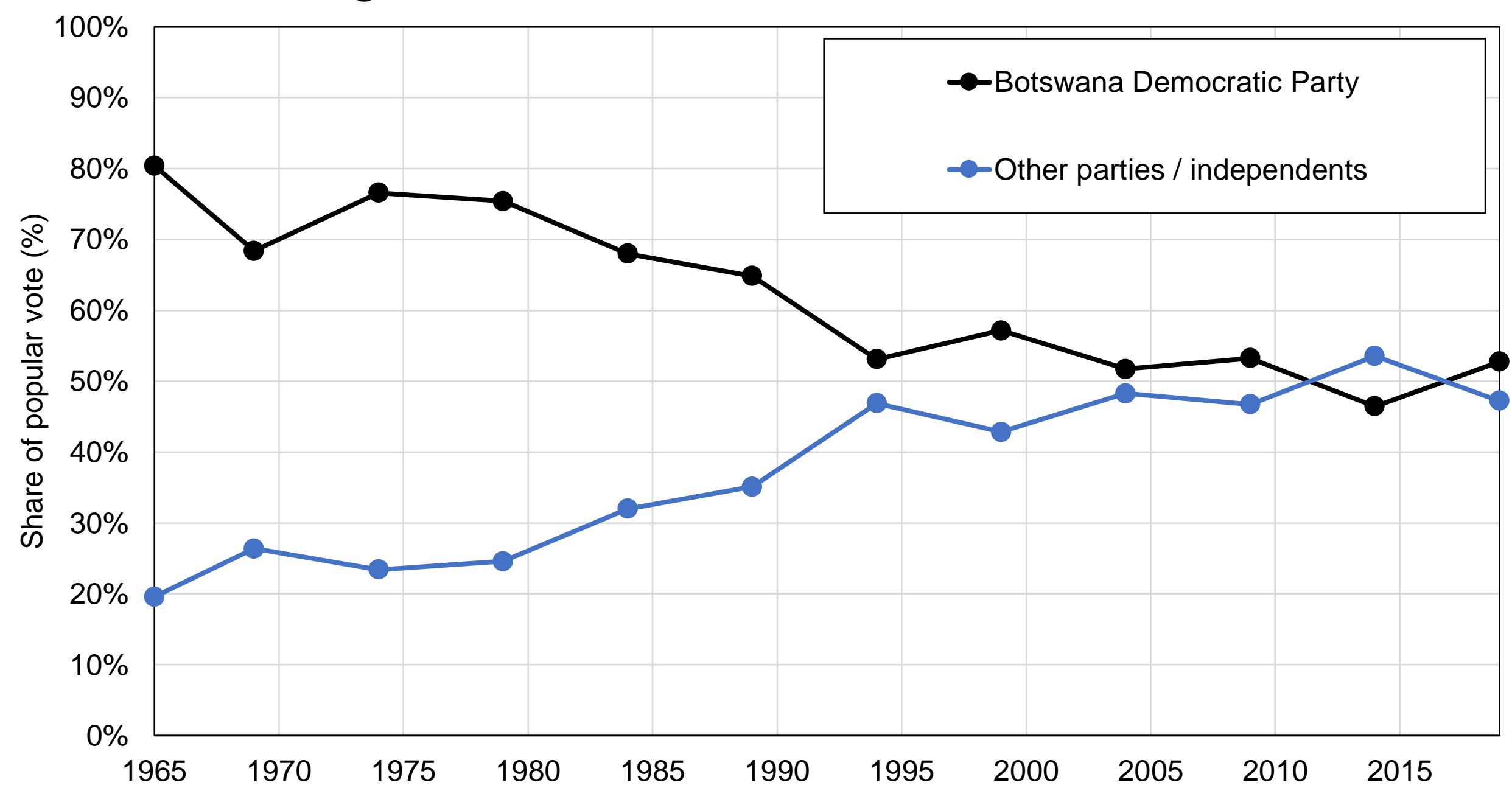

Source: authors' computations using official election results.

Note: the figure shows the share of votes received by selected groups of political parties in Botswana in general elections between 1965 and 2019. 
Figure 2 - Ethnolinguistic educational inequalities in Botswana

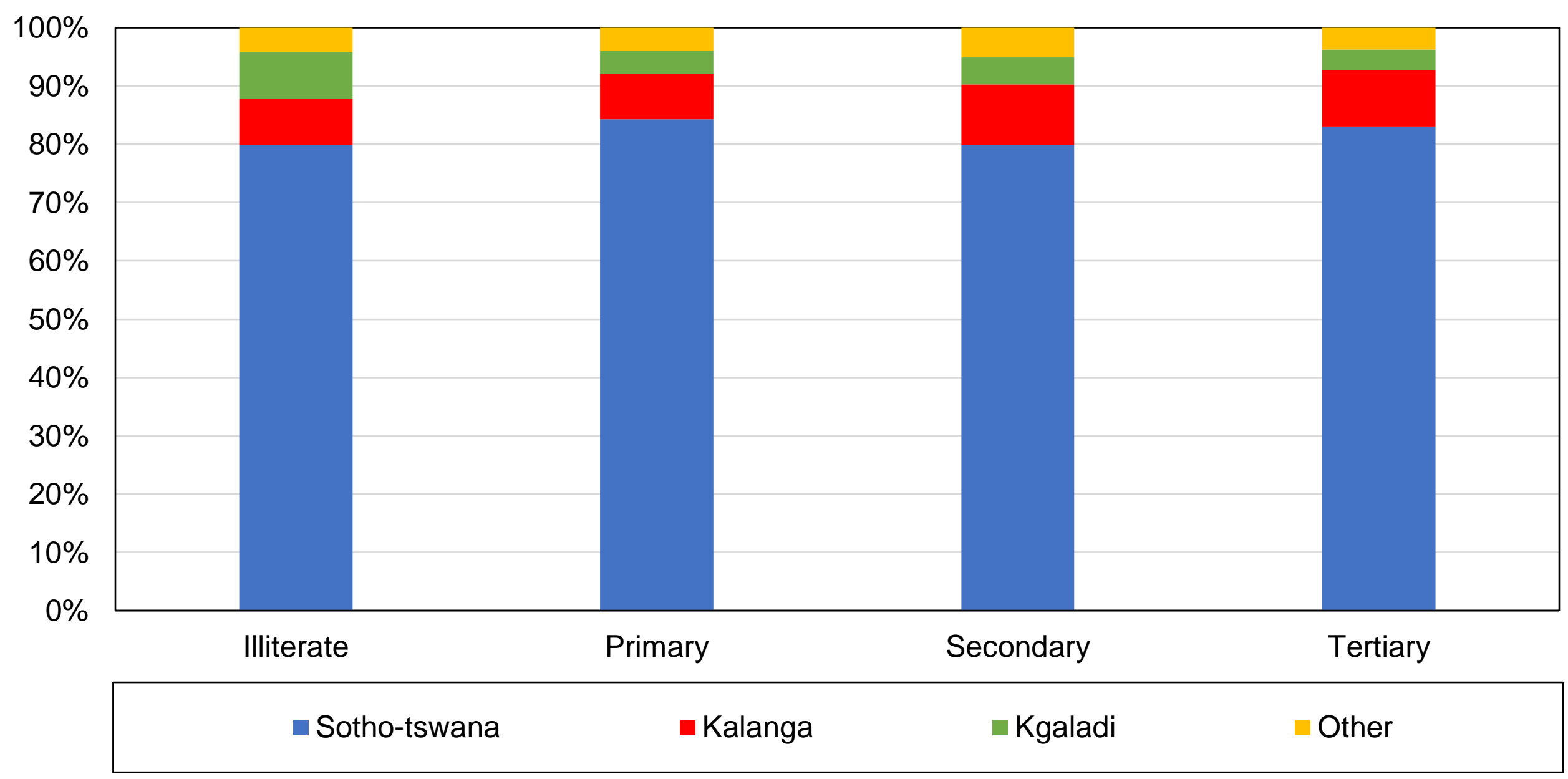

Source: authors' computations using Afrobarometer surveys.

Note: the figure shows the composition of education groups by language in Botswana in 2019. Illiterates represent $11 \%$ of the electorate, primary-educated respondents $18 \%$, secondary-educated respondents $49 \%$, and tertiary-educated respondents $22 \%$. 
Figure 3 - Vote for the Botswana Democratic Party by language

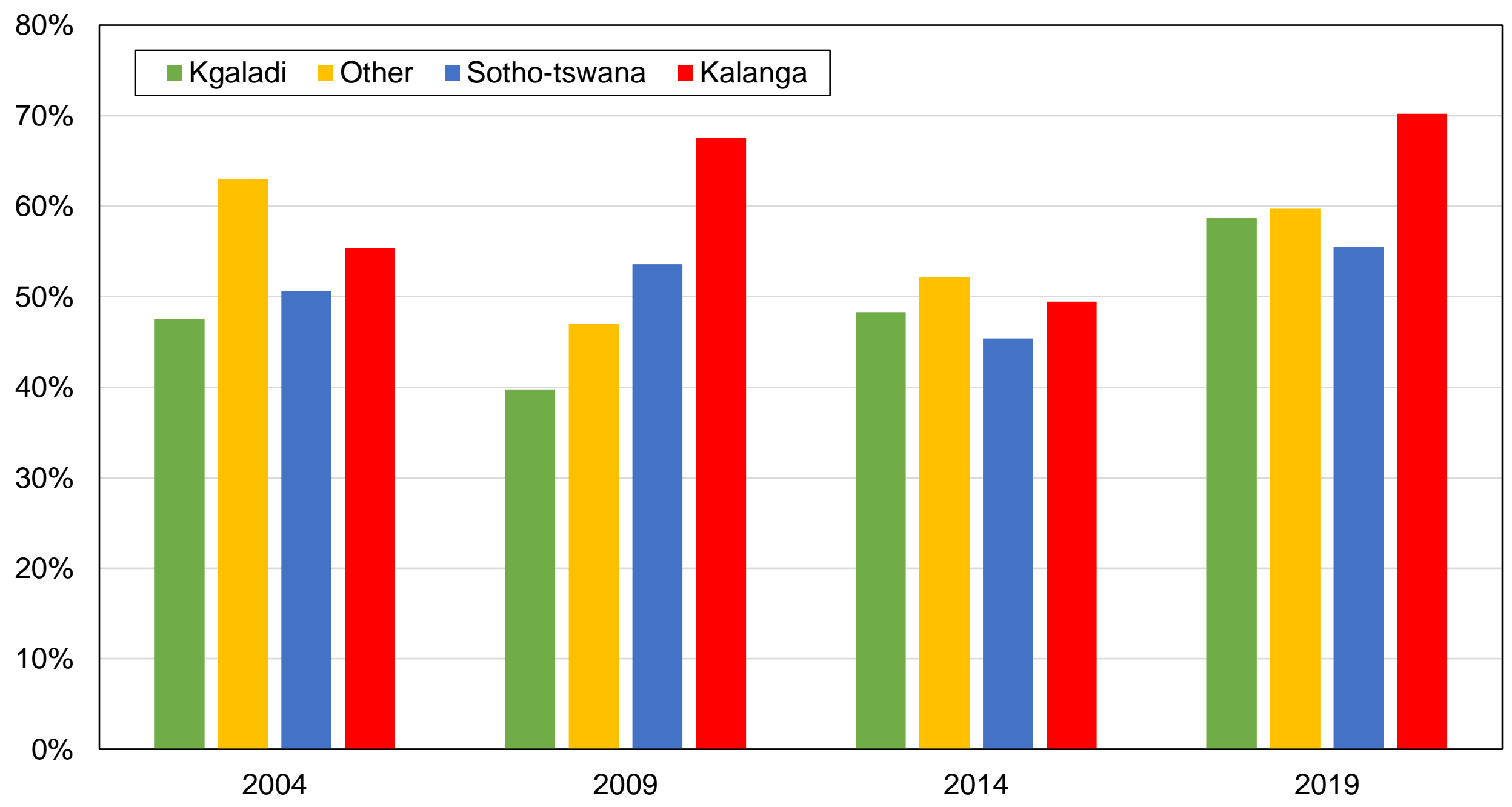

Source: authors' computations using Afrobarometer surveys.

Note: the figure shows the share of votes received by the BDP by language. In 2019, Sotho-Tswana represents about $81 \%$ of the electorate, Kalanga $10 \%$, Kgaladi $5 \%$, and other languages $5 \%$. 
Figure 4 - Vote for the Botswana Democratic Party among rural areas

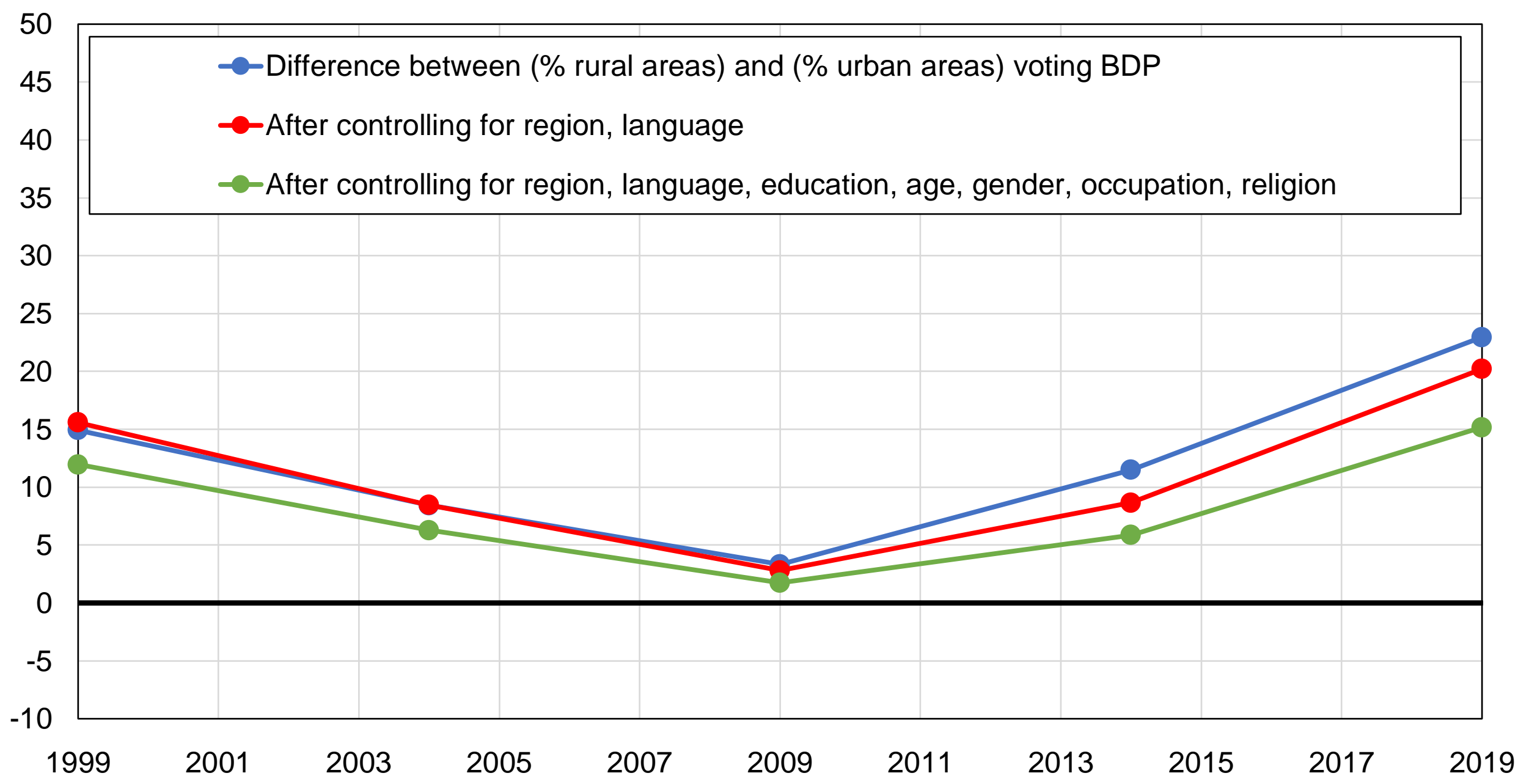

Source: authors' computations using Afrobarometer surveys.

Note: the figure shows the difference between the share of voters from rural areas and the share of urban voters voting for BDP, before and after controlling for other variables. Rural areas represent about $32 \%$ of the electorate in 2019, down from 55\% in 1999. 
Figure 5 - Vote for the Botswana Democratic Party among highereducated voters

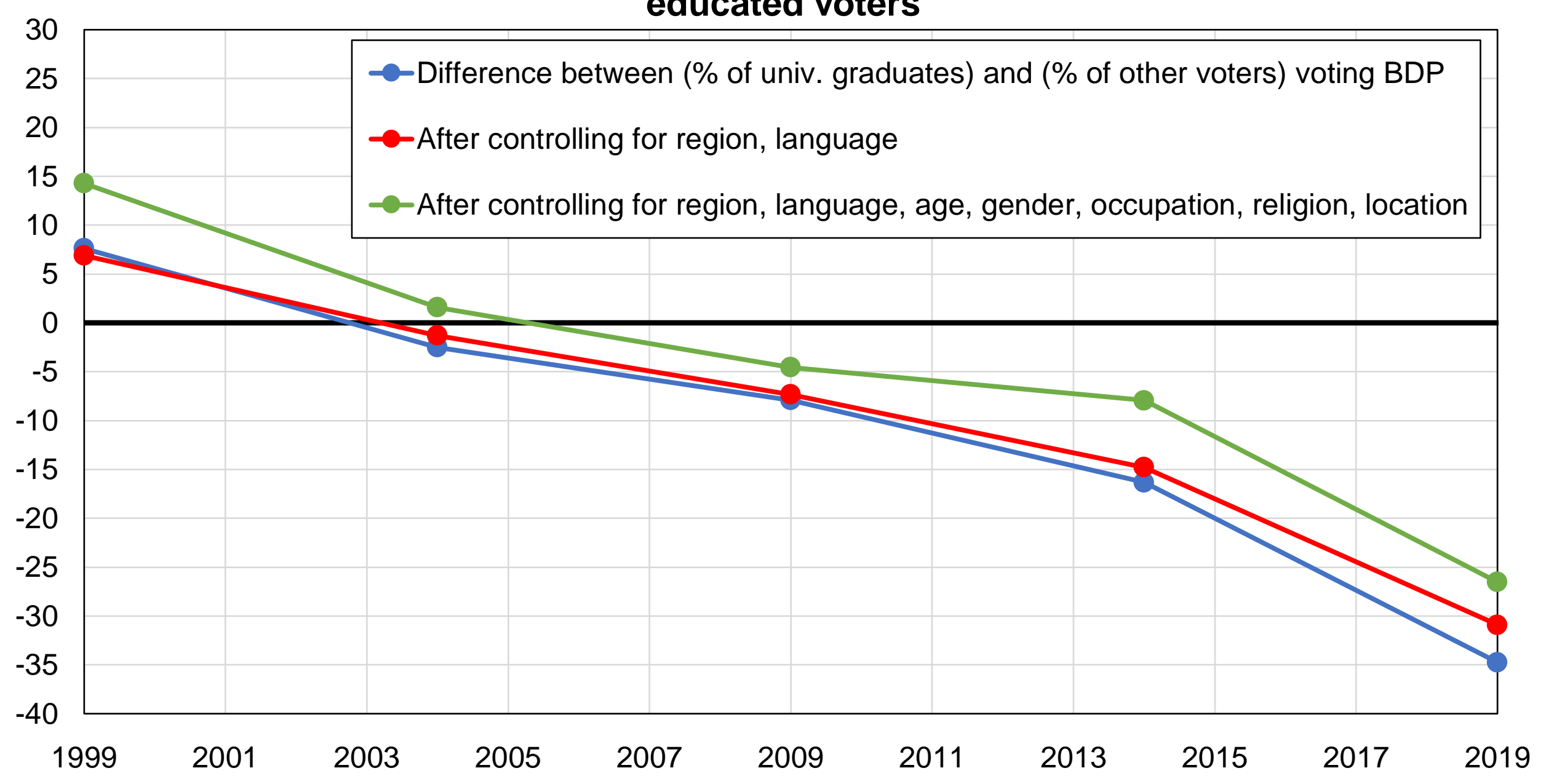

Source: authors' computations using Afrobarometer surveys.

Note: the figure shows the difference between the share of university graduates and the share of other voters voting for BDP, before and after controlling for other variables. The share of tertiary-educated voters represents about $22 \%$ of the electorate in 2019 compared to $9 \%$ in 1999. 
Figure 6 - Presidential election results in Ghana, 1960-2016

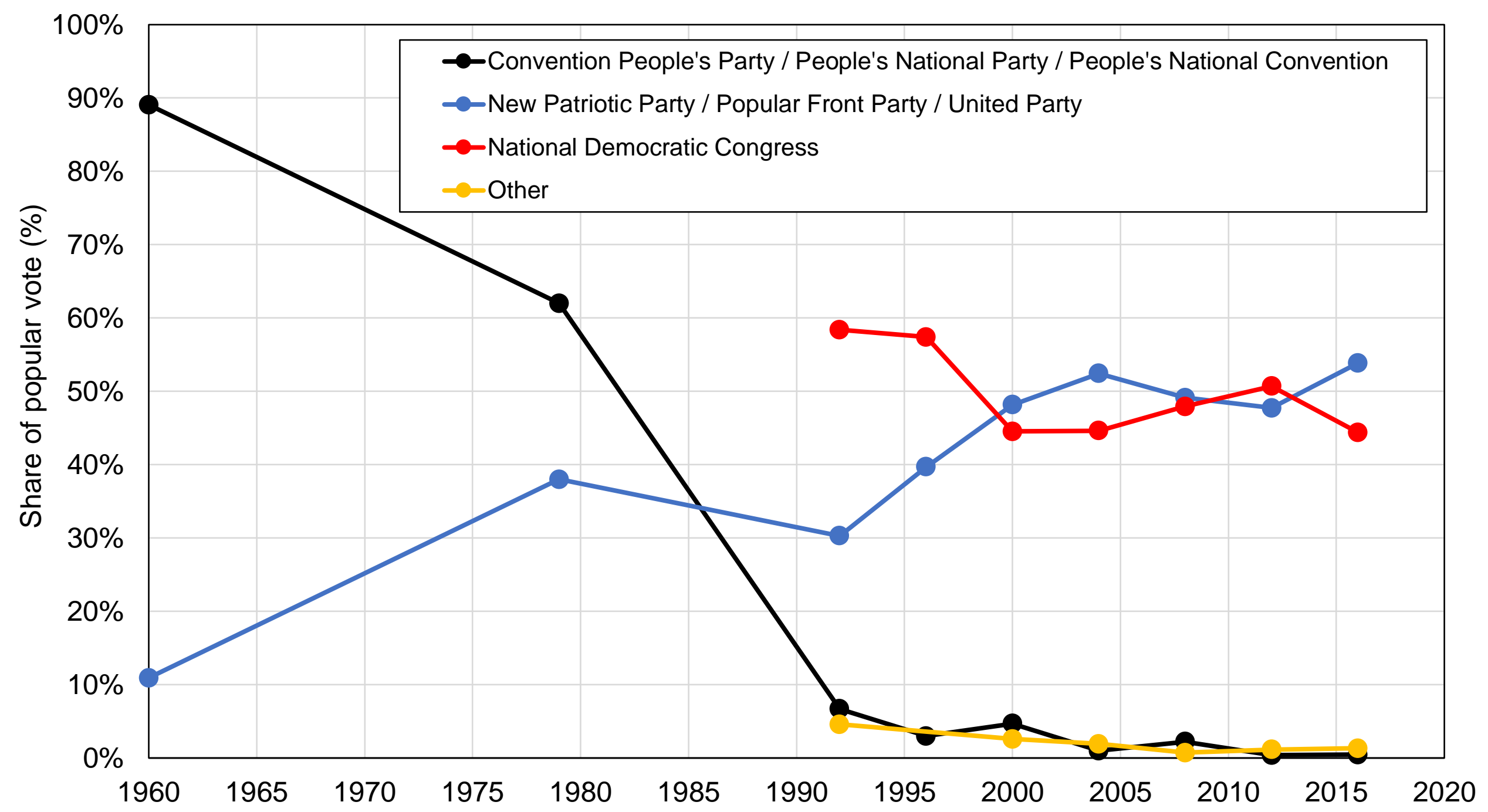

Source: authors' computations using official election results.

Note: the figure shows the share of votes received by selected groups of political parties in Ghana in general elections between 1960 and 2016. 
Figure 7 - Regional educational inequalities in Ghana

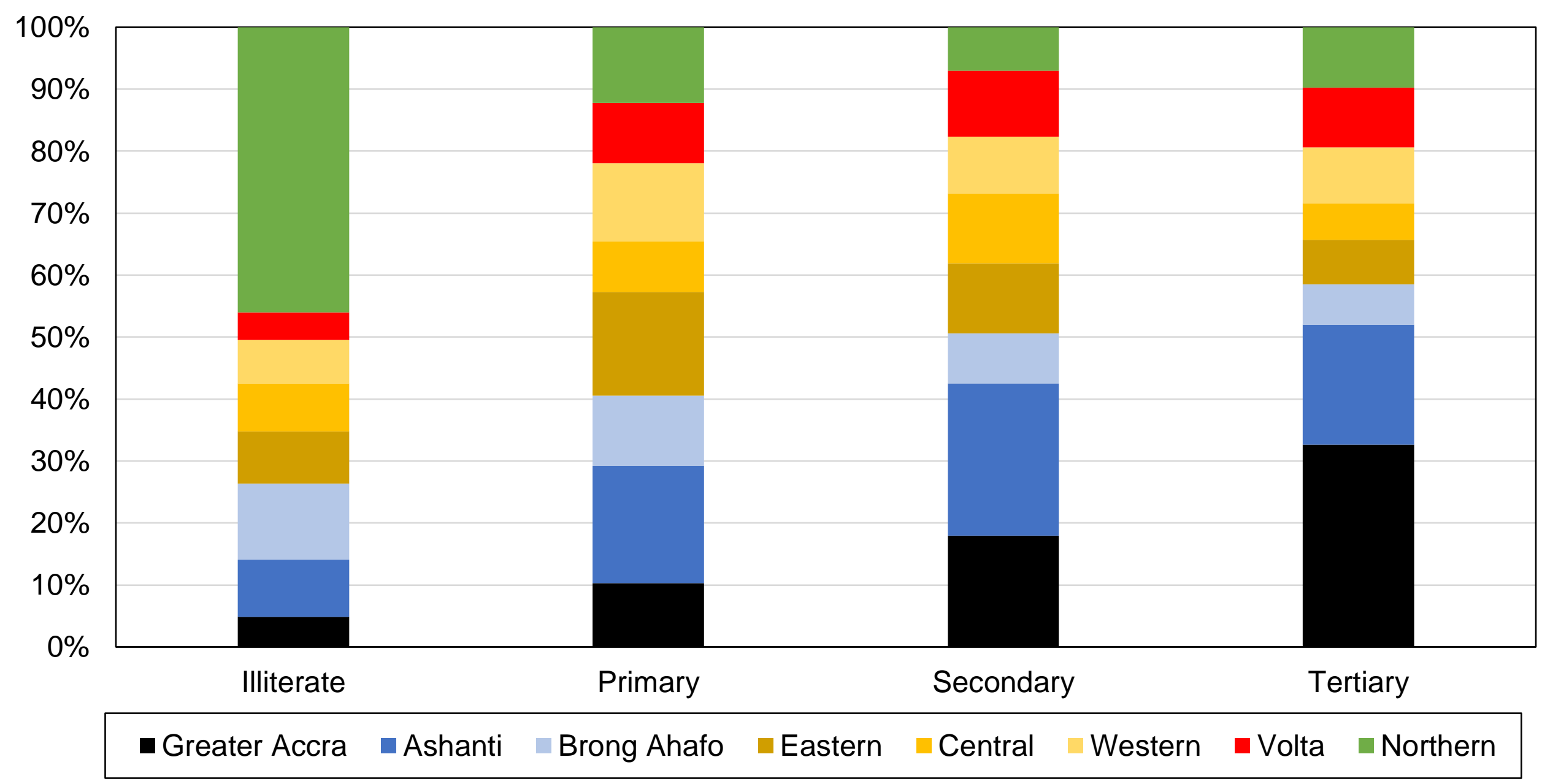

Source: authors' computations using Afrobarometer surveys.

Note: the figure shows the distribution of education groups by region in Ghana in 2016 . \%. In 2016, illiterates represent $18 \%$ of the electorate, primary-educated respondents $16 \%$, secondary-educated respondents $38 \%$, and post-secondary-educated respondents (including high school graduates) $28 \%$. 
Figure 8 - Vote for the National Democratic Congress by language

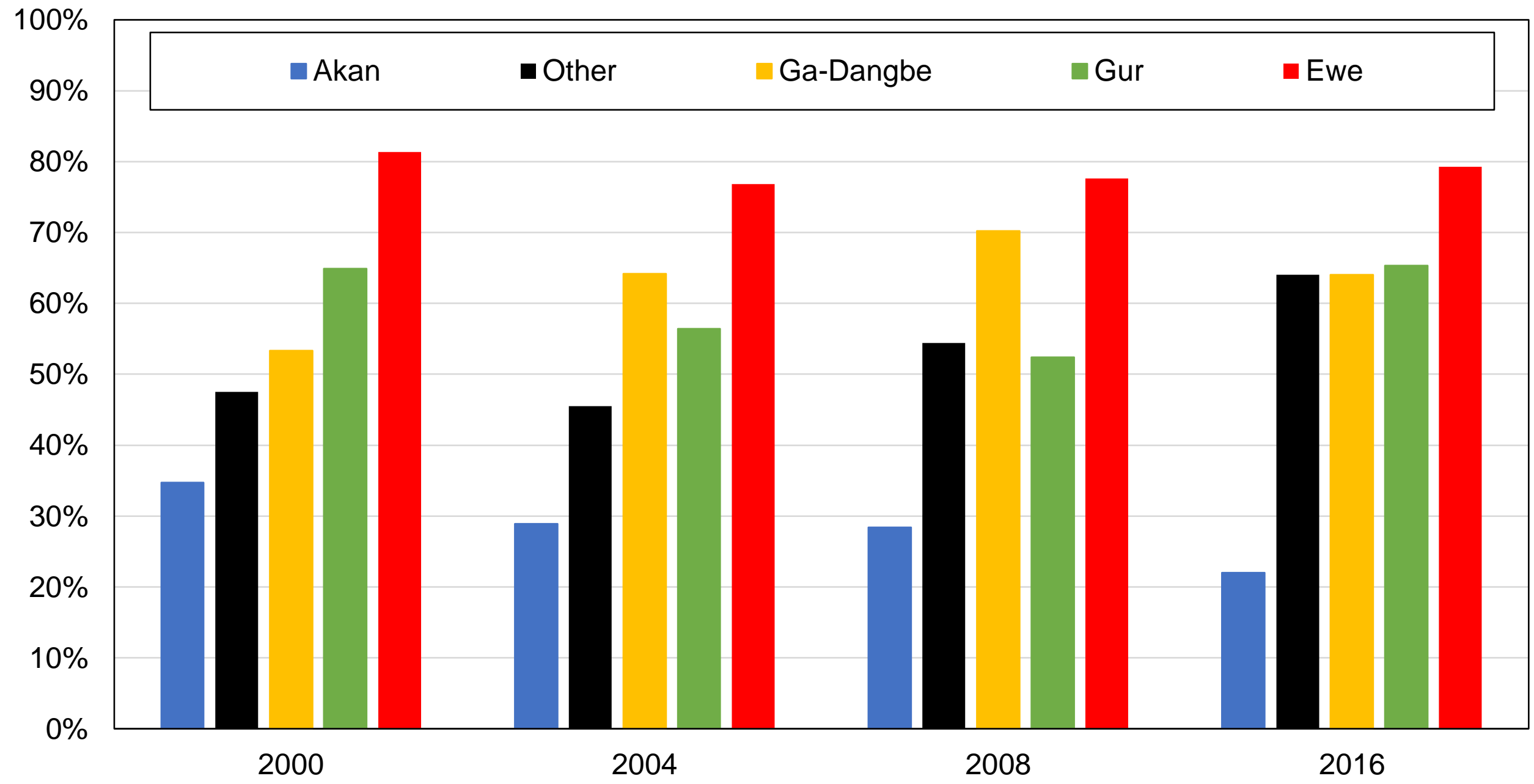

Source: authors' computations using Afrobarometer surveys.

Note: the figure shows the share of votes received by NDC by language. Ewe speakers represent about $15 \%$ of the electorate in 2016, speakers of Gur languages $19 \%$, speakers of Ga-Dangbe languages $8 \%$, and speakers of Akan languages 53\%. 
Figure 9 - Vote for the National Democratic Congress by region

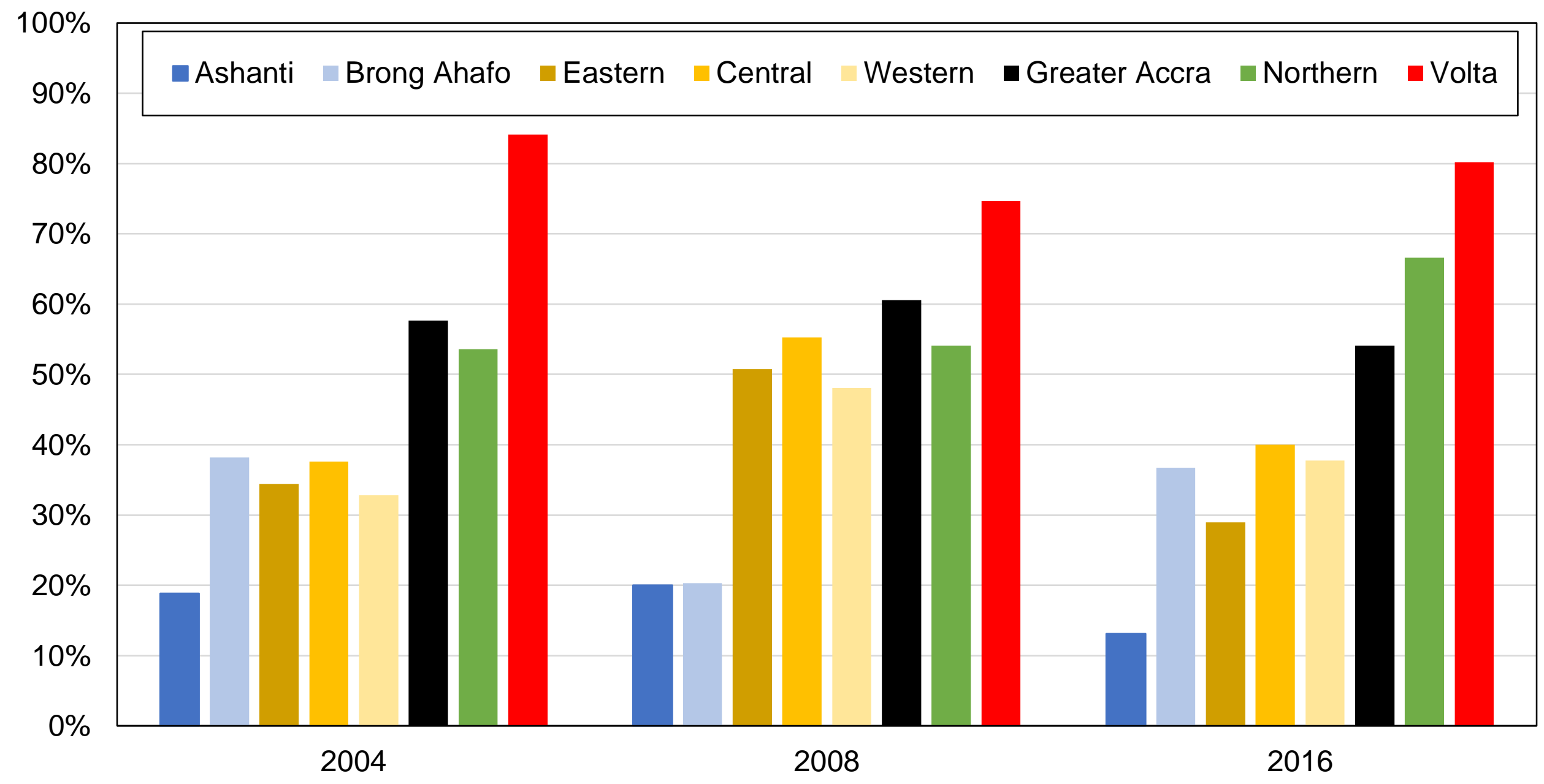

Source: authors' computations using Afrobarometer surveys.

Note: the figure shows the share of votes received by NDC by region. The Northern region includes the Upper East and the Upper West. In 2016, the Ashanti region represents about 19\% of the electorate, Brong Ahafo 9\%, Eastern 10\%, Central 9\%, Western 9\%, Greater Accra 18\%, Northern 16\%, and Volta 6\%. 


\section{Figure 10 - Vote for the National Democratic Congress in rural areas}

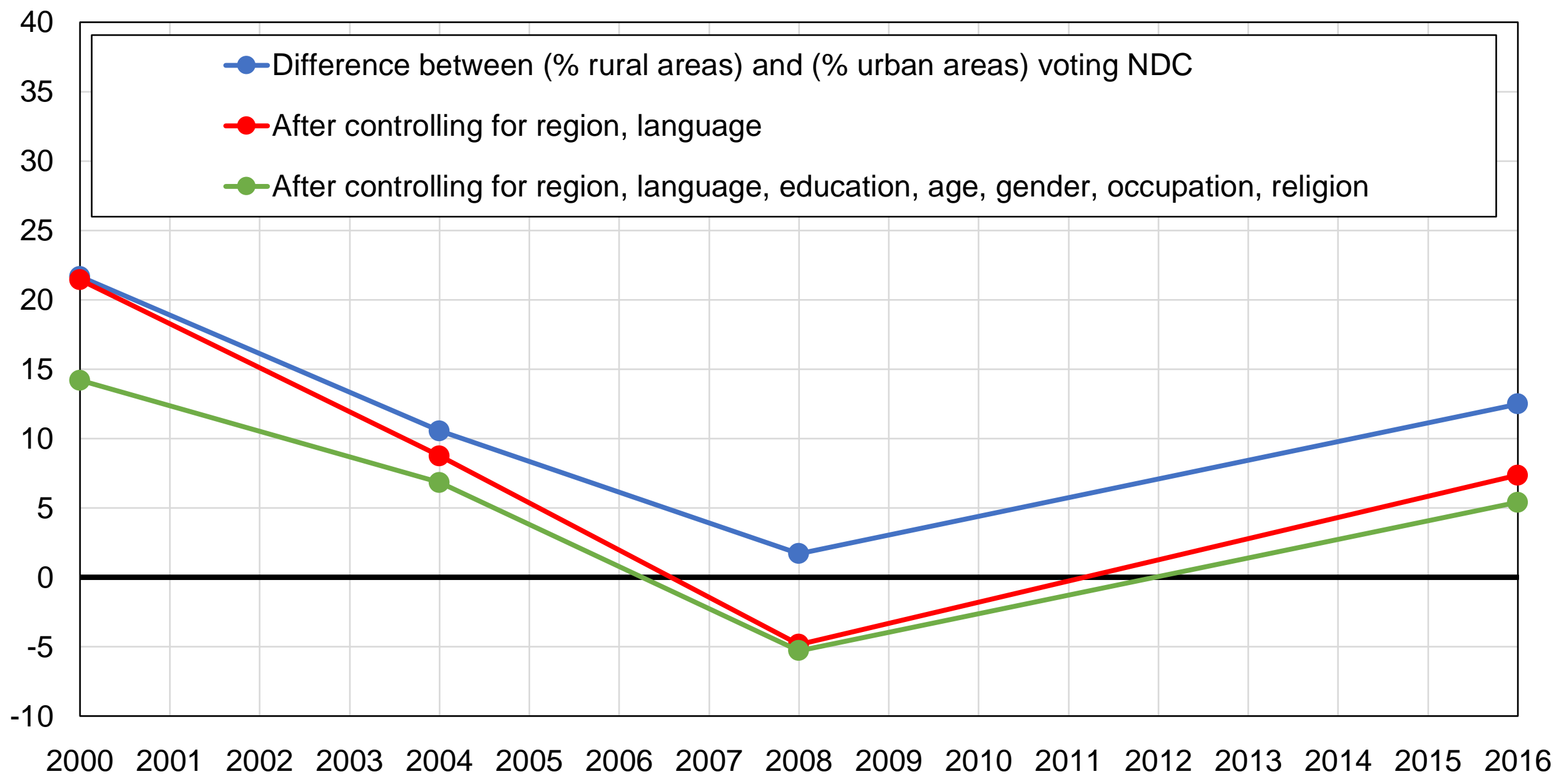

Source: authors' computations using Afrobarometer surveys.

Note: the figure shows the difference between the share of voters from rural areas and the share of other voters voting for NDC, before and after controlling for other variables. Rural areas represent about $46 \%$ of the electorate in 2016 , down from $63 \%$ in 2000. 
Figure 11 - Vote for the National Democratic Congress among highereducated voters

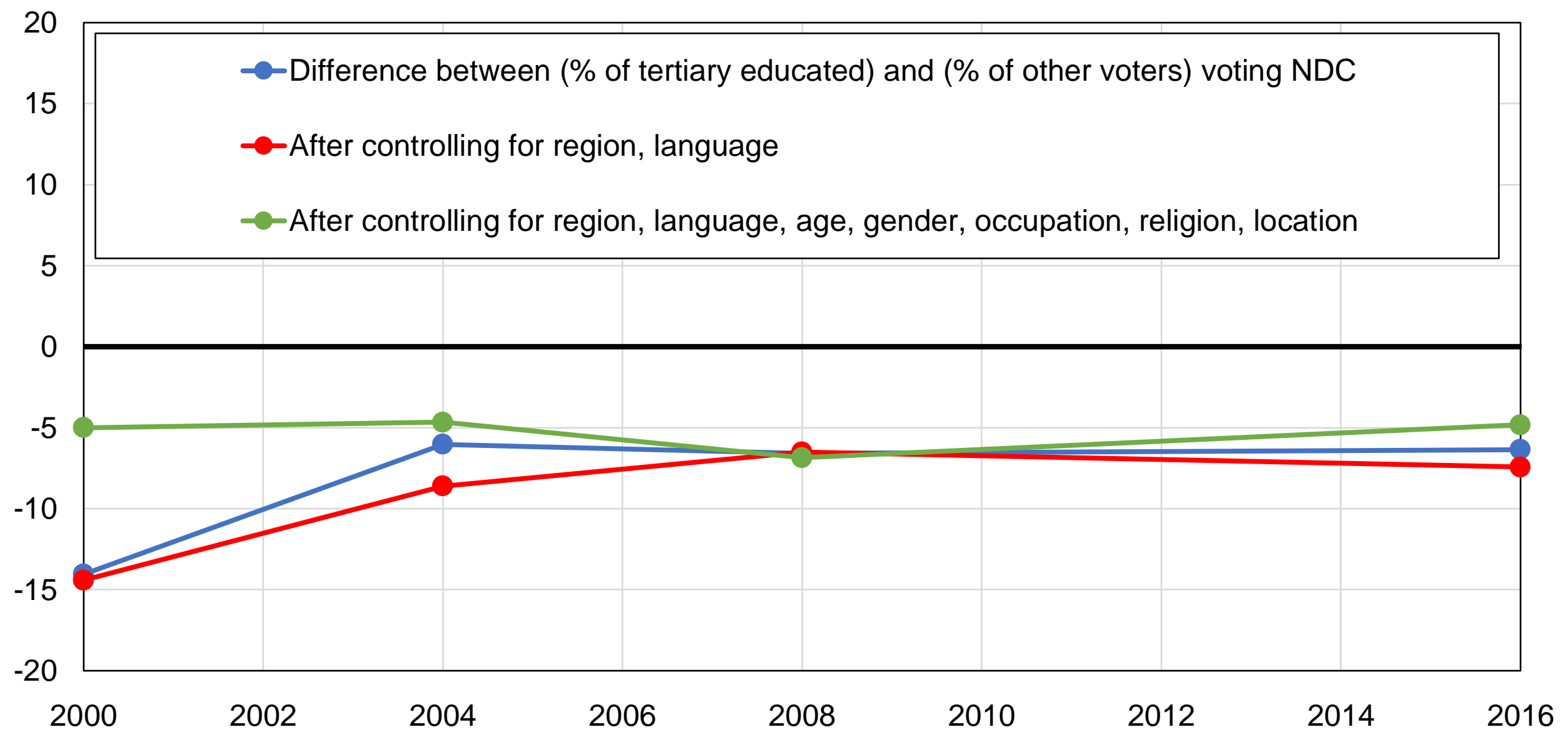

Source: authors' computations using Afrobarometer surveys.

Note: the figure shows the difference between the share of tertiary-educated voters and the share of other voters voting for NDC, before and after controlling for other variables. Tertiary-educated voters (including high-school graduates) represent about $28 \%$ of the electorate in 2016. 
Figure 12 - Presidential election results in Nigeria, 1999-2019

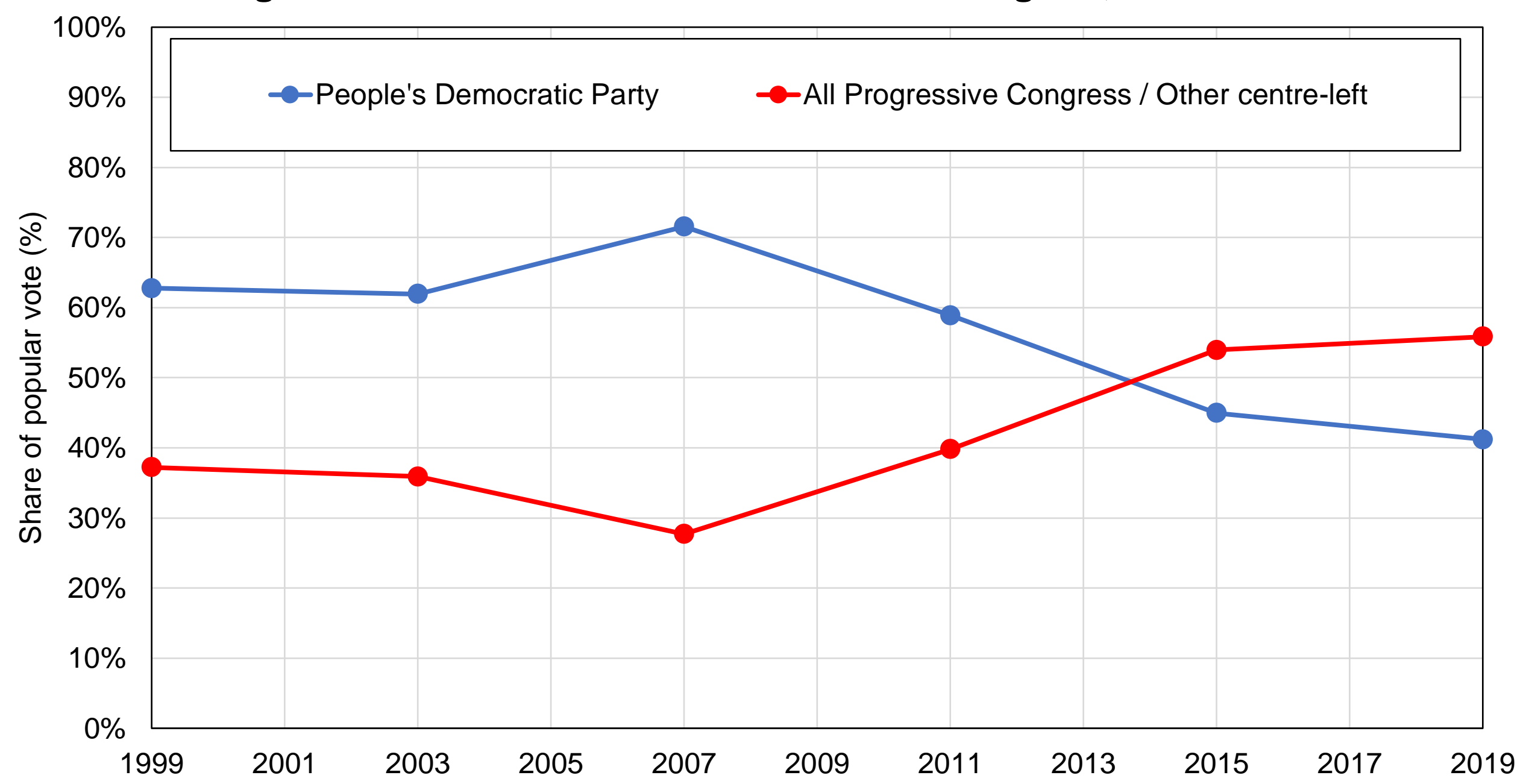

Source: authors' computations using official election results.

Note: the figure shows the share of votes received by selected groups of Nigerian political parties in presidential elections between 1999 and 2019. 


\section{Figure 13 - Ethnoreligious educational inequalities in Nigeria}

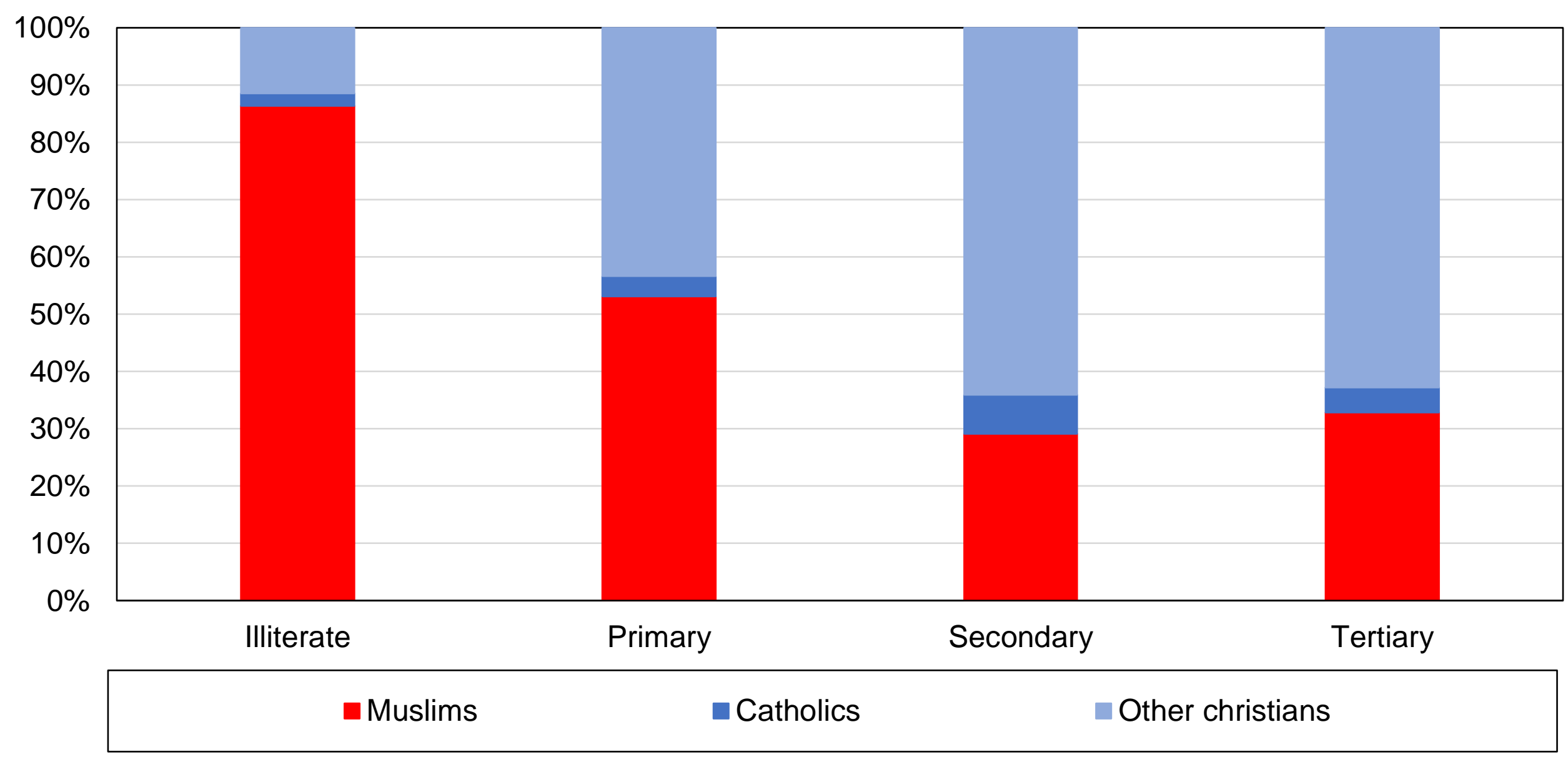

Source: authors' computations using Afrobarometer surveys.

Note: the figure shows the composition of education groups by religion in Nigeria in 2019. Muslims represent about $41 \%$ of the electorate, Catholics $5 \%$, and other Christians $53 \%$. Illiterates represent $14 \%$ of the electorate, primary-educated respondents $13 \%$, secondary-educated respondents $45 \%$, and tertiaryeducated respondents $28 \%$. 
Figure 14 - Vote for the People's Democratic Party by religion

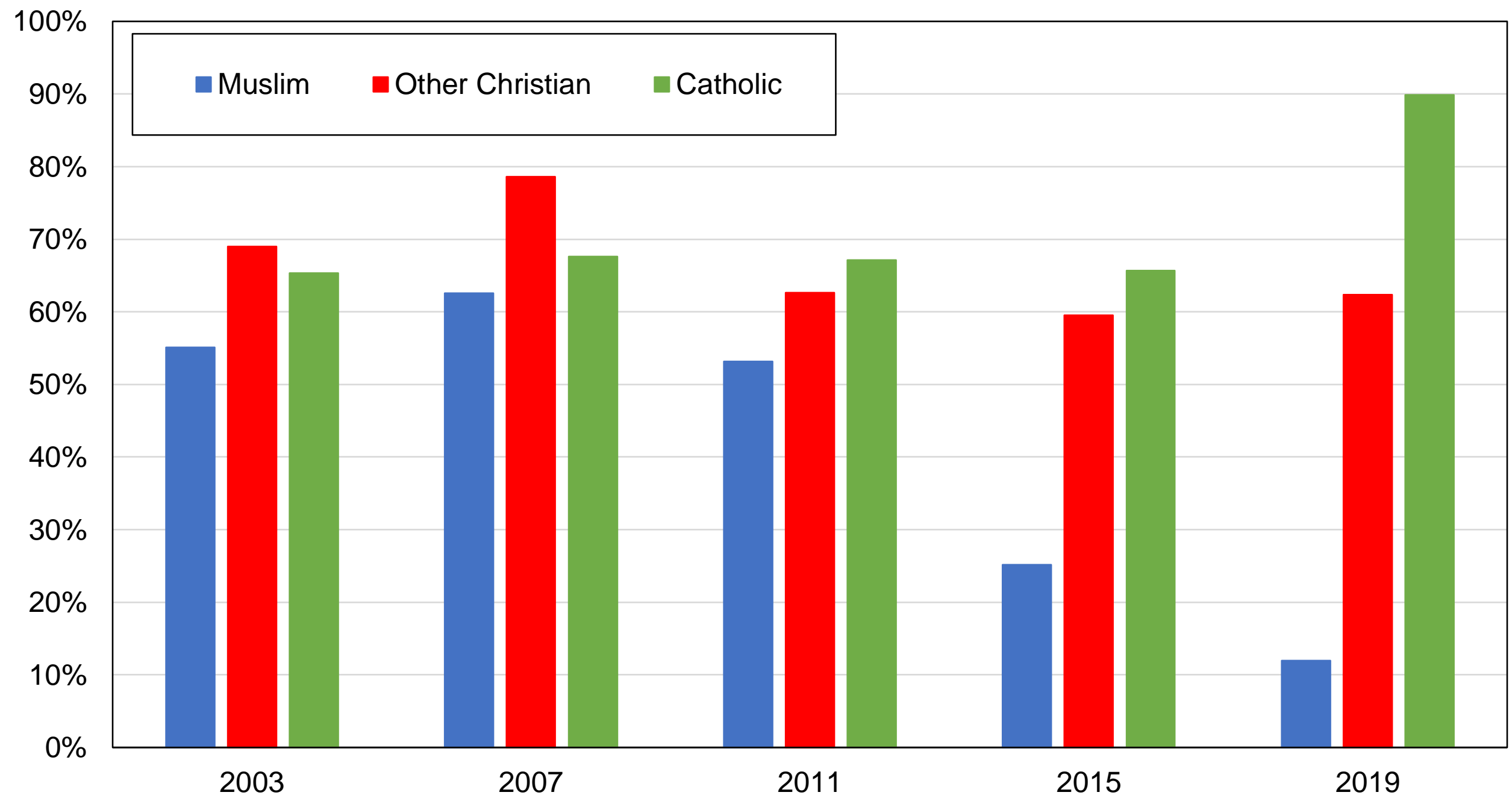

Source: authors' computations using Afrobarometer surveys.

Note: the figure shows the share of votes received by the PDP by religious affiliation. In 2019, Muslims represent about $41 \%$ of the electorate, Catholics 5\%, and other Christians $53 \%$. 


\section{Figure 15 - The rise of ethnoreligious polarization in Nigeria}

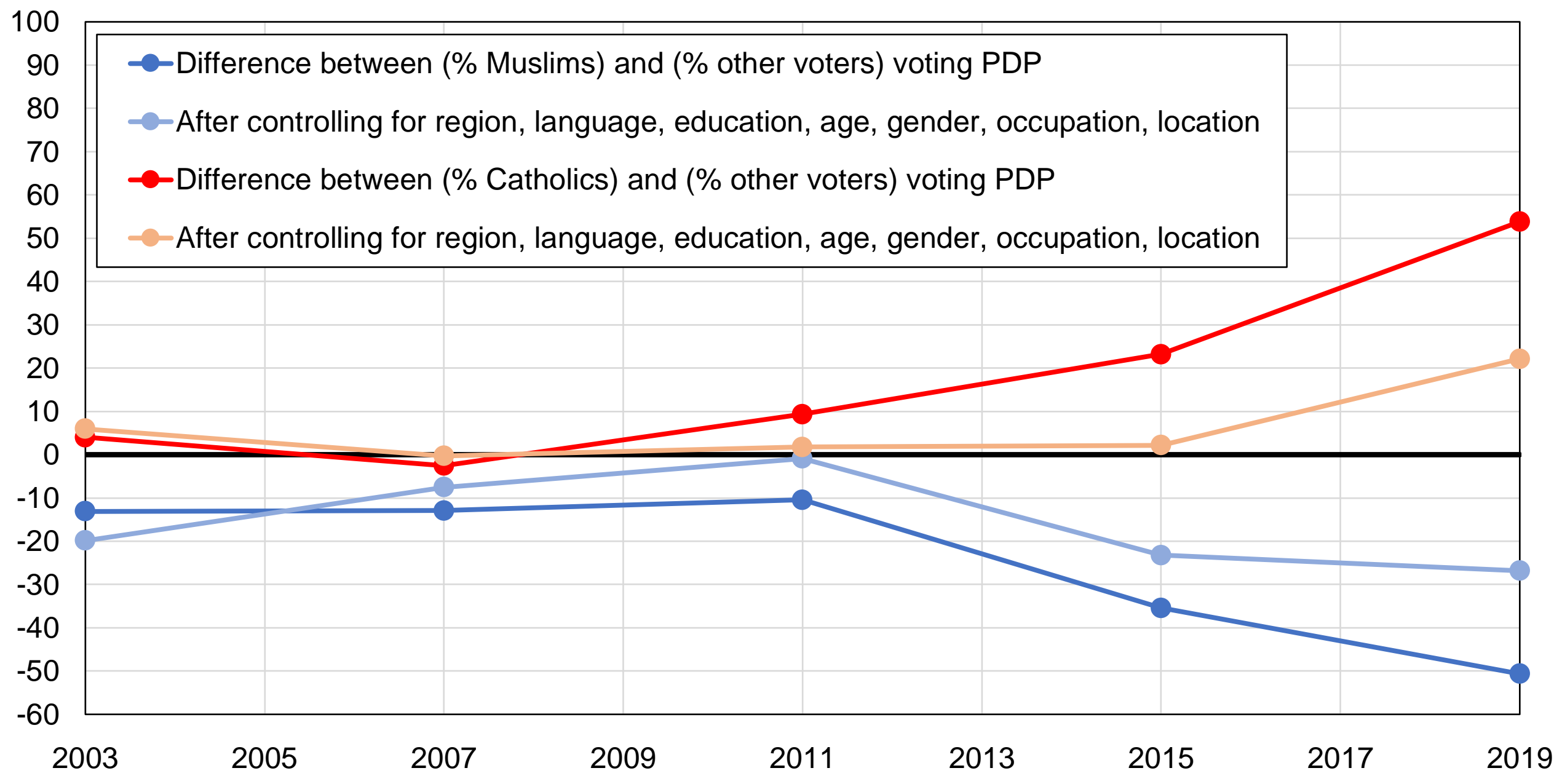

Source: authors' computations using Afrobarometer surveys.

Note: the figure shows the difference between the share of Muslim voters and the share of other voters voting for PDP, and the same difference for Catholics, before and after controlling for other variables. In 2019, Muslims represent about $41 \%$ of the electorate, Catholics 5\%, and other Christians 53\%. 
Figure 16 - Vote for the People's Democratic Party among highereducated voters

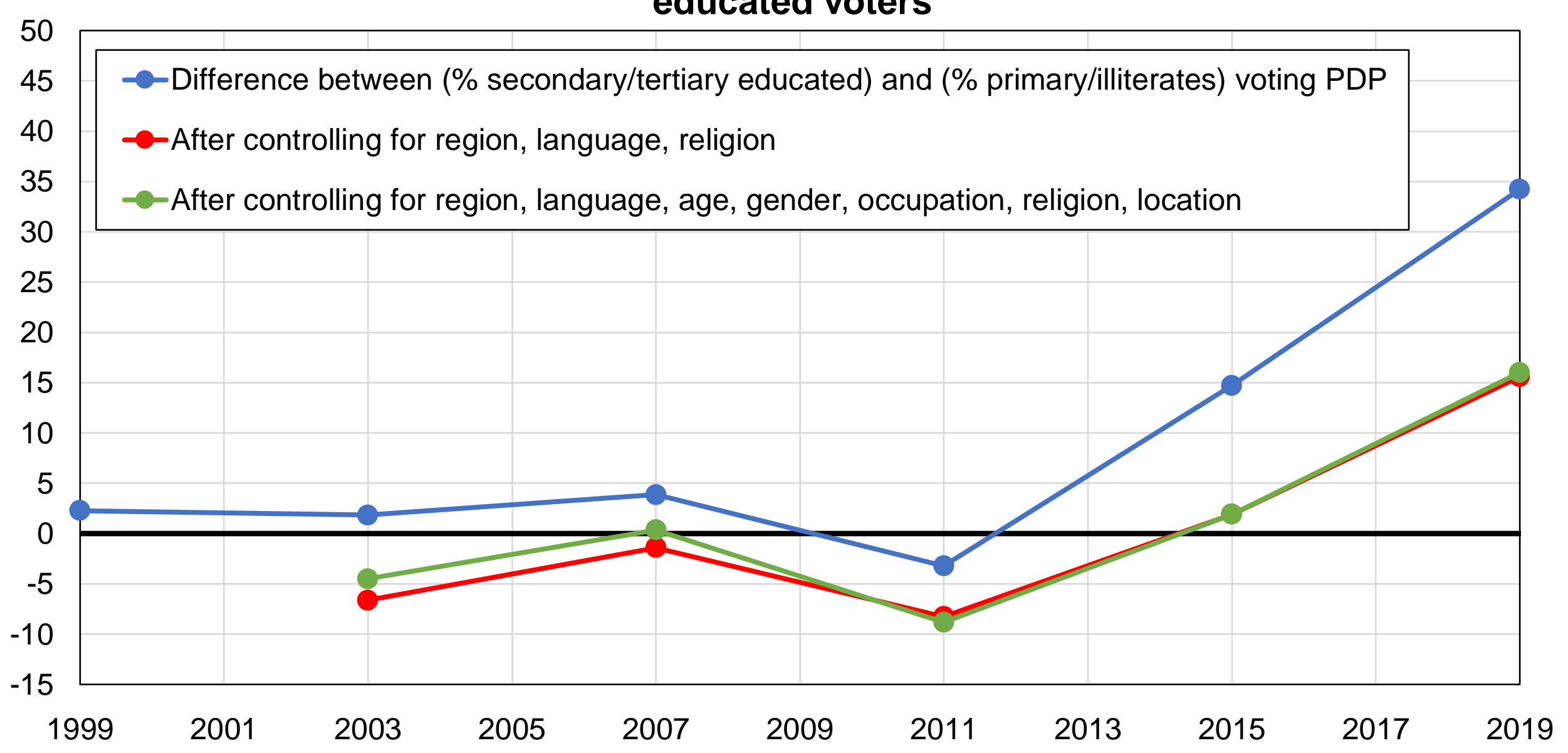

Source: authors' computations using Afrobarometer surveys.

Note: the figure shows the difference between the share of secondary- and tertiary-educated voters and the share of primary-educated voters and illiterates voting PDP, before and after controlling for other variables. In 2019 , illiterates represent $14 \%$ of the electorate, primary-educated respondents $13 \%$, secondaryeducated respondents $45 \%$, and tertiary-educated respondents $28 \%$. 
Figure 17 - Presidential election results in Senegal, 2000-2019

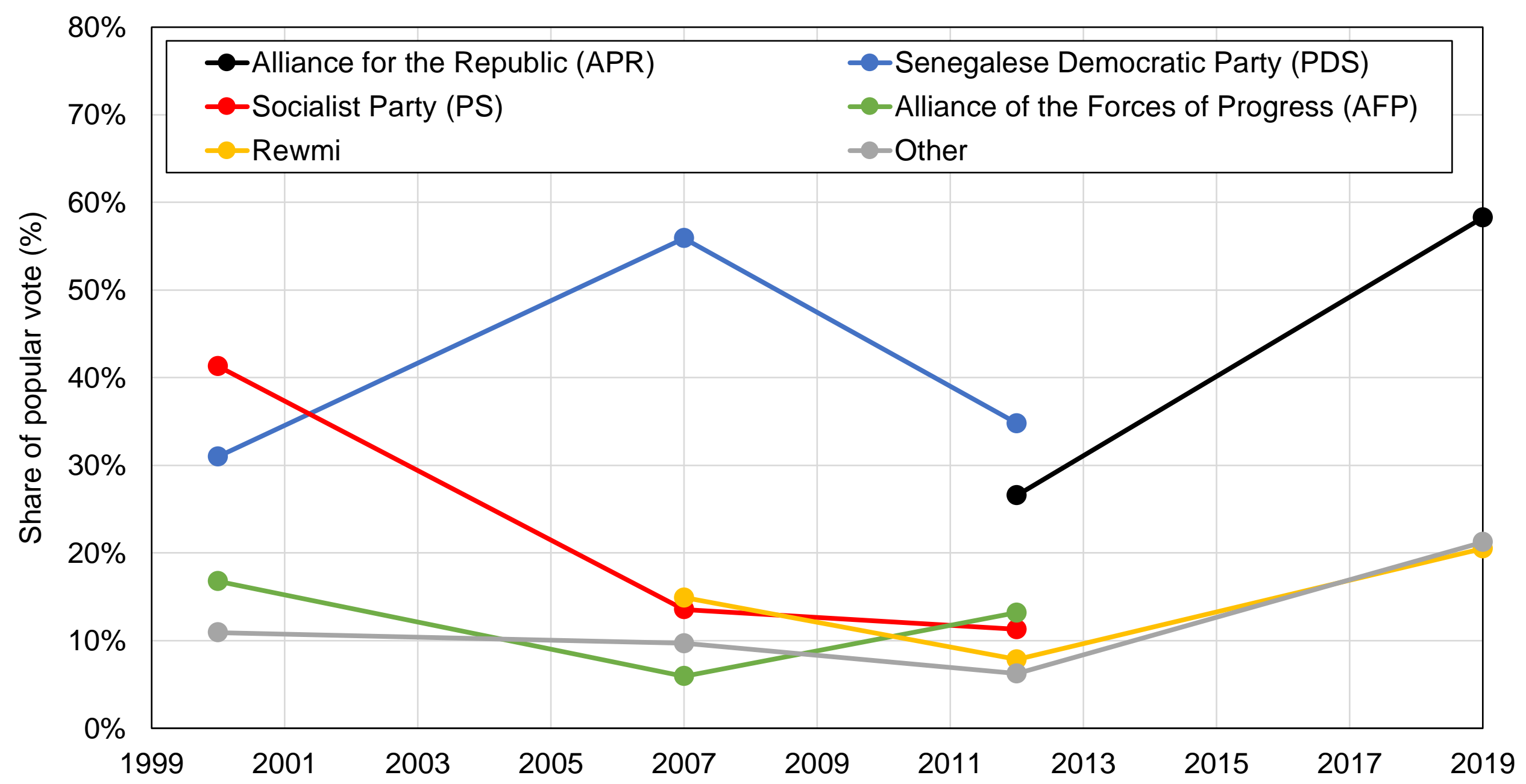

Source: authors' computations using official election results.

Note: the figure shows the share of votes received by selected groups of Senegalese political parties in presidential elections between 2000 and 2019. 
Figure 18 - Ethnolinguistic educational inequalities in Senegal

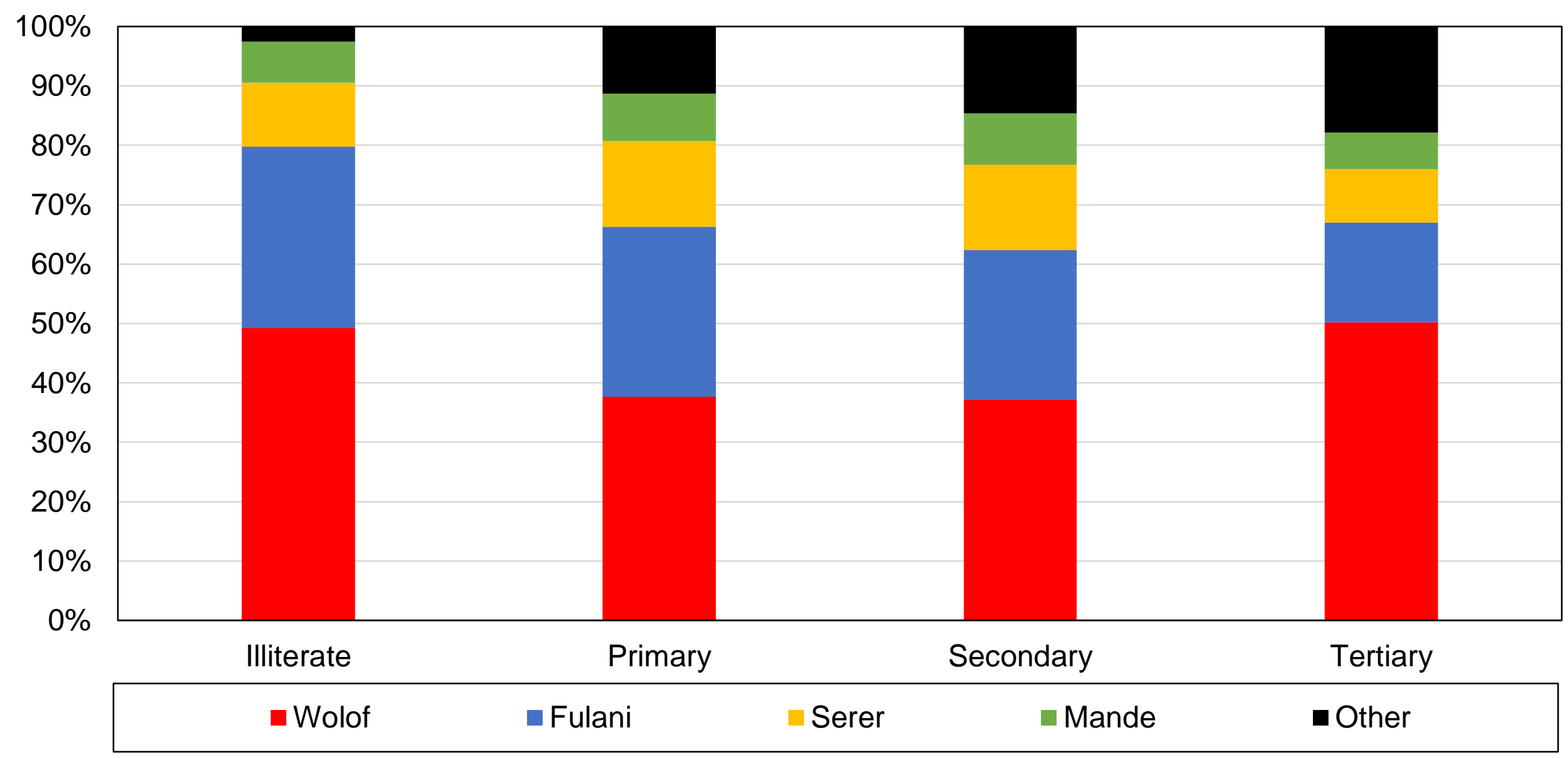

Source: authors' computations using Afrobarometer surveys.

Note: the figure shows the composition of education groups by language in Senegal in 2019. Wolof represents about $44 \%$ of the electorate, Fulani $28 \%$, Serer $12 \%$, Mande $7 \%$ and other languages $8 \%$. Illiterates represent $51 \%$ of the electorate, primary-educated respondents $18 \%$, secondary-educated respondents $23 \%$, and tertiary-educated respondents $9 \%$. 
Figure 19 - Vote for the Senegalese Democratic Party / Alliance for the Republic by language

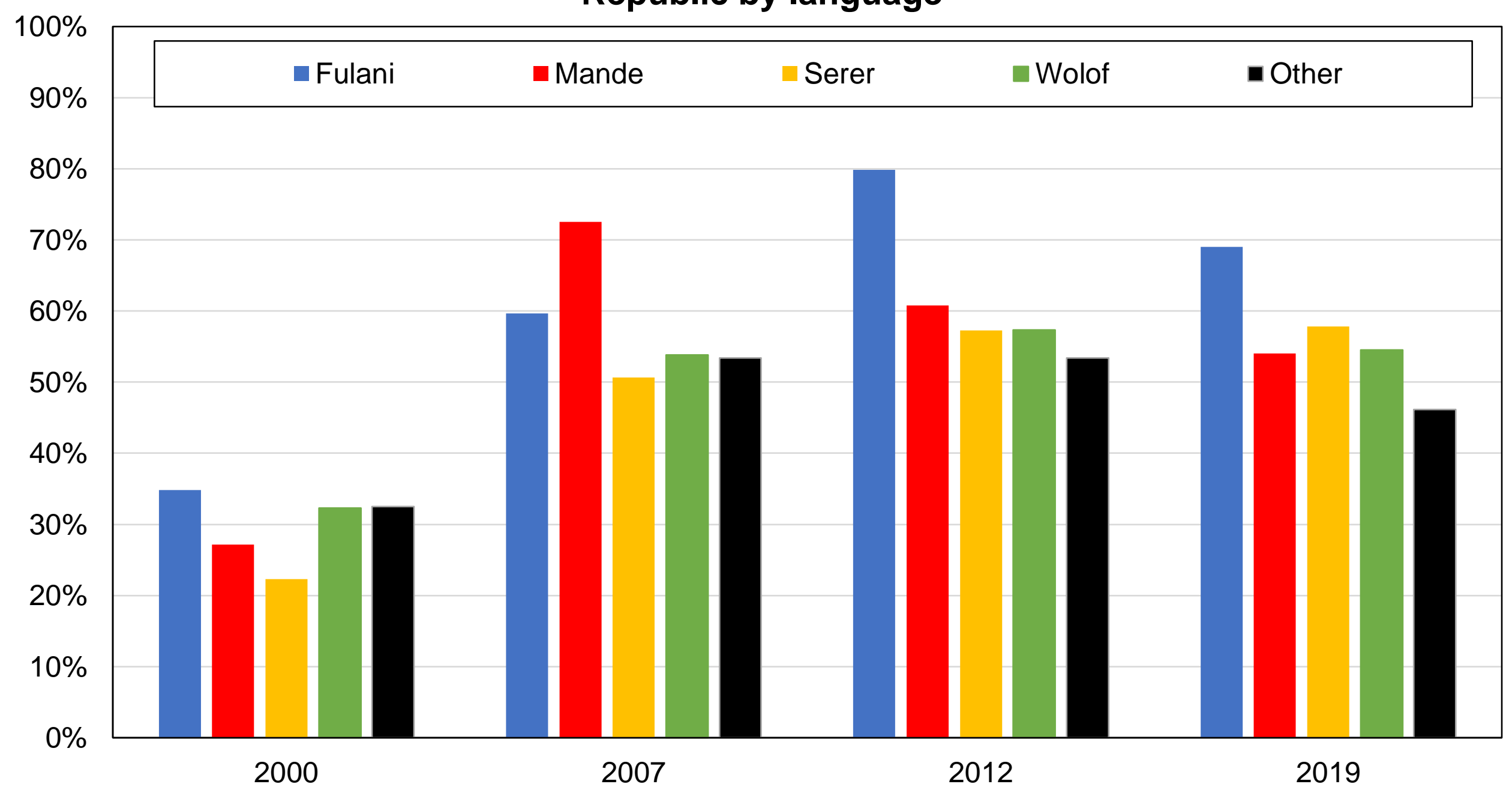

Source: authors' computations using Afrobarometer surveys.

Note: the figure shows the share of votes received by the PDS/APR by language. In 2019, Wolof represents about $44 \%$ of the electorate, Fulani $28 \%$, Serer $12 \%$, Mande $7 \%$ and other languages $8 \%$. 
Figure 20 - Vote for the Senegalese Democratic Party / Alliance for the Republic by location

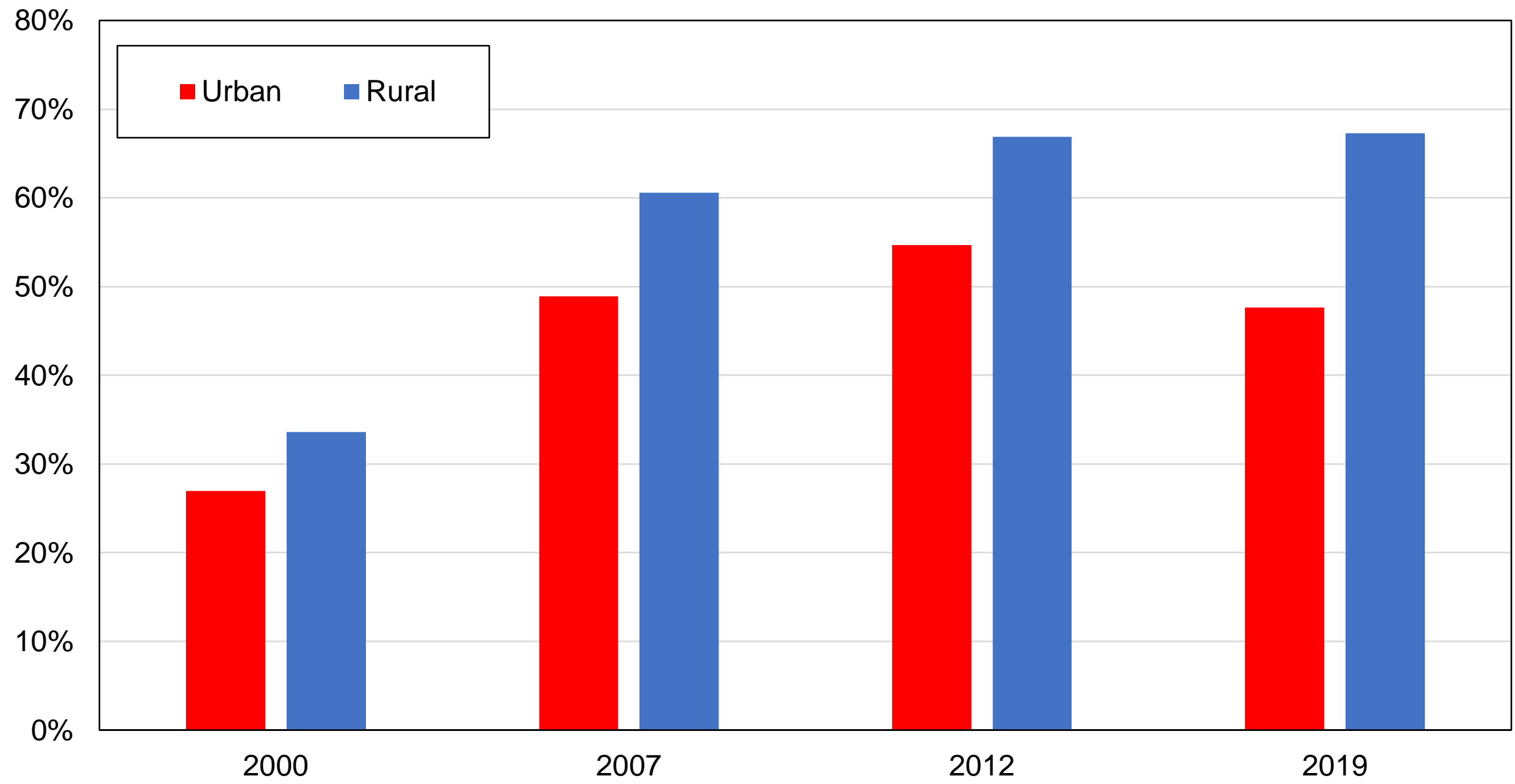

Source: authors' computations using Afrobarometer surveys.

Note: the figure shows the share of votes received by PDS/APR by location. Rural areas represent about $54 \%$ of the electorate in 2019. 
Figure 21 - Vote for the Senegalese Democratic Party / Alliance for the Republic among higher-educated voters

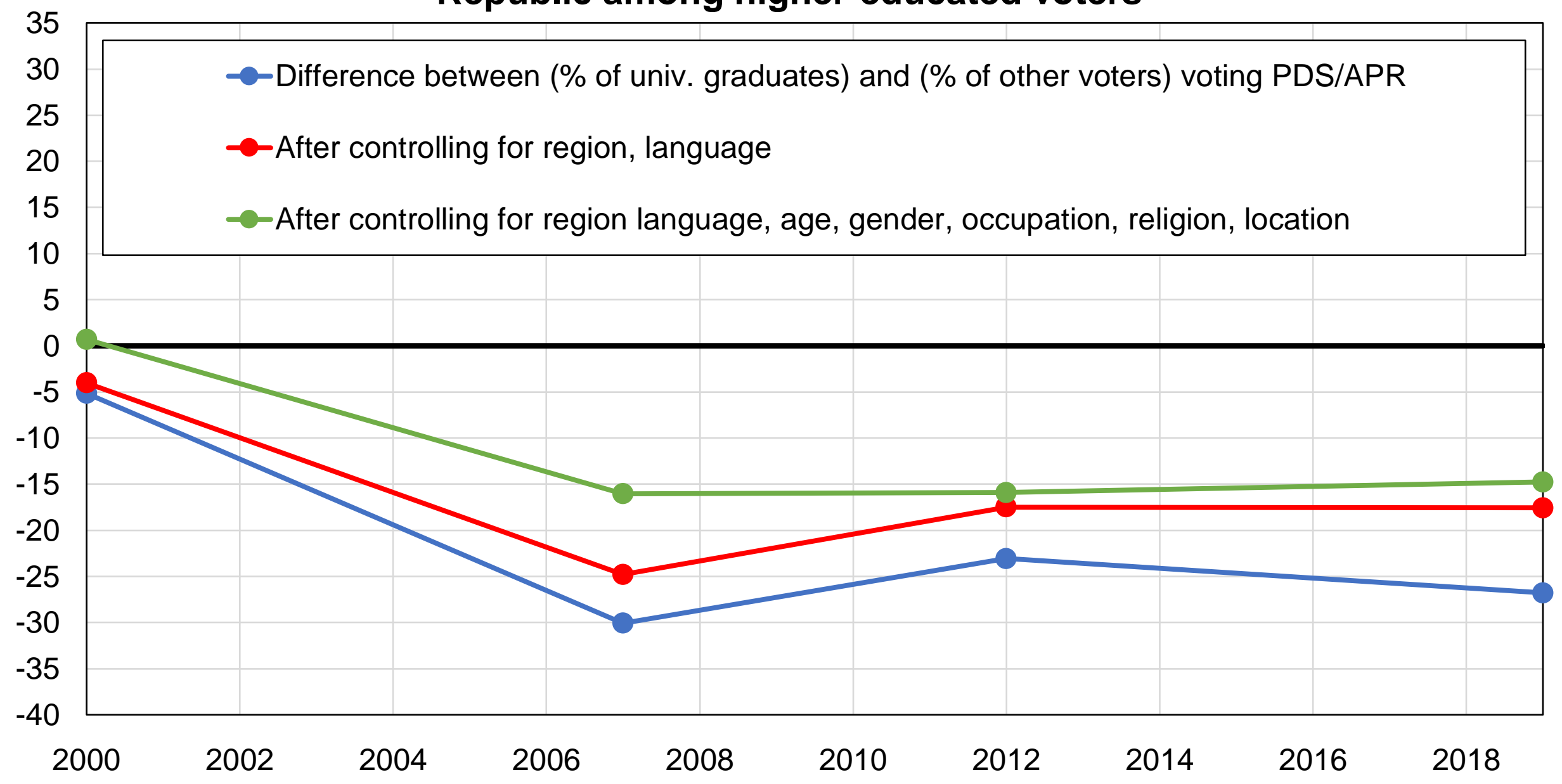

Source: authors' computations using Afrobarometer surveys.

Note: the figure shows the difference between the share of university graduates and the share of other voters voting for PDS / APR, before and after controlling for other variables. University graduates represented $9 \%$ of the electorate in 2019, up from $6 \%$ in 2000. 
Figure A1 - Election results in Botswana, 1965-2019

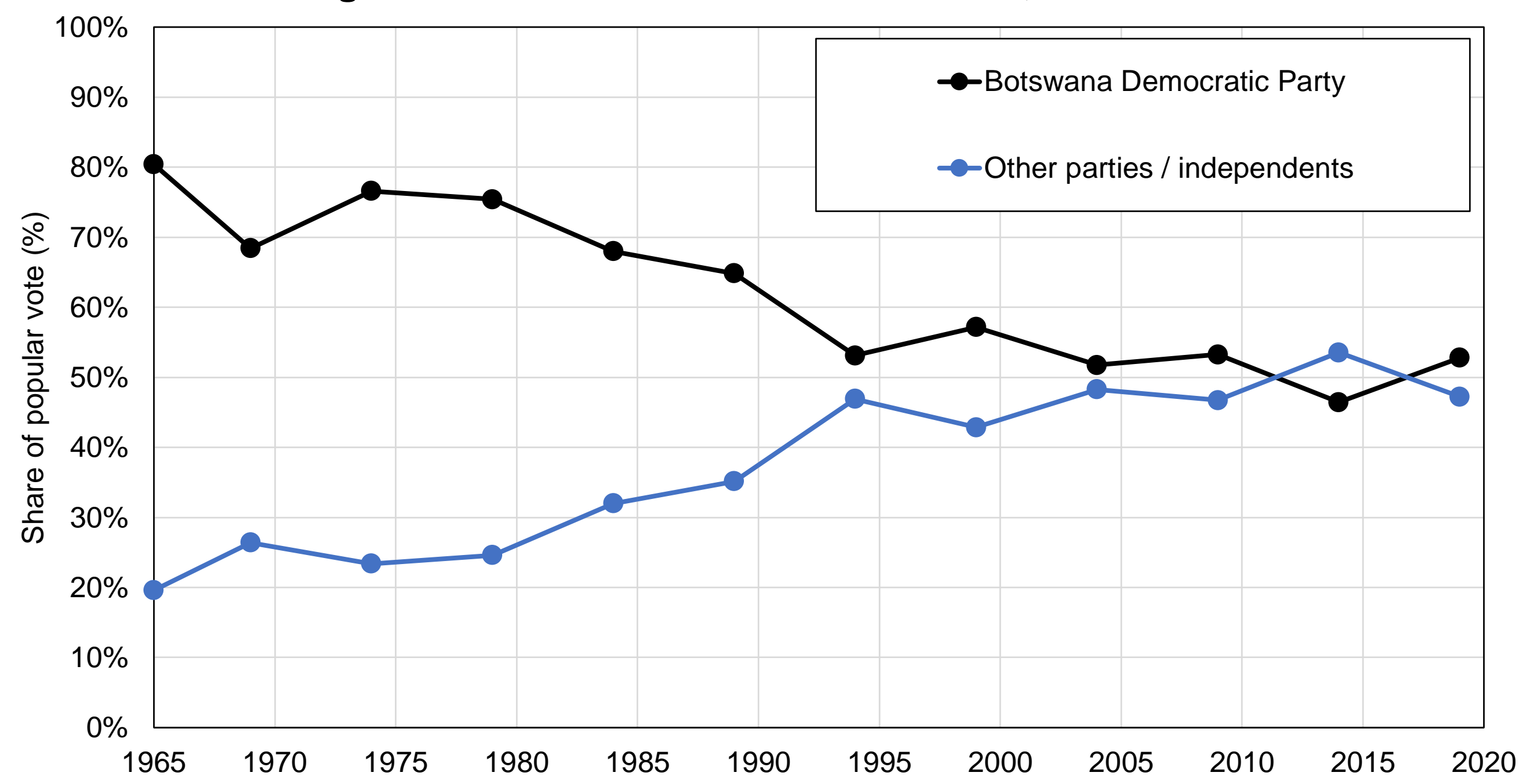

Source: authors' computations using official election results.

Note: the figure shows the share of votes received by selected groups of political parties in Botswana in general elections between 1965 and 2019. 
Figure A2 - Ethnolinguistic educational inequalities in Botswana

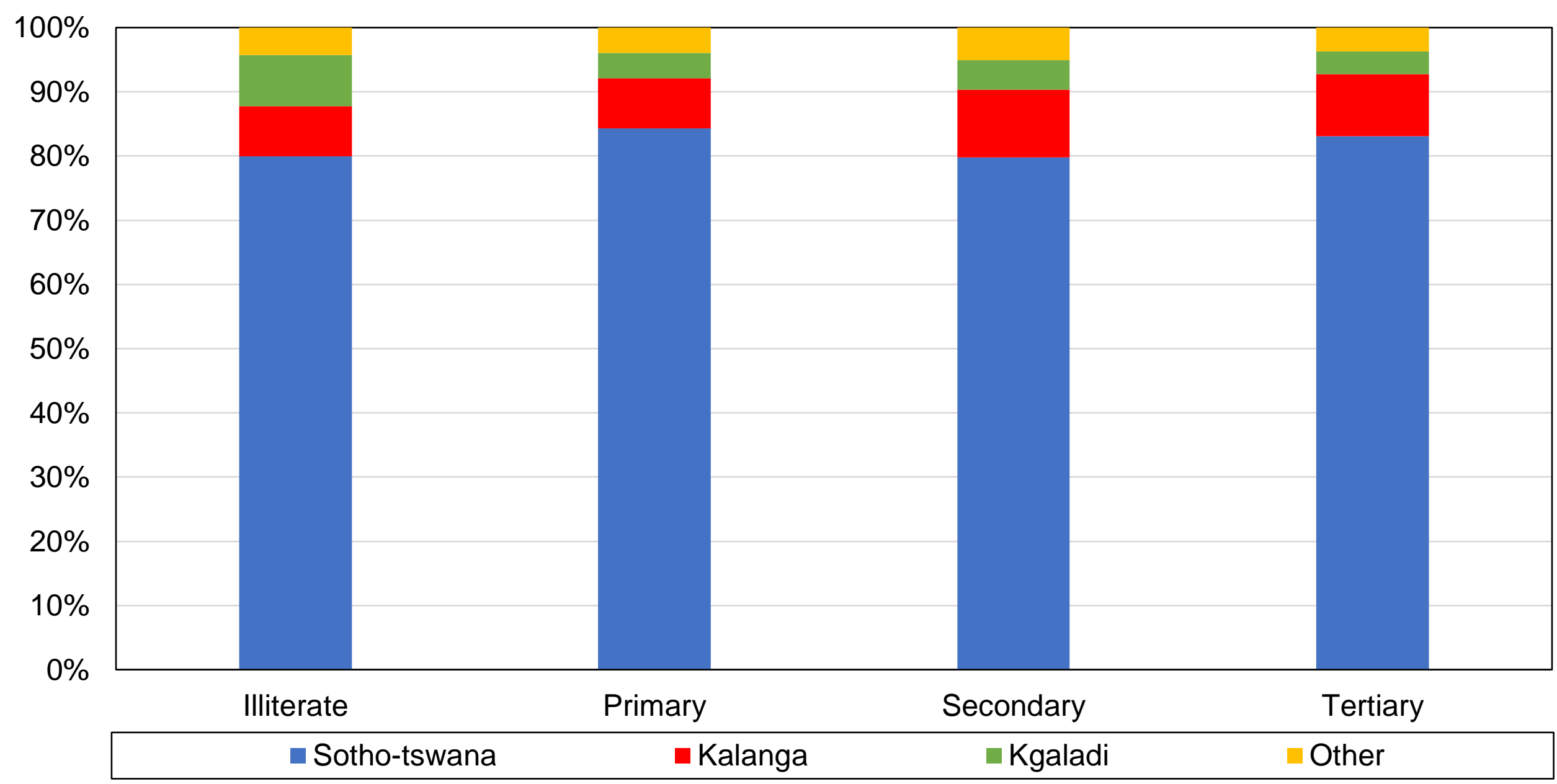

Source: authors' computations using Afrobarometer surveys.

Note: the figure shows composition of education groups by language of the population in Botswana in 2019. 
Figure A3 - Vote for the Botswana Democratic Party by language

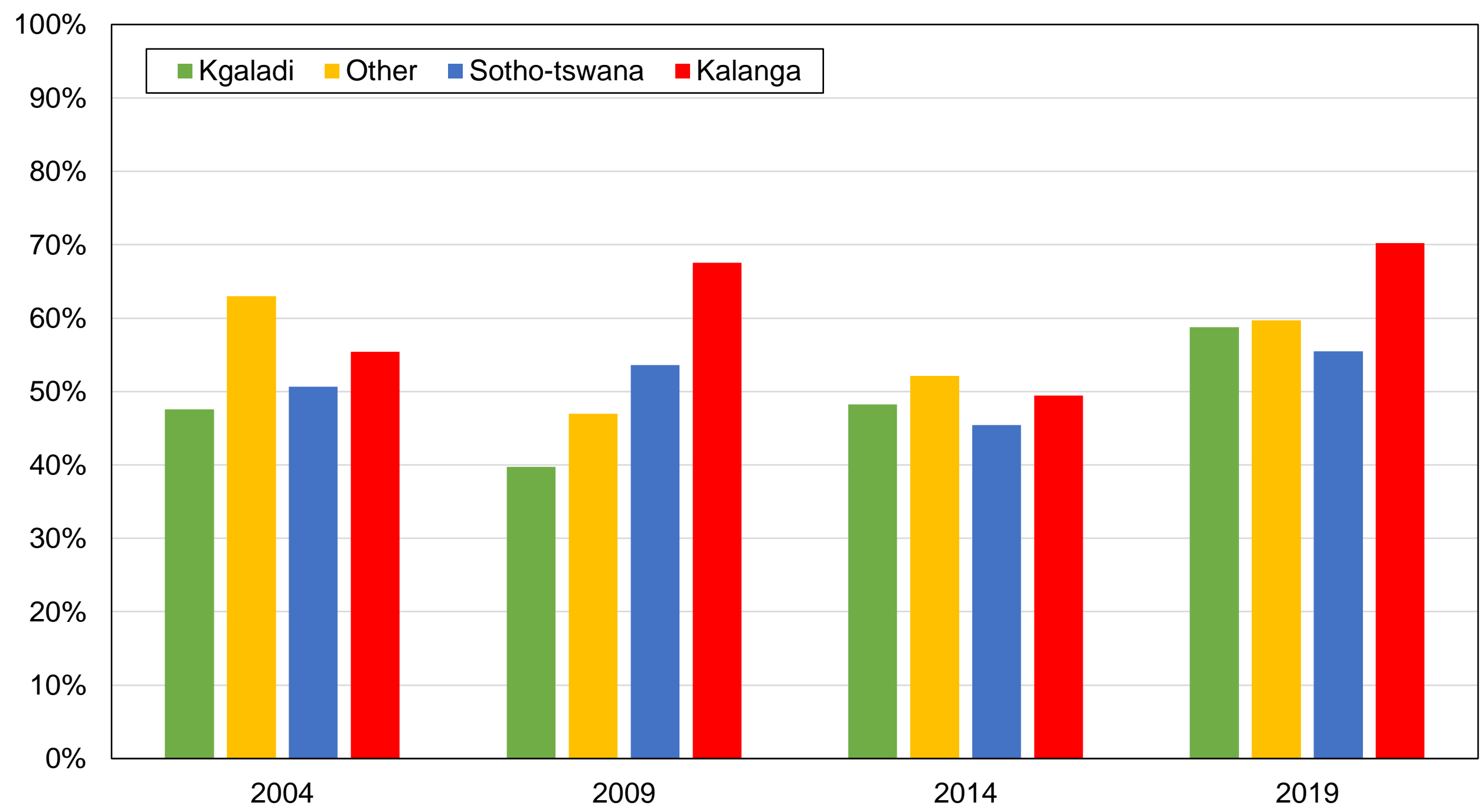

Source: authors' computations using Afrobarometer surveys.

Note: the figure shows the share of votes received by BDP by language. 


\section{Figure A4 - Vote for the Botswana Democratic Party among rural areas}

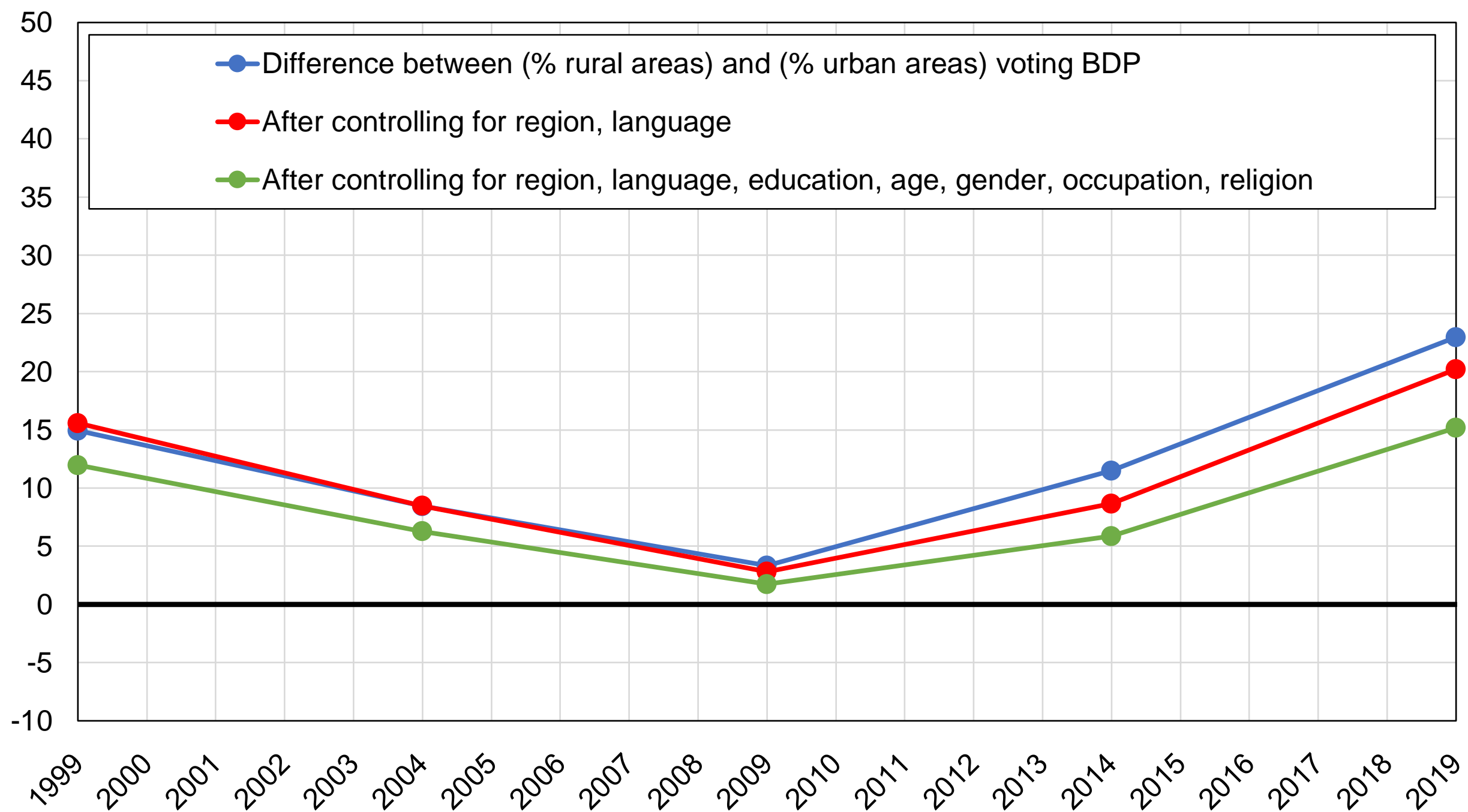

Source: authors' computations using Afrobarometer surveys.

Note: the figure shows the difference between the share of voters from rural areas and the share of other voters voting for BDP, before and after controlling for other variables. 


\section{Figure A5 - Vote for the Botswana Democratic Party among higher- educated voters}

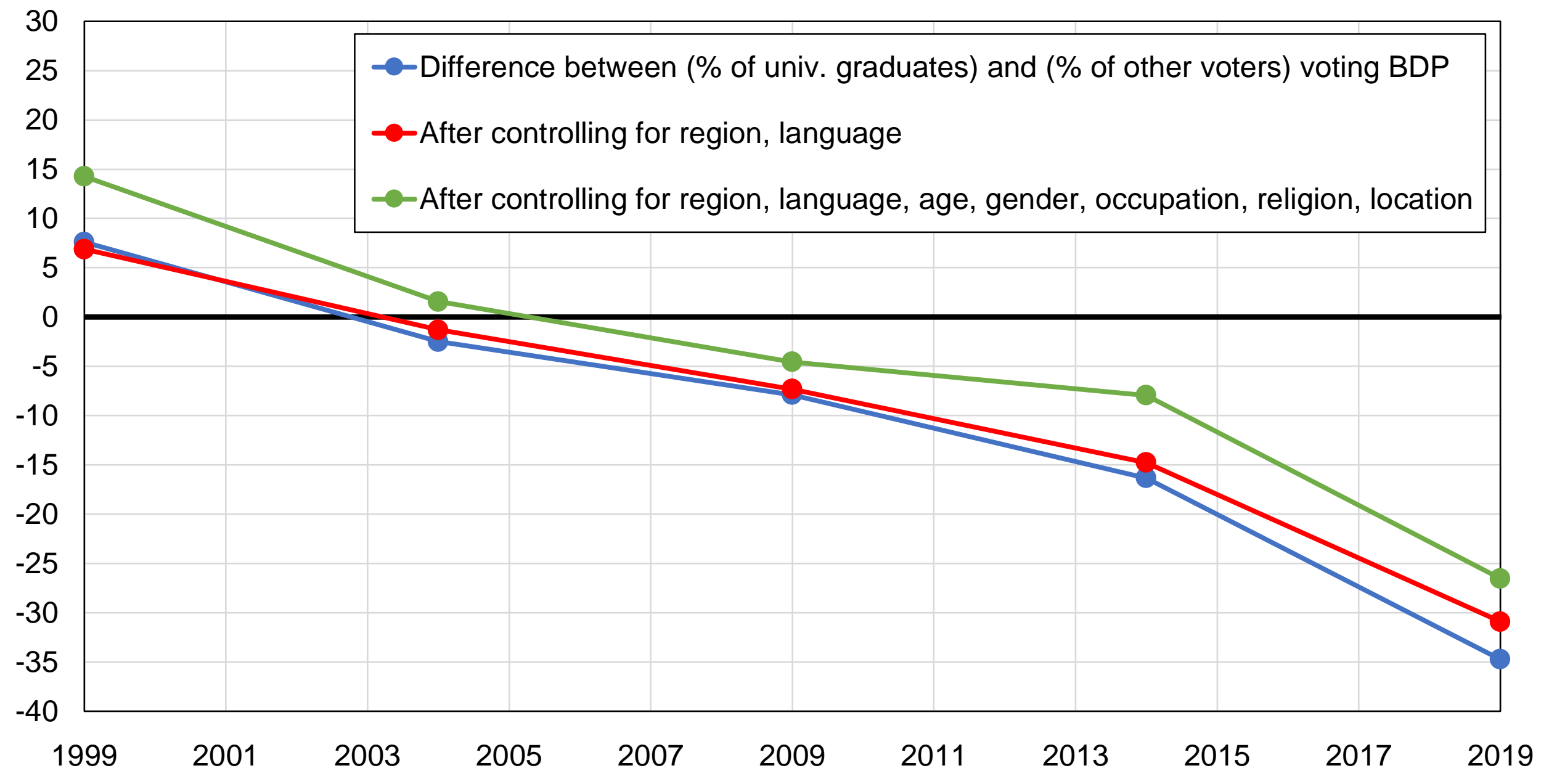

Source: authors' computations using Afrobarometer surveys.

Note: the figure shows the difference between the share of university graduates and the share of other voters voting for BDP, before and after controlling for other variables. 
Figure AA1 - The composition of the electorate by education

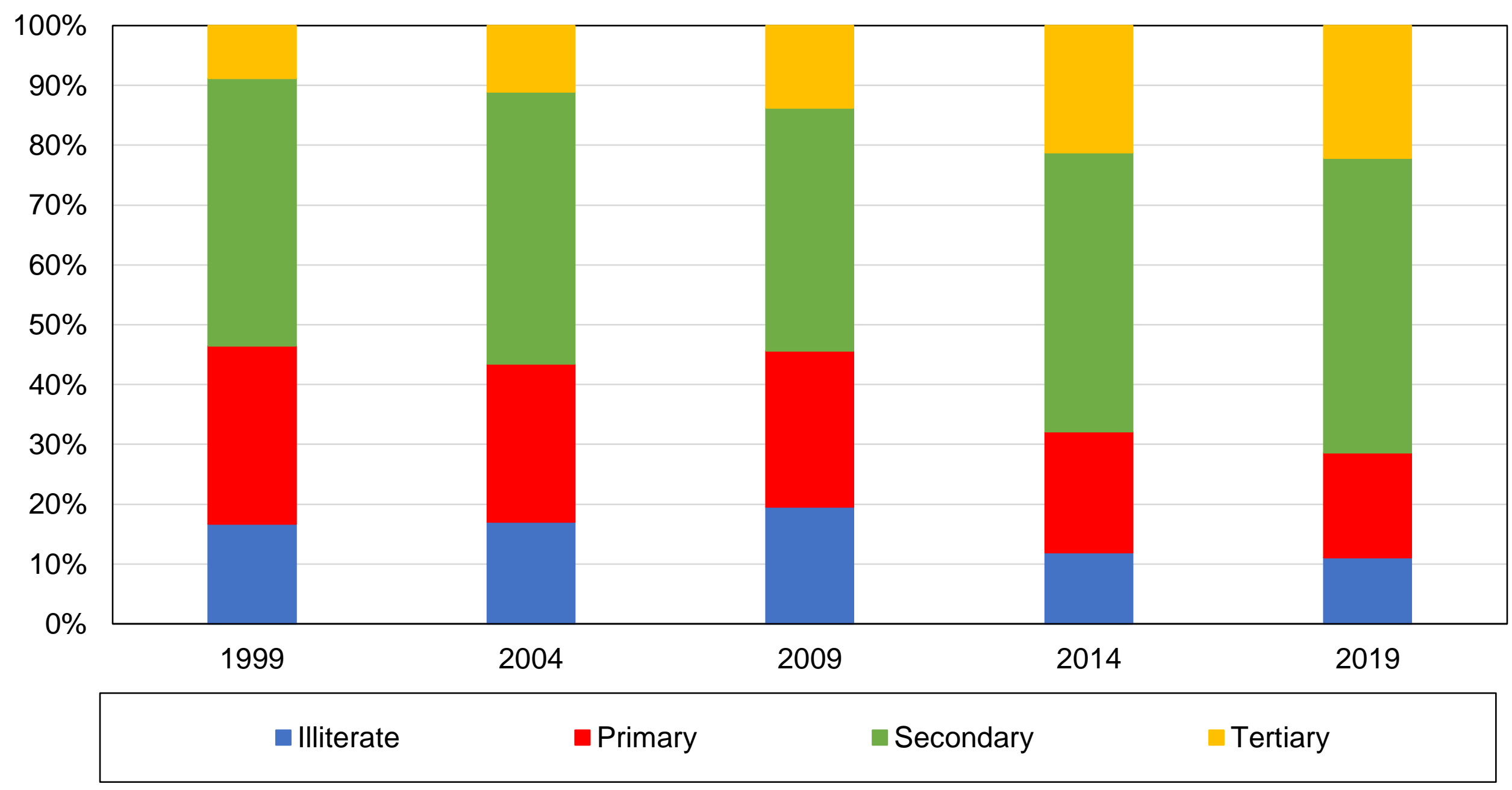

Source: authors' computations using Afrobarometer surveys.

Note: the figure shows the distribution of education levels of the adult population in Botswana and its evolution over time. 
Figure AA2 - The composition of the electorate by age

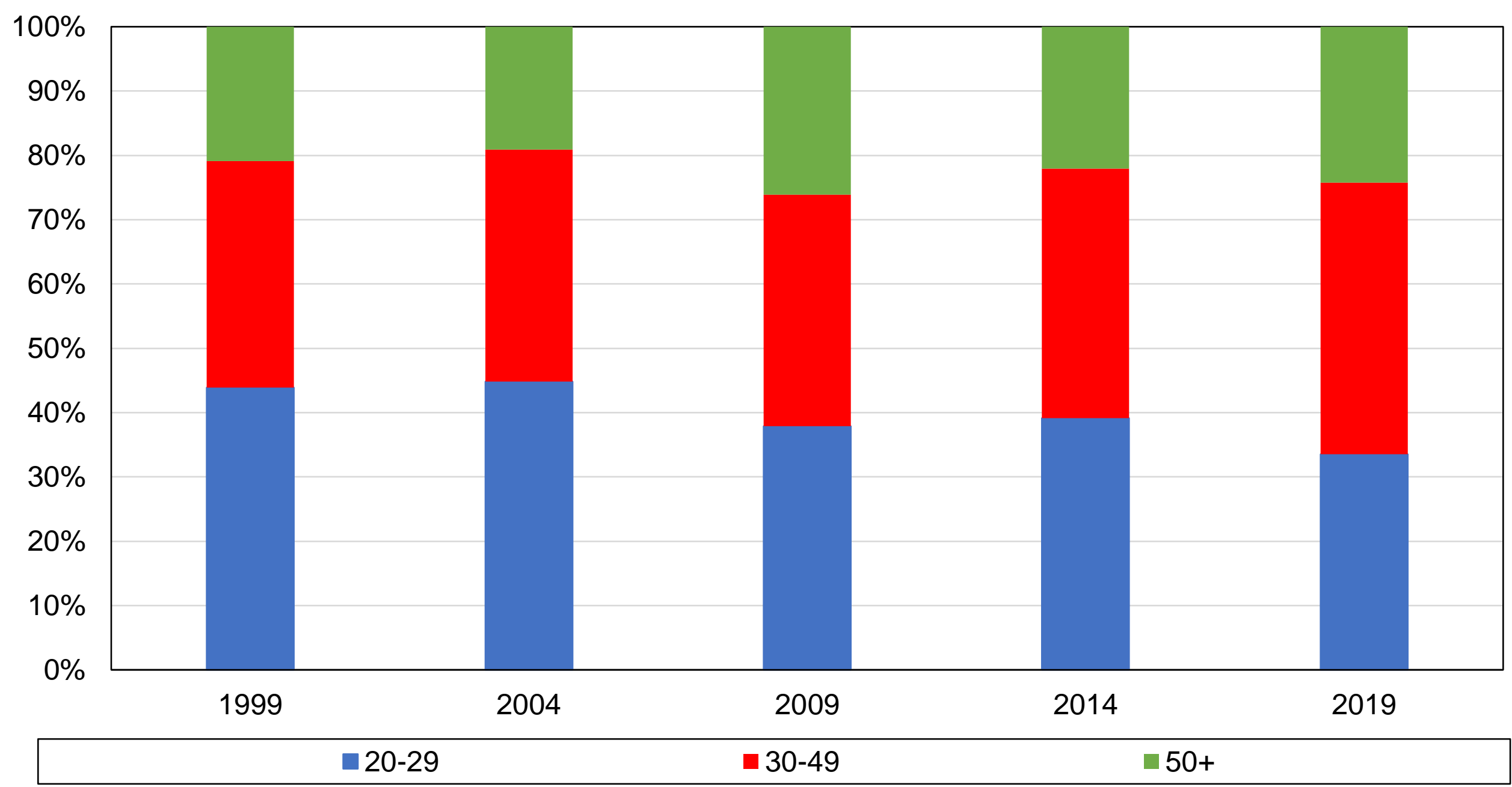

Source: authors' computations using Afrobarometer surveys.

Note: the figure shows the distribution of age groups in the adult population in Botswana and its evolution over time. 
Figure AA3 - The composition of the electorate by religion

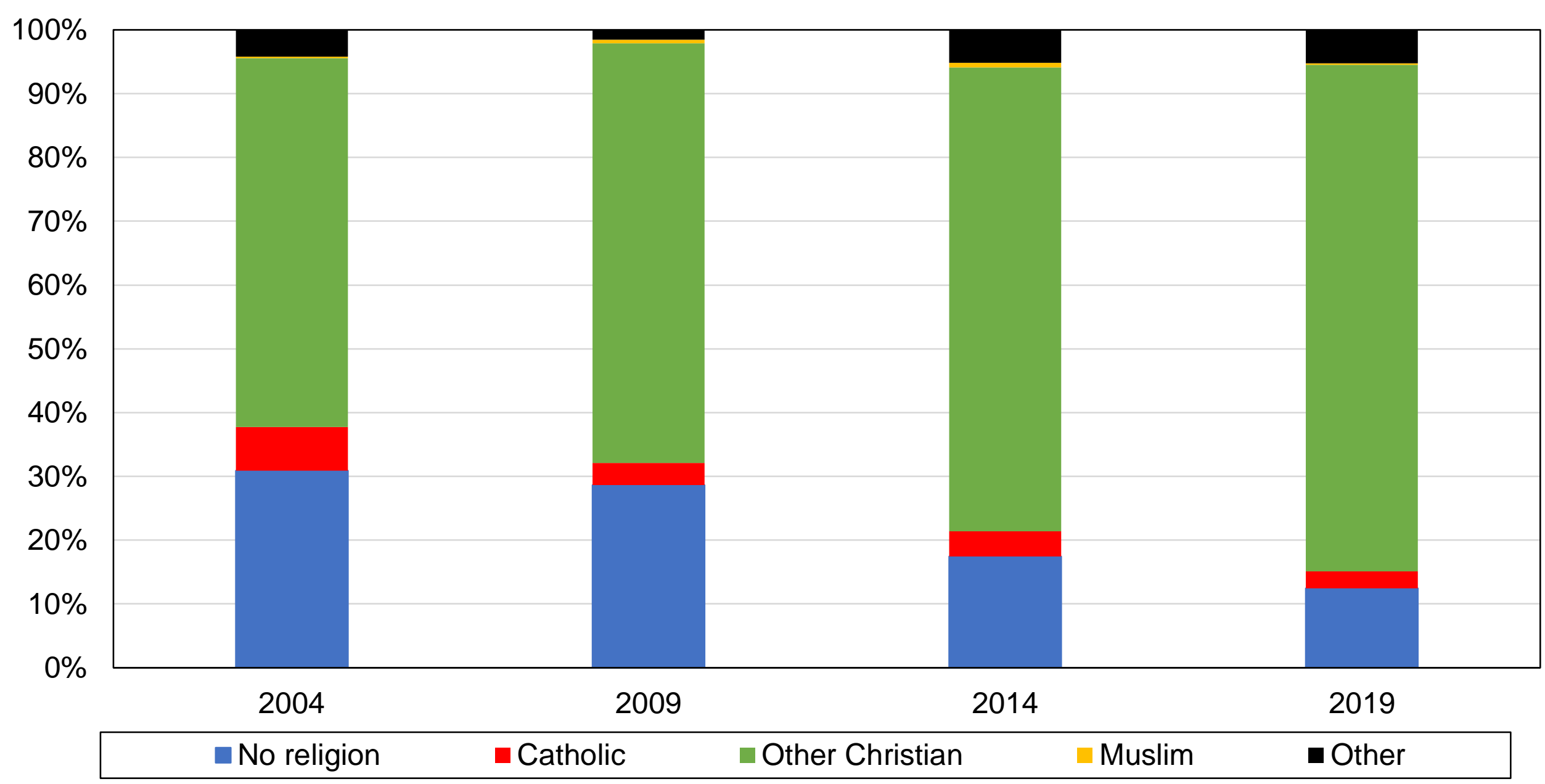

Source: authors' computations using Afrobarometer surveys.

Note: the figure shows the distribution of religious affiliations in the adult population in Botswana and its evolution over time. 
Figure AA4 - The composition of the electorate by location

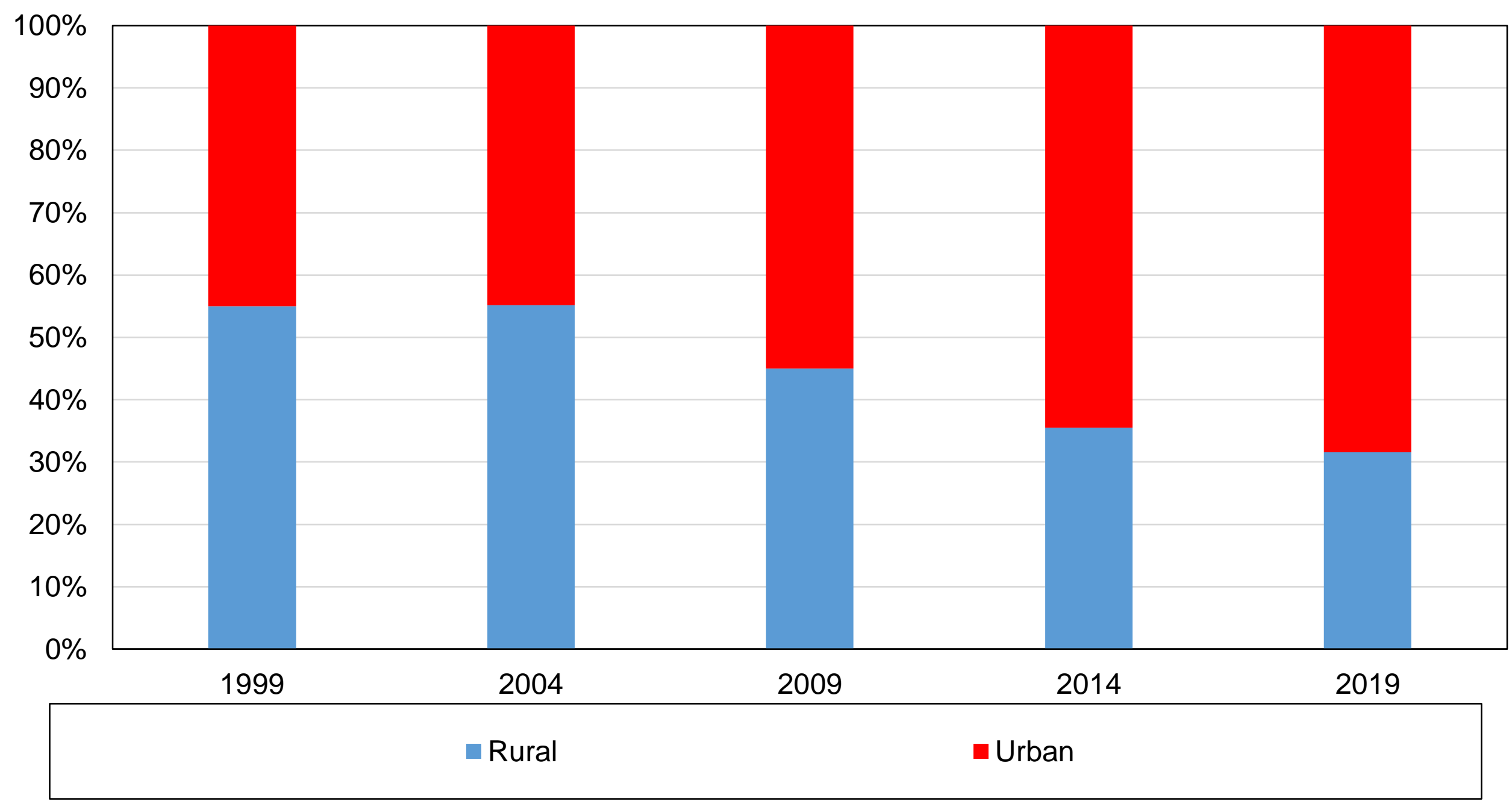

Source: authors' computations using Afrobarometer surveys.

Note: the figure shows the share of rural and urban adult population in Botswana and its evolution over time. 
Figure AA5 - The composition of the electorate by language

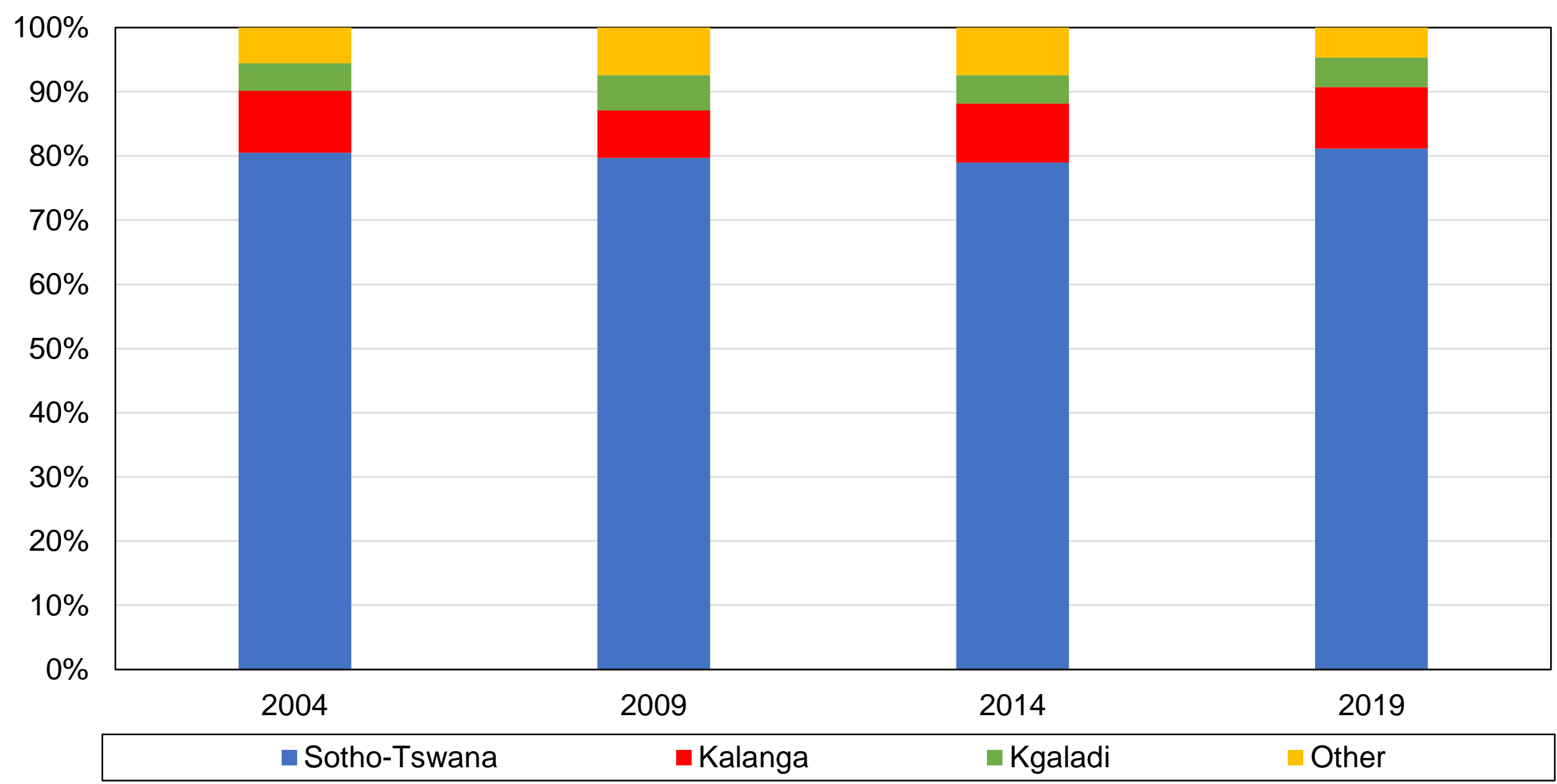

Source: authors' computations using Afrobarometer surveys.

Note: the figure shows the distribution of languages in the adult population in Botswana and its evolution over time. 
Figure AA6 - The composition of the electorate by occupation

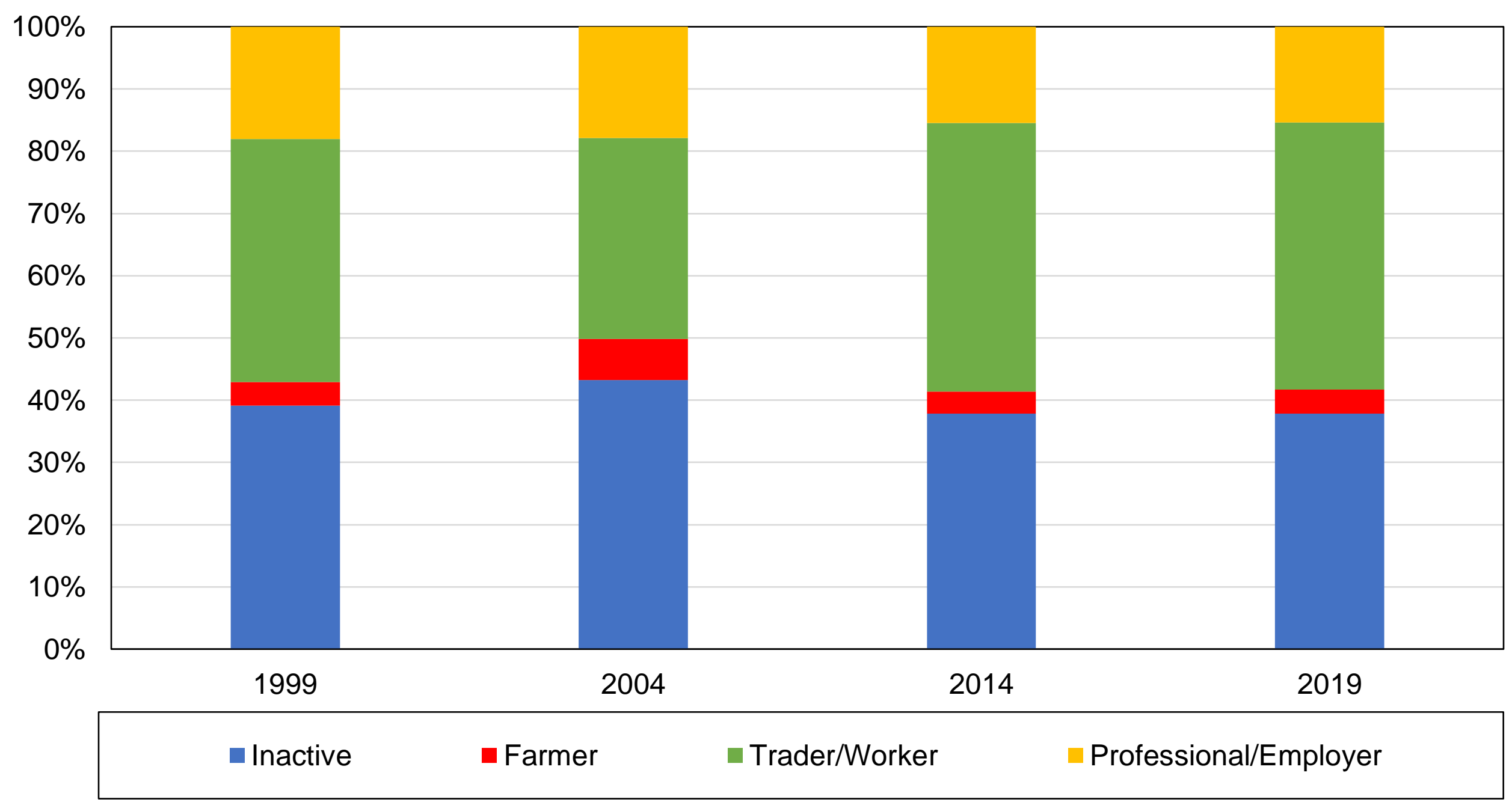

Source: authors' computations using Afrobarometer surveys.

Note: the figure shows the distribution of occupations in the adult population in Botswana and its evolution over time. 
Figure AA7- Linguistic composition of education, 2004

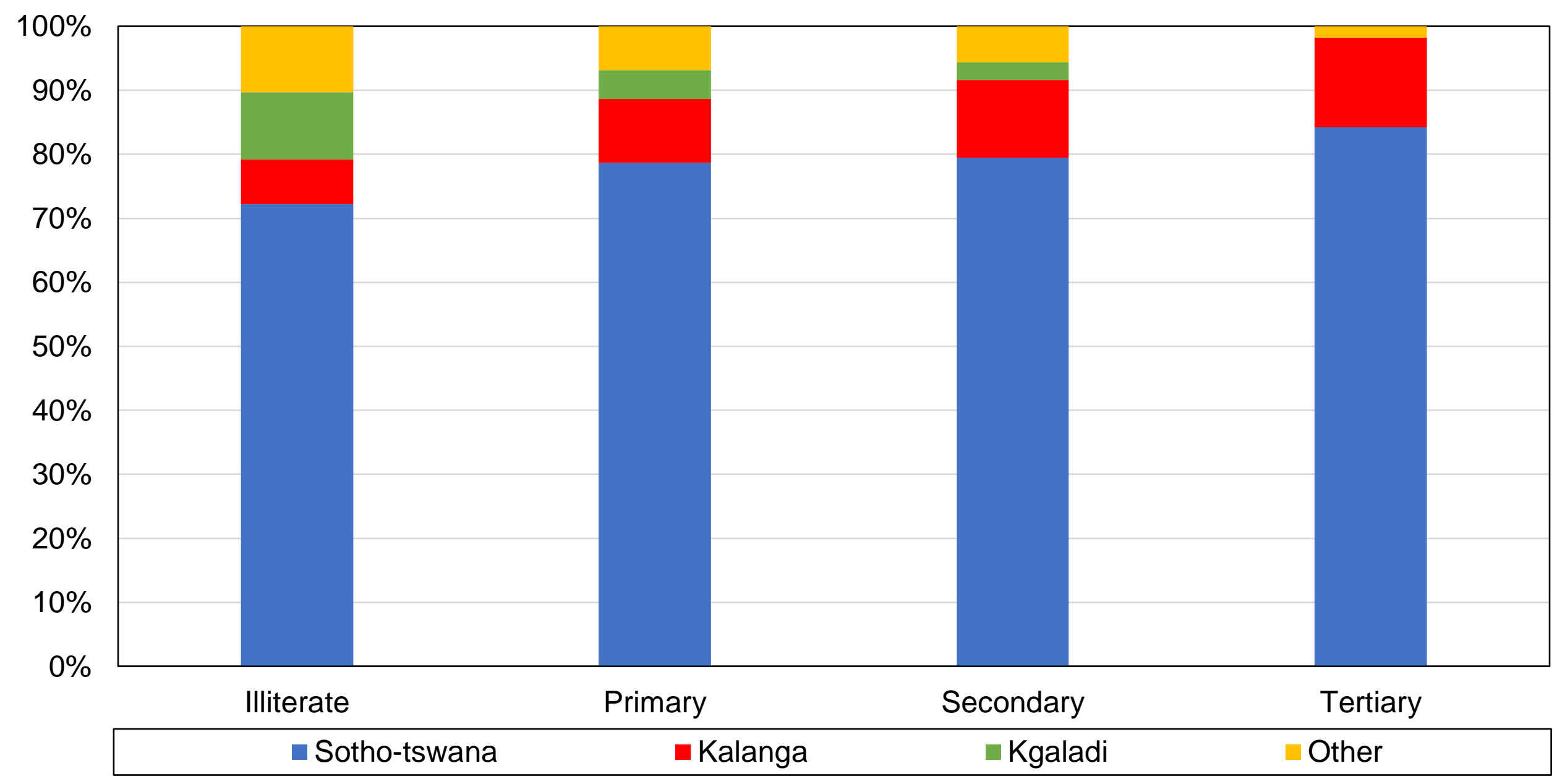

Source: authors' computations using Afrobarometer surveys.

Note: the figure shows composition of education groups by language of the population in Botswana in 2004 . 
Figure AA8 - Linguistic composition of education, 2019

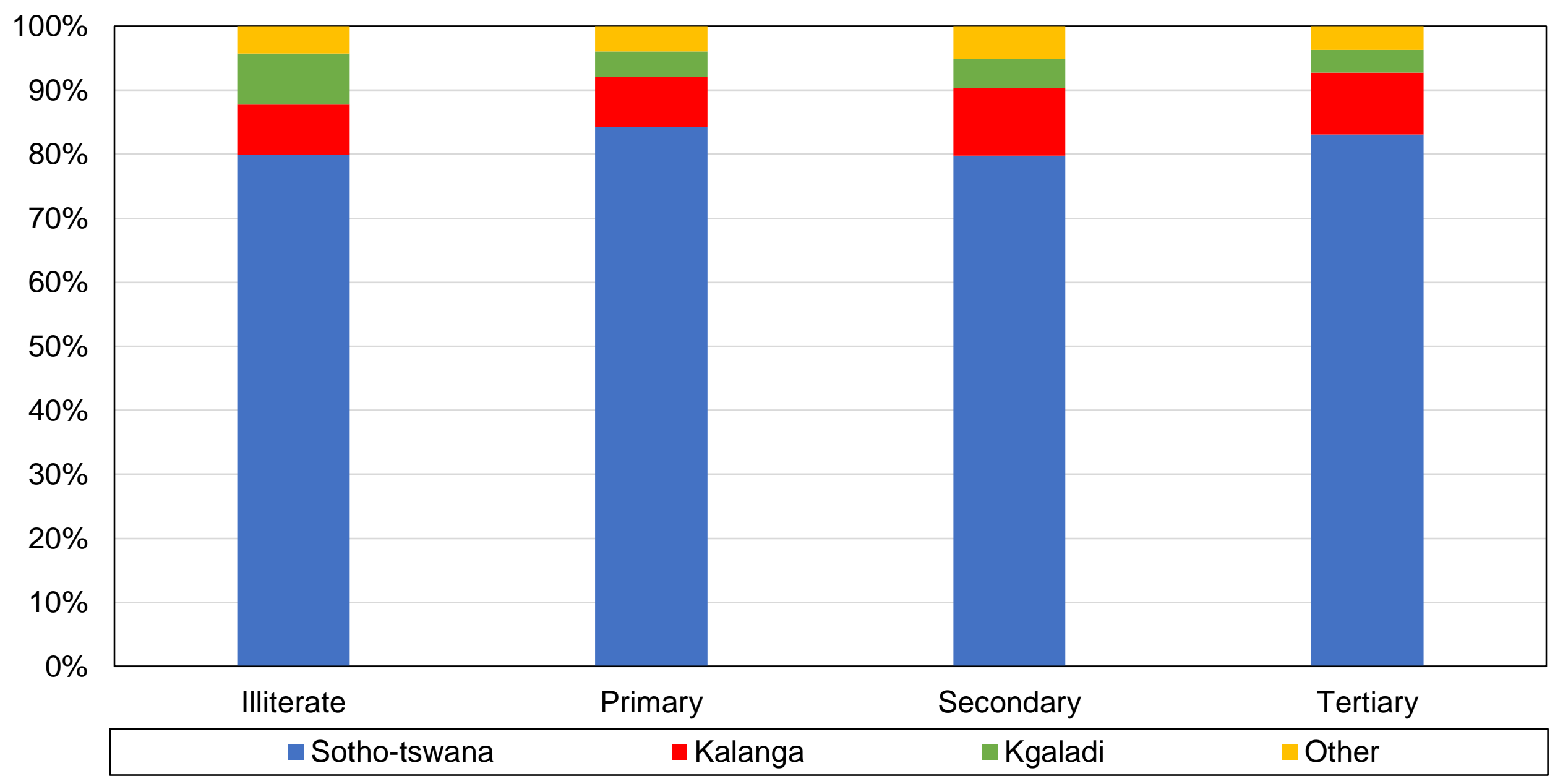

Source: authors' computations using Afrobarometer surveys.

Note: the figure shows composition of education groups by language of the population in Botswana in 2019. 


\section{Figure AA9 - Occupational composition of education, 2004}

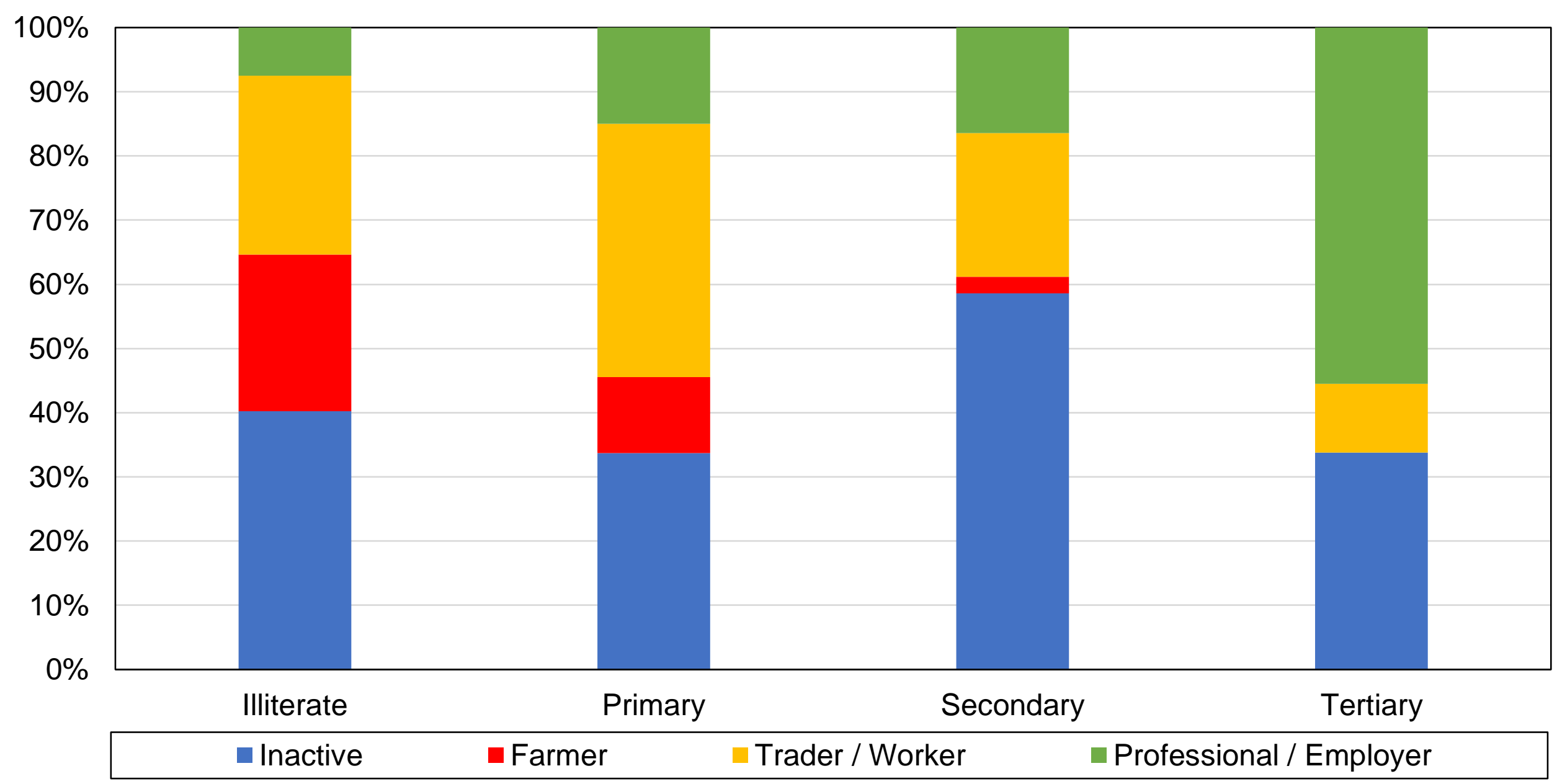

Source: authors' computations using Afrobarometer surveys.

Note: the figure shows the composition of education groups by occupation of the population in Botswana in 2004. 


\section{Figure AA10 - Occupational composition of education, 2019}

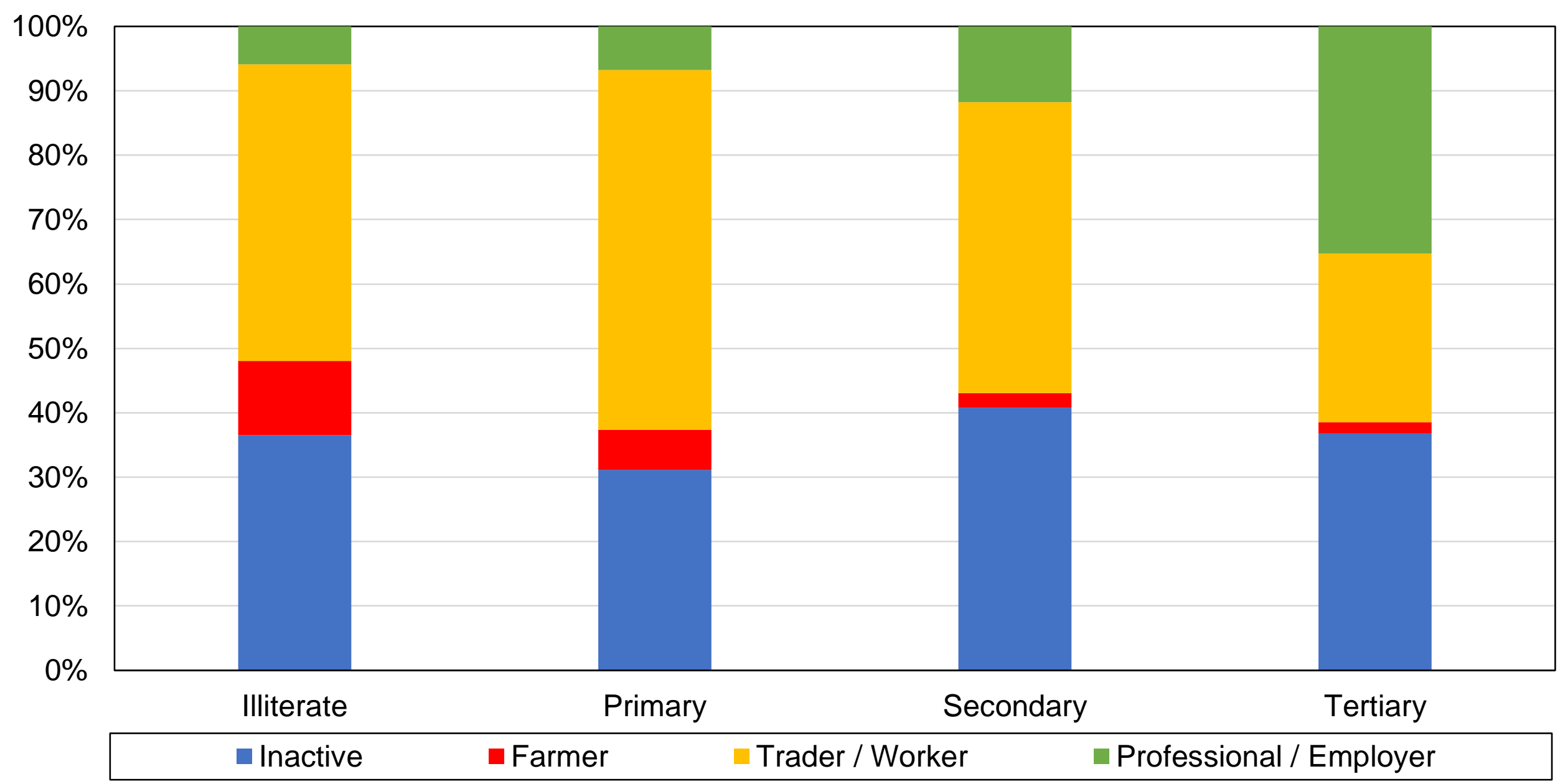

Source: authors' computations using Afrobarometer surveys.

Note: the figure shows the composition of education groups by occupation of the population in Botswana in 2019. 
Figure AA11 - Rural-urban composition of education, 2004

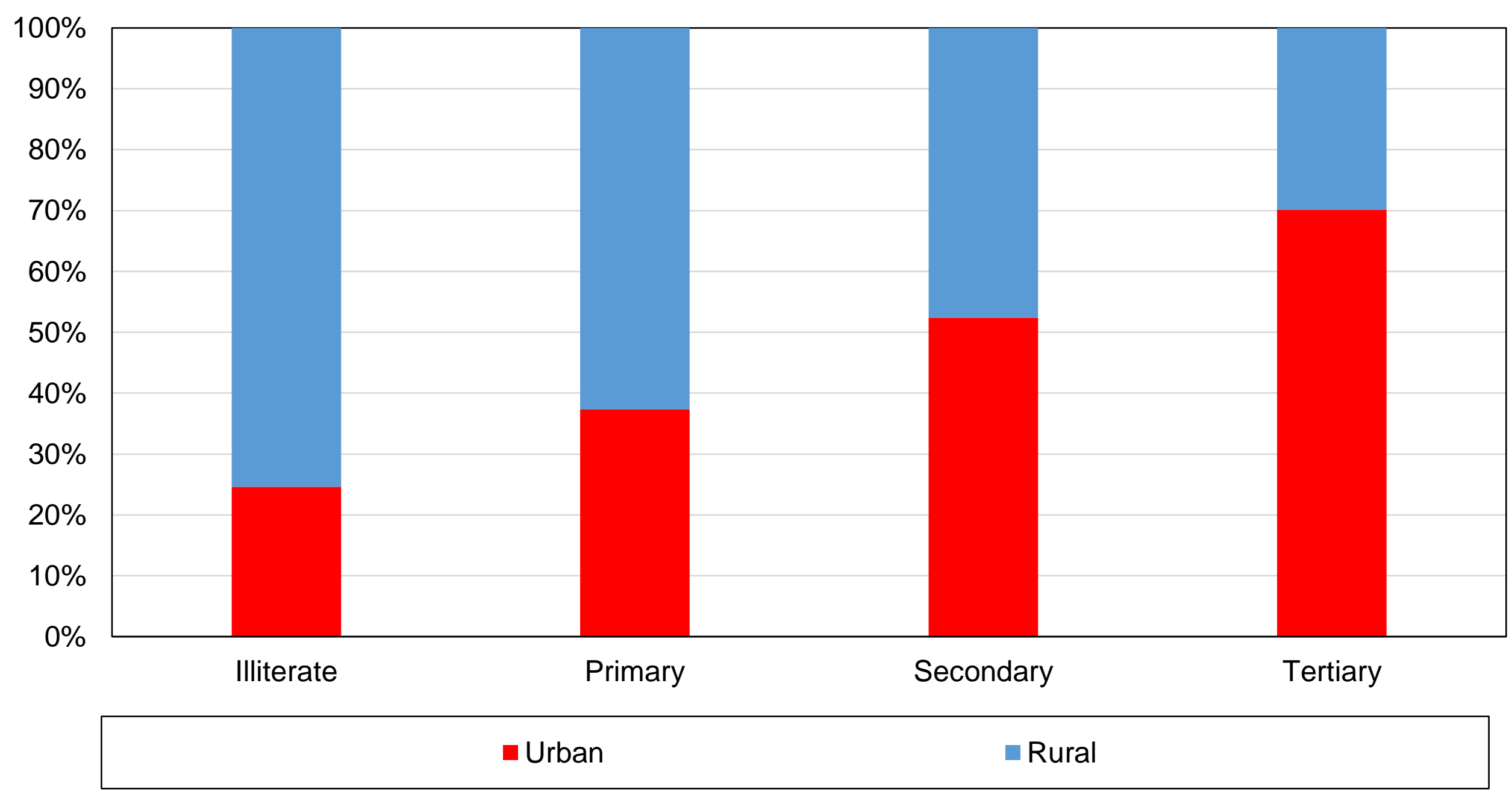

Source: authors' computations using Afrobarometer surveys.

Note: the figure shows the distribution of education groups by location in 2004 in Botswana. 
Figure AA12 - Rural-urban composition of education, 2019

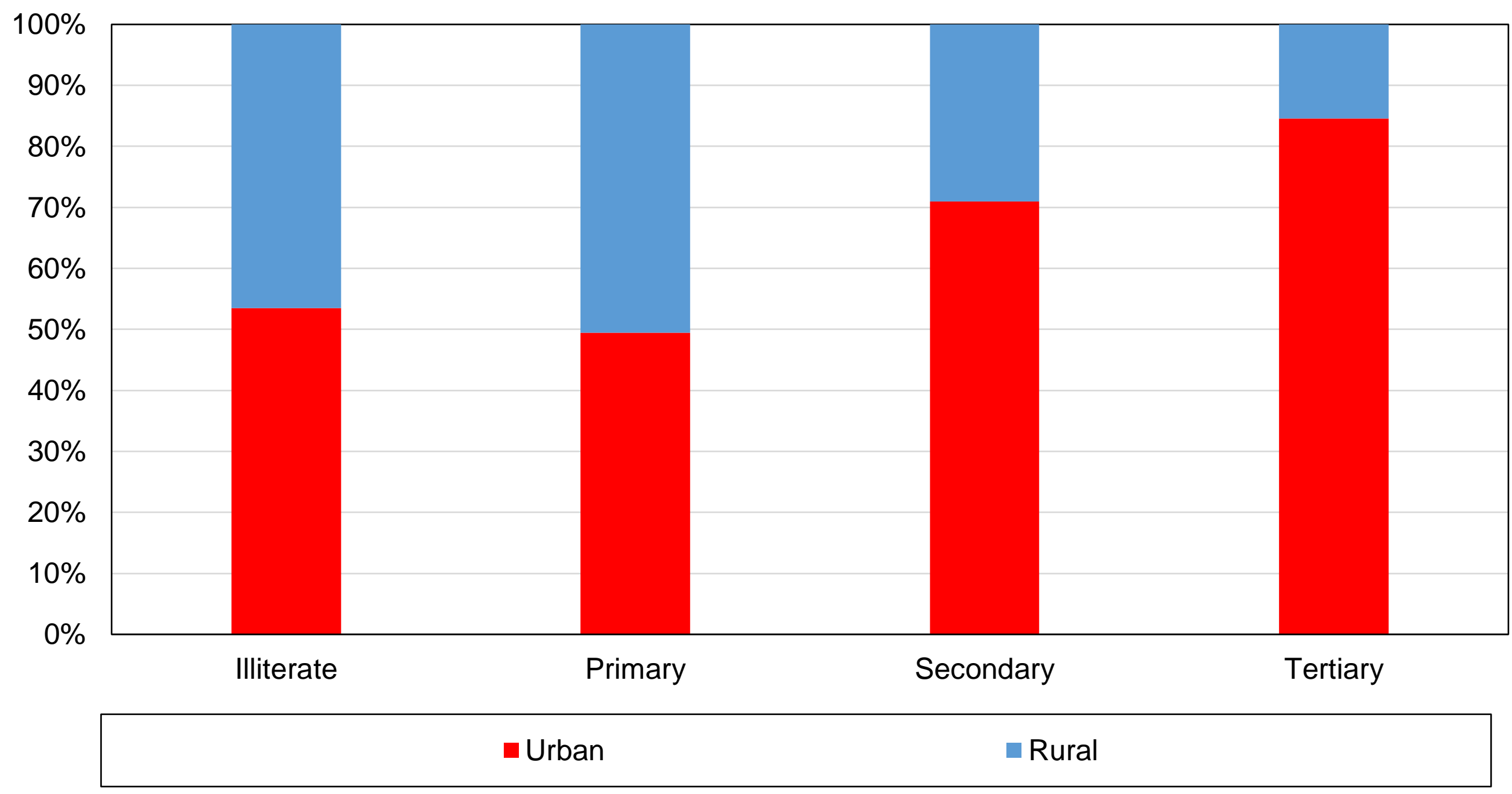

Source: authors' computations using Afrobarometer surveys.

Note: the figure shows the distribution of education groups by location in 2019 in Botswana. 
Figure AA13 - The composition of the electorate by region

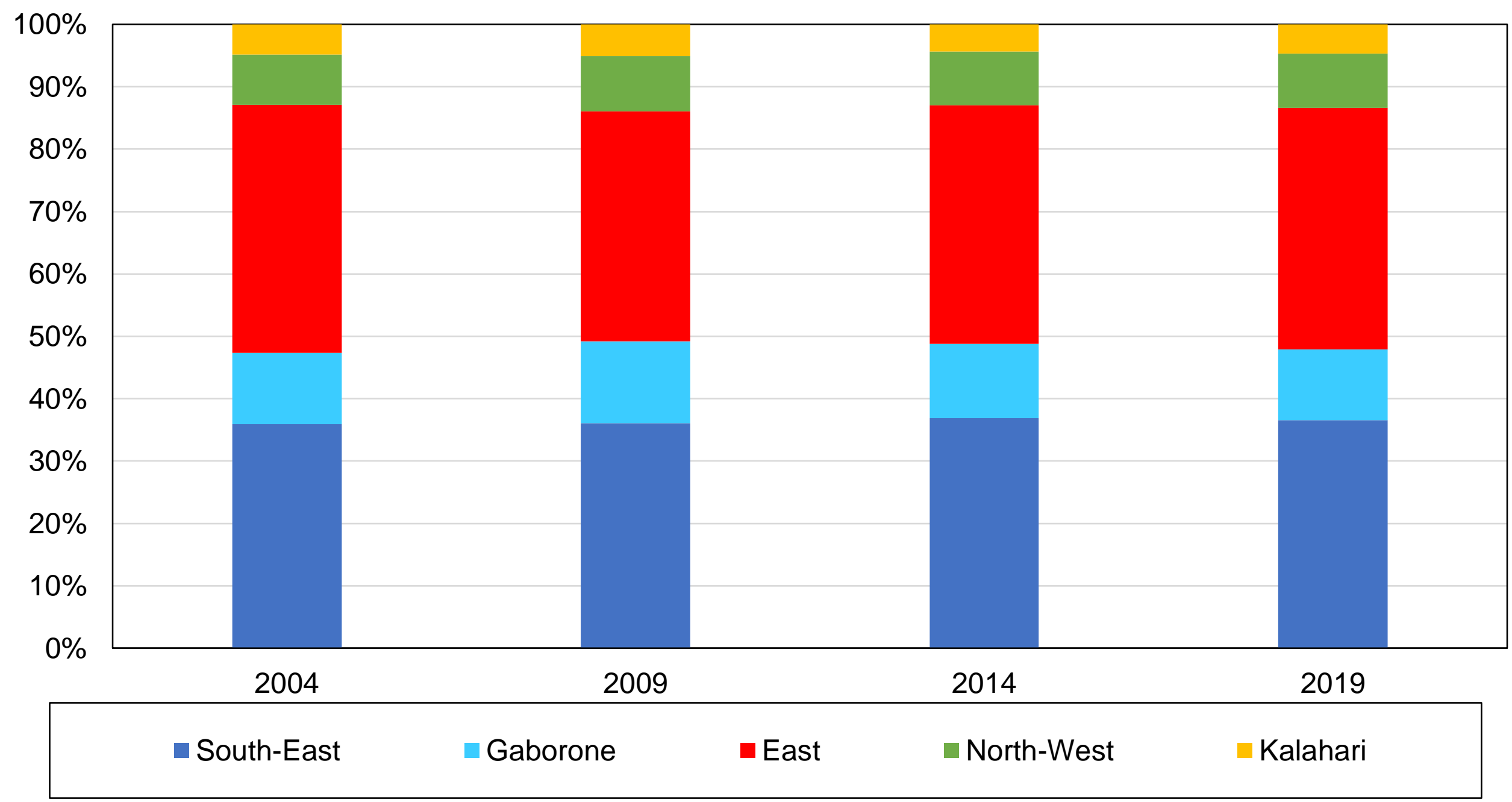

Source: authors' computations using Afrobarometer surveys.

Note: the figure shows the distribution of regions in the adult population in Botswana and its evolution over time. 
Figure AA14 - Regional composition of education, 2004

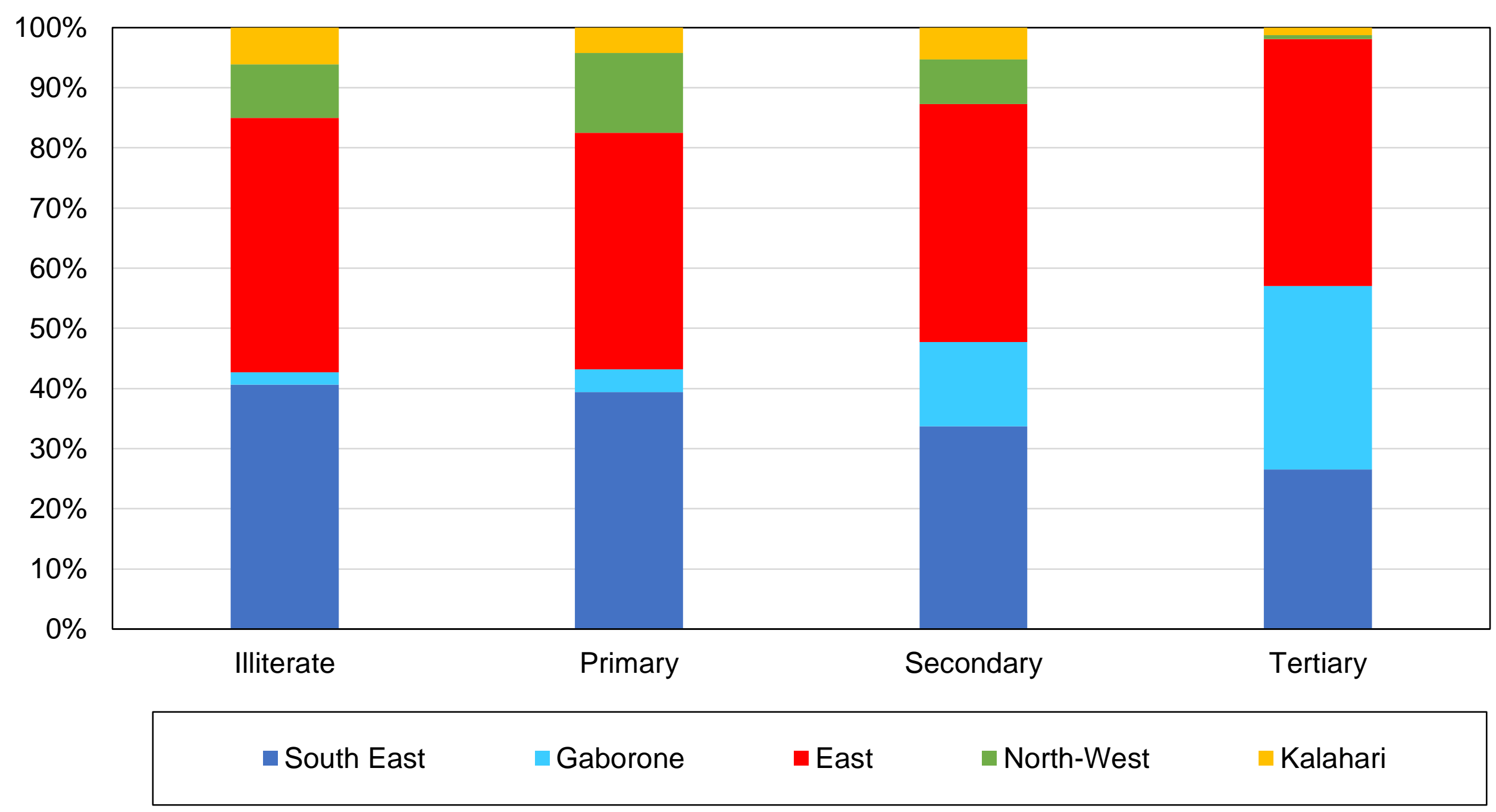

Source: authors' computations using Afrobarometer surveys.

Note: the figure shows the composition of education groups by region in Botswana in 2004. 
Figure AA15 - Regional composition of education, 2019

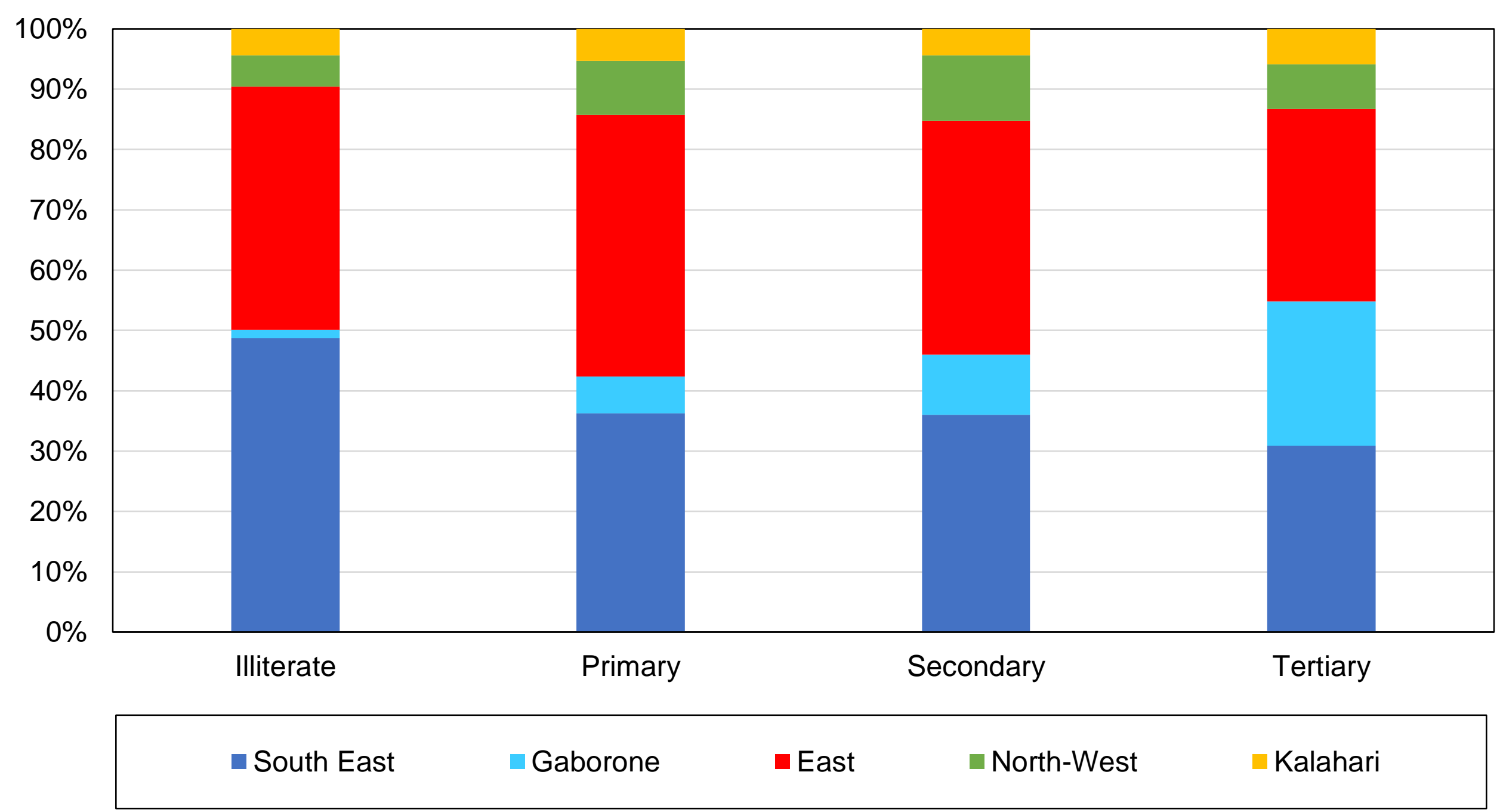

Source: authors' computations using Afrobarometer surveys.

Note: the figure shows the distribution of education groups by region in Botswana in 2019. 
Figure AA16 - Linguistic composition of regions, 2004

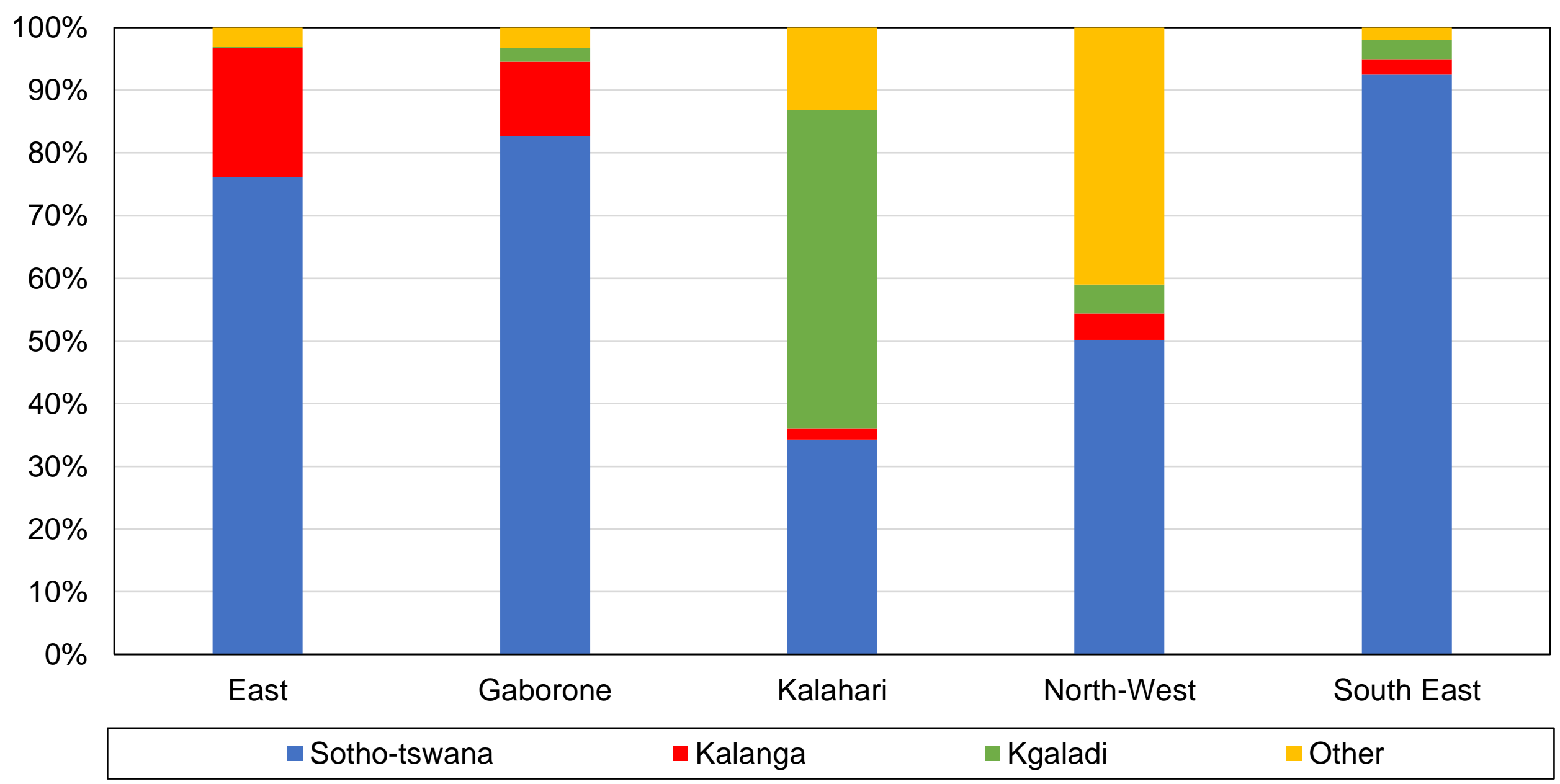

Source: authors' computations using Afrobarometer surveys.

Note: the figure shows the distribution of languages among regions in Botswana in 2004. 
Figure AA17 - Linguistic composition of regions, 2019

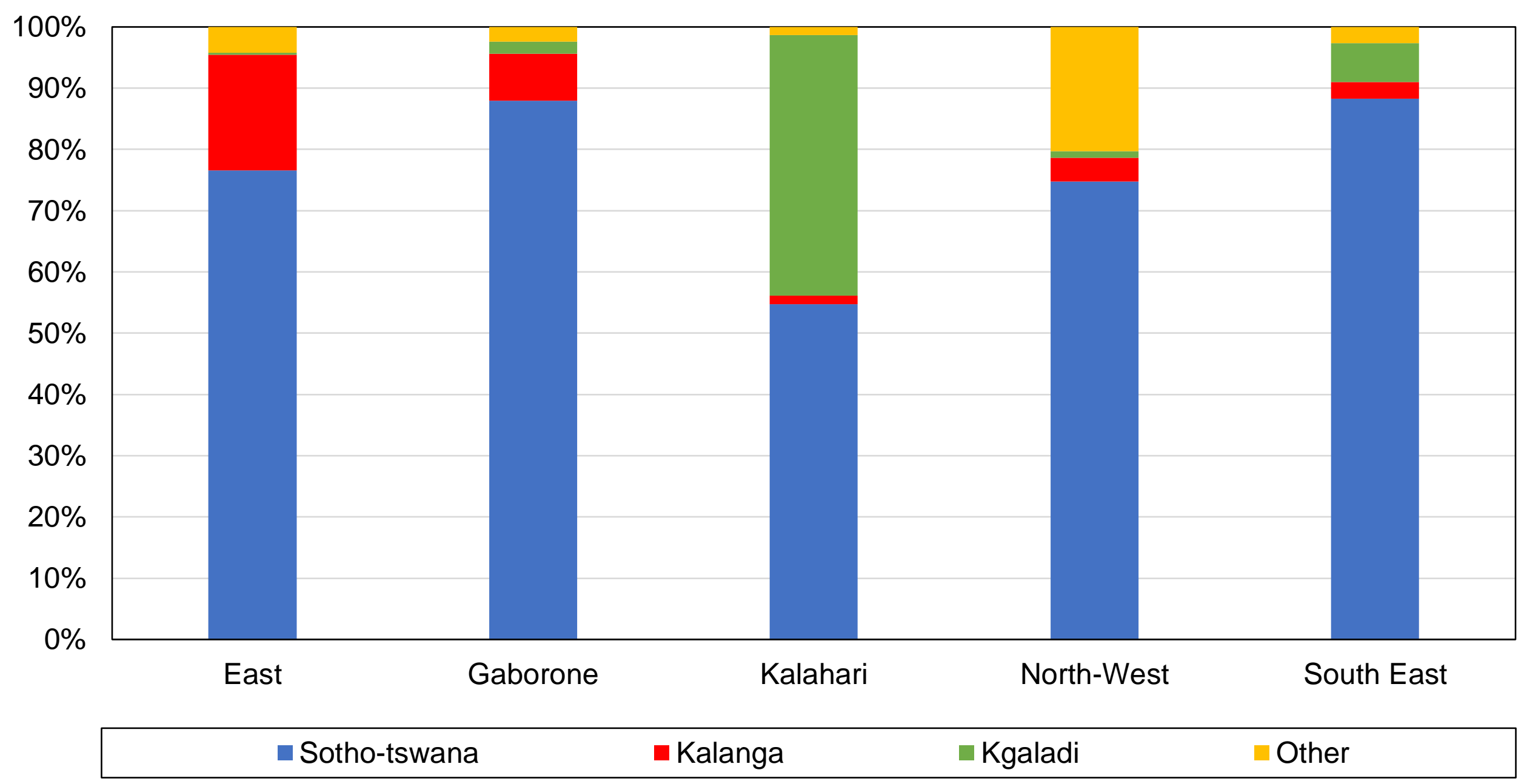

Source: authors' computations using Afrobarometer surveys.

Note: the figure shows the distribution of languages among regions in Botswana in 2019. 
Figure AB1 - Vote for BDP by education level

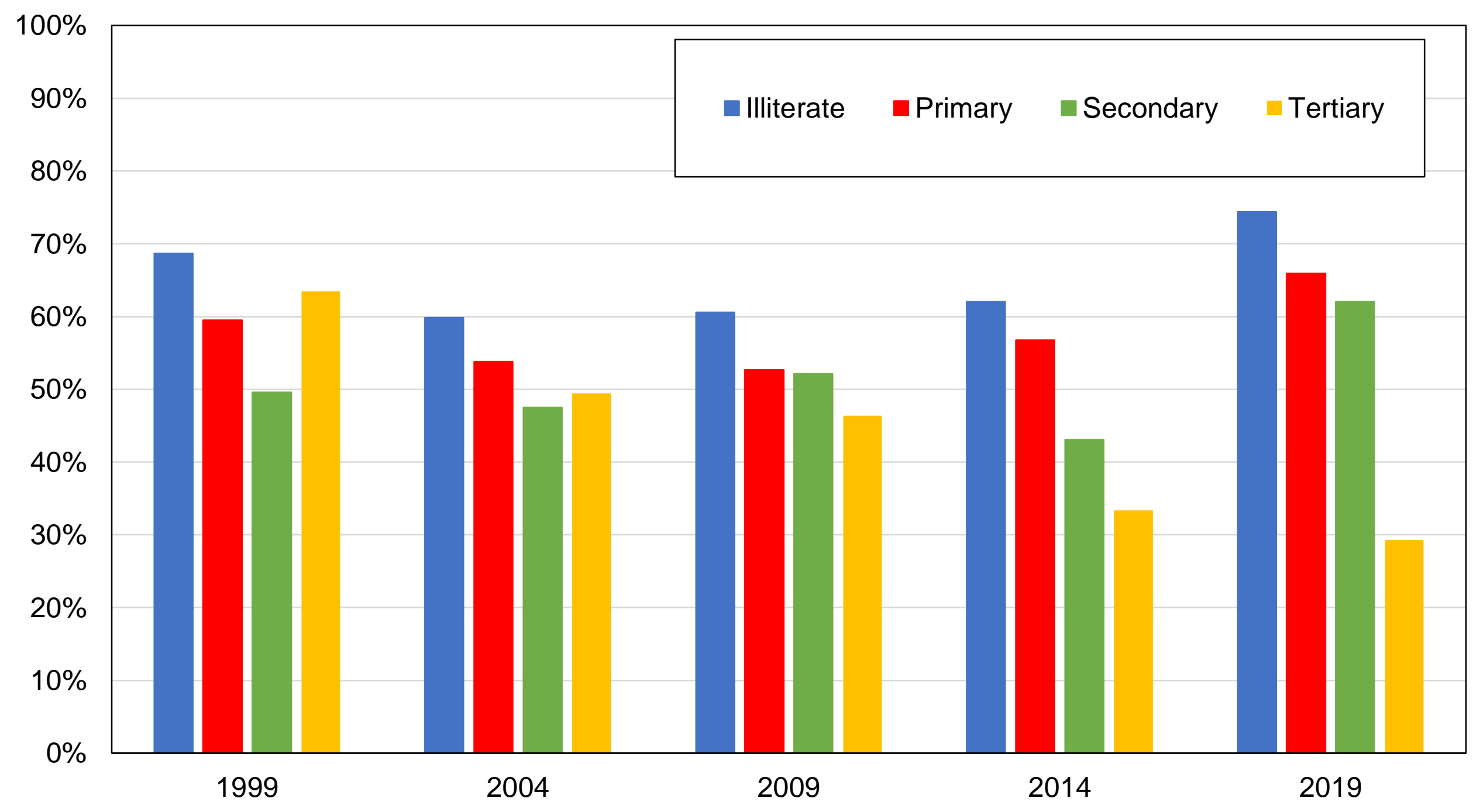

Source: authors' computations using Afrobarometer surveys.

Note: the figure shows the share of votes received by the BDP by education level. 
Figure AB2 - Vote for BDP by education group

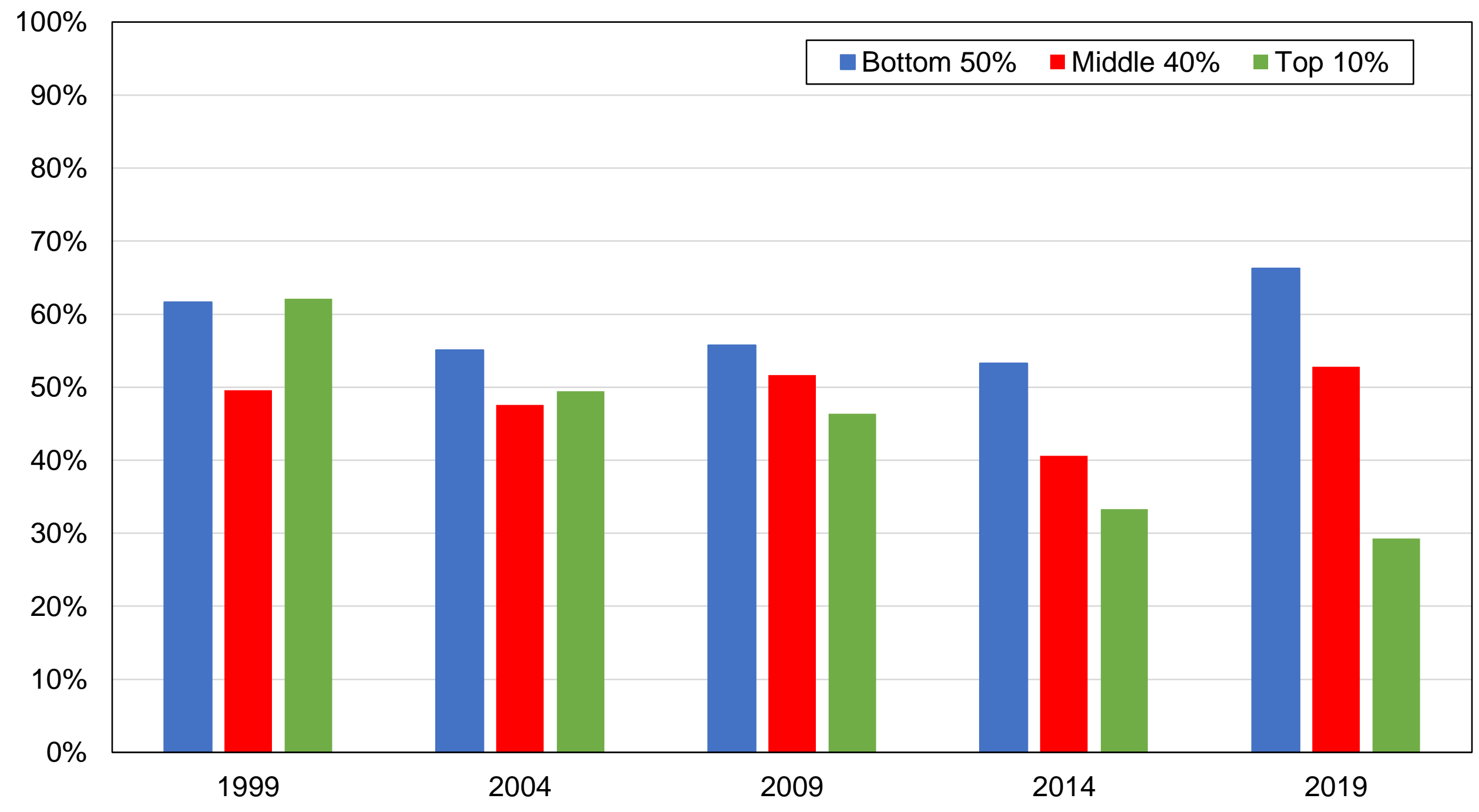

Source: authors' computations using Afrobarometer surveys.

Note: the figure shows the share of votes received by the BDP by education group. 
Figure AB3 - Vote for BDP by location

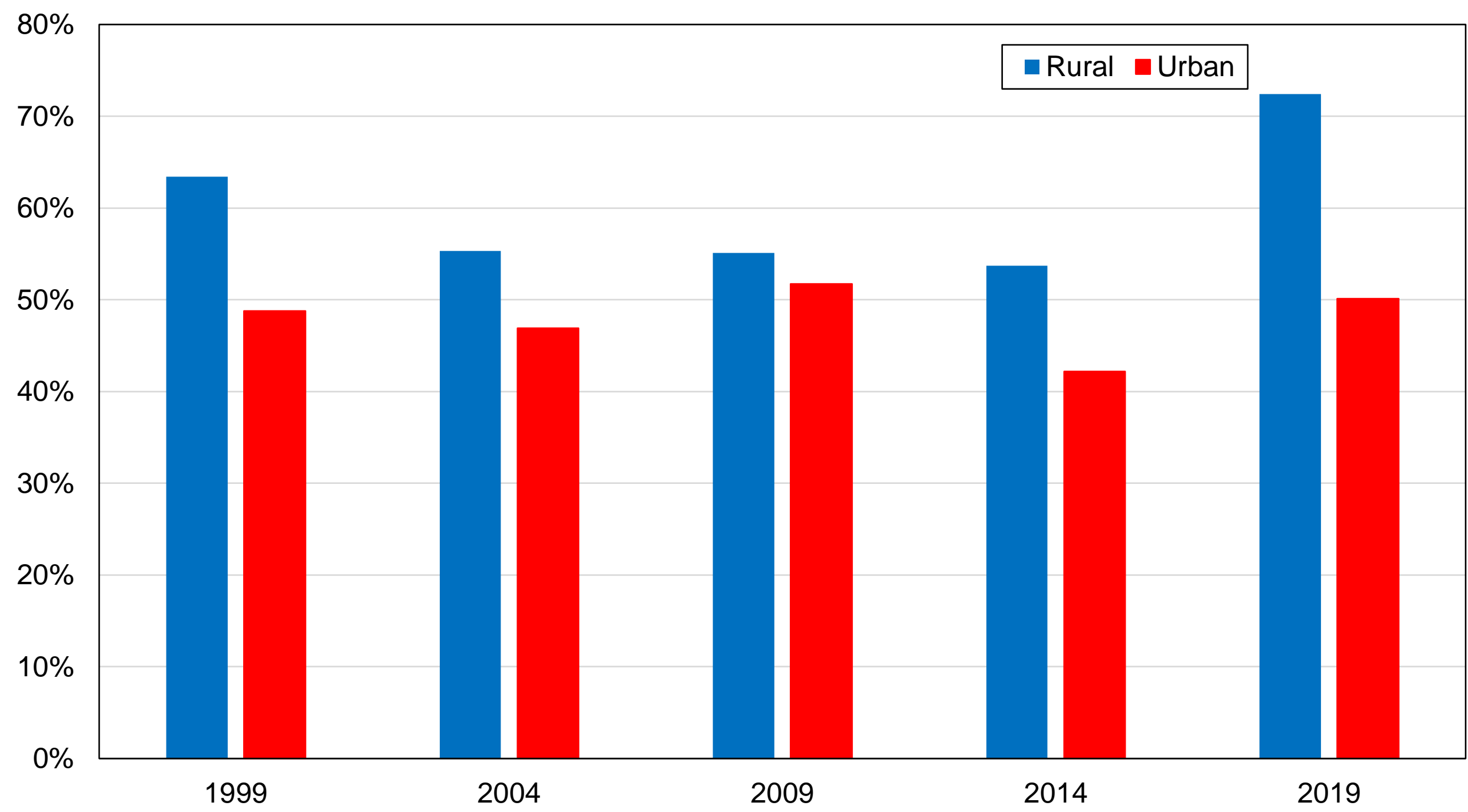

Source: authors' computations using Afrobarometer surveys.

Note: the figure shows the share of votes received by BDP by location. 
Figure AB4 - Vote for BDP by region

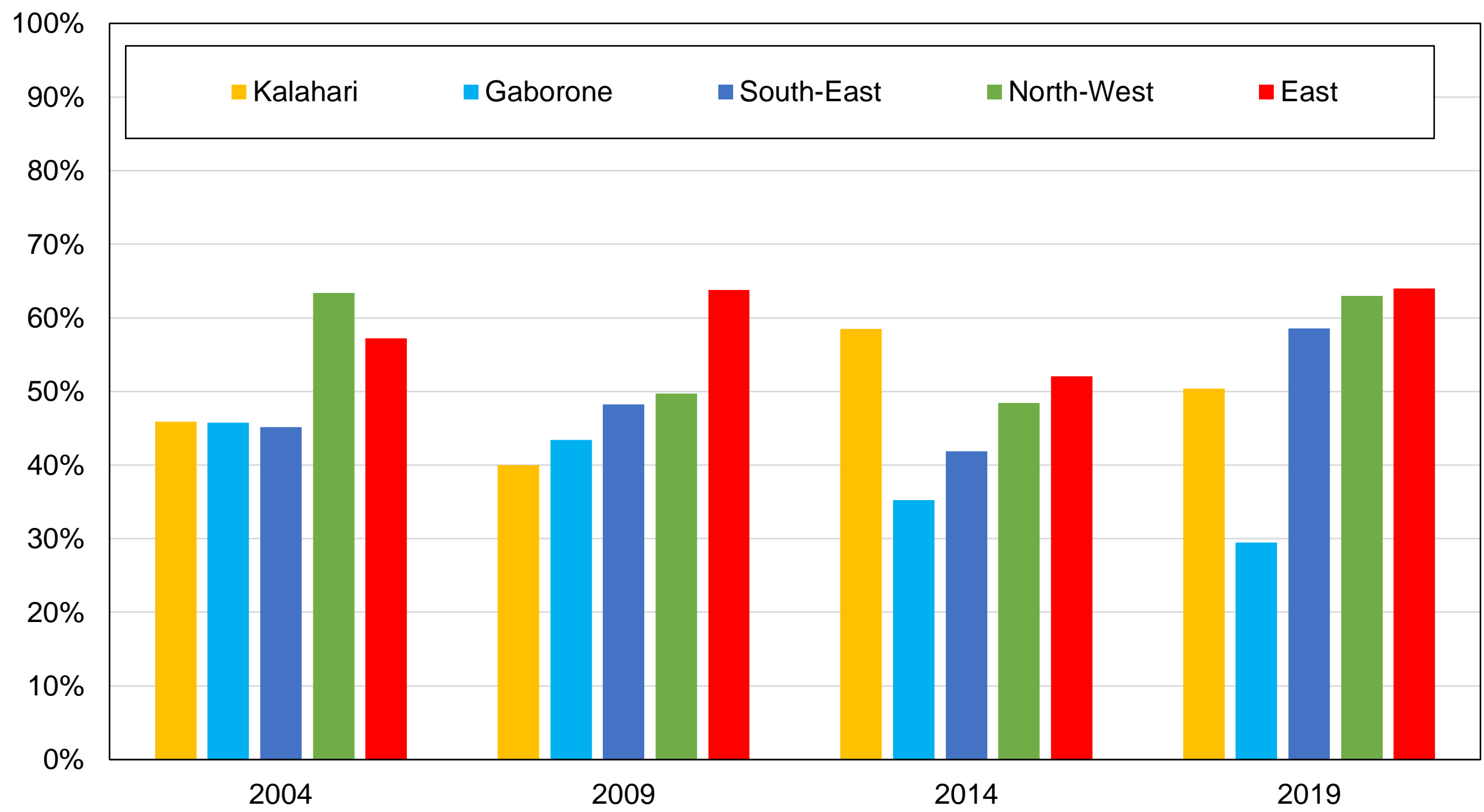

Source: authors' computations using Afrobarometer surveys.

Note: the figure shows the share of votes received by BDP by region. 
Figure AB5 - Vote for BDP by language

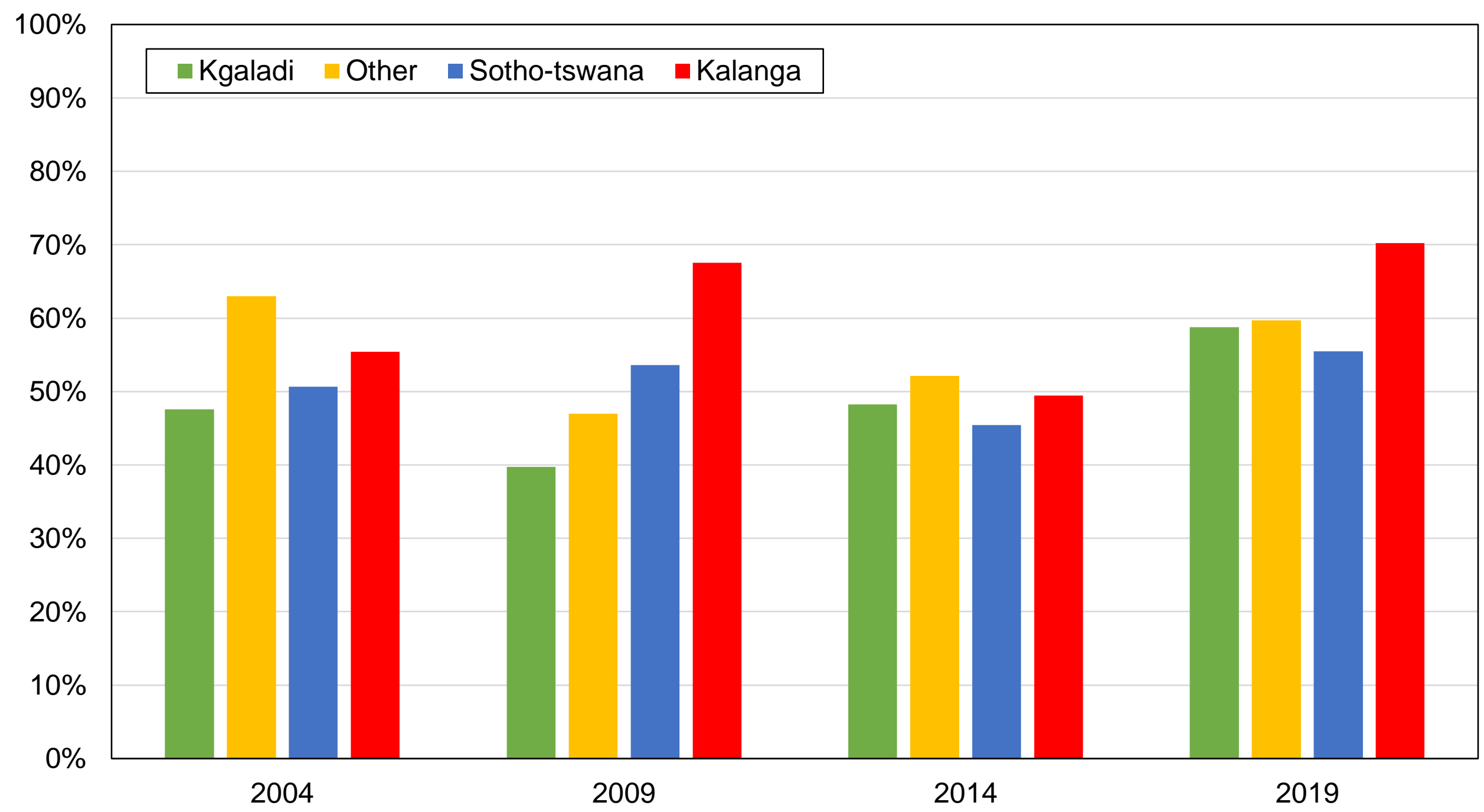

Source: authors' computations using Afrobarometer surveys.

Note: the figure shows the share of votes received by BDP by language. 
Figure AB6 - Vote for BDP by age group

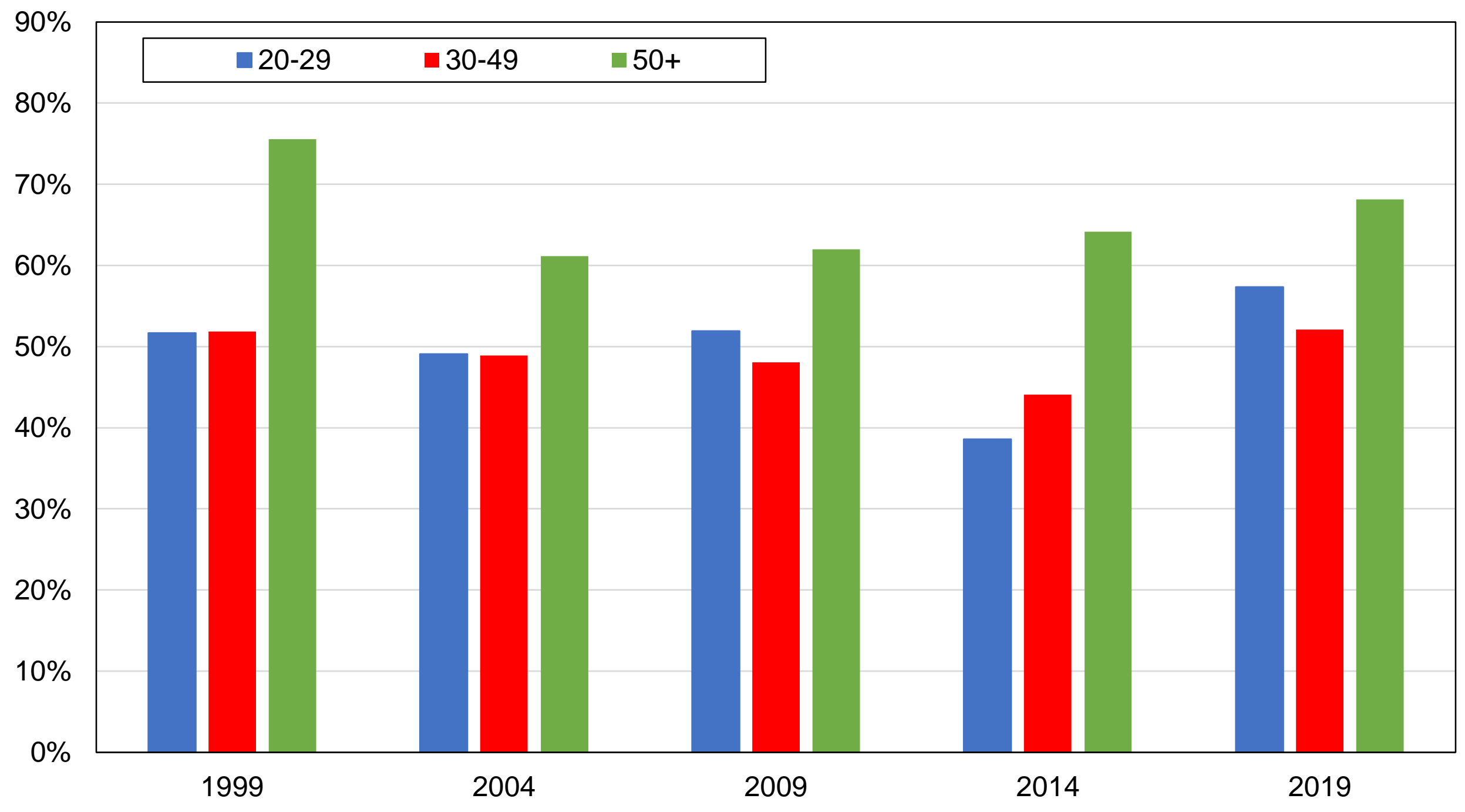

Source: authors' computations using Afrobarometer surveys.

Note: the figure shows the share of votes received by BDP by age group. 
Figure AB7 - Vote for BDP by gender

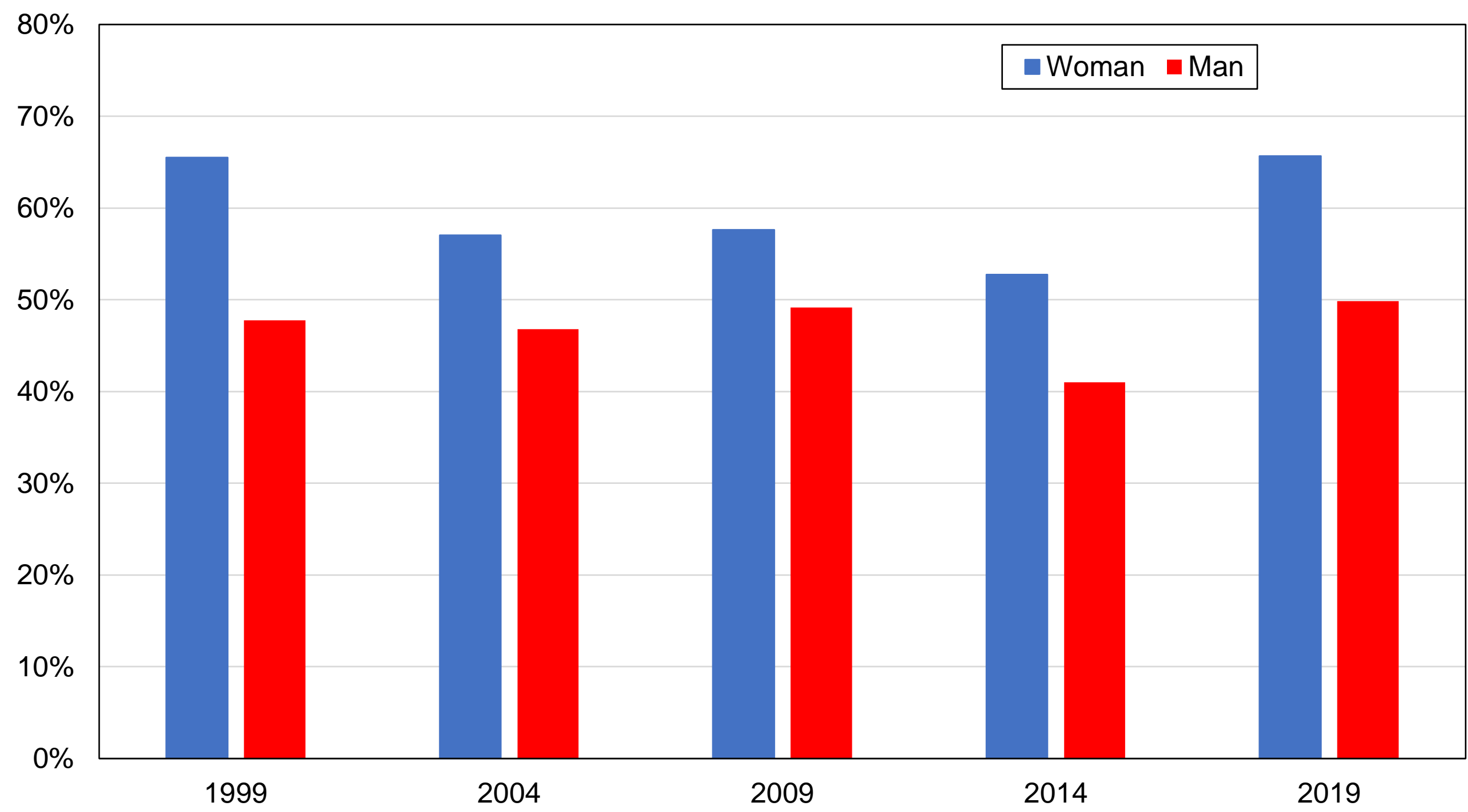

Source: authors' computations using Afrobarometer surveys.

Note: the figure shows the share of votes received by BDP by gender. 
Figure AB8 - Vote for BDP by religion

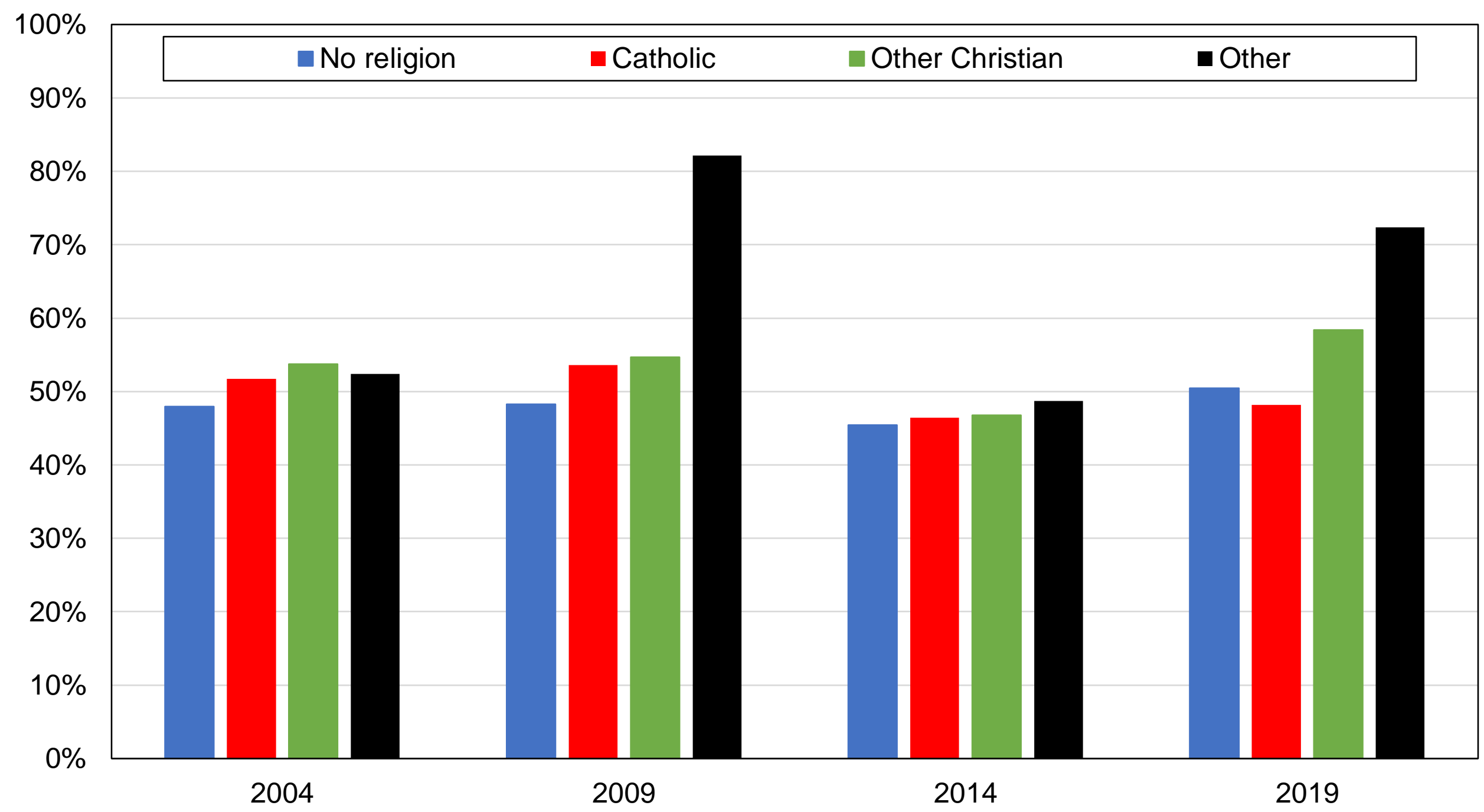

Source: authors' computations using Afrobarometer surveys.

Note: the figure shows the share of votes received by BDP by religious affiliation. 
Figure AB8 - Vote for BDP by employment status

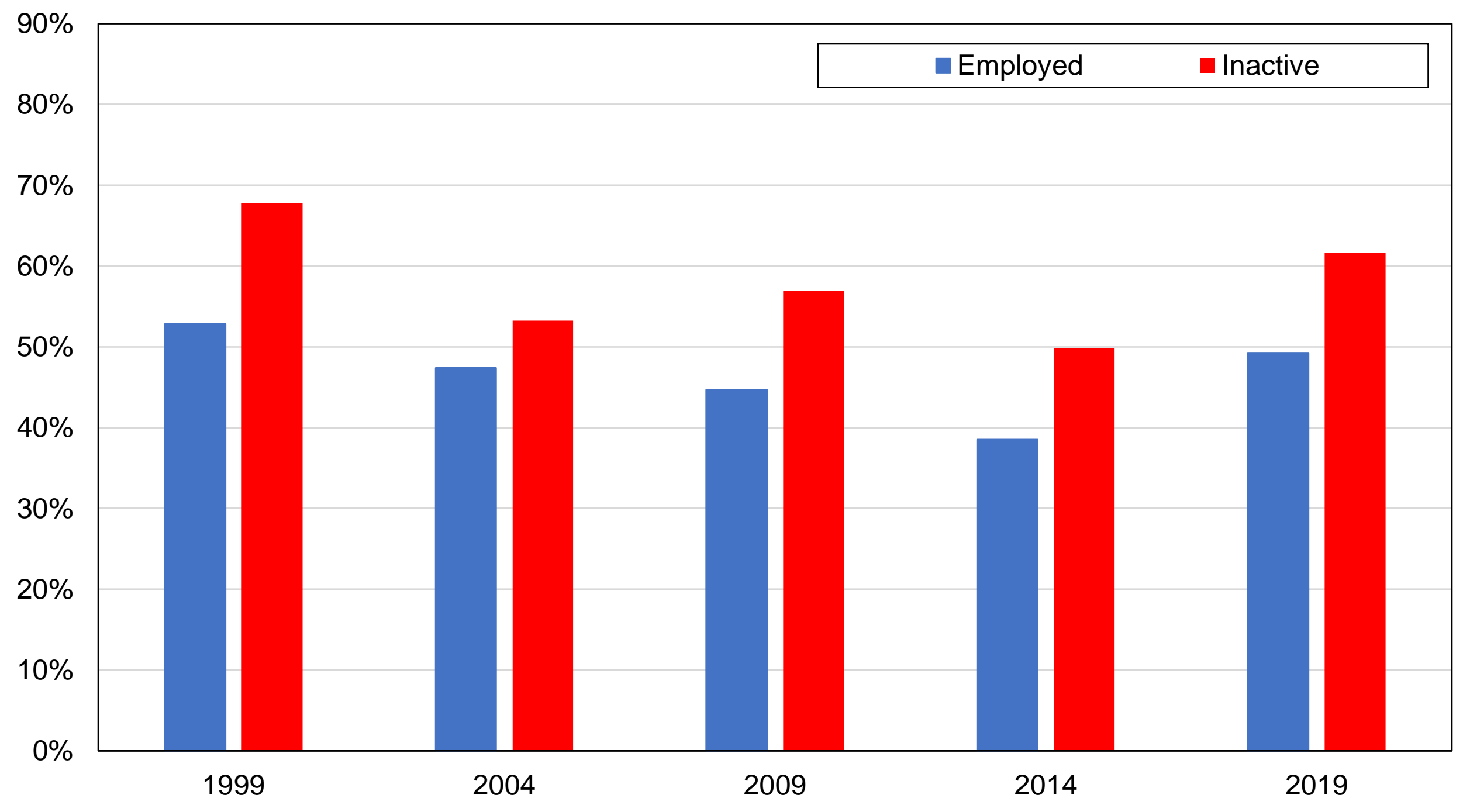

Source: authors' computations using Afrobarometer surveys.

Note: the figure shows the share of votes received by BDP by employment status. 
Figure AB10 - Vote for BDP by occupation

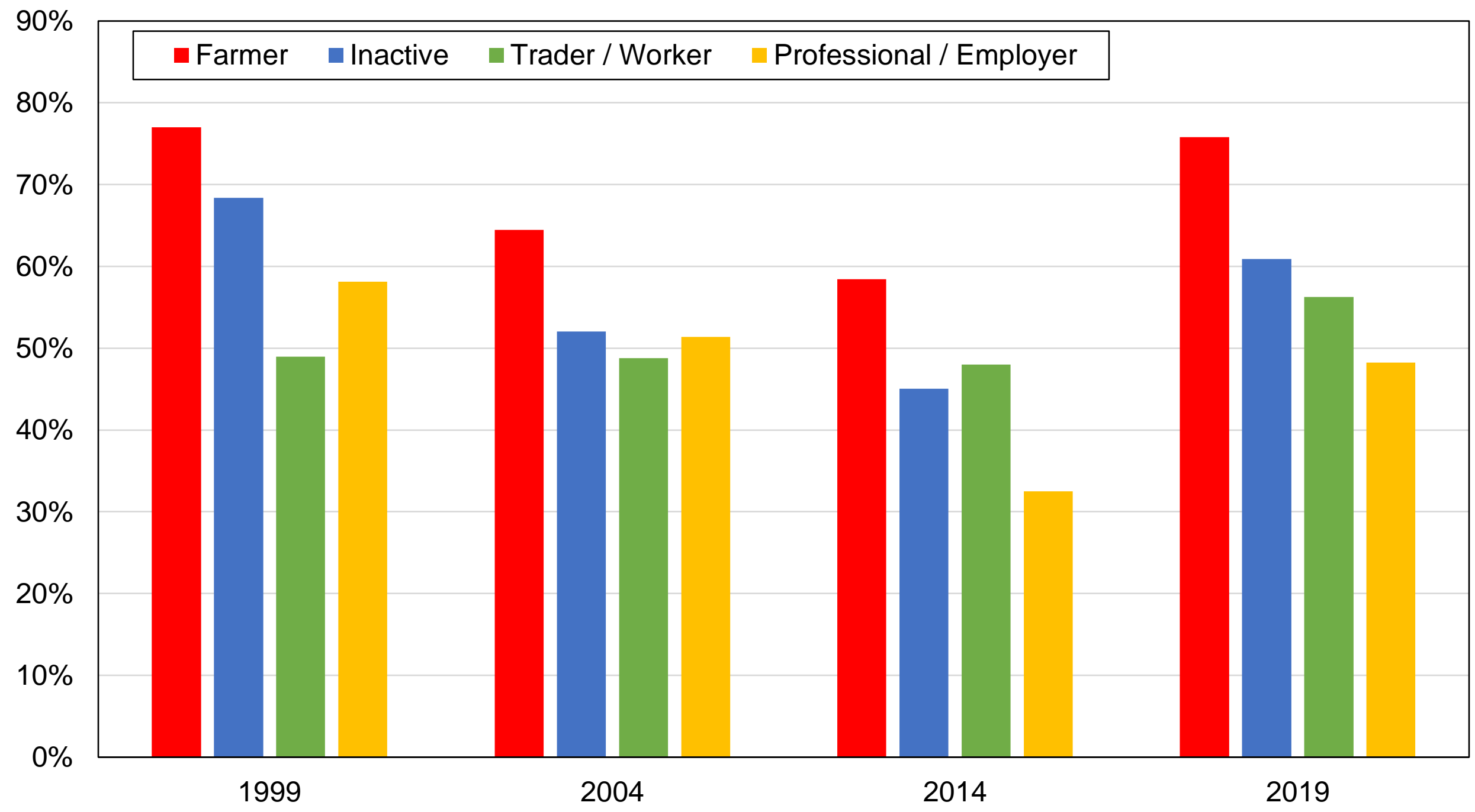

Source: authors' computations using Afrobarometer surveys.

Note: the figure shows the share of votes received by BDP by occupation. 


\section{Figure AC1 - Vote for BDP among highest-educated voters}

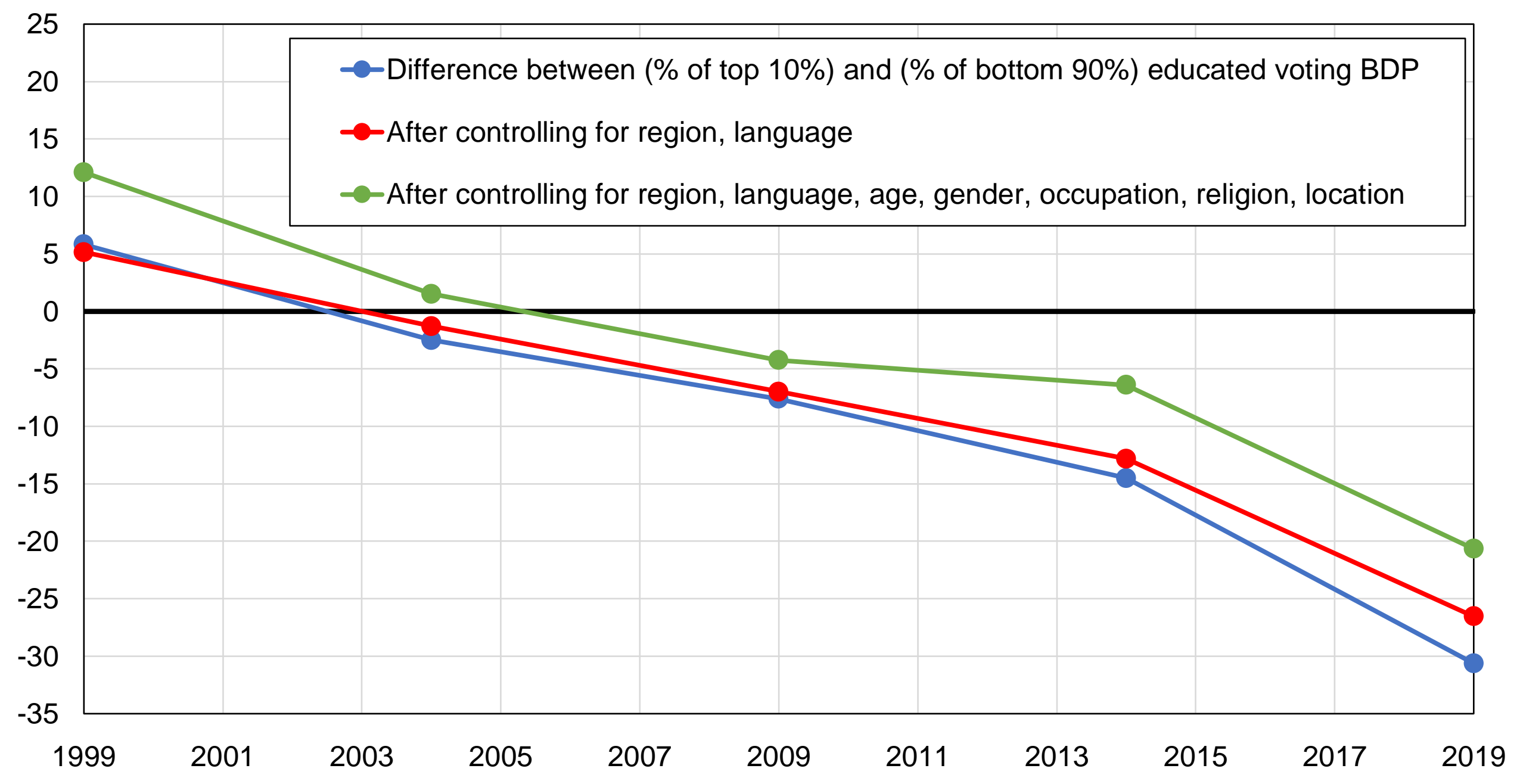

Source: authors' computations using Afrobarometer surveys.

Note: the figure shows the difference between the share of top $10 \%$ educated voters and the share of other voters voting for BDP, before and after controlling for other variables. 


\section{Figure AC2 - Vote for BDP among university graduates}

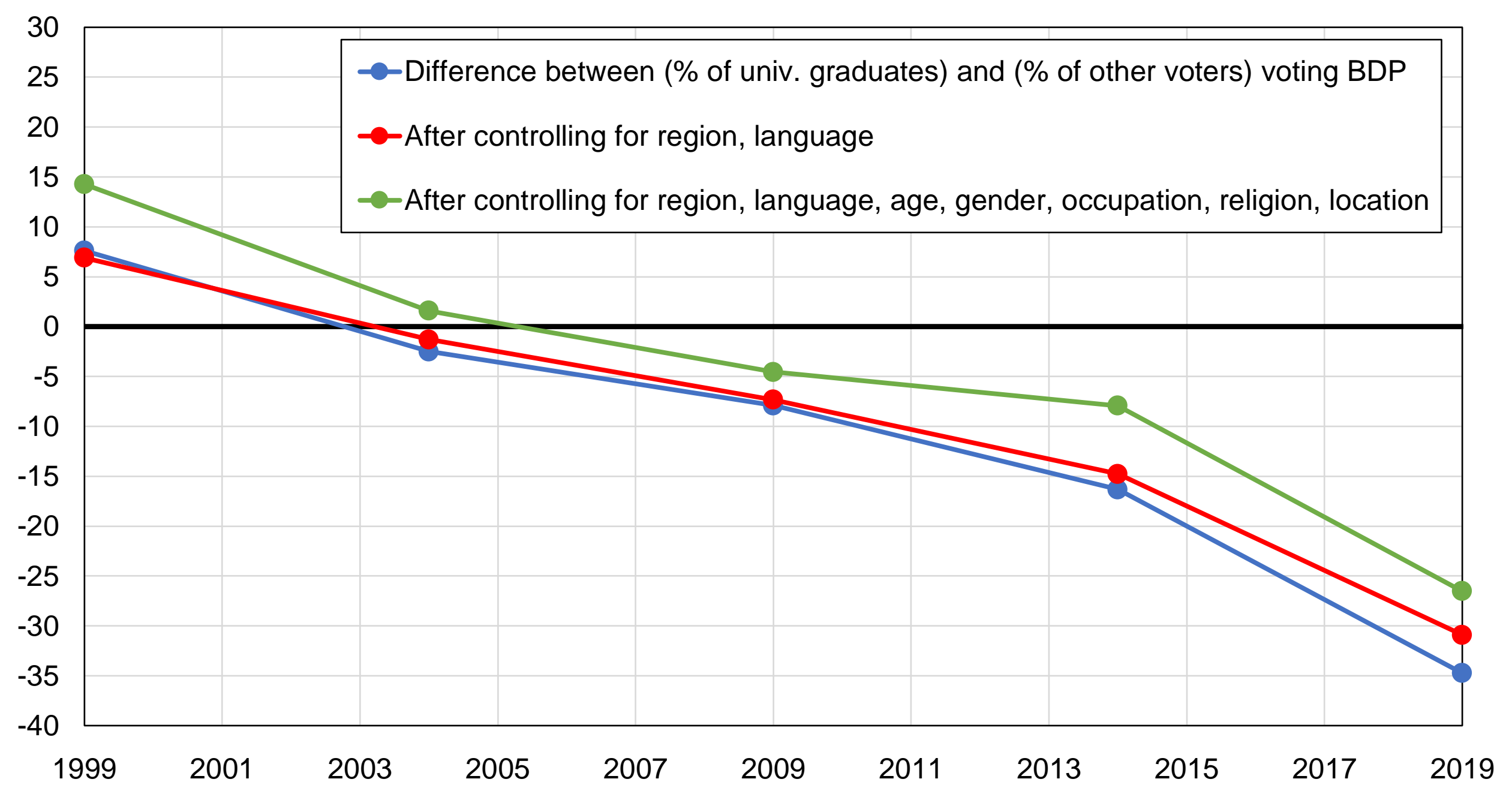

Source: authors' computations using Afrobarometer surveys.

Note: the figure shows the difference between the share of university graduates and the share of other voters voting for BDP, before and after controlling for other variables. 


\section{Figure AC3 - Vote for BDP among lowest-educated voters}

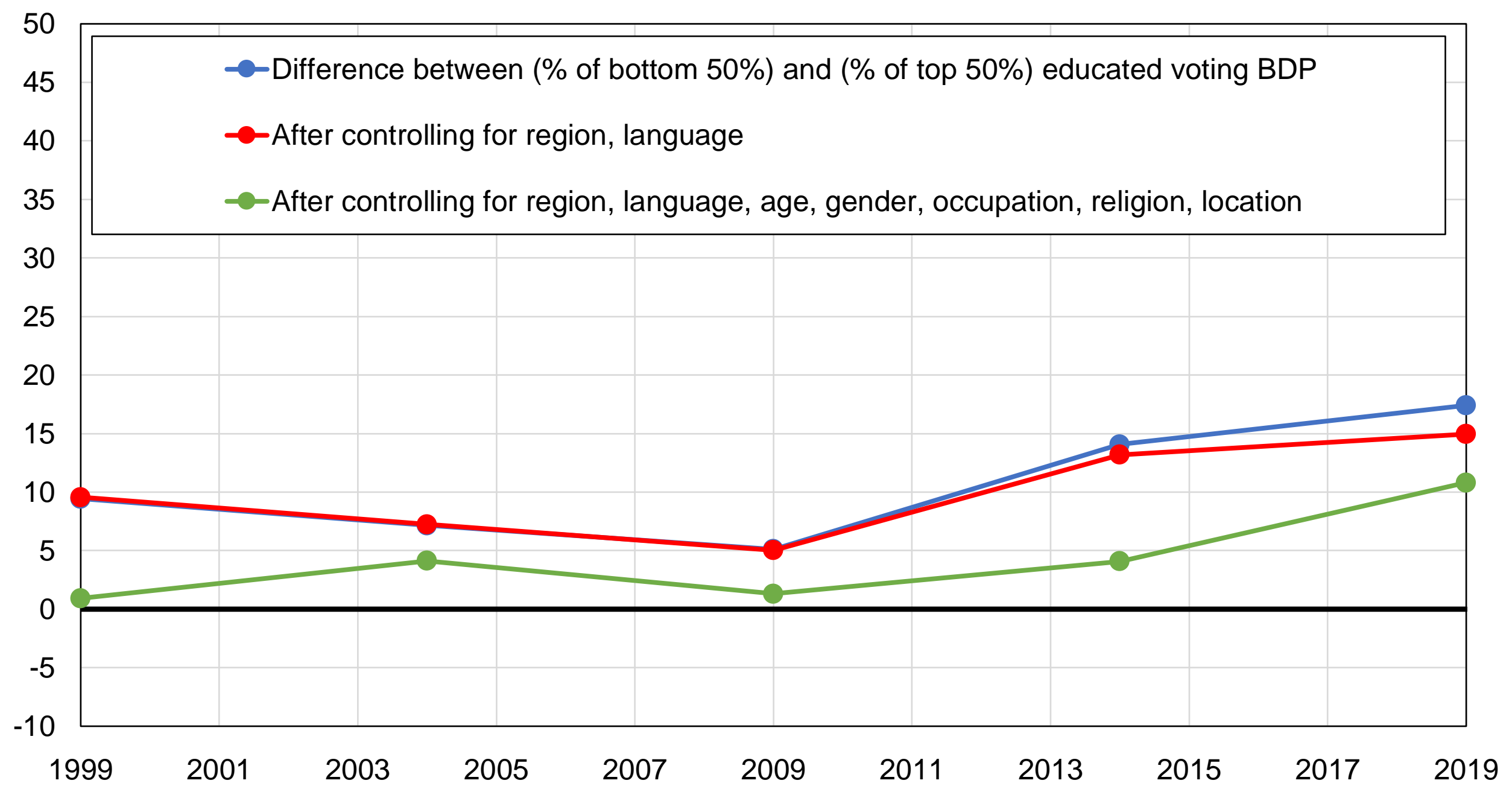

Source: authors' computations using Afrobarometer surveys.

Note: the figure shows the difference between the share of bottom $50 \%$ education and the share top $50 \%$ education voters voting for BDP, before and after controlling for other variables. 


\section{Figure AC4 - Vote for BDP among women}

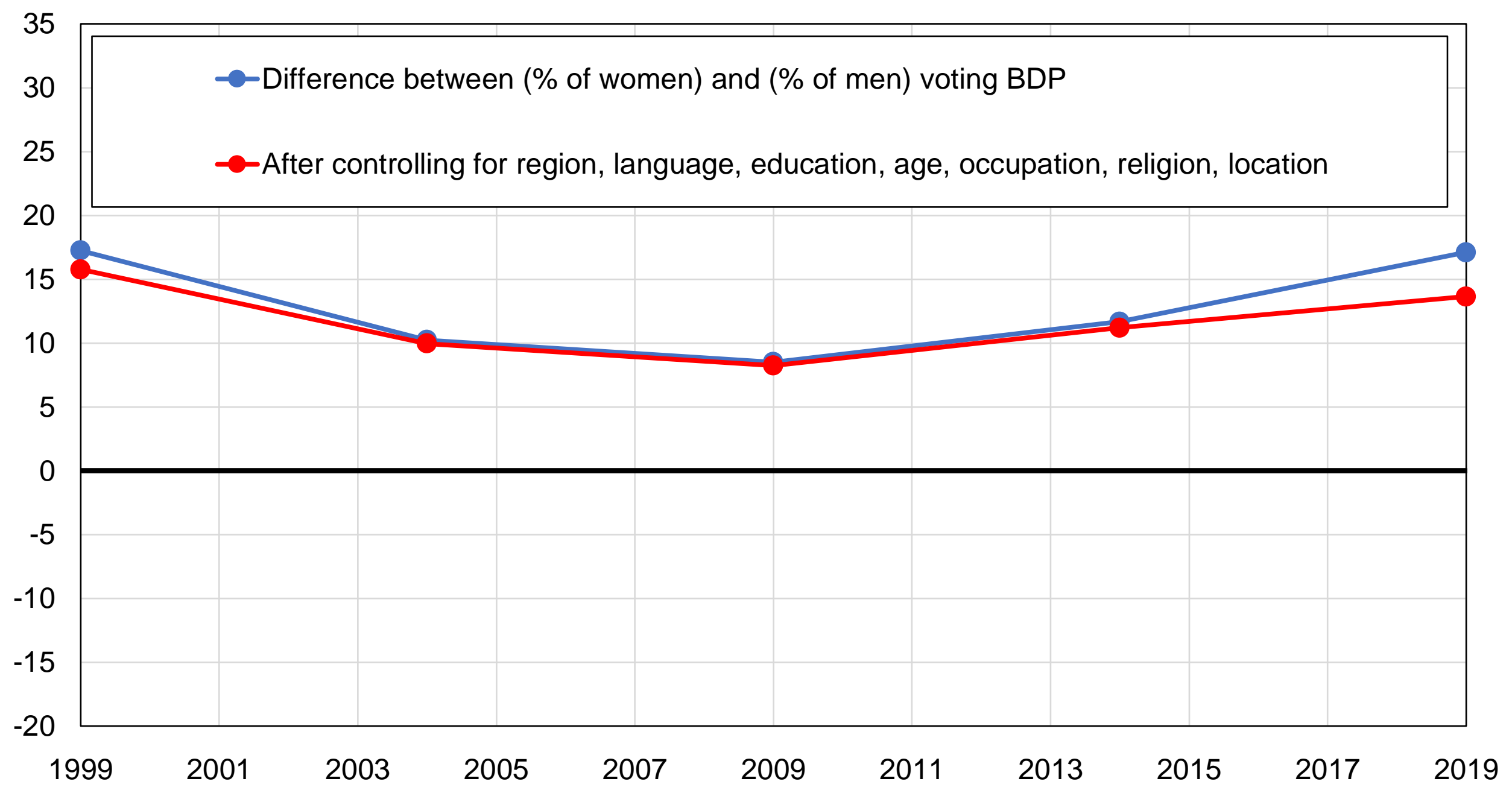

Source: authors' computations using Afrobarometer surveys.

Note: the figure shows the difference between the share of women and the share of men voting for BDP, before and after controlling for other variables. 


\section{Figure AC5 - Vote for BDP among rural areas}

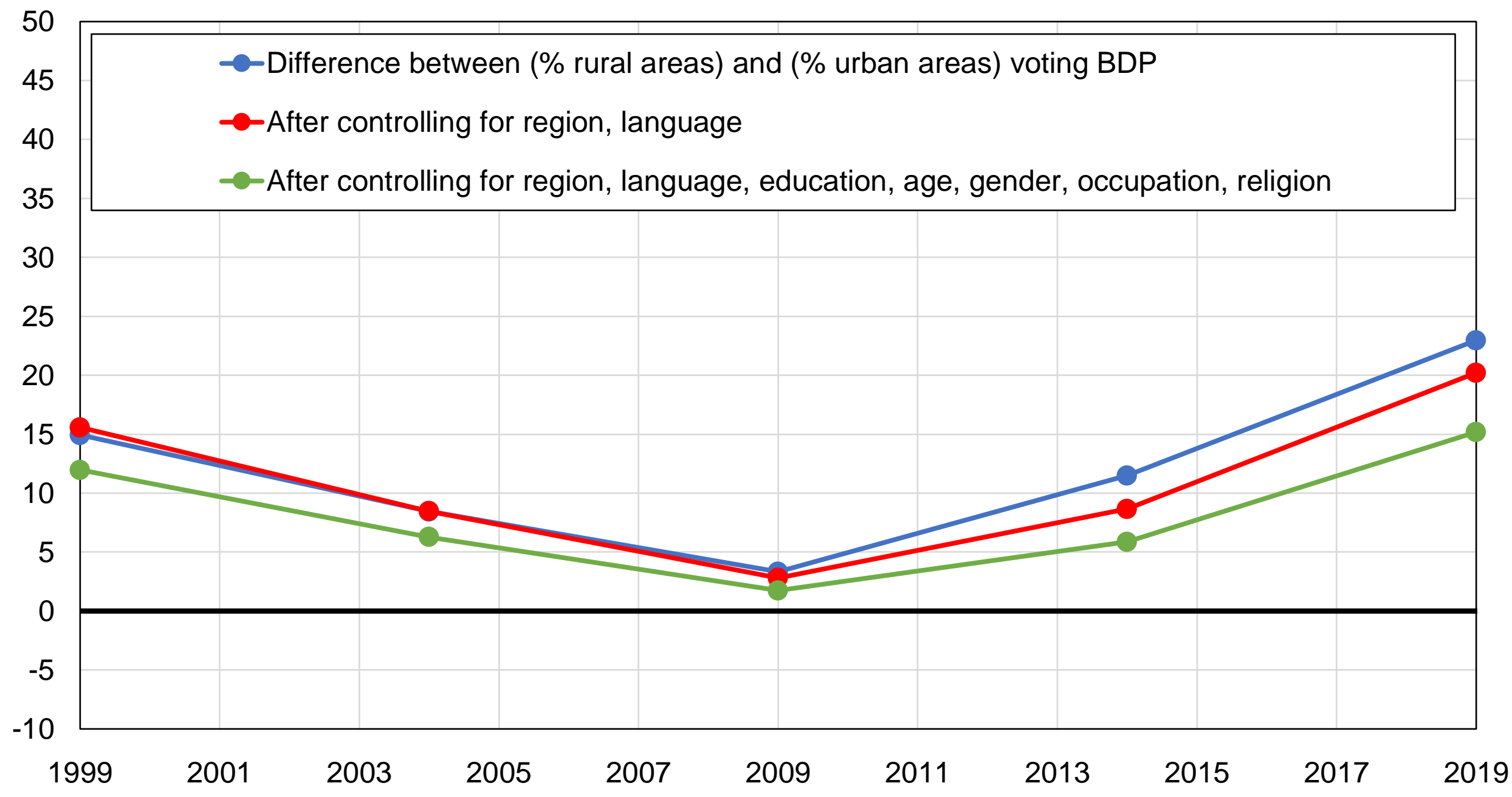

Source: authors' computations using Afrobarometer surveys.

Note: the figure shows the difference between the share of voters from rural areas and the share of urban voters voting for BDP, before and after controlling for other variables. 


\section{Figure AC6 - Ethnolinguistic cleavages in Botswana}

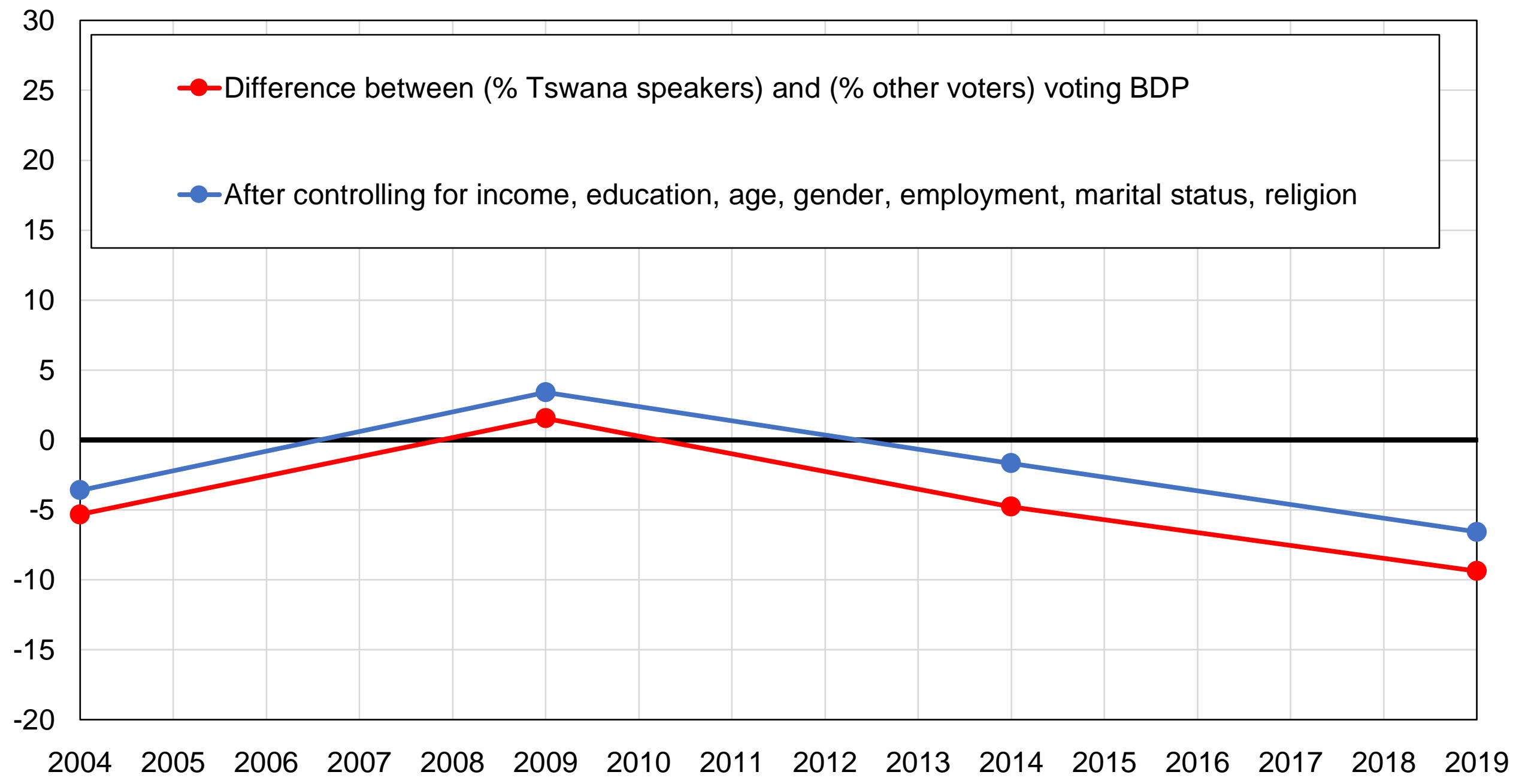

Source: authors' computations using Afrobarometer surveys.

Note: the figure shows the difference between the share of Tswana voters and the share of non-Tswana voters voting for BDP, before and after controlling for other variables. 


\section{Figure AC7 - Vote for BDP among farmers}

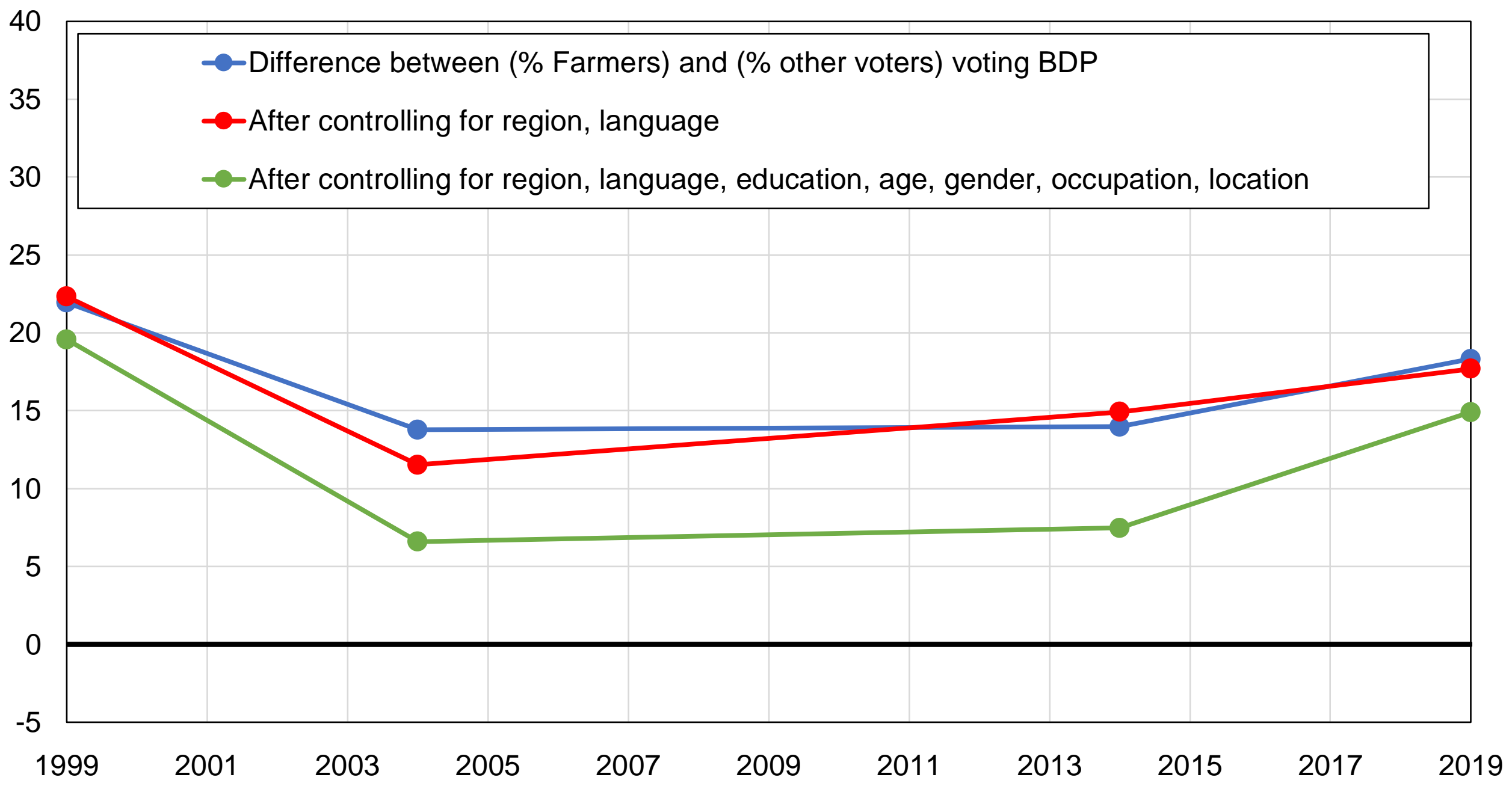

Source: authors' computations using Afrobarometer surveys.

Note: the figure shows the difference between the share of farmers and the share of other voters voting for $\mathrm{BDP}$, before and after controlling for other variables. 


\begin{tabular}{|cllc|}
\hline \multicolumn{5}{|c|}{ Table A1 - Survey data sources } \\
\hline Year & \multicolumn{1}{|c|}{ Survey } & Source & Sample size \\
\hline 2000 & Afrobarometers Wave 1 & Afrobarometers & 2004 \\
2004 & Afrobarometers Wave 2-3 & Afrobarometers & 2397 \\
2008 & Afrobarometers Wave 4 & Afrobarometers & 1200 \\
2016 & Afrobarometers Wave 5-6 & Afrobarometers & 4800 \\
2019 & Afrobarometers Wave 7 & Afrobarometers & 1600 \\
\hline Source: authors' elaboration. & & \\
Note: the table shows the surveys used, the source from which these surveys can be & & \\
obtained, and the sample size of each survey. & & \\
\end{tabular}




\begin{tabular}{|c|c|c|c|c|c|}
\hline \multicolumn{6}{|c|}{ Table A2 - Complete descriptive statistics by year } \\
\hline & 1999 & 2004 & 2009 & 2014 & 2019 \\
\hline Education: Illiterate & $17 \%$ & $17 \%$ & $20 \%$ & $12 \%$ & $11 \%$ \\
\hline Education: Primary & $30 \%$ & $26 \%$ & $26 \%$ & $20 \%$ & $18 \%$ \\
\hline Education: Secondary & $45 \%$ & $45 \%$ & $41 \%$ & $47 \%$ & $49 \%$ \\
\hline Education: Tertiary & $9 \%$ & $11 \%$ & $14 \%$ & $21 \%$ & $22 \%$ \\
\hline Age: $20-29$ & $44 \%$ & $45 \%$ & $38 \%$ & $39 \%$ & $34 \%$ \\
\hline Age: $30-49$ & $35 \%$ & $36 \%$ & $36 \%$ & $39 \%$ & $42 \%$ \\
\hline Age: $50+$ & $21 \%$ & $19 \%$ & $26 \%$ & $22 \%$ & $24 \%$ \\
\hline Gender: Man & $50 \%$ & $51 \%$ & $52 \%$ & $53 \%$ & $50 \%$ \\
\hline Employment status: Employed & $69 \%$ & $29 \%$ & $31 \%$ & $32 \%$ & $32 \%$ \\
\hline Employment status: Unemployed & $0 \%$ & $45 \%$ & $45 \%$ & $44 \%$ & $45 \%$ \\
\hline Employment status: Inactive & $31 \%$ & $26 \%$ & $24 \%$ & $25 \%$ & $23 \%$ \\
\hline Religion: No religion & & $31 \%$ & $29 \%$ & $17 \%$ & $12 \%$ \\
\hline Religion: Catholic & & $7 \%$ & $3 \%$ & $4 \%$ & $3 \%$ \\
\hline Religion: Other Christian & & $58 \%$ & $66 \%$ & $73 \%$ & $79 \%$ \\
\hline Religion: Muslim & & $0 \%$ & $1 \%$ & $1 \%$ & $0 \%$ \\
\hline Religion: Other & & $4 \%$ & $2 \%$ & $5 \%$ & $5 \%$ \\
\hline Location: Rural & $55 \%$ & $55 \%$ & $45 \%$ & $36 \%$ & $32 \%$ \\
\hline Location: Urban & $45 \%$ & $45 \%$ & $55 \%$ & $64 \%$ & $68 \%$ \\
\hline Region: East & & $40 \%$ & $37 \%$ & $38 \%$ & $39 \%$ \\
\hline Region: Gaborone & & $11 \%$ & $13 \%$ & $12 \%$ & $11 \%$ \\
\hline Region: Kalahari & & $5 \%$ & $5 \%$ & $4 \%$ & $5 \%$ \\
\hline Region: North-West & & $8 \%$ & $9 \%$ & $9 \%$ & $9 \%$ \\
\hline Region: South East & & $36 \%$ & $36 \%$ & $37 \%$ & $37 \%$ \\
\hline Language: Kalanga & $0 \%$ & $10 \%$ & $7 \%$ & $9 \%$ & $10 \%$ \\
\hline Language: Kgaladi & $0 \%$ & $4 \%$ & $5 \%$ & $4 \%$ & $5 \%$ \\
\hline Language: Other & $2 \%$ & $6 \%$ & $7 \%$ & $7 \%$ & $5 \%$ \\
\hline Language: Sotho-tswana & $98 \%$ & $80 \%$ & $80 \%$ & $79 \%$ & $81 \%$ \\
\hline Occupation: Farmer & $4 \%$ & $7 \%$ & & $4 \%$ & $4 \%$ \\
\hline Occupation: Inactive & $39 \%$ & $43 \%$ & & $38 \%$ & $38 \%$ \\
\hline Occupation: Professional / Employe & $18 \%$ & $18 \%$ & & $15 \%$ & $15 \%$ \\
\hline Occupation: Trader / Worker & $39 \%$ & $32 \%$ & & $43 \%$ & $43 \%$ \\
\hline \multicolumn{6}{|c|}{$\begin{array}{l}\text { Source: authors' computations using Afrobarometer surveys. } \\
\text { Note: the table shows descriptive statistics by year for selected available } \\
\text { variables. }\end{array}$} \\
\hline
\end{tabular}


Figure B1 - Presidential election results in Ghana, 1960-2016

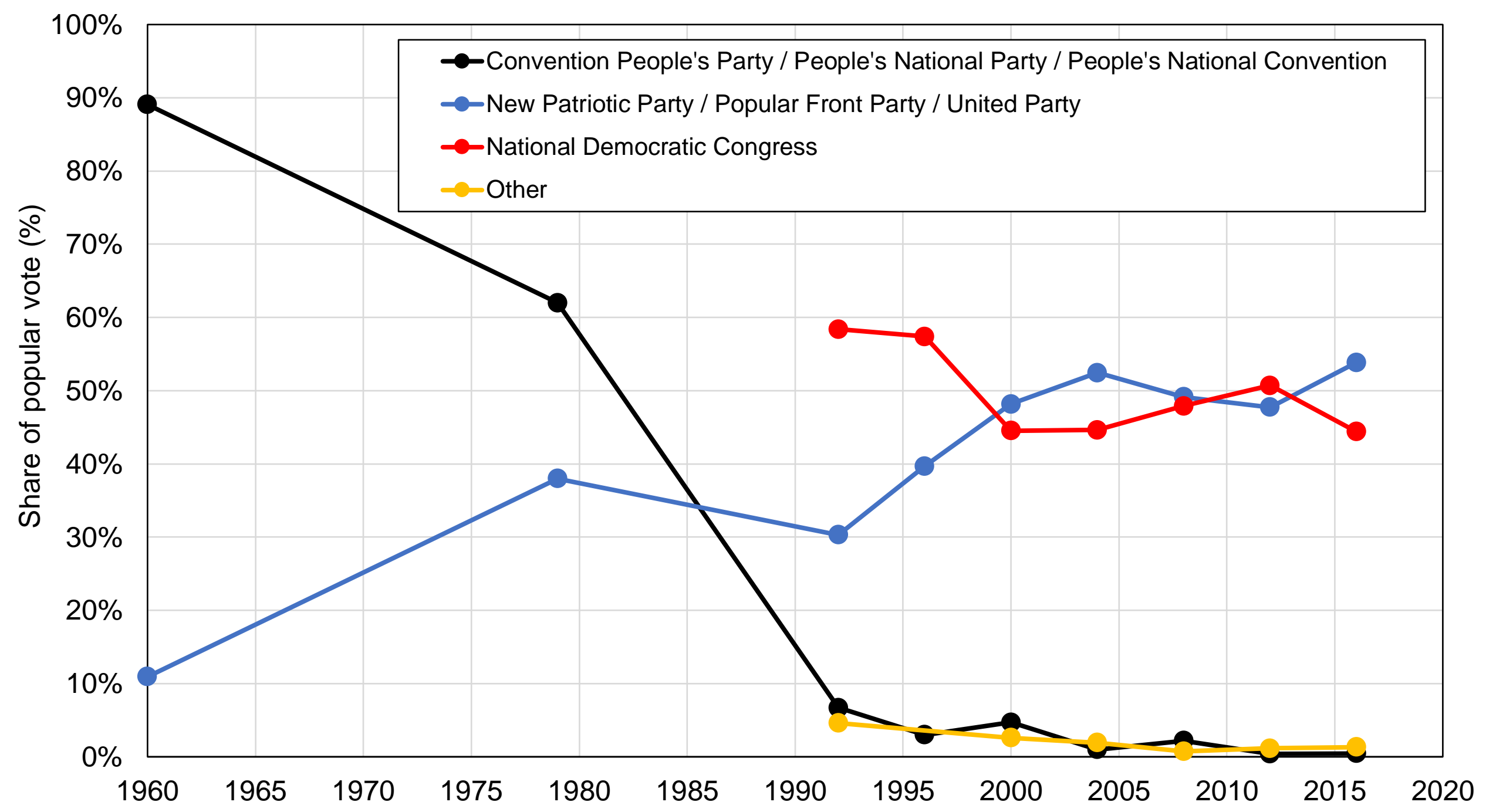

Source: authors' computations using official election results.

Note: the figure shows the share of votes received by selected groups of political parties in Ghana in the first round of presidential elections between 1960 and 2016. 
Figure B2 - Regional educational inequalities in Ghana

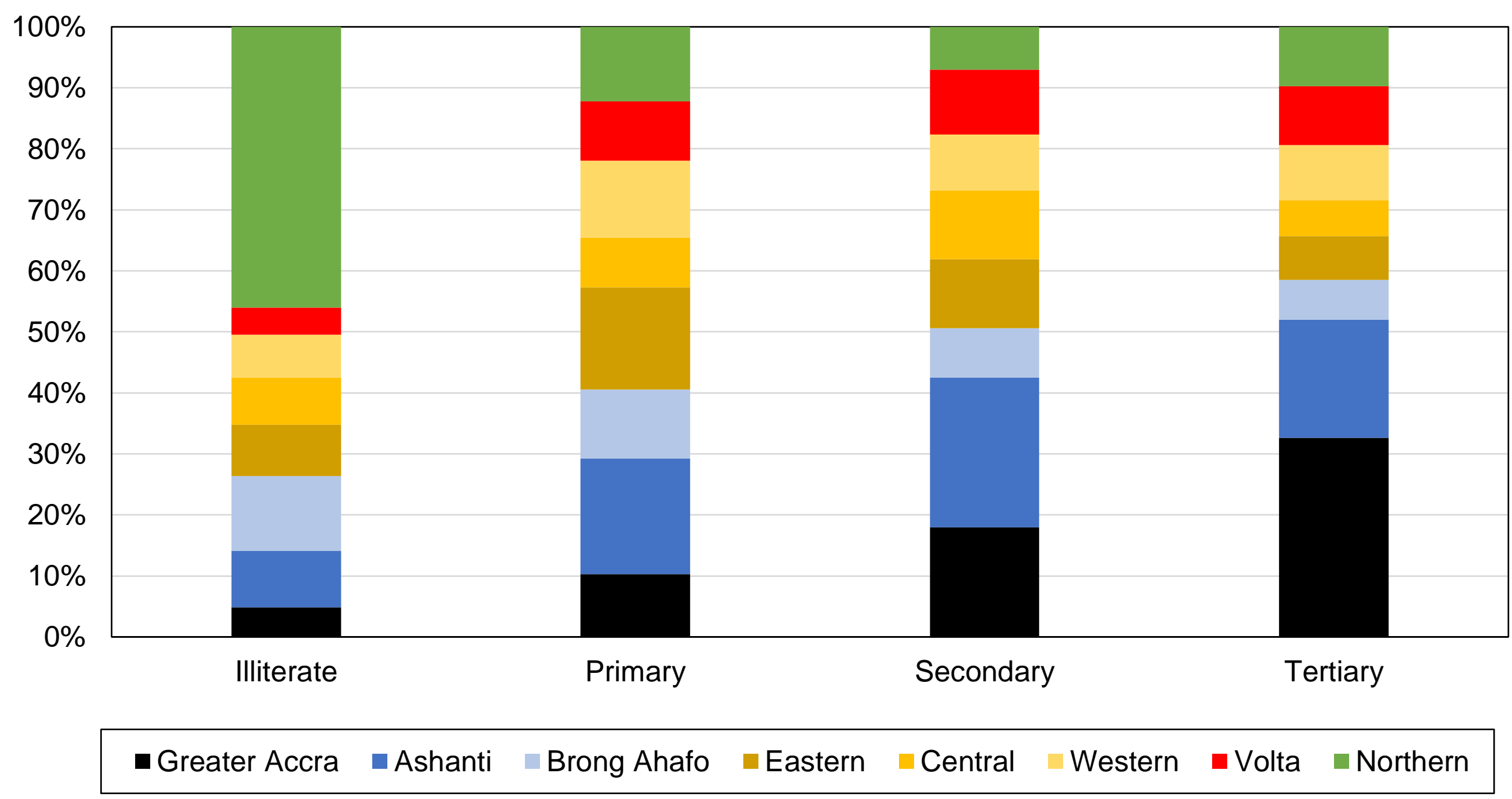

Source: authors' computations using Afrobarometer surveys.

Note: the figure shows the distribution of education groups by region in Ghana in 2016. 
Figure B3 - Vote for the National Democratic Congress by language

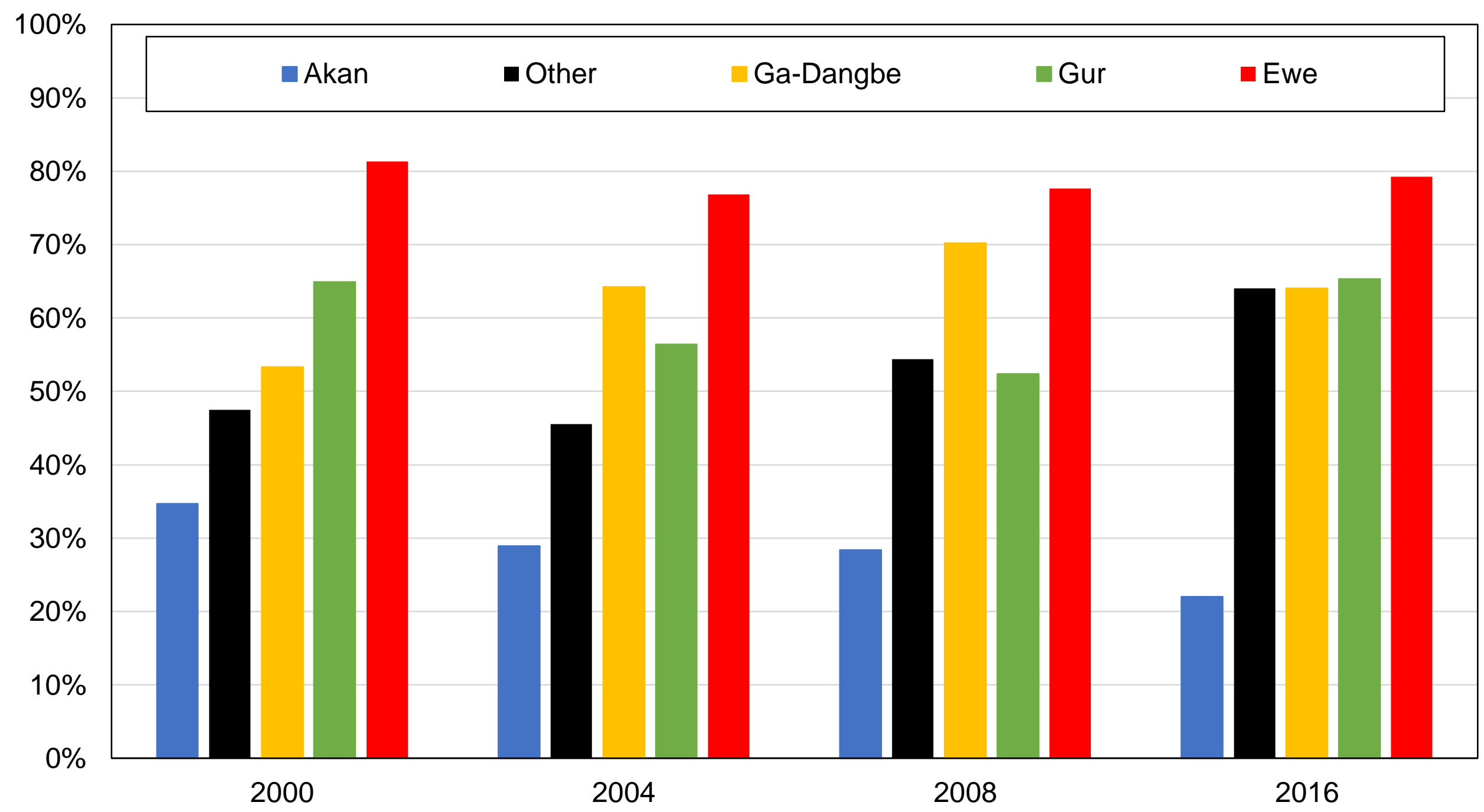

Source: authors' computations using Afrobarometer surveys.

Note: the figure shows the share of votes received by NDC by language. 
Figure B4 - Vote for National Democratic Congress by region

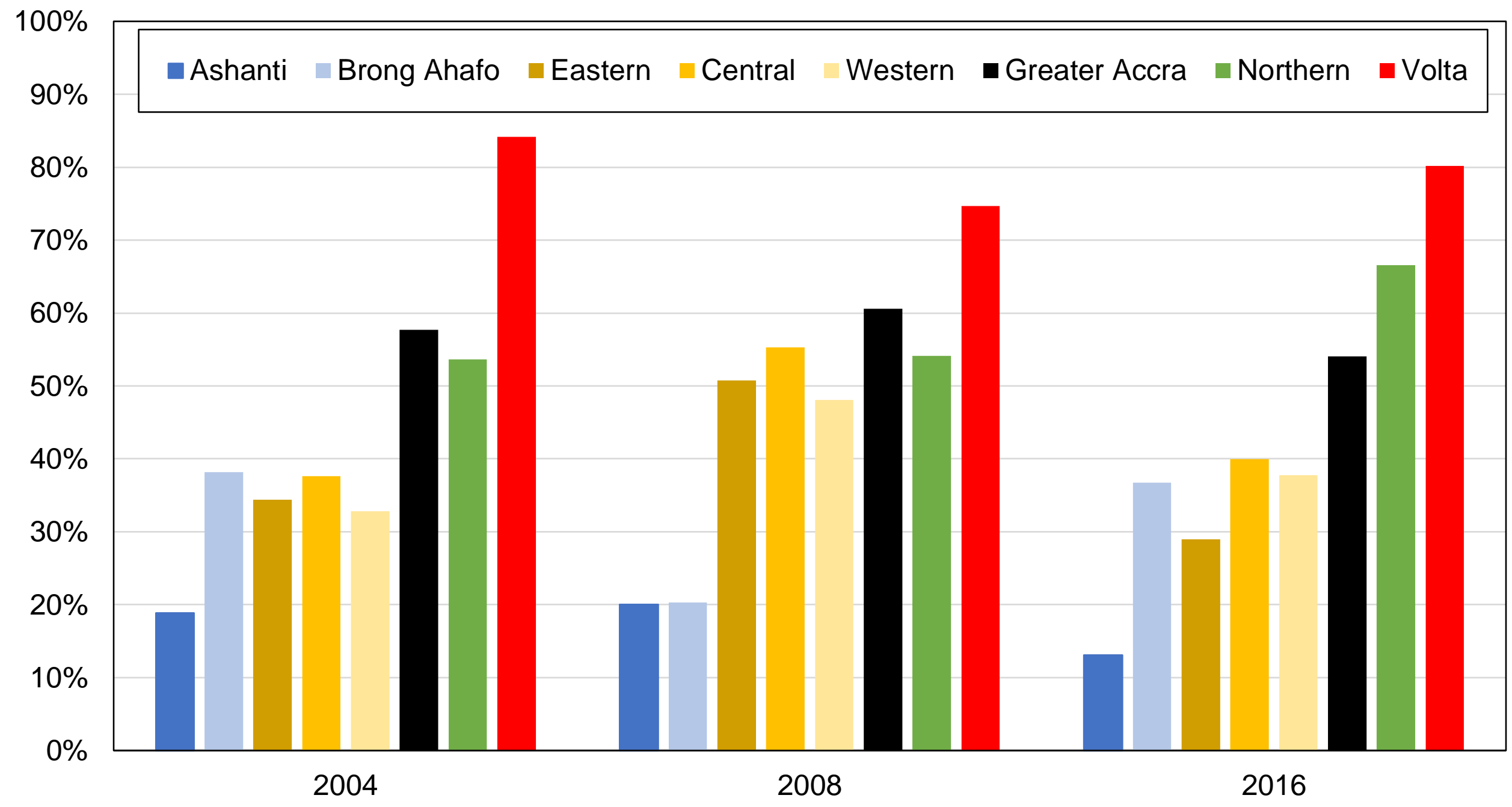

Source: authors' computations using Afrobarometer surveys.

Note: the figure shows the share of votes received by NDC by region. The Northern region includes the Upper East and the Upper West. 


\section{Figure B5 - Vote for National Democratic Congress among rural areas}

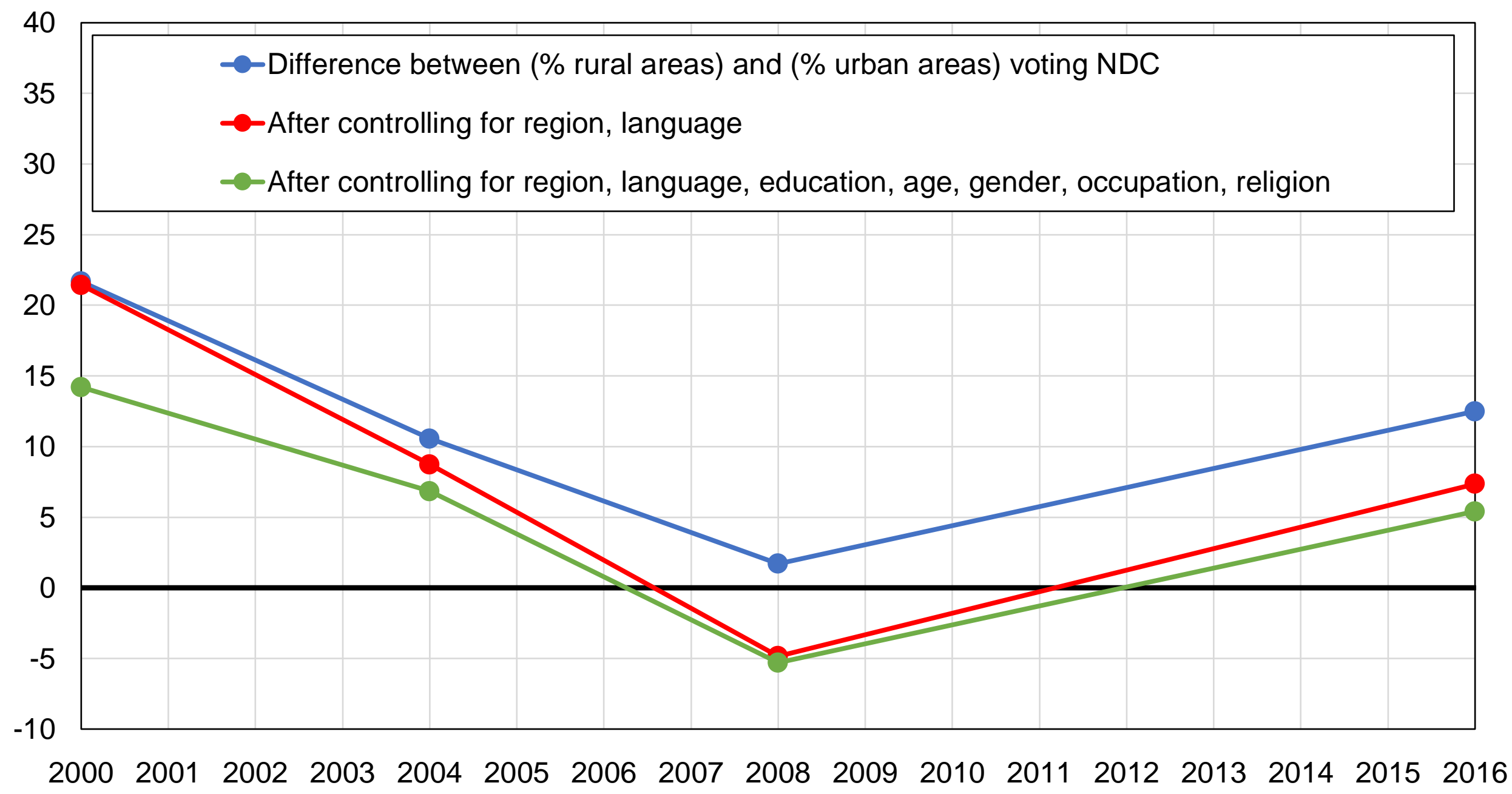

Source: authors' computations using Afrobarometer surveys.

Note: the figure shows the difference between the share of voters from rural areas and the share of other voters voting for NDC, before and after controlling for other variables. 


\section{Figure B6 - Vote for National Democratic Congress among higher-}

educated voters

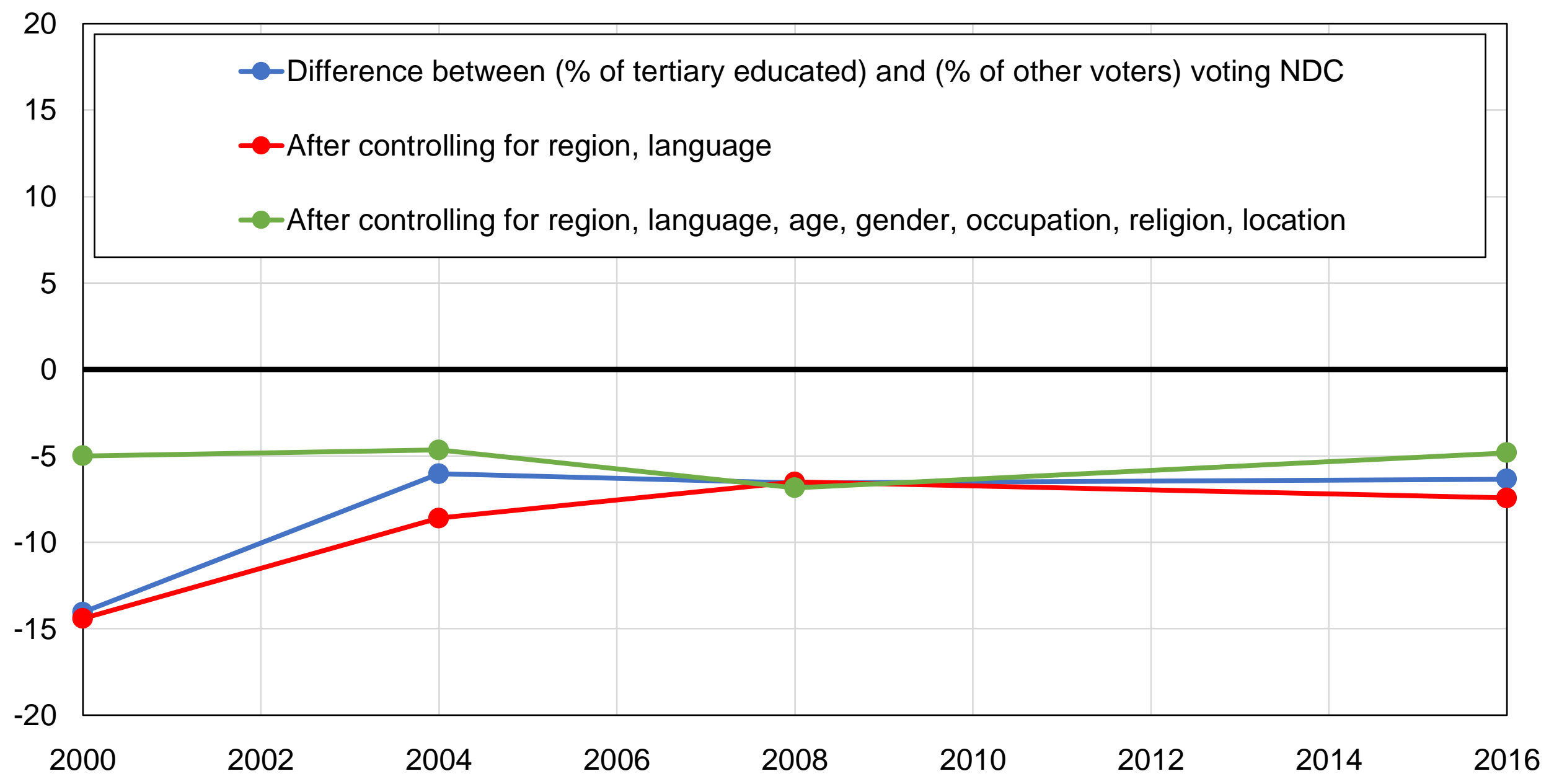

Source: authors' computations using Afrobarometer surveys.

Note: the figure shows the difference between the share of tertiary-educated voters and the share of other voters voting for NDC, before and after controlling for other variables. 
Figure BA1 - The composition of the electorate by education

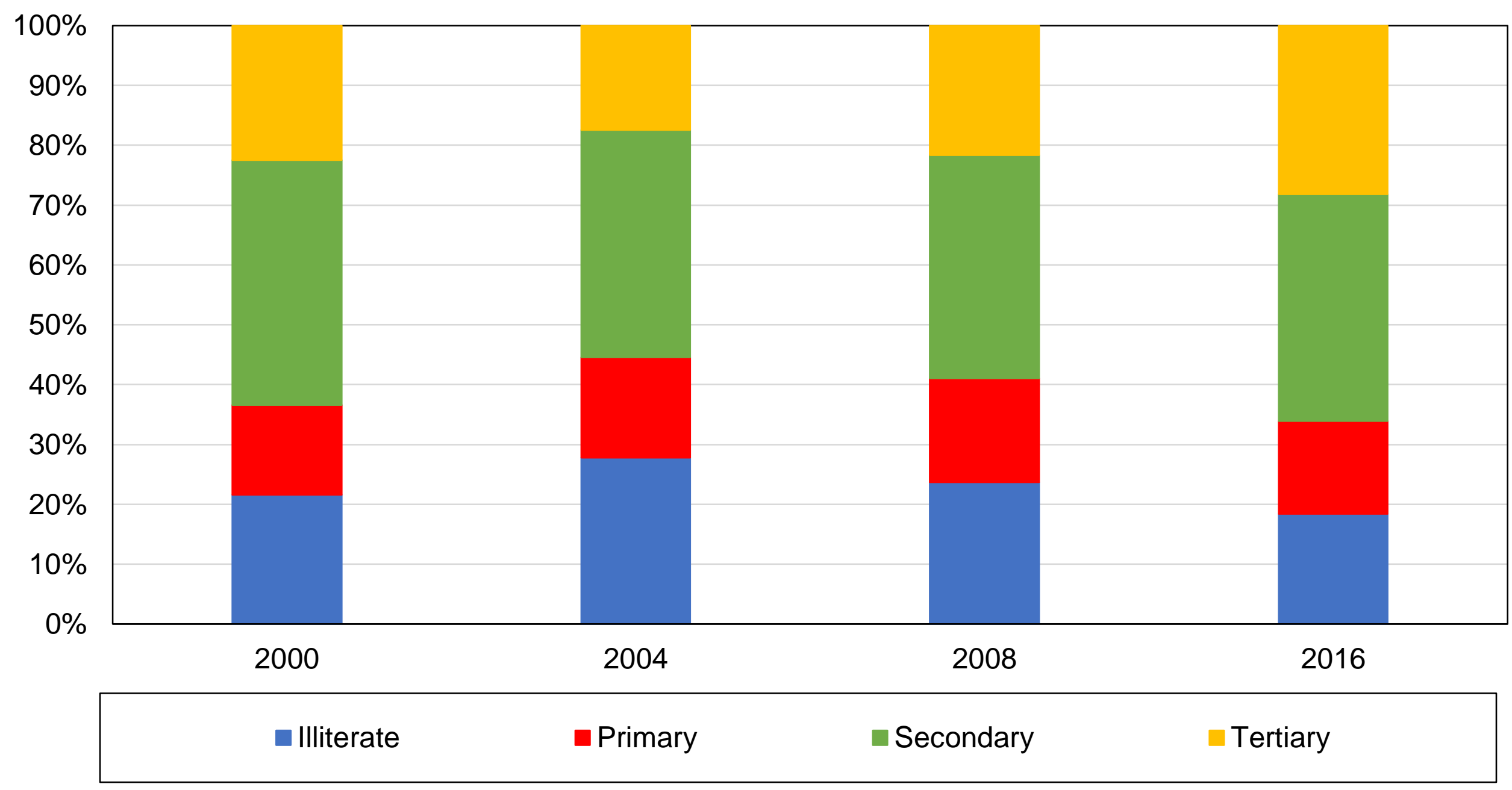

Source: authors' computations using Afrobarometer surveys.

Note: the figure shows the distribution of education levels of the adult population in Ghana and its evolution over time. 
Figure BA2 - The composition of the electorate by age

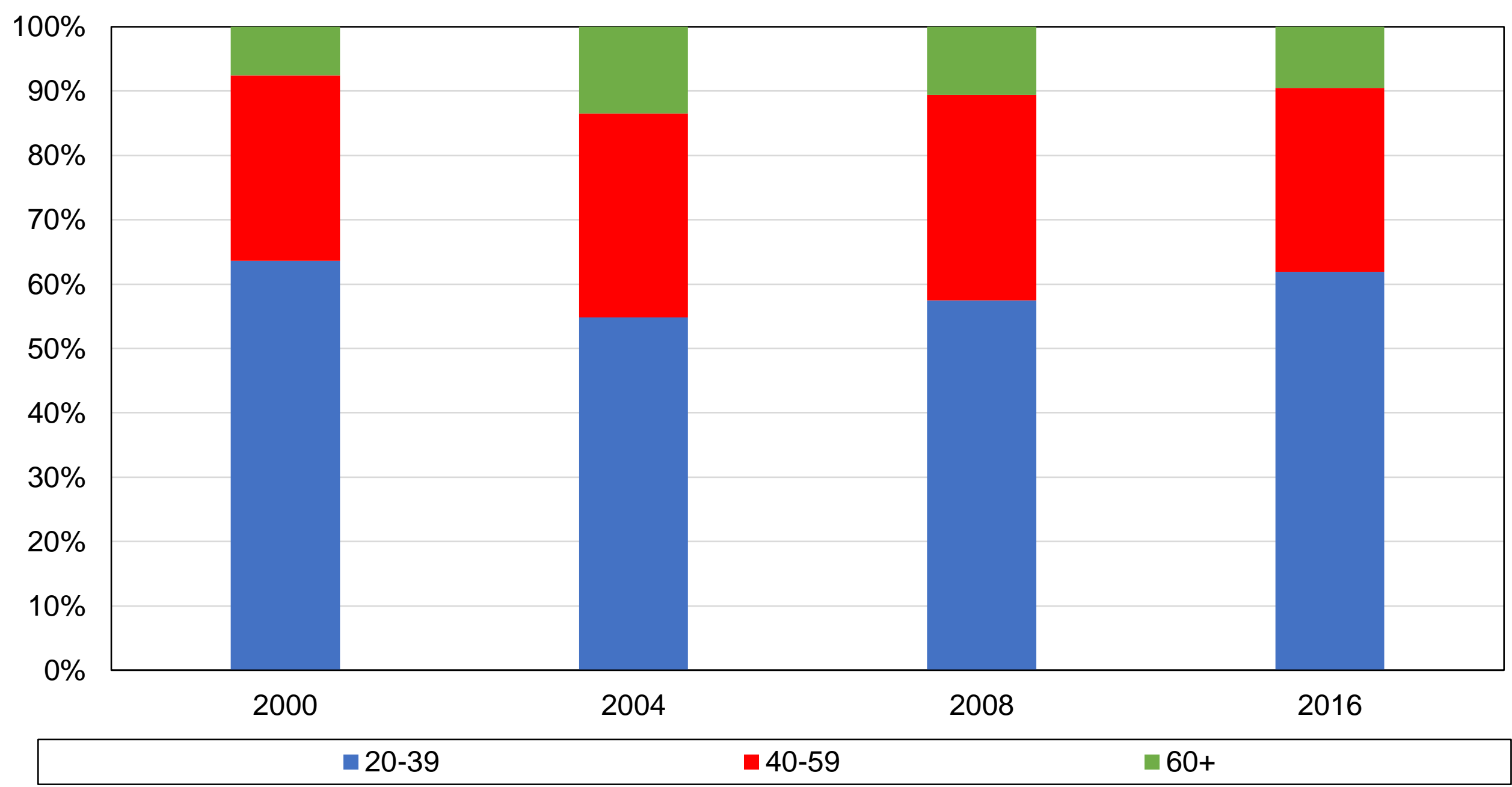

Source: authors' computations using Afrobarometer surveys.

Note: the figure shows the distribution of age groups in the adult population in Ghana and its evolution over time. 
Figure BA3 - The composition of the electorate by religion

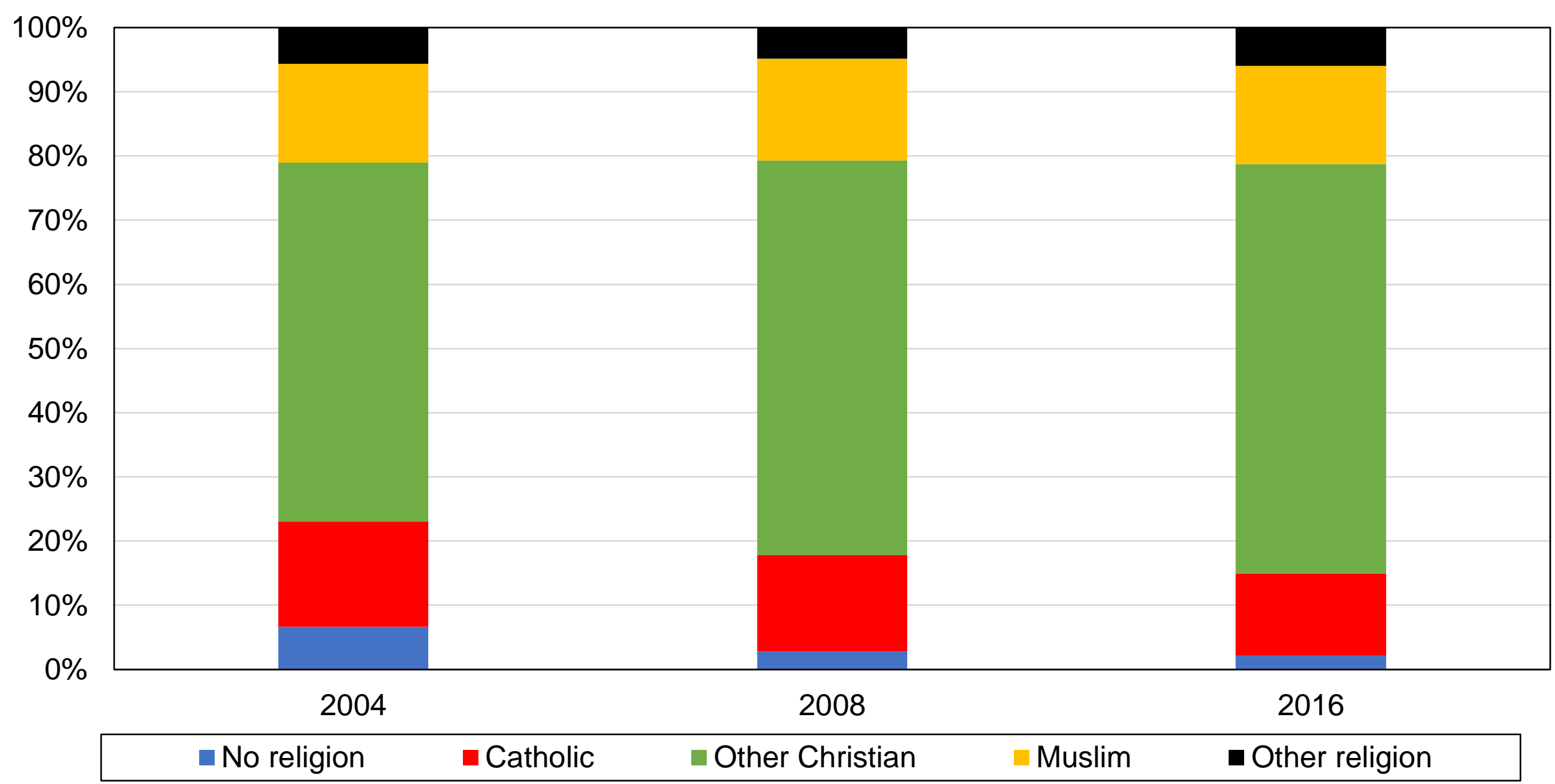

Source: authors' computations using Afrobarometer surveys.

Note: the figure shows the distribution of religious affiliations in the adult population in Ghana and its evolution over time. 
Figure BA4 - The composition of the electorate by region

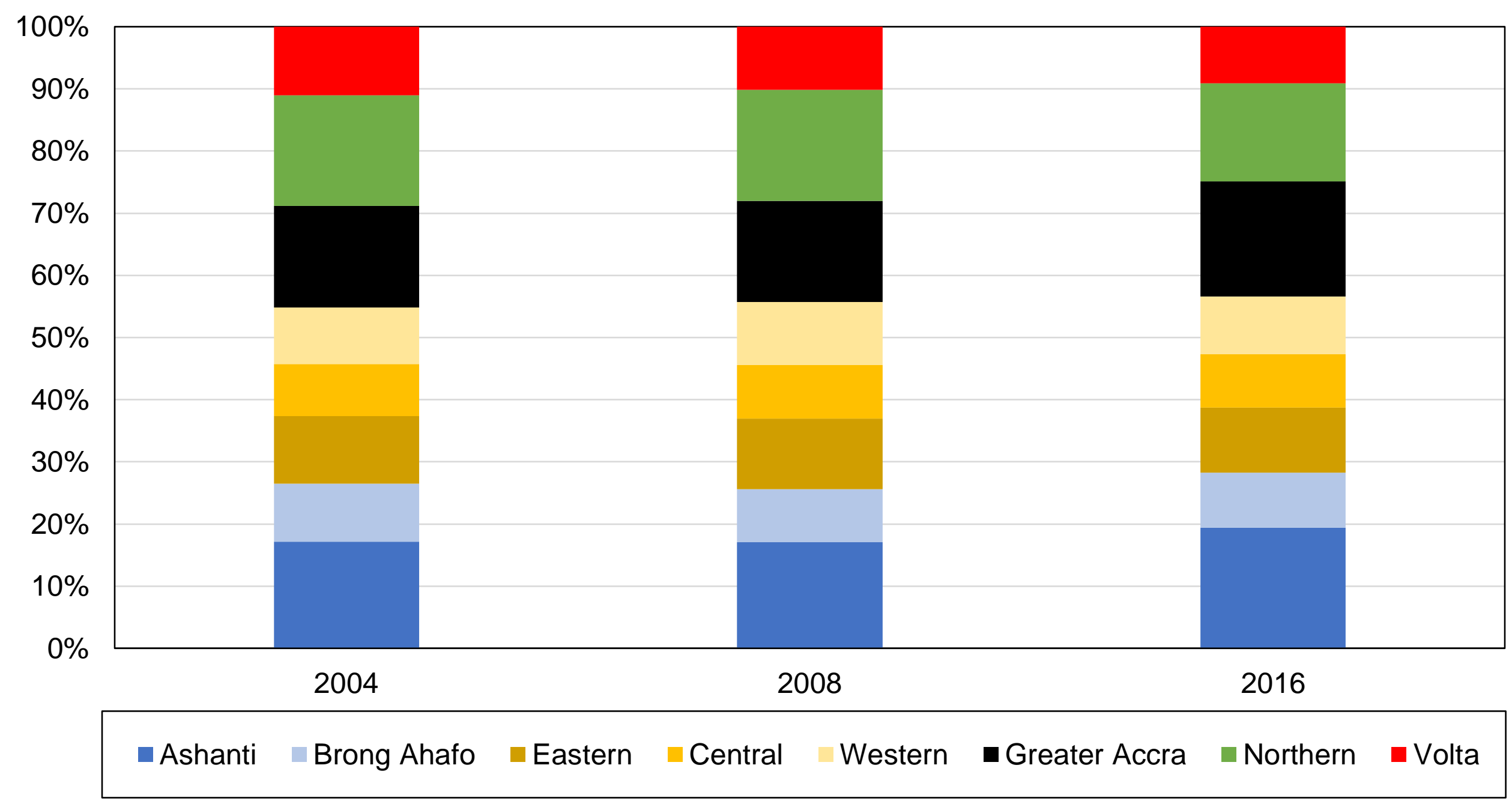

Source: authors' computations using Afrobarometer surveys.

Note: the figure shows the distribution of regions in Ghana and its evolution over time. 
Figure BA5 - The composition of the electorate by linguistic group

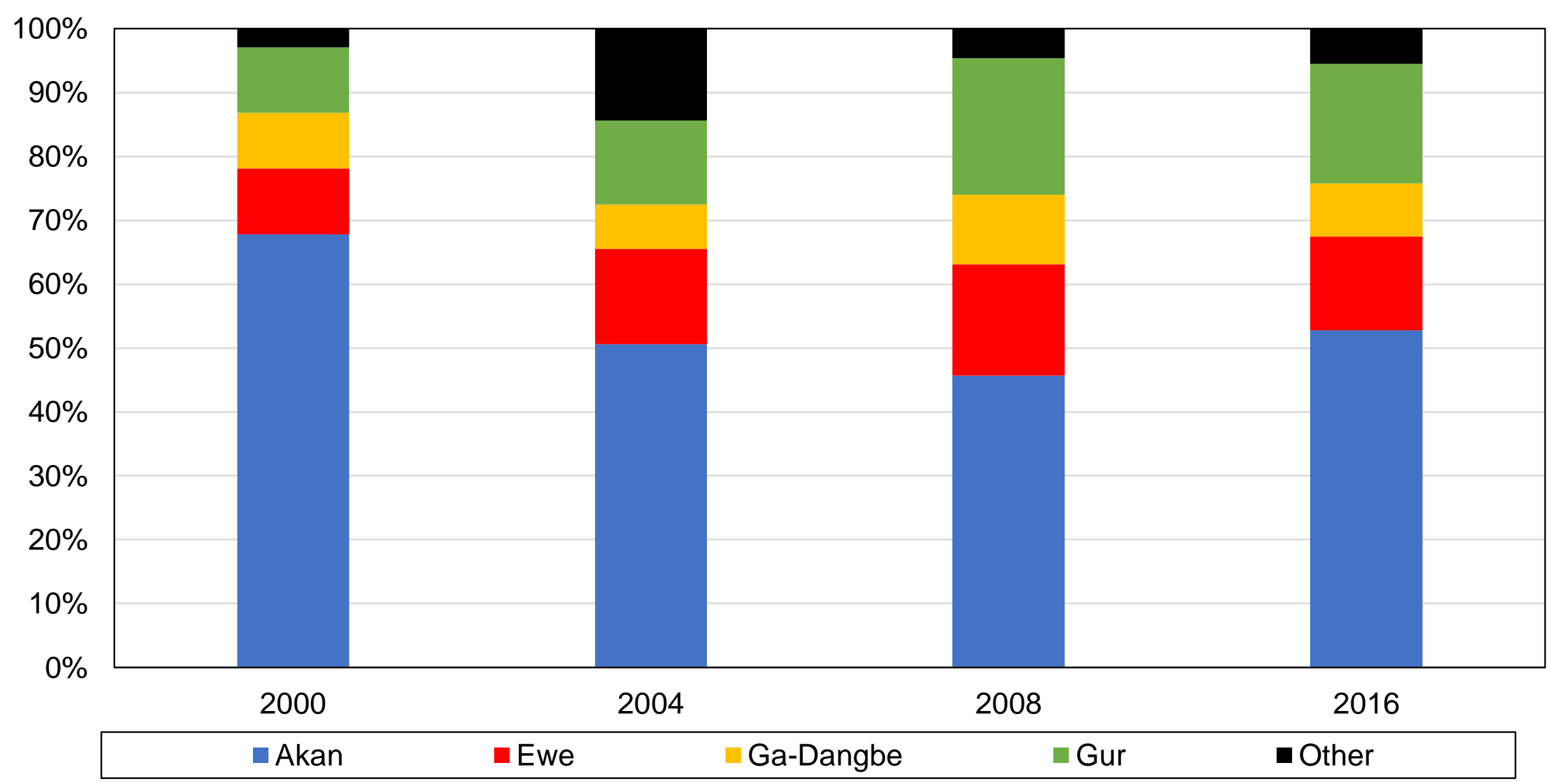

Source: authors' computations using Afrobarometer surveys.

Note: the figure shows the distribution of linguistic affiliations in the adult population in Ghana and its evolution over time. 
Figure BA6 - The composition of the electorate by occupation

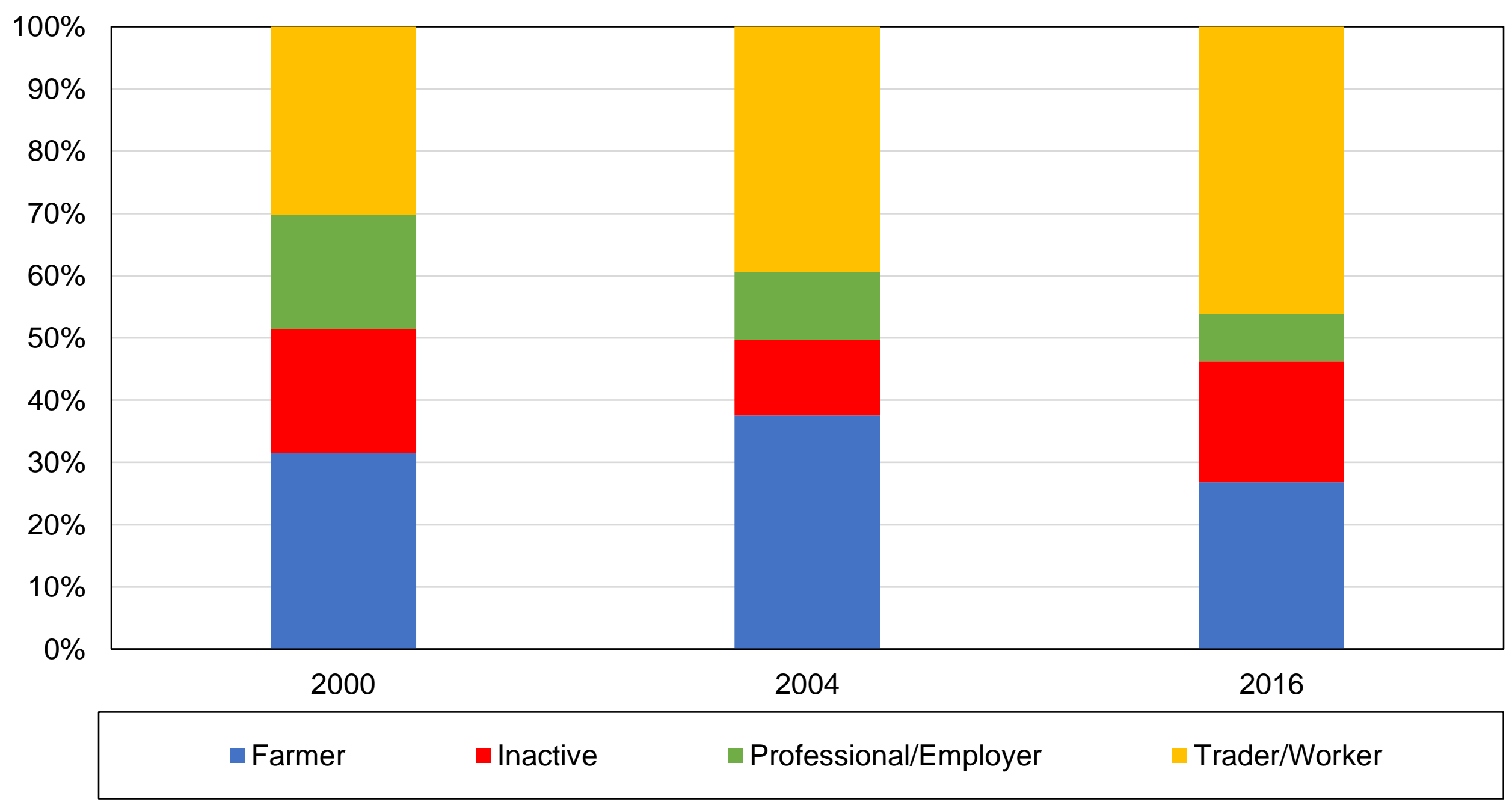

Source: authors' computations using Afrobarometer surveys.

Note: the figure shows the distribution of occupations in the adult population in Ghana and its evolution over time. 
Figure BA7 - Composition of education by language, 2000

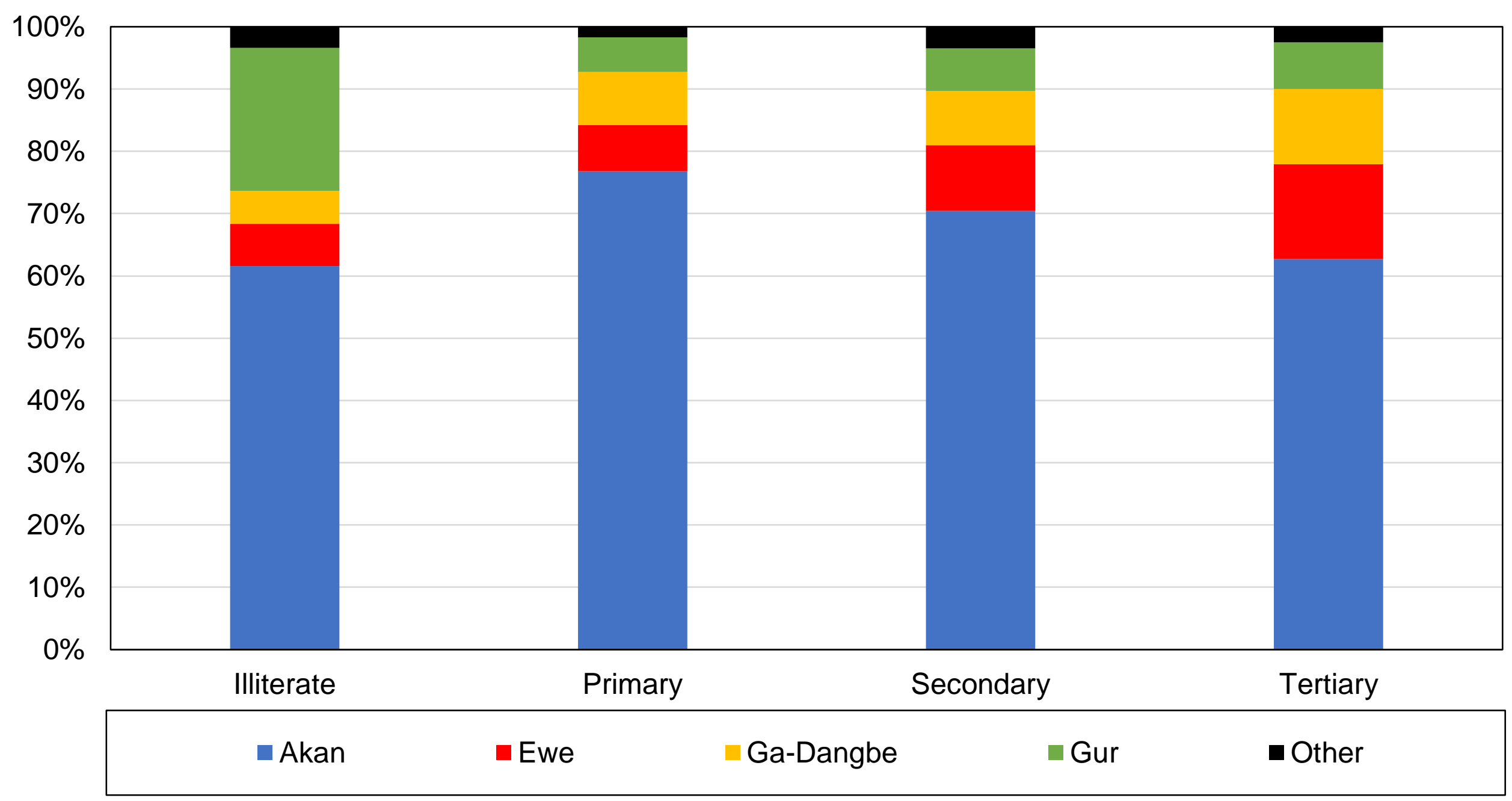

Source: authors' computations using Afrobarometer surveys.

Note: the figure shows composition of education groups by language of the population in Ghana in 2000. 
Figure BA8 - Composition of education by language, 2016

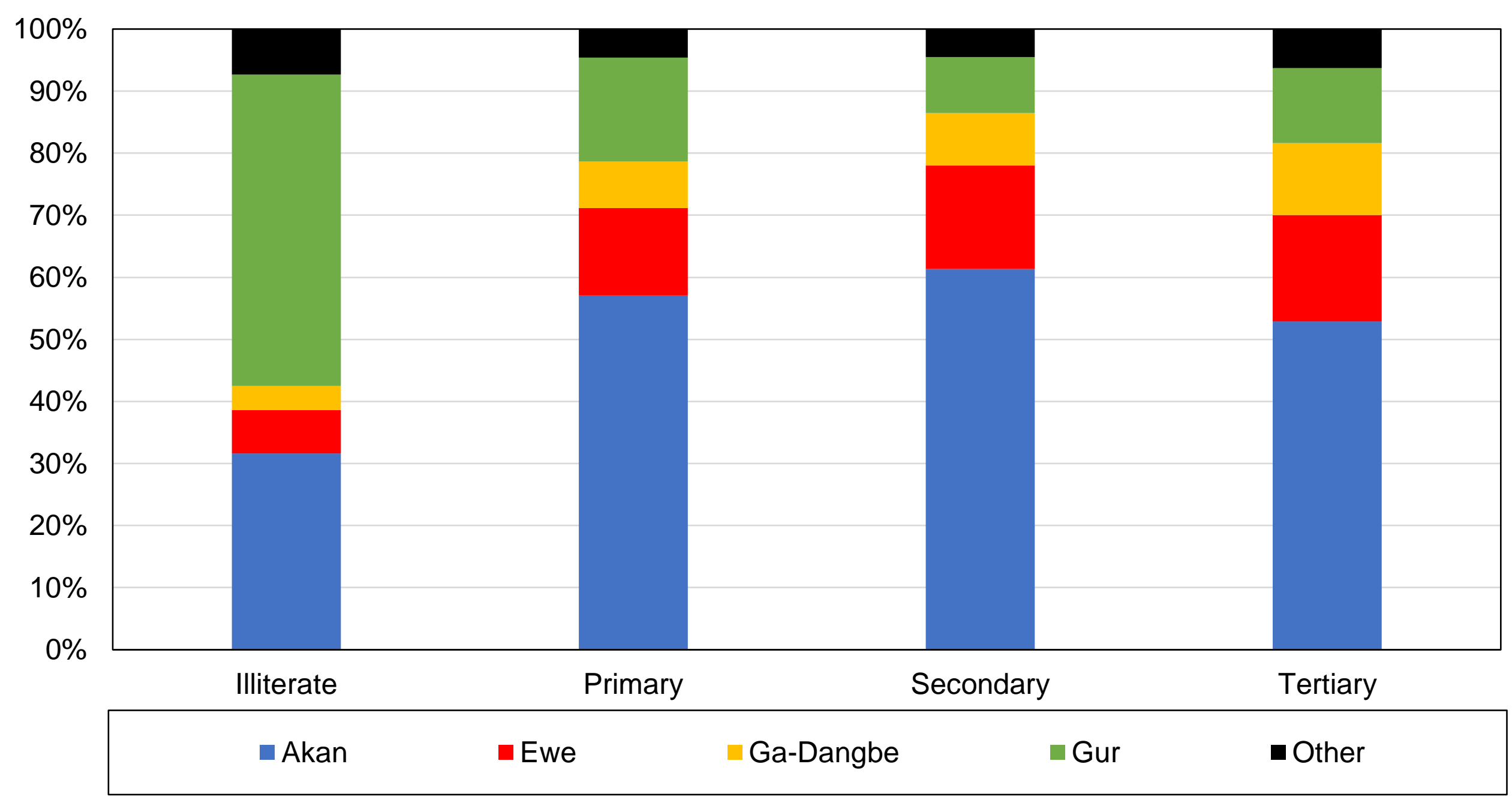

Source: authors' computations using Afrobarometer surveys.

Note: the figure the composition of education groups by language of the population in Ghana in 2016. 
Figure BA9 - Occupational composition of education, 2000

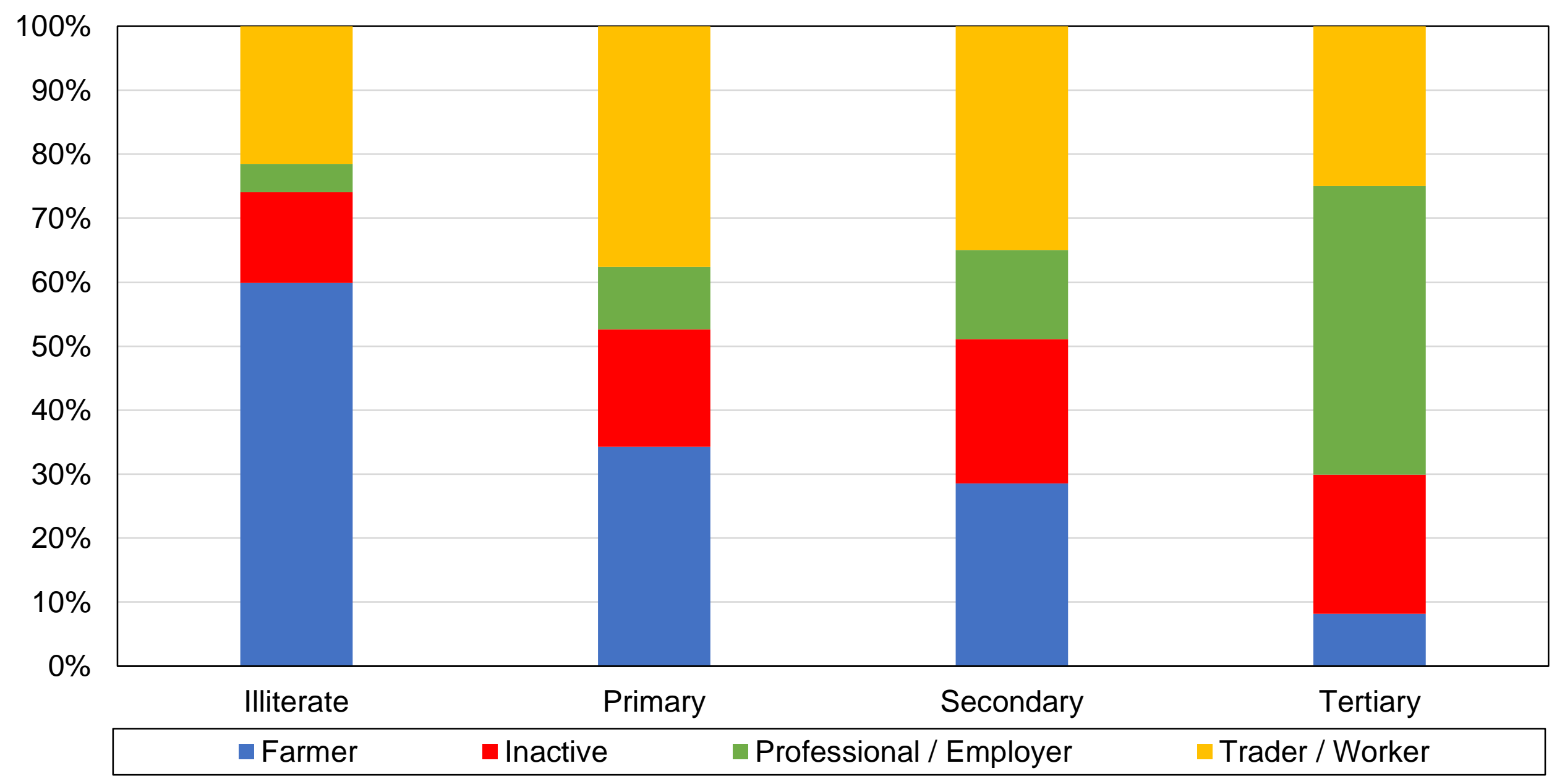

Source: authors' computations using Afrobarometer surveys.

Note: the figure shows the composition of education groups by occupation of the population in Ghana in 2000. 
Figure BA10 - Occupational composition of education, 2016

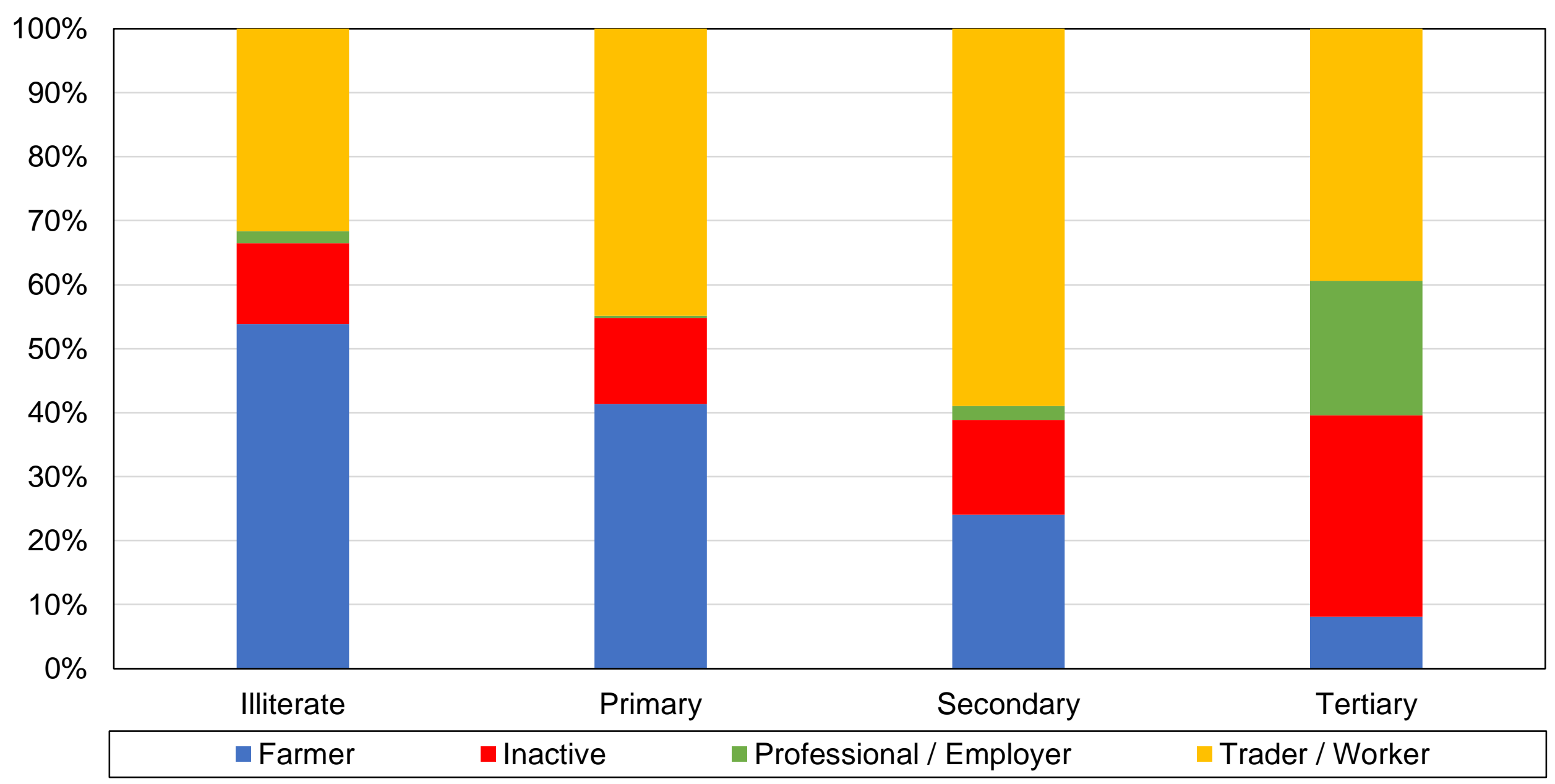

Source: authors' computations using Afrobarometer surveys.

Note: the figure shows the composition of education groups by occupation of the population in Ghana in 2016. 
Figure BA11 - Rural-urban composition of education, 2000

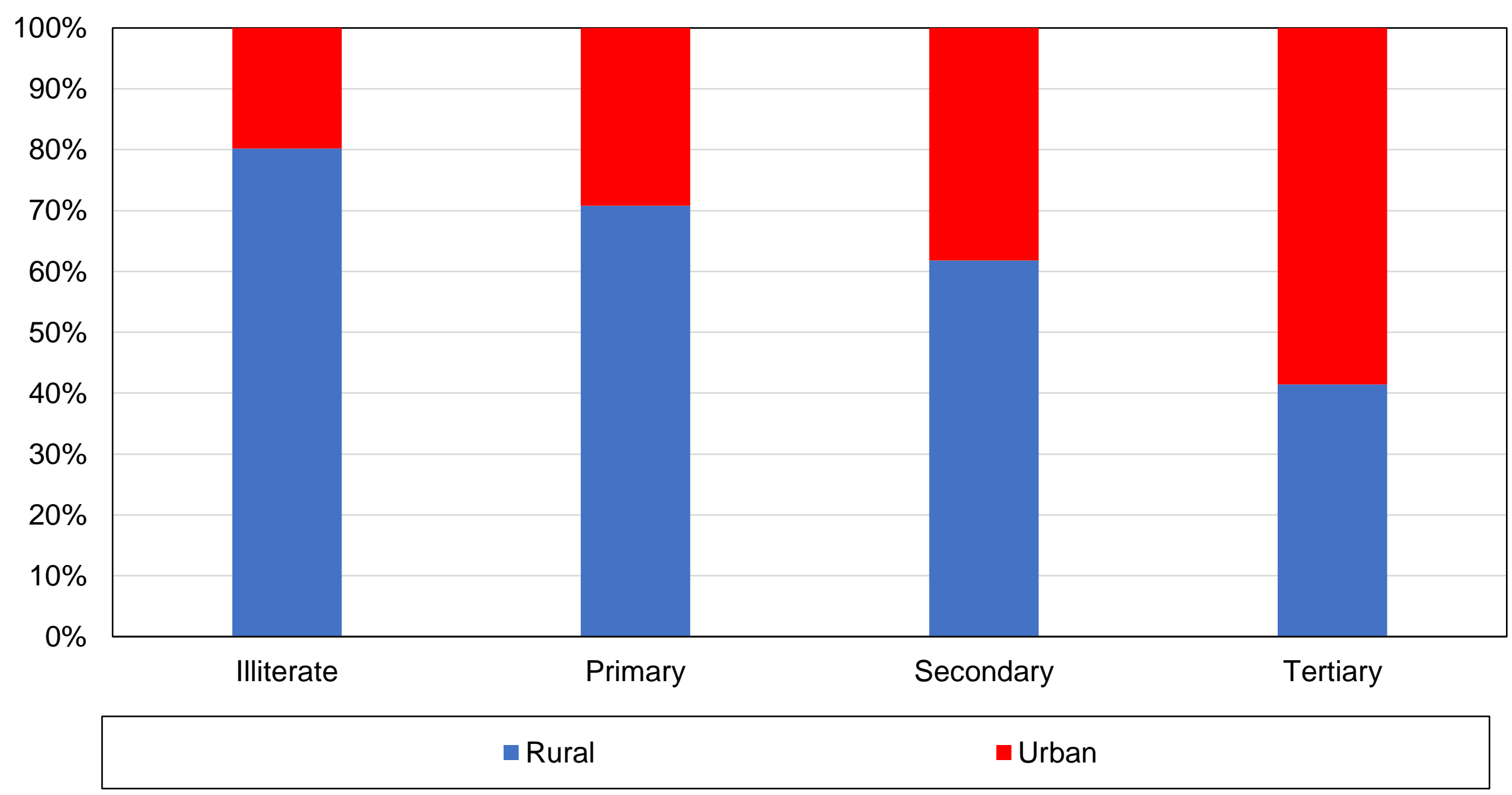

Source: authors' computations using Afrobarometer surveys.

Note: the figure shows the distribution of education groups by location in 2000 . 
Figure BA12 - Rural-urban composition of education, 2016

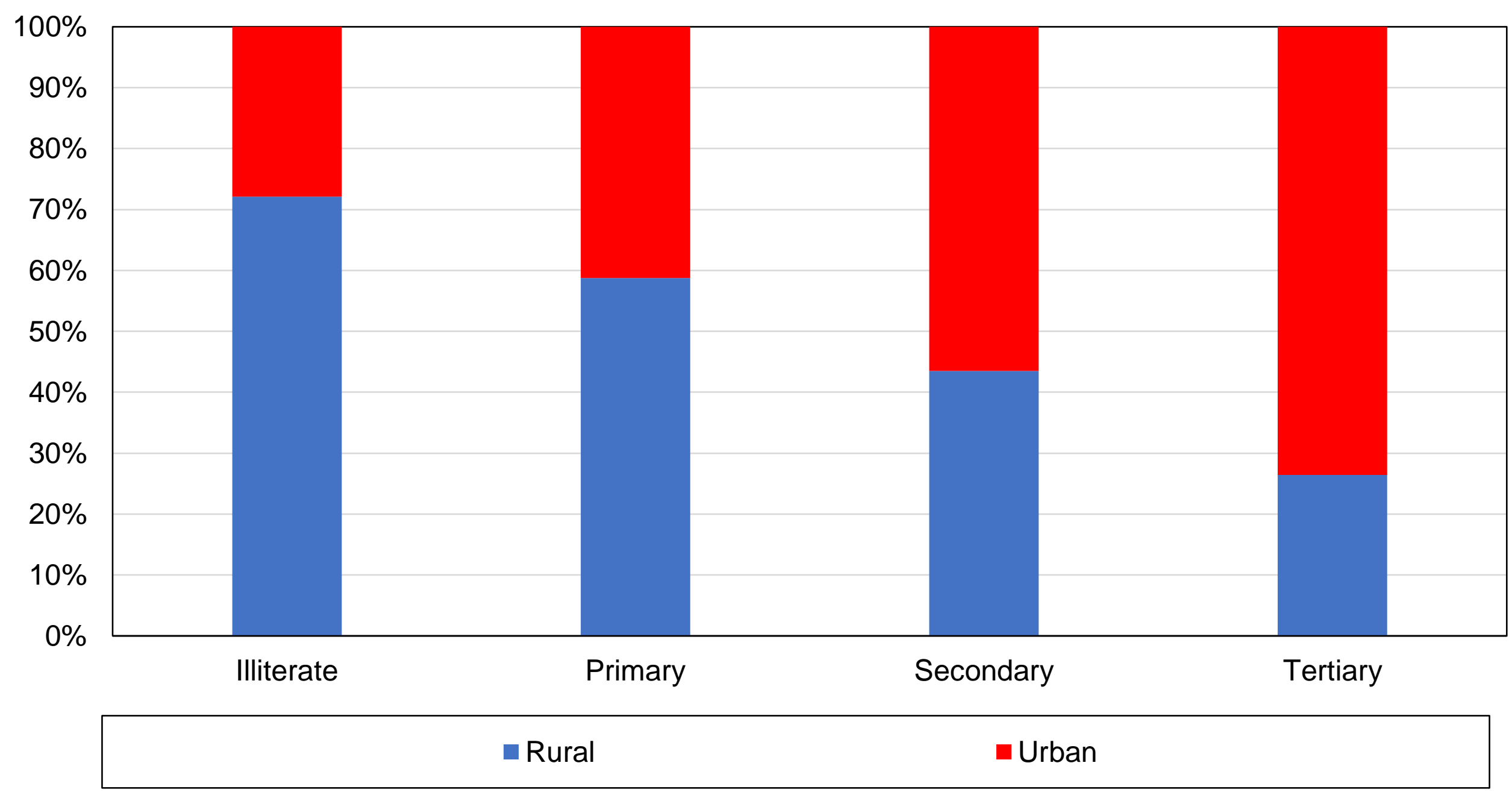

Source: authors' computations using Afrobarometer surveys.

Note: the figure shows the distribution of education groups by location in 2016 . 
Figure BA13 - Composition of education by region, 2004

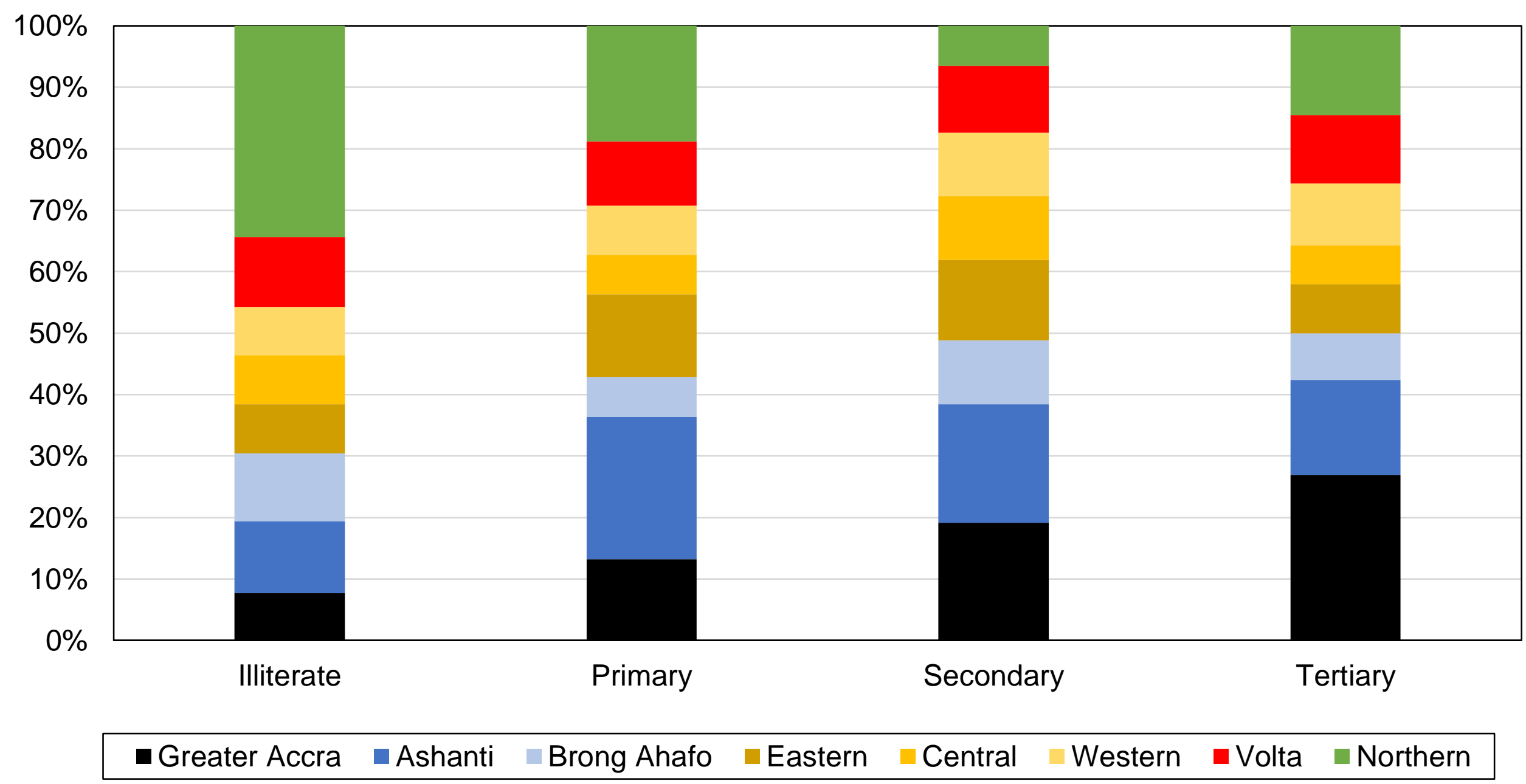

Source: authors' computations using Afrobarometer surveys.

Note: the figure shows the composition of education groups by region in Ghana in 2004. 
Figure BA14 - Composition of education by region, 2016

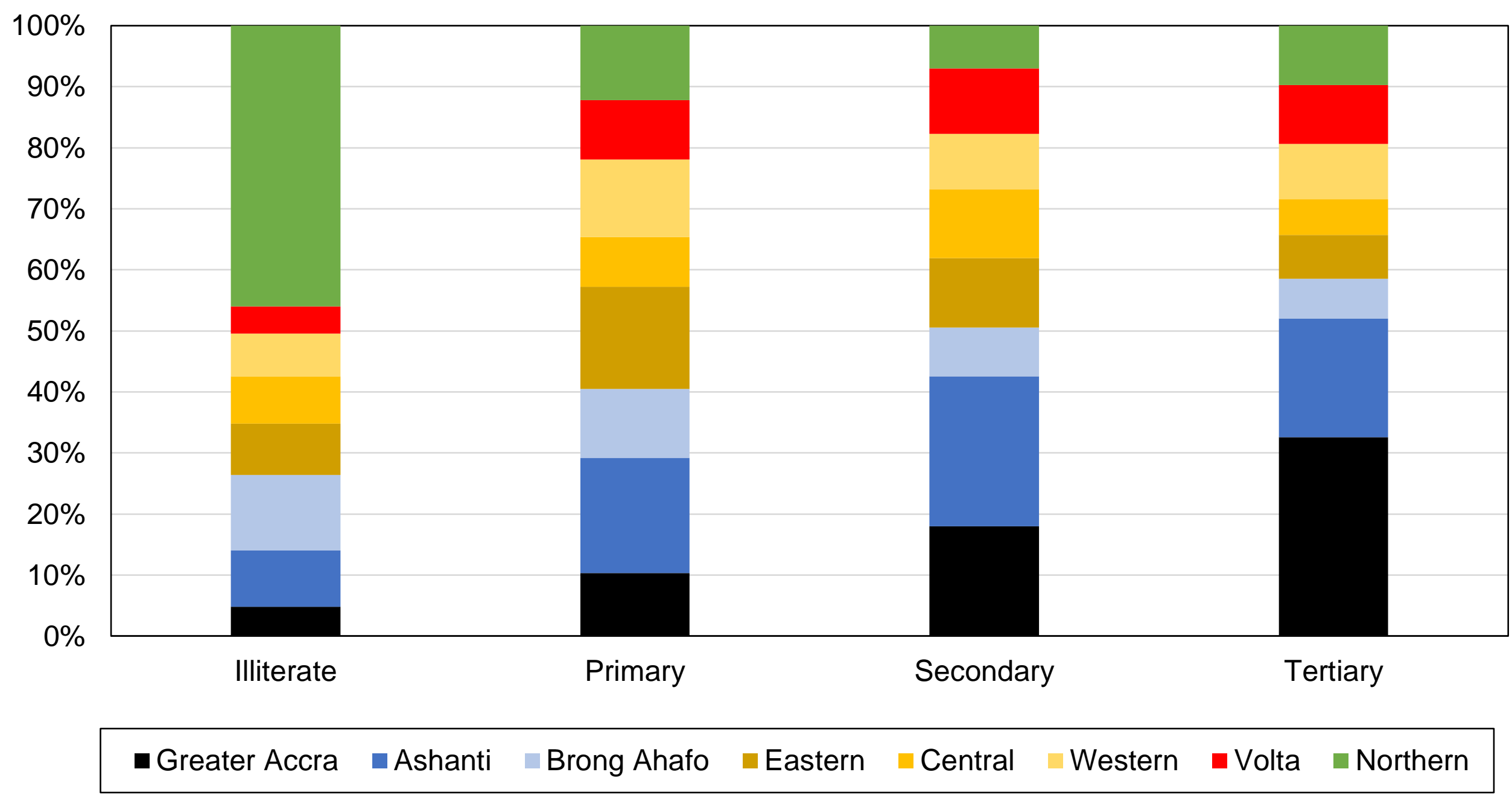

Source: authors' computations using Afrobarometer surveys.

Note: the figure shows the distribution of education groups by region in Ghana in 2016. 
Figure BA15 - Linguistic composition of regions, 2004

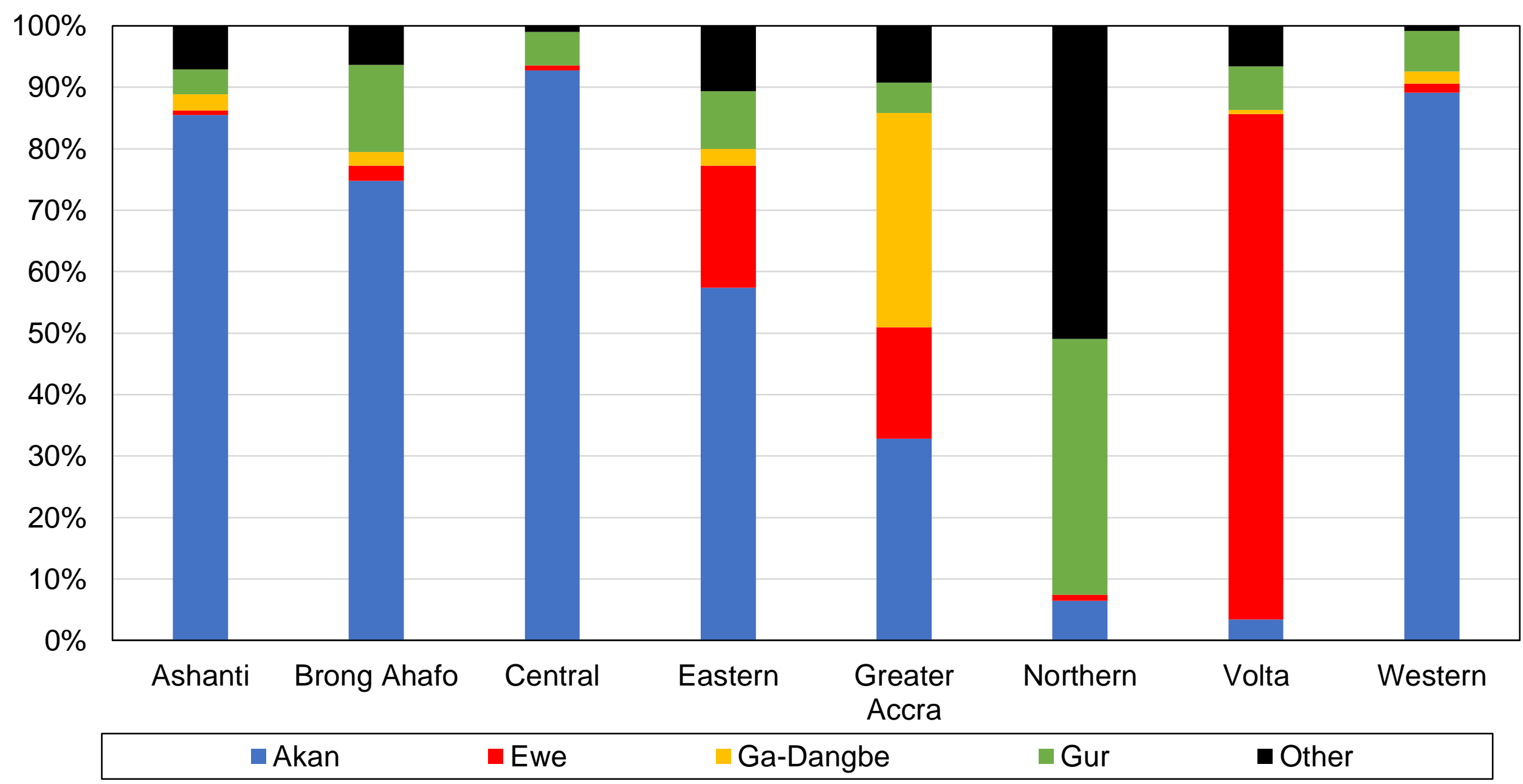

Source: authors' computations using Afrobarometer surveys.

Note: the figure shows the distribution of languages among regions in Ghana in 2004. 
Figure BA16 - Linguistic composition of regions, 2016

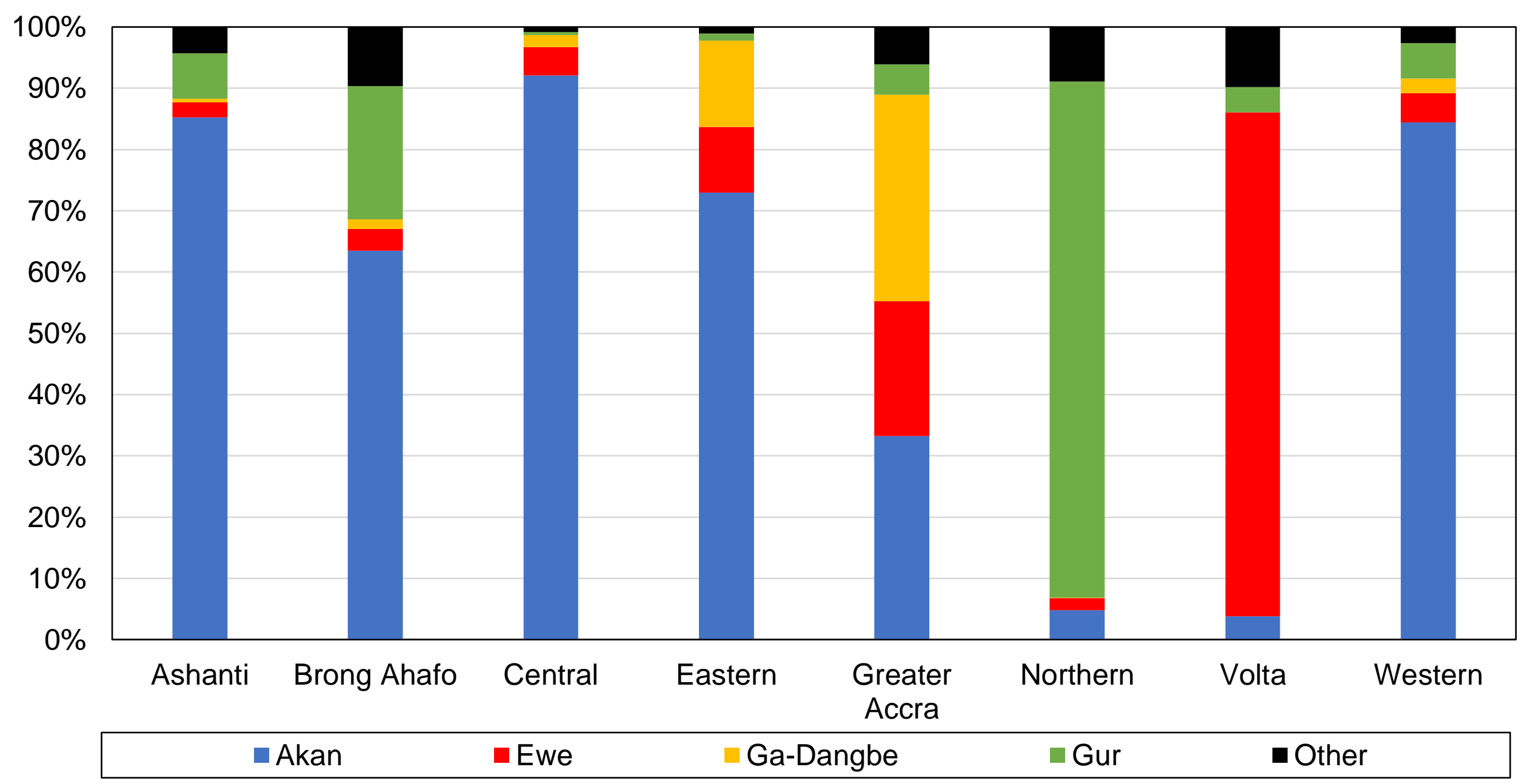

Source: authors' computations using Afrobarometer surveys.

Note: the figure shows the distribution of languages among regions in Ghana in 2016. 
Figure BB1 - Vote for NDC by education level

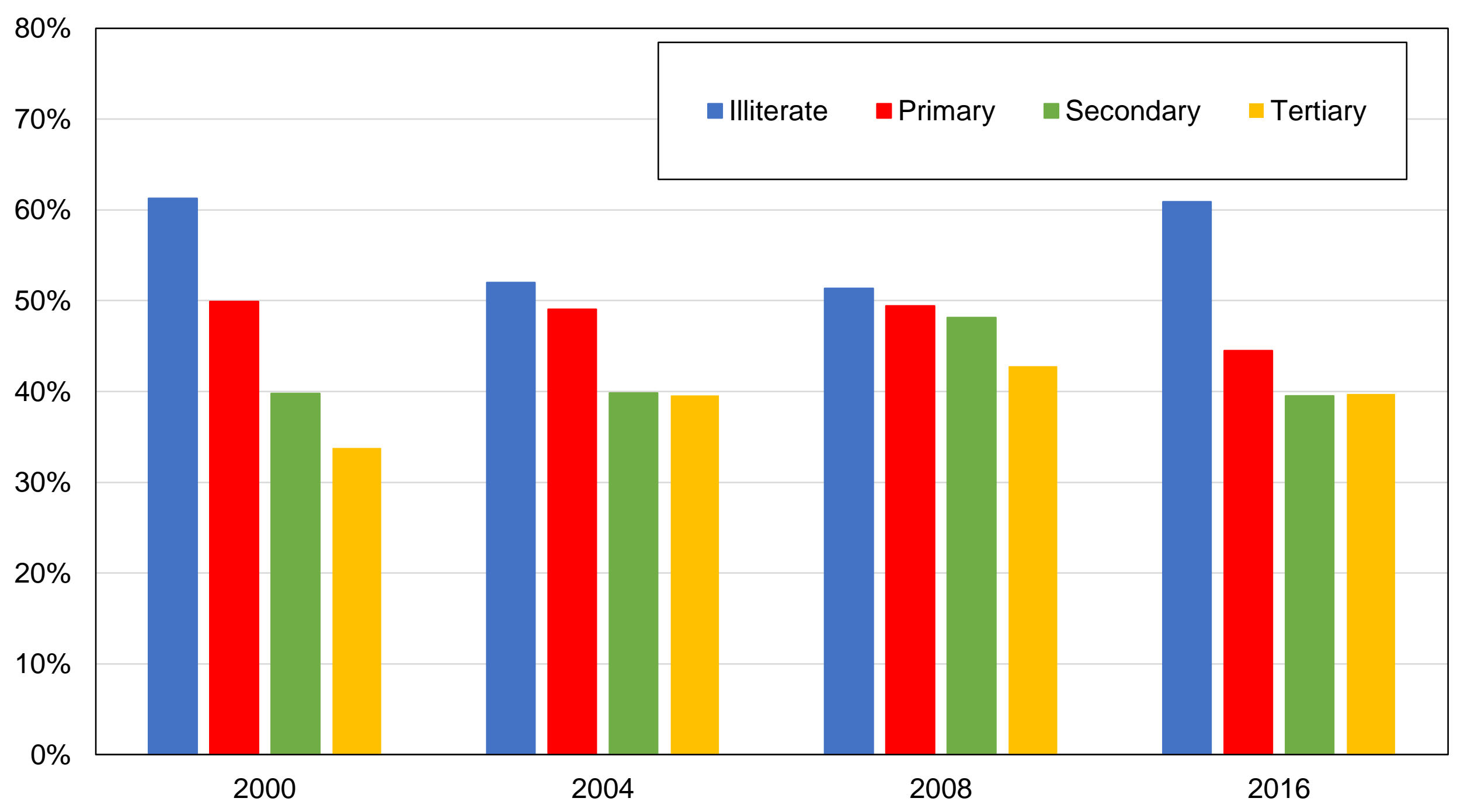

Source: authors' computations using Afrobarometer surveys.

Note: the figure shows the share of votes received by the NDC by education level. 
Figure BB2 - Vote for NDC by education group

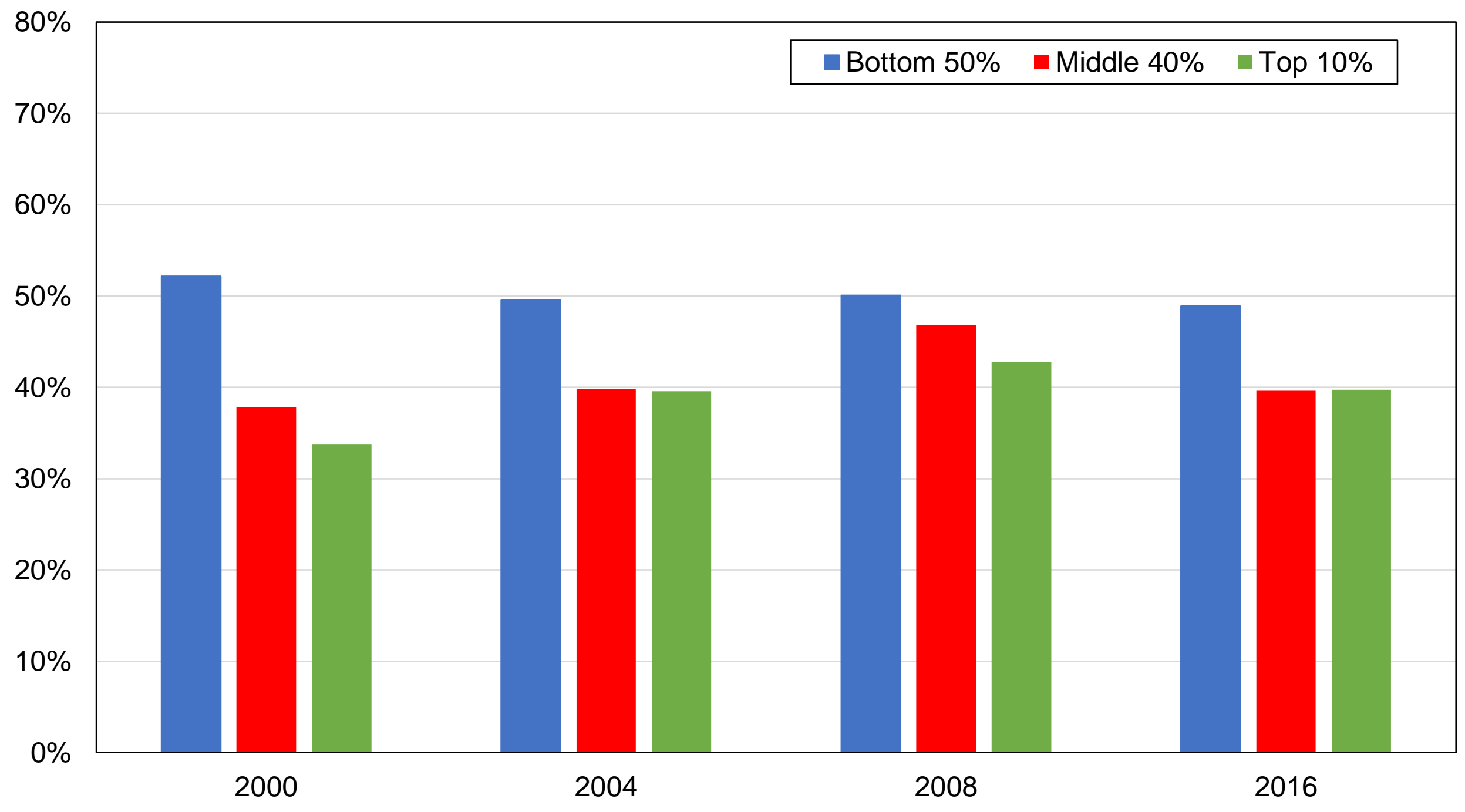

Source: authors' computations using Afrobarometer surveys.

Note: the figure shows the share of votes received by NDC by education group. 
Figure BB3 - Vote for NDC by location

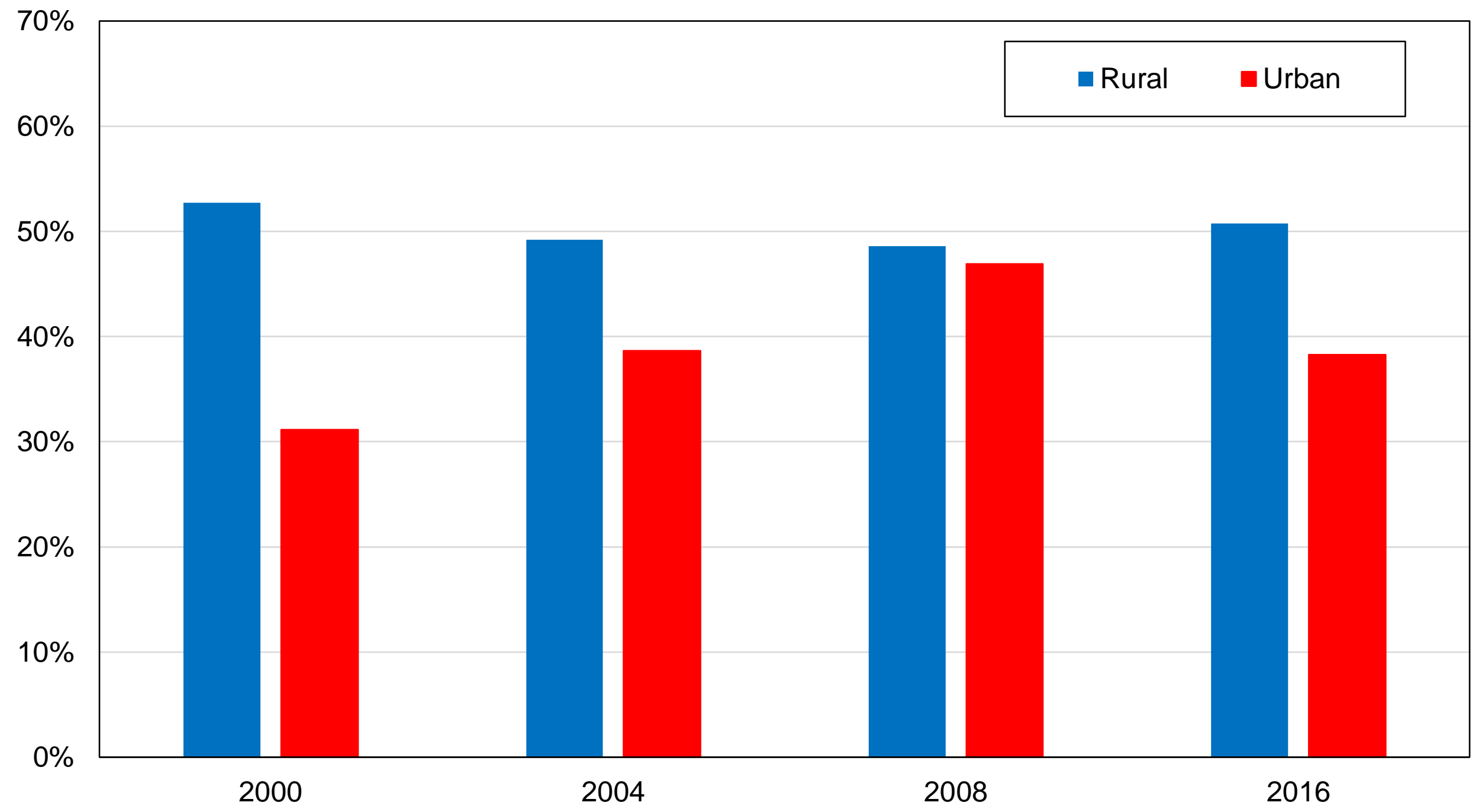

Source: authors' computations using Afrobarometer surveys.

Note: the figure shows the share of votes received by NDC by location. 
Figure BB4 - Vote for NDC by region

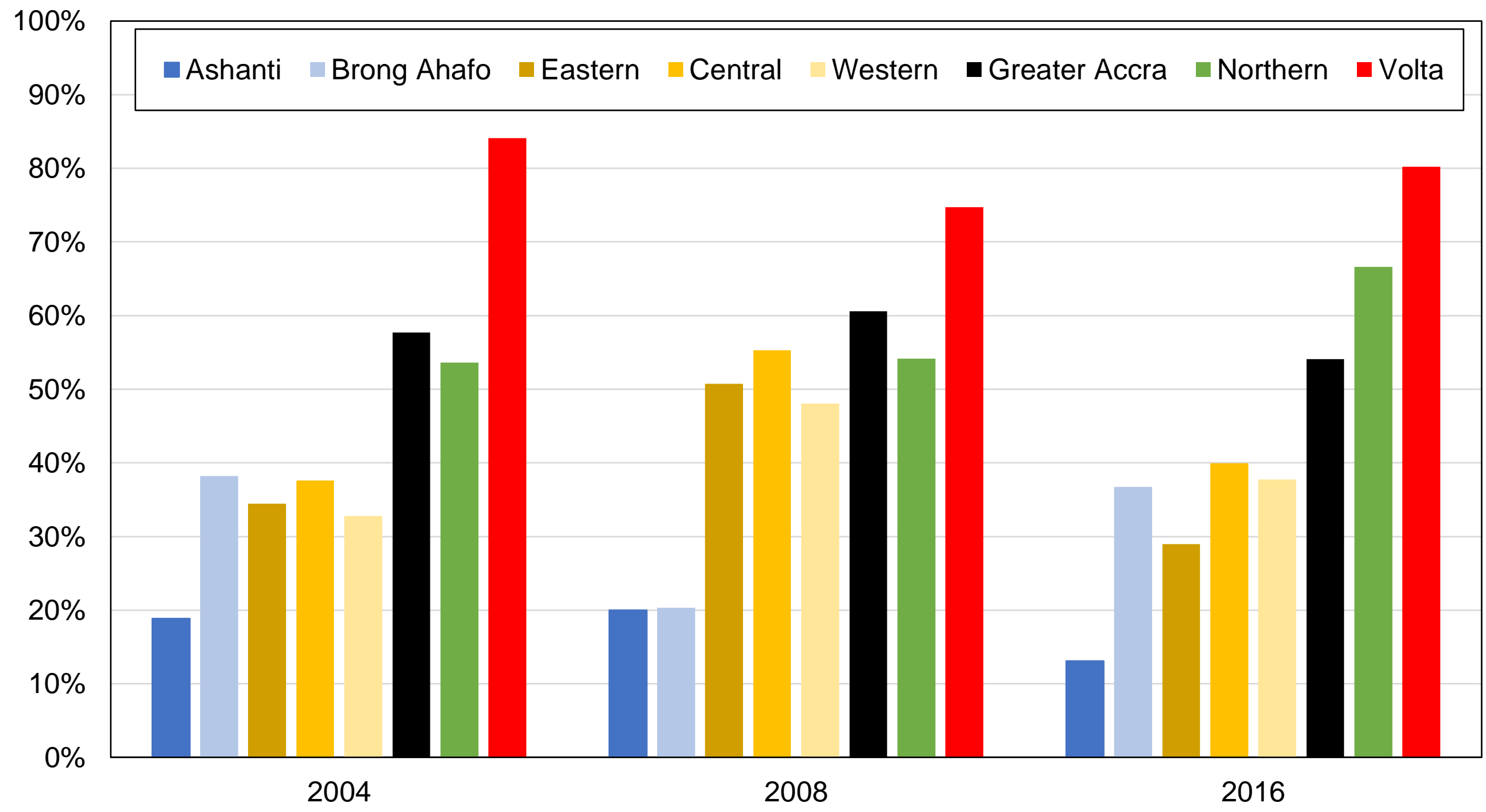

Source: authors' computations using Afrobarometer surveys.

Note: the figure shows the share of votes received by NDC by region. 
Figure BB5 - Vote for NDC by language

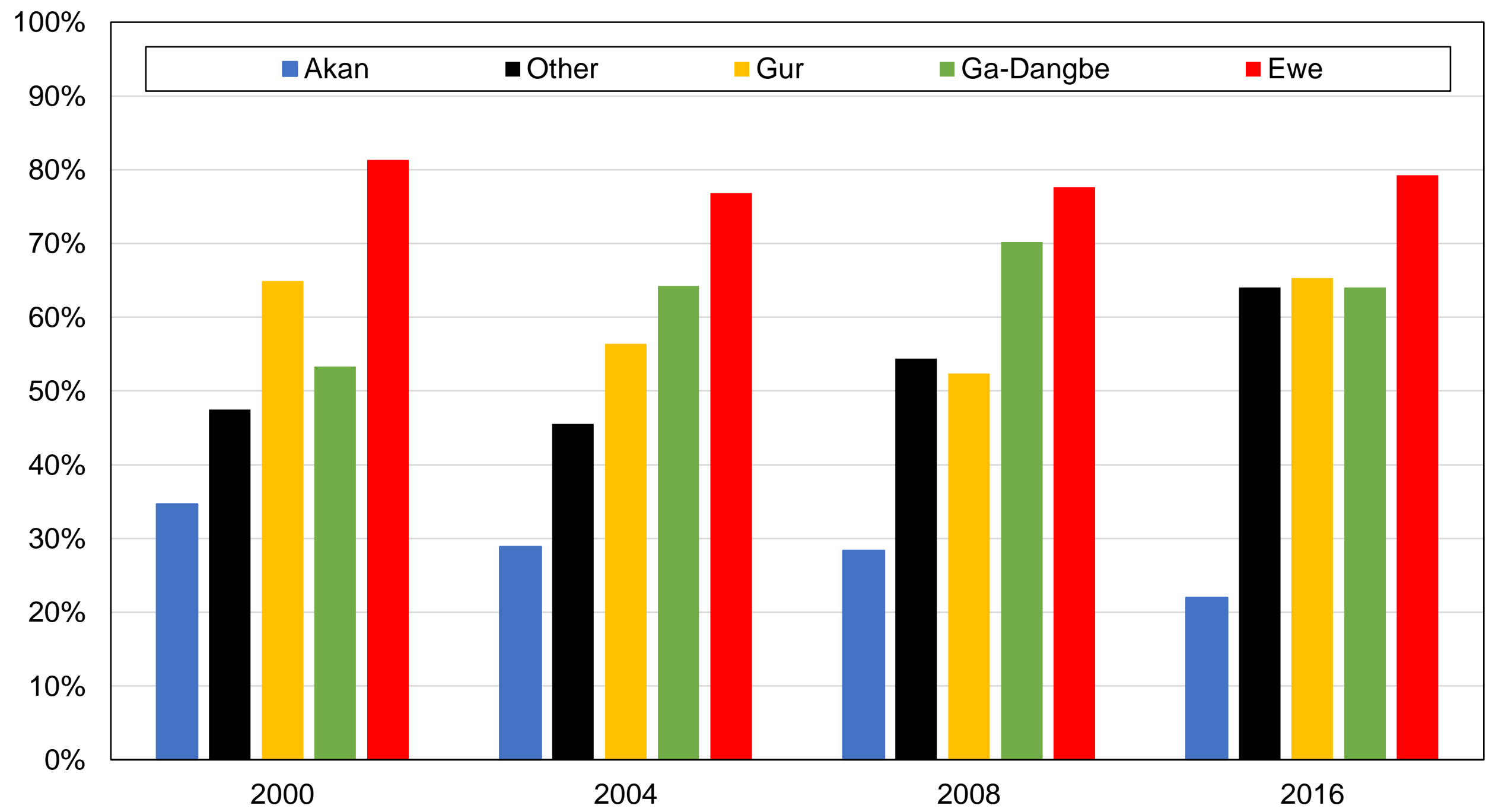

Source: authors' computations using Afrobarometer surveys.

Note: the figure shows the share of votes received by NDC by language. 
Figure BB6 - Vote for NDC by age group

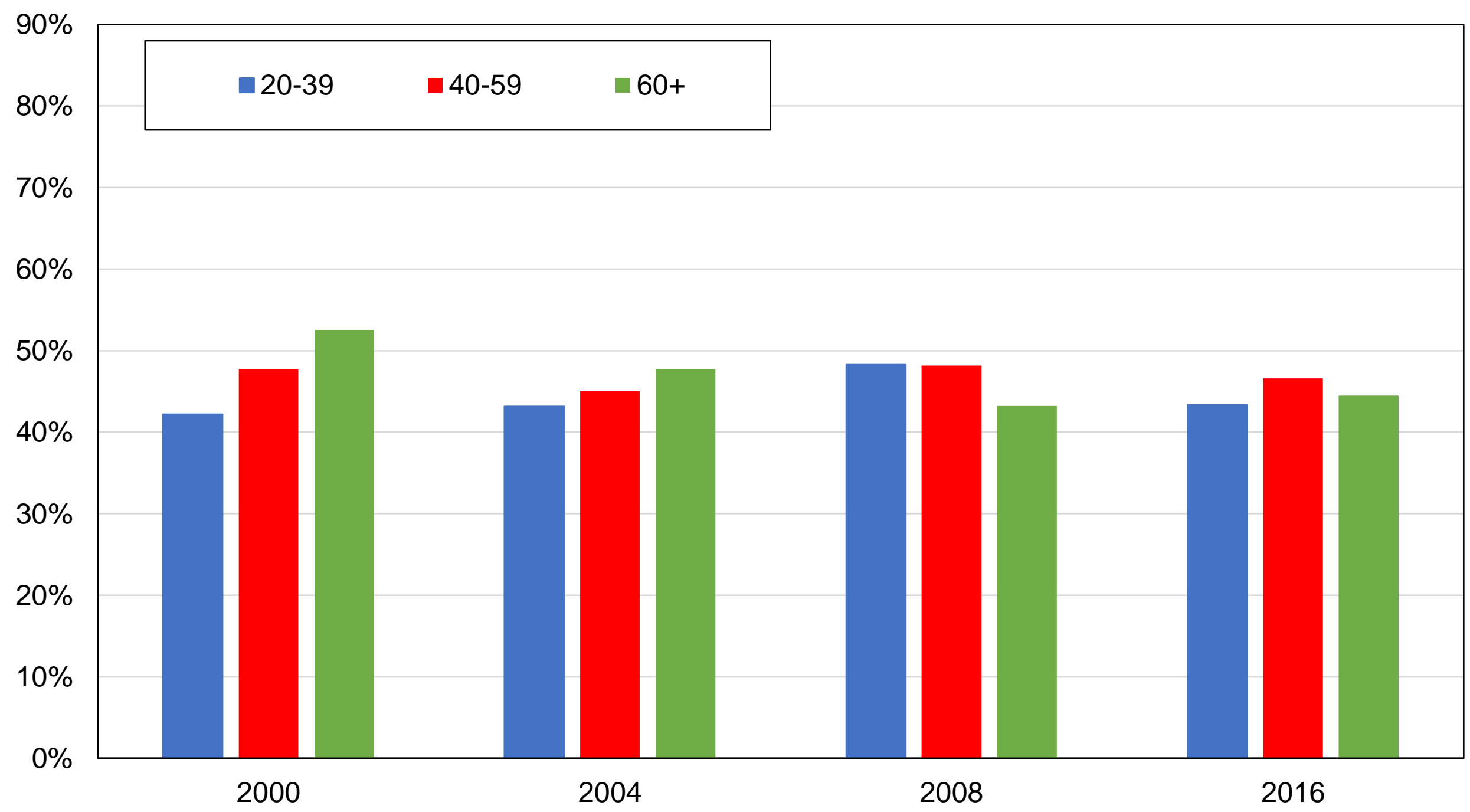

Source: authors' computations using Afrobarometer surveys.

Note: the figure shows the share of votes received by NDC by age group. 
Figure BB7 - Vote for NDC by gender

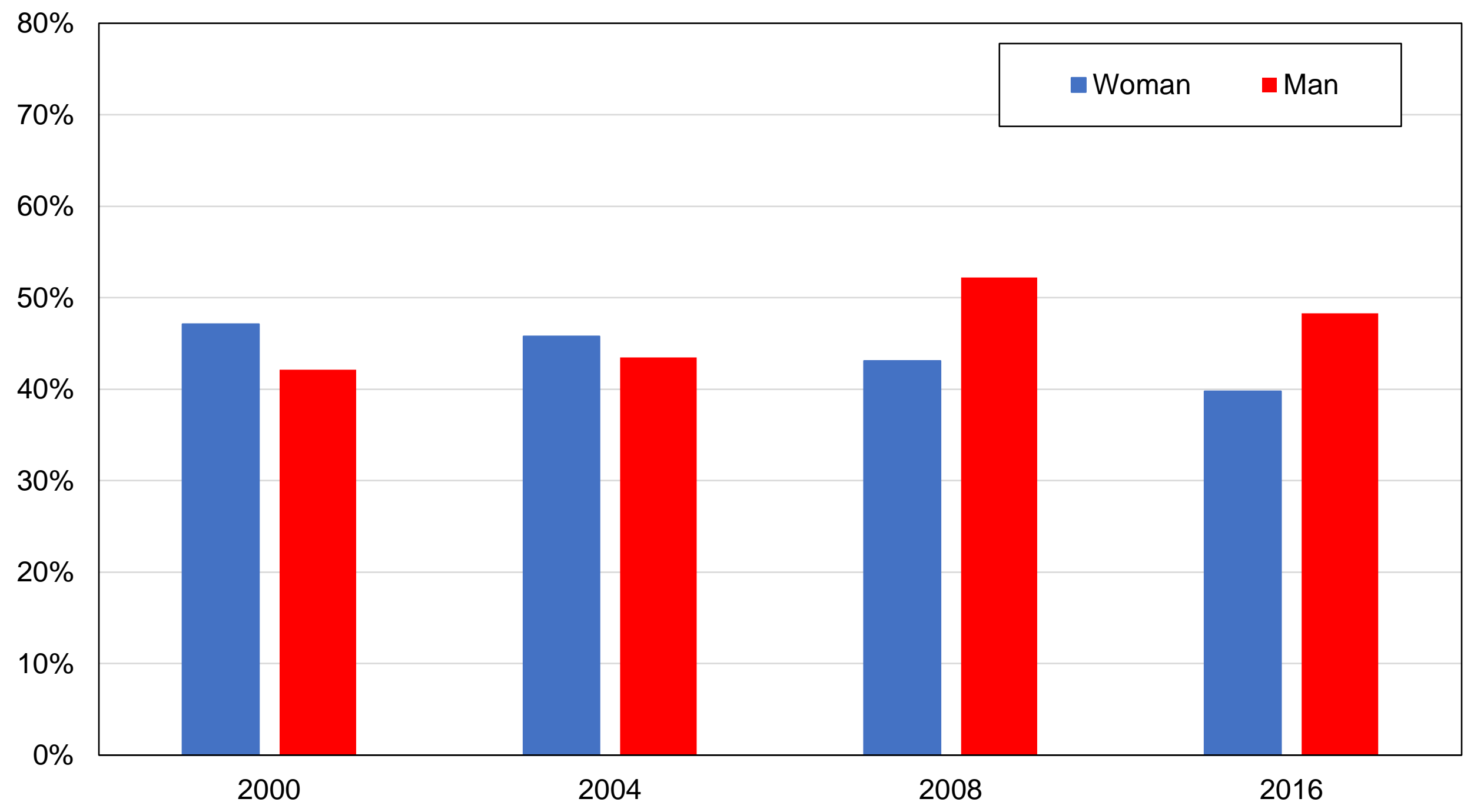

Source: authors' computations using Afrobarometer surveys.

Note: the figure shows the share of votes received by NDC by gender. 
Figure BB8 - Vote for NDC by religion

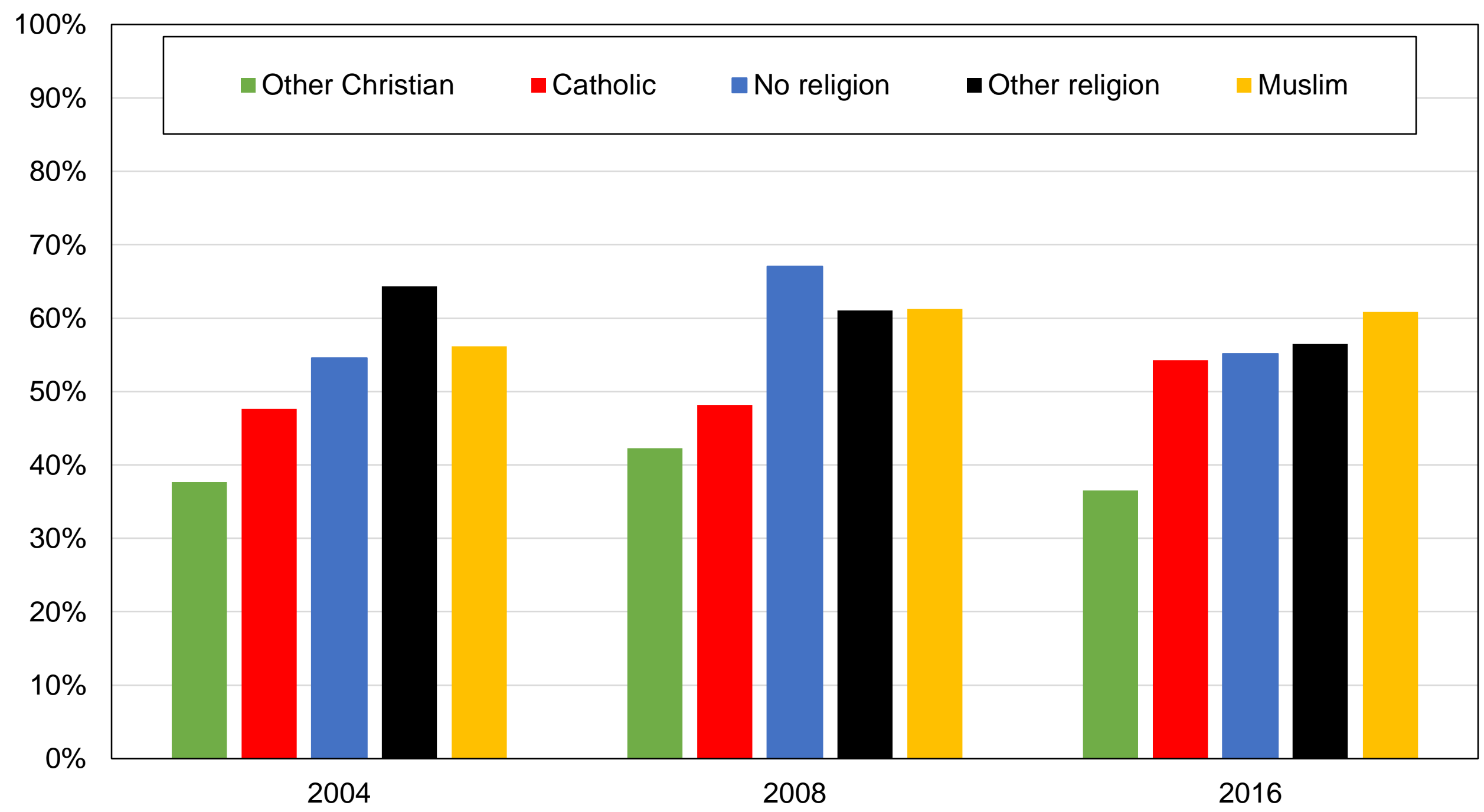

Source: authors' computations using Afrobarometer surveys.

Note: the figure shows the share of votes received by NDC by religious affiliation. 
Figure BB9 - Vote for NDC by employment status

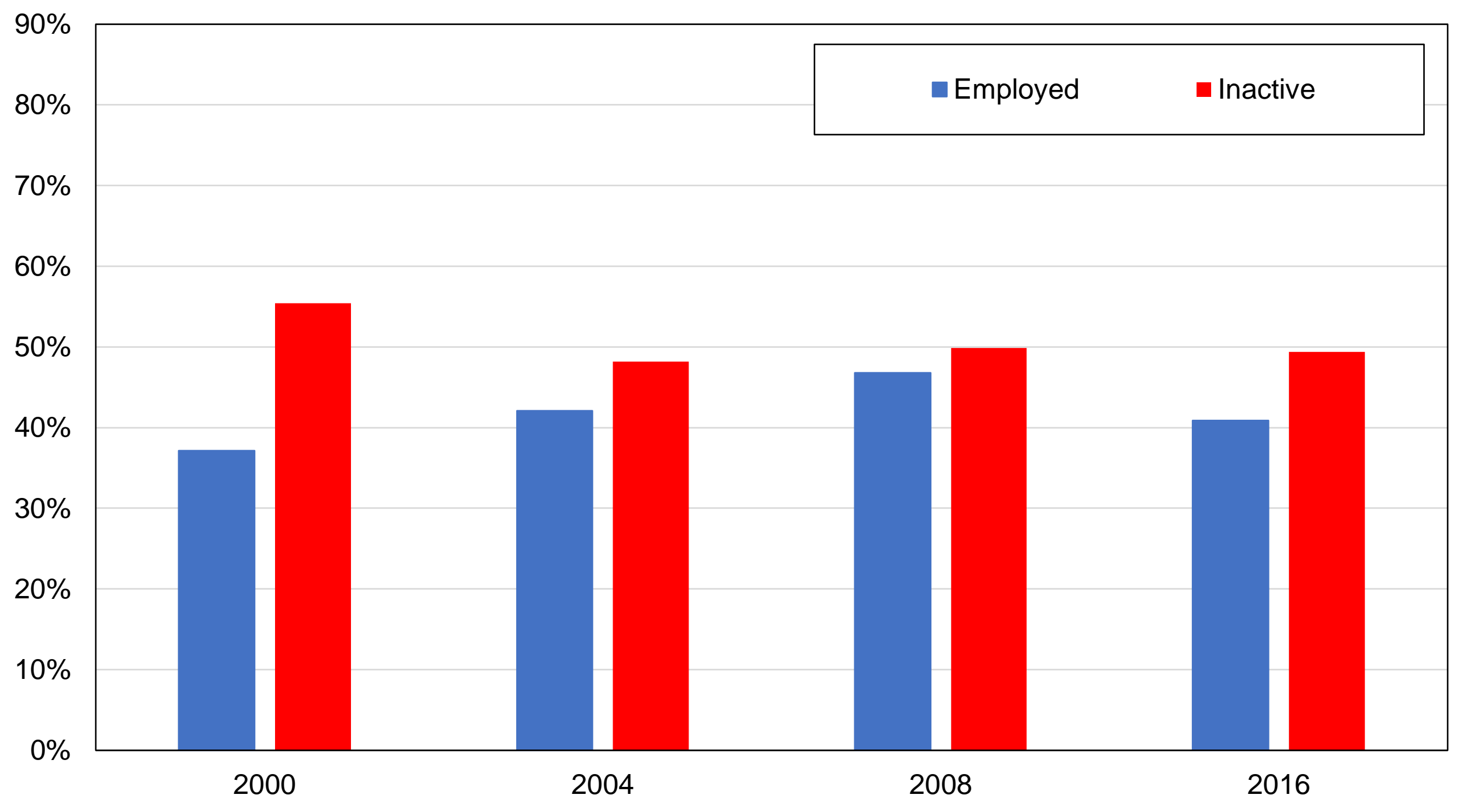

Source: authors' computations using Afrobarometer surveys.

Note: the figure shows the share of votes received by NDC by employment status. 
Figure BB10 - Vote for NDC by occupation

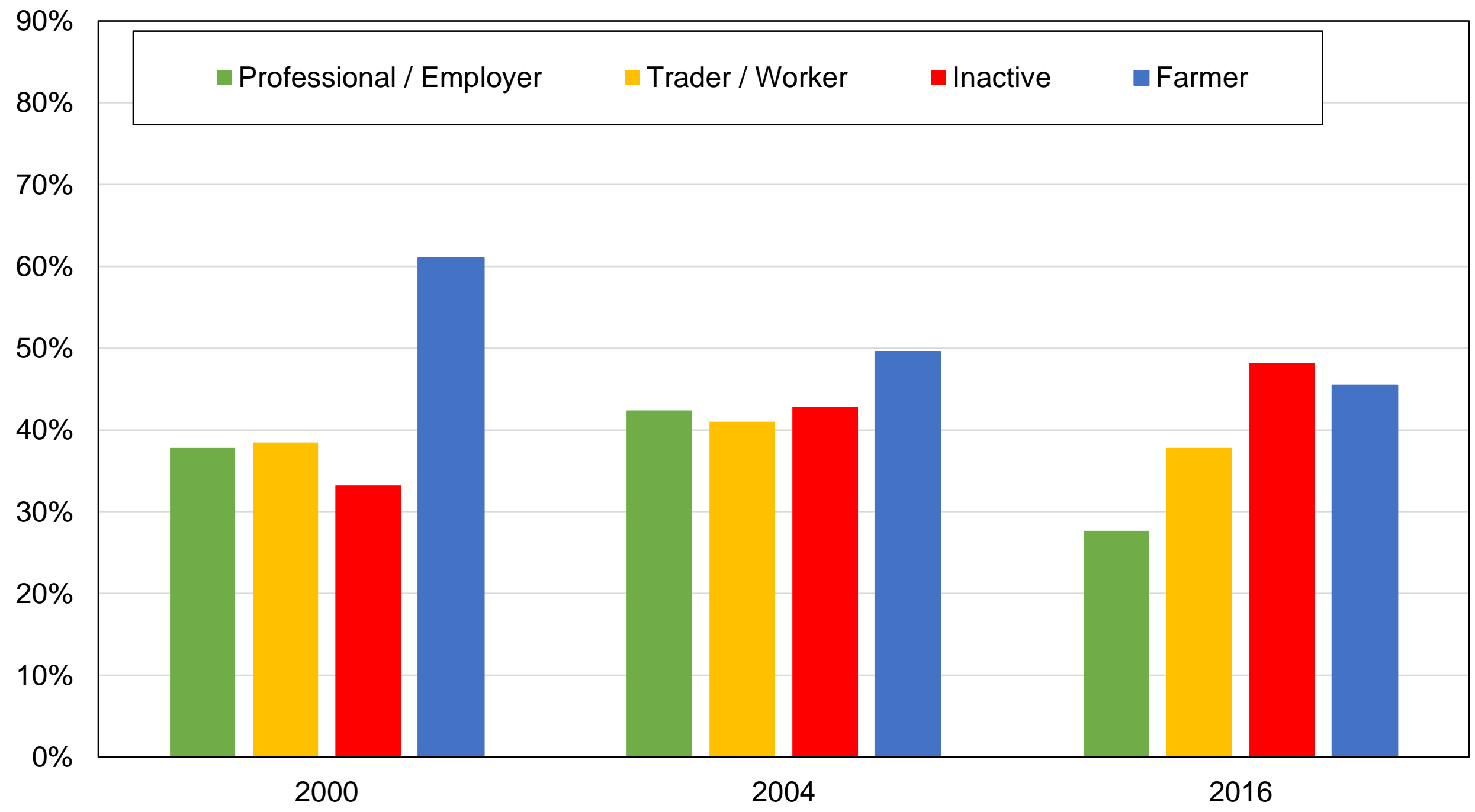

Source: authors' computations using Afrobarometer surveys.

Note: the figure shows the share of votes received by NDC by occupation. 


\section{Figure BC1 - Vote for NDC among highest-educated voters}

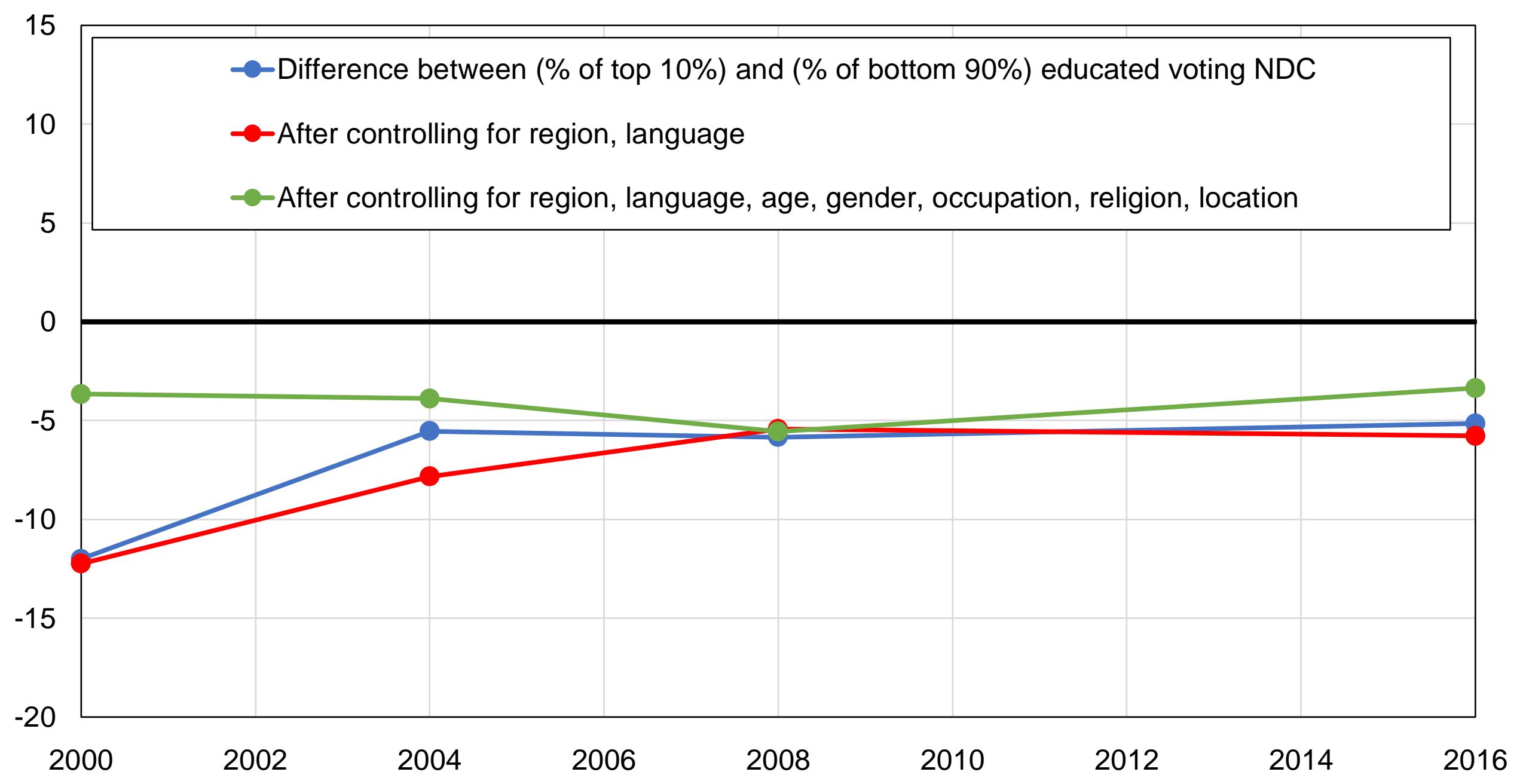

Source: authors' computations using Afrobarometer surveys.

Note: the figure shows the difference between the share of top $10 \%$ educated voters and the share of other voters voting for NDC, before and after controlling for other variables. 
Figure BC2 - Vote for National Democratic Congress among highereducated voters

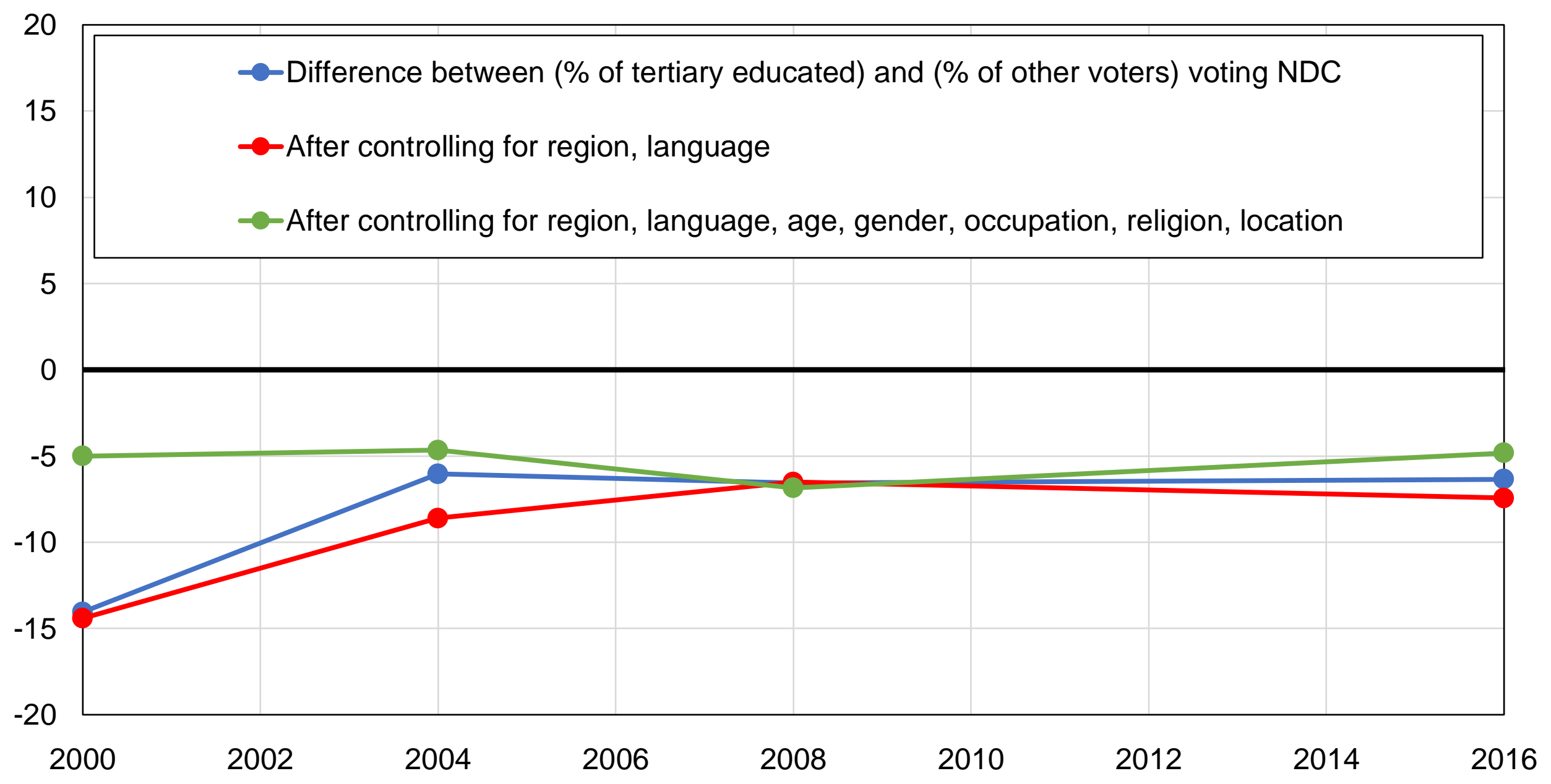

Source: authors' computations using Afrobarometer surveys.

Note: the figure shows the difference between the share of tertiary-educated voters and the share of other voters voting for NDC, before and after controlling for other variables. 


\section{Figure BC3 - Vote for NDC among lowest-educated voters}

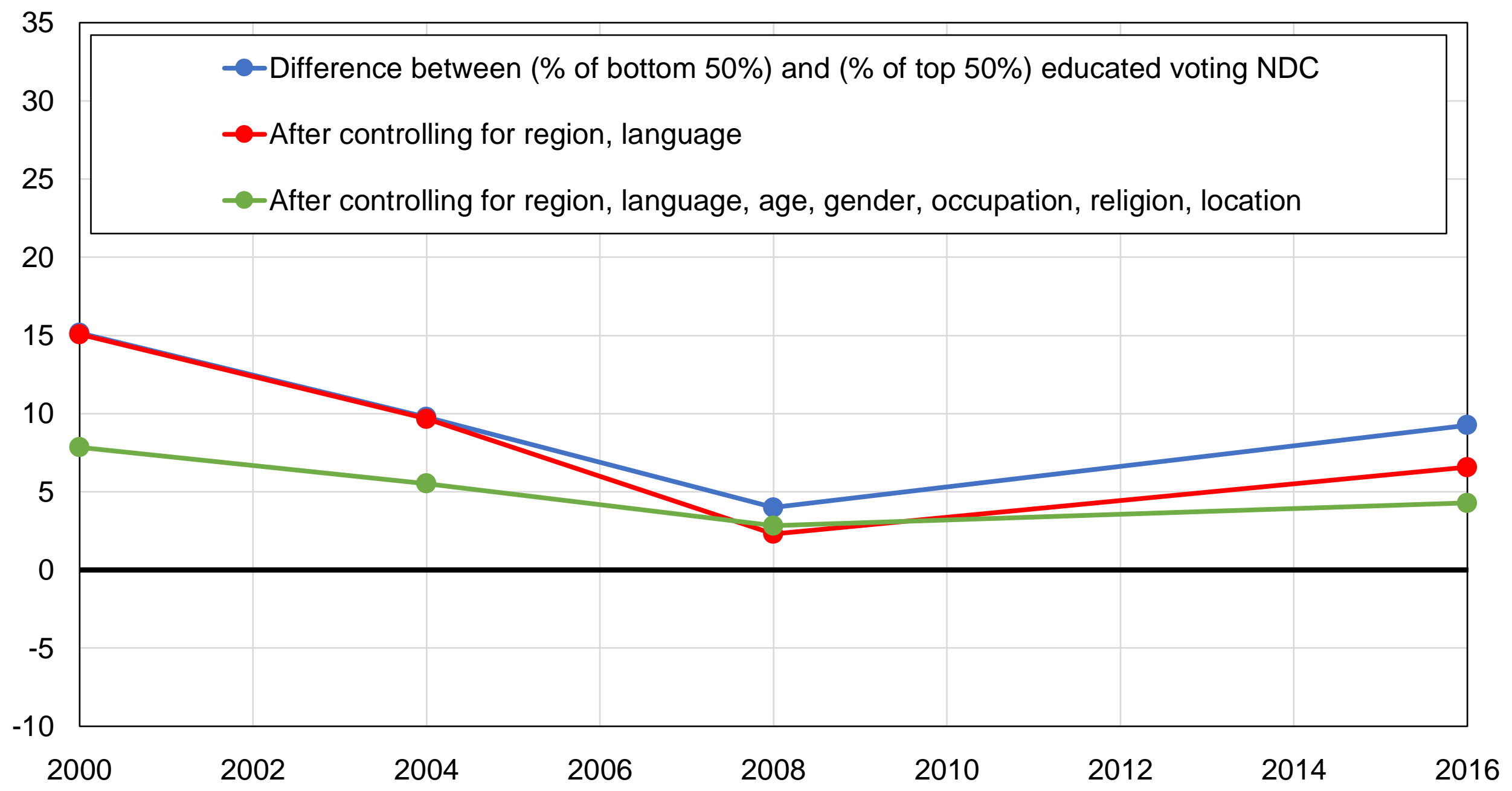

Source: authors' computations using Afrobarometer surveys.

Note: the figure shows the difference between the share of lowest $50 \%$ educated voters and the share of other voters voting for NDC, before and after controlling for other variables. 


\section{Figure BC4 - Vote for NDC among women}

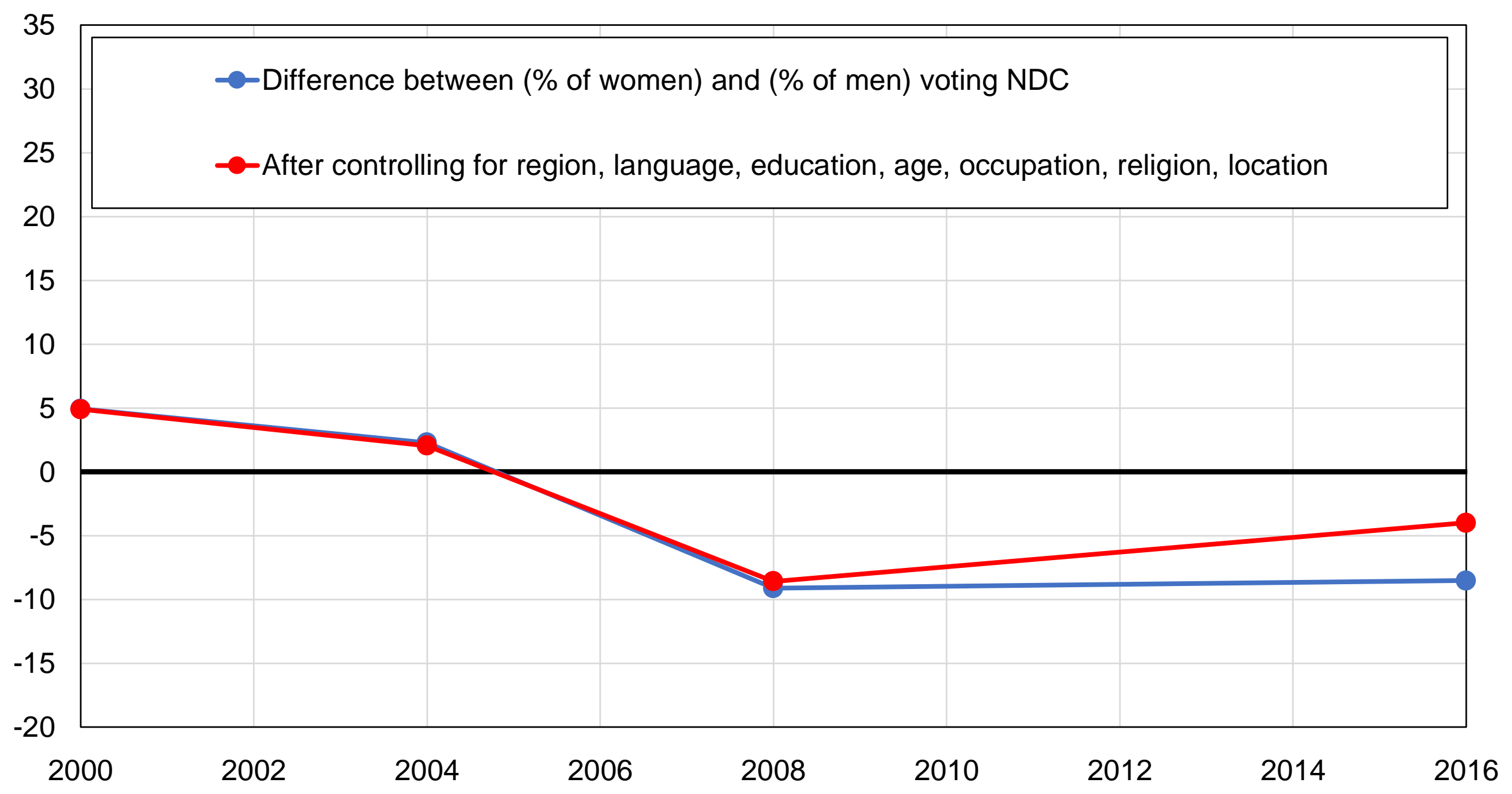

Source: authors' computations using Afrobarometer surveys.

Note: the figure shows the difference between the share of women and the share of men voting for NDC, before and after controlling for other variables. 


\section{Figure BC5 - Vote for NDC among rural areas}

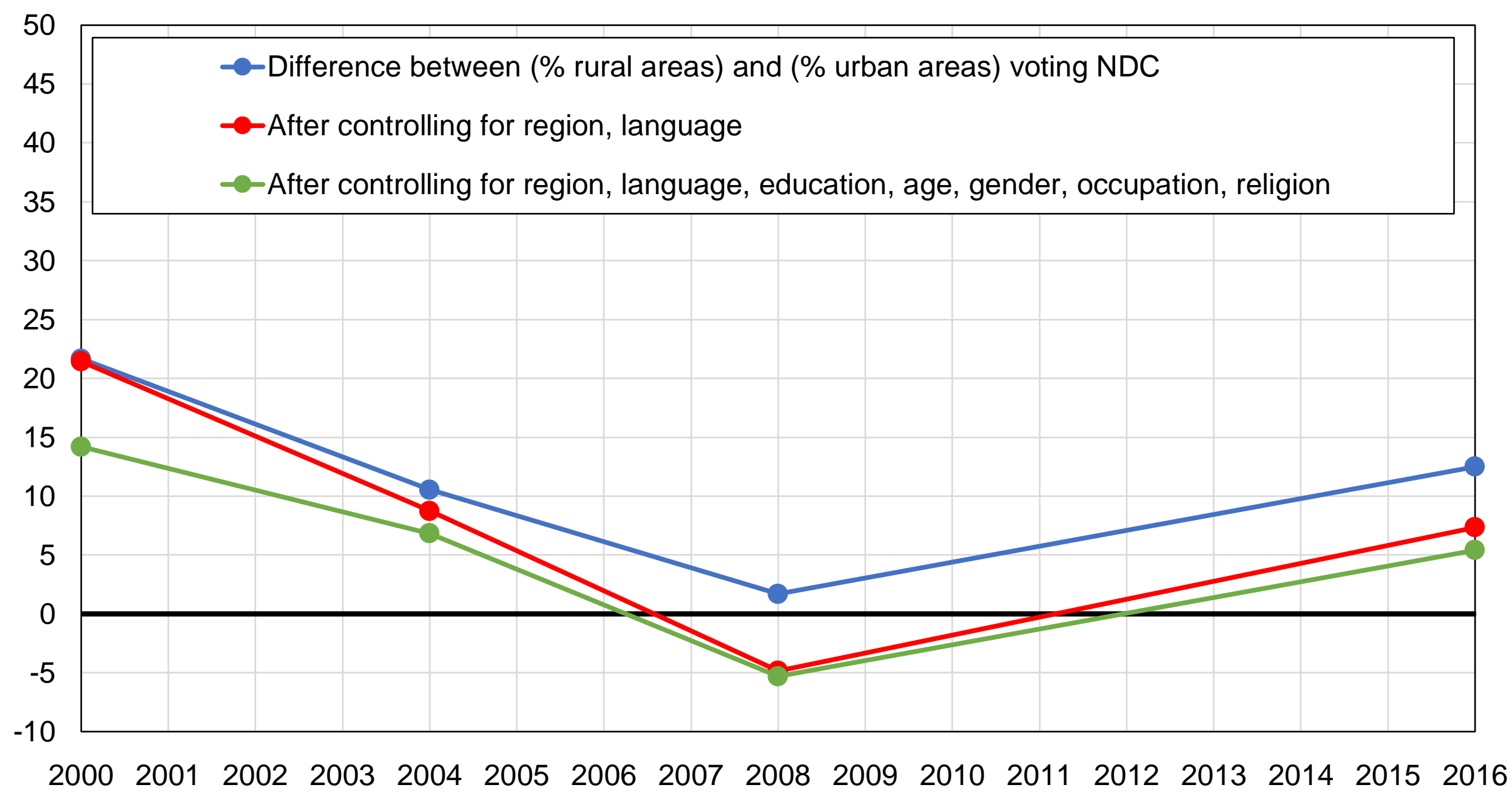

Source: authors' computations using Afrobarometer surveys.

Note: the figure shows the difference between the share of voters from rural areas and the share of other voters voting for NDC, before and after controlling for other variables. 


\section{Figure BC6 - Vote for NDC among Volta region residents}

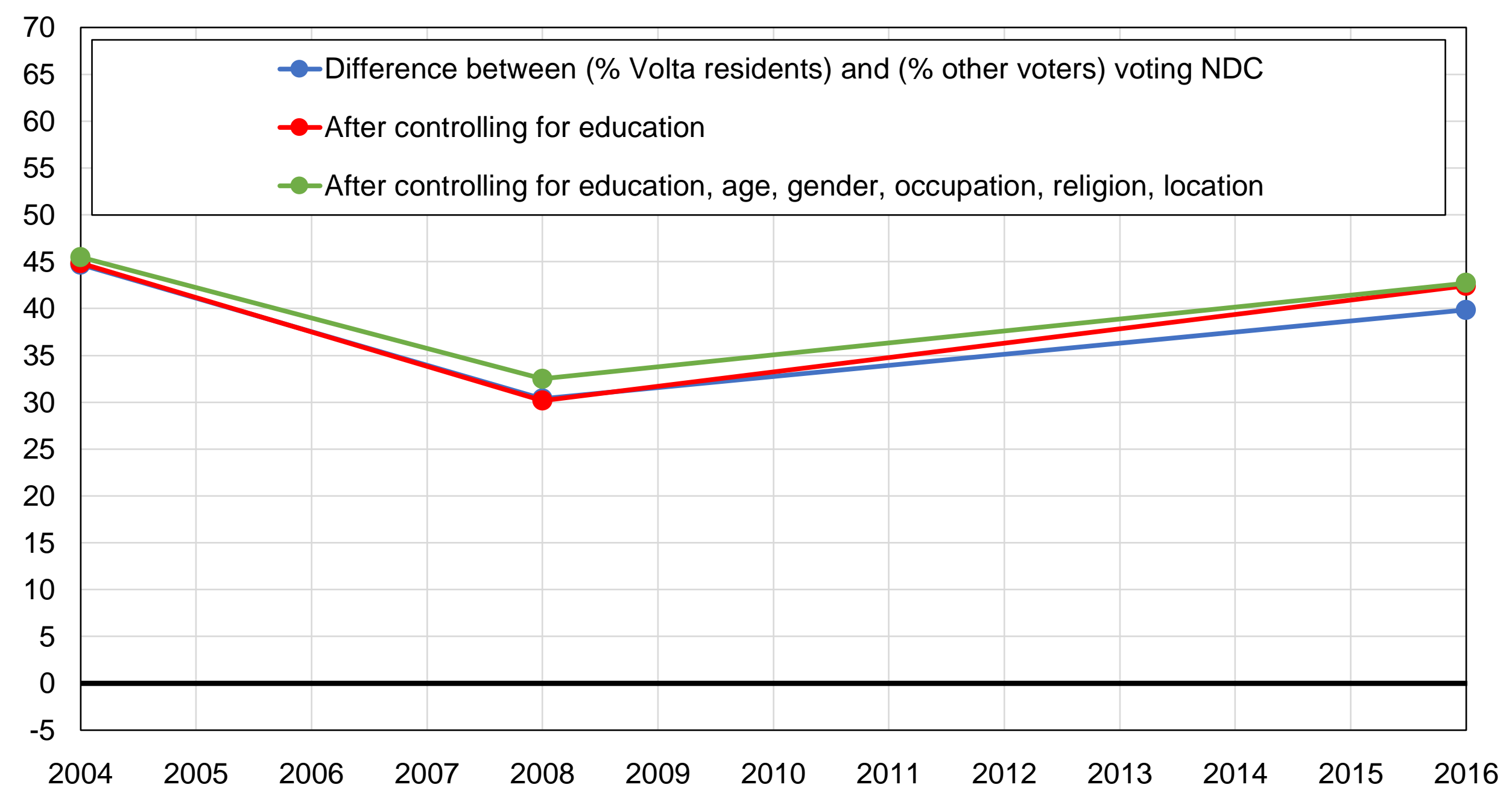

Source: authors' computations using Afrobarometer surveys.

Note: the figure shows the difference between the Volta voters and the share of other voters voting for NDC, before and after controlling for other variables. 


\section{Figure BC7 - Ethnolinguistic cleavages in Ghana}

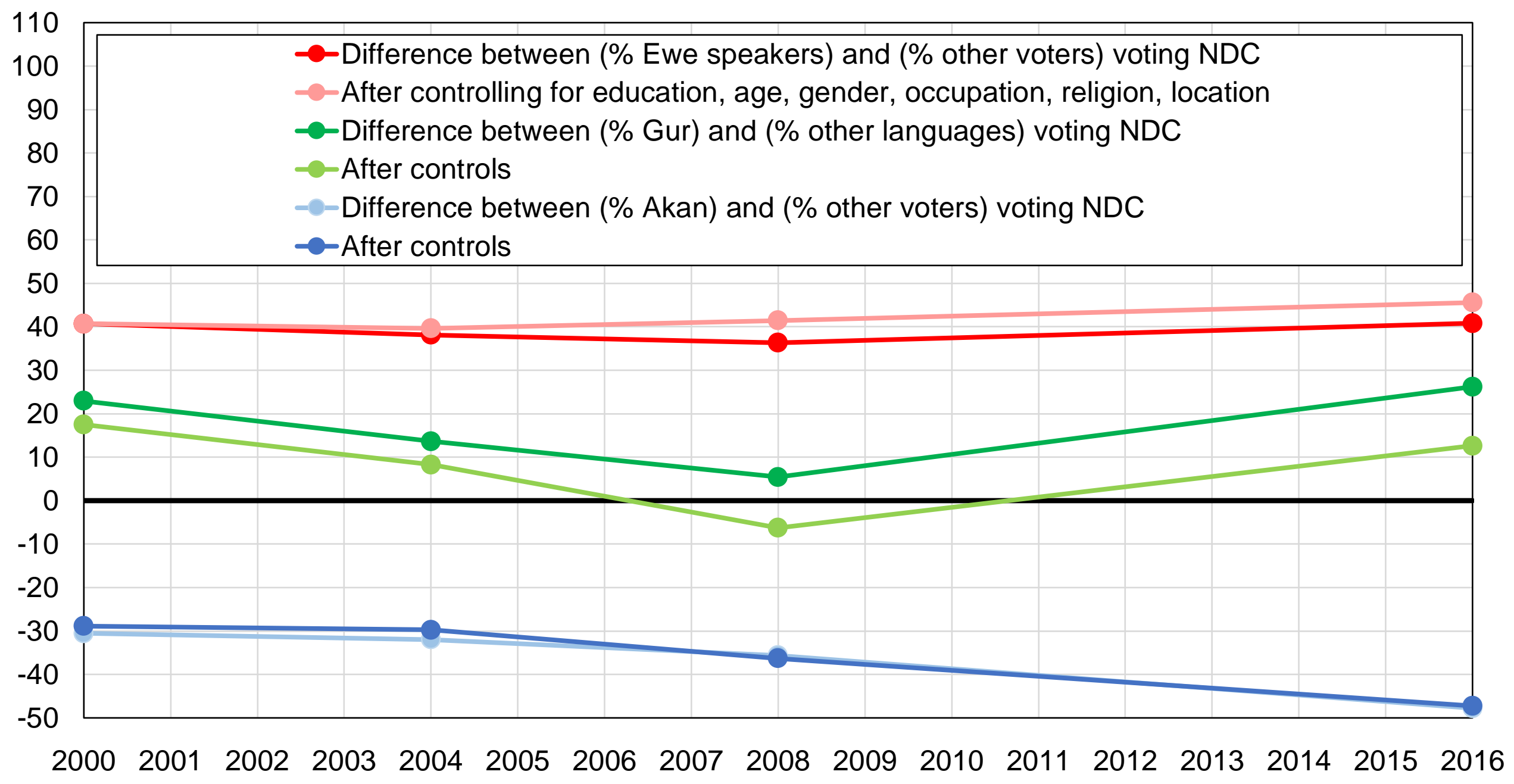

Source: authors' computations using Afrobarometer surveys.

Note: the figure shows differences between the share of speakers of selected languages and the share of other voters voting for NDC, before and after controlling for other variables. 


\section{Figure BC8 - Vote for NDC among farmers}

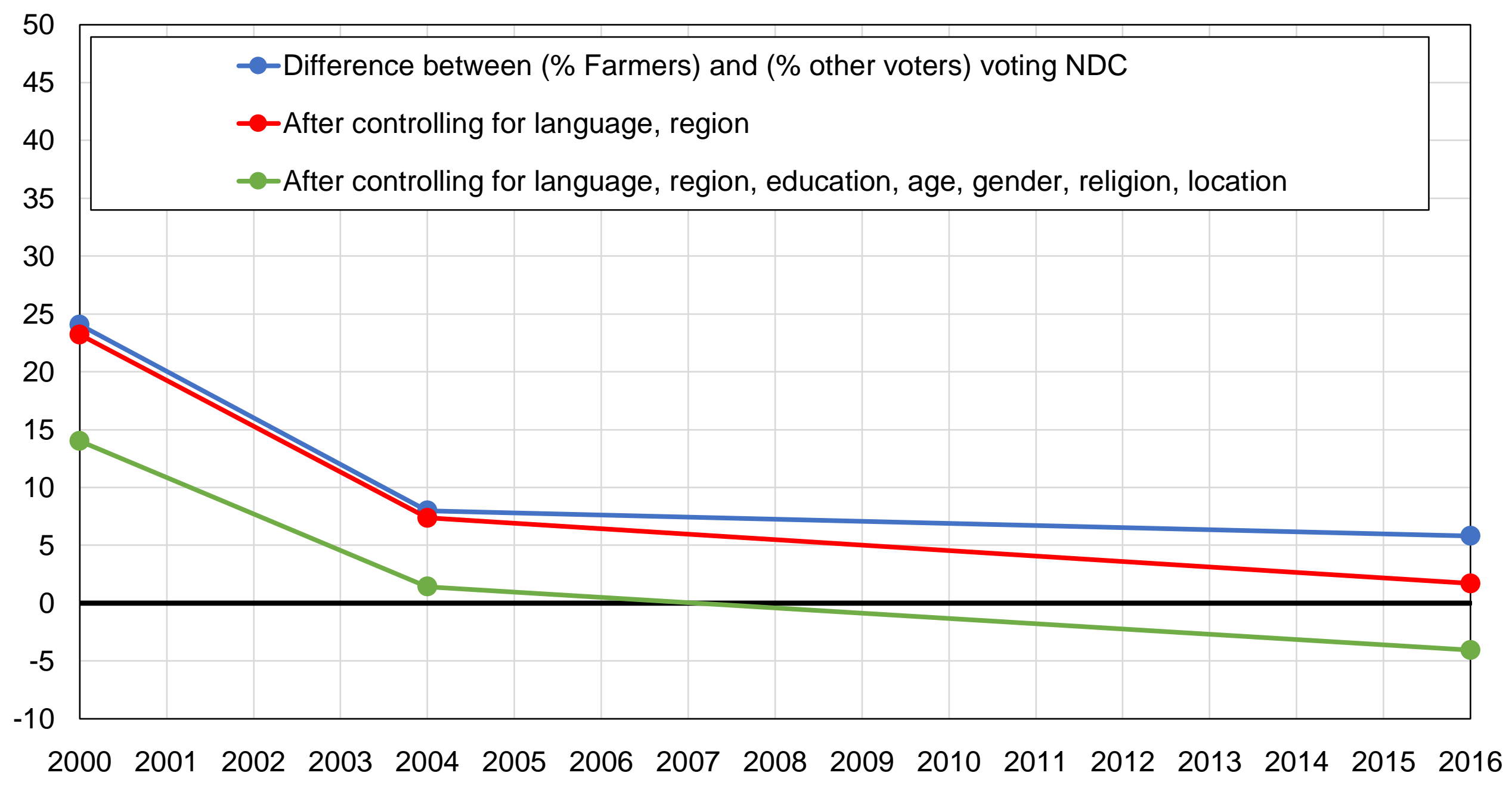

Source: authors' computations using Afrobarometer surveys.

Note: the figure shows the difference between the share of farmers voters and the share of other voters voting for NDC, before and after controlling for other variables. 


\begin{tabular}{|cllr|}
\hline \multicolumn{4}{|c|}{ Table B1 - Survey data sources } \\
\hline Year & \multicolumn{1}{|c|}{ Survey } & Source & Sample size \\
\hline 2000 & Afrobarometers Wave 1 & Afrobarometers & 2004 \\
2004 & Afrobarometers Wave 2-3 & Afrobarometers & 2397 \\
2008 & Afrobarometers Wave 4 & Afrobarometers & 1200 \\
2016 & Afrobarometers Wave 5-6 & Afrobarometers & 4800 \\
\hline Source: authors' elaboration. & & \\
Note: the table shows the surveys used, the source from which these surveys can be \\
obtained, and the sample size of each survey.
\end{tabular}




\begin{tabular}{|c|c|c|c|c|}
\hline \multicolumn{5}{|c|}{ Table B2 - Complete descriptive statistics by year } \\
\hline & 2000 & 2004 & 2008 & 2016 \\
\hline Education: Illiterate & $22 \%$ & $28 \%$ & $24 \%$ & $18 \%$ \\
\hline Education: Primary & $15 \%$ & $17 \%$ & $17 \%$ & $16 \%$ \\
\hline Education: Secondary & $41 \%$ & $38 \%$ & $37 \%$ & $38 \%$ \\
\hline Education: Tertiary & $22 \%$ & $17 \%$ & $22 \%$ & $28 \%$ \\
\hline Age: 20-39 & $64 \%$ & $55 \%$ & $57 \%$ & $62 \%$ \\
\hline Age: $40-59$ & $29 \%$ & $32 \%$ & $32 \%$ & $29 \%$ \\
\hline Age: $60+$ & $8 \%$ & $13 \%$ & $11 \%$ & $9 \%$ \\
\hline Gender: Man & $49 \%$ & $49 \%$ & $51 \%$ & $54 \%$ \\
\hline Employment status: Employed & $60 \%$ & $56 \%$ & $59 \%$ & $59 \%$ \\
\hline Employment status: Unemployed & $31 \%$ & $20 \%$ & $28 \%$ & $24 \%$ \\
\hline Employment status: Inactive & $10 \%$ & $24 \%$ & $13 \%$ & $17 \%$ \\
\hline Religion: No religion & & $7 \%$ & $3 \%$ & $2 \%$ \\
\hline Religion: Catholic & & $16 \%$ & $15 \%$ & $13 \%$ \\
\hline Religion: Other Christian & & $56 \%$ & $61 \%$ & $64 \%$ \\
\hline Religion: Muslim & & $15 \%$ & $16 \%$ & $15 \%$ \\
\hline Religion: Other & & $6 \%$ & $5 \%$ & $6 \%$ \\
\hline Location: Rural & $63 \%$ & $54 \%$ & $56 \%$ & $46 \%$ \\
\hline Region: Ashanti & & $17 \%$ & $17 \%$ & $19 \%$ \\
\hline Region: Brong Ahafo & & $9 \%$ & $9 \%$ & $9 \%$ \\
\hline Region: Central & & $8 \%$ & $9 \%$ & $9 \%$ \\
\hline Region: Eastern & & $11 \%$ & $11 \%$ & $10 \%$ \\
\hline Region: Greater Accra & & $16 \%$ & $16 \%$ & $18 \%$ \\
\hline Region: Northern & & $18 \%$ & $18 \%$ & $16 \%$ \\
\hline Region: Volta & & $11 \%$ & $10 \%$ & $9 \%$ \\
\hline Region: Western & & $9 \%$ & $10 \%$ & $9 \%$ \\
\hline Language: Gbe & $10 \%$ & $15 \%$ & $17 \%$ & $15 \%$ \\
\hline Language: Gur & $10 \%$ & $13 \%$ & $21 \%$ & $19 \%$ \\
\hline Language: Kwa & $9 \%$ & $7 \%$ & $11 \%$ & $8 \%$ \\
\hline Language: Other & $3 \%$ & $14 \%$ & $5 \%$ & $6 \%$ \\
\hline Language: Potou-tano & $68 \%$ & $51 \%$ & $46 \%$ & $53 \%$ \\
\hline Occupation: Farmer & $31 \%$ & $38 \%$ & & $27 \%$ \\
\hline Occupation: Inactive & $20 \%$ & $12 \%$ & & $19 \%$ \\
\hline Occupation: Professional / Employe & $18 \%$ & $11 \%$ & & $8 \%$ \\
\hline Occupation: Trader / Worker & $30 \%$ & $39 \%$ & & $46 \%$ \\
\hline \multicolumn{5}{|c|}{$\begin{array}{l}\text { Source: authors' computations using Afrobarometer surveys. } \\
\text { Note: the table shows descriptive statistics by year for selected } \\
\text { available variables. }\end{array}$} \\
\hline
\end{tabular}


Figure C1 - Presidential election results in Nigeria, 1999-2019

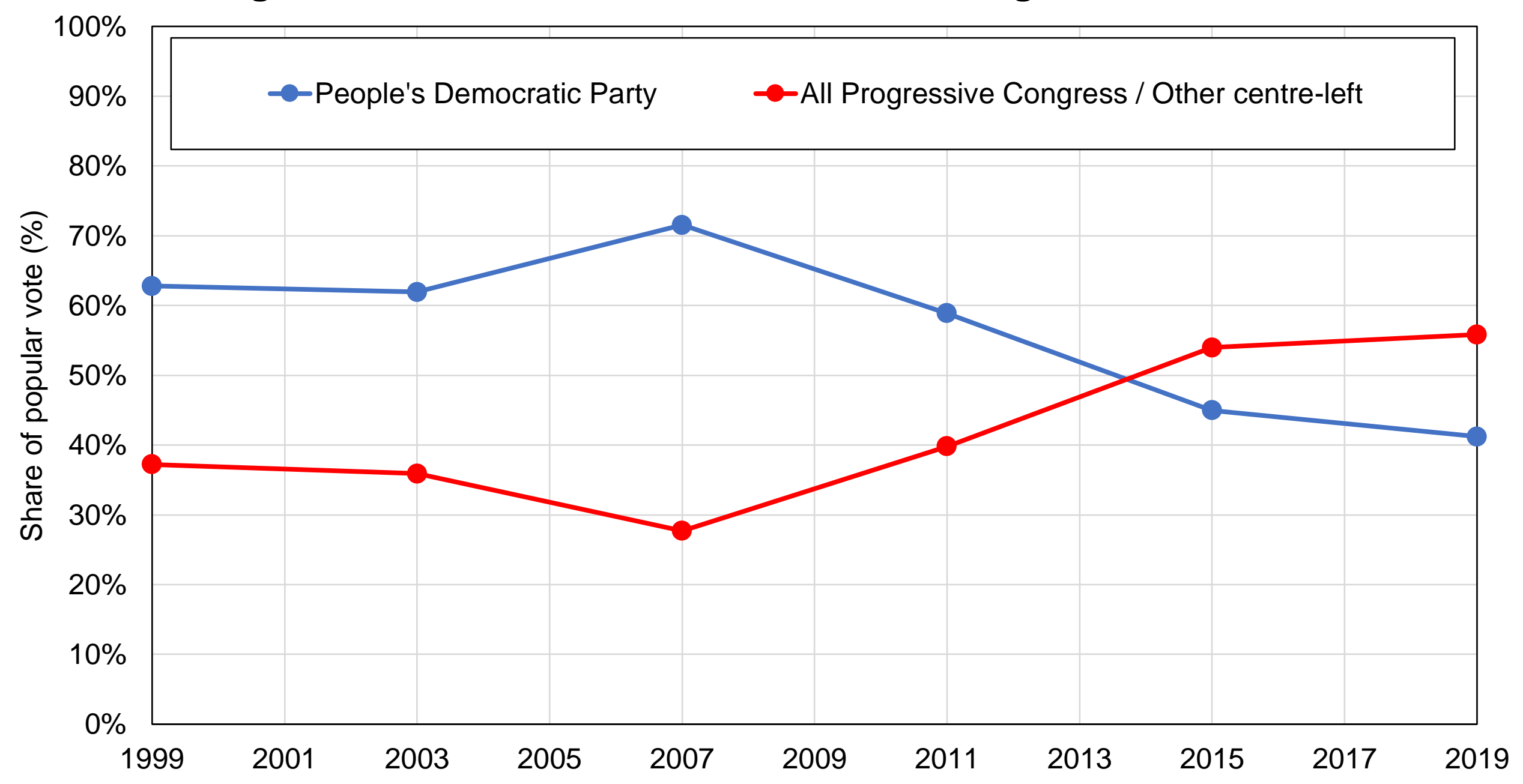

Source: authors' computations using official election results.

Note: the figure shows the share of votes received by selected groups of Nigerian political parties in presidential elections between 1999 and 2019. 
Figure C2 - Ethnoreligious educational inequalities in Nigeria

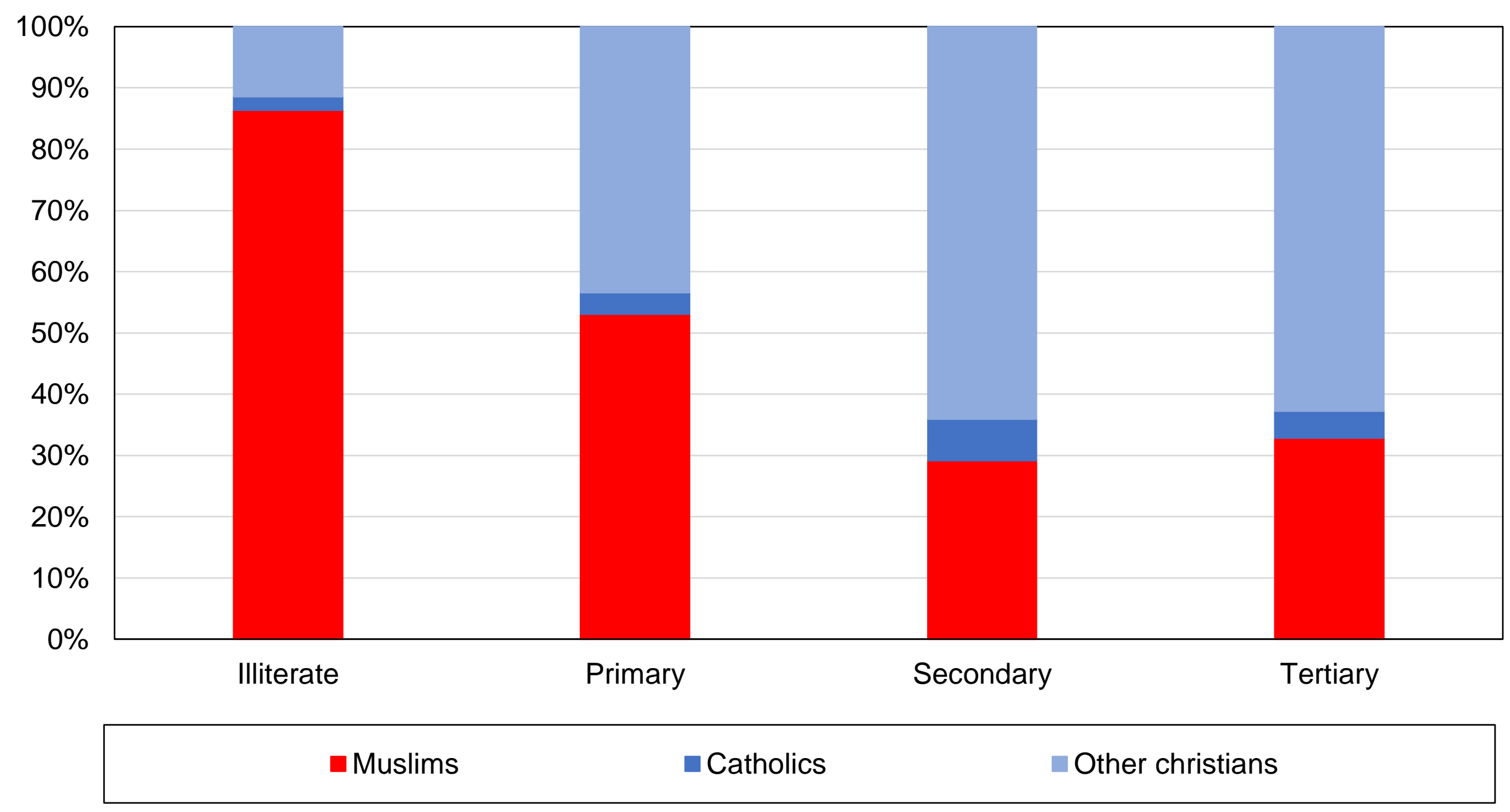

Source: authors' computations using Afrobarometer surveys.

Note: the figure shows the distribution of religious groups by education level in Nigeria in 2019. 
Figure C3 - Vote for People's Democratic Party by religion

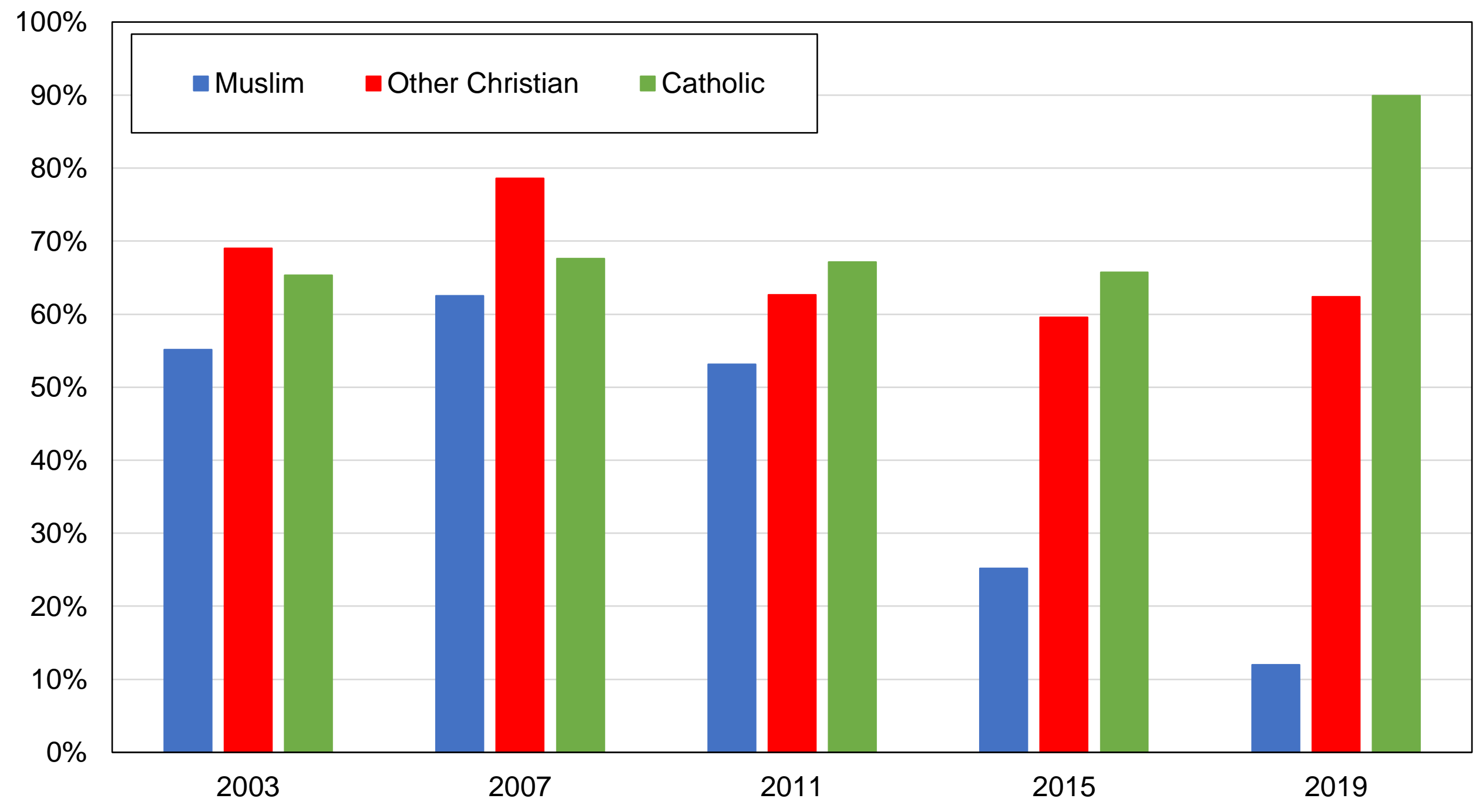

Source: authors' computations using Afrobarometer surveys.

Note: the figure shows the share of votes received by PDP by religious affiliation. 


\section{Figure C4 - The rise of ethnoreligious polarization in Nigeria}

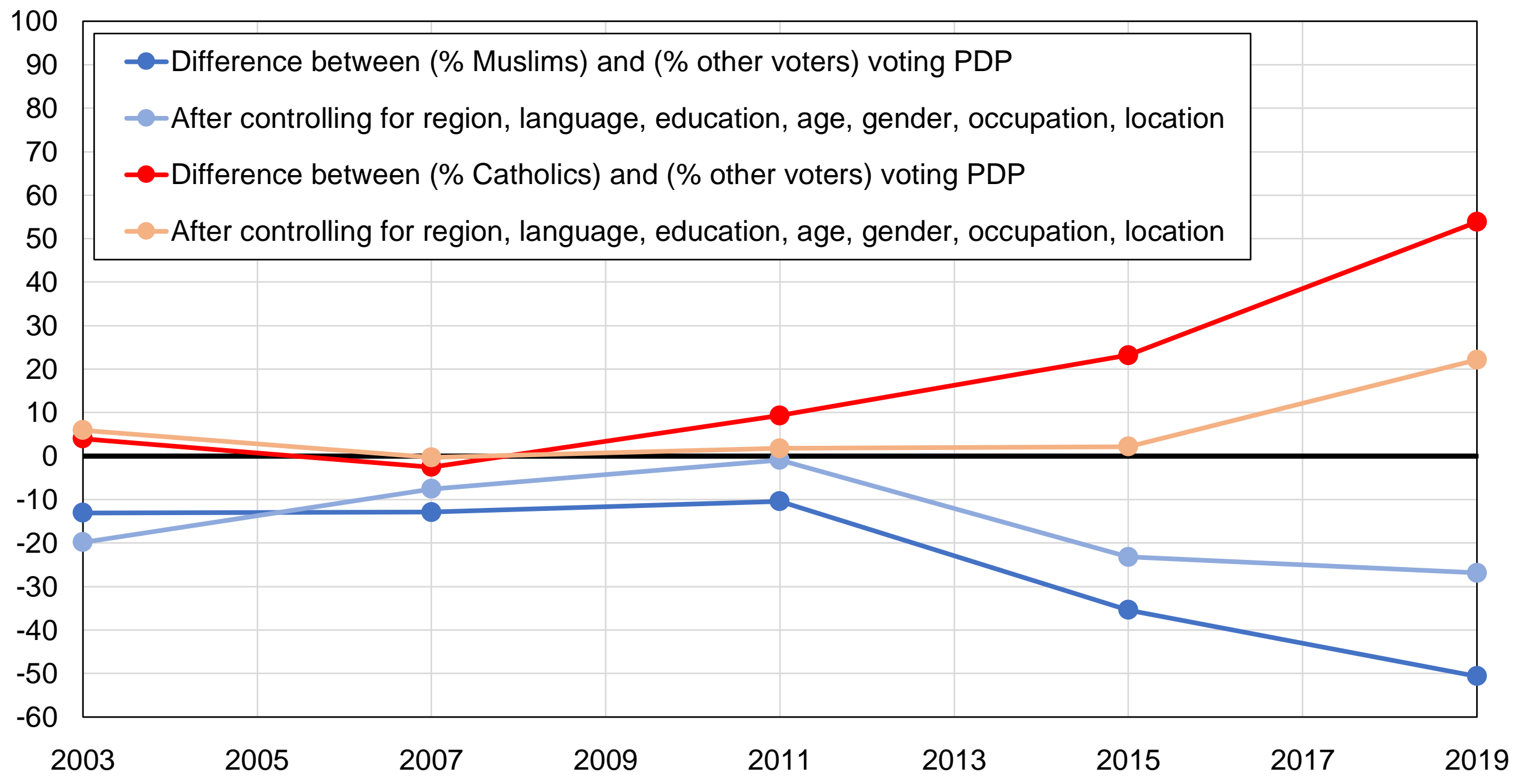

Source: authors' computations using Afrobarometer surveys.

Note: the figure shows the difference between the share of Muslim voters and the share of other voters voting for PDP, and the same difference for Catholics, before and after controlling for other variables. 


\section{Figure C5 - Vote for PDP among highest-educated voters}

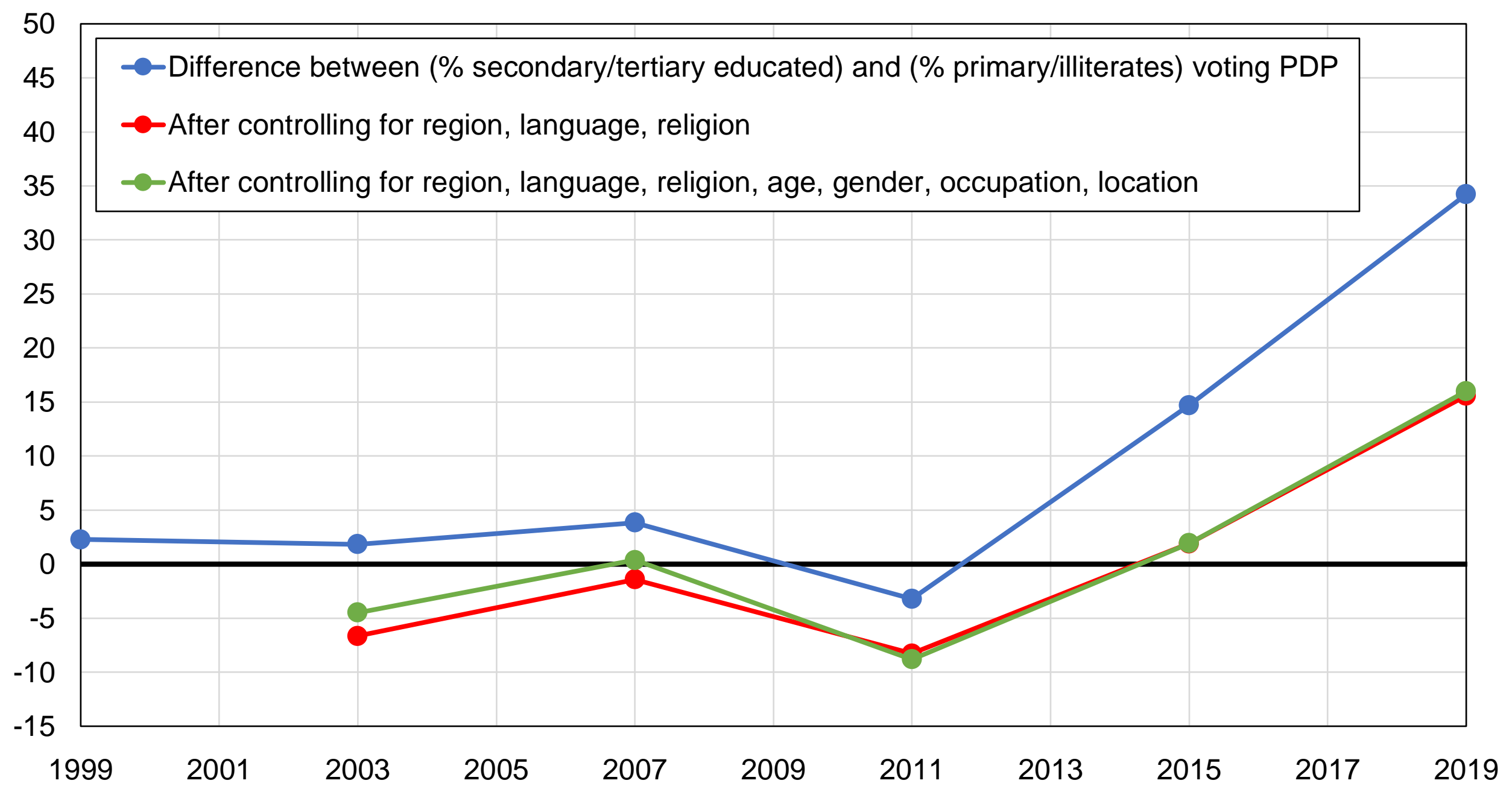

Source: authors' computations using Afrobarometer surveys.

Note: the figure shows the difference between the share of secondary- and tertiary-educated voters and the share of primary-educated voters and illiterates voting PDP, before and after controlling for other variables. 
Figure CA1 - The composition of the electorate by education

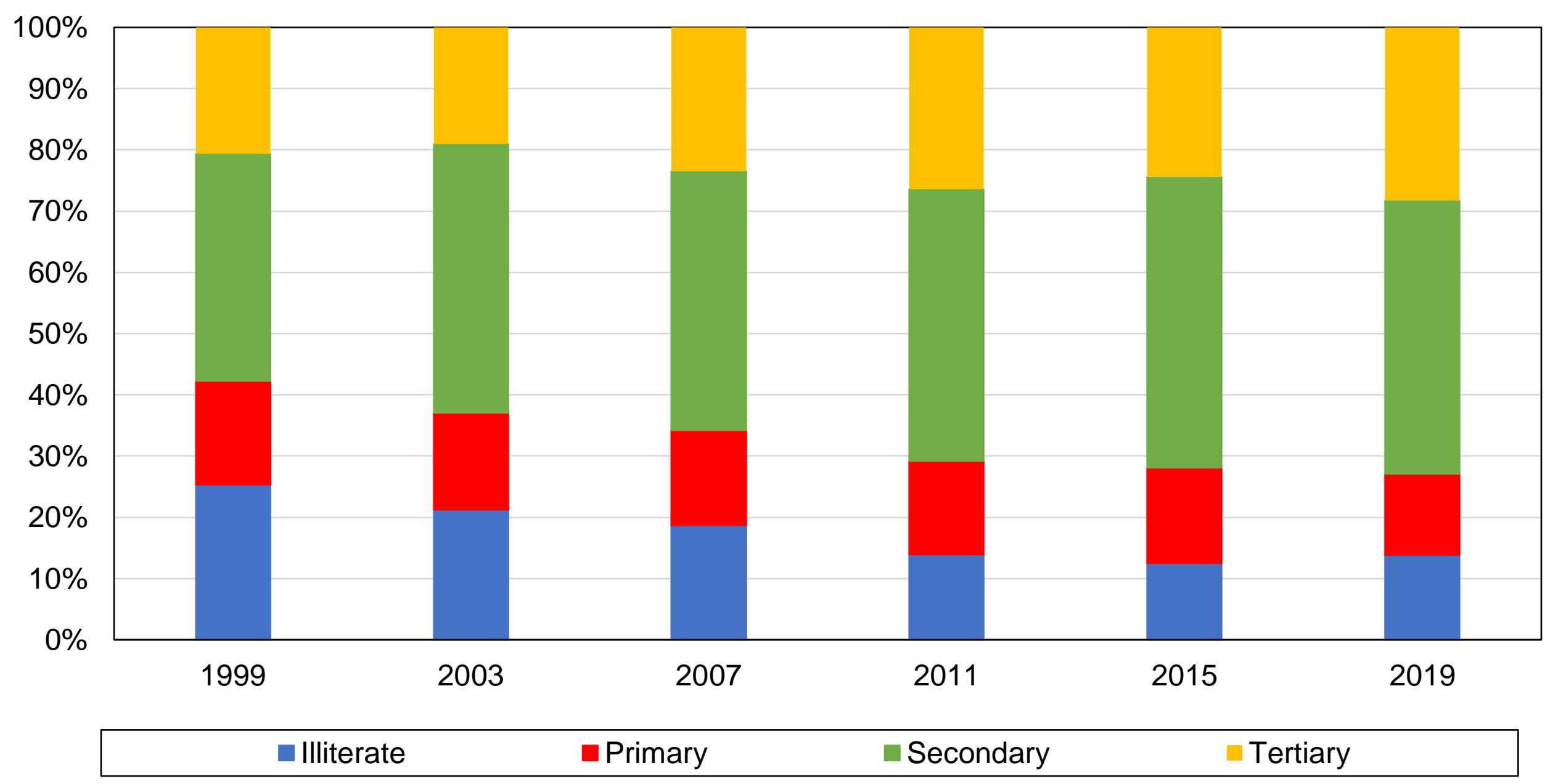

Source: authors' computations using Afrobarometer surveys.

Note: the figure shows the distribution of education levels of the Nigerian adult population and its evolution over time. 
Figure CA2 - The composition of the electorate by age

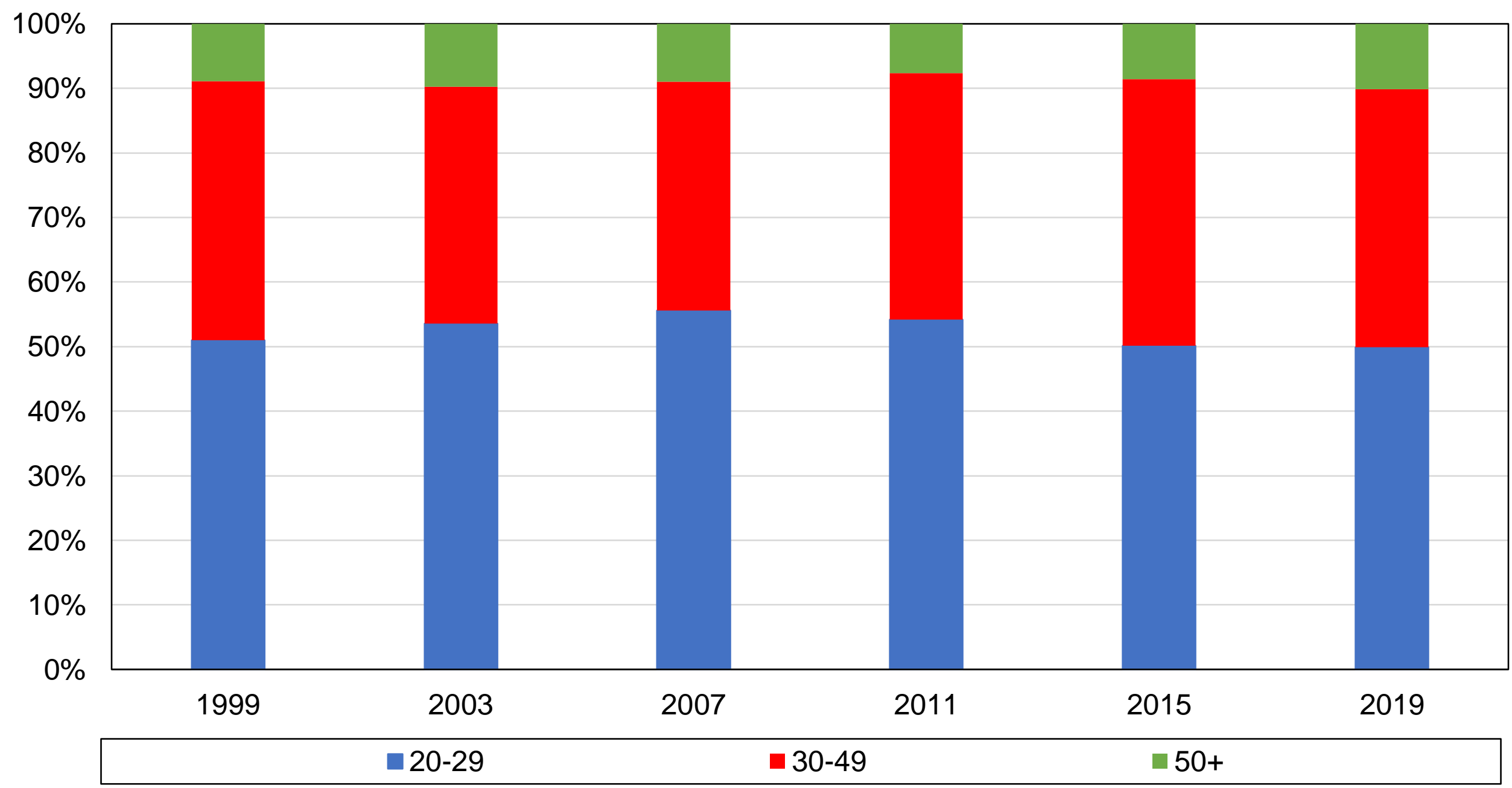

Source: authors' computations using Afrobarometer surveys.

Note: the figure shows the distribution of age groups in the Nigerian adult population and its evolution over time. 
Figure CA3 - The composition of the electorate by religion

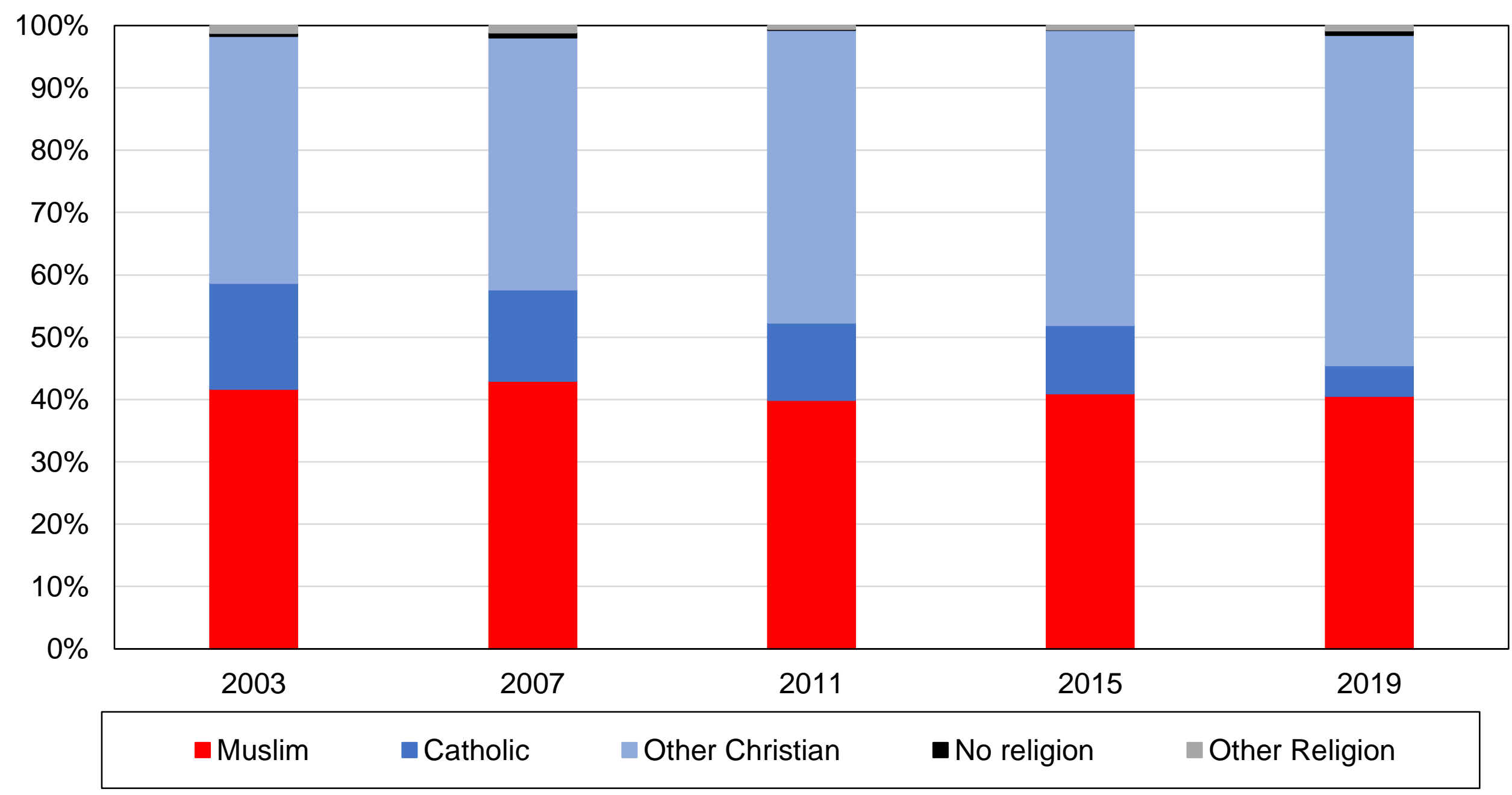

Source: authors' computations using Afrobarometer surveys.

Note: the figure shows the distribution of religious affiliations in the Nigerian adult population and its evolution over time. 
Figure CA4 - The composition of the electorate by region

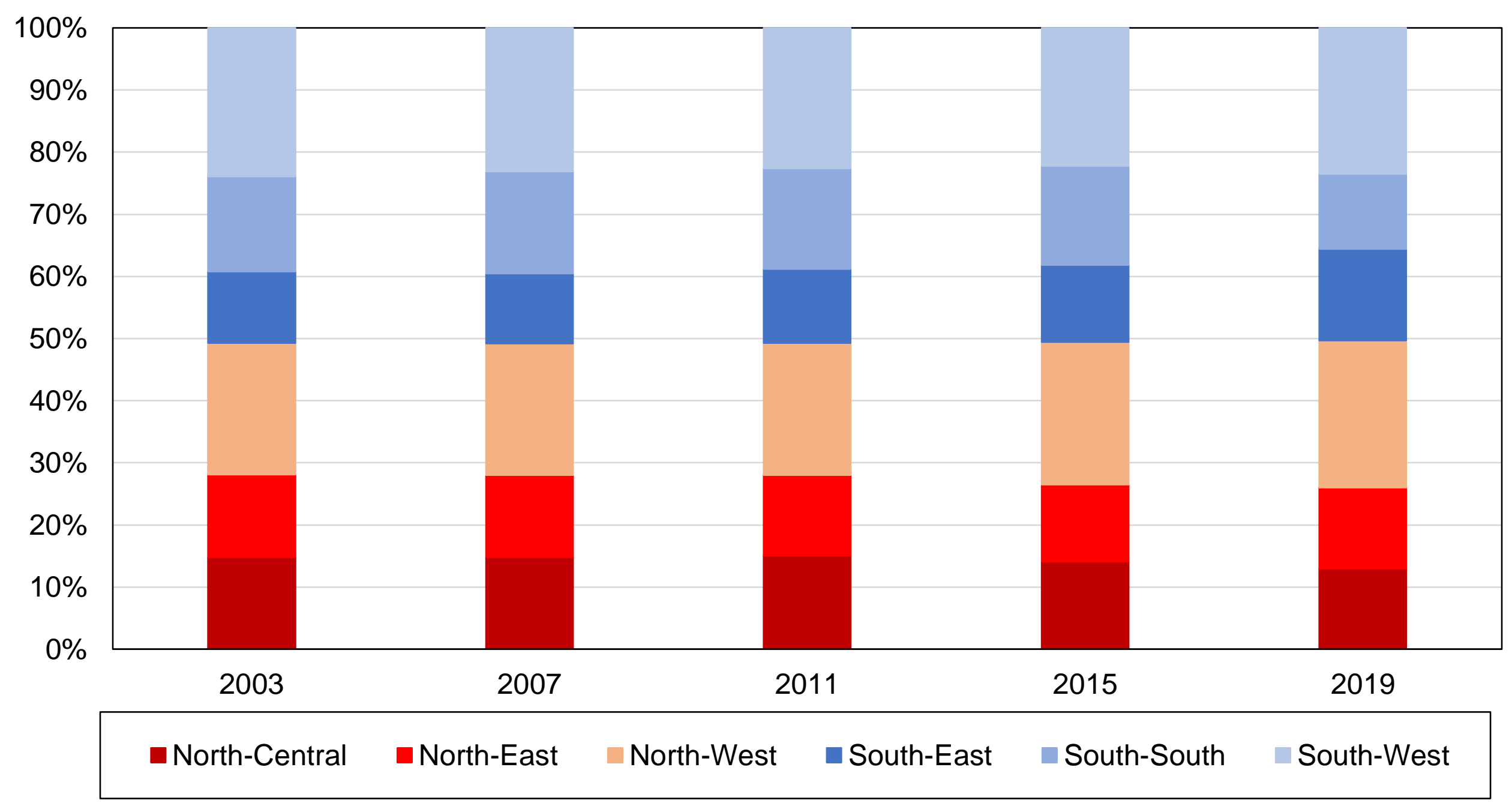

Source: authors' computations using Afrobarometer surveys.

Note: the figure shows the share of the electorate living in different regions of Nigeria. 
Figure CA5 - The composition of the electorate by linguistic group

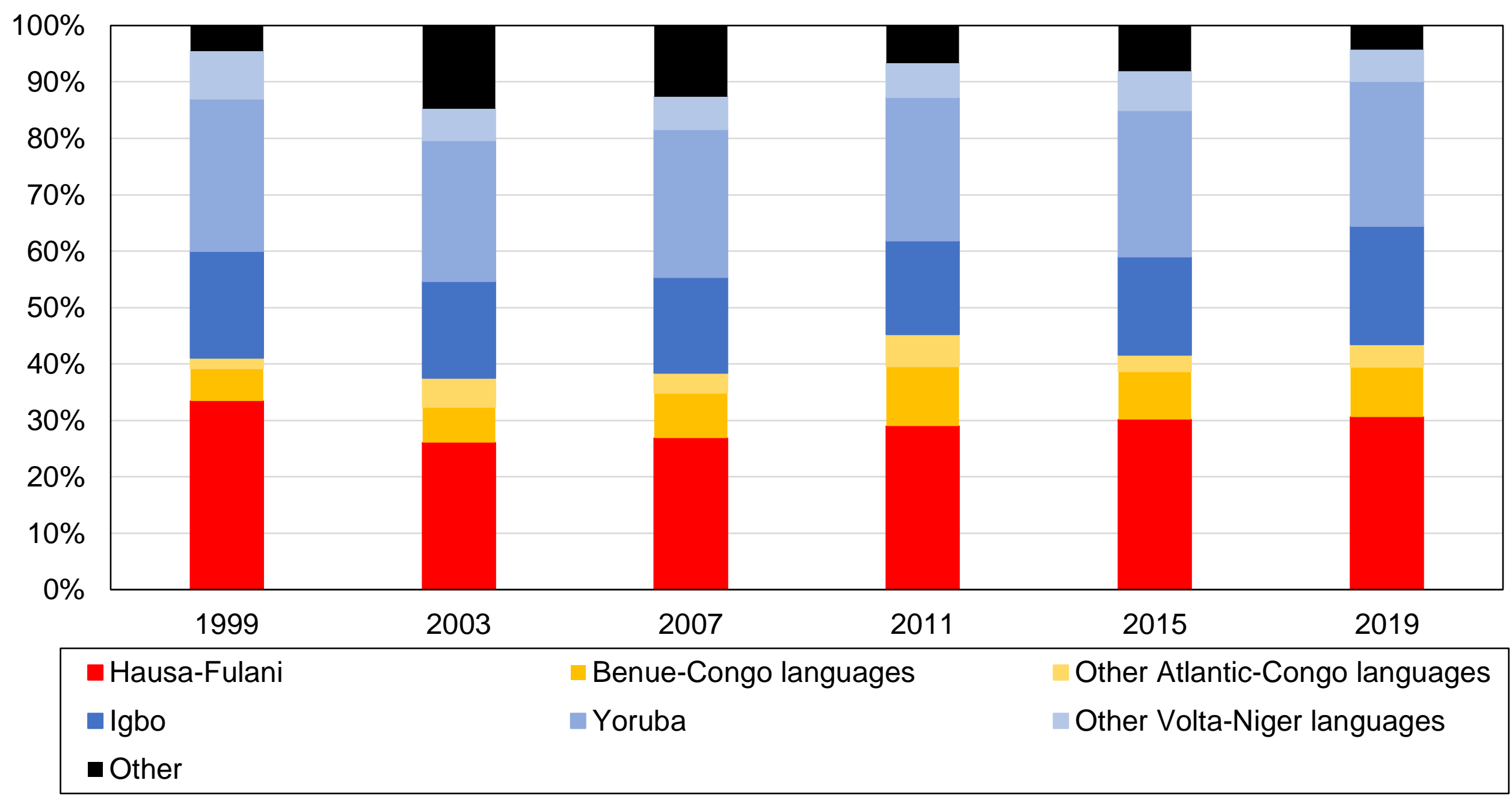

Source: authors' computations using Afrobarometer surveys.

Note: the figure shows the distribution of languages in the Nigerian adult population and its evolution over time. 
Figure CA6 - The composition of the electorate by occupation

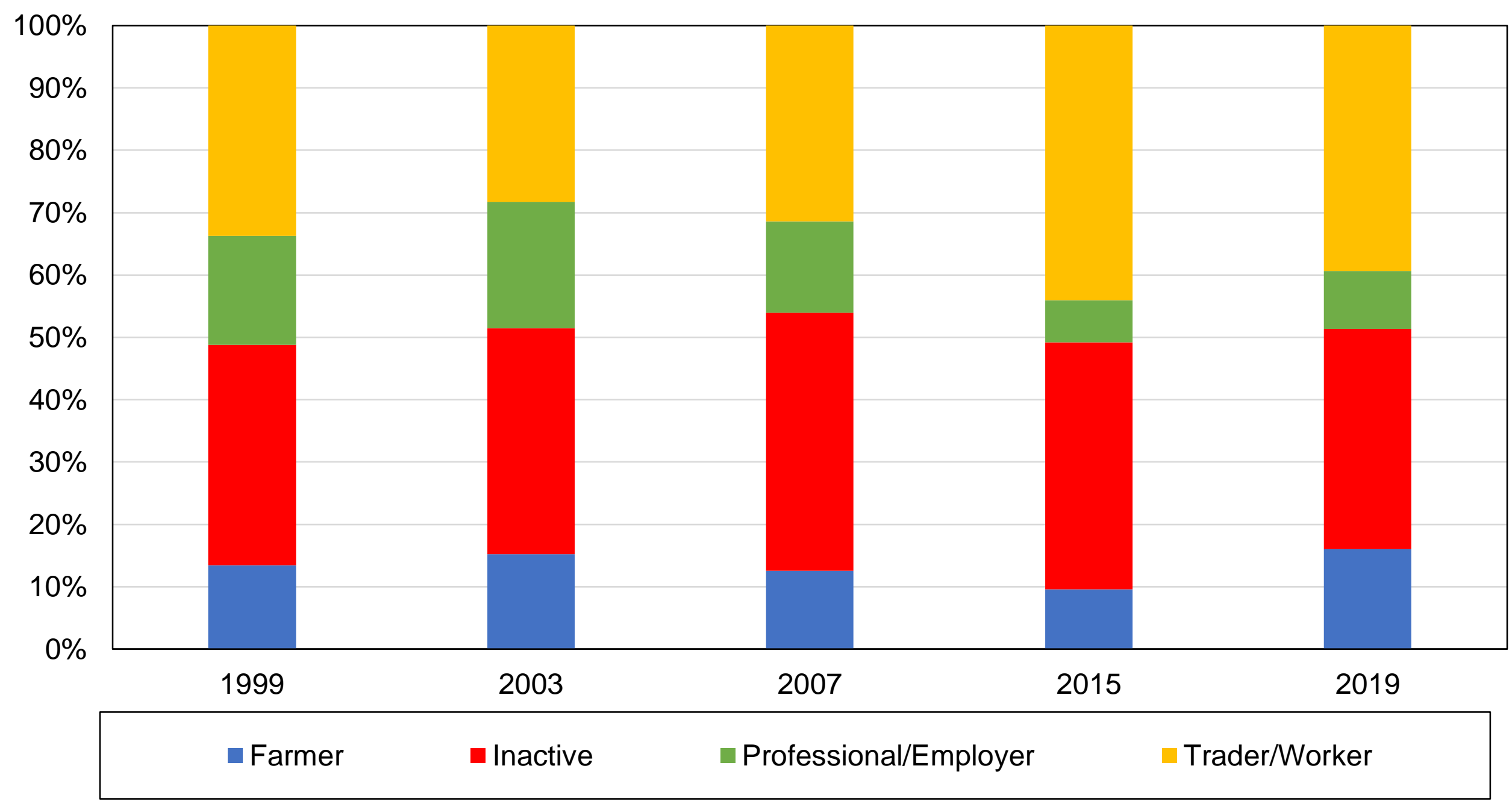

Source: authors' computations using Afrobarometer surveys.

Note: the figure shows the distribution of occupations in the Nigerian adult population and its evolution over time. 
Figure CA7 - Composition of education by language, 2000

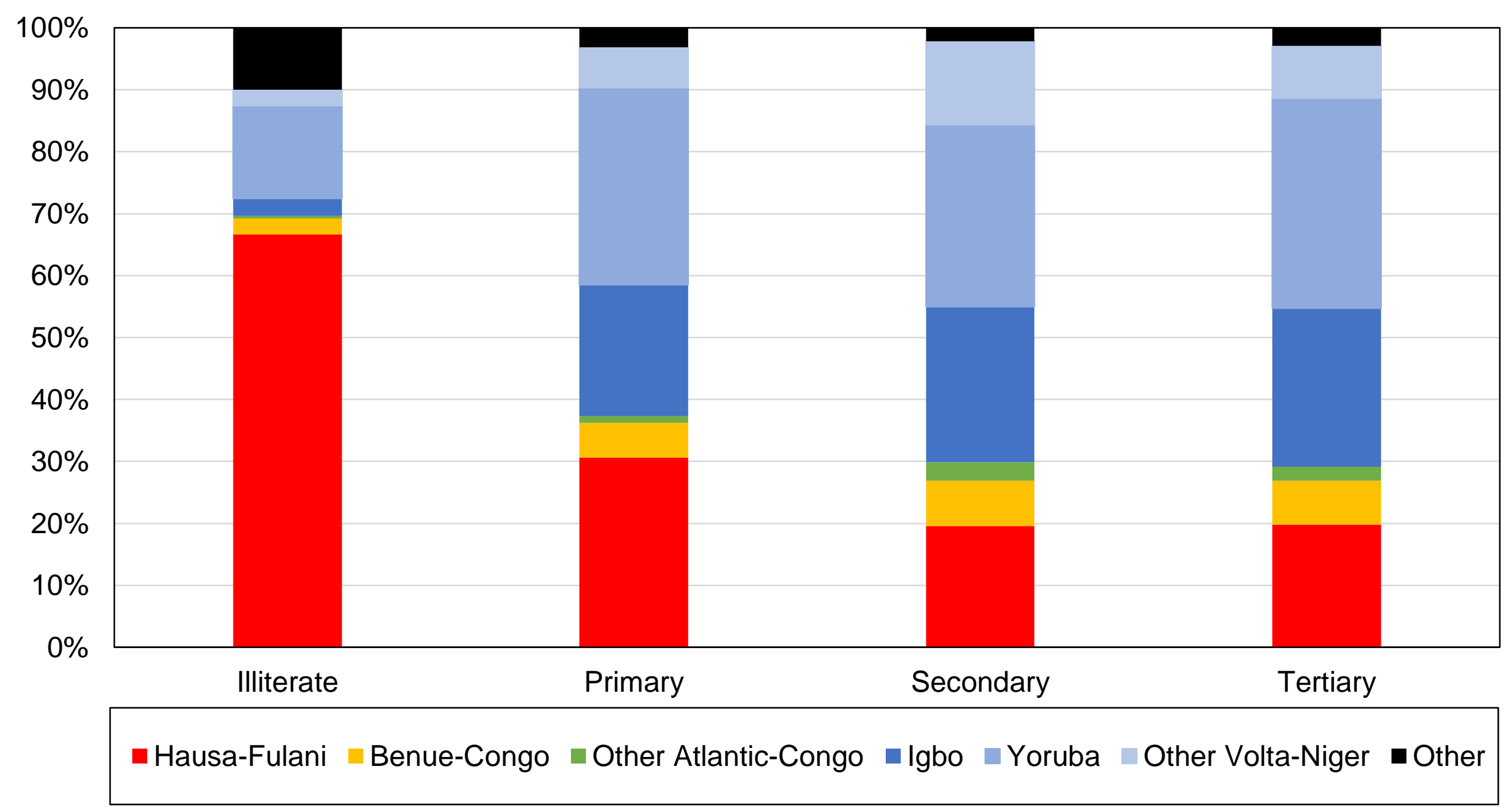

Source: authors' computations using Afrobarometer surveys.

Note: the figure shows the composition of education groups by language in 2000 . 
Figure CA8 - Composition of education by language, 2019

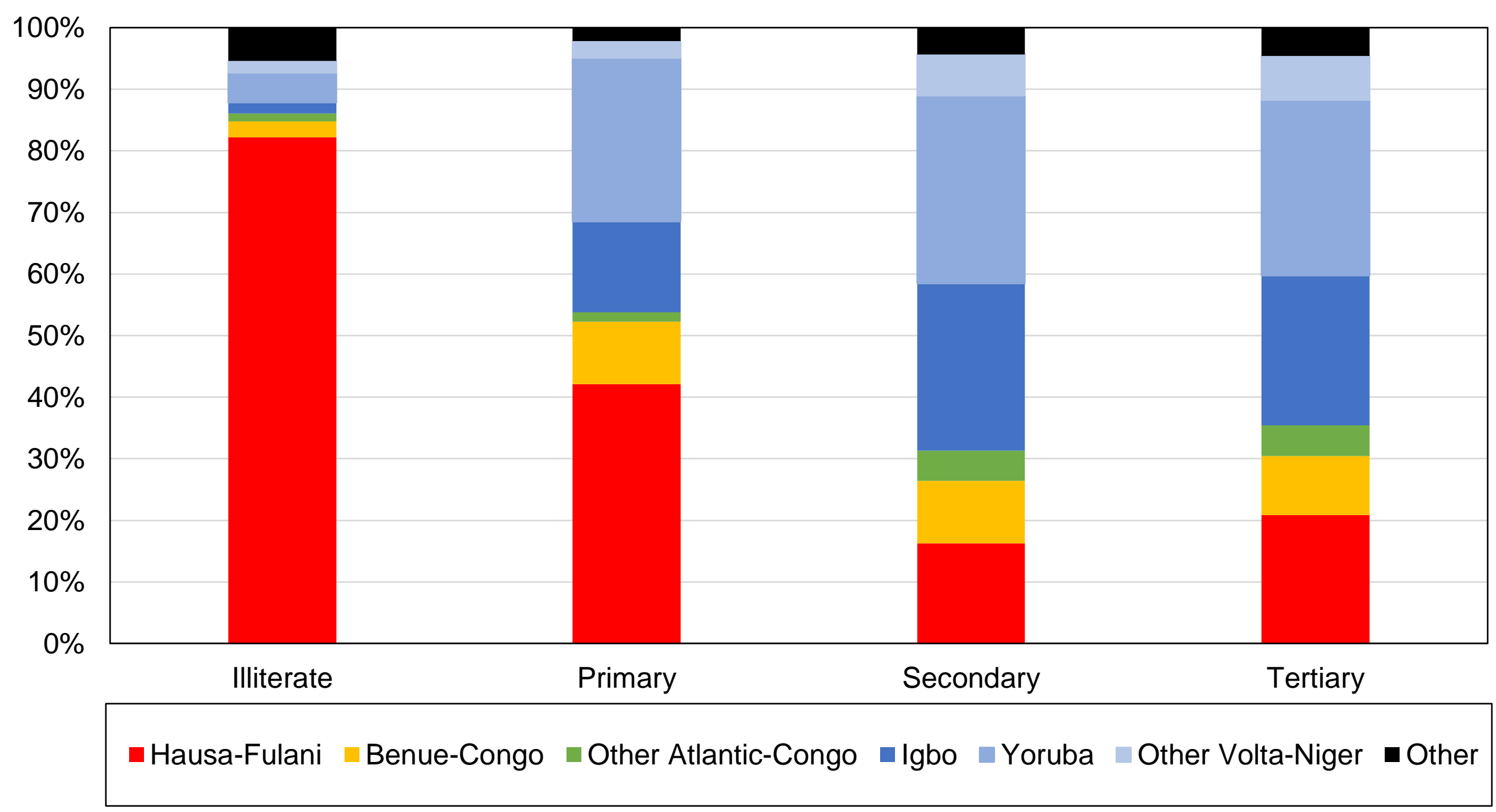

Source: authors' computations using Afrobarometer surveys.

Note: the figure shows the composition of education groups by language in 2019 . 
Figure CA9 - Composition of education by religion, 2003

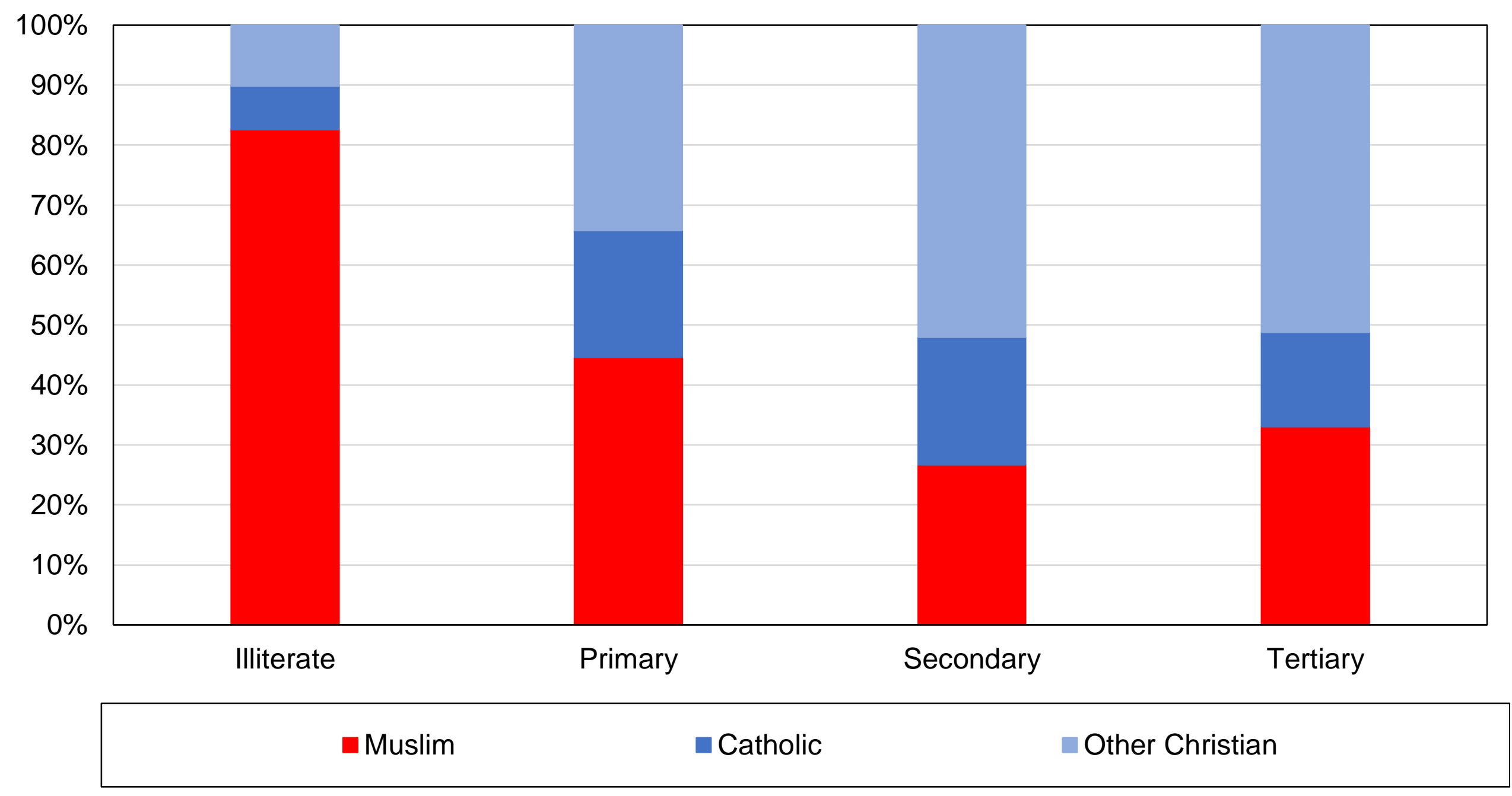

Source: authors' computations using Afrobarometer surveys.

Note: the figure shows the composition of education groups by religion in 2003. 
Figure CA10 - Composition of education by religion, 2019

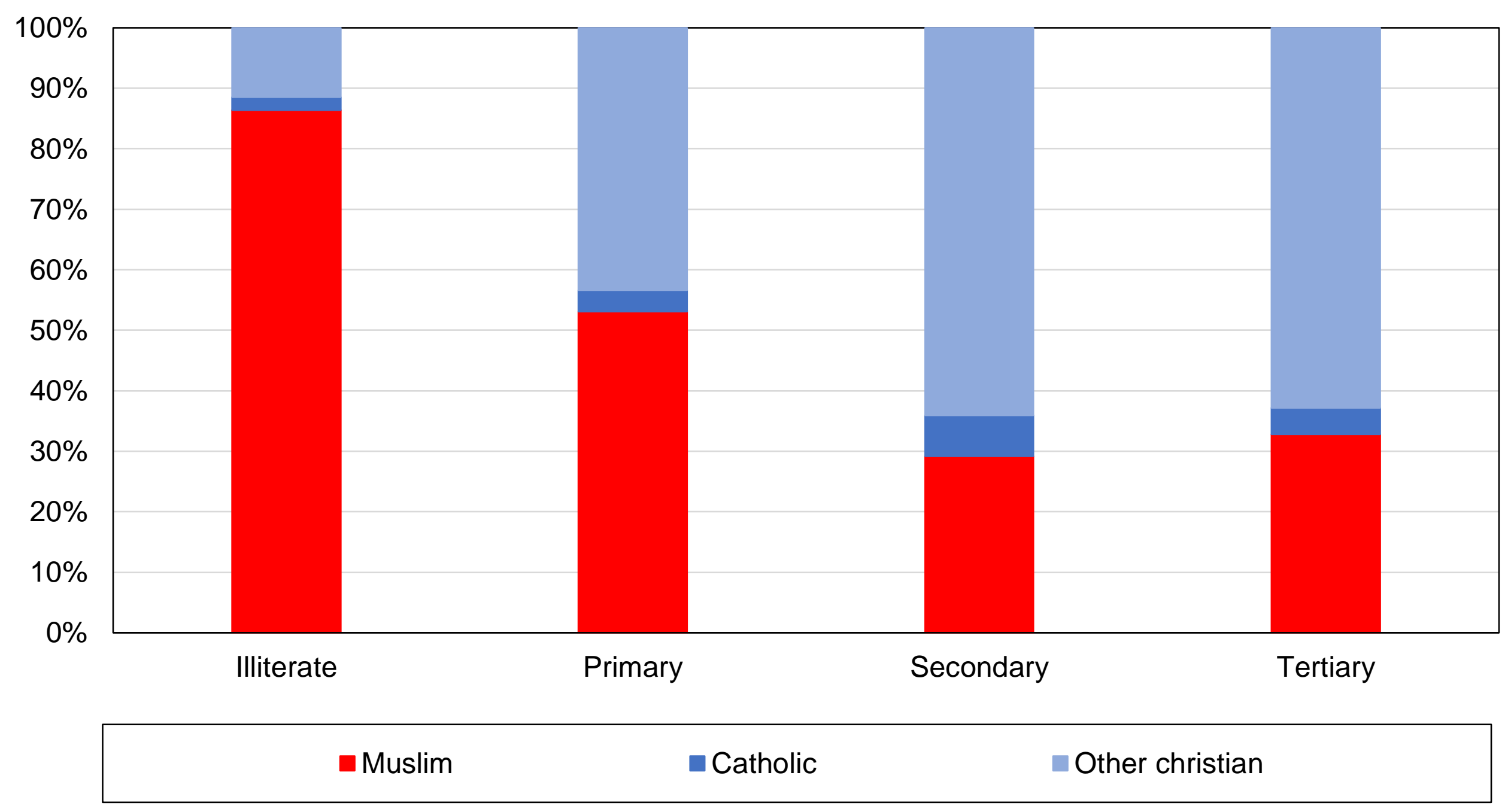

Source: authors' computations using Afrobarometer surveys.

Note: the figure shows the composition of education groups by religion in 2019 . 
Figure CA11 - Rural-urban composition of education, 2003

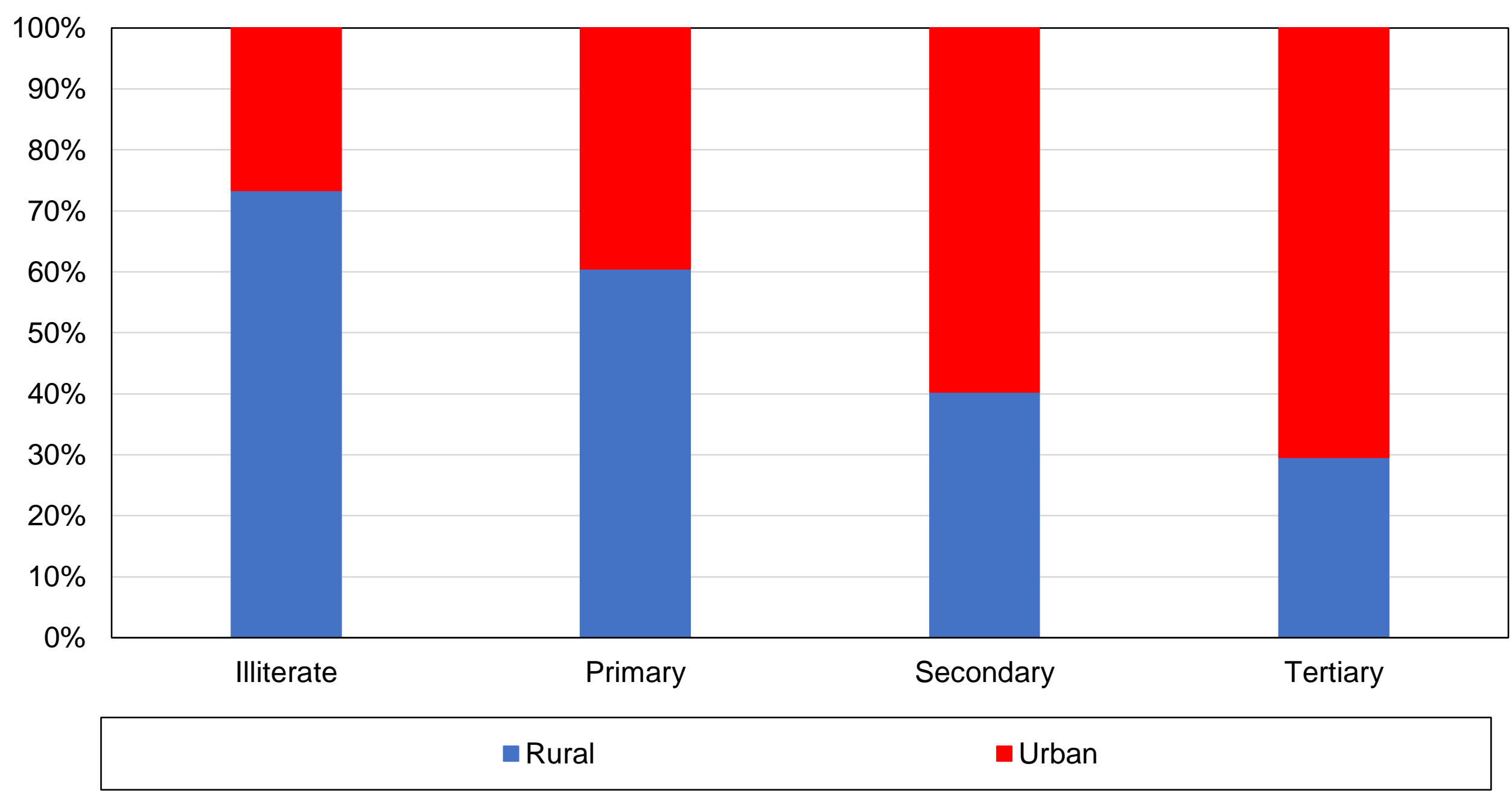

Source: authors' computations using Afrobarometer surveys.

Note: the figure shows the composition of education groups by location in 2003. 
Figure CA12 - Rural-urban composition of education, 2019

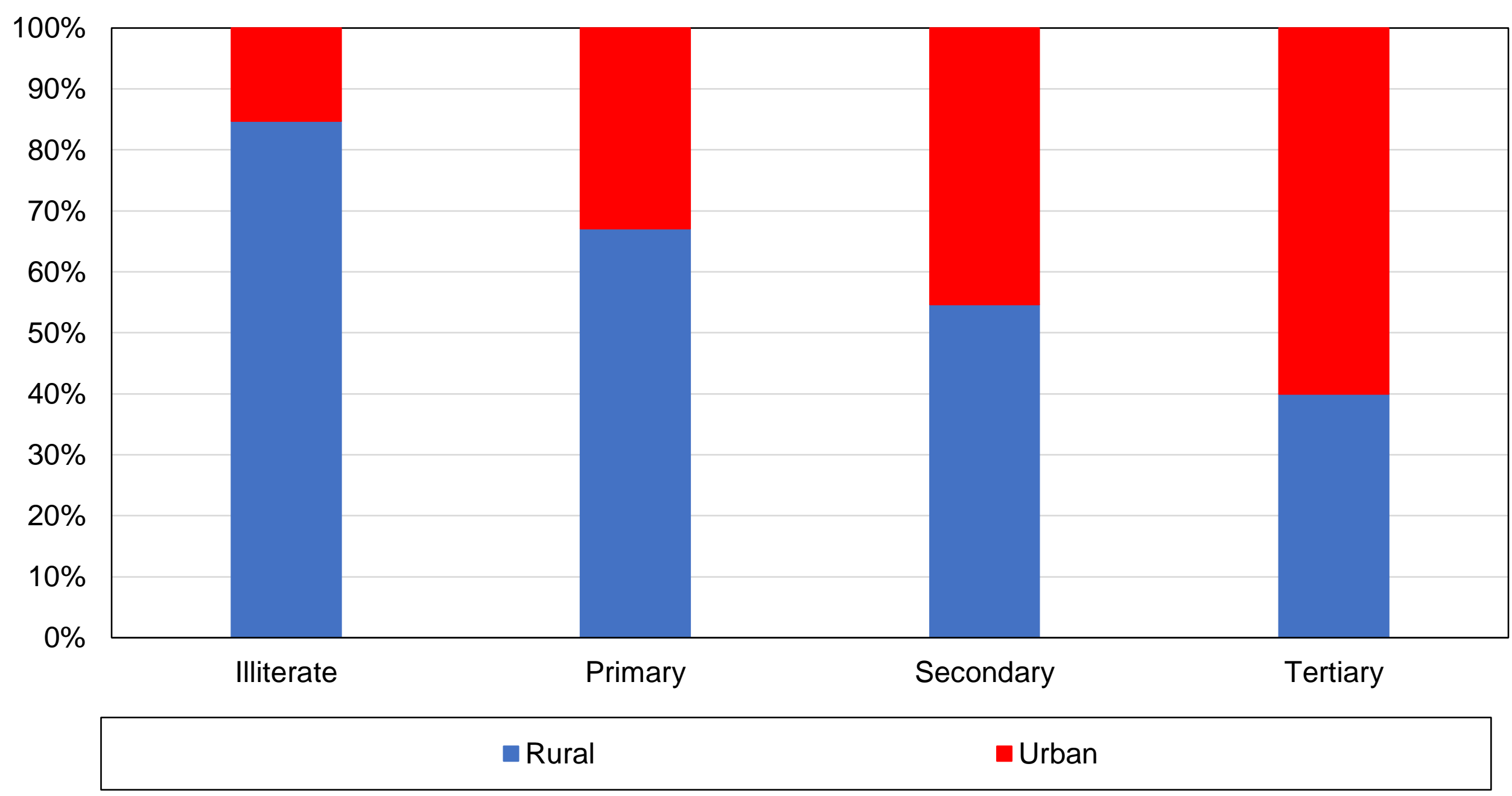

Source: authors' computations using Afrobarometer surveys.

Note: the figure shows the composition of education groups by location in 2019. 
Figure CA13 - Composition of education by region, 2003

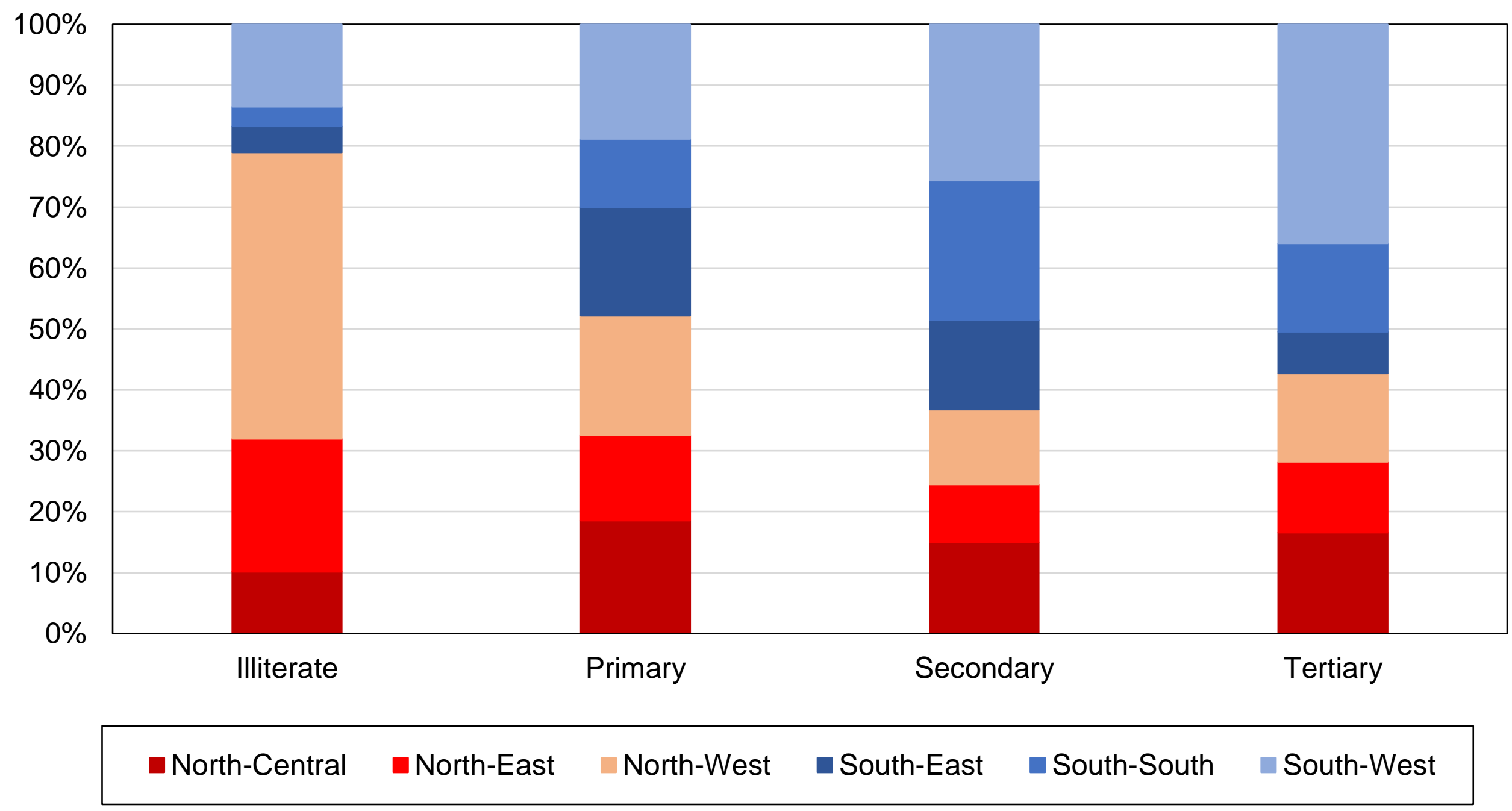

Source: authors' computations using Afrobarometer surveys.

Note: the figure shows the composition of education groups by region in 2003. 
Figure CA14 - Composition of education by region, 2019

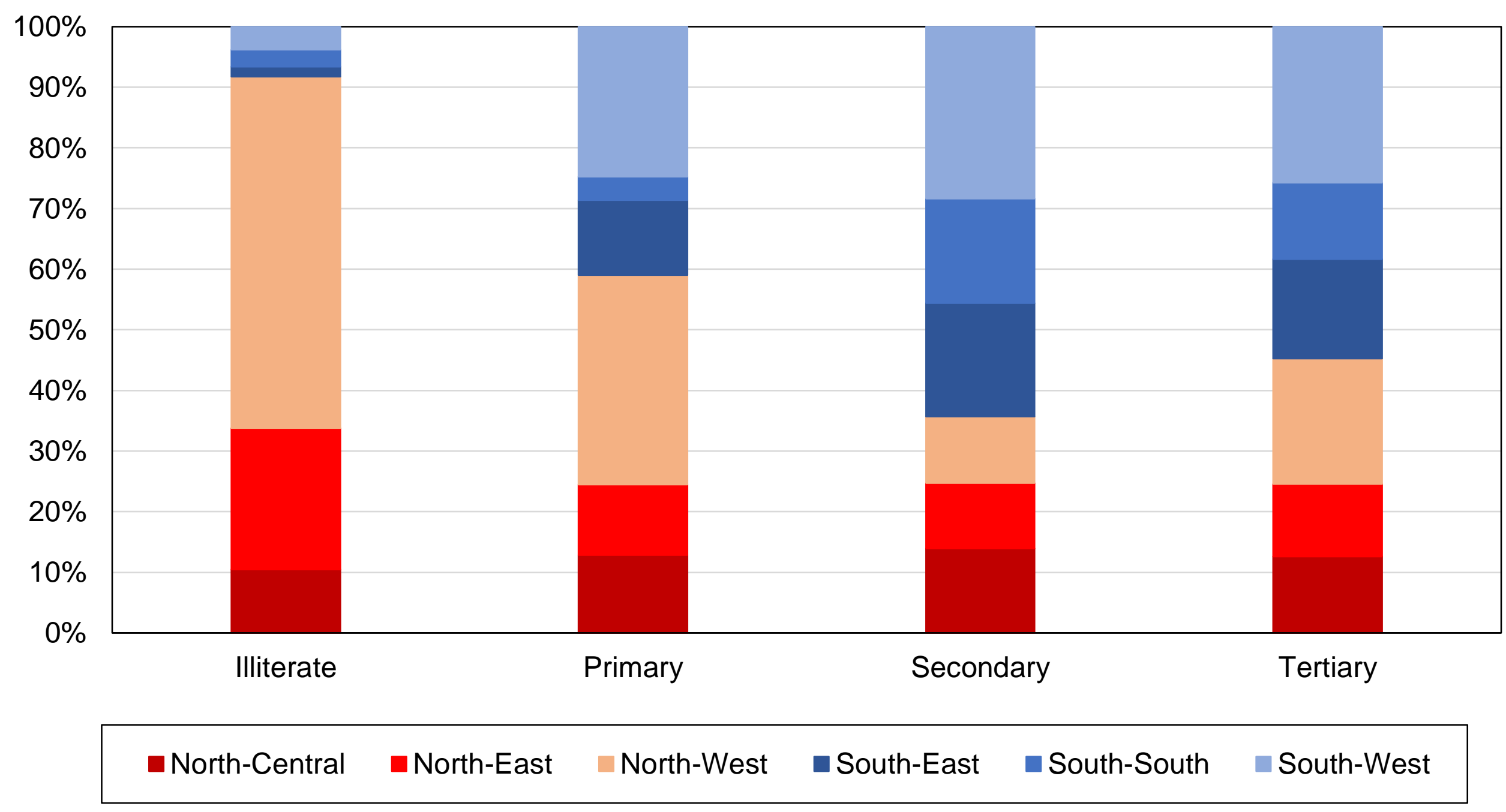

Source: authors' computations using Afrobarometer surveys.

Note: the figure shows the composition of education groups by region in 2019 . 
Figure CA15 - Ethnolinguistic composition of regions, 2000

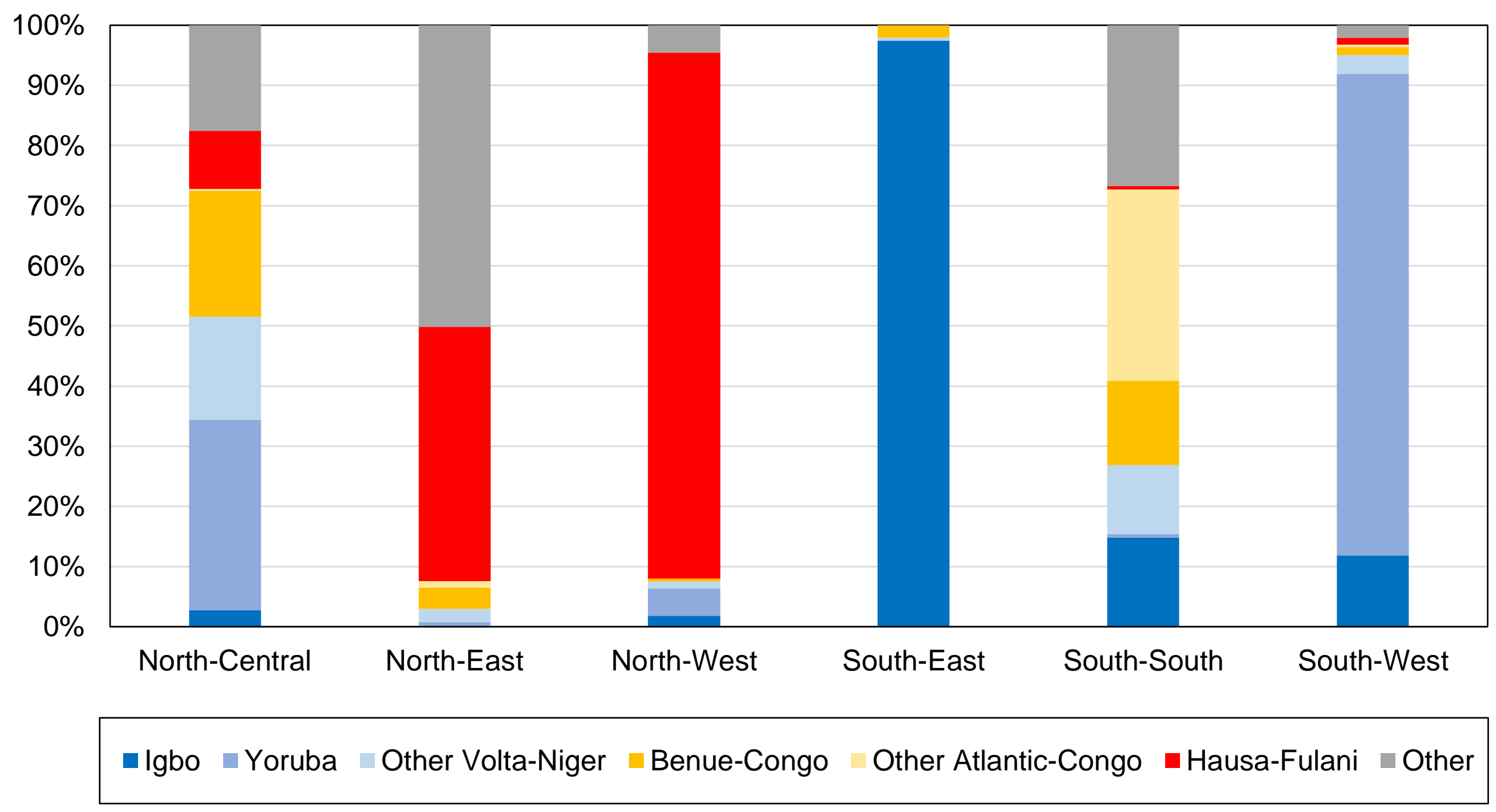

Source: authors' computations using Afrobarometer surveys.

Note: the figure shows the distribution of languages among regions in 2000. 
Figure CA16 - Ethnolinguistic composition of regions, 2019

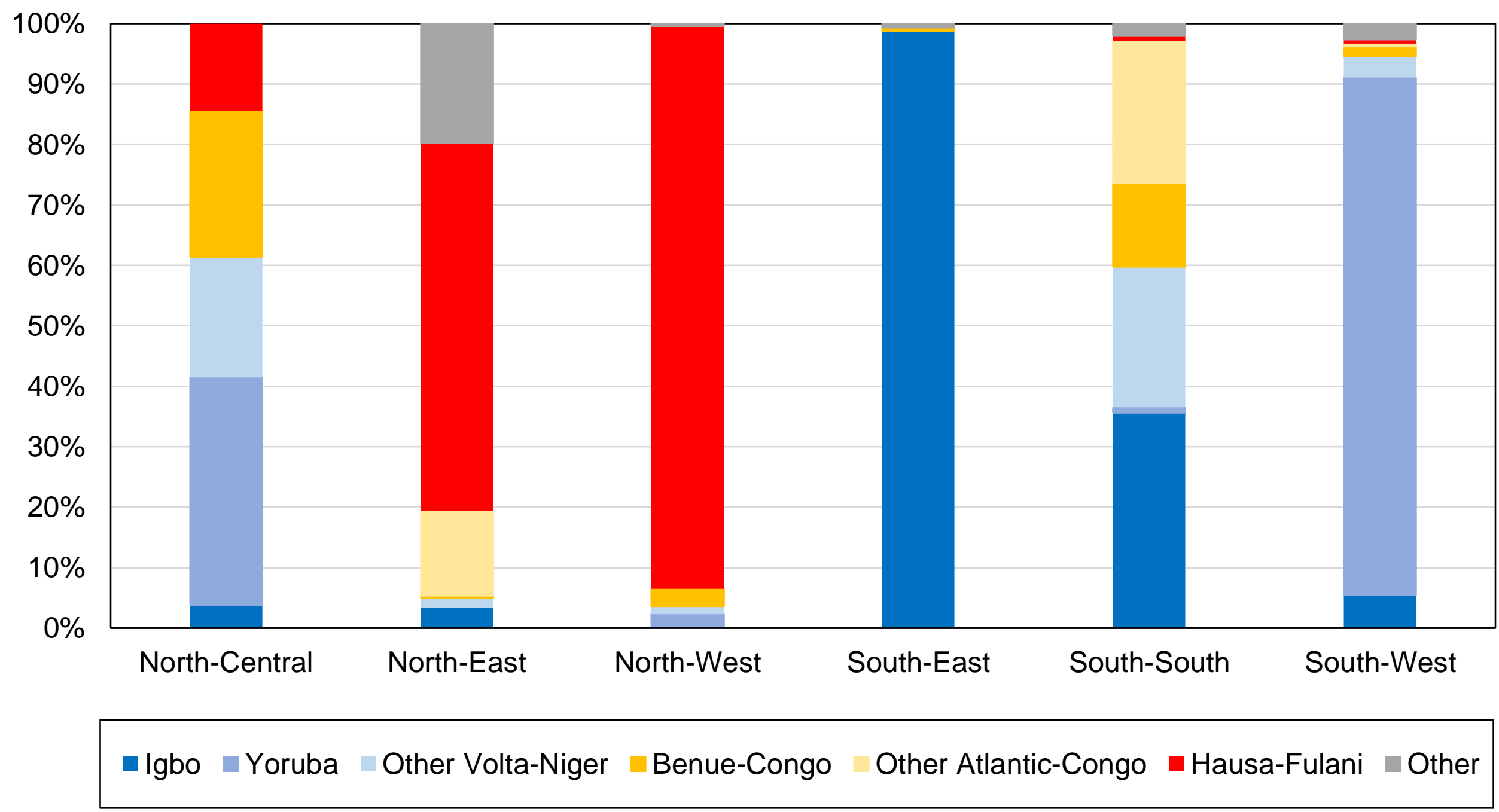

Source: authors' computations using Afrobarometer surveys.

Note: the figure shows the distribution of languages among regions in 2019. 
Figure CA17 - Composition of regions by religion, 2003

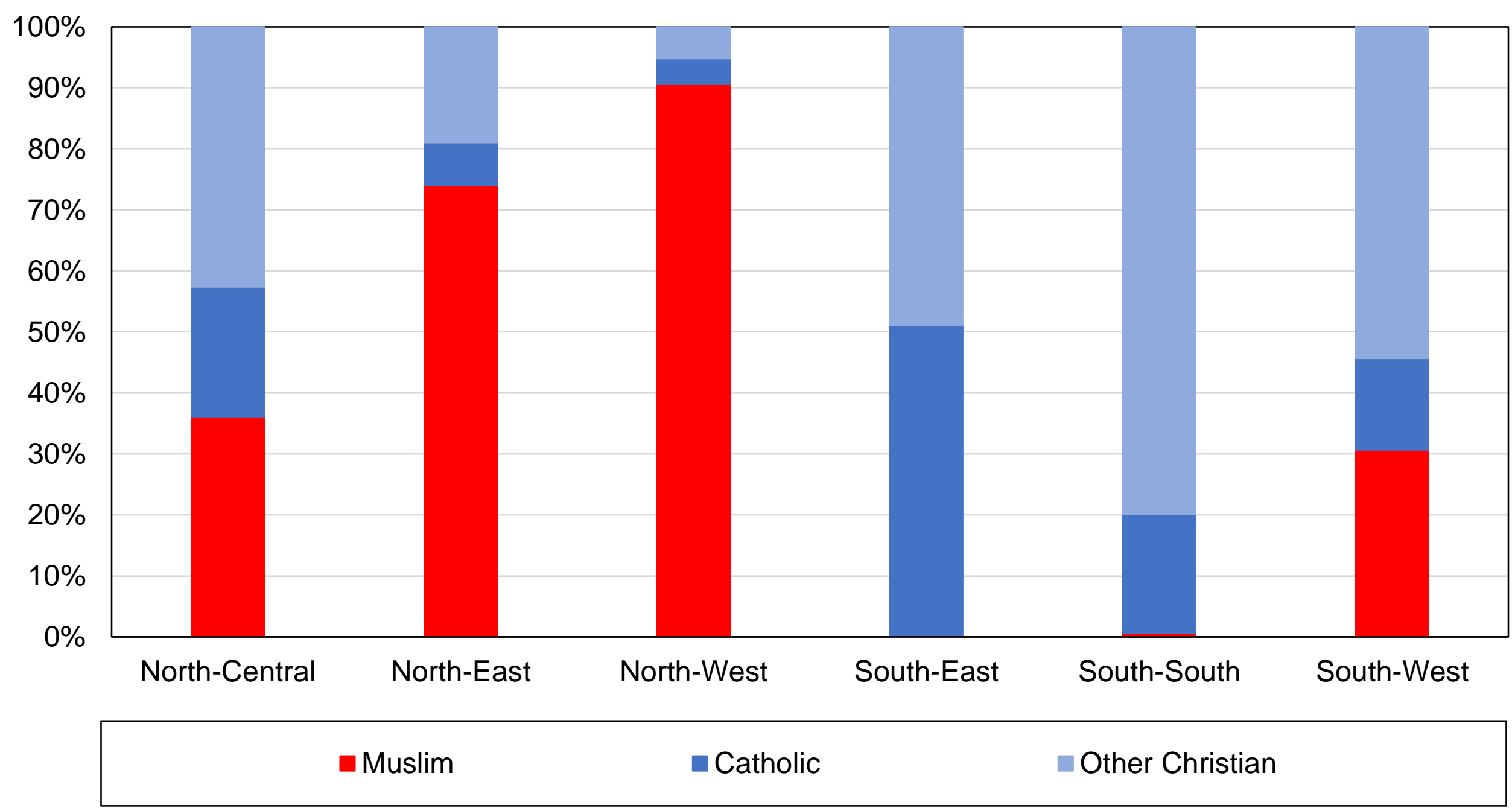

Source: authors' computations using Afrobarometer surveys.

Note: the figure shows the distribution of religious groups by region in 2003. Excludes respondents with no religion or other religions (about $1.5 \%$ of the adult population). 
Figure CA18 - Composition of regions by religion, 2019

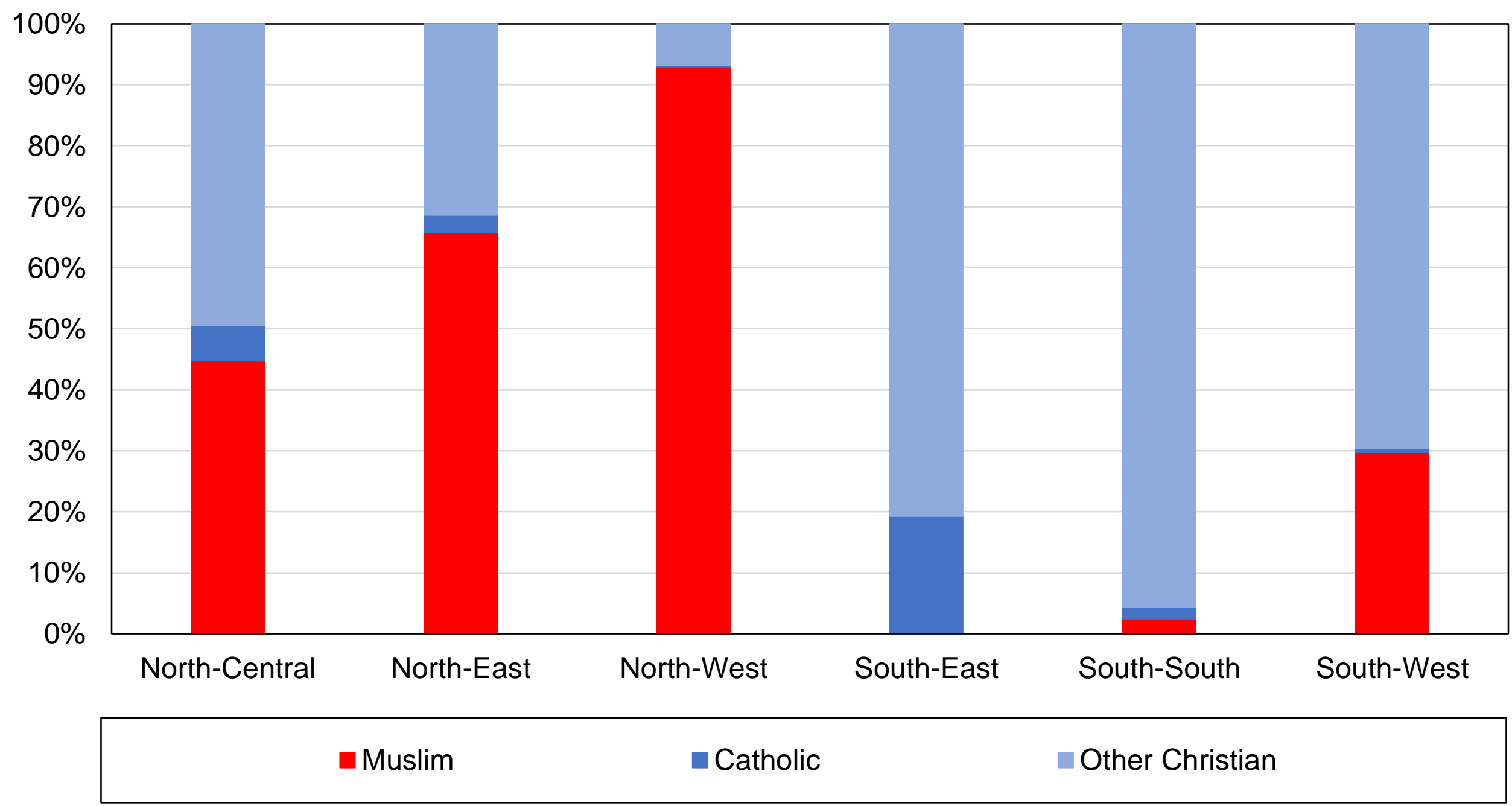

Source: authors' computations using Afrobarometer surveys.

Note: the figure shows the distribution of religious groups by region in 2019. Excludes respondents with no religion or other religions (about $1.5 \%$ of the adult population). 
Figure CB1 - Vote for PDP by education level

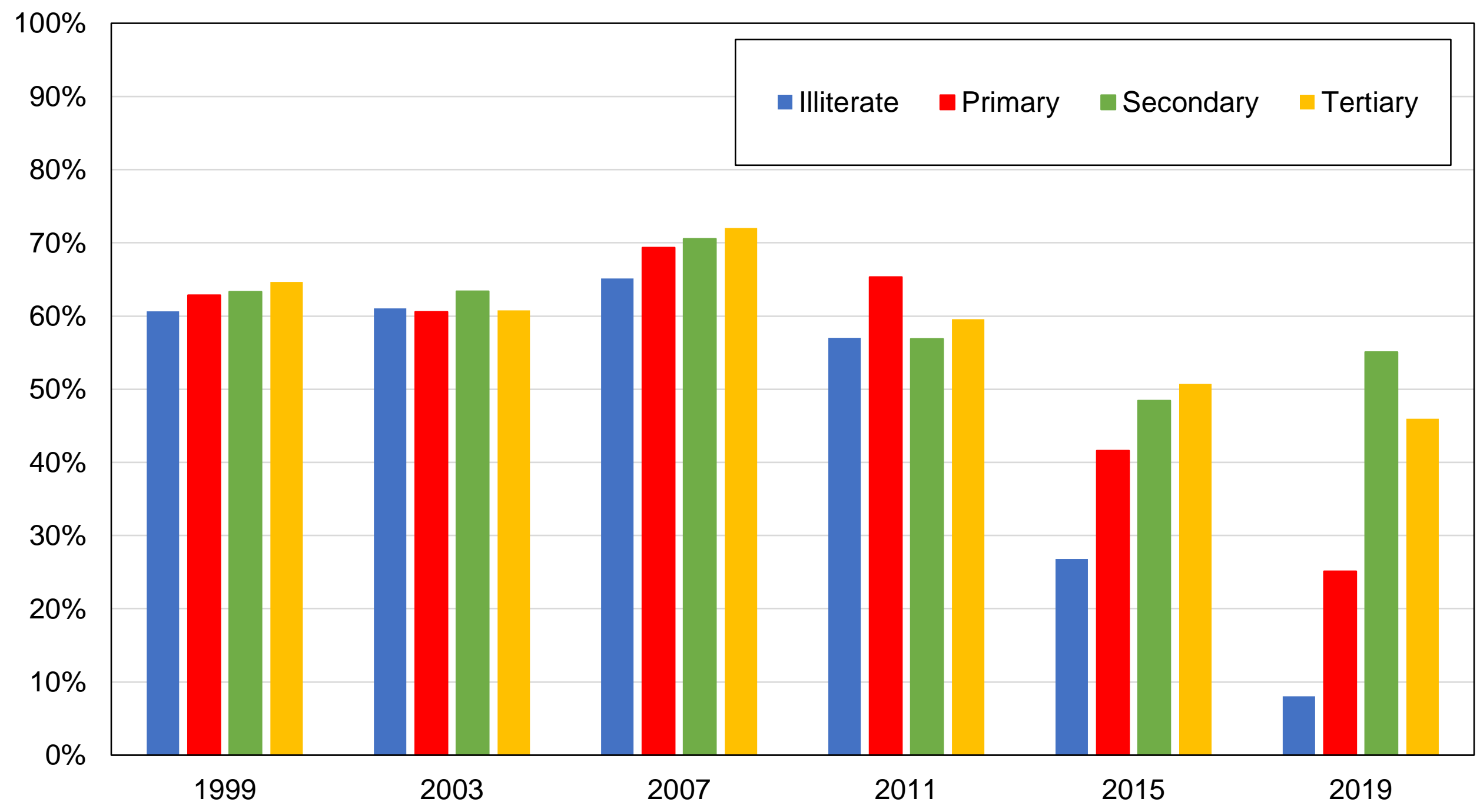

Source: authors' computations using Afrobarometer surveys.

Note: the figure shows the share of votes received by the PDP by education level. 
Figure CB2 - Vote for PDP by education group

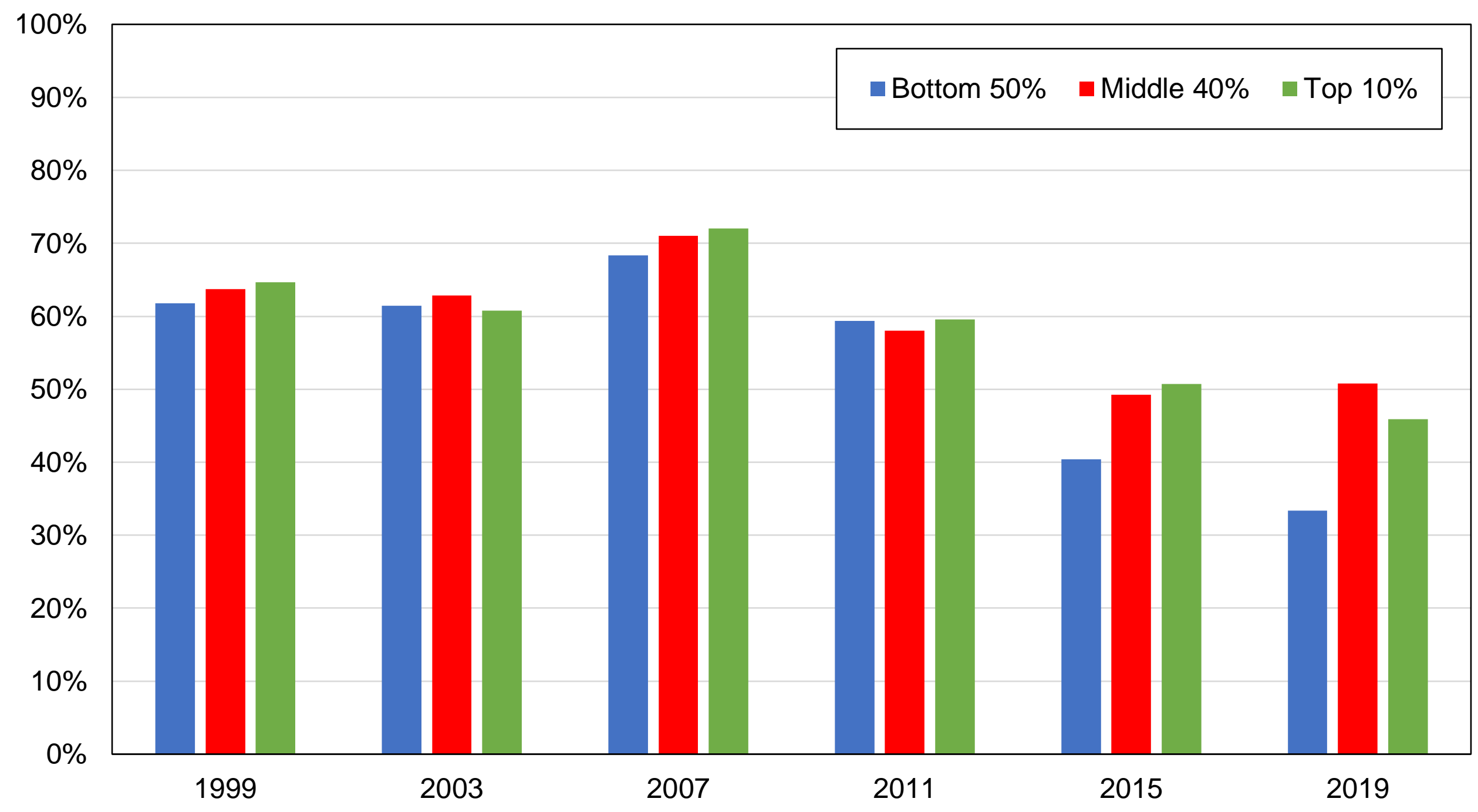

Source: authors' computations using Afrobarometer surveys.

Note: the figure shows the share of votes received by PDP by education group. 
Figure CB3 - Vote for PDP by location

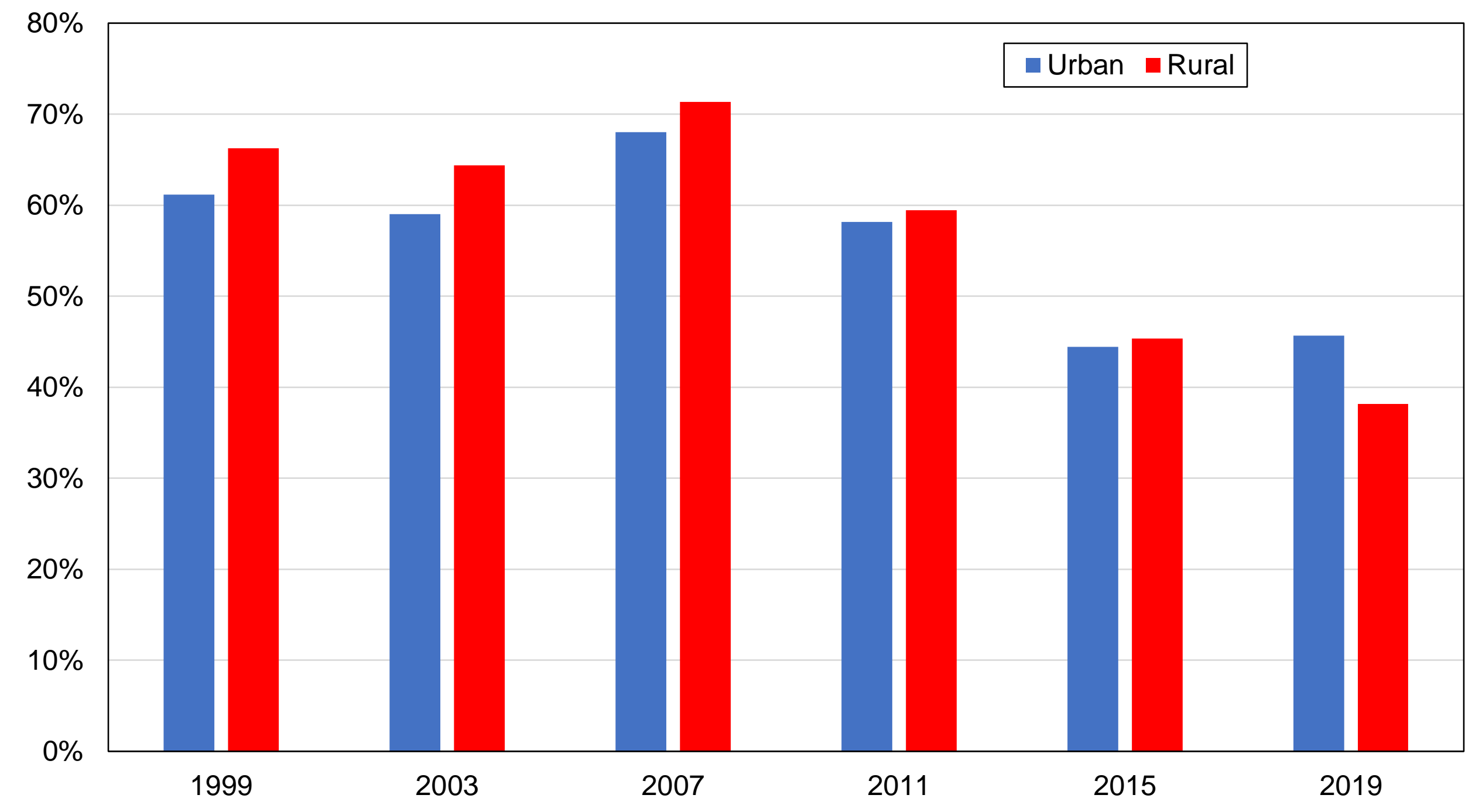

Source: authors' computations using Afrobarometer surveys.

Note: the figure shows the share of votes received by PDP by location. 
Figure CB4 - Vote for PDP by region

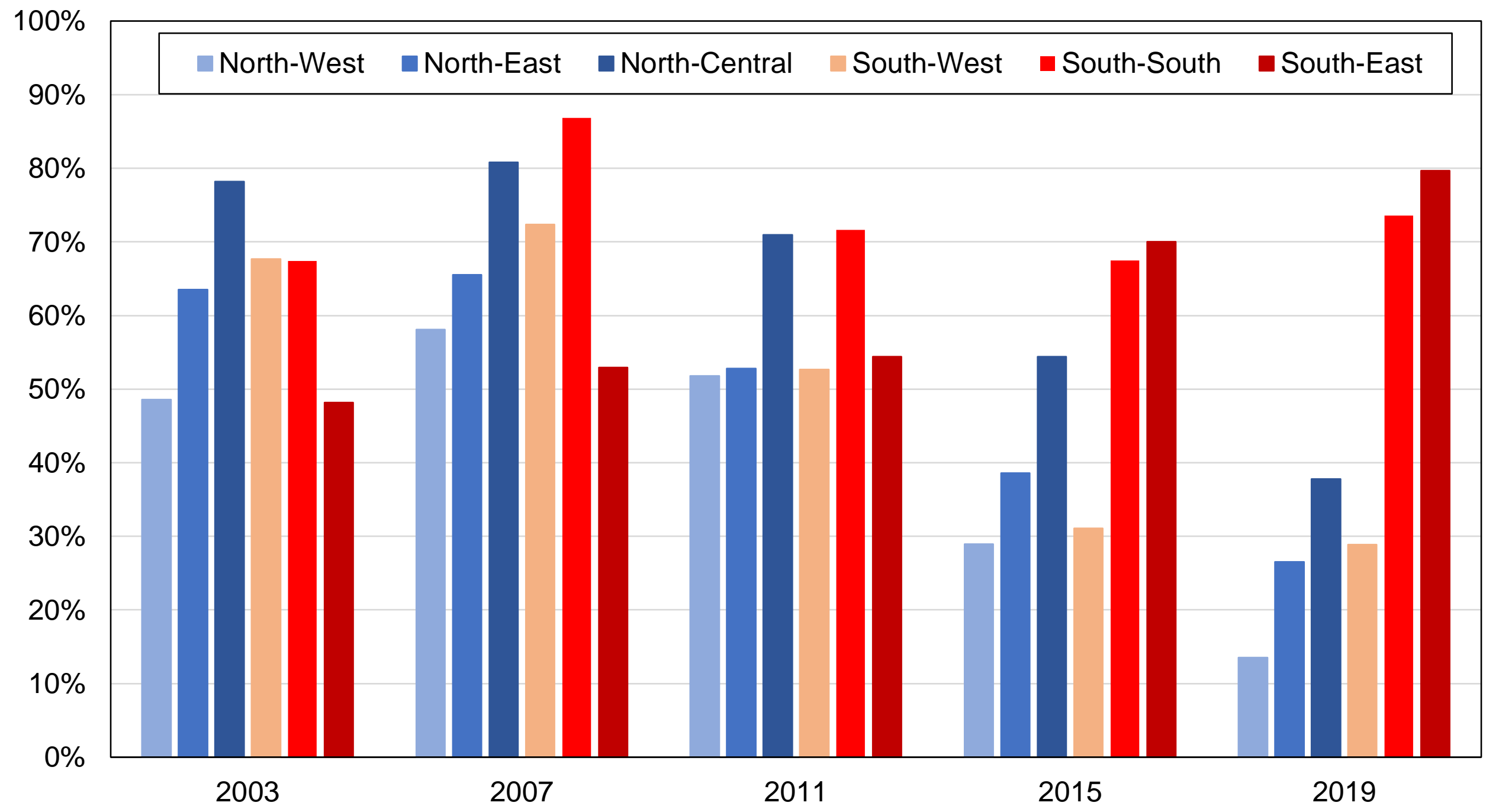

Source: authors' computations using Afrobarometer surveys.

Note: the figure shows the share of votes received by PDP by region of residence. 
Figure CB5 - Vote for PDP by ethnolinguistic group

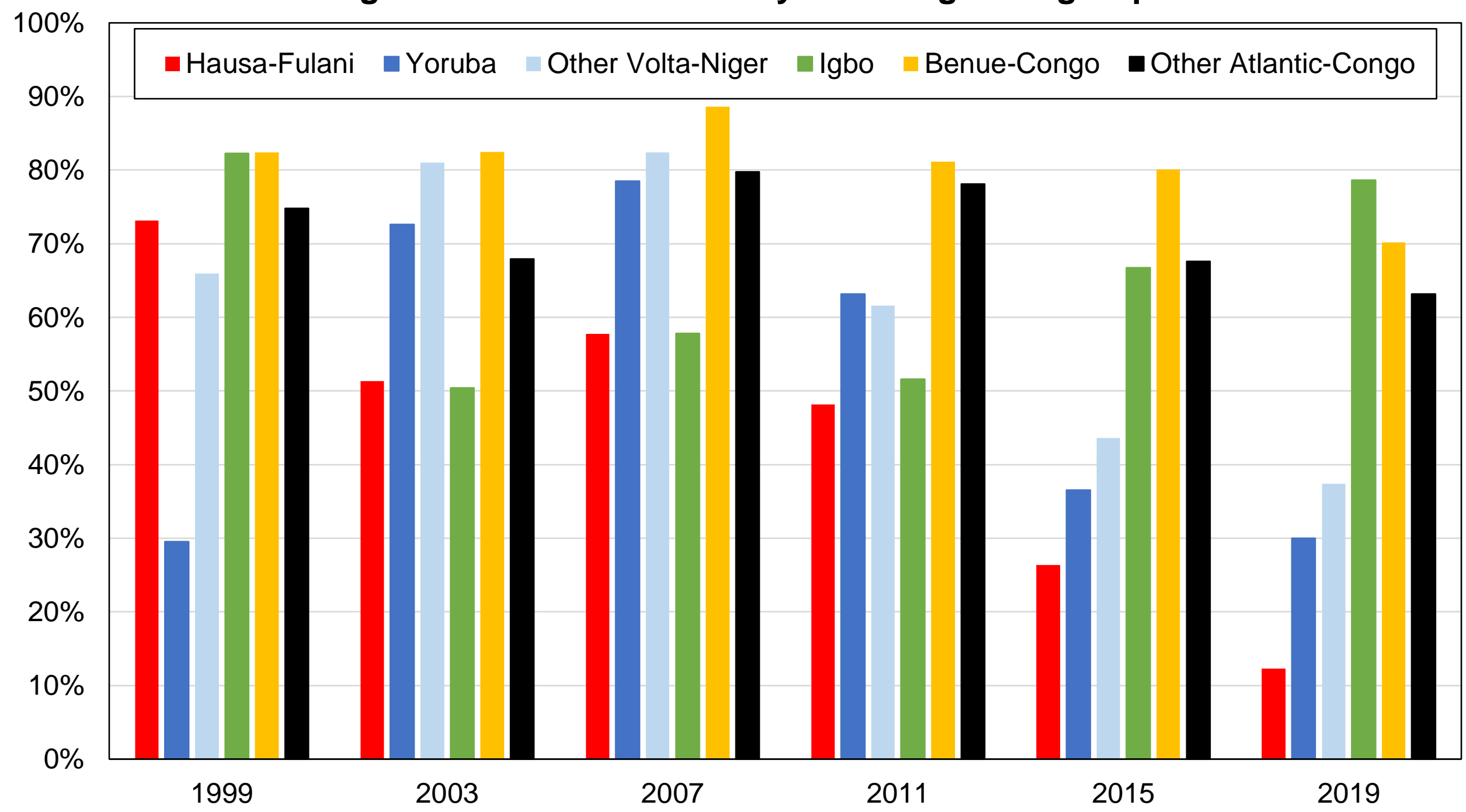

Source: authors' computations using Afrobarometer surveys.

Note: the figure shows the share of votes received by PDP by ethnolinguistic affiliation. 
Figure CB6 - Vote for PDP by age group

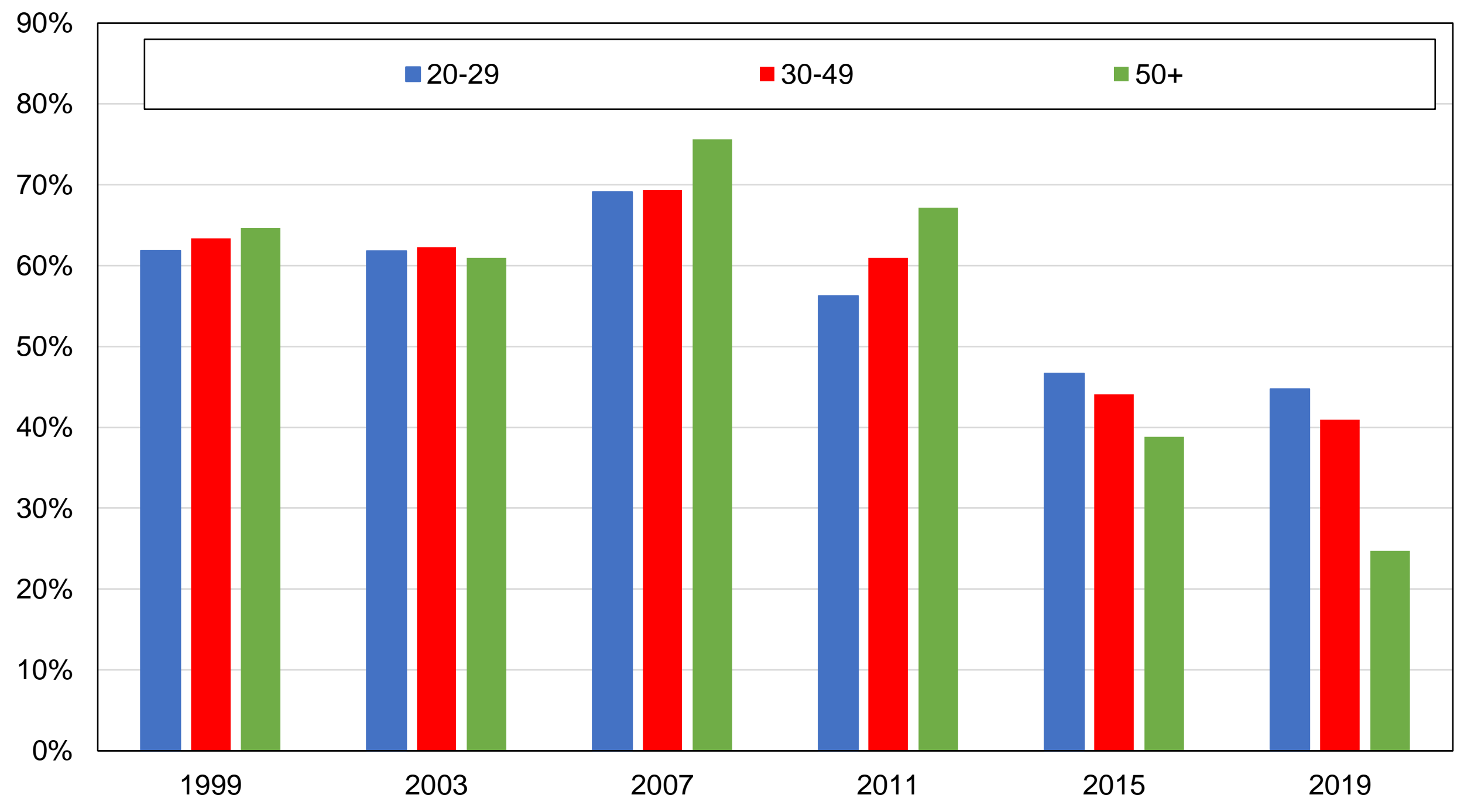

Source: authors' computations using Afrobarometer surveys.

Note: the figure shows the share of votes received by PDP by age group. 
Figure CB7 - Vote for PDP by gender

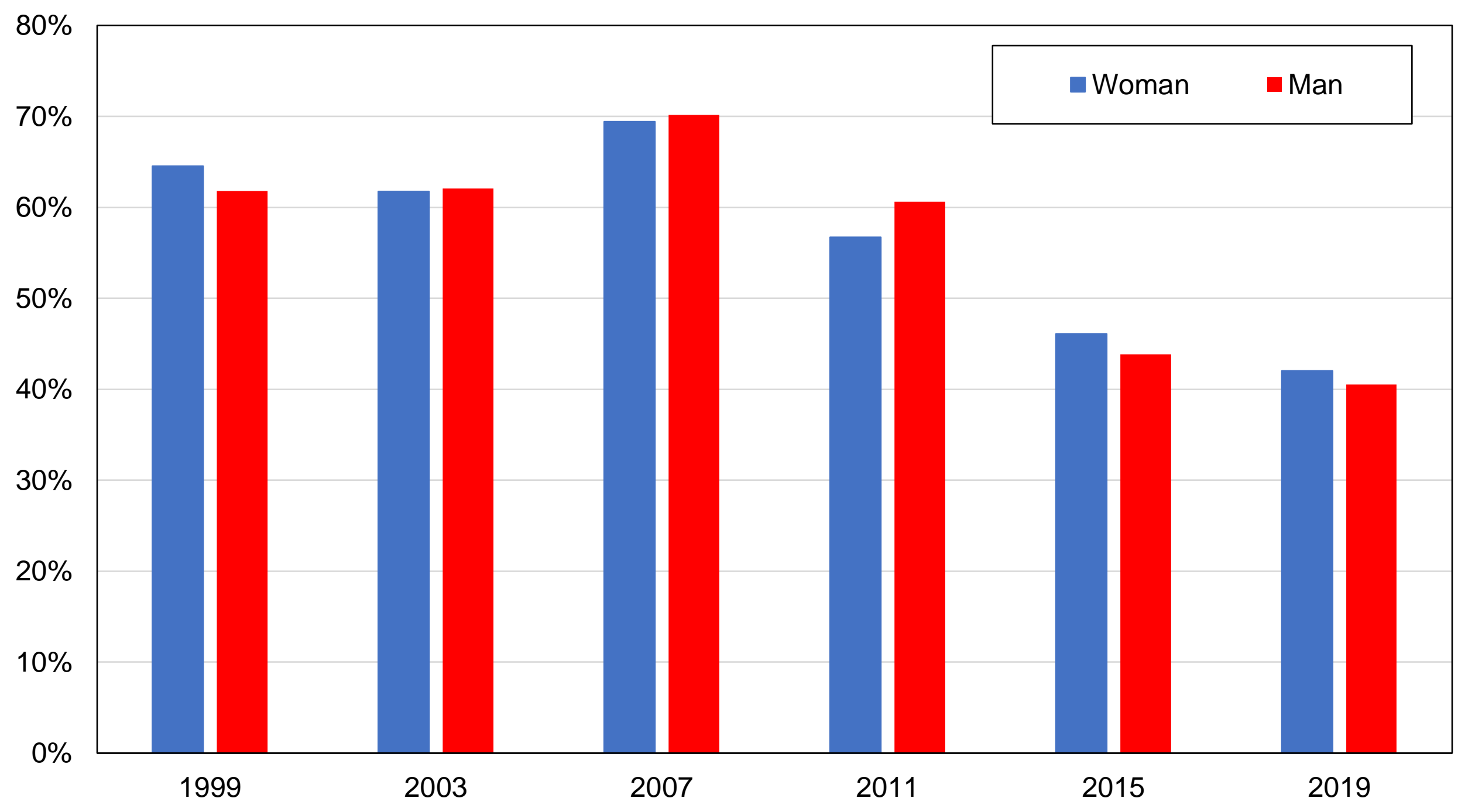

Source: authors' computations using Afrobarometer surveys.

Note: the figure shows the share of votes received by PDP by gender. 
Figure CB8 - Vote for People's Democratic Party by religion

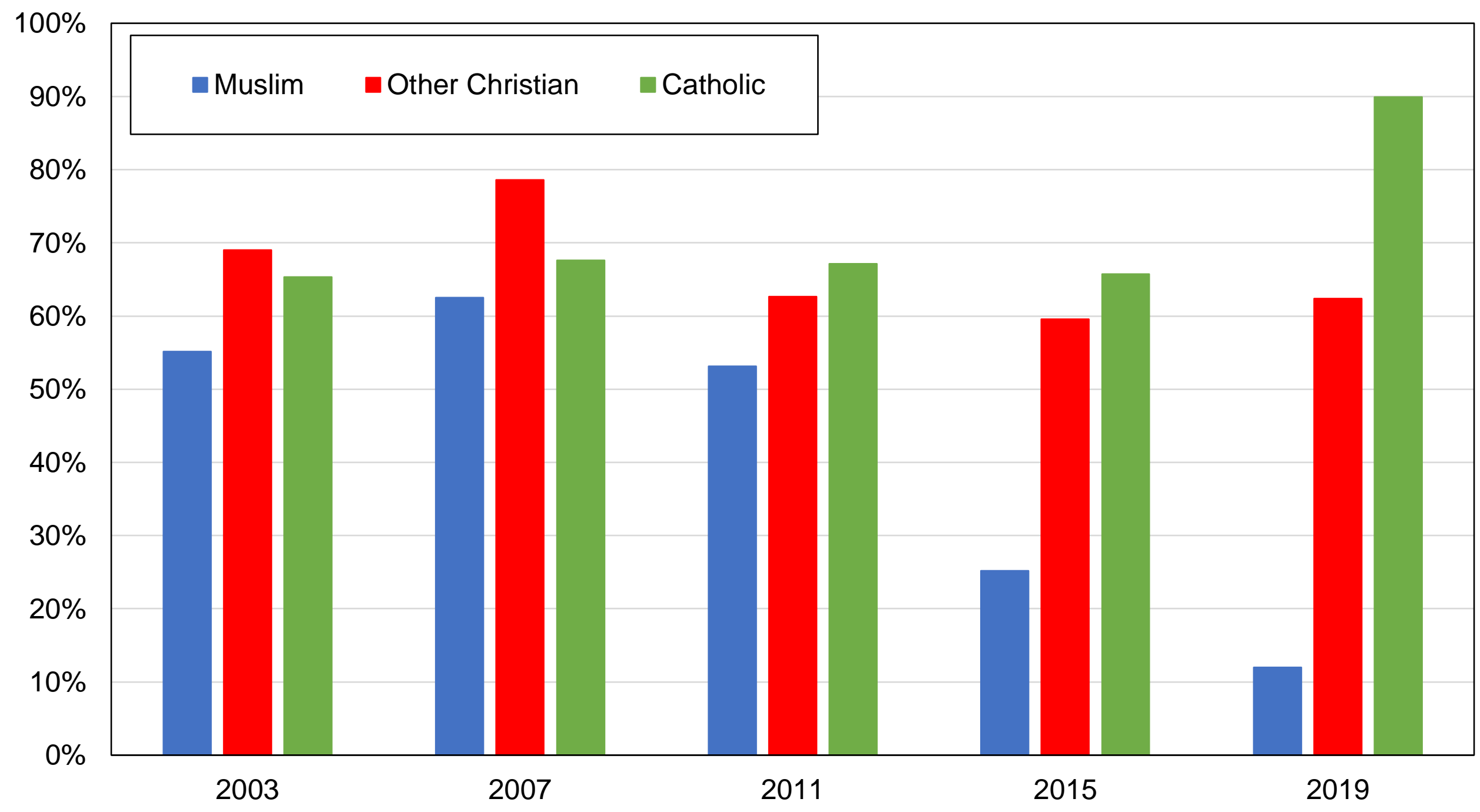

Source: authors' computations using Afrobarometer surveys.

Note: the figure shows the share of votes received by PDP by religious affiliation. 
Figure CB9 - Vote for PDP by employment status

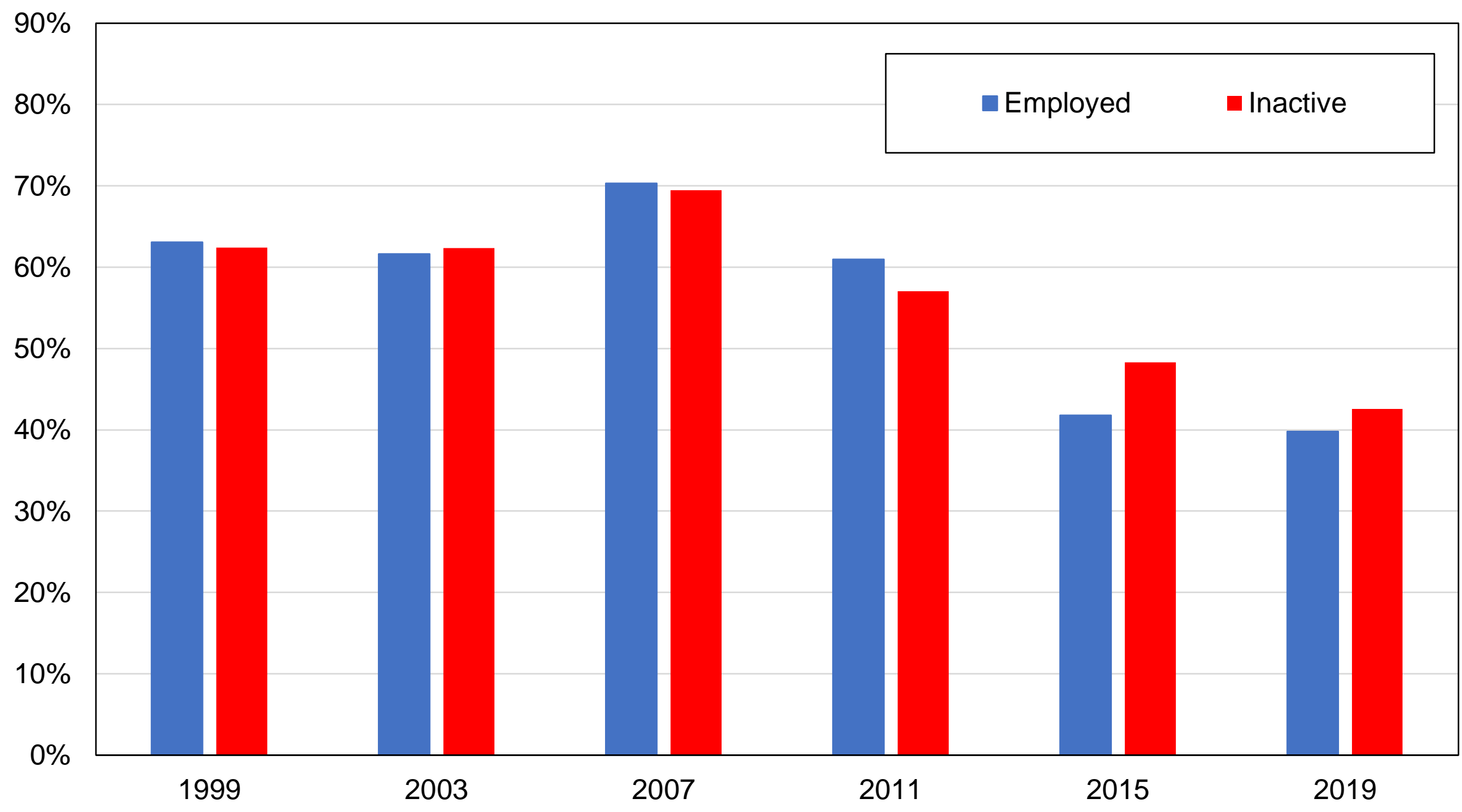

Source: authors' computations using Afrobarometer surveys.

Note: the figure shows the share of votes received by PDP by employment status. 
Figure CB10 - Vote for PDP by occupation

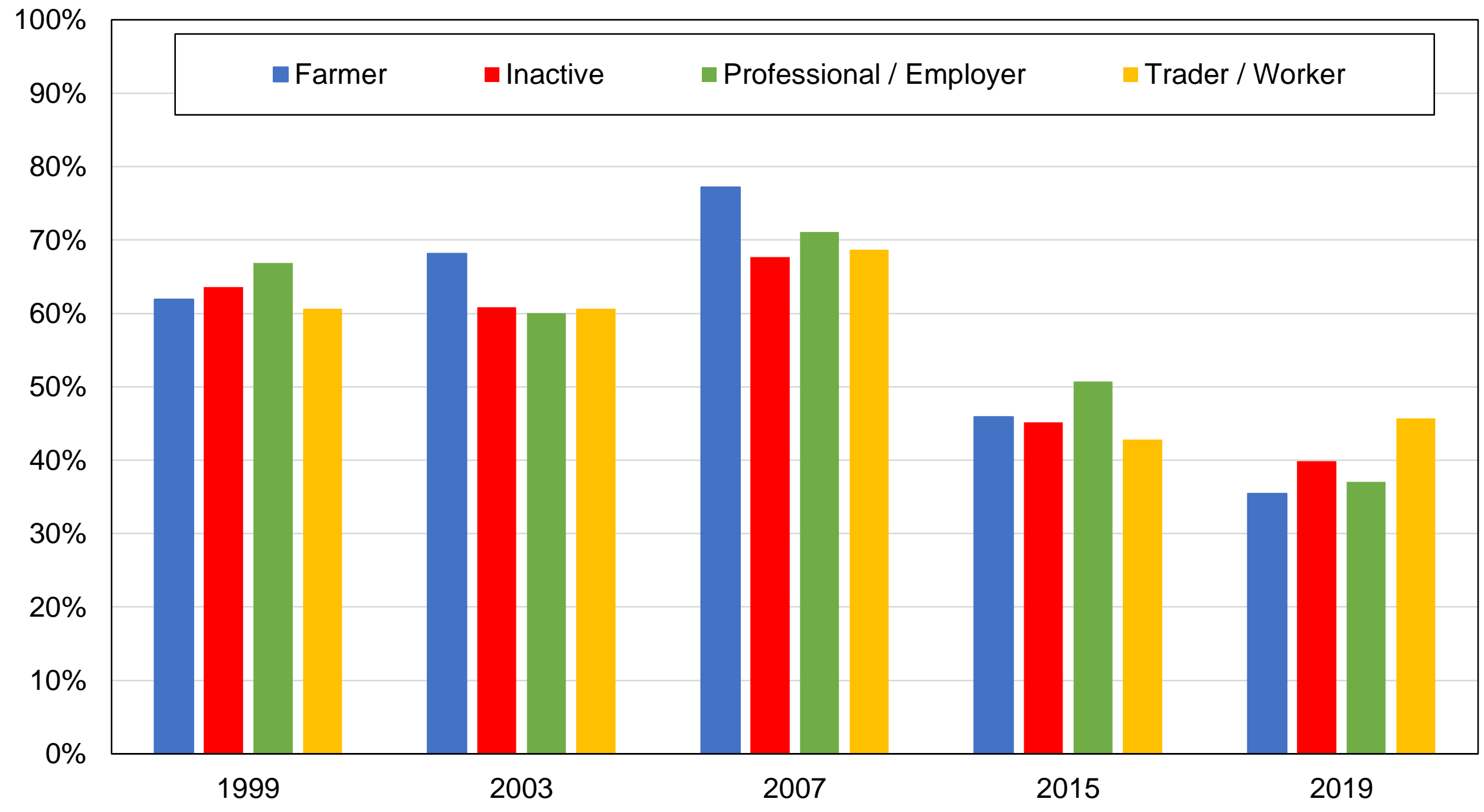

Source: authors' computations using Afrobarometer surveys.

Note: the figure shows the share of votes received by PDP by occupation. 
Figure CB11 - Vote for PDP by religion and education, 2003

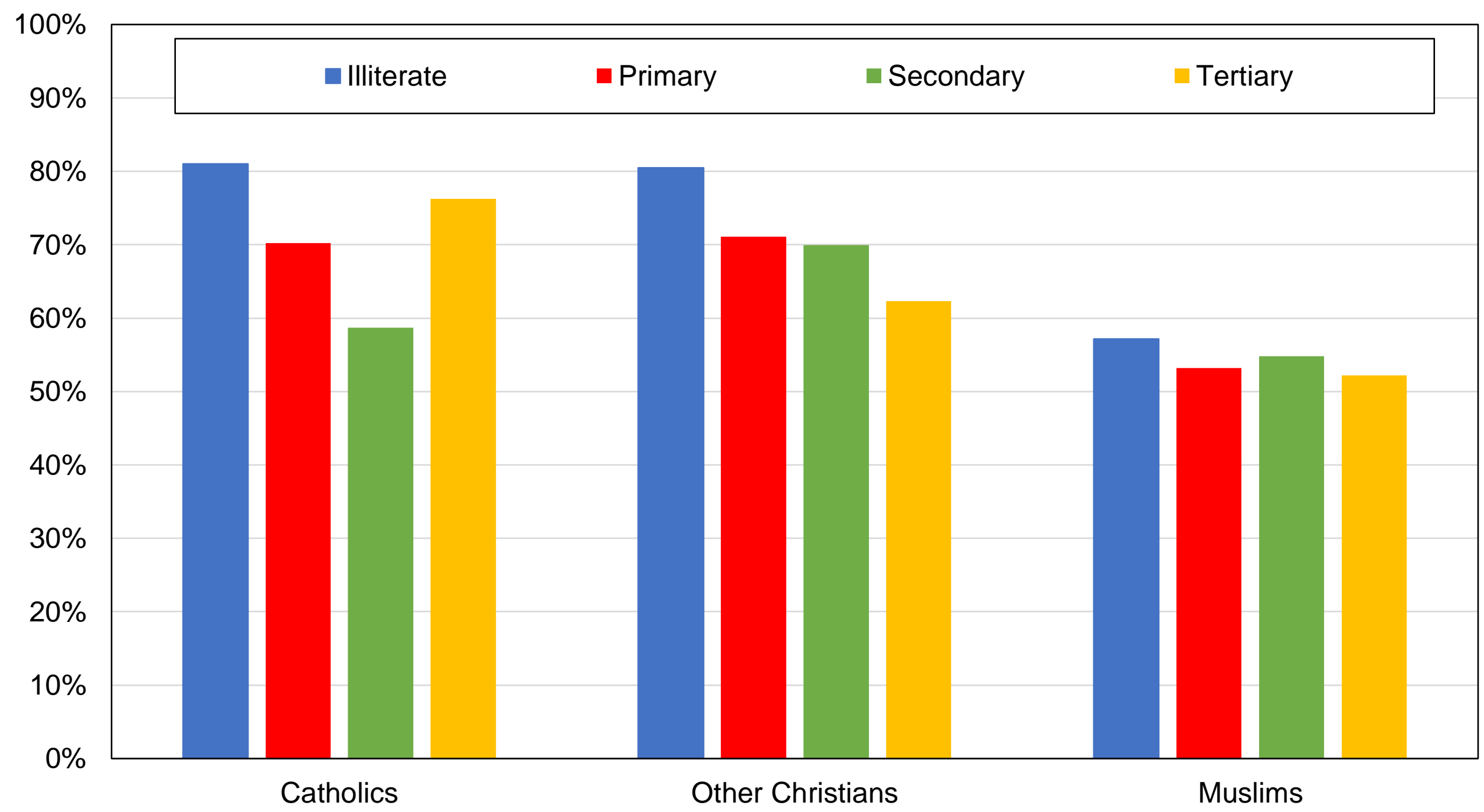

Source: authors' computations using Afrobarometer surveys.

Note: the figure shows the share of votes received by the PDP by education among each religious group. 
Figure CB12 - Vote for PDP by religion and education, 2019

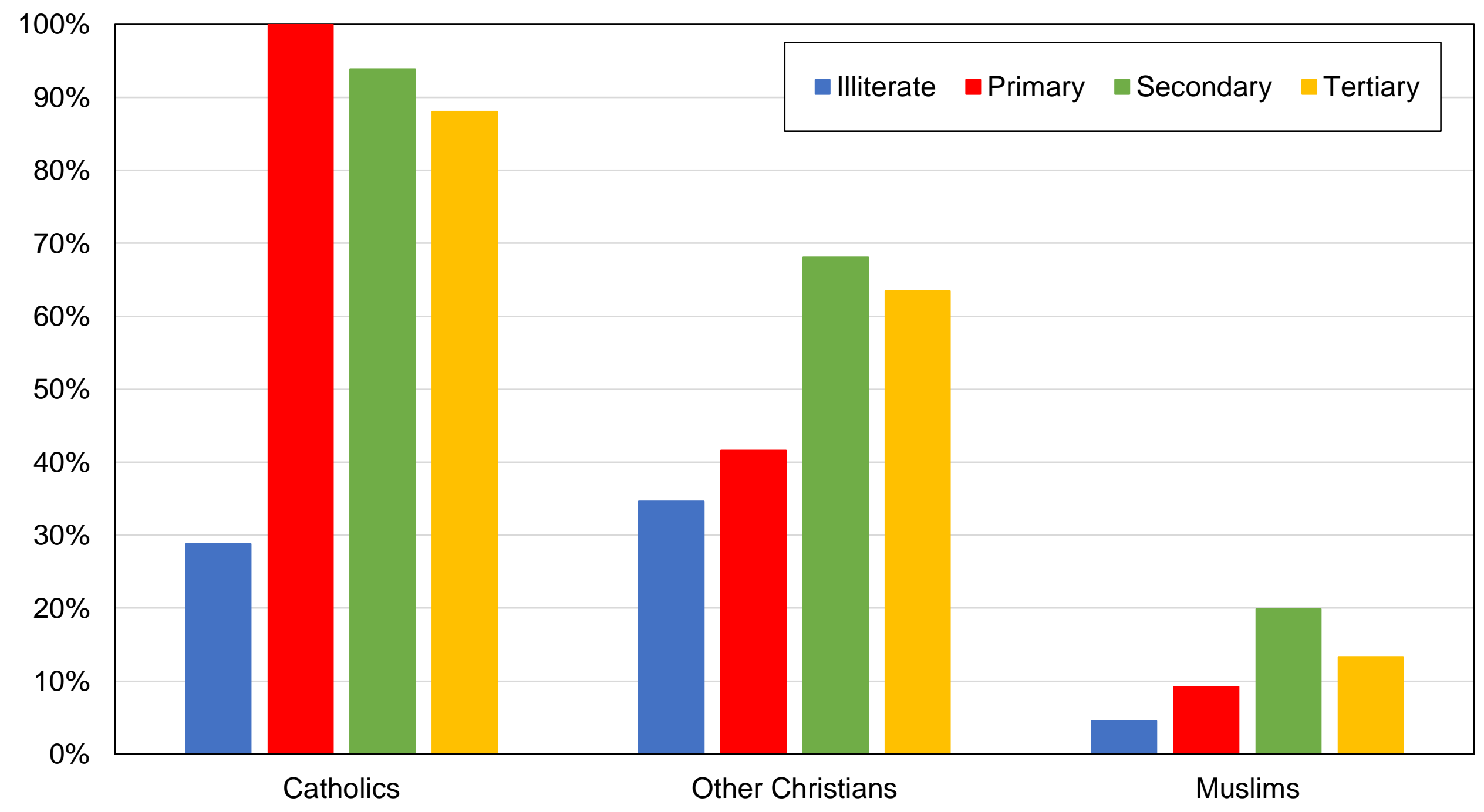

Source: authors' computations using Afrobarometer surveys.

Note: the figure shows the share of votes received by the PDP by education among each religious group. 
Figure CB13 - Vote for PDP by religion and region, 2003

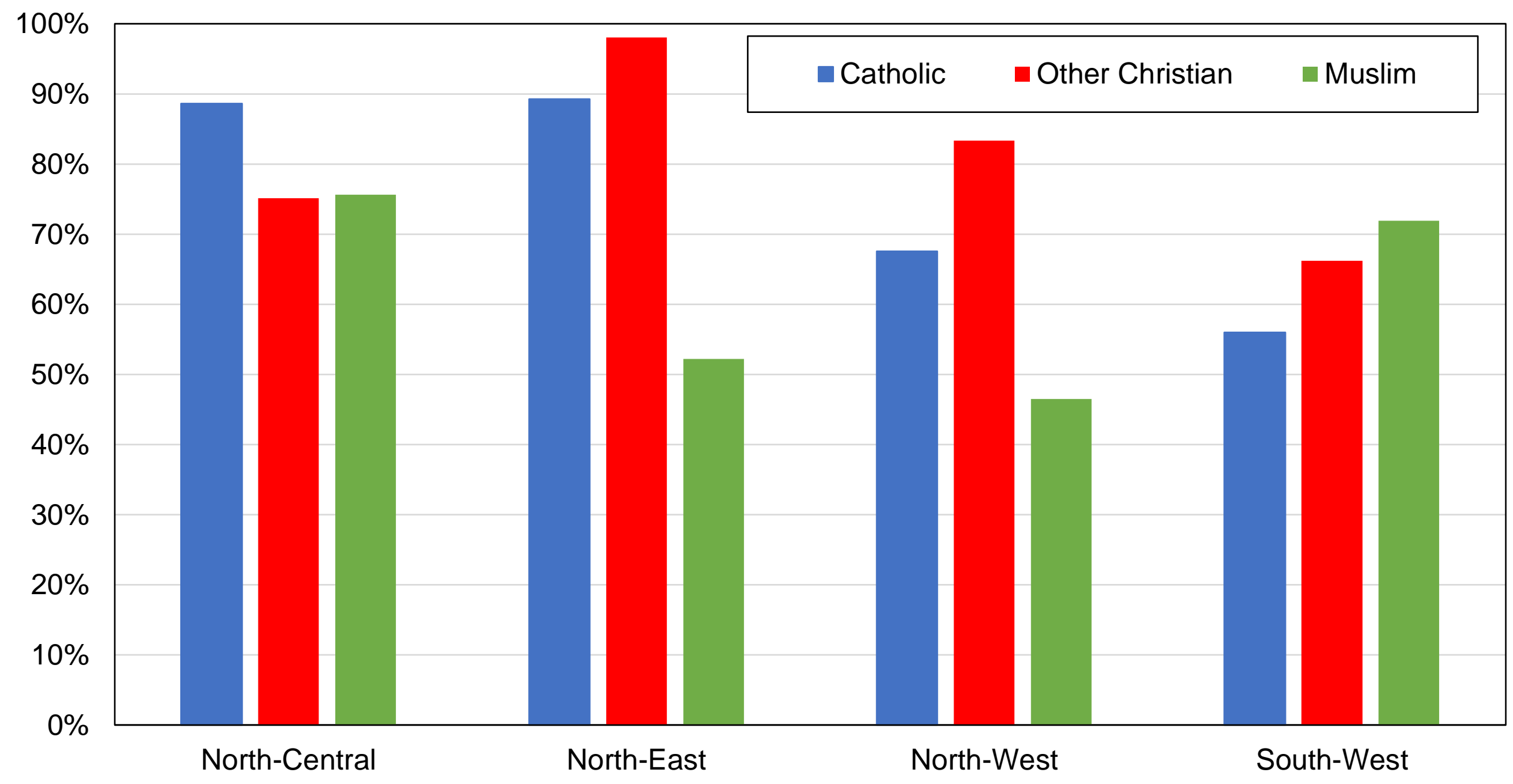

Source: authors' computations using Afrobarometer surveys.

Note: the figure shows the share of votes received by the PDP by religion within each region. Excludes the South-South and South-East regions due to low sample sizes and their higher religious homogeneity. 
Figure CB14 - Vote for PDP by religion and region, 2019

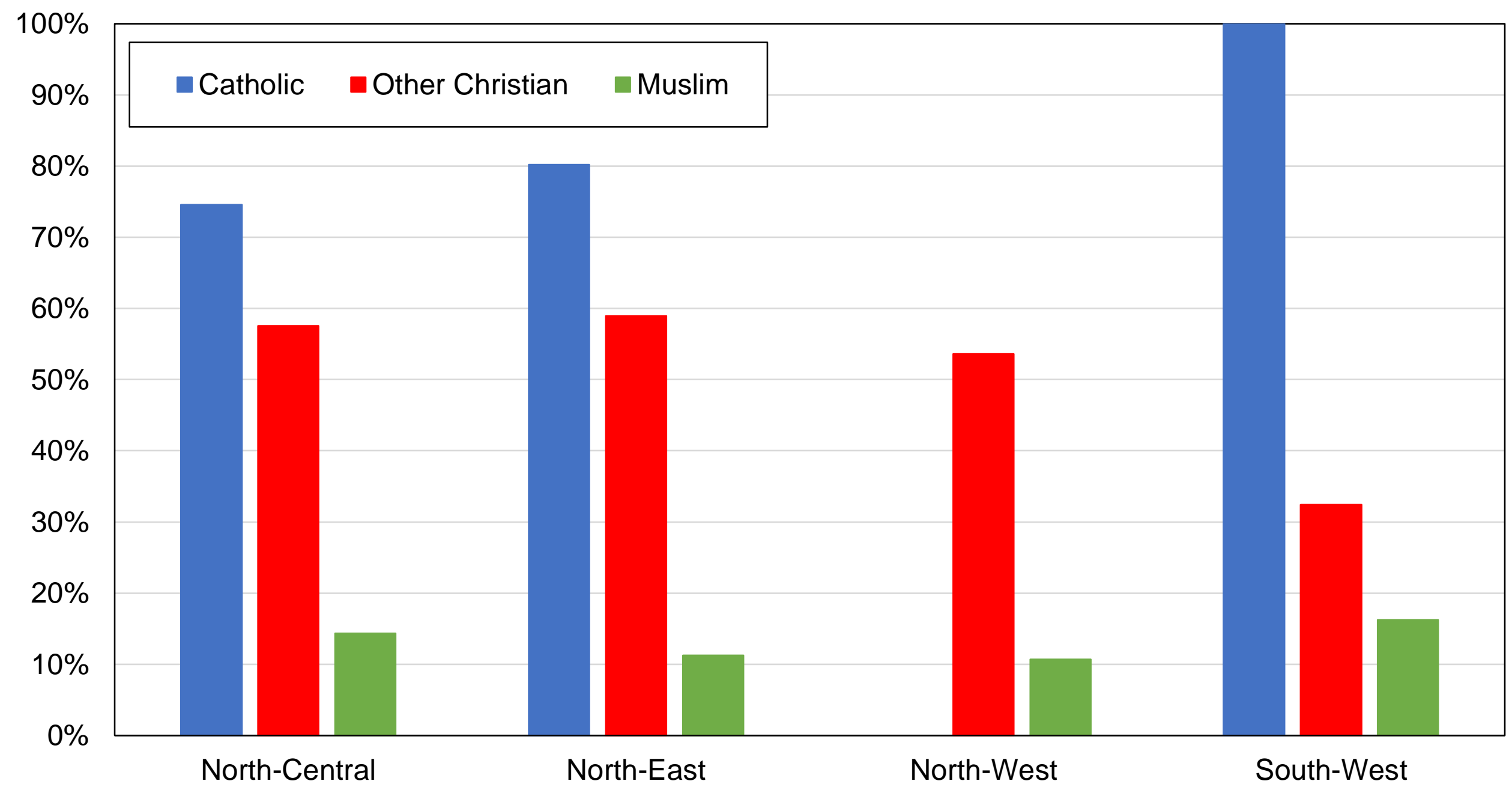

Source: authors' computations using Afrobarometer surveys.

Note: the figure shows the share of votes received by the PDP by religion within each region. Excludes the South-South and South-East regions due to low sample sizes and their higher religious homogeneity. 
Figure CC1 - Vote for PDP among the secondary- and tertiary-educated

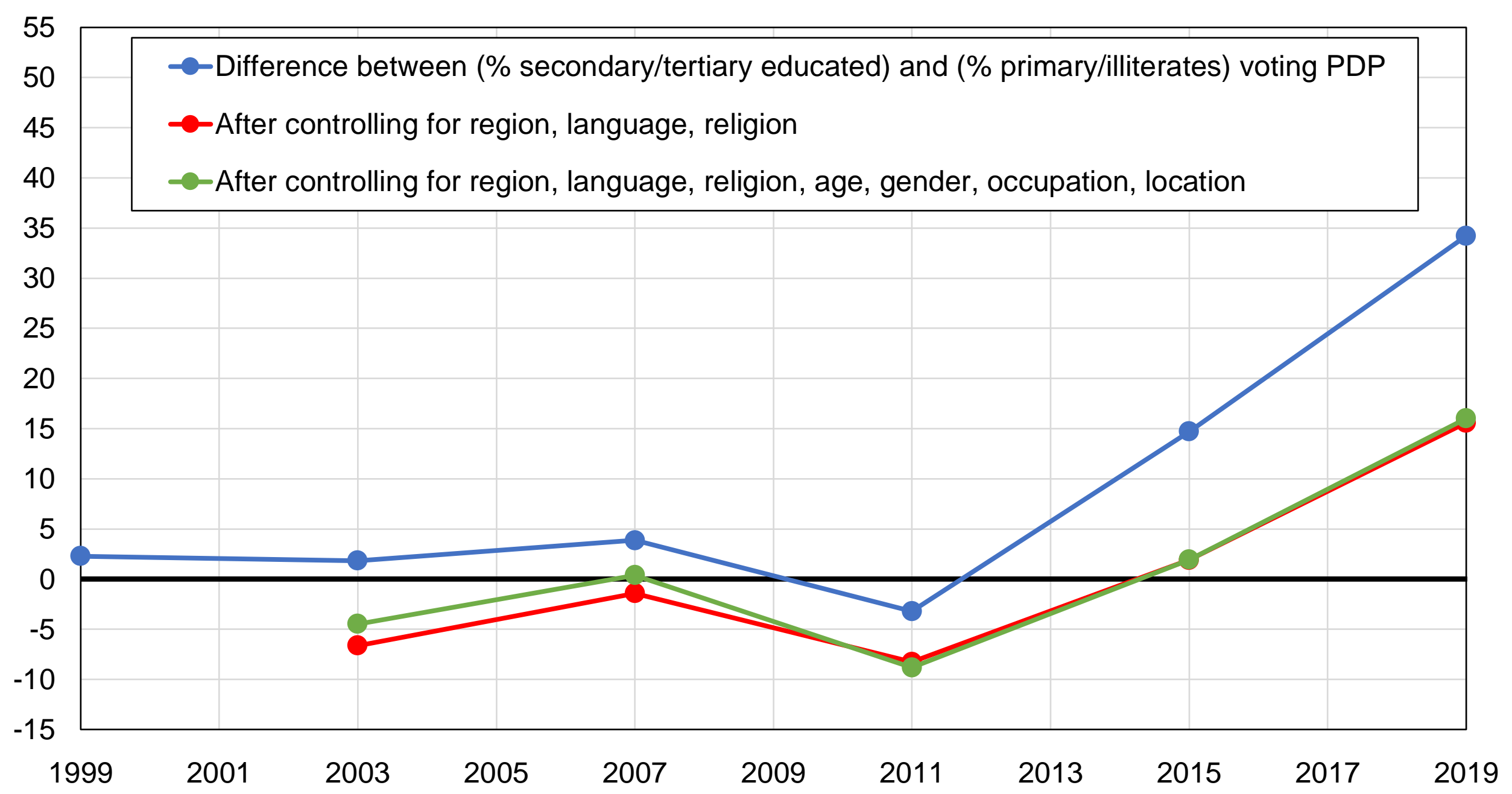

Source: authors' computations using Afrobarometer surveys.

Note: the figure shows the difference between the share of secondary- and tertiary-educated and the share of primary-educated voters and illiterates voting PDP, before and after controlling for other variables. 


\section{Figure CC2 - Vote for PDP among highest-educated voters}

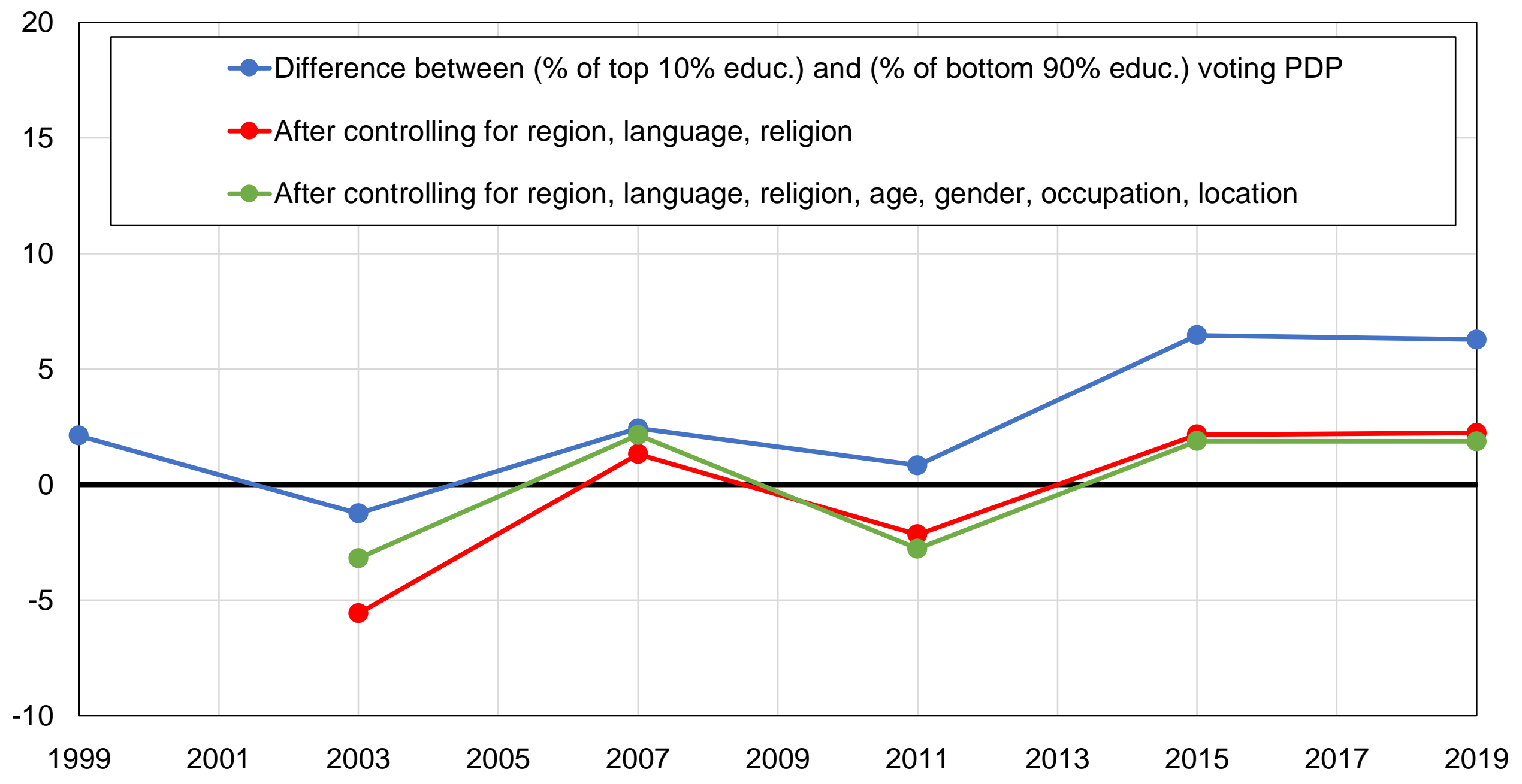

Source: authors' computations using Afrobarometer surveys.

Note: the figure shows the difference between the share of top $10 \%$ educated voters and the share of lowest $90 \%$ educated voting for the PDP, before and after controlling for other variables. 


\section{Figure CC3 - Vote for PDP among lowest-educated voters}

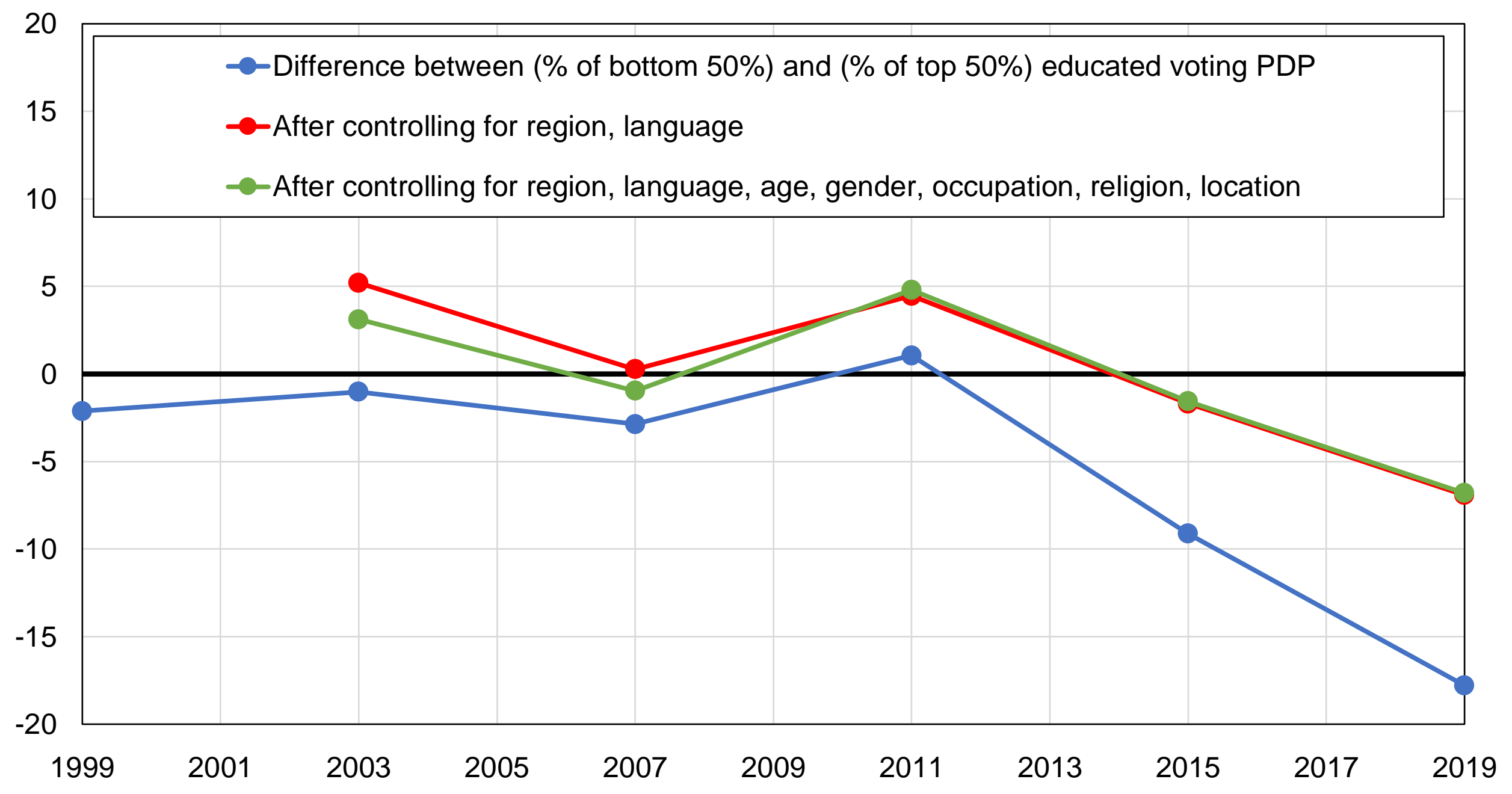

Source: authors' computations using Afrobarometer surveys.

Note: the figure shows the difference between the share of bottom $50 \%$ voters and the share of top $50 \%$ voters in terms of education voting for the PDP, before and after controlling for other variables. 


\section{Figure CC4 - Vote for PDP among women}

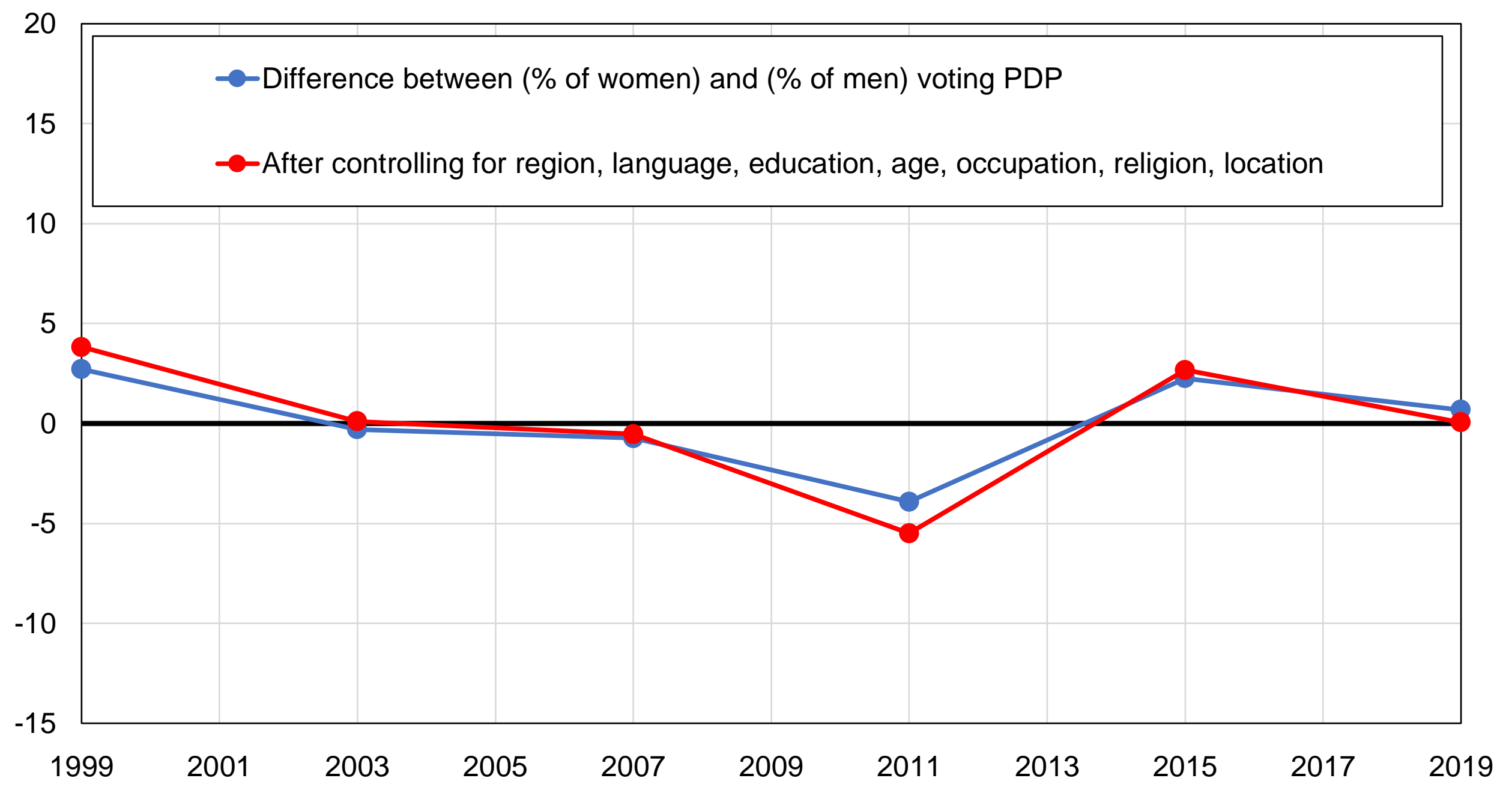

Source: authors' computations using Afrobarometer surveys.

Note: the figure shows the difference between the share of women and the share of men voting for the PDP, before and after controlling for other variables. 


\section{Figure CC5 - Vote for PDP among rural areas}

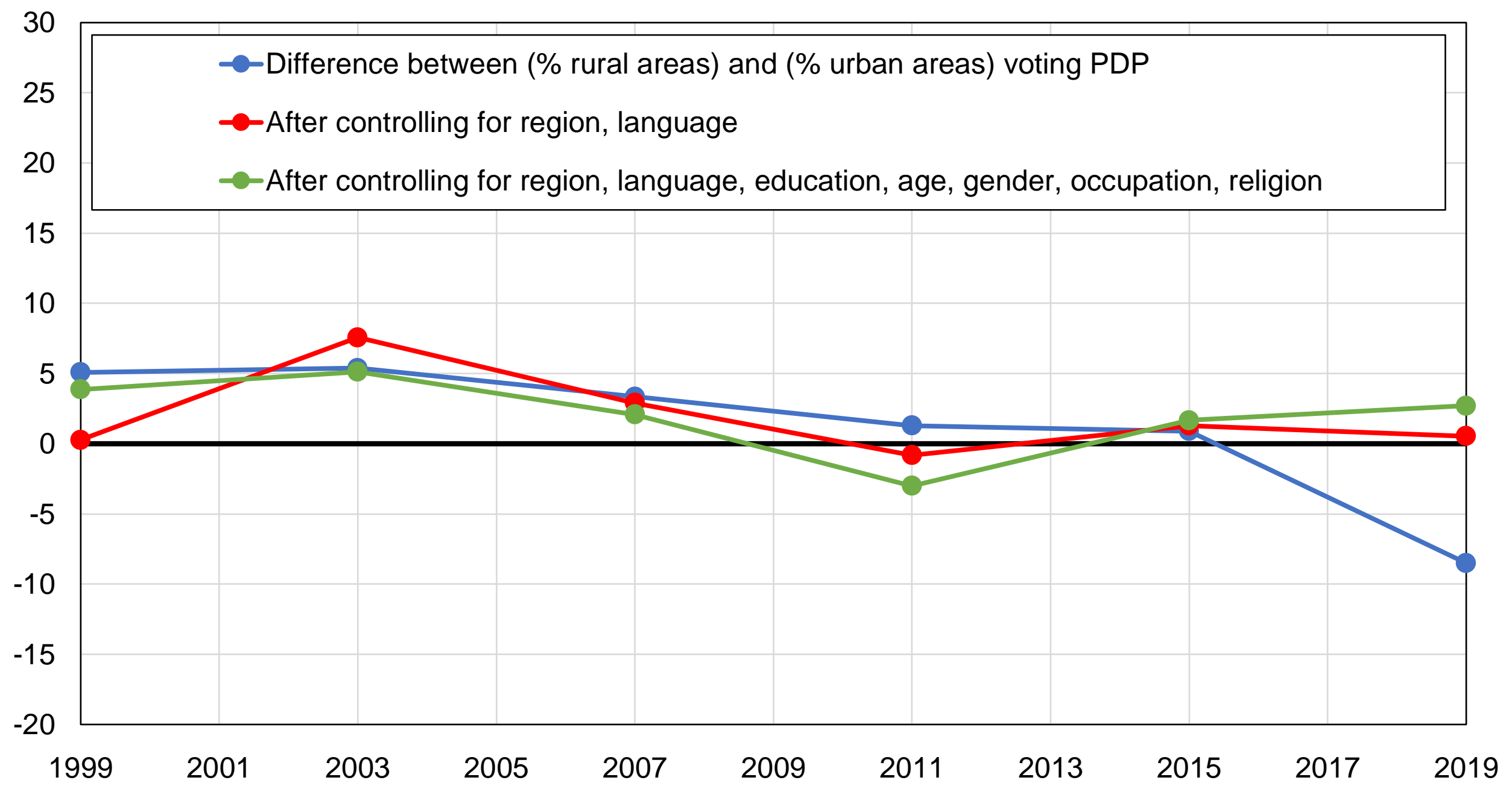

Source: authors' computations using Afrobarometer surveys.

Note: the figure shows the difference between the share of voters from rural areas and the share of urban voters voting for the PDP, before and after controlling for other variables. 


\section{Figure CC6 - Vote for PDP among North-West region residents}

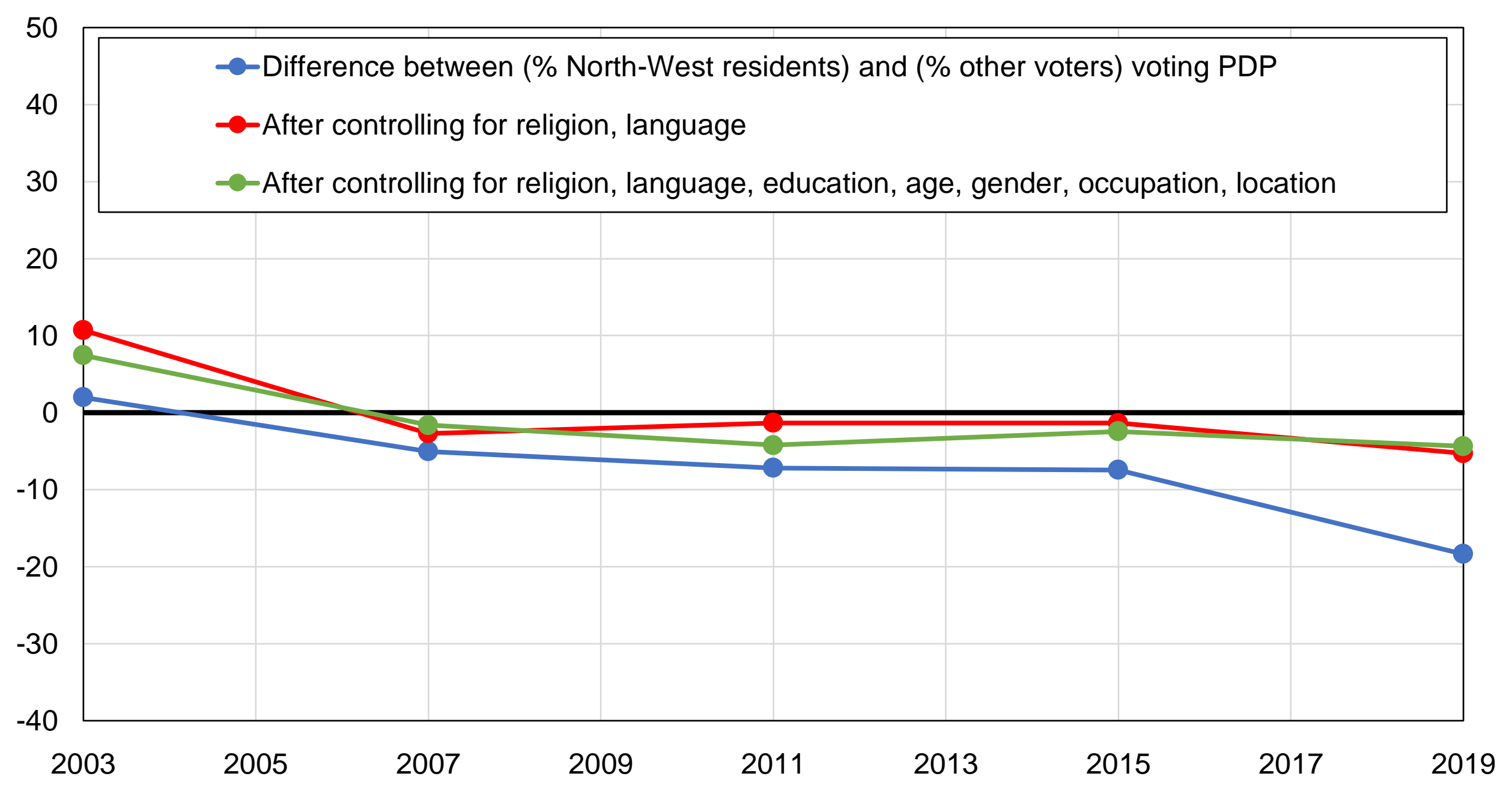

Source: authors' computations using Afrobarometer surveys.

Note: the figure shows the difference between the share of North-West region residents and the share of other voters voting for the PDP, before and after controlling for other variables. 


\section{Figure CC7 - Vote for PDP among the Igbo and the Hausa-Fulani}

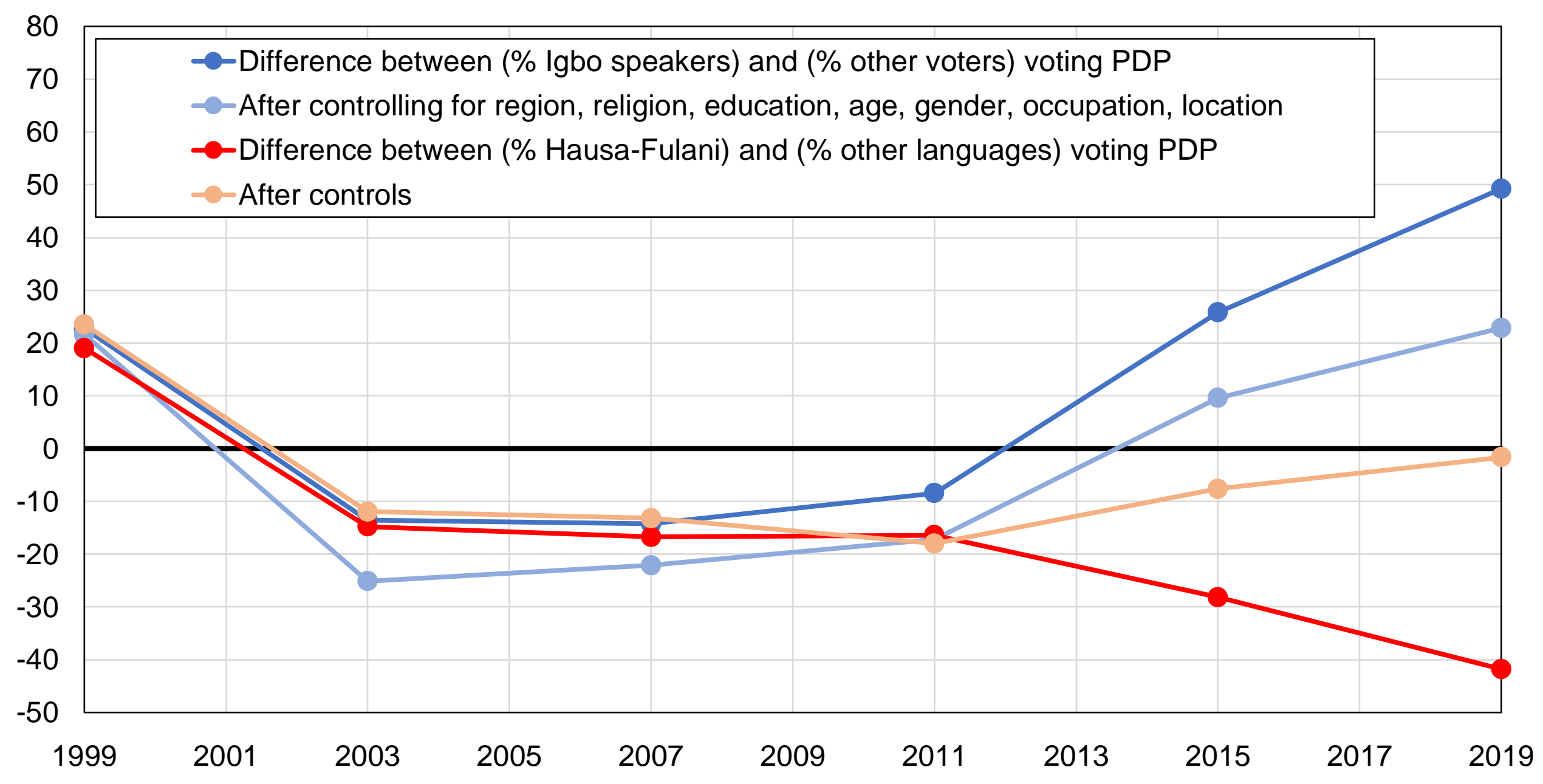

Source: authors' computations using Afrobarometer surveys.

Note: the figure shows the difference between the share of voters speaking lgbo and the share of other voters voting for the PDP, and the same difference for Hausa-Fulani speakers, before and after controlling for other variables. 


\section{Figure CC8 - Vote for PDP among farmers}

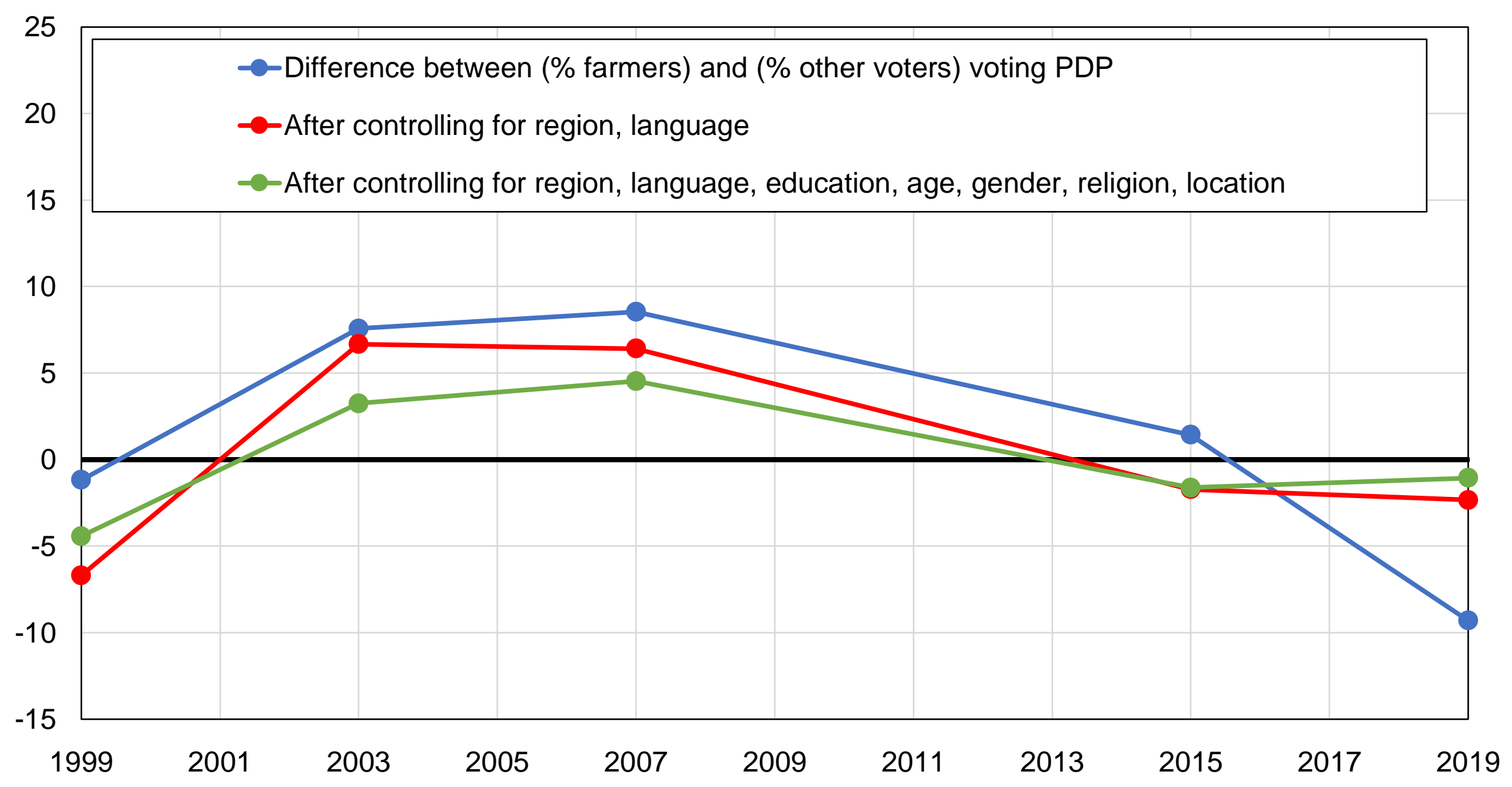

Source: authors' computations using Afrobarometer surveys.

Note: the figure shows the difference between the share of farmers and the share of other voters voting for the PDP, before and after controlling for other variables. 


\section{Figure CC9 - Vote for PDP among Catholics and Muslims}

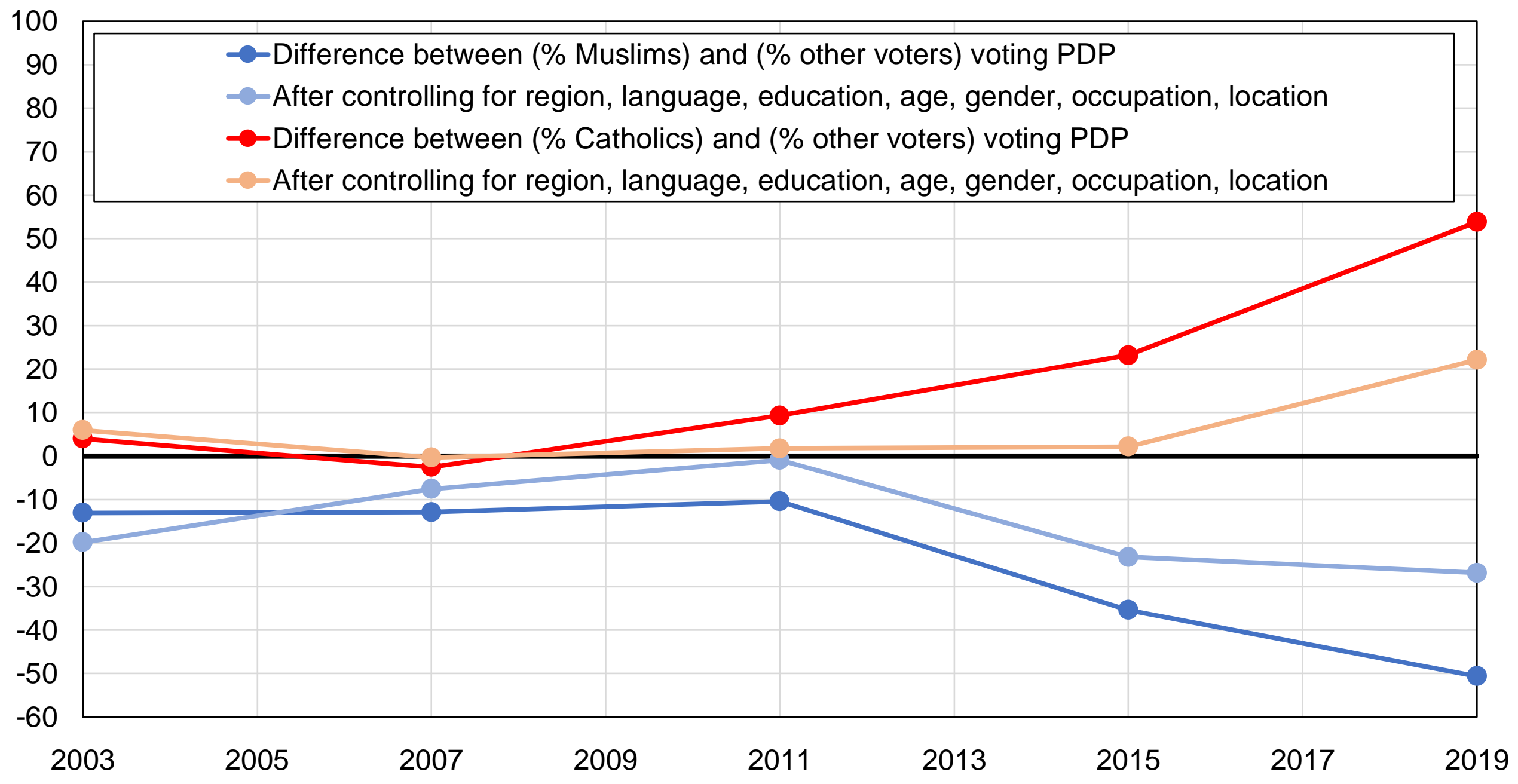

Source: authors' computations using Afrobarometer surveys.

Note: the figure shows the difference between the share of Muslim voters and the share of other voters voting for PDP, and the same difference for Catholics, before and after controlling for other variables. 


\begin{tabular}{|cllc|}
\hline \multicolumn{4}{|c|}{ Table C1 - Survey data sources } \\
\hline Year & Survey & Source & Sample size \\
\hline 2000 & Afrobarometers Wave 1 & Afrobarometers & 2004 \\
2004 & Afrobarometers Wave 2-3 & Afrobarometers & 2397 \\
2008 & Afrobarometers Wave 4 & Afrobarometers & 1200 \\
2016 & Afrobarometers Wave 5-6 & Afrobarometers & 4800 \\
2019 & Afrobarometers Wave 7 & Afrobarometers & 1600 \\
\hline Source: authors' elaboration. & & \\
Note: the table shows the surveys used, the source from which these surveys can be obtained, and the sample size of each survey. & & \\
& & & \\
\end{tabular}




\begin{tabular}{|c|c|c|c|c|c|c|}
\hline \multicolumn{7}{|c|}{ Table C2 - Complete descriptive statistics by year } \\
\hline & 1999 & 2003 & 2007 & 2011 & 2015 & 2019 \\
\hline Education: Illiterate & $25 \%$ & $21 \%$ & $19 \%$ & $14 \%$ & $13 \%$ & $14 \%$ \\
\hline Education: Primary & $17 \%$ & $16 \%$ & $15 \%$ & $15 \%$ & $16 \%$ & $13 \%$ \\
\hline Education: Secondary & $37 \%$ & $44 \%$ & $42 \%$ & $44 \%$ & $47 \%$ & $45 \%$ \\
\hline Education: Tertiary & $21 \%$ & $19 \%$ & $23 \%$ & $26 \%$ & $24 \%$ & $28 \%$ \\
\hline Age: $20-29$ & $51 \%$ & $54 \%$ & $56 \%$ & $54 \%$ & $50 \%$ & $50 \%$ \\
\hline Age: $30-49$ & $40 \%$ & $37 \%$ & $35 \%$ & $38 \%$ & $41 \%$ & $40 \%$ \\
\hline Age: $50+$ & $9 \%$ & $10 \%$ & $9 \%$ & $8 \%$ & $9 \%$ & $10 \%$ \\
\hline Gender: Man & $50 \%$ & $50 \%$ & $50 \%$ & $51 \%$ & $50 \%$ & $50 \%$ \\
\hline Employment status: Employed & $57 \%$ & $43 \%$ & $47 \%$ & $51 \%$ & $52 \%$ & $49 \%$ \\
\hline Employment status: Unemployed & $13 \%$ & $21 \%$ & $23 \%$ & $22 \%$ & $24 \%$ & $24 \%$ \\
\hline Employment status: Inactive & $29 \%$ & $36 \%$ & $30 \%$ & $27 \%$ & $24 \%$ & $26 \%$ \\
\hline Religion: No religion & & $1 \%$ & $1 \%$ & $0 \%$ & $0 \%$ & $1 \%$ \\
\hline Religion: Catholic & & $17 \%$ & $15 \%$ & $12 \%$ & $11 \%$ & $5 \%$ \\
\hline Religion: Other Christian & & $40 \%$ & $40 \%$ & $47 \%$ & $47 \%$ & $53 \%$ \\
\hline Religion: Muslim & & $42 \%$ & $43 \%$ & $40 \%$ & $41 \%$ & $41 \%$ \\
\hline Religion: Other & & $1 \%$ & $1 \%$ & $1 \%$ & $1 \%$ & $1 \%$ \\
\hline Location: Rural & $29 \%$ & $48 \%$ & $52 \%$ & $55 \%$ & $56 \%$ & $56 \%$ \\
\hline Region: North-Central & & $15 \%$ & $15 \%$ & $15 \%$ & $14 \%$ & $13 \%$ \\
\hline Region: North-East & & $13 \%$ & $13 \%$ & $13 \%$ & $12 \%$ & $13 \%$ \\
\hline Region: North-West & & $21 \%$ & $21 \%$ & $21 \%$ & $23 \%$ & $24 \%$ \\
\hline Region: South-East & & $12 \%$ & $11 \%$ & $12 \%$ & $12 \%$ & $15 \%$ \\
\hline Region: South-South & & $15 \%$ & $16 \%$ & $16 \%$ & $16 \%$ & $12 \%$ \\
\hline Region: South-West & & $24 \%$ & $23 \%$ & $23 \%$ & $22 \%$ & $24 \%$ \\
\hline Language: Benue-Congo & $6 \%$ & $6 \%$ & $8 \%$ & $11 \%$ & $9 \%$ & $9 \%$ \\
\hline Language: Hausa-Fulani & $33 \%$ & $26 \%$ & $27 \%$ & $29 \%$ & $30 \%$ & $31 \%$ \\
\hline Language: Igbo & $19 \%$ & $17 \%$ & $17 \%$ & $17 \%$ & $17 \%$ & $21 \%$ \\
\hline Language: Other & $4 \%$ & $15 \%$ & $13 \%$ & $7 \%$ & $8 \%$ & $4 \%$ \\
\hline Language: Other Atlantic-Congo & $2 \%$ & $5 \%$ & $4 \%$ & $6 \%$ & $3 \%$ & $4 \%$ \\
\hline Language: Other Volta-Niger & $8 \%$ & $6 \%$ & $6 \%$ & $6 \%$ & $7 \%$ & $6 \%$ \\
\hline Language: Yoruba & $27 \%$ & $25 \%$ & $26 \%$ & $25 \%$ & $26 \%$ & $26 \%$ \\
\hline Occupation: Farmer & $13 \%$ & $15 \%$ & $13 \%$ & & $10 \%$ & $16 \%$ \\
\hline Occupation: Inactive & $35 \%$ & $36 \%$ & $41 \%$ & & $40 \%$ & $35 \%$ \\
\hline
\end{tabular}


Occupation: Professional / Employer

Source: authors' computations using Afrobarometer surveys.

Note: the table shows descriptive statistics by year for selected available variables. 
Figure D1 - Presidential election results in Senegal, 2000-2019

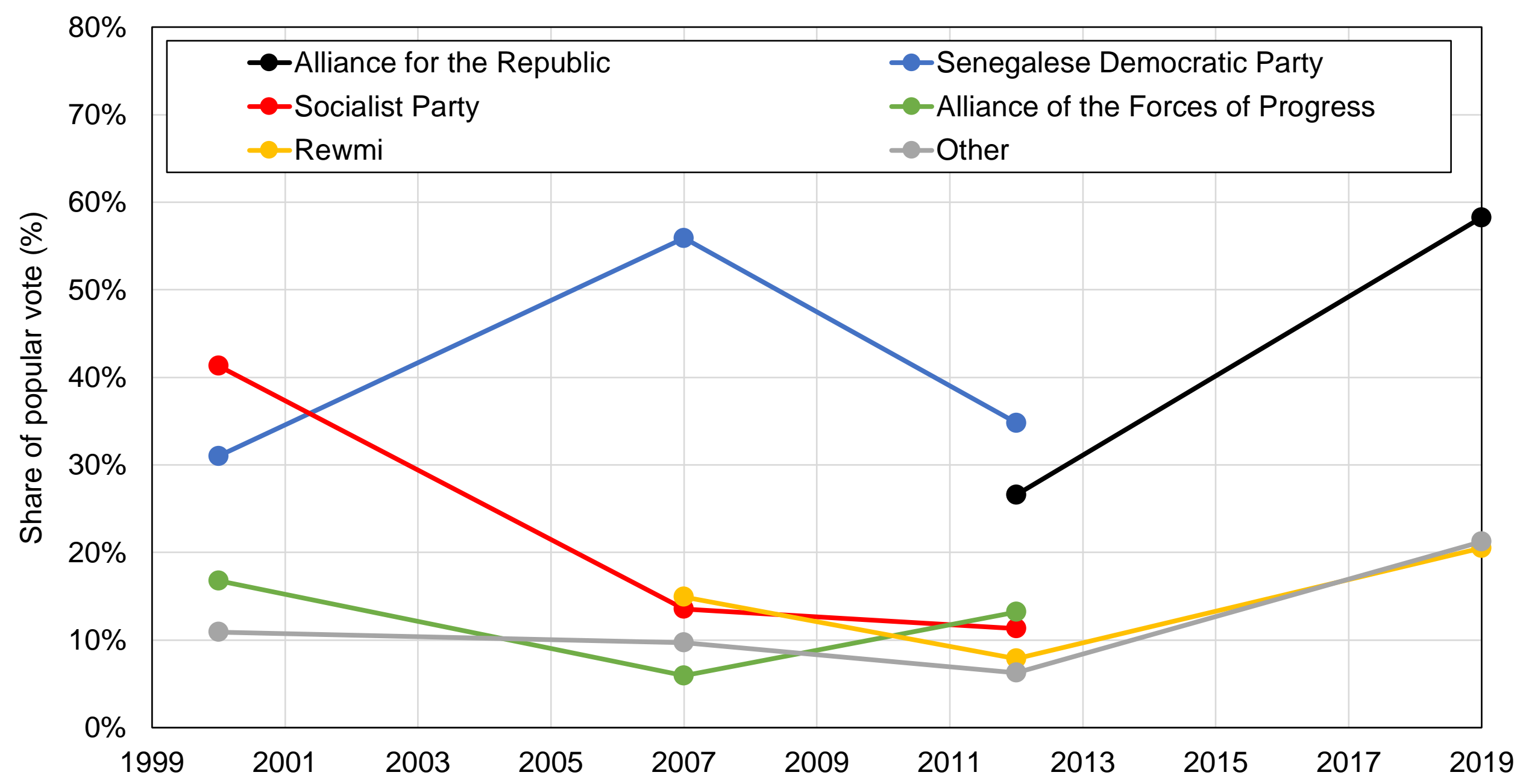

Source: authors' computations using official election results.

Note: the figure shows the share of votes received by selected groups of Senegalese political parties in presidential elections between 2000 and 2019. 
Figure D2 - Linguistic composition of education, 2019

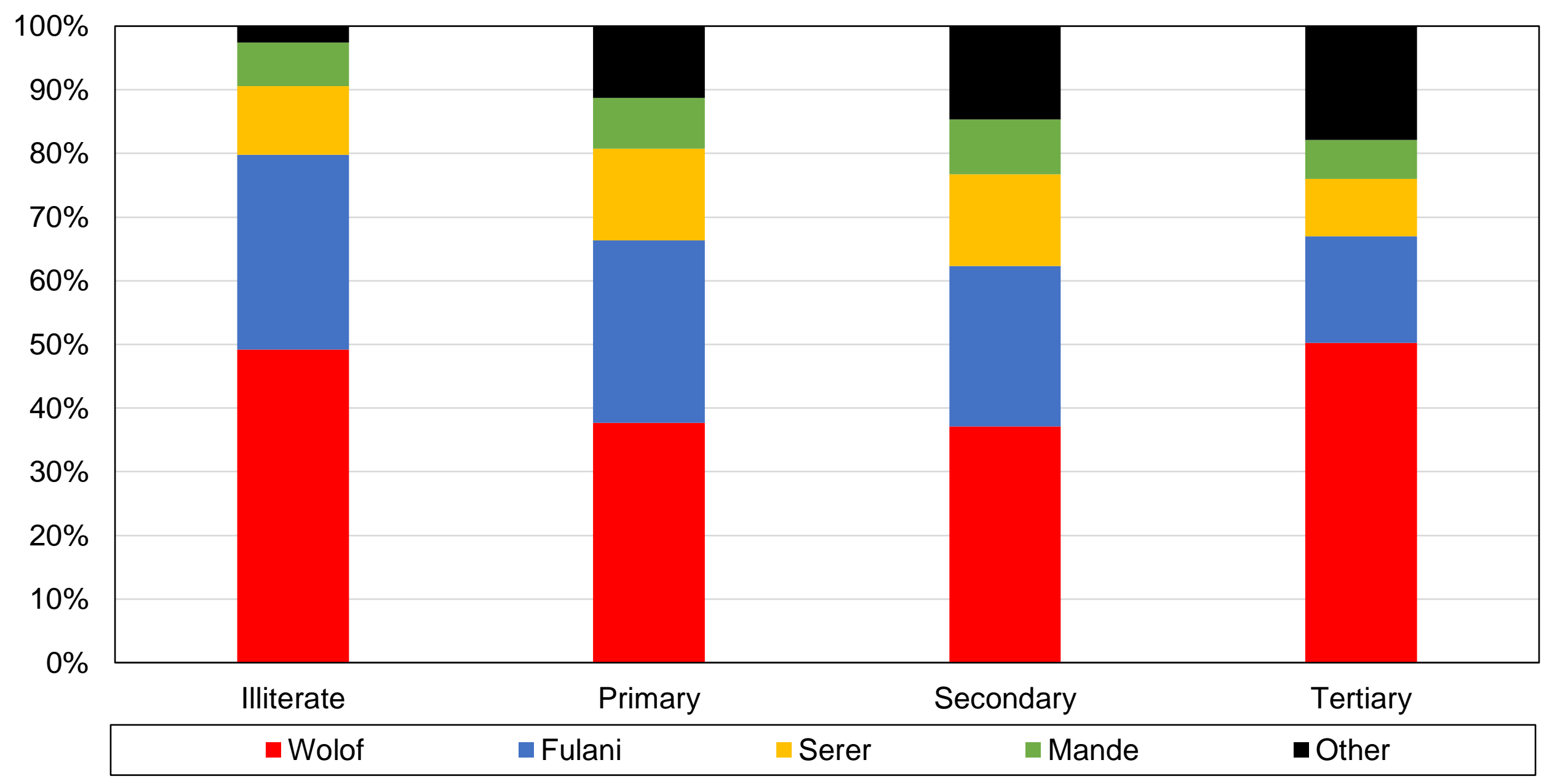

Source: authors' computations using Afrobarometer surveys.

Note: the figure shows the distribution of language by educational levels in 2019. 
Figure D3 - Vote for the Senegalese Democratic Party / Alliance for the Republic by language

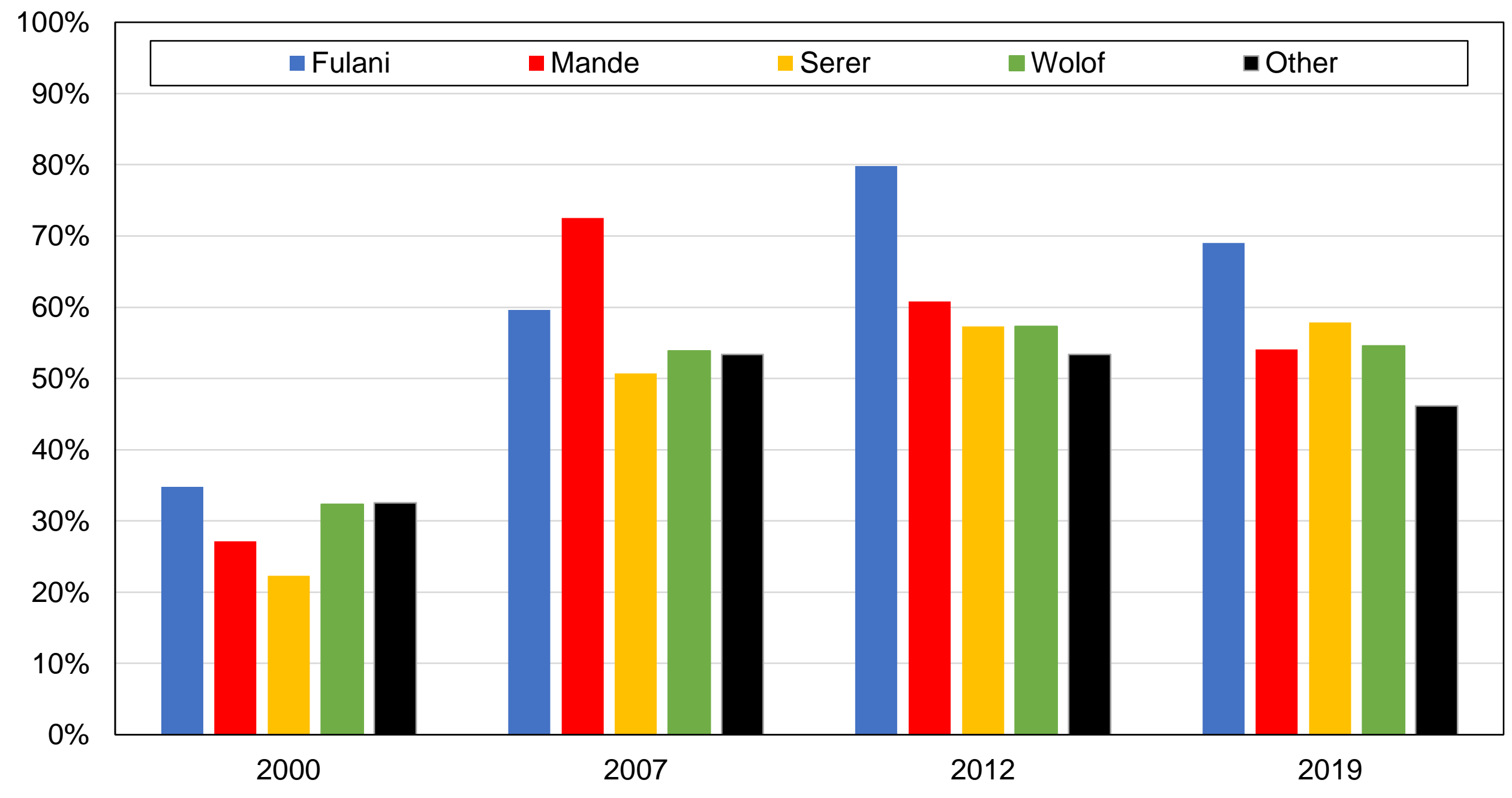

Source: authors' computations using Afrobarometer surveys.

Note: the figure shows the share of votes received by PDS / APR by language. 
Figure D4 - Vote for the Senegalese Democratic Party / Alliance for the Republic by location

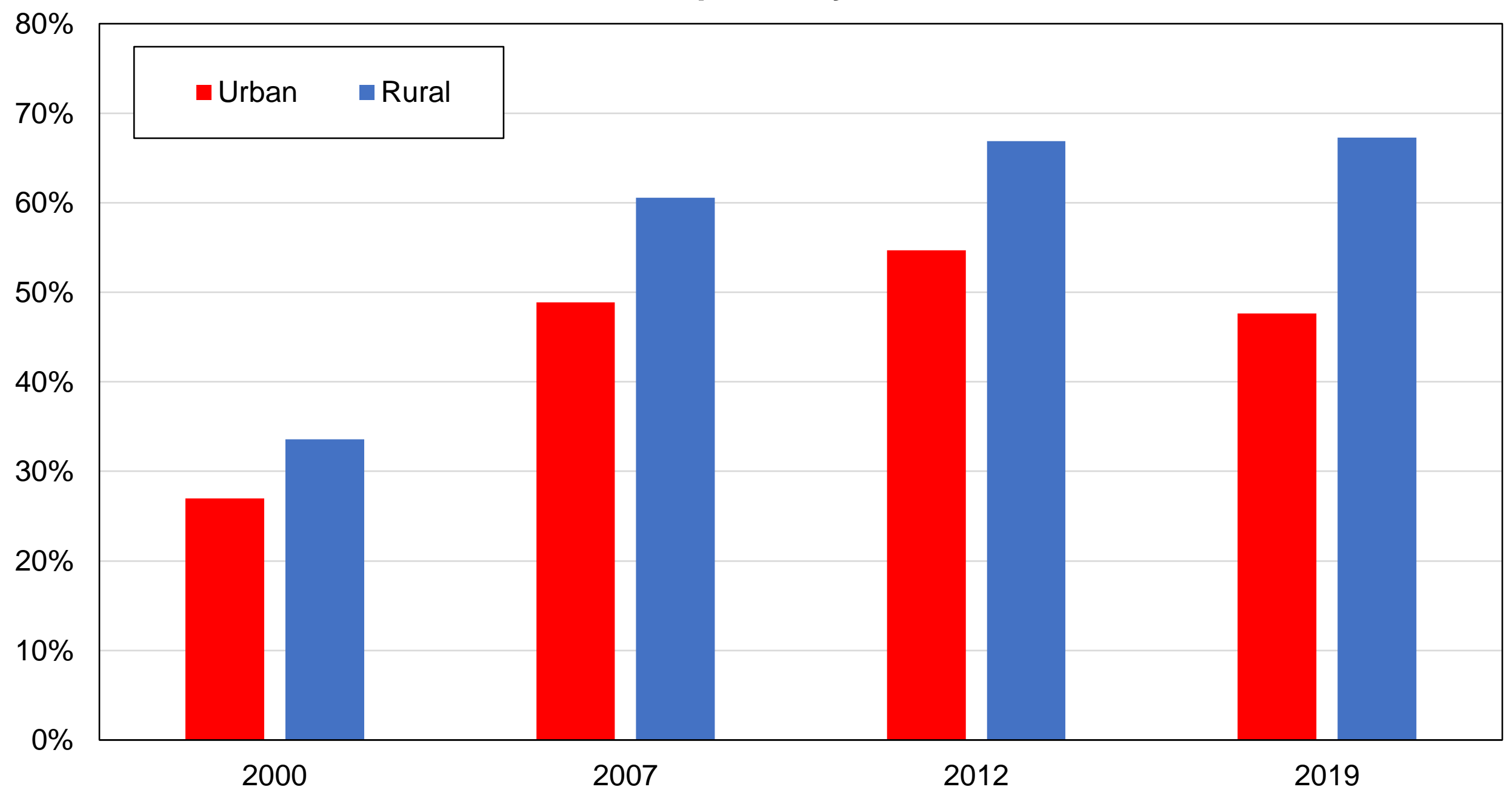

Source: authors' computations using Afrobarometer surveys.

Note: the figure shows the share of votes received by PDS / APR by location. 


\section{Figure D5 - Vote for the Senegalese Democratic Party / Alliance for the Republic among higher-educated voters}

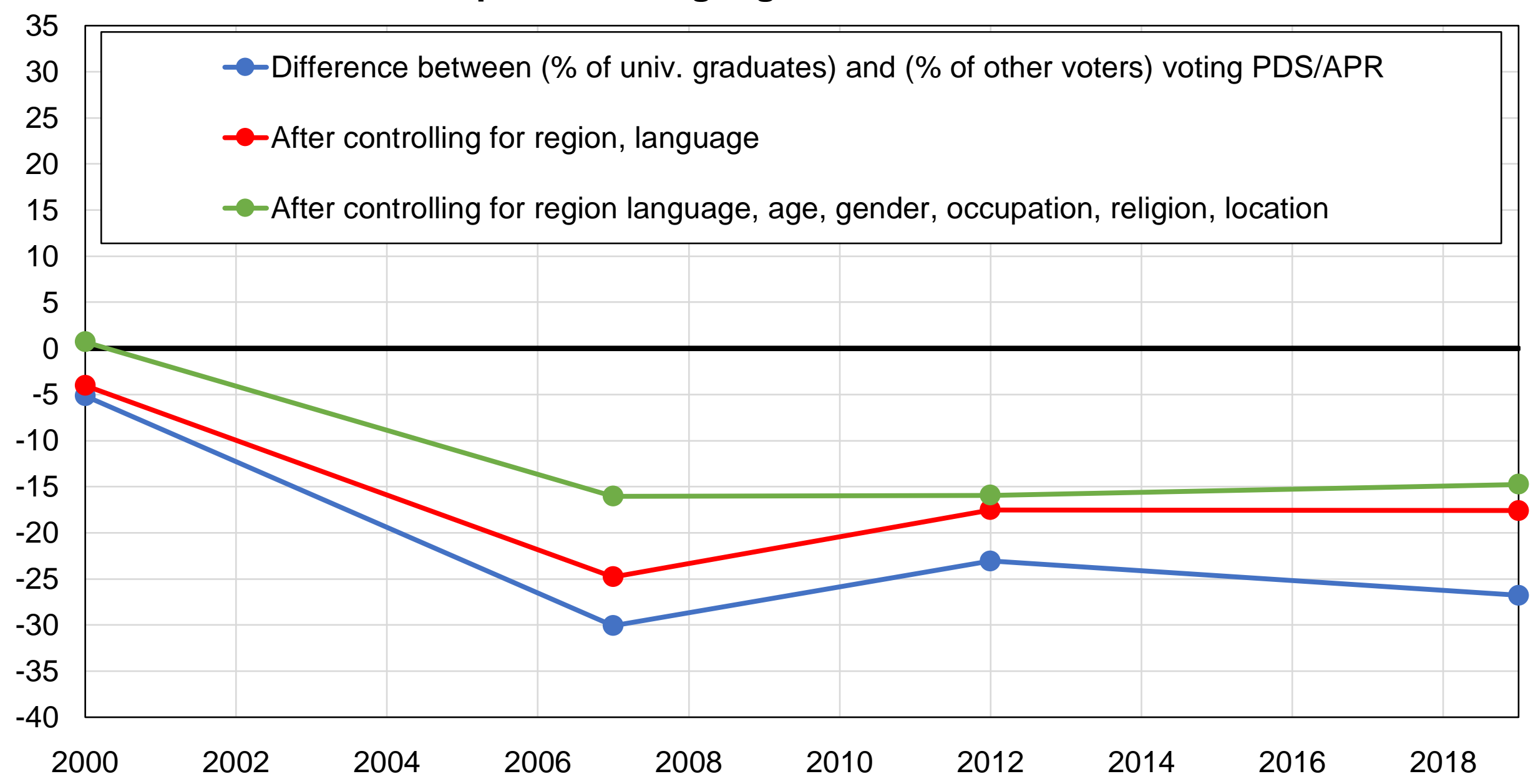

Source: authors' computations using Afrobarometer surveys.

Note: the figure shows the difference between the share of university graduates and the share of other voters voting for PDS / APR, before and after controlling for other variables. 
Figure DA1 - The composition of the electorate by education

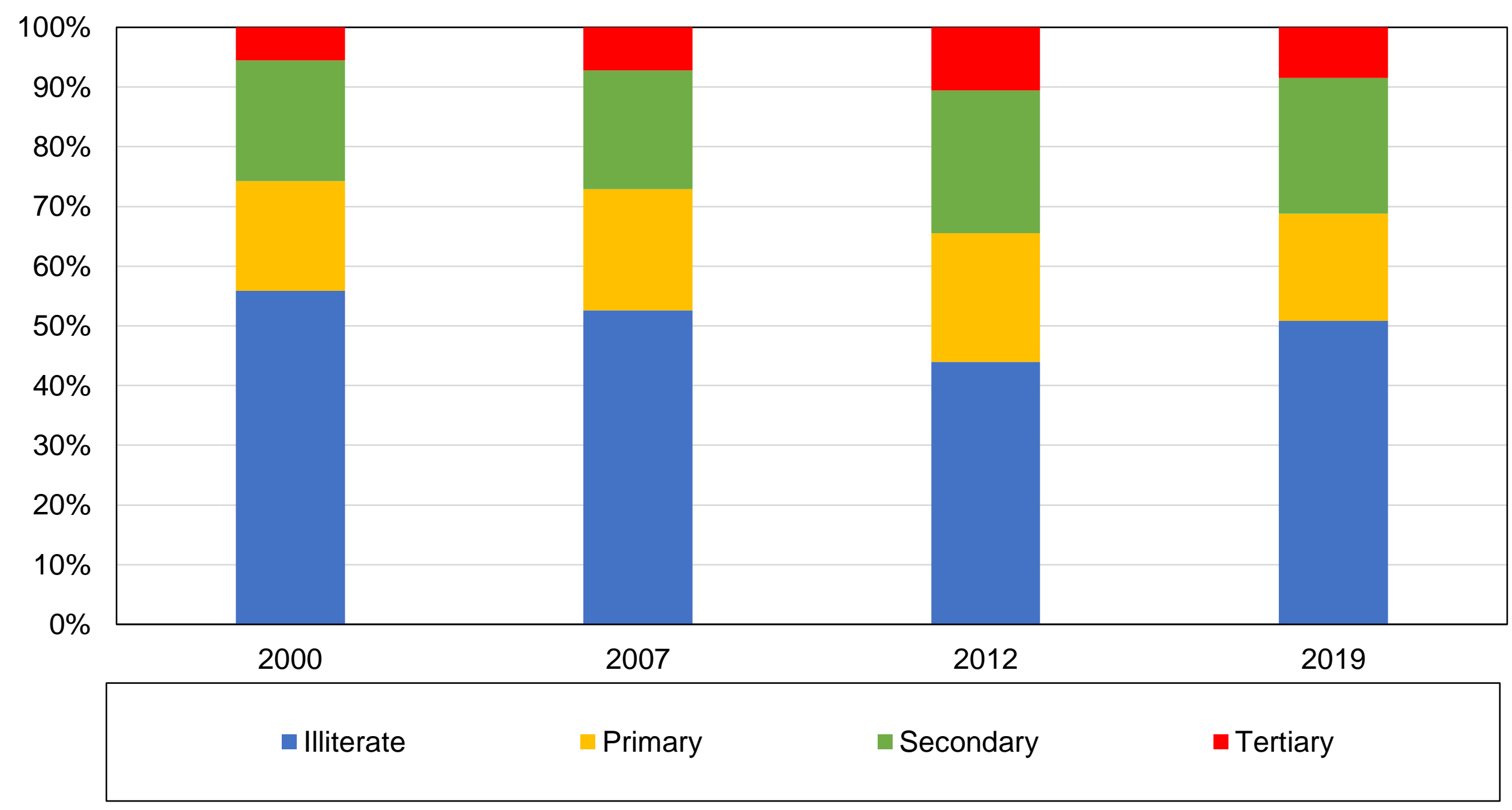

Source: authors' computations using Afrobarometer surveys.

Note: the figure shows the distribution of education levels of the Senegalese adult population and its evolution over time. 
Figure DA2 - The composition of the electorate by age

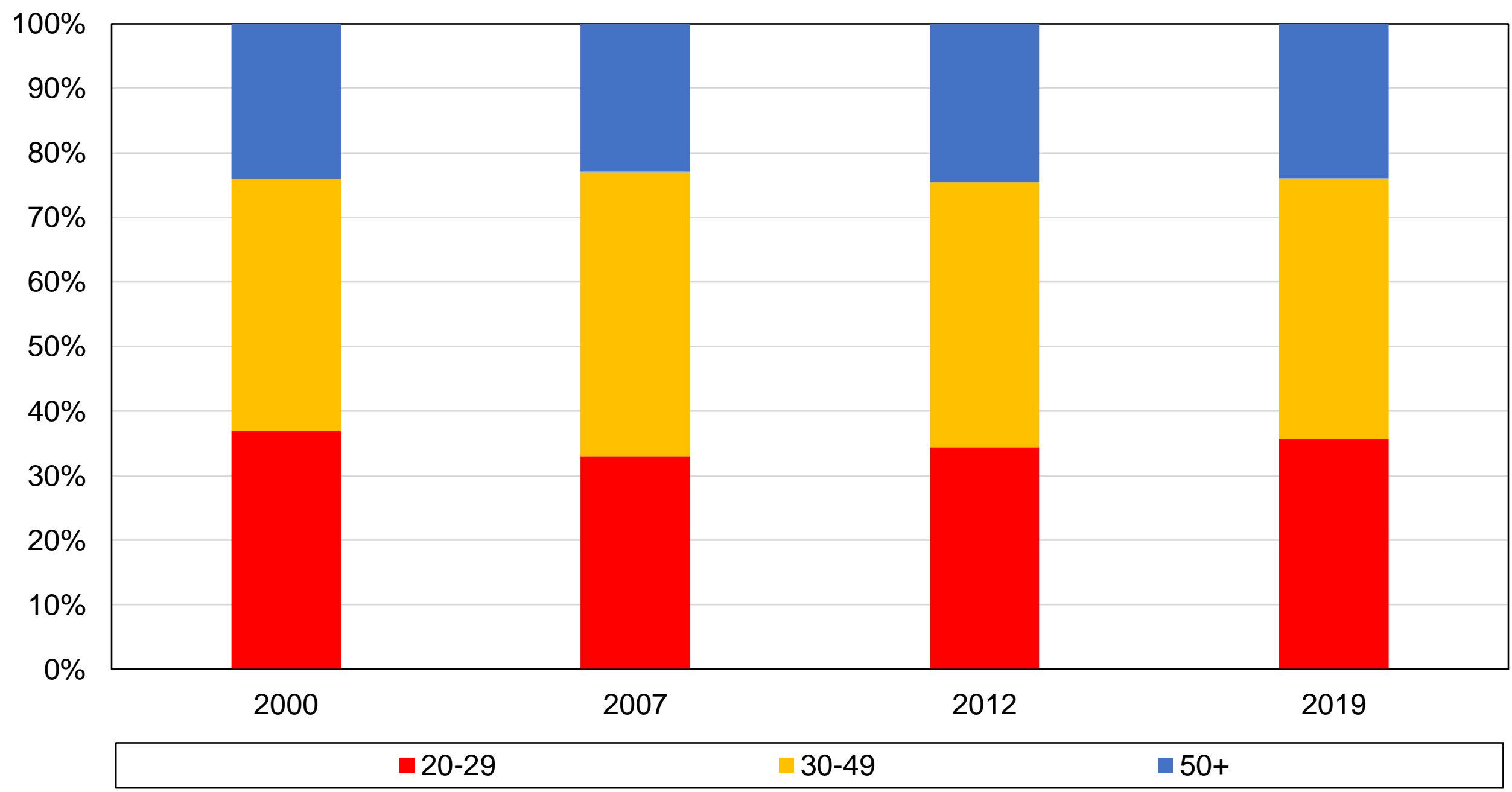

Source: authors' computations using AfroBarometer surveys

Note: the figure shows the distribution of age groups in the Senegalese adult population and its evolution over time. 
Figure DA3 - The composition of the electorate by religion

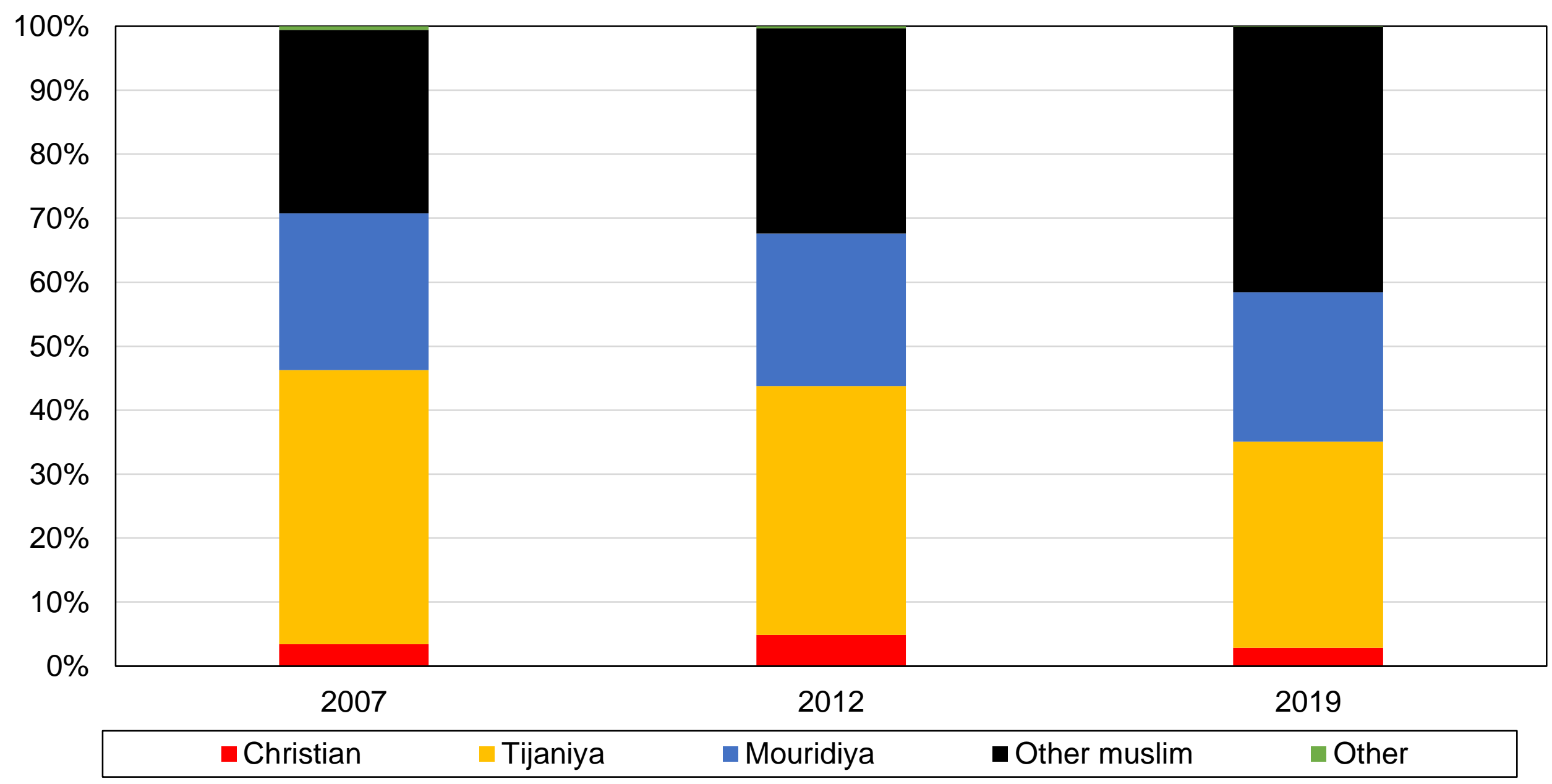

Source: authors' computations using AfroBarometer surveys.

Note: the figure shows the distribution of religious affiliations in the Senegalese adult population and its evolution over time. 
Figure DA4 - The composition of the electorate by region

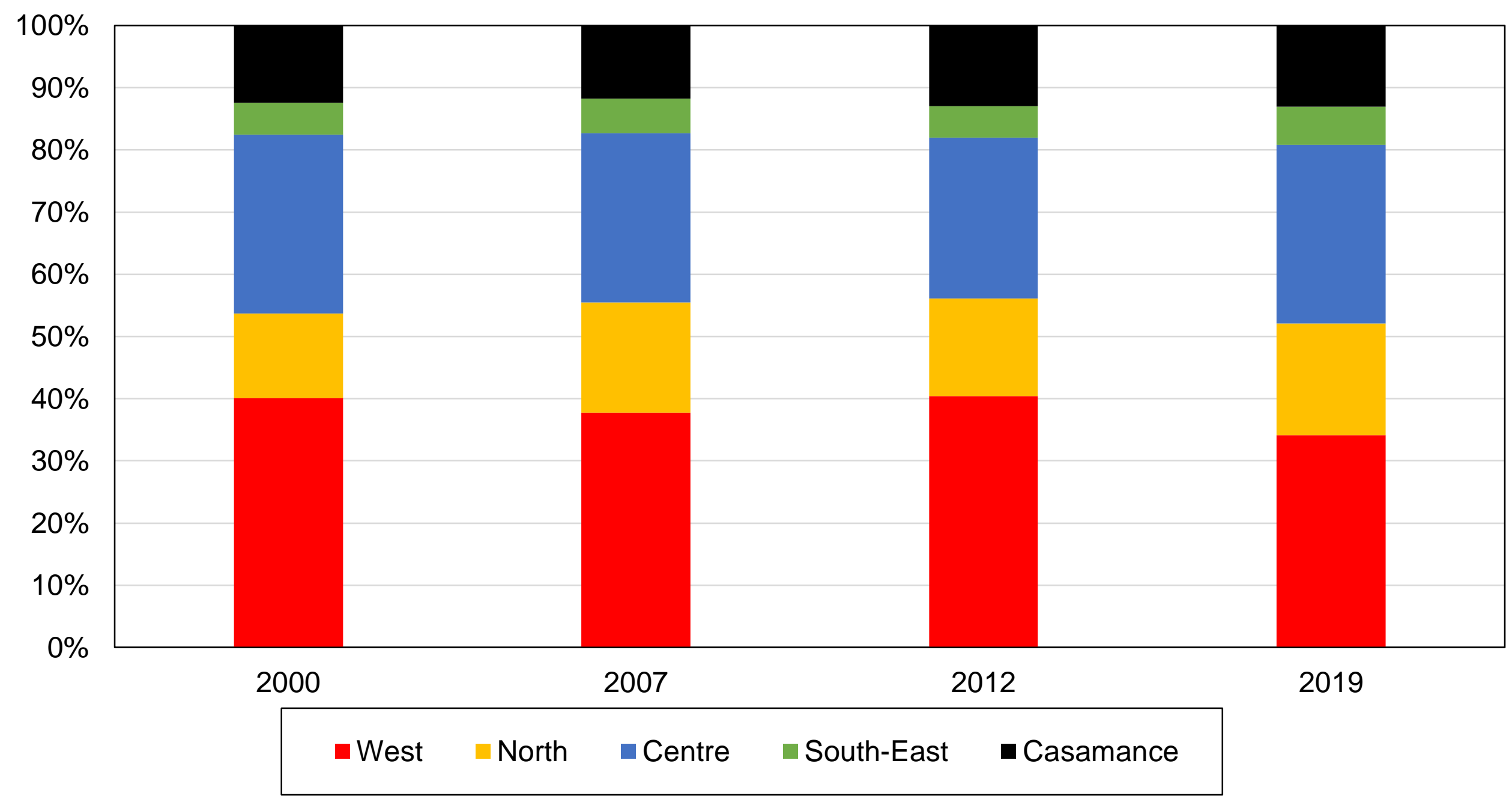

Source: authors' computations using Afrobarometer surveys.

Note: the figure shows the regional distribution in the Senegalese adult population and its evolution over time. 
Figure DA5 - The composition of the electorate by language

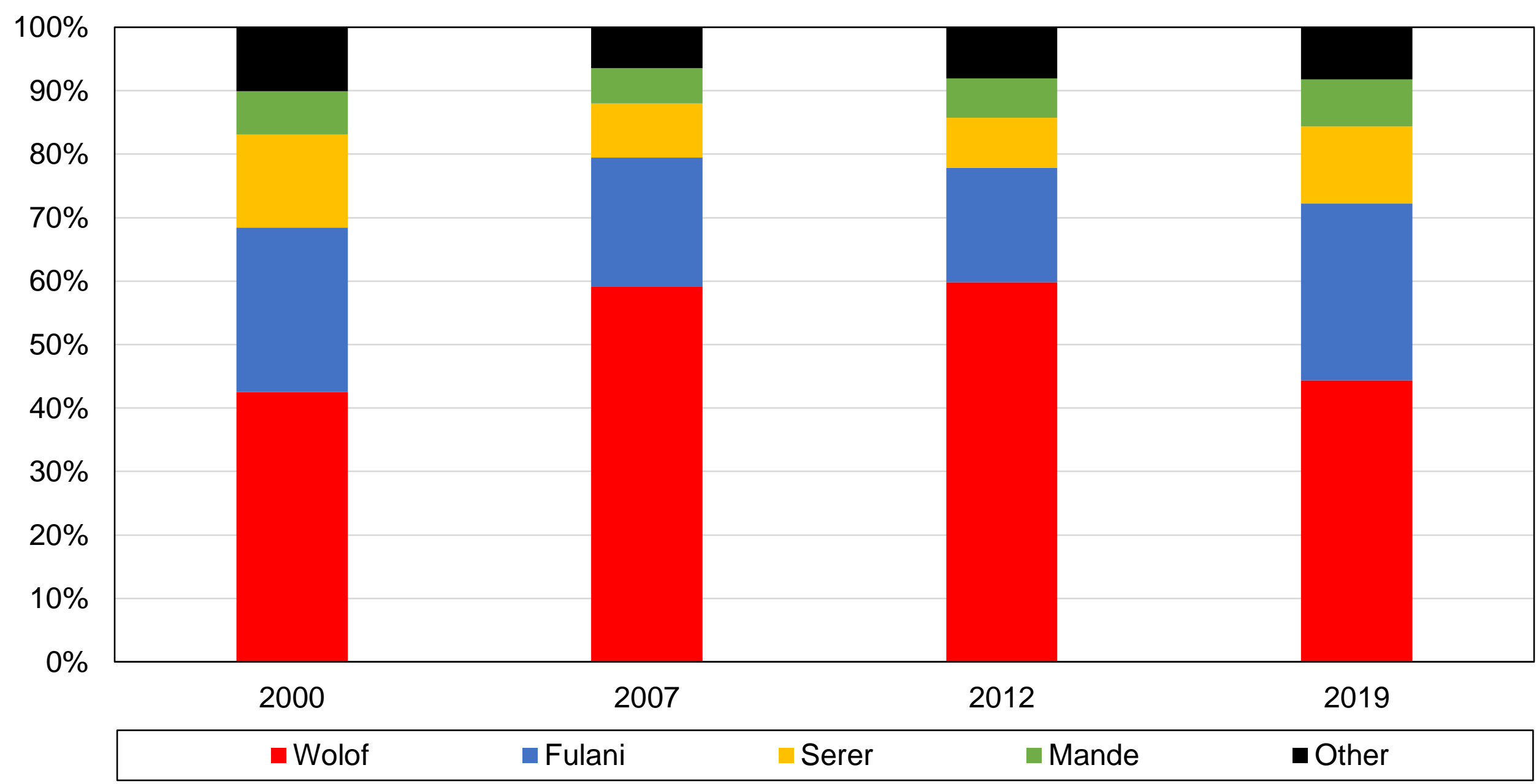

Source: authors' computations using Afrobarometer surveys.

Note: the figure shows the distribution of language spoken in the Senegalese adult population and its evolution over time. 
Figure DA6 - The composition of the electorate by occupation

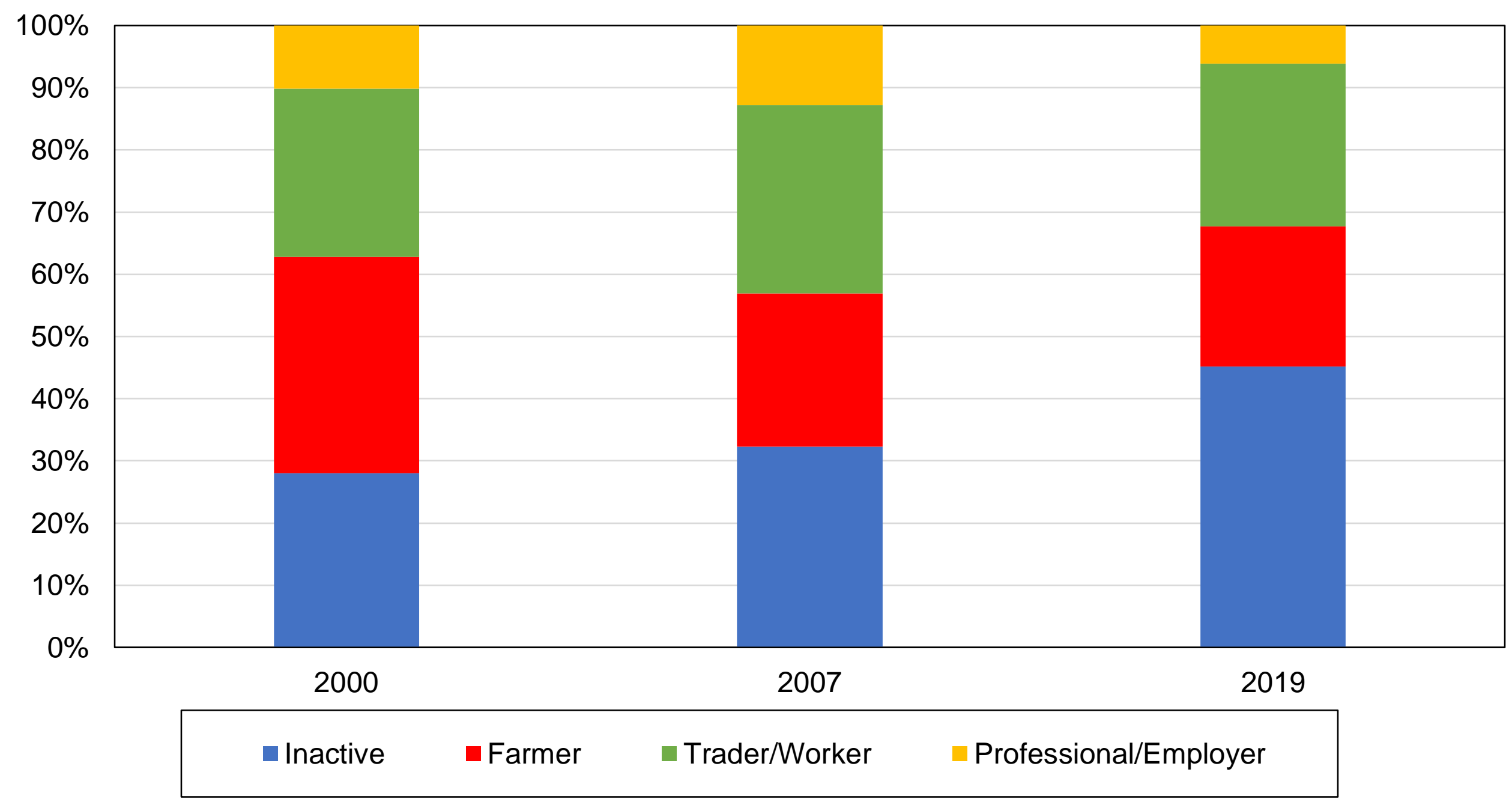

Source: authors' computations using Afrobarometer surveys.

Note: the figure shows the distribution of occupational activity in the Senegalese adult population and its evolution over time. 
Figure DA7 - Linguistic composition of education, 2004

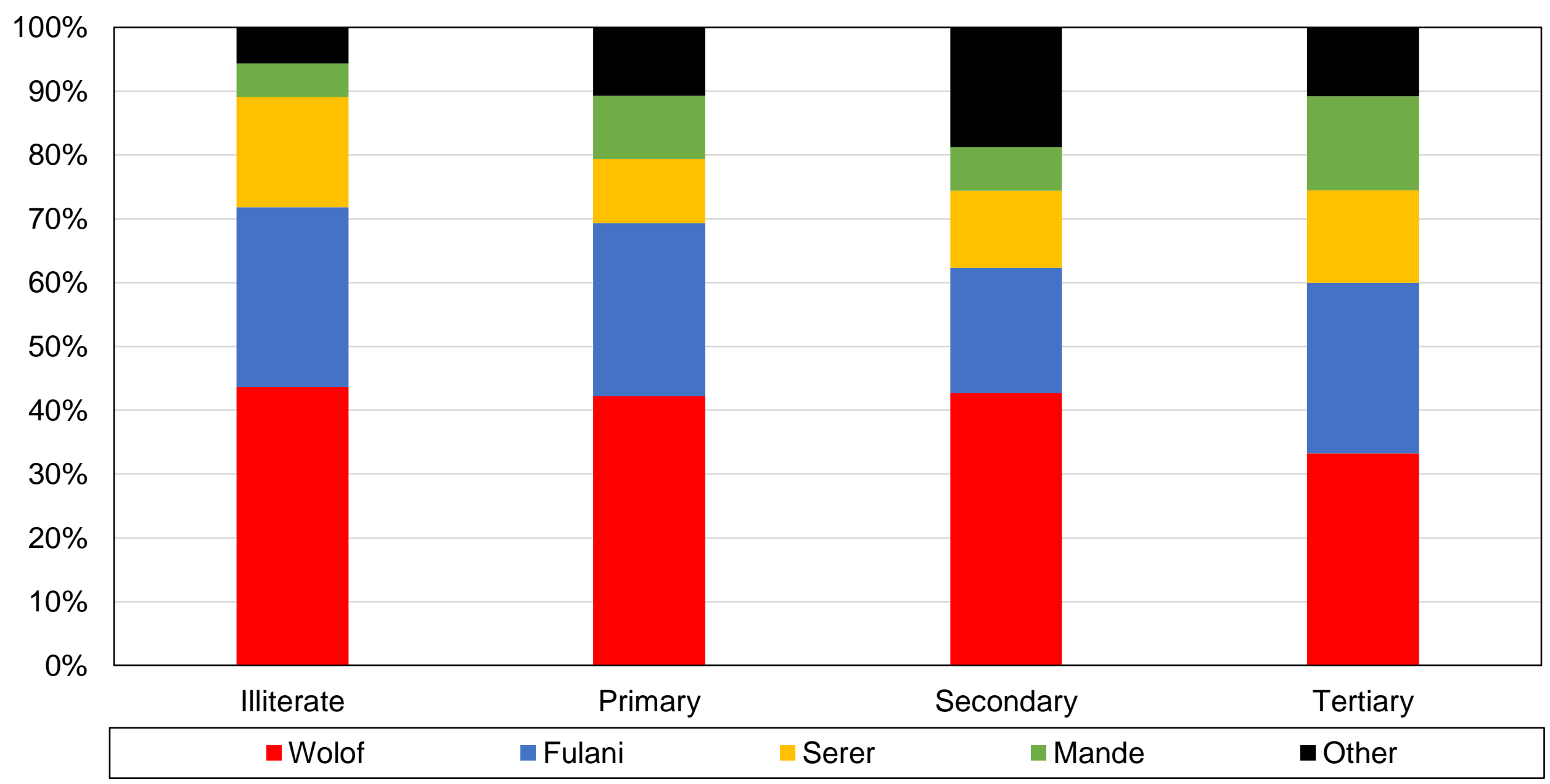

Source: authors' computations using Afrobarometer surveys.

Note: the figure shows the distribution of languages by educational levels in 2004 . 
Figure DA8 - Linguistic composition of education, 2019

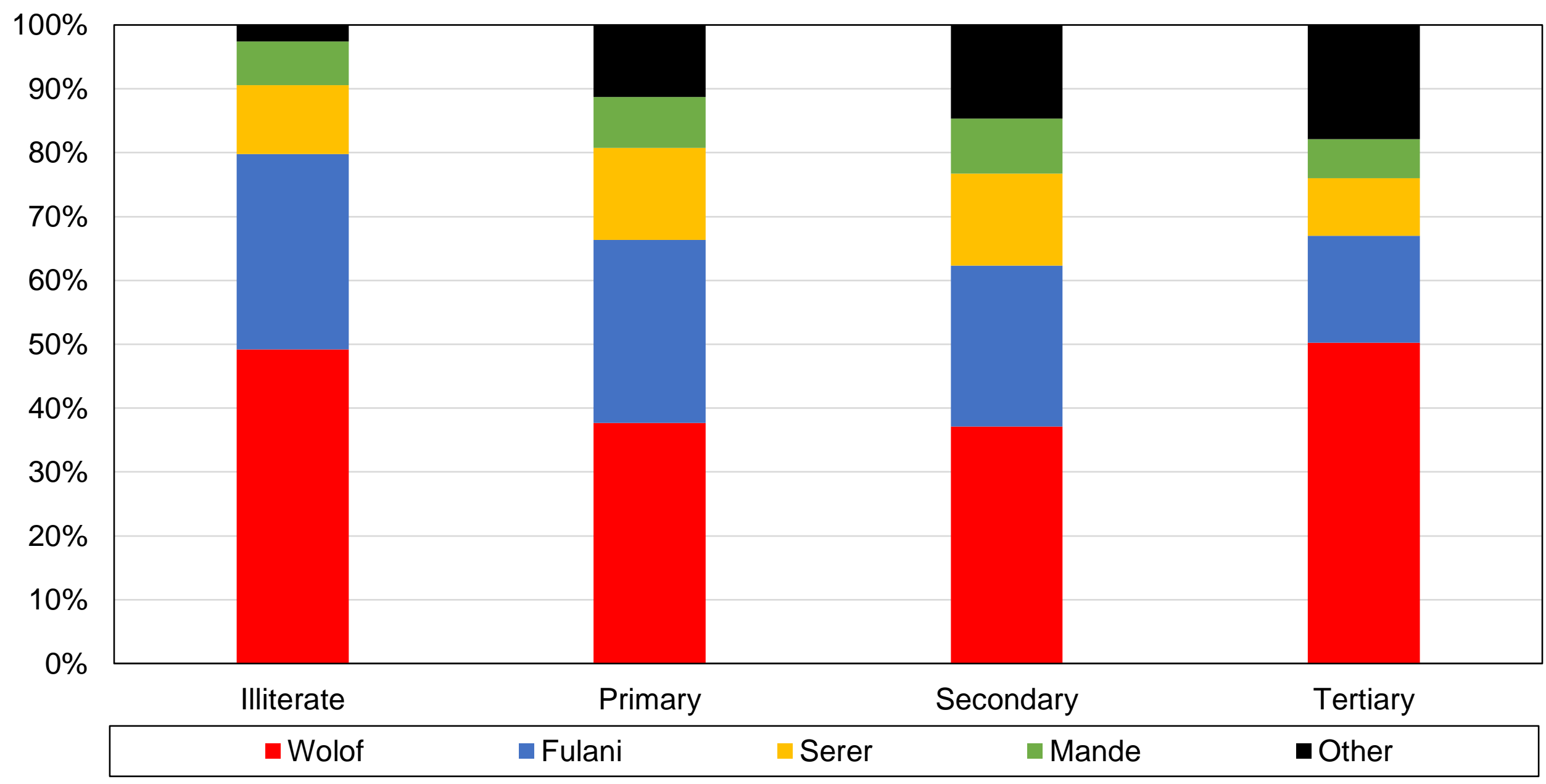

Source: authors' computations using Afrobarometer surveys.

Note: the figure shows the distribution of language by educational levels in 2019. 


\section{Figure DA9 - Occupational composition of education, 2004}

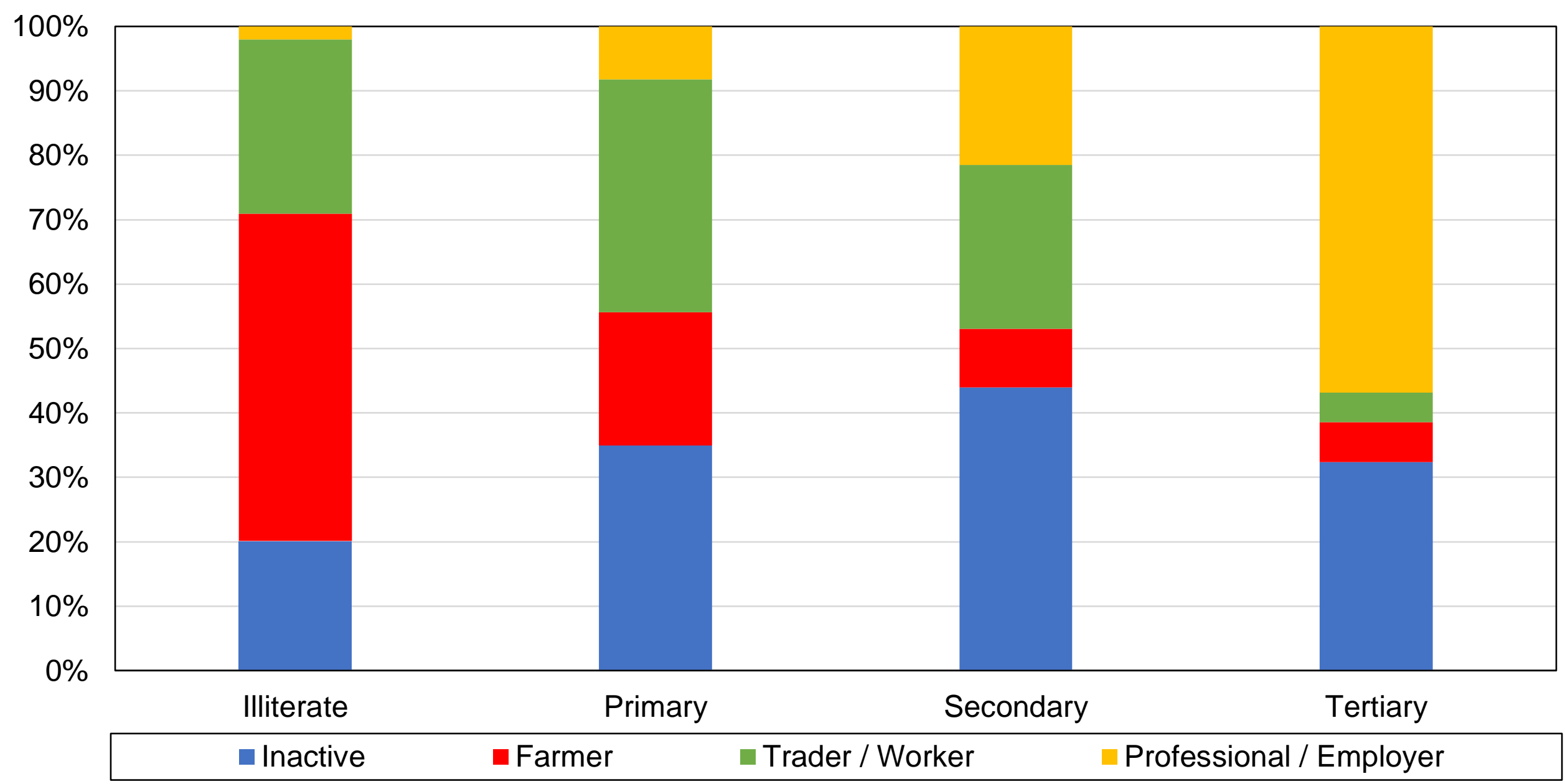

Source: authors' computations using Afrobarometer survey

Note: the figure shows the distribution of occupations by education levels in 2004. 
Figure DA10 - Occupational composition of education, 2019

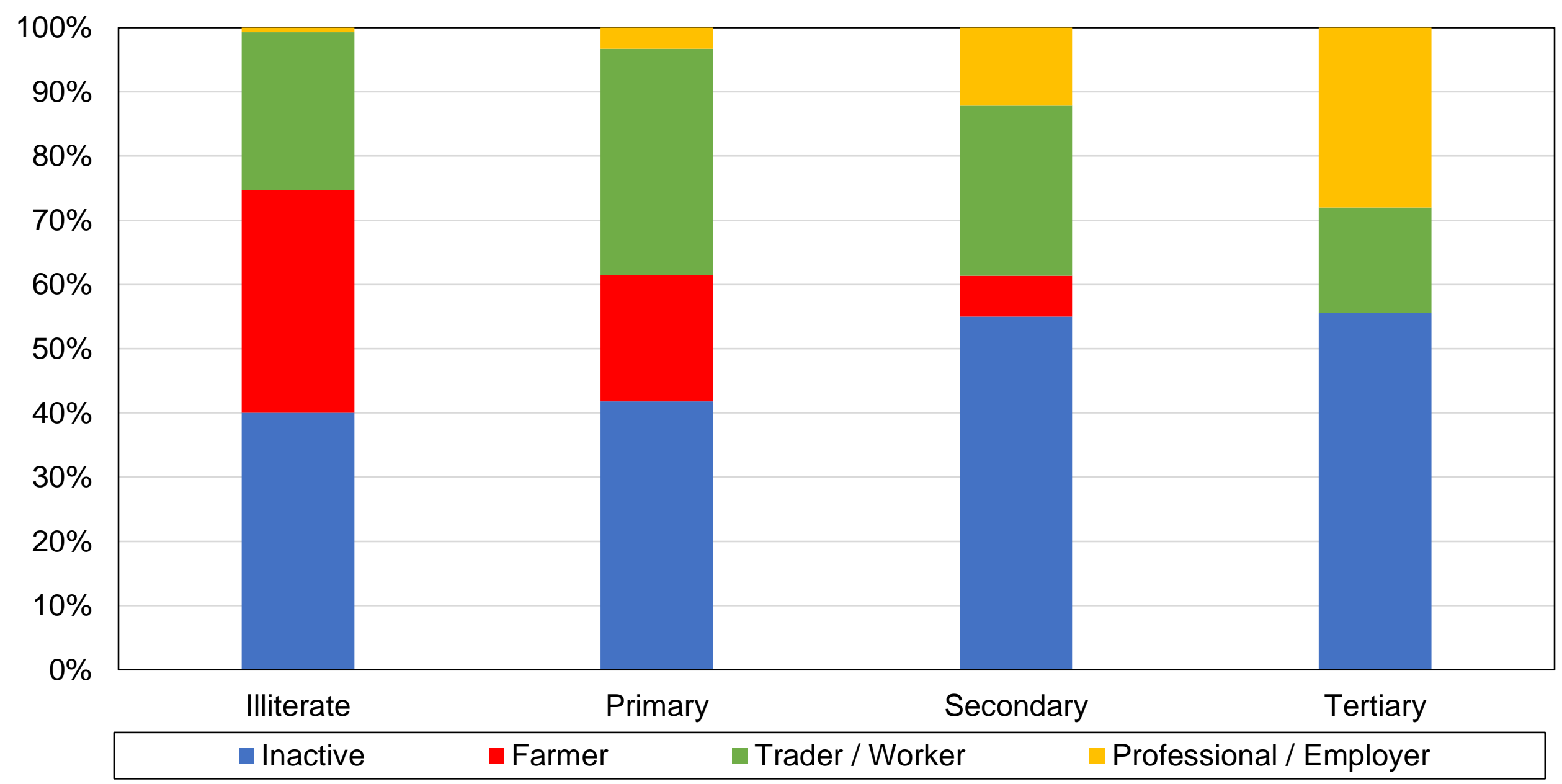

Source: authors' computations using Afrobarometer surveys.

Note: the figure shows the distribution of occupations by education levels in 2019 . 
Figure DA11 - Rural-urban composition of education, 2004

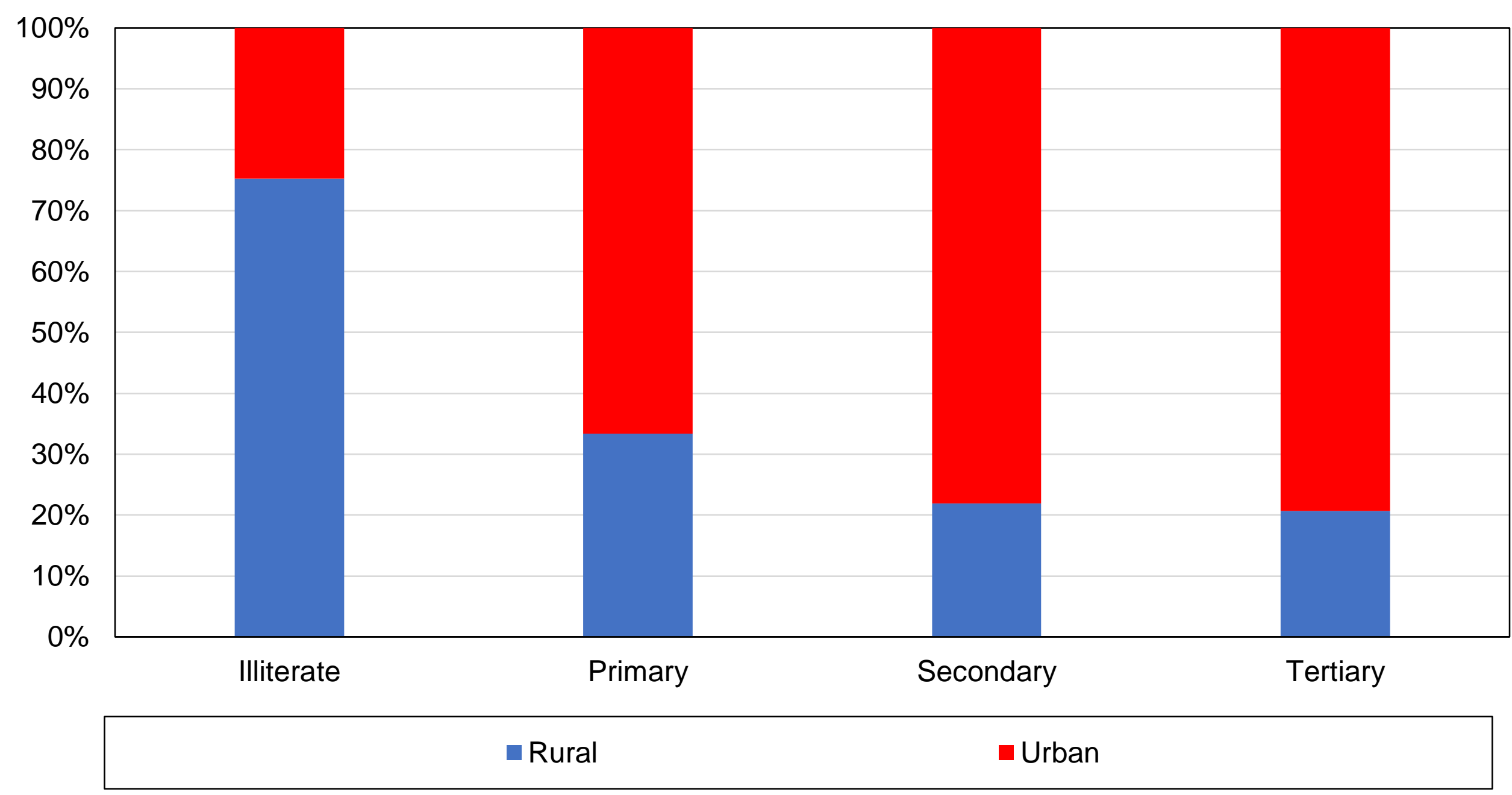

Source: authors' computations using Afrobarometer surveys.

Note: the figure shows the distribution of rural-urban locations by education level in 2004. 
Figure DA12 - Rural-urban composition of education, 2019

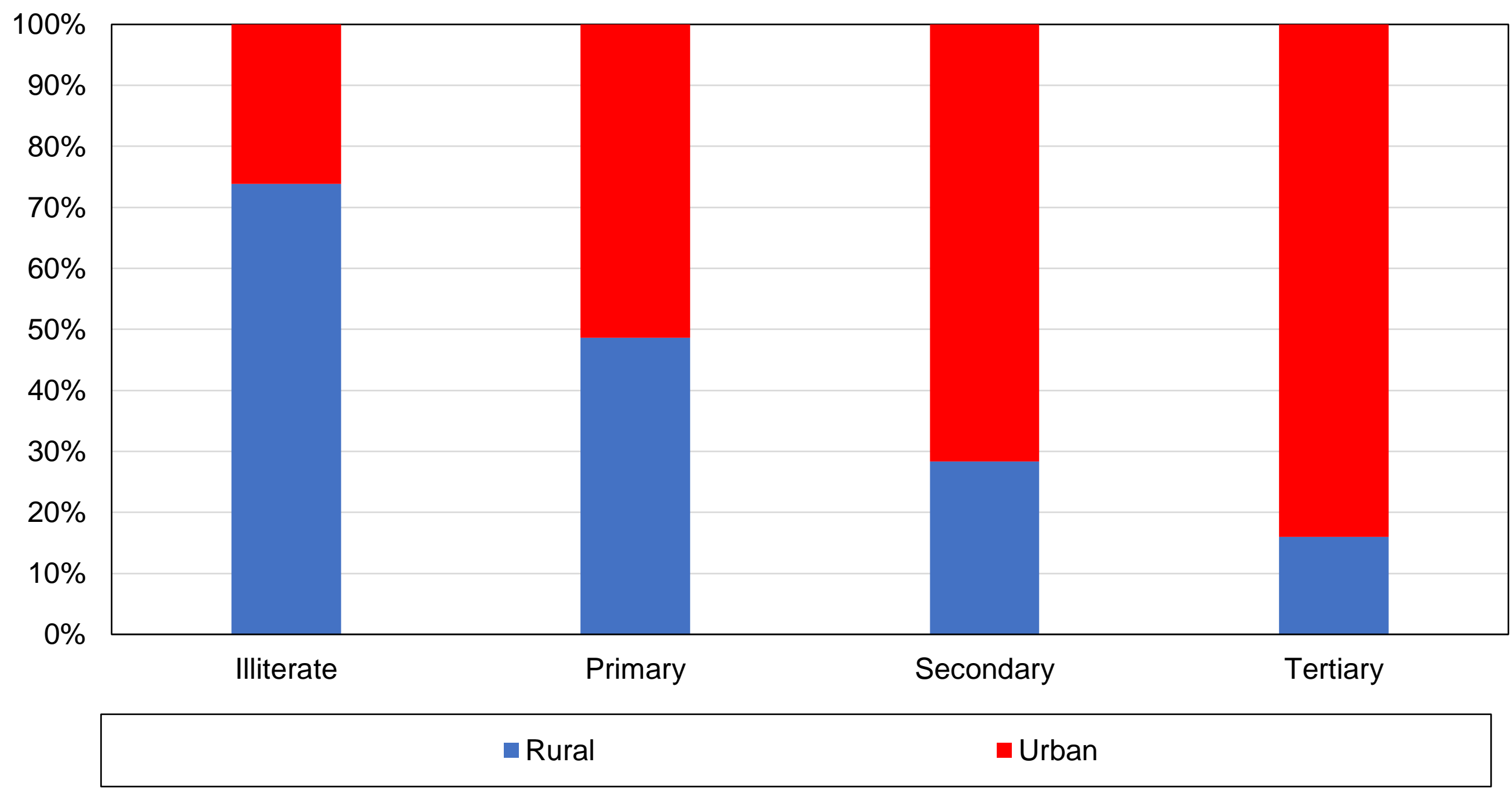

Source: authors' computations using Afrobarometer surveys.

Note: the figure shows the distribution of rural-urban locations by education level in 2019. 
Figure DA13 - Regional composition of education, 2004

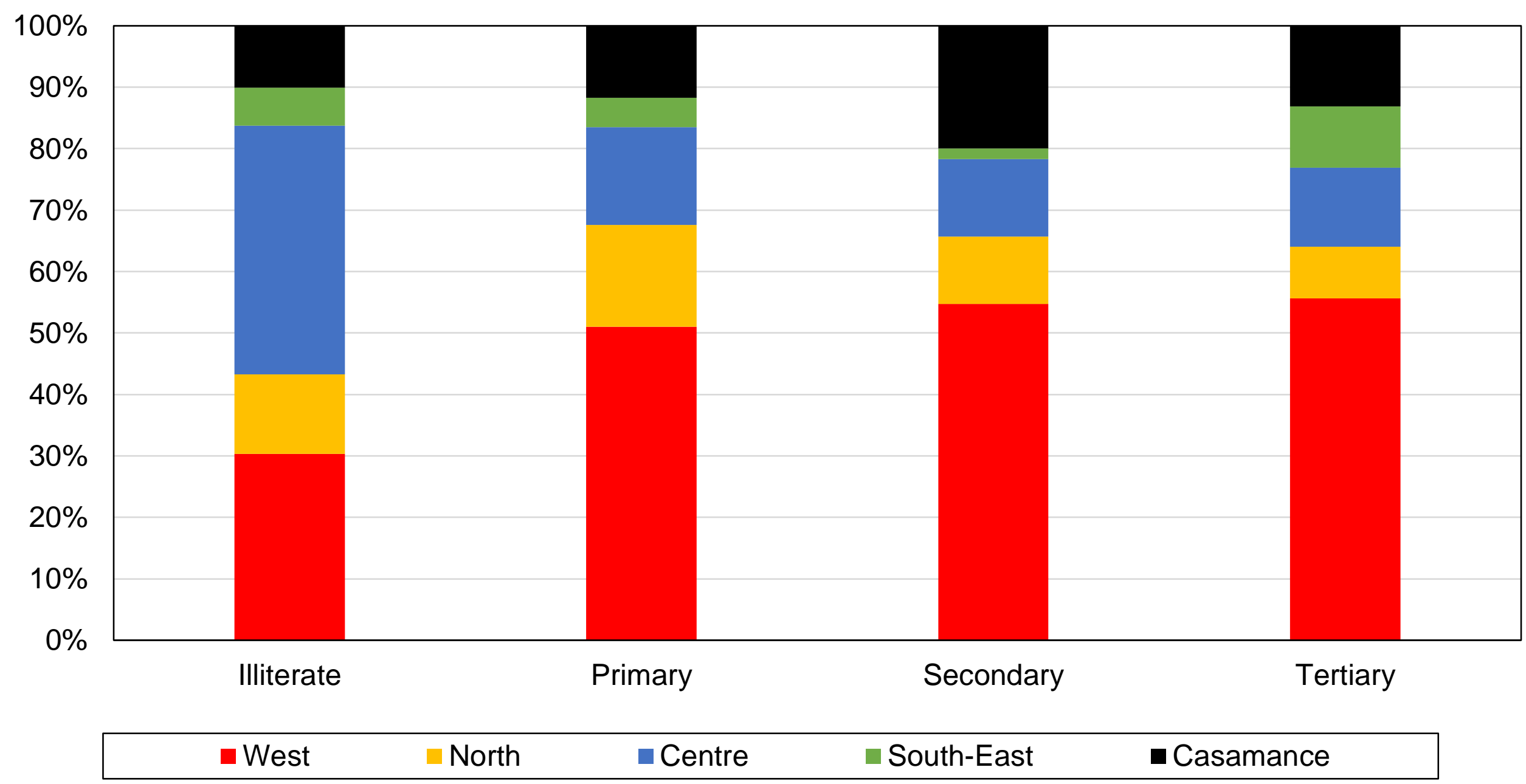

Source: authors' computations using Afrobarometer surveys.

Note: the figure shows the distribution of regions by education level of the Selegalese population in 2004. 
Figure DA14 - Regional composition of education, 2019

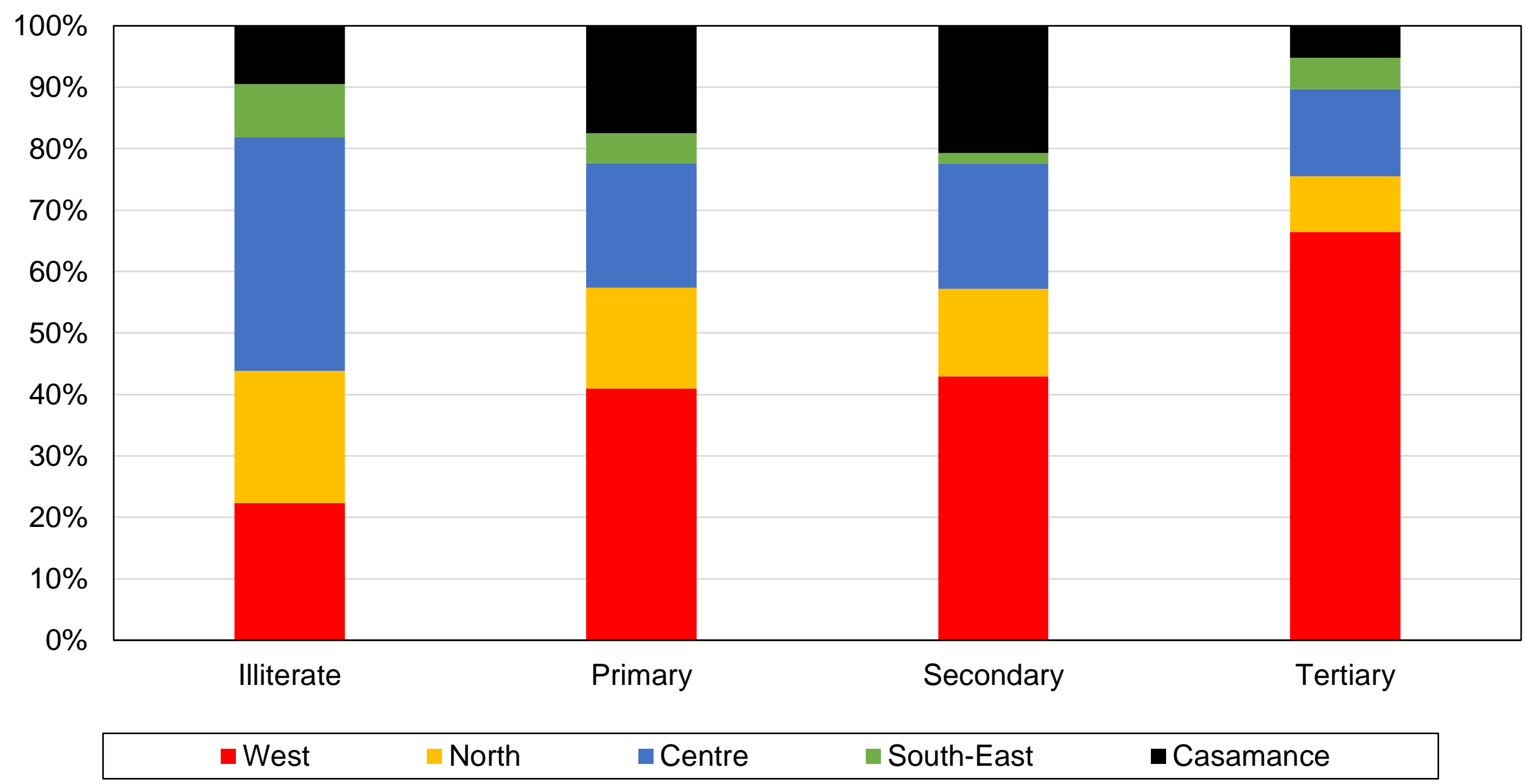

Source: authors' computations using Afrobarometer surveys.

Note: the figure shows the distribution of regions by education level of the Selegalese population in 2019. 
Figure DA15 - Religious composition of education, 2005

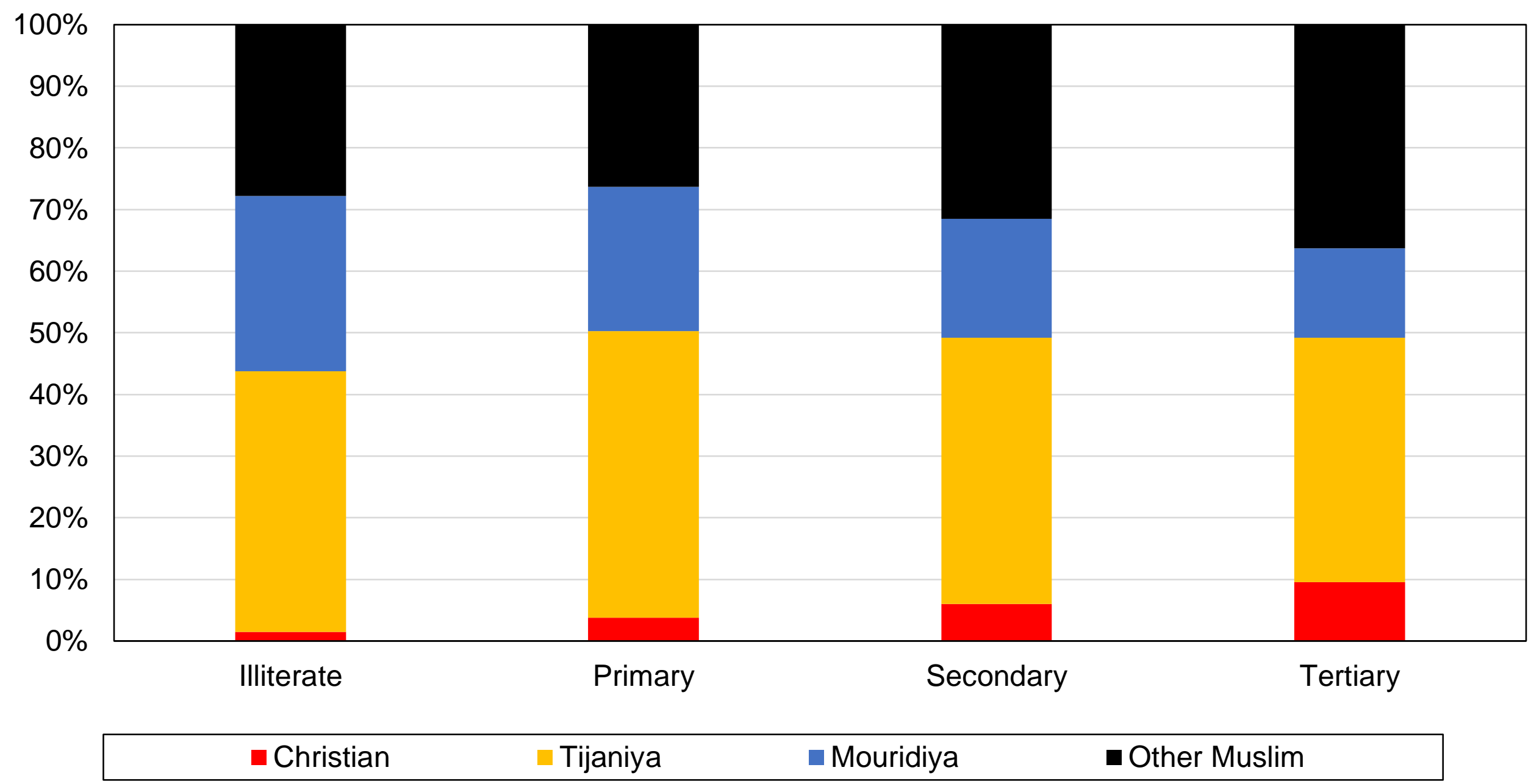

Source: authors' computations using Afrobarometer surveys.

Note: the figure shows the distribution of religions by education level of the Selegalese population in 2004. 
Figure DA16 - Religious composition of education, 2019

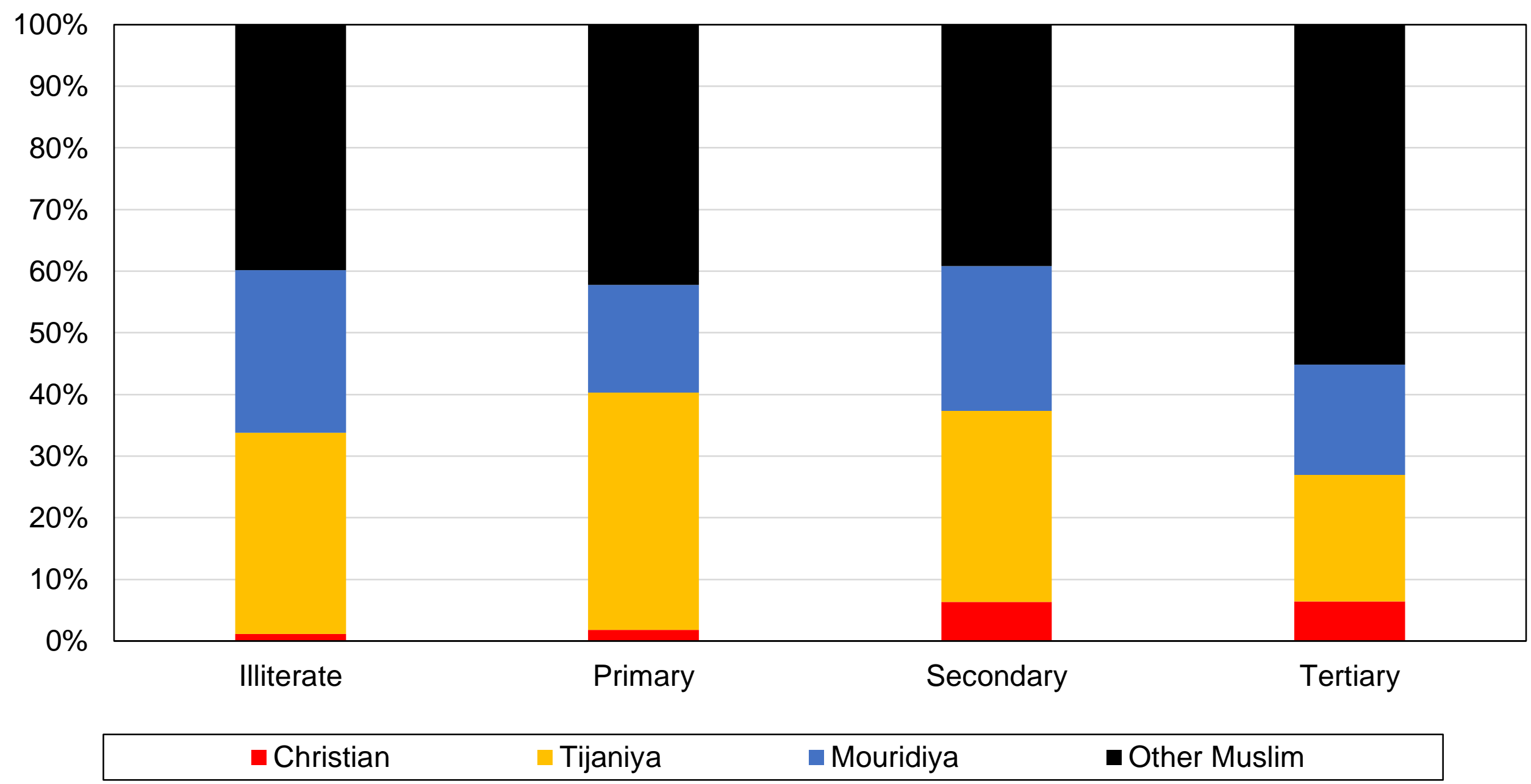

Source: authors' computations using Afrobarometer surveys.

Note: the figure shows the distribution of religions by education level of the Selegalese population in 2019. 
Figure DA17 - Linguistic composition of regions, 2004

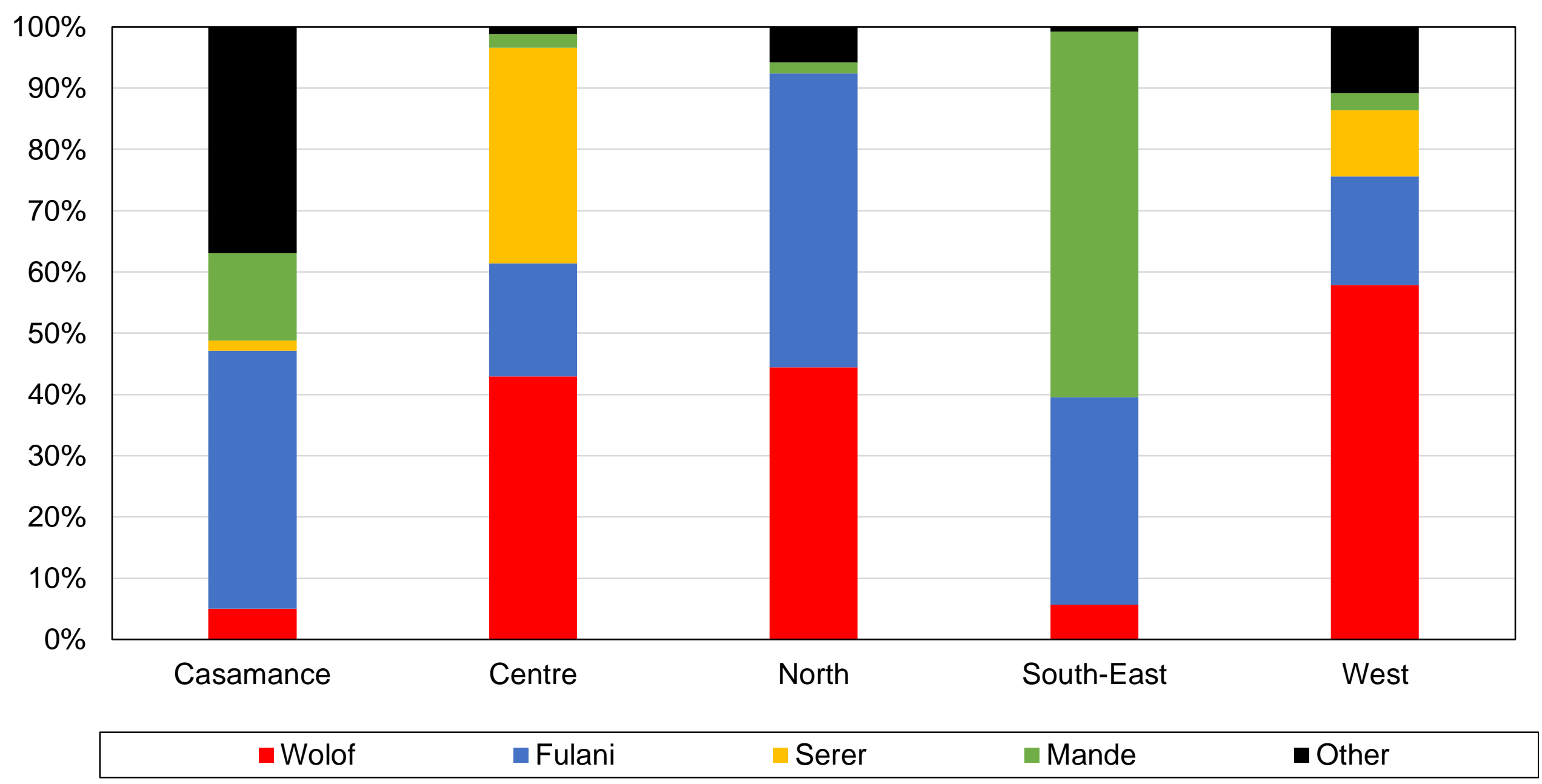

Source: authors' computations using Afrobarometer surveys.

Note: the figure shows the distribution of languages by region of the Senegal population in 2004. 
Figure DA18 - Linguistic composition of regions, 2019

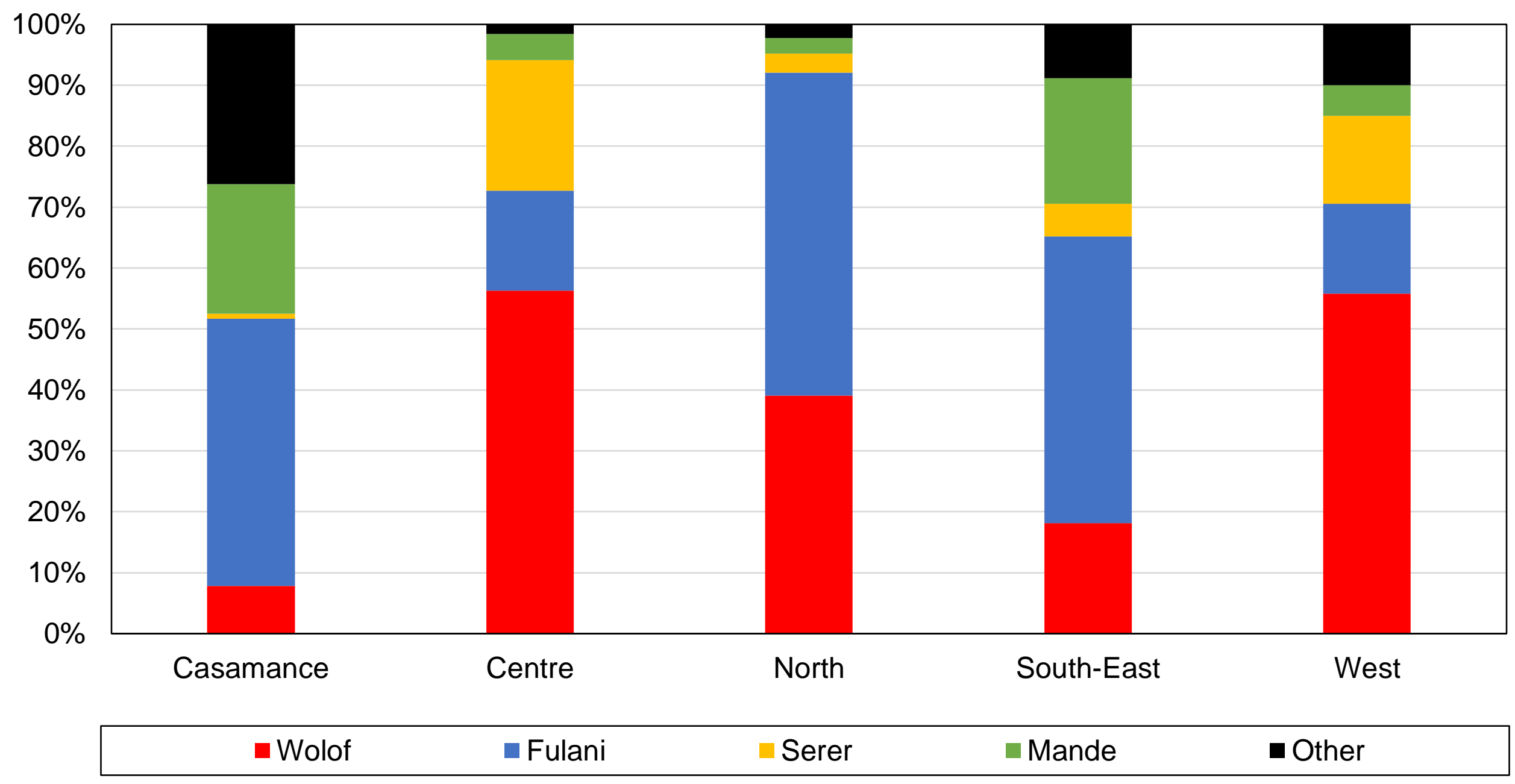

Source: authors' computations using Afrobarometer surveys.

Note: the figure shows the distribution of languages by region of the Senegal population in 2019. 
Figure DA19 - Age composition of education, 2004

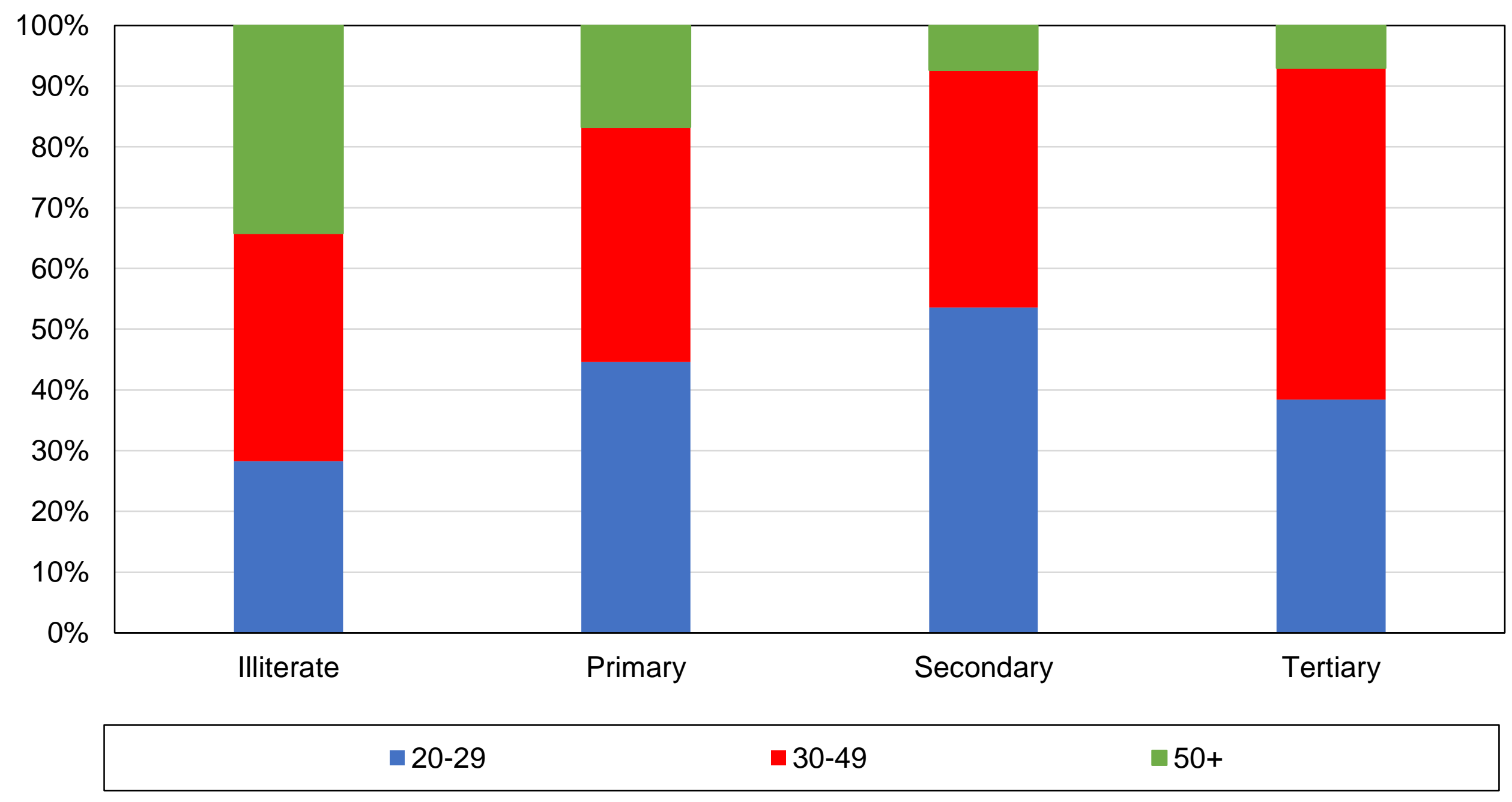

Source: authors' computations using Afrobarometer surveys.

Note: the figure shows the distribution of age by education level of the Selegalese population in 2004. 
Figure DA20 - Age composition of education, 2019

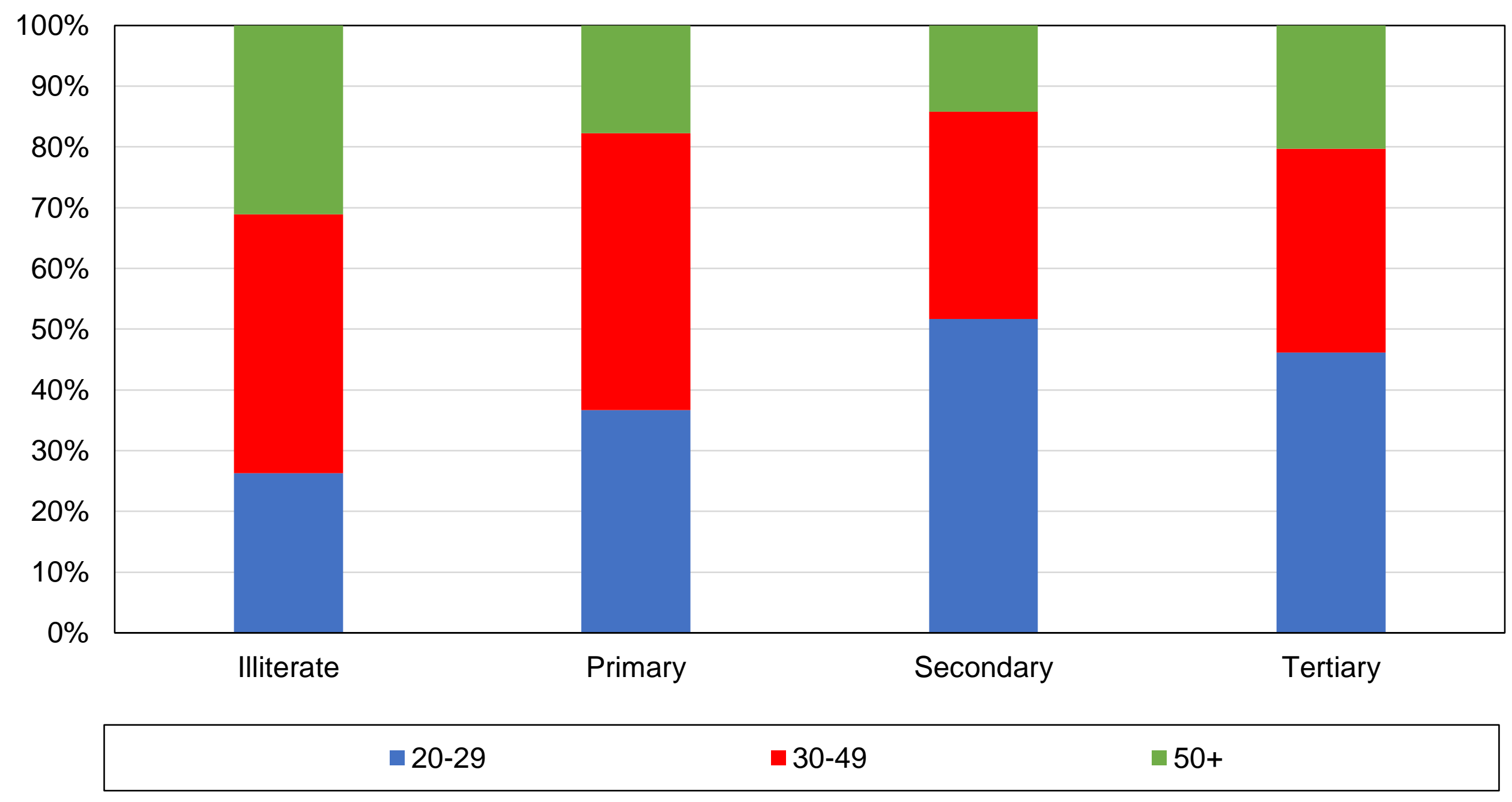

Source: authors' computations using Afrobarometer surveys.

Note: the figure shows the distribution of age by education level of the Selegalese population in 2019. 
Figure DA21 - Age composition of rural-urban locations, 2004

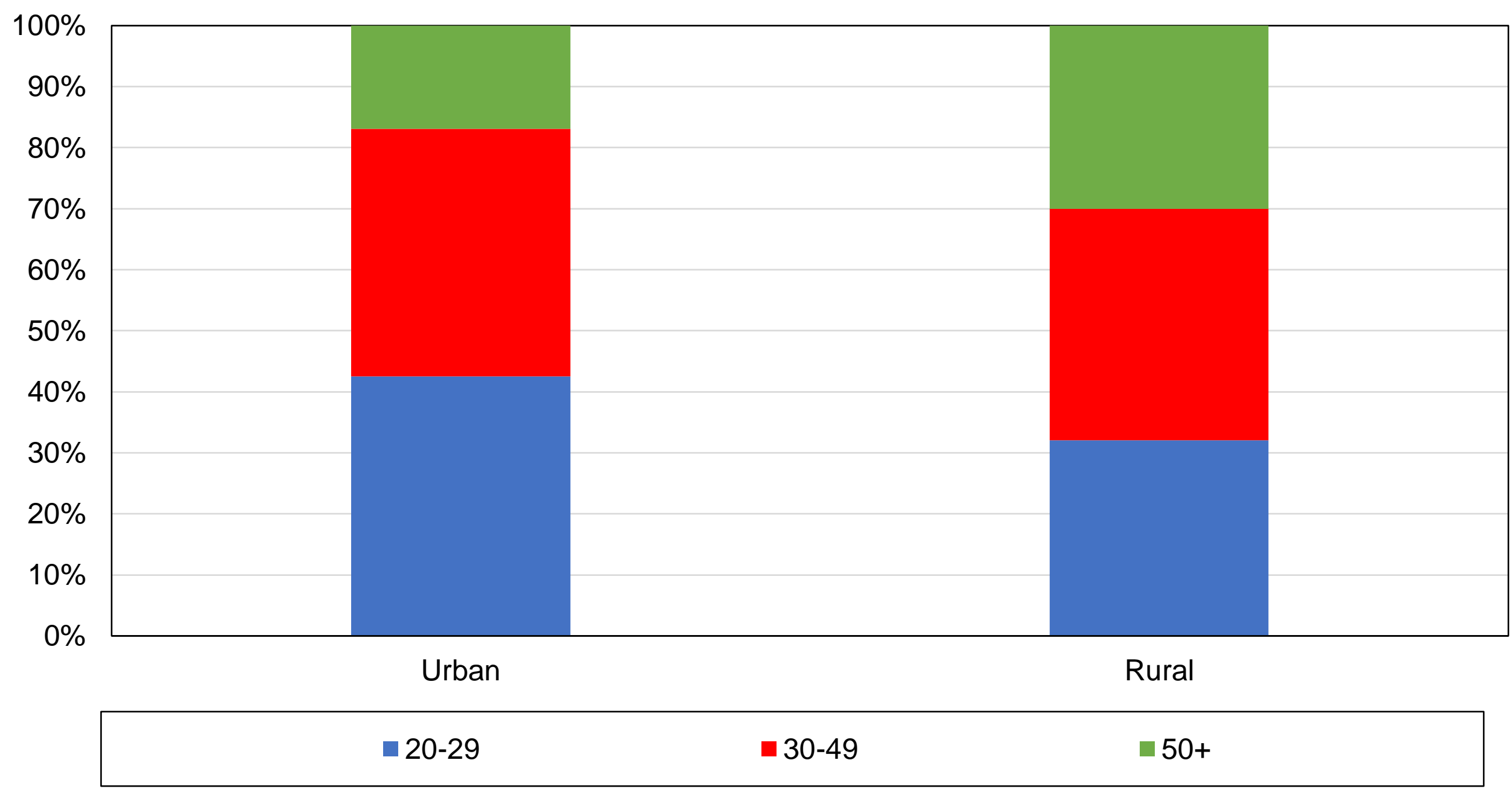

Source: authors' computations using Afrobarometer surveys.

Note: the figure shows the distribution of age by rural-urban location in 2004. 
Figure DA22 - Age composition of rural-urban locations, 2019

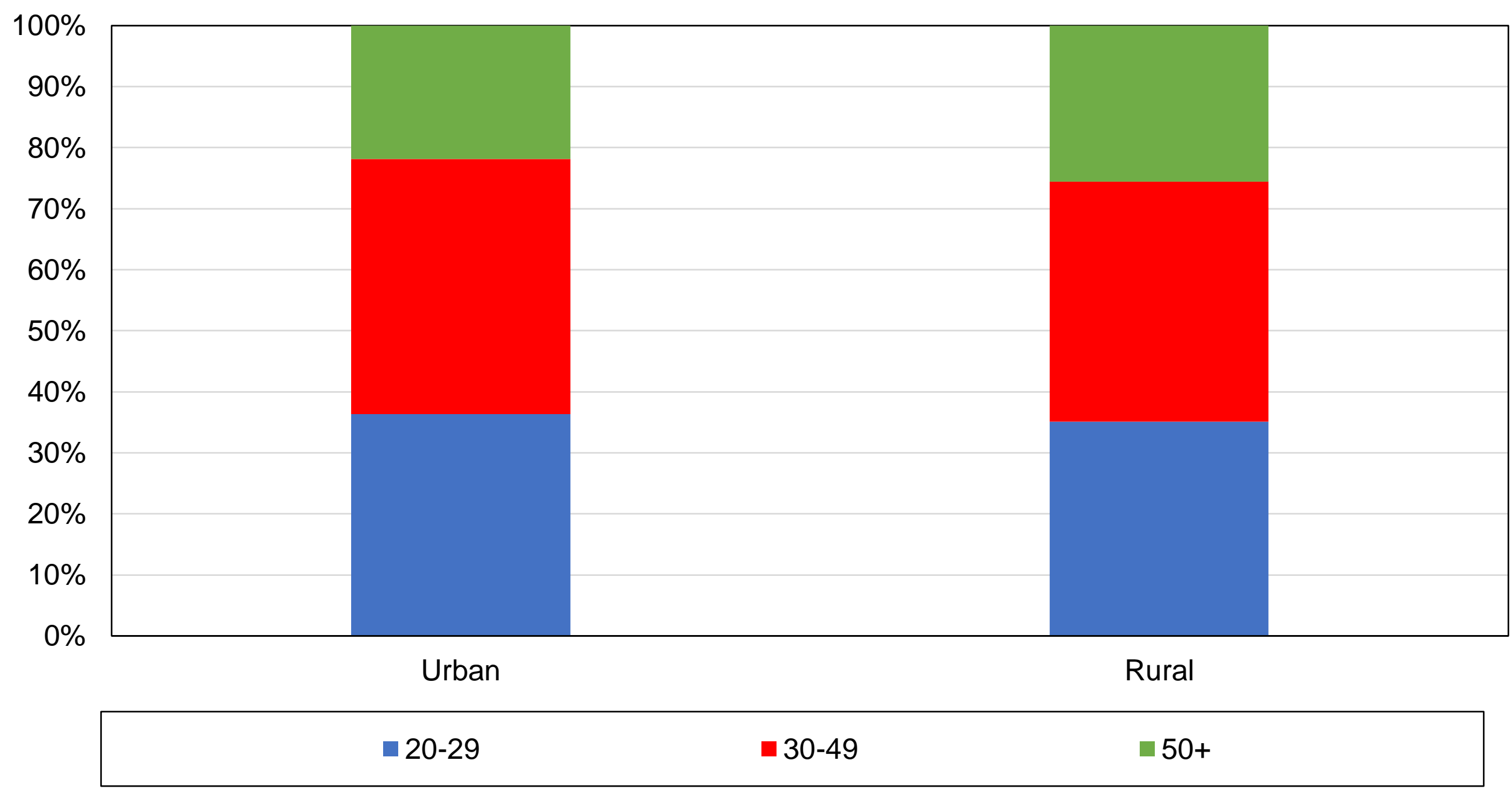

Source: authors' computations using Afrobarometer surveys.

Note: the figure shows the distribution of age by rural-urban location in 2019. 
Figure DB1 - Vote for PDS/APR by education level

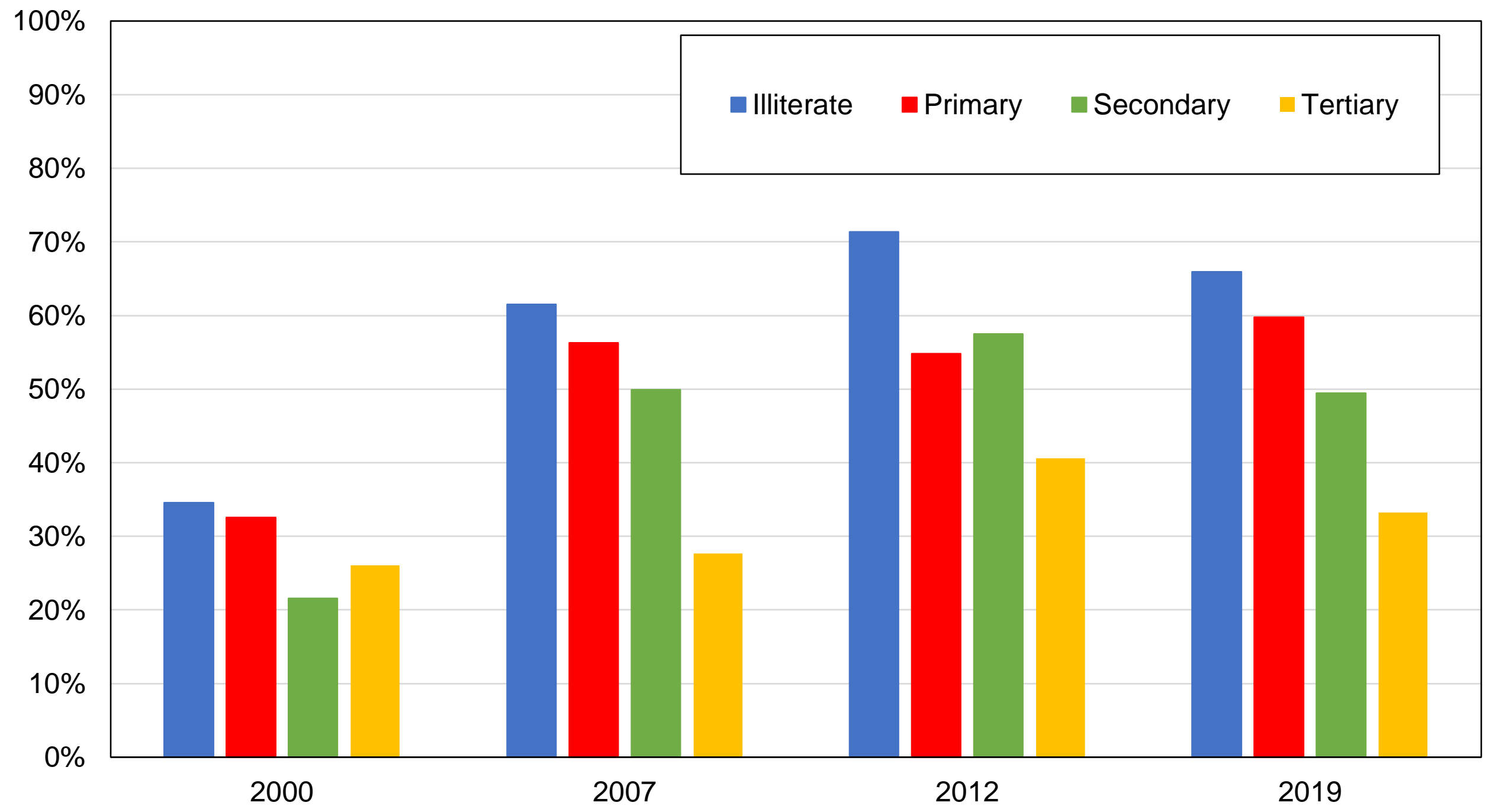

Source: authors' computations using Afrobarometer surveys.

Note: the figure shows the share of votes received by the PDS / APR by education level. 
Figure DB2 - Vote for PDS/APR by education group

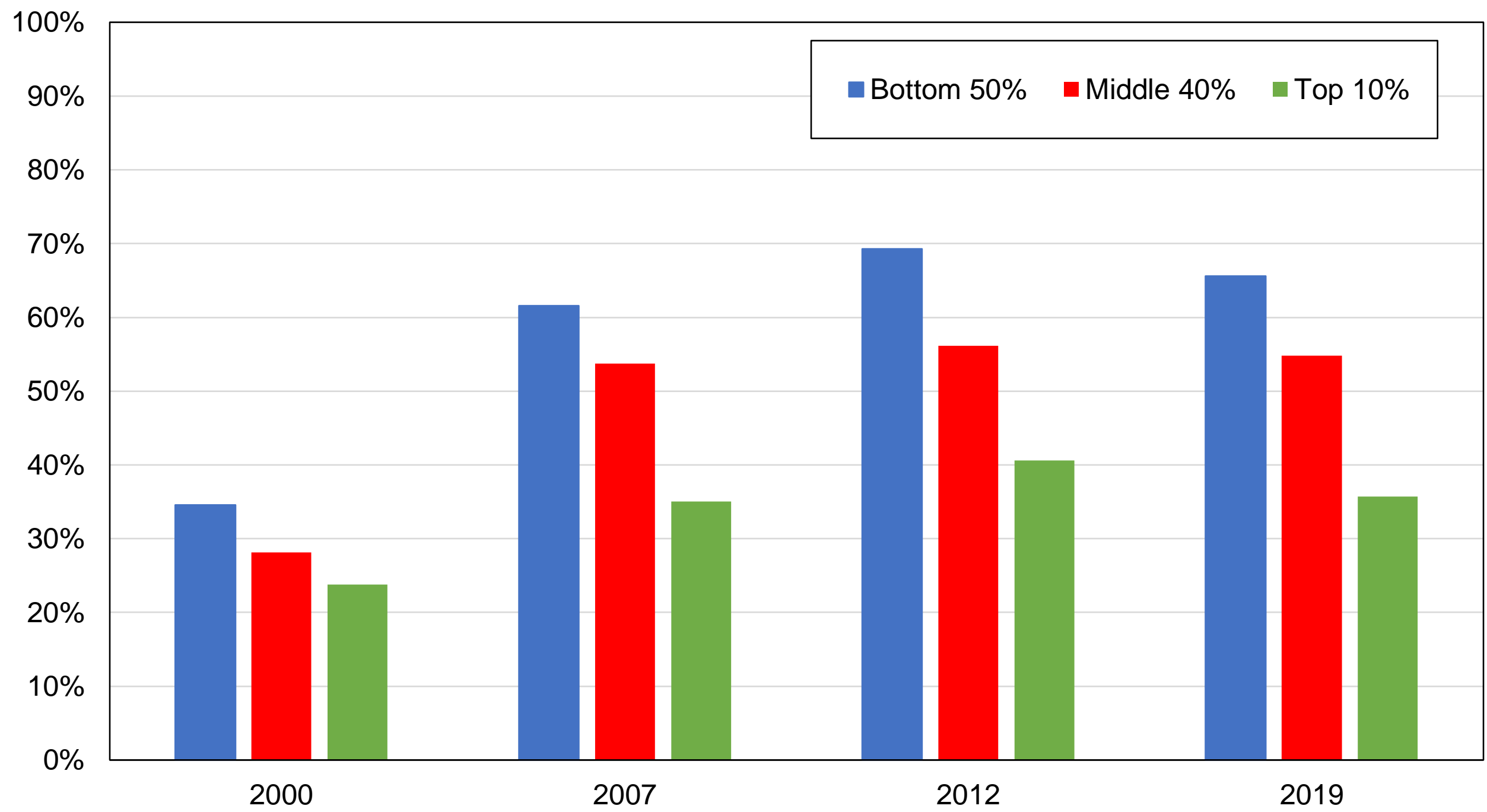

Source: authors' computations using Afrobarometer surveys.

Note: the figure shows the share of votes received by PDS / APR by education group. 
Figure DB3 - Vote for PDS/APR by location

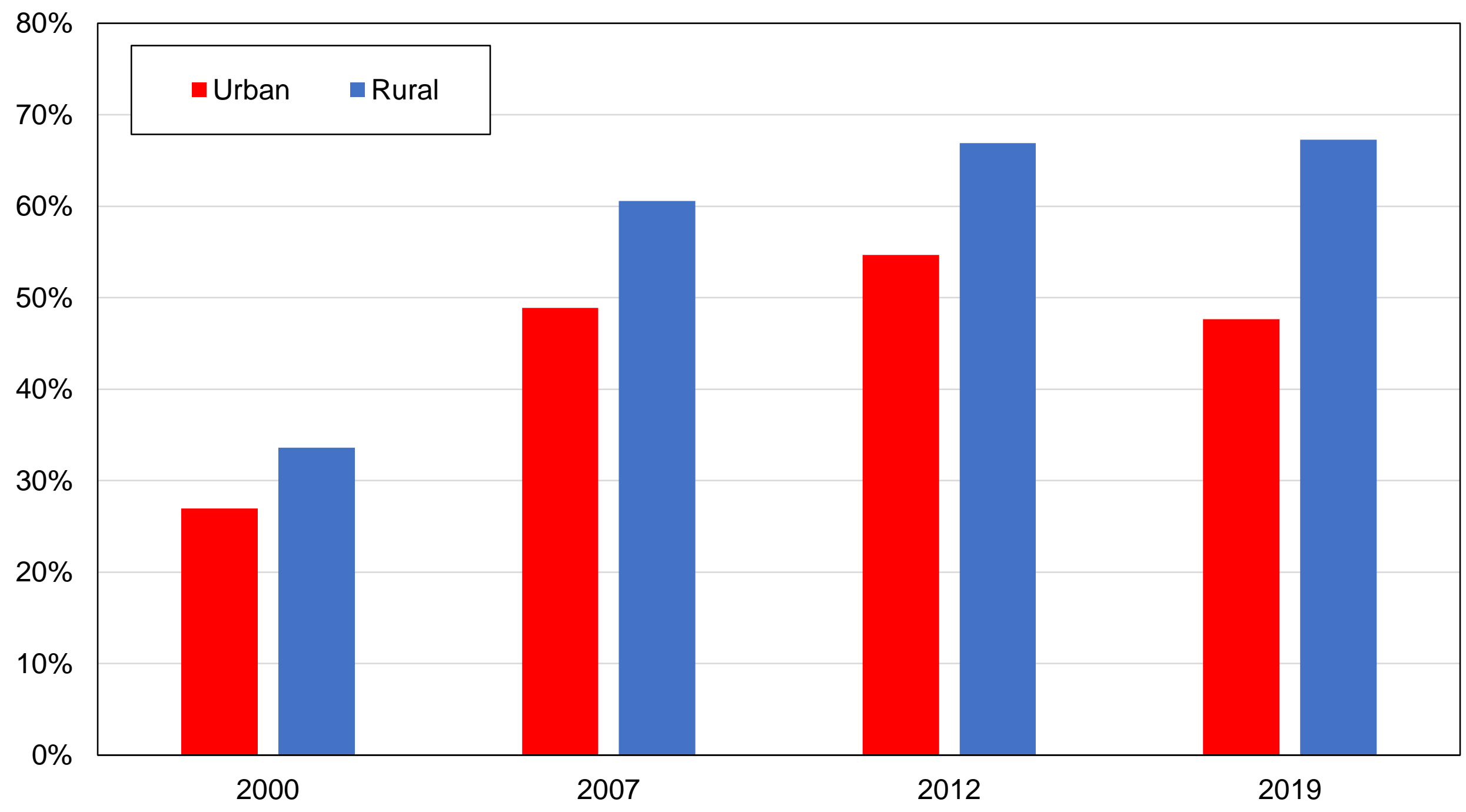

Source: authors' computations using Afrobarometer surveys.

Note: the figure shows the share of votes received by PDS / APR by location. 
Figure DB4 - Vote for PDS/APR by region

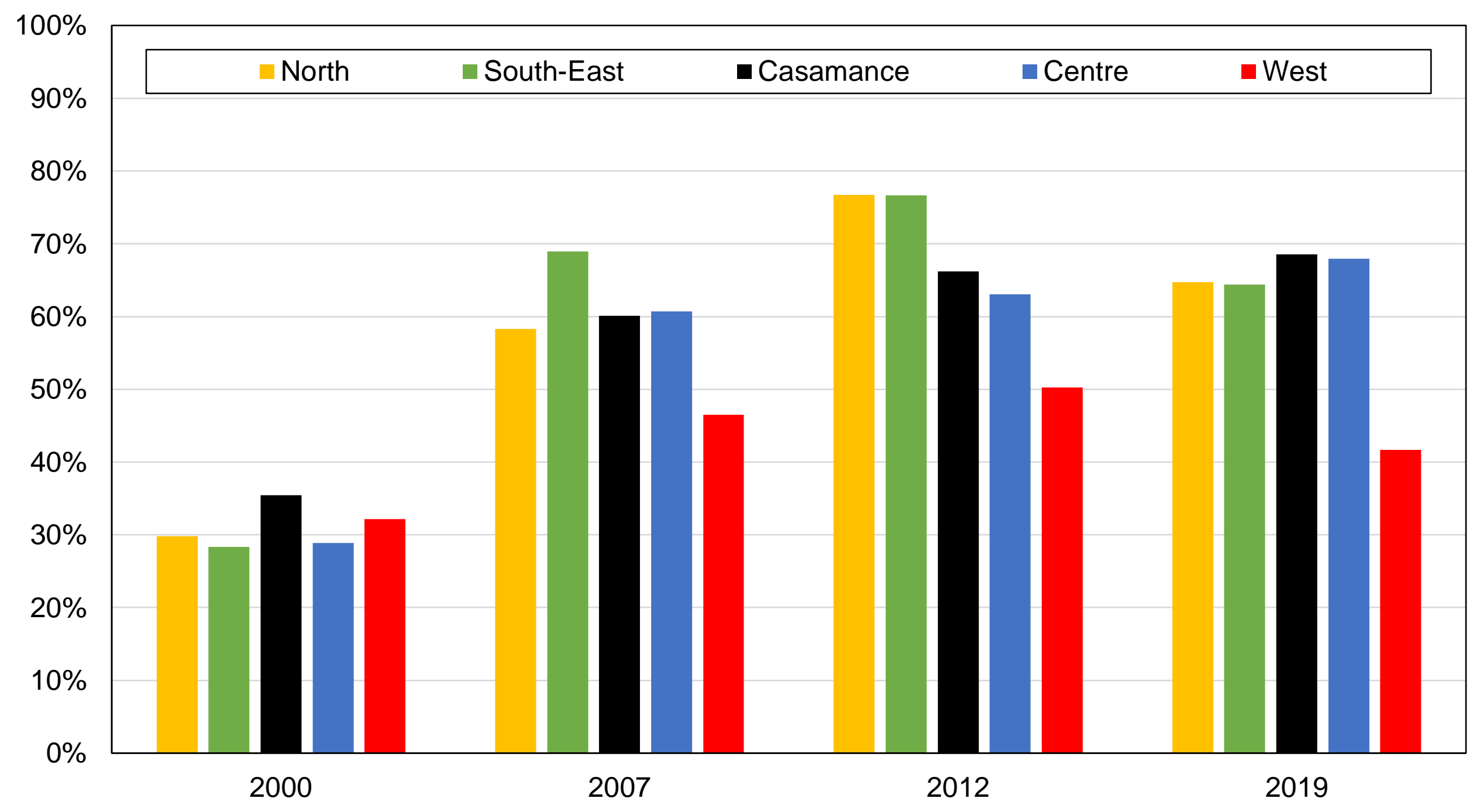

Source: authors' computations using Afrobarometer surveys.

Note: the figure shows the share of votes received by PDS / APR by region. 
Figure DB5 - Vote for PDS/APR by language

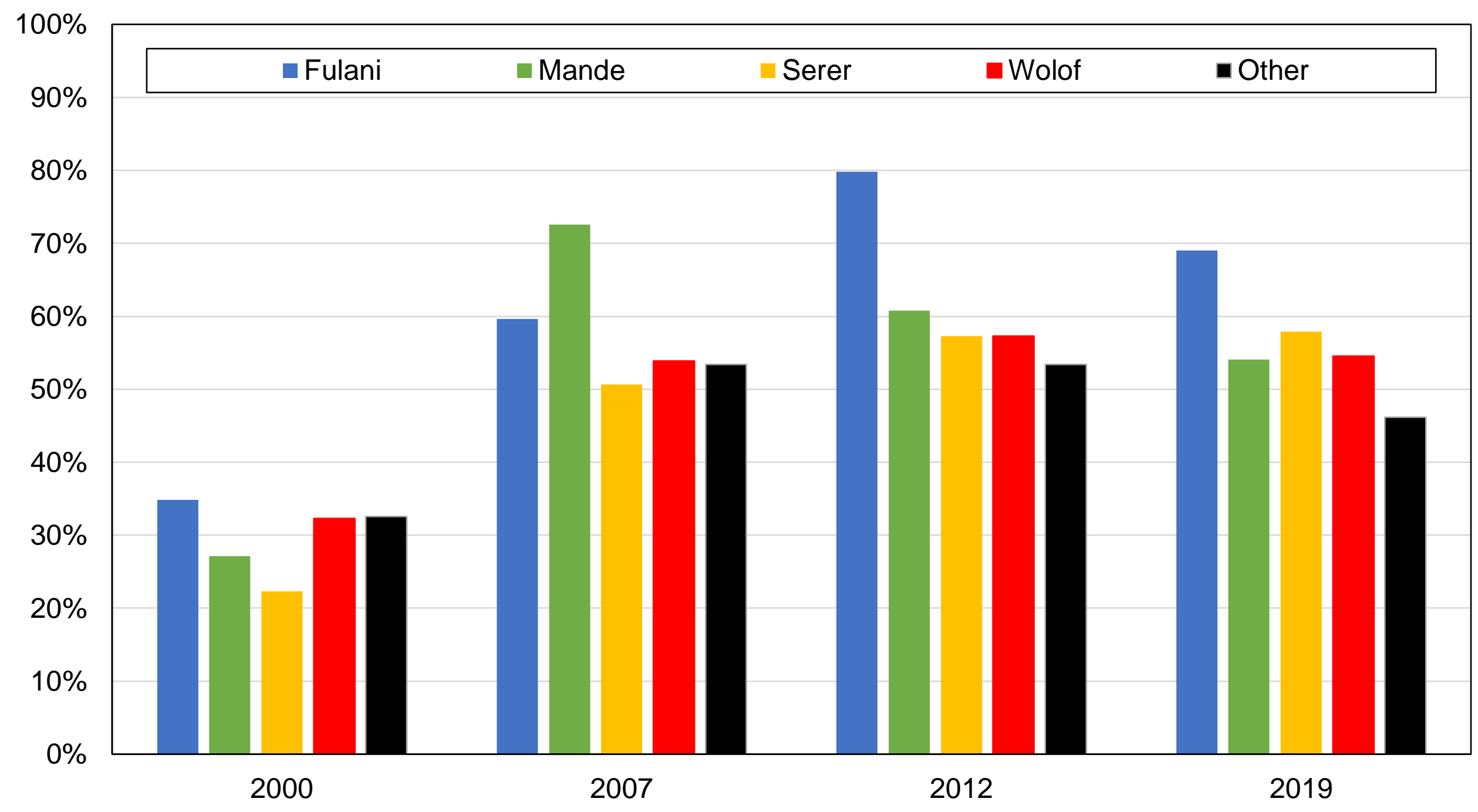

Source: authors' computations using Afrobarometer surveys.

Note: the figure shows the share of votes received by PDS / APR by language. 
Figure DB6 - Vote for PDS/APR by age group

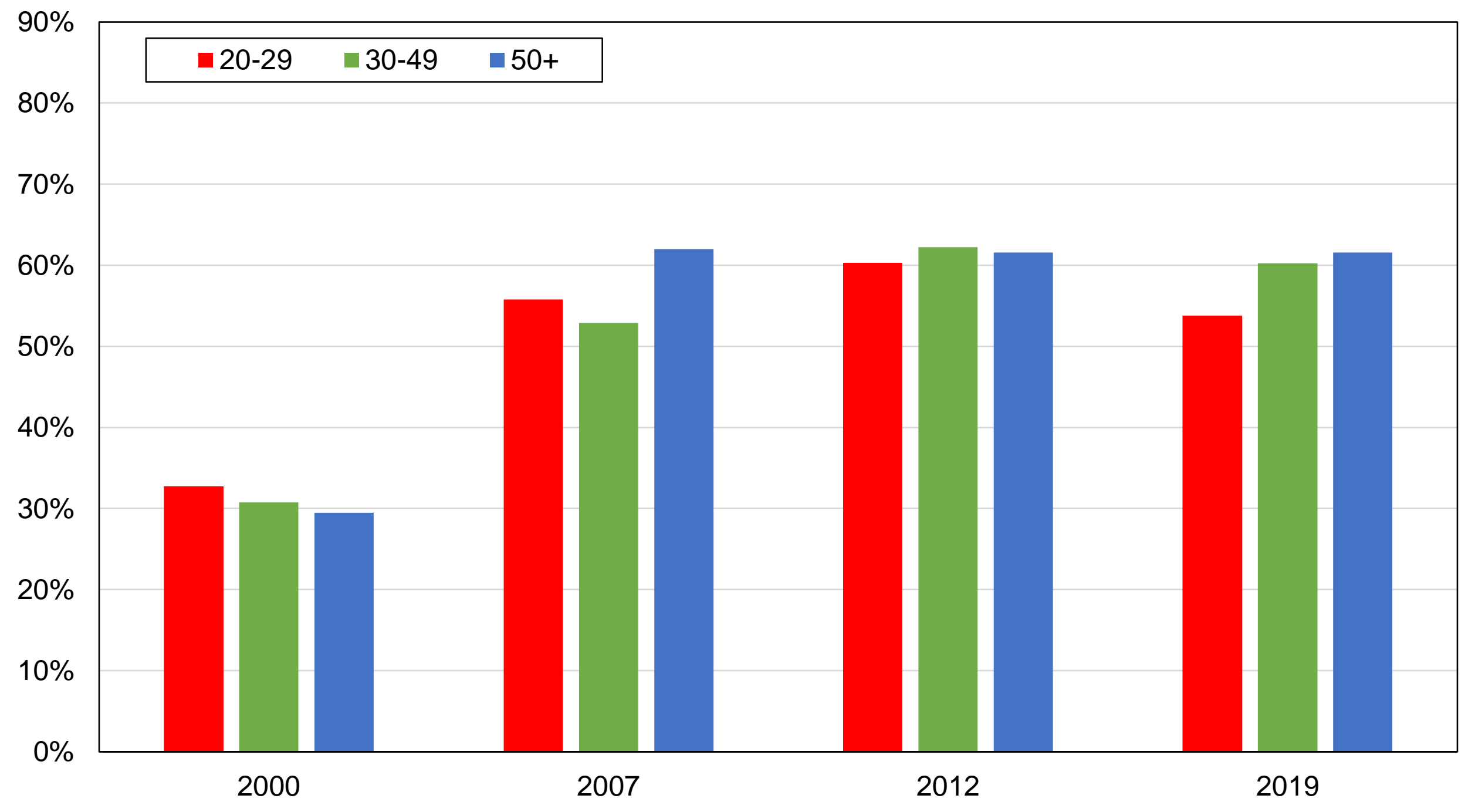

Source: authors' computations using Afrobarometer surveys.

Note: the figure shows the share of votes received by PDS / APR by age group. 
Figure DB7 - Vote for PDS/APR by gender

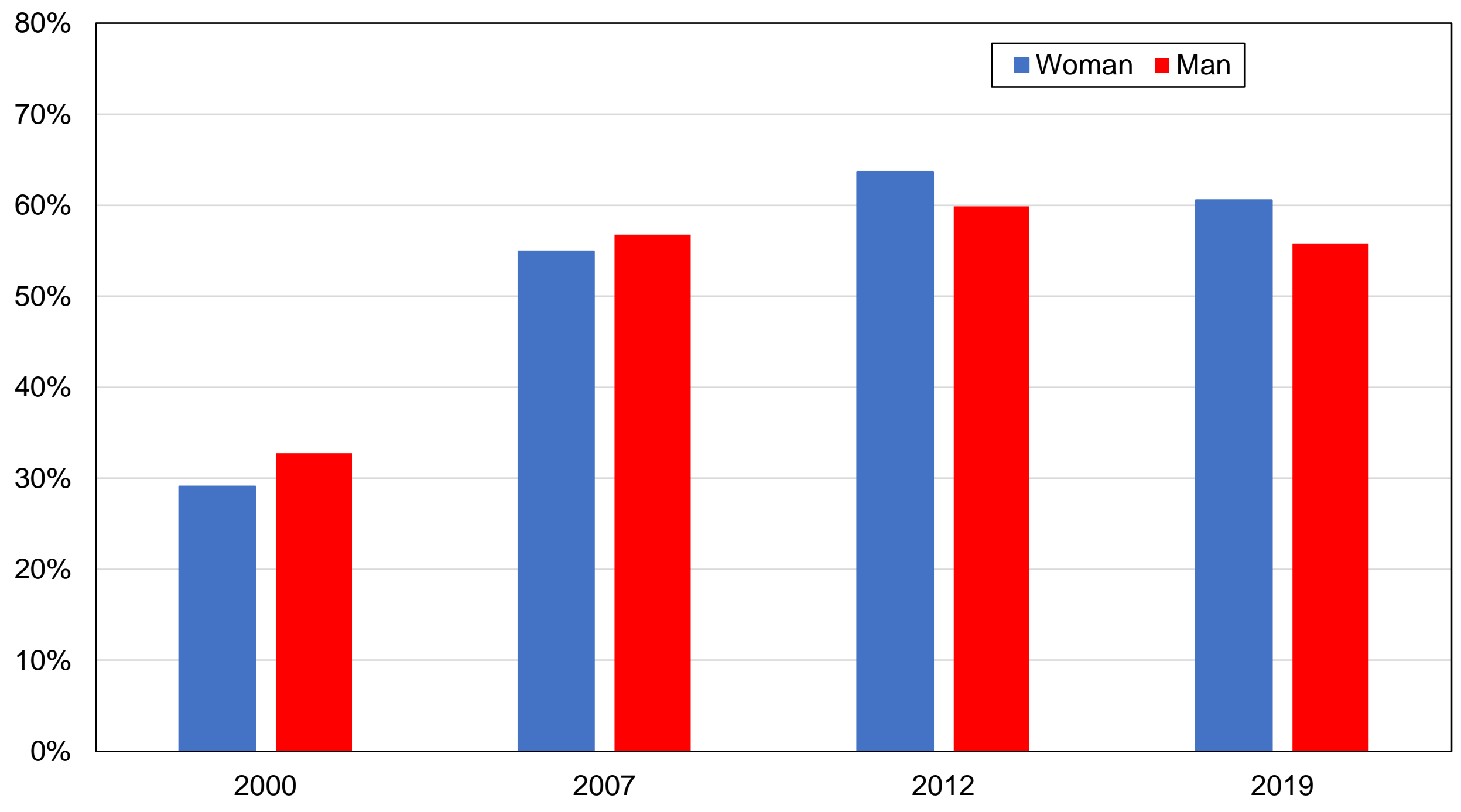

Source: authors' computations using Afrobarometer surveys.

Note: the figure shows the share of votes received by PDS / APR by gender. 
Figure DB8 - Vote for PDS/APR by religion

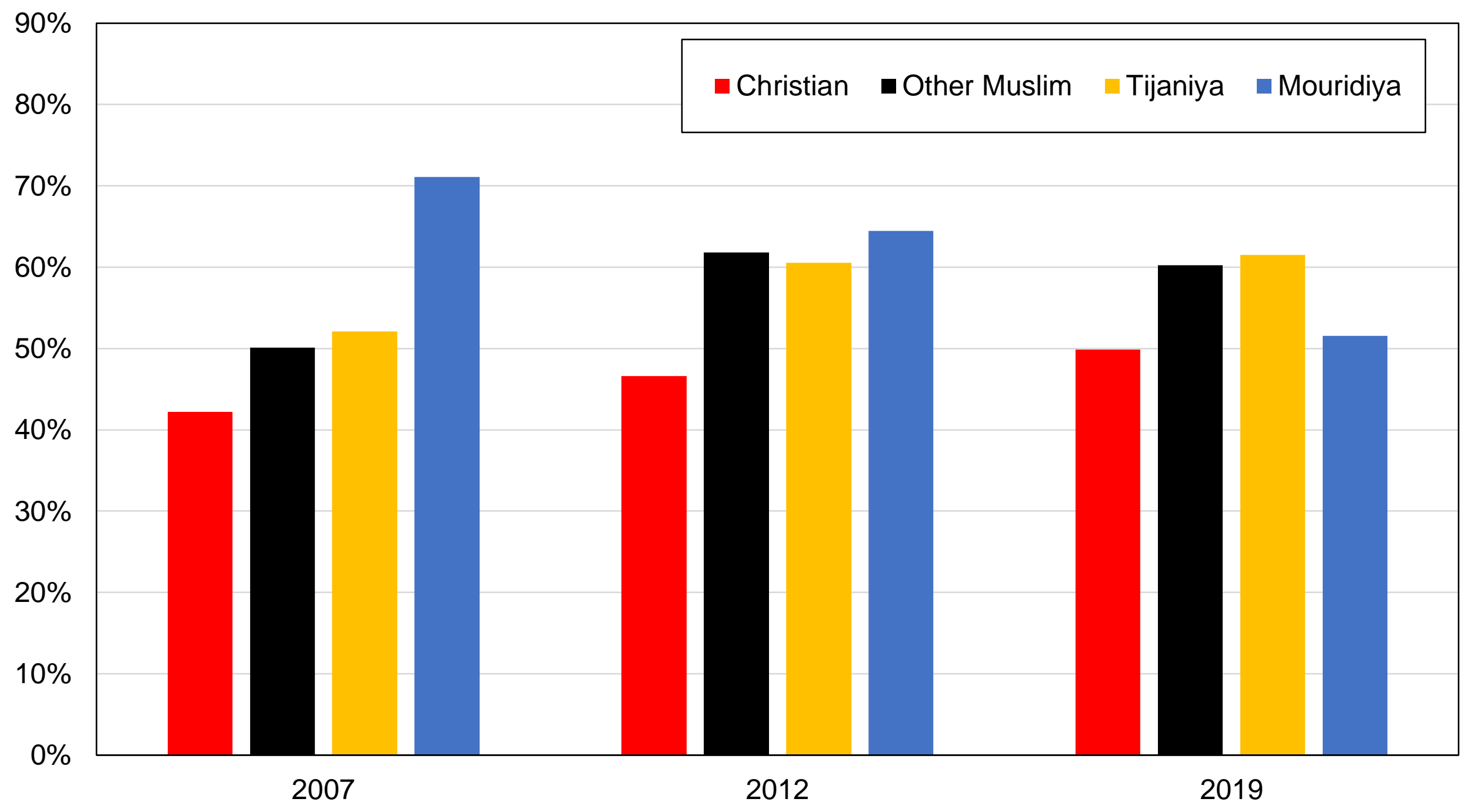

Source: authors' computations using Afrobarometer surveys.

Note: the figure shows the share of votes received by PDS / APR by religious affiliation. 
Figure DB9 - Vote for PDS/APR by employment status

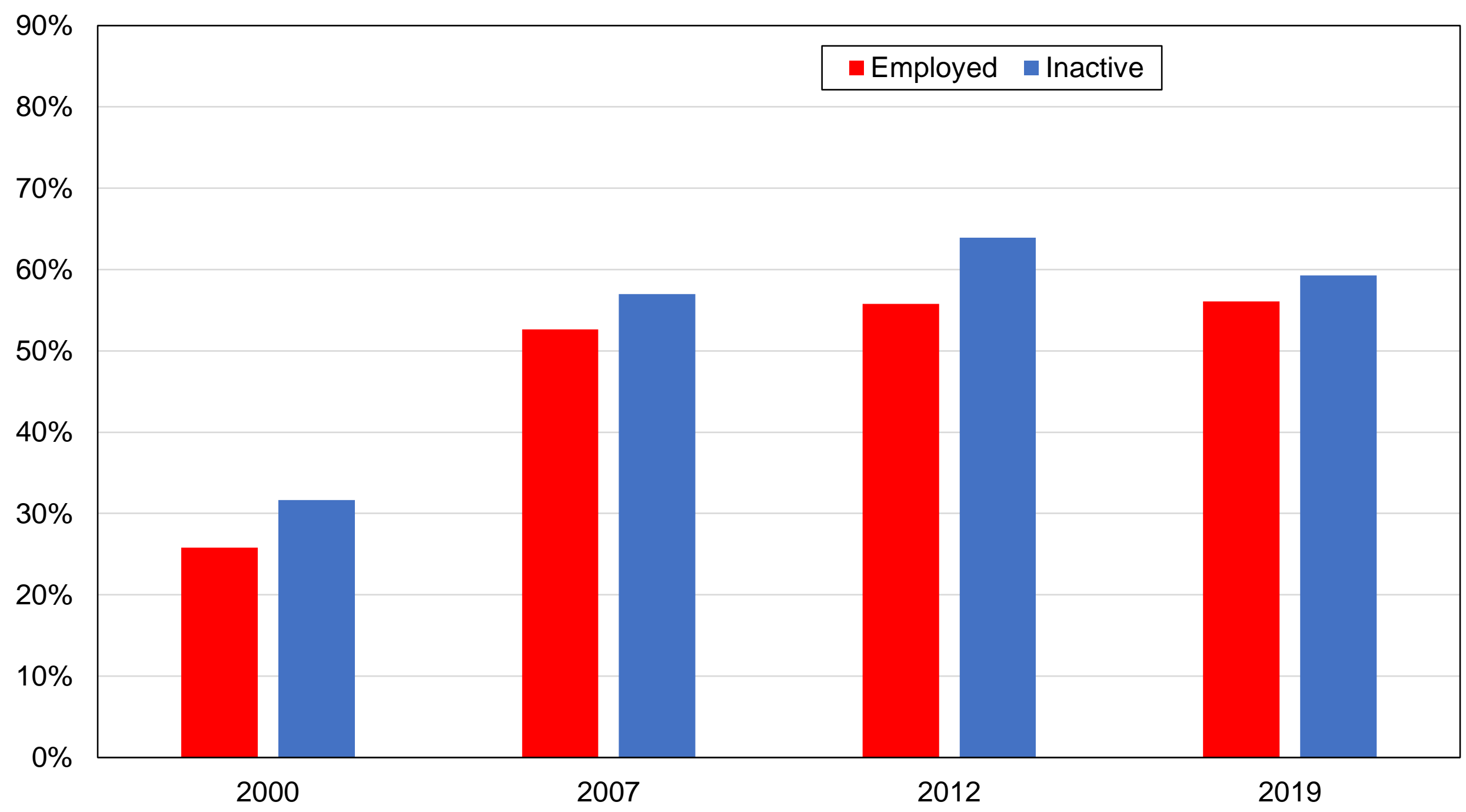

Source: authors' computations using Afrobarometer surveys.

Note: the figure shows the share of votes received by PDS / APR by employment status. 
Figure DB10 - Vote for PDS/APR by occupation

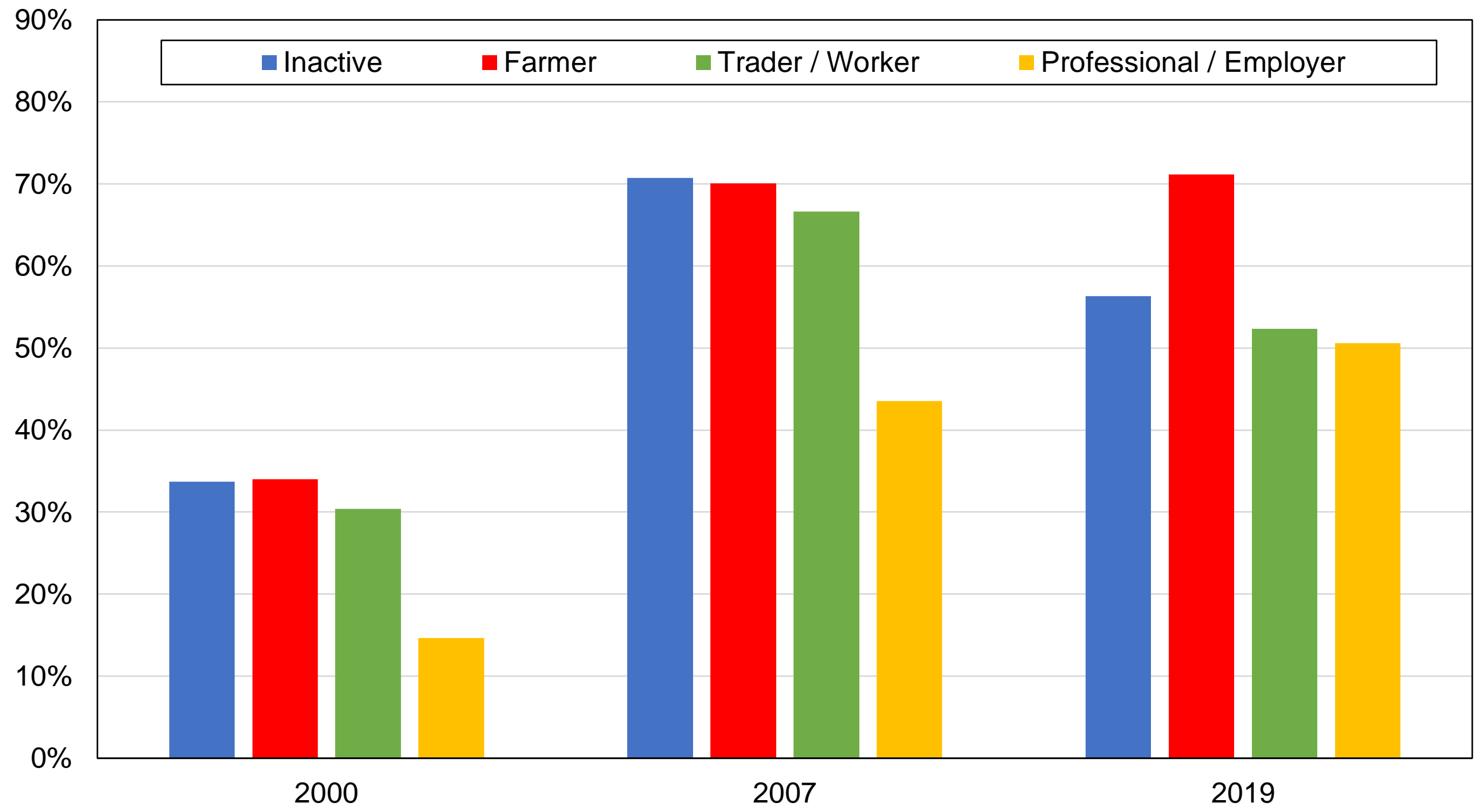

Source: authors' computations using Afrobarometer surveys.

Note: the figure shows the share of votes received by PDS / APR by occupation. 
Figure DB11 - Vote for PDS by region and location, 2000

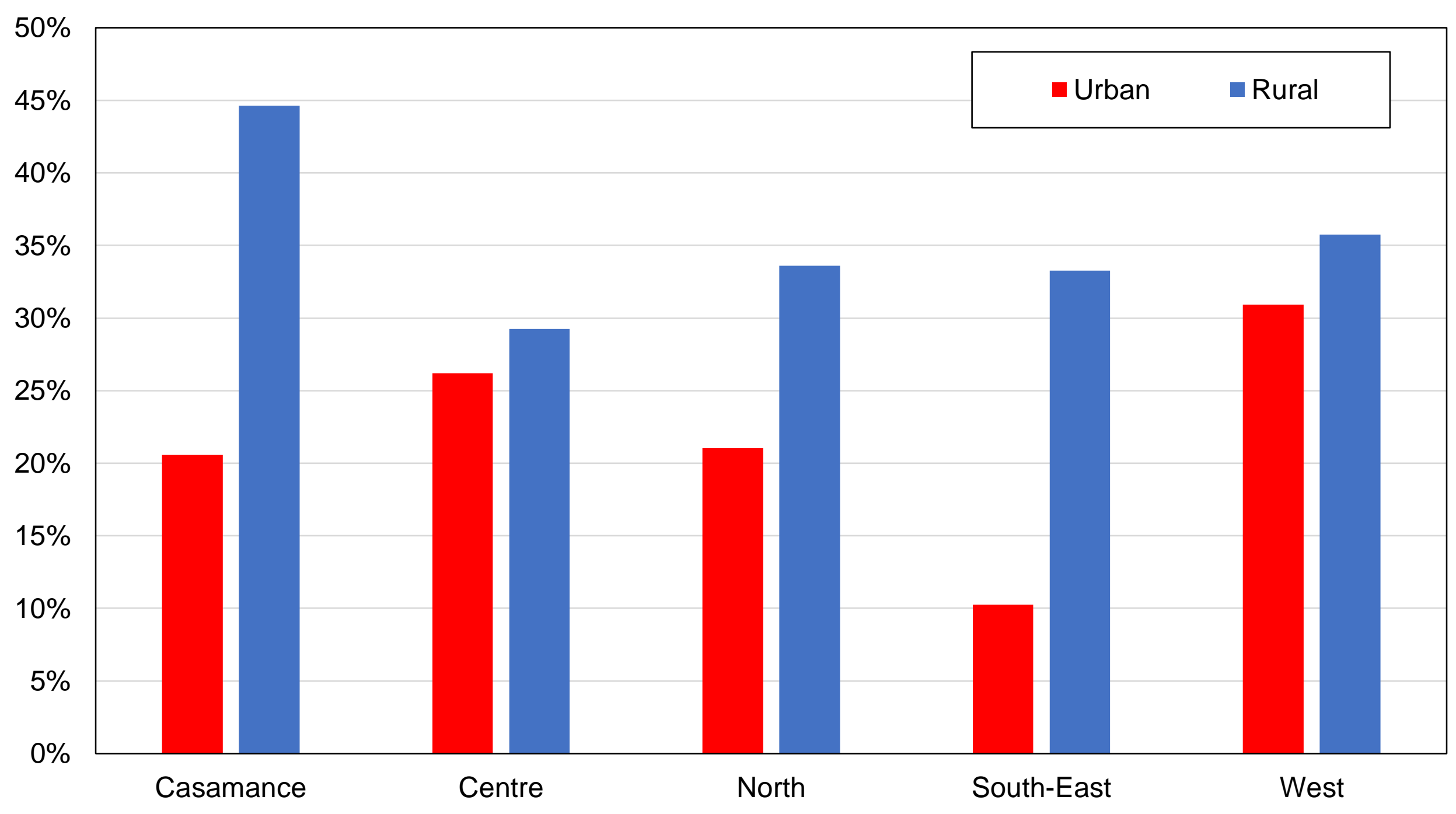

Source: authors' computations using Afrobarometer surveys.

Note: the figure shows the share of votes received by the PDS / APR by region and location in 2000. 
Figure DB12 - Vote for APR by region and location, 2019

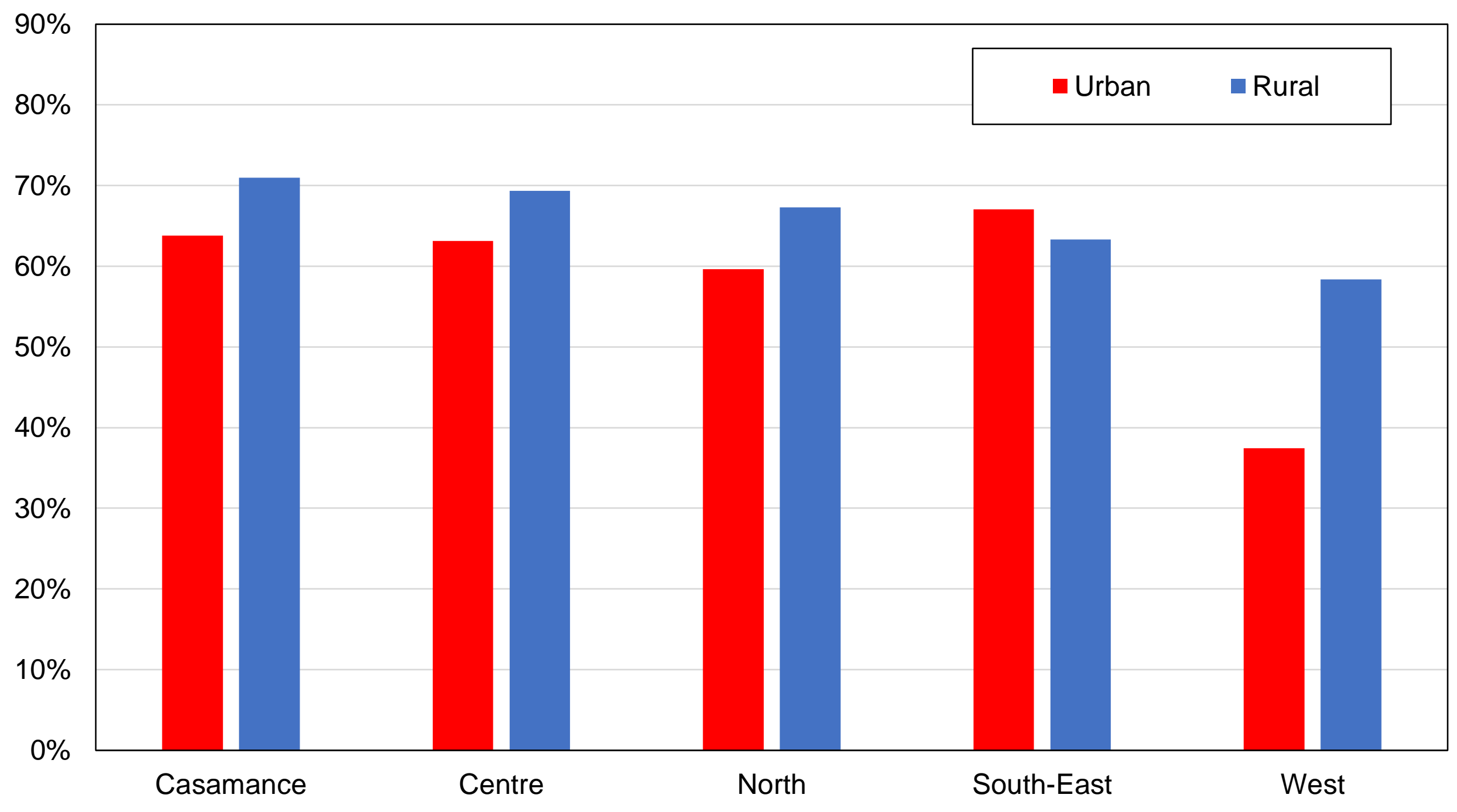

Source: authors' computations using Afrobarometer surveys.

Note: the figure shows the share of votes received by the PDS / APR by region and location in 2019. 
Figure DB13 - Vote for PDS by region and education, 2000

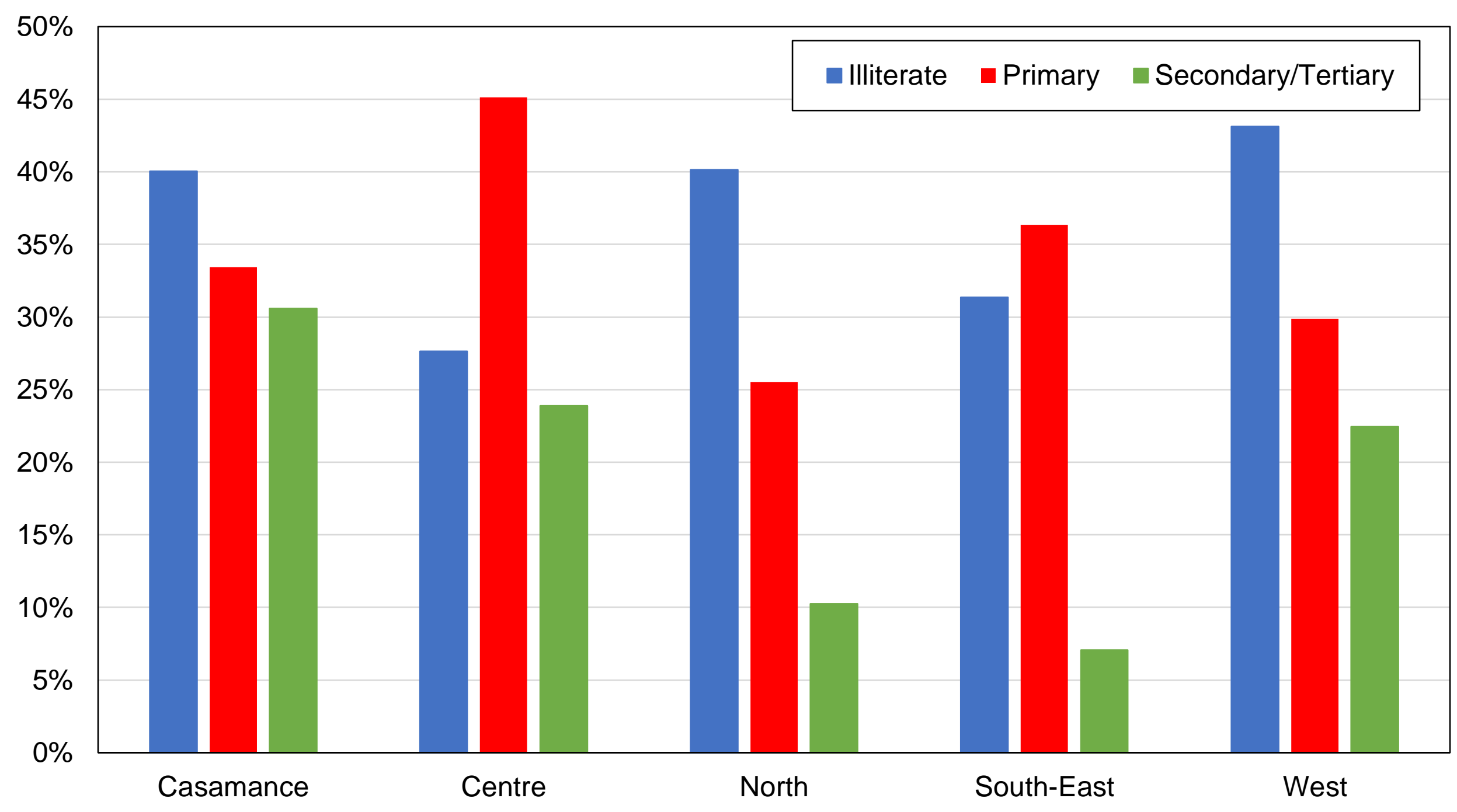

Source: authors' computations using Afrobarometer surveys.

Note: the figure shows the share of votes received by the PDS / APR by region and education in 2000. 
Figure DB14 - Vote for APR by region and education, 2019

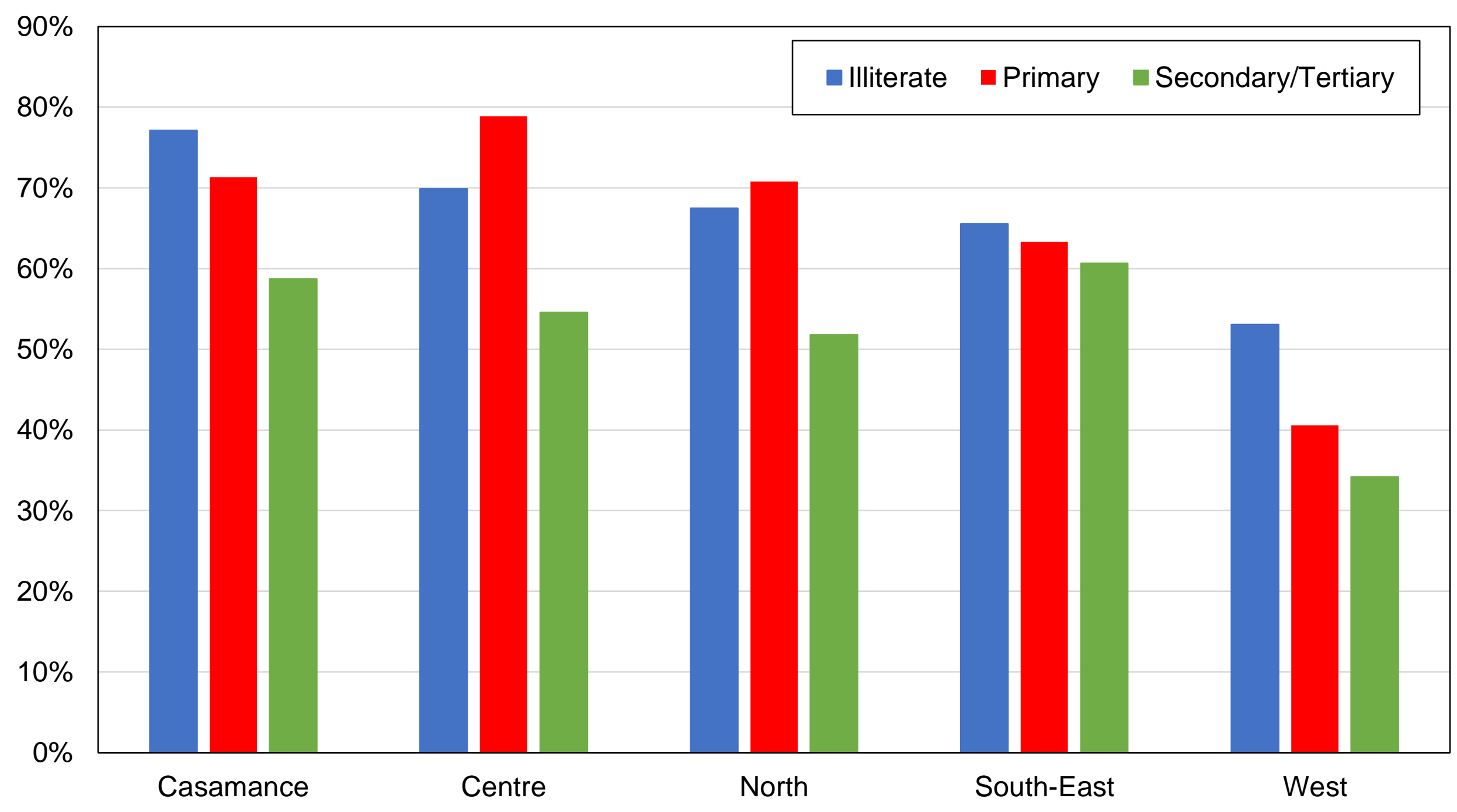

Source: authors' computations using Afrobarometer surveys.

Note: the figure shows the share of votes received by the PDS / APR by region and education in 2019. 
Figure DB15 - Vote for PDS by location and education, 2000

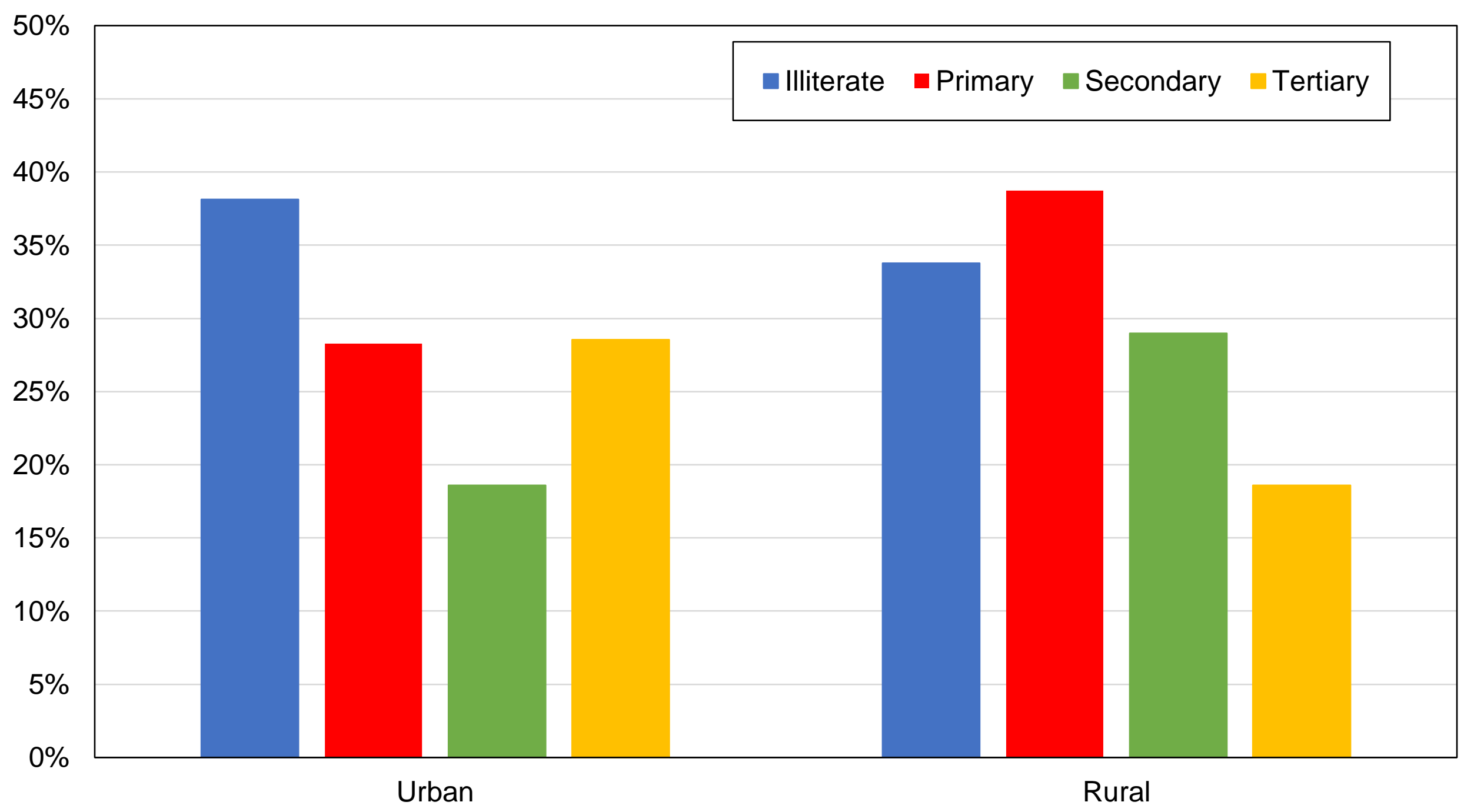

Source: authors' computations using Afrobarometer surveys.

Note: the figure shows the share of votes received by the PDS / APR by location and education in 2000. 
Figure DB16 - Vote for APR by location and education, 2019

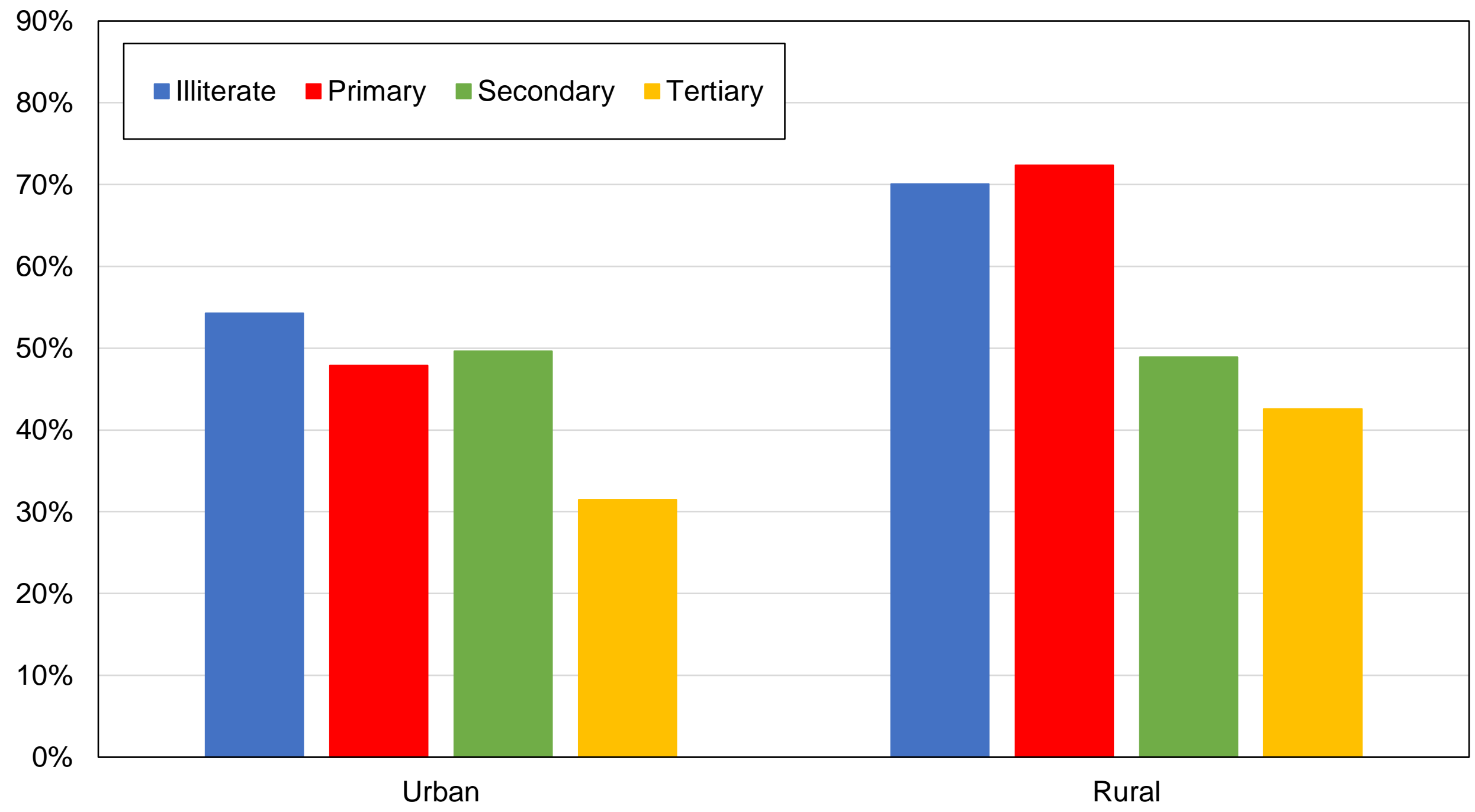

Source: authors' computations using Afrobarometer surveys.

Note: the figure shows the share of votes received by the PDS / APR by location and education in 2019. 


\section{Figure DC1 - Vote for PDS/APR among highest-educated voters}

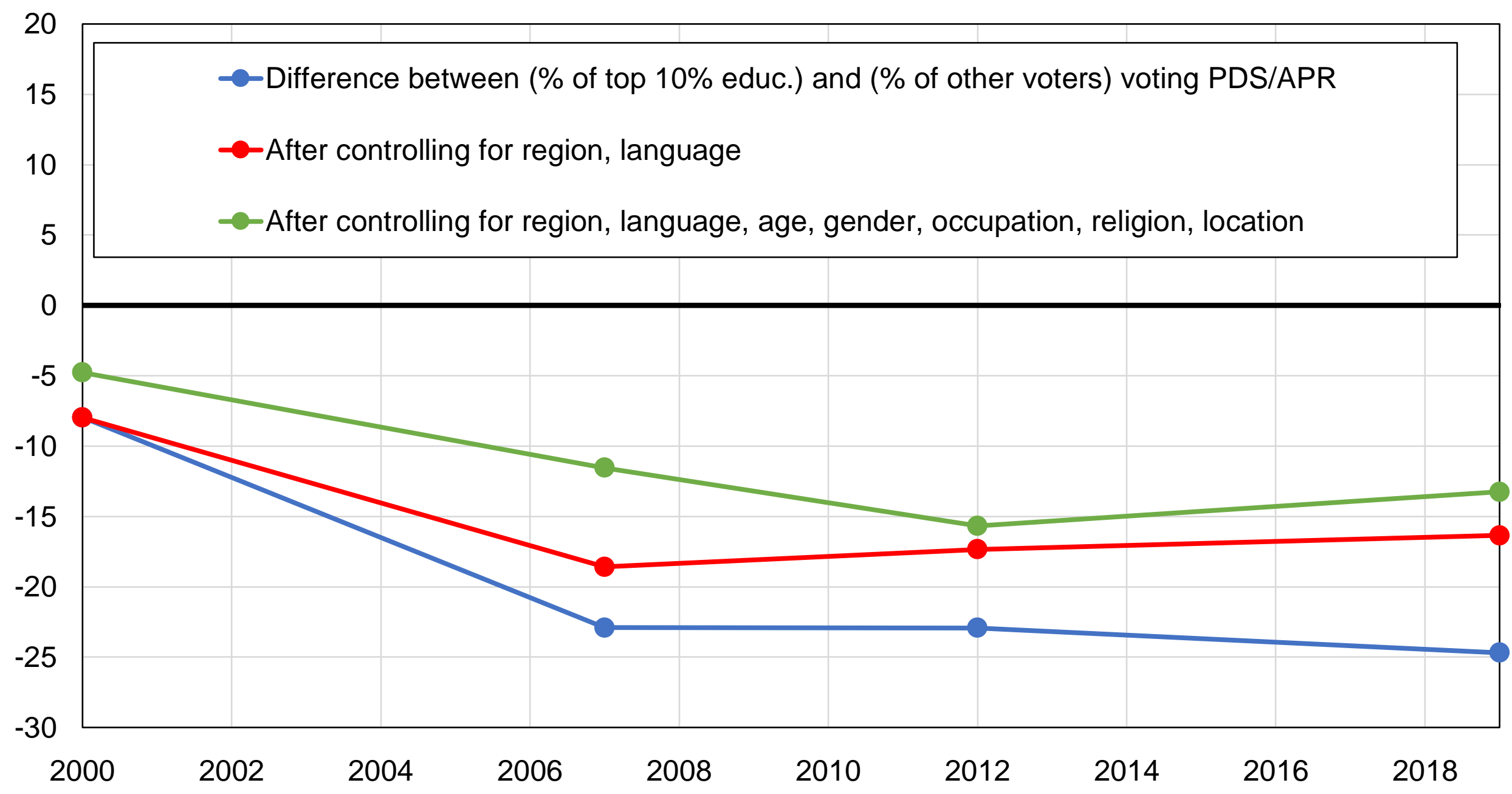

Source: authors' computations using Afrobarometer surveys.

Note: the figure shows the difference between the share of top $10 \%$ educated voters and the share of other voters voting for PDS / APR, before and after controlling for other variables. 


\section{Figure DC2 - Vote for PDS/APR among university graduates}

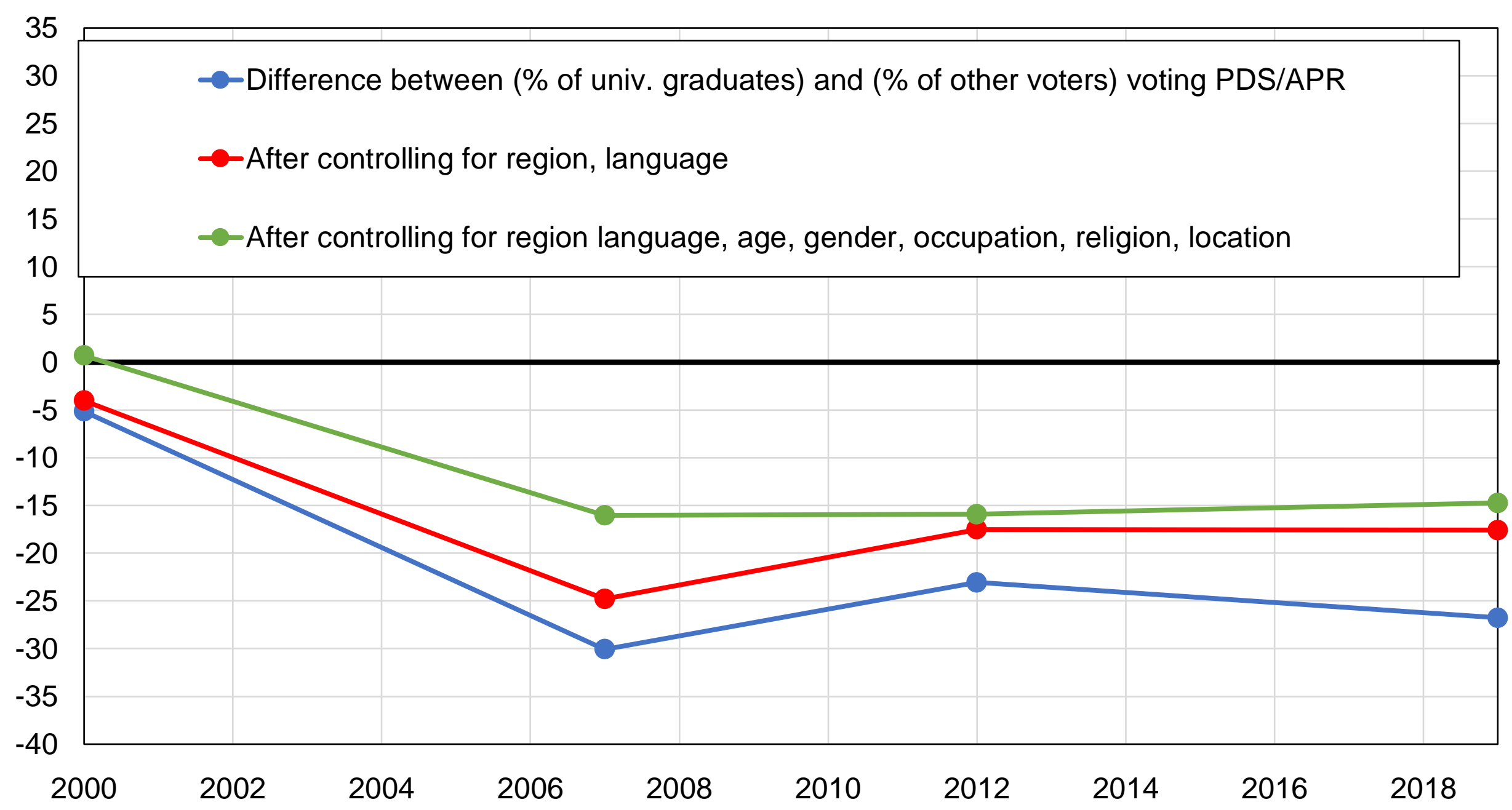

Source: authors' computations using Afrobarometer surveys.

Note: the figure shows the difference between the share of university graduates and the share of other voters voting for PDS / APR, before and after controlling for other variables. 


\section{Figure DC3 - Vote for PDS/APR among lowest-educated voters}

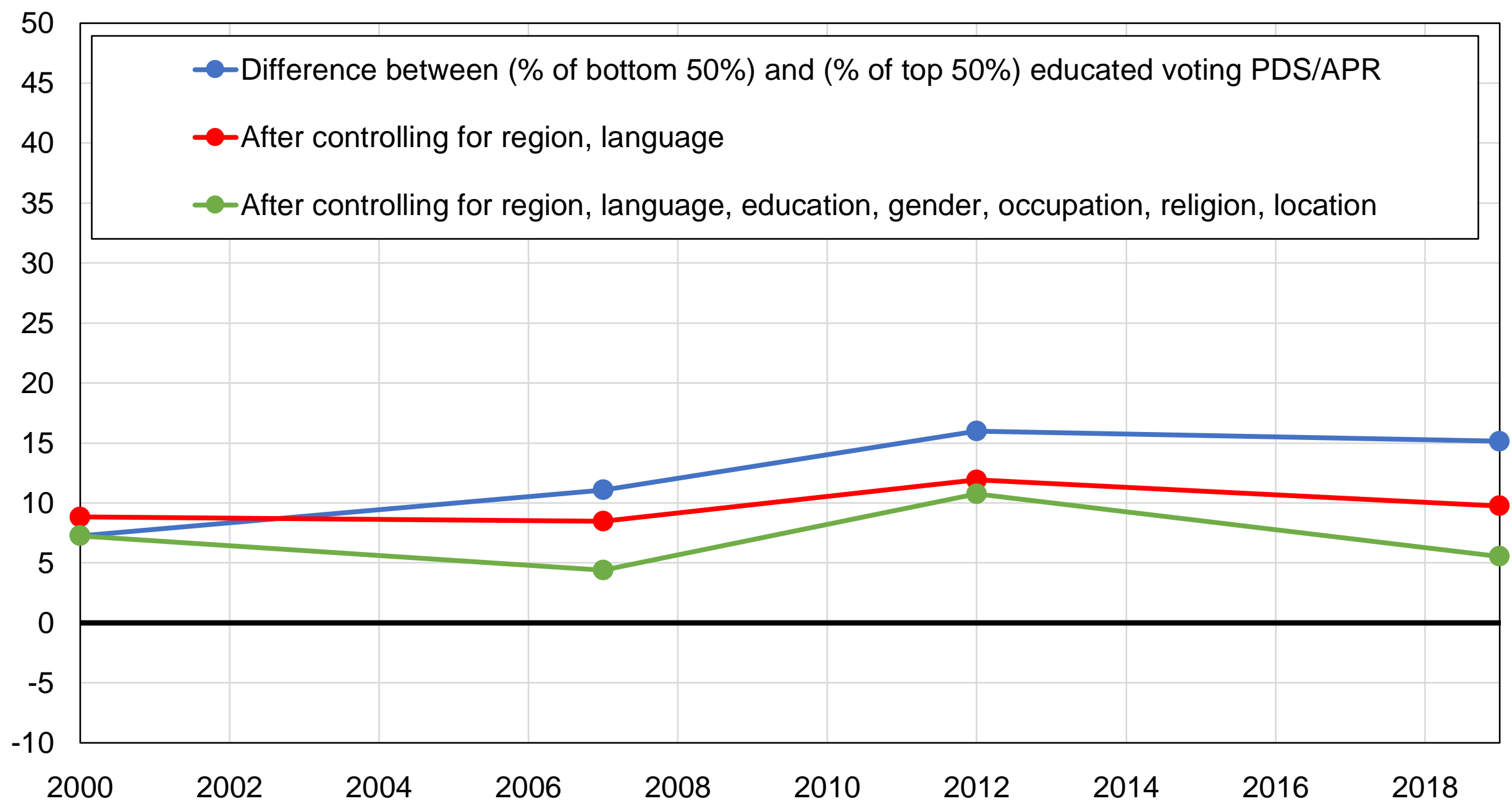

Source: authors' computations using Afrobarometer surveys.

Note: the figure shows the difference between the share of lowest $50 \%$ educated voters and the share of other voters voting for PDS / APR, before and after controlling for other variables. 


\section{Figure DC4 - Vote for PDS/APR among women}

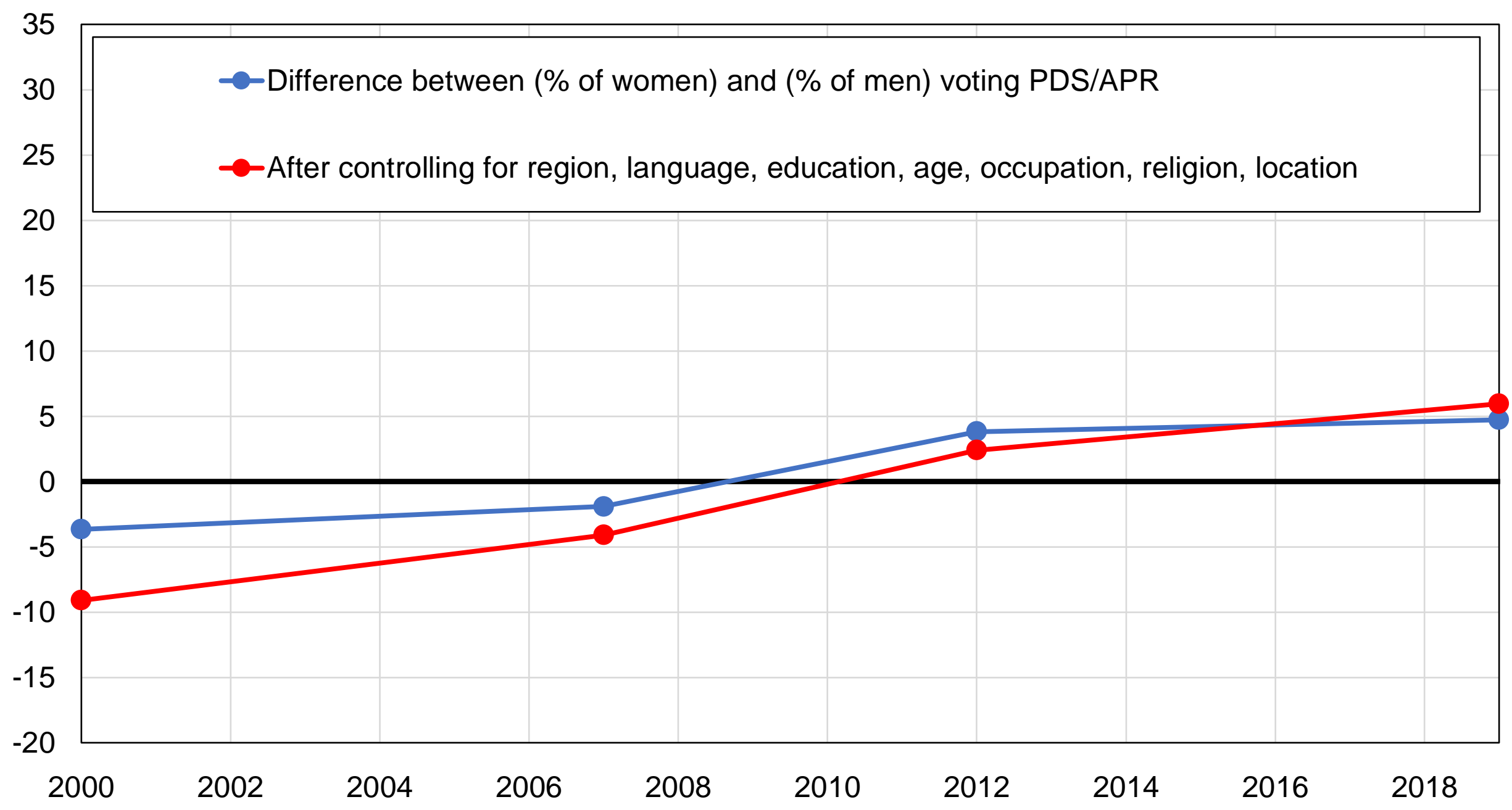

Source: authors' computations using Afrobarometer surveys.

Note: the figure shows the difference between the share of women and the share of men voting for PDS / APR, before and after controlling for other variables. 
Figure DC5 - Vote for PDS/APR among rural areas

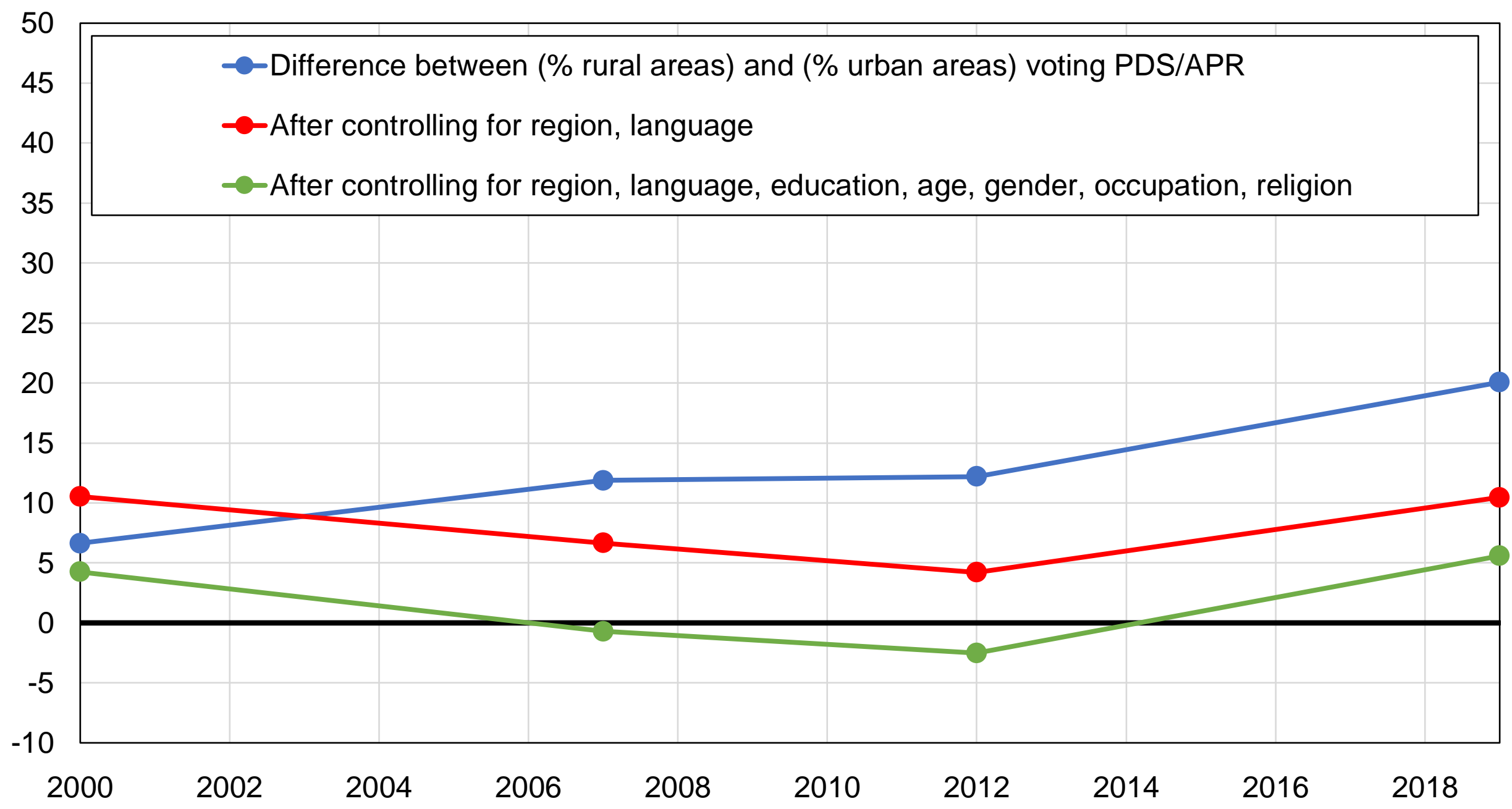

Source: authors' computations using Afrobarometer surveys.

Note: the figure shows the difference between the share of rural areas and the share of urban areas voting for PDS / APR, before and after controlling for other variables. 


\section{Figure DC6 - Vote for PDS/APR among West region residents}

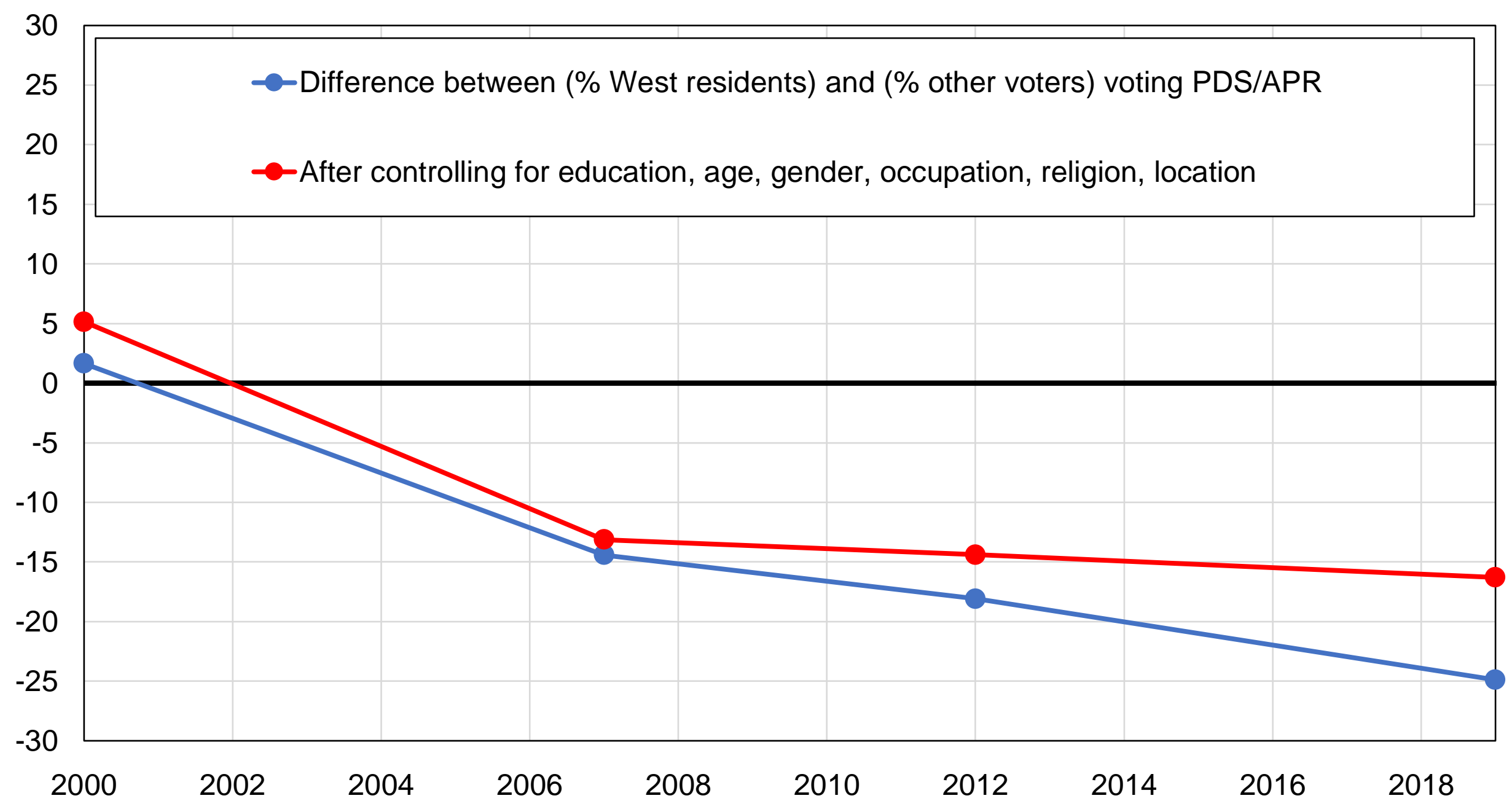

Source: authors' computations using Afrobarometer surveys.

Note: the figure shows the difference between the share of West region residents and the share of other voters voting for PDS / APR, before and after controlling for other variables. 


\section{Figure DC7 - Vote for PDS/APR among Fulani speakers}

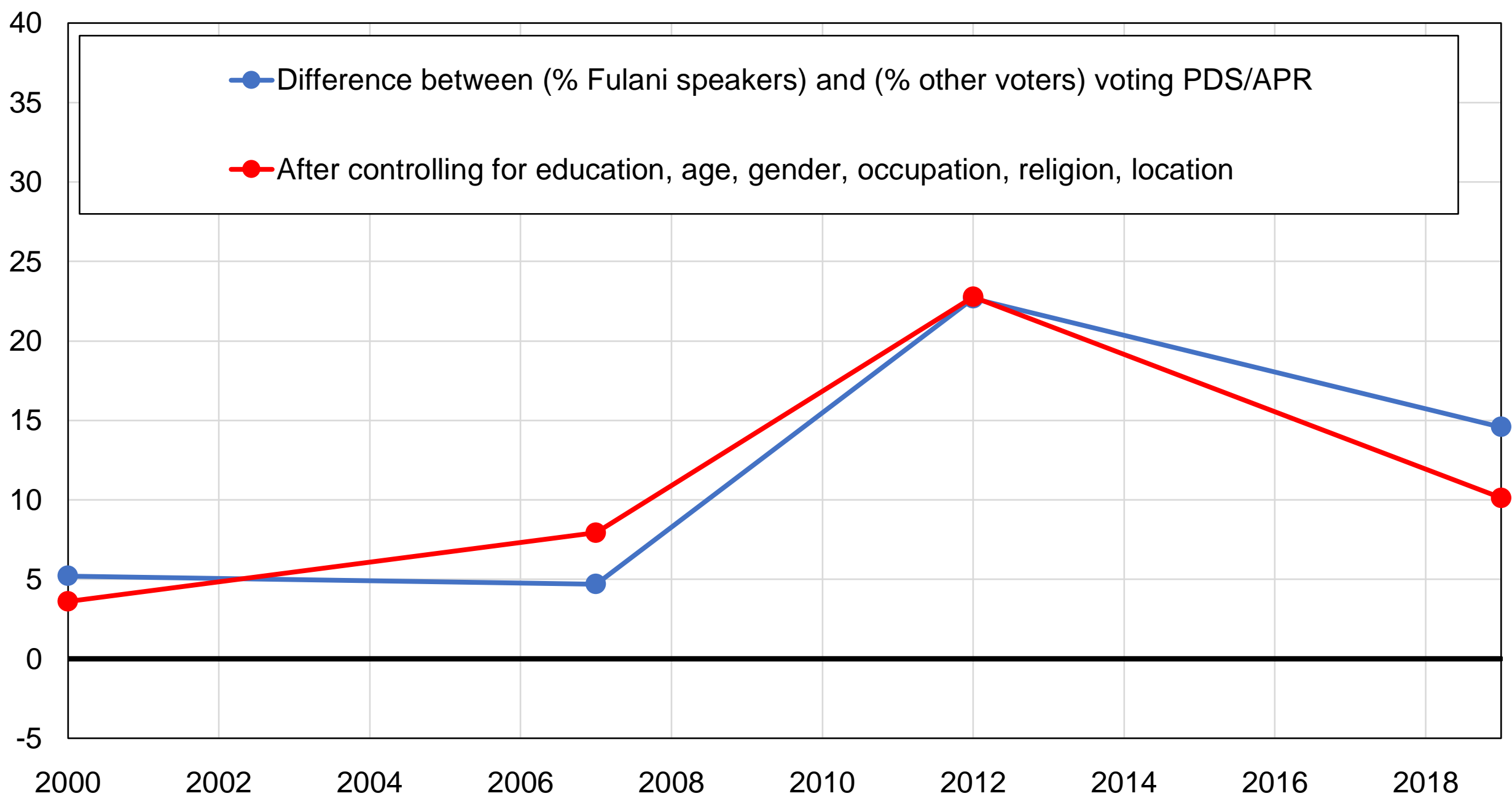

Source: authors' computations using Afrobarometer surveys.

Note: the figure shows the difference between the share of Fulani-speaking voters and the share of other voters voting for PDS / APR, before and after controlling for other variables. 
Figure DC8 - Vote for PDS/APR among professionals / employers

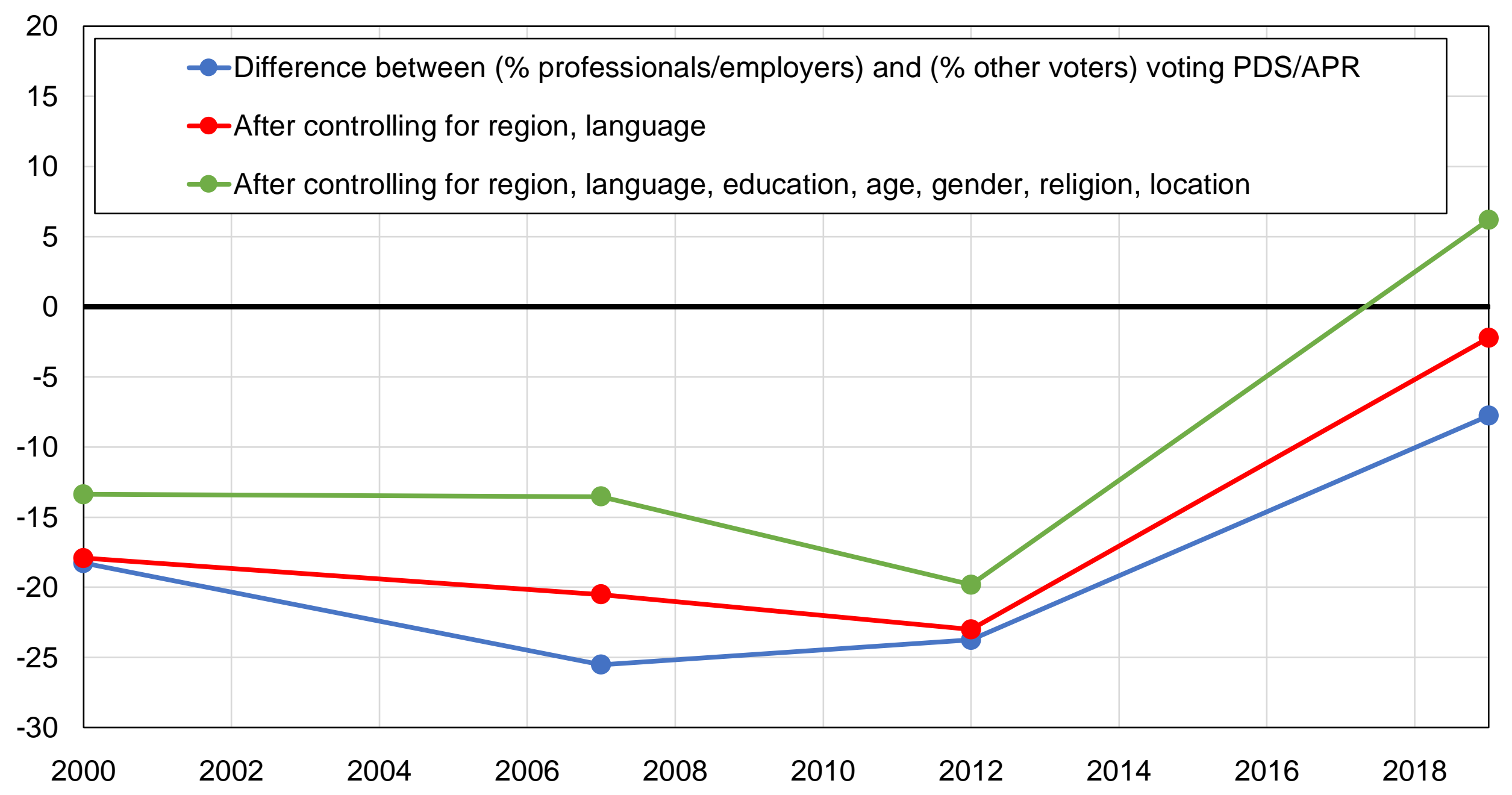

Source: authors' computations using Afrobarometer surveys.

Note: the figure shows the difference between the share of professionals and employers and the share of other voters voting for PDS / APR, before and after controlling for other variables. 


\section{Figure DC9 - Vote for PDS/APR among Christians}

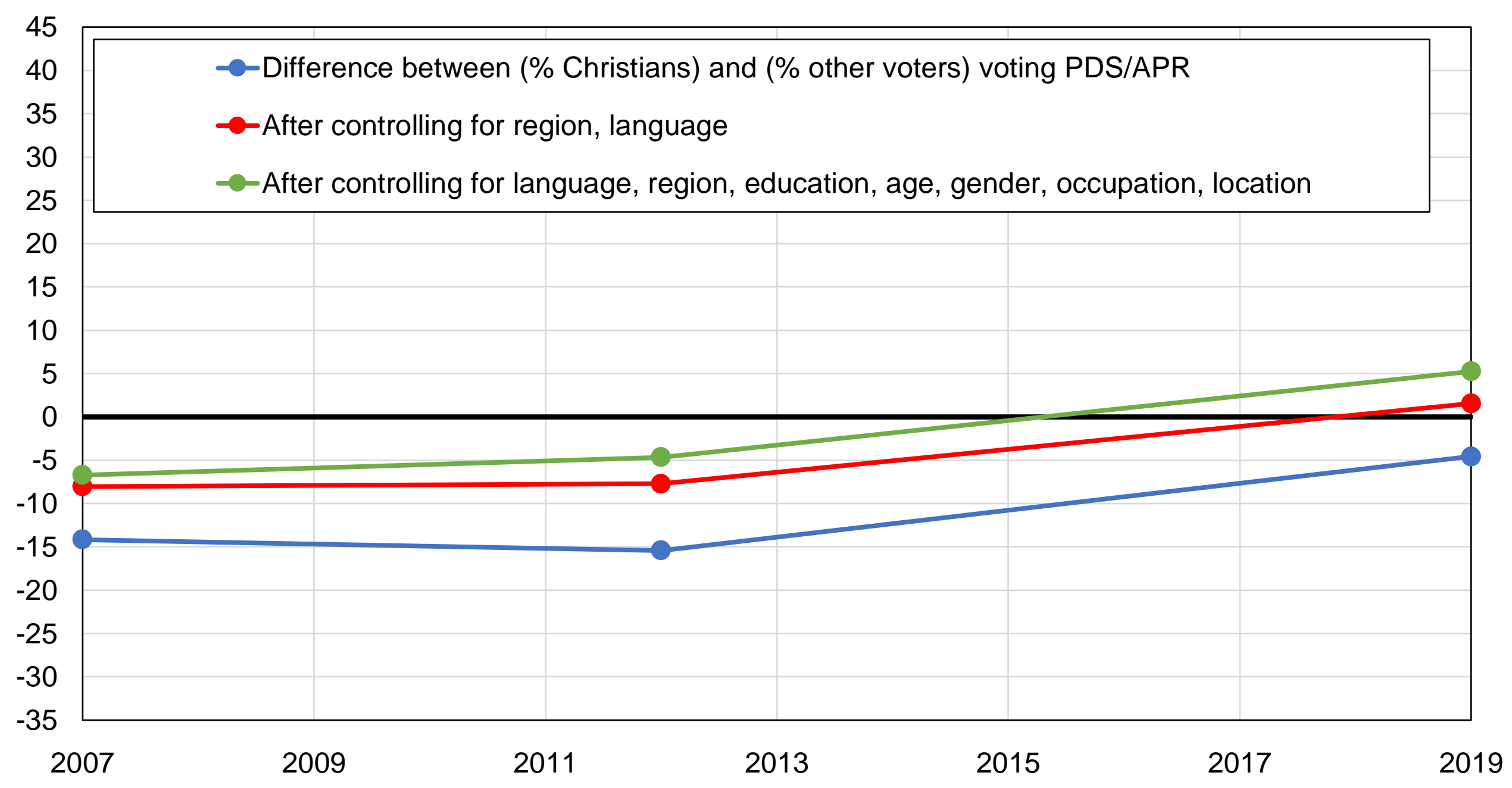

Source: authors' computations using Afrobarometer surveys.

Note: the figure shows the difference between the share of Christians and the share of other voters voting for PDS / APR, before and after controlling for other variables. 


\section{Figure DC10 - Vote for PDS/APR among young voters}

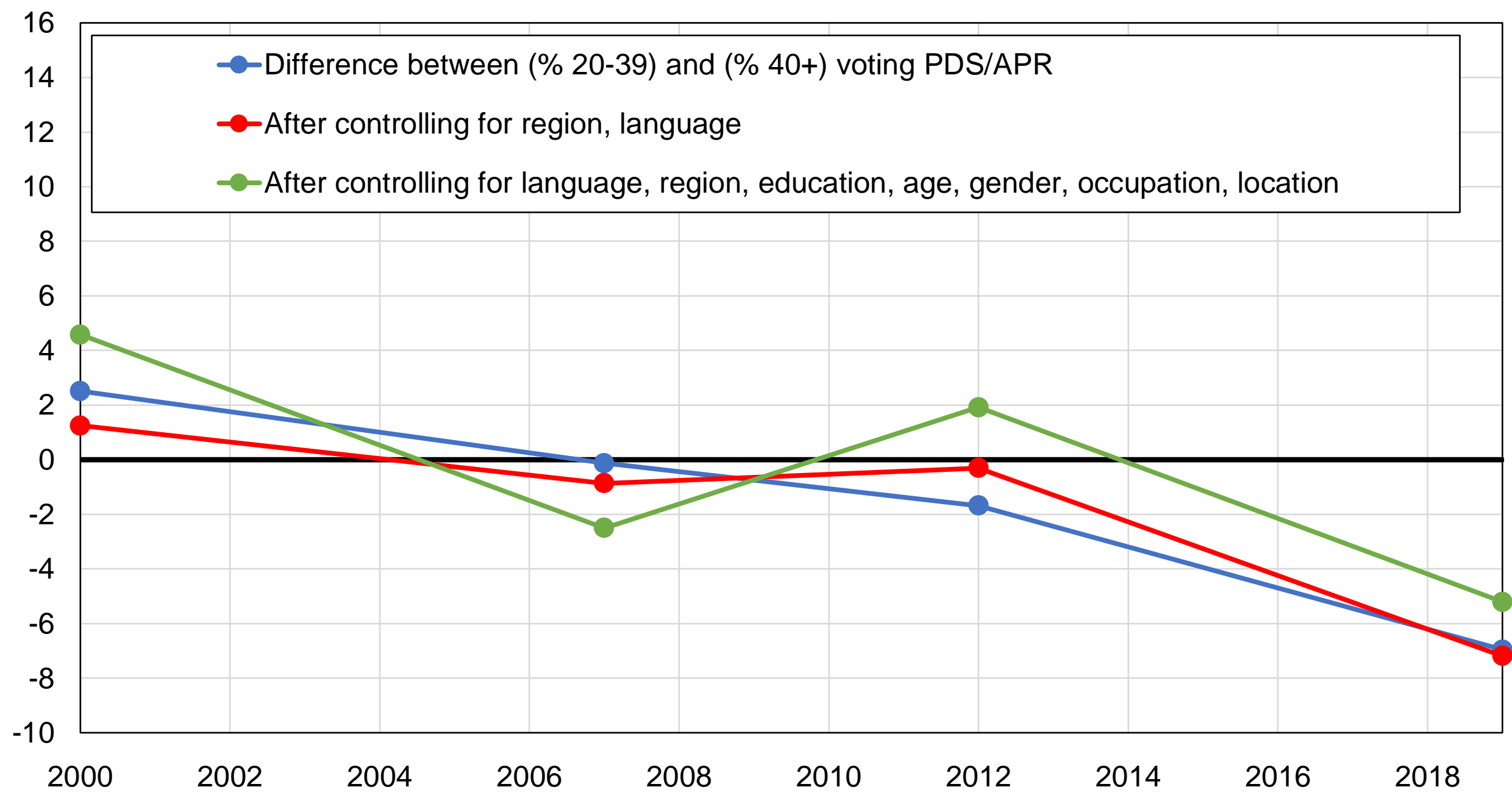

Source: authors' computations using Afrobarometer surveys.

Note: the figure shows the difference between the share of voters aged 20 to 39 and the share of voters aged 40 or more voting PDS / APR, before and after controlling for other variables. 


\begin{tabular}{|cllc|}
\hline \multicolumn{5}{|c|}{ Table D1 - Survey data sources } \\
\hline Year & \multicolumn{1}{|c|}{ Survey } & Source & Sample size \\
\hline 2000 & Afrobarometers Wave 1 & Afrobarometers & 2004 \\
2004 & Afrobarometers Wave 2-3 & Afrobarometers & 2397 \\
2008 & Afrobarometers Wave 4 & Afrobarometers & 1200 \\
2016 & Afrobarometers Wave 5-6 & Afrobarometers & 4800 \\
2019 & Afrobarometers Wave 7 & Afrobarometers & 1600 \\
\hline Source: authors' elaboration. & & \\
Note: the table shows the surveys used, the source from which these surveys can be \\
obtained, and the sample size of each survey.
\end{tabular}




\begin{tabular}{|l|cccc|}
\hline \multicolumn{4}{|c|}{ Table D2 - Complete descriptive statistics by year } \\
\hline & 2000 & 2007 & 2012 & 2019 \\
\hline Education: Illiterate & $56 \%$ & $53 \%$ & $44 \%$ & $51 \%$ \\
Education: Primary & $18 \%$ & $20 \%$ & $22 \%$ & $18 \%$ \\
Education: Secondary & $20 \%$ & $20 \%$ & $24 \%$ & $23 \%$ \\
Education: Tertiary & $6 \%$ & $7 \%$ & $11 \%$ & $9 \%$ \\
Age: $20-29$ & $37 \%$ & $33 \%$ & $34 \%$ & $36 \%$ \\
Age: $30-49$ & $39 \%$ & $44 \%$ & $41 \%$ & $40 \%$ \\
Age: $50+$ & $24 \%$ & $23 \%$ & $25 \%$ & $24 \%$ \\
Gender: Man & $48 \%$ & $50 \%$ & $61 \%$ & $48 \%$ \\
Employment status: Employed & $18 \%$ & $25 \%$ & $32 \%$ & $36 \%$ \\
Employment status: Unemployed & $25 \%$ & $30 \%$ & $23 \%$ & $23 \%$ \\
Employment status: Inactive & $57 \%$ & $45 \%$ & $45 \%$ & $41 \%$ \\
Religion: Other & $1 \%$ & $1 \%$ & $0 \%$ & $0 \%$ \\
Religion: Christian & $7 \%$ & $3 \%$ & $5 \%$ & $3 \%$ \\
Religion: Tijaniya & $0 \%$ & $43 \%$ & $39 \%$ & $32 \%$ \\
Religion: Mouridiya & $0 \%$ & $25 \%$ & $24 \%$ & $23 \%$ \\
Religion: Other Muslim & $92 \%$ & $29 \%$ & $32 \%$ & $41 \%$ \\
Location: Rural & $54 \%$ & $56 \%$ & $52 \%$ & $54 \%$ \\
Region: Casamance & $12 \%$ & $12 \%$ & $13 \%$ & $13 \%$ \\
Region: Centre & $29 \%$ & $27 \%$ & $26 \%$ & $29 \%$ \\
Region: North & $14 \%$ & $18 \%$ & $16 \%$ & $18 \%$ \\
Region: South-East & $5 \%$ & $6 \%$ & $5 \%$ & $6 \%$ \\
Region: West & $40 \%$ & $38 \%$ & $40 \%$ & $34 \%$ \\
Language: Mande & $7 \%$ & $6 \%$ & $6 \%$ & $7 \%$ \\
Language: Other & $10 \%$ & $6 \%$ & $8 \%$ & $8 \%$ \\
Language: Fulani & $26 \%$ & $20 \%$ & $18 \%$ & $28 \%$ \\
Language: Serer & $15 \%$ & $9 \%$ & $8 \%$ & $12 \%$ \\
Language: Wolof & $43 \%$ & $59 \%$ & $60 \%$ & $44 \%$ \\
Occupation: Farmer & $35 \%$ & $25 \%$ & $19 \%$ & $23 \%$ \\
Occupation: Inactive & $28 \%$ & $32 \%$ & $38 \%$ & $45 \%$ \\
Occupation: Professional / Employer & $10 \%$ & $13 \%$ & $9 \%$ & $6 \%$ \\
Occupation: Trader / Worker & $27 \%$ & $30 \%$ & $35 \%$ & $26 \%$ \\
\hline Source: authors' computations using Afrobarometer surveys. & & & \\
Note: the table shows descriptive statistics & by year for selected available variables. \\
& & & & \\
\hline
\end{tabular}

